Departamento de Microbiología y Genética Instituto de Biología Funcional y Genómica

(USAL / CSIC)

VNiVERSiDAD

B SALAMANCA
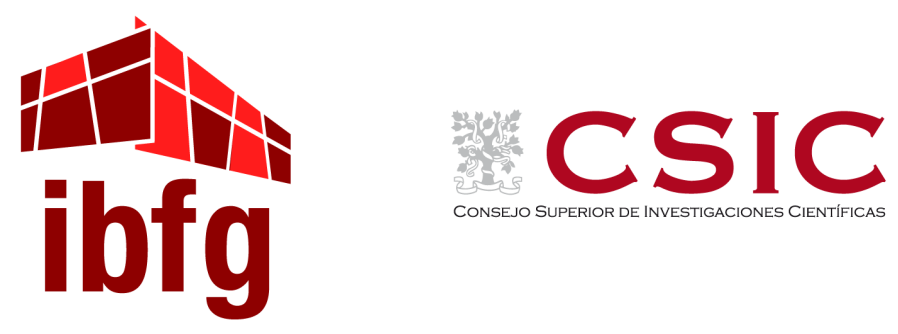

\title{
Importancia de la plasticidad del anillo de septinas en la biología de $C$. albicans
}

Memoria presentada por Sara Orellana Muñoz para optar al Grado de Doctor en Biología ("Mención Internacional") por la Universidad de Salamanca (dentro del Programa de Doctorado de Biología Funcional y Genómica)

Salamanca, 2016 

EL Dr. Francisco del Rey Iglesias, Coordinador del Programa de Doctorado de Biología Funcional y Genómica de la Universidad de Salamanca.

\section{CERTIFICA:}

Que la memoria titulada "Importancia de la plasticidad del anillo de septinas en la biología de $C$. albicans" presentada por la licenciada Sara Orellana Muñoz para optar al Grado de Doctor en Biología ("Mención Internacional") por la Universidad de Salamanca (dentro del Programa de Doctorado de Biología Funcional y Genómica), ha sido realizada bajo la direccion del Dr. Carlos Rodríguez Vázquez de Aldana y el Dr. Francisco del Rey Iglesias, en el Instituto de Biología Funcional y Genómica, Centro Mixto de la Universidad de Salamanca y el Consejo Superior de Investigaciones Científicas.

Y para autorizar su presentación y evaluación por el tribunal correspondiente, firma el presente certificado en Salamanca, a de de 2016.

Fdo. Dr. Francisco del Rey Iglesias. 

El Dr. Carlos Rodríguez Vázquez de Aldana, Investigador Científico del CSIC y el Dr. Francisco del Rey Iglesias, Catedrático de Microbiología en la Universidad de Salamanca,

\section{CERTIFICAN:}

Que la licenciada Sara Orellana Muñoz ha realizado el trabajo titulado "Importancia de la plasticidad del anillo de septinas en la biología de C. albicans" bajo su direccion, en el Centro Mixto Instituto de Biología Funcional y Genómica (Consejo Superior de Investigaciones Científicas y Universidad de Salamanca).

Y para autorizar su presentación y evaluación por el tribunal correspondiente, firman el presente certificado en Salamanca, a de de 2016.

Fdo. Dr. Carlos Rodríguez Vázquez de Aldana Fdo. Dr. Francisco del Rey Iglesias 

Esta tesis doctoral ha sido financiada por una beca predoctoral de Formación de Personal Investigador (FPI) del Ministerio de Economía y Competitividad del Gobierno de España con referencia BES-2011-049632 y asociada al proyecto de investigación BFU2010-15884 en el Organismo CONSEJO SUPERIOR DE INVESTIGACIONES CIENTÍFICAS (CSIC) y por ayudas de la Universidad de Salamanca (Programa I). 

Era tradición en el lugar que cuando los jóvenes alcanzaban el cuarto de siglo debían emprender un camino que les conduciría hasta la persona que llegarían a ser. Fue entonces cuando Atenea recibió el papiro, un delicado papel que sus manos temblorosas apenas podían sostener. El Dios Zeus le hacía una llamada a su Reino, le proponía vivir allí durante cuatro años en los que su esfuerzo se transformaría en un valioso aprendizaje. Nerviosa e ilusionada. Atenea abrió una pequeña caja de madera alojada junto a su corazón, para ataviarse de lo más valioso que poseía antes de su viaje. En ella metió la dedicación de sus padres, la sonrisa de sus hermanos, el amor de Eros y un pequeño espejo, aquel en el que cada vez que se miraba, el cristal le devolvía la imagen de una mujer centenaria de largos cabellos blancos.

Después de un duro viaje, en el que Atenea se separó de la tierra que le había dado la vida, llegó por fin al Reino que compartían Zeus y su padre Crono. La chica llegó intranquila, pero cuando los dioses la entrelazaron entre sus brazos, Atenea llegó a sentir que ese Reino también podría llegar a ser el suyo. Como parte de sus labores, Zeus le encomendó la tarea de guiar las nubes hacia tierras en sequedad y hacer brillar el sol en lugares lúgubres. Él le prometió que después de cada jornada le entregaría una perla. Si conseguía un número determinado de cuentas, al final de la travesía, podría formar un collar tan sólido que protegería la vida de Atenea para siempre. Por suerte, en esta afanada tarea, Atenea no estaba sola. Hera y Hestia velaban porque no le faltaran telares para controlar el viento los días en los que éste soplaba con fuerza. Artemisa, que controlaba las nubes como si de títeres se tratase, enseñó a Atenea a desplazar las nubes usando el corazón. También estaba Ares, el joven más instruido del Reino, que después de leer cientos de manuscritos había conseguido que el sol estuviera más brillante que nunca, y Afrodita que era capaz de hacer senderos invisibles que ayudaban a Atenea a completar su labor. Por otro lado, Poseidón, que gobernaba un Reino diferente al de su hermano Zeus, siempre estaba atento de que la tierra de sus familiares emanara vida y sus consejos eran considerados como prodigiosa sabiduría.

Mientras Atenea se encargaba de dirigir el cielo, muchos jóvenes al servicio de otros Dioses se encargaban de mantener fértil la tierra. Era el caso de Aura, una joven que con su dulzura era capaz de dibujar un luminoso arcoíris cada vez que llovía, irradiando de optimismo el Reino. Era tan maravilloso contemplar esas franjas de colores, que Atenea sentía que su vida no sería la misma si Aura no estuviera cerca. Así también, Teseo se encargaba de labrar el campo de una forma muy especial, iba desprendiendo pequeñas partículas de oro a su paso, llenando de luz todo lo que tocaba. De esta forma, aunque Atenea estuviera cansada de tirar de las nubes, mirar a Aura y Teseo desde las alturas le transmitía una paz y una felicidad que le llenaba de energía. Otros chicos también se encargaban de cuidar el bienestar de los habitantes del Reino, era el caso de Anfítrite, Cárites, Circe, Enio, Eos, Eris, Estigia, Ilitía, Cratos, Eolo y Helios, que siempre estaban pendientes de que a Atenea no le faltara de nada.

Algunos días, Atenea se sentía cansada, y en esos momentos sólo recordar a Eros le reconfortaba, pues aunque estuviera lejos, el amor que él le transmitía le hacía volar por encima de las nubes. En esos momentos, al caer la noche, Atenea siempre cogía el espejo guardado en su corazón, el reflejo que desprendía le recordaba que pasara lo que pasara, la señora de cabello blanco estaría siempre ahí para protegerla.

Un día parecía que todos los Dioses se habían aliado para generar una tormenta de tal magnitud, que por mucho que se esforzaba Atenea, las lluvias empezaron a caer sobre los cultivos nacientes. Desbordada, Atenea pidió ayuda a Harmonía, una muchacha que se cruzó en su camino por casualidad pero que le colmaría de felicidad. Harmonía era capaz de convertir un día lluvioso, en el más luminoso, 
pues ella encerraba en su interior una estrella que daba vida hasta los objetos más inmóviles.

A medida que pasaba el tiempo, tal y como le prometió Zeus, Atenea iba consiguiendo una cuenta de collar después de cada jornada. En ocasiones, gracias a la ayuda de Hera, Hestia, Artemisa, Ares y Afrodita, Atenea conseguía que el sol brillara más aún de lo que lo hacía normalmente. En esos días, Zeus y Crono, que siempre tenían palabras de aliento para Atenea, le recompensaban con más de una cuenta de collar. Además, sin explicación aparente, cuando Atenea tenía algún contacto con Aura, Teseo o Harmonía, siempre encontraba alguna perla de camino a casa. Por otro lado, los veladores del bienestar, siempre atentos, regalaban a Atenea alguna cuenta de collar para contentarla.

Cuando se cumplieron los cuatro años, Atenea se presentó ante Zeus con su saco repleto de perlas. Las contaron una por una y, para desdicha de la chica, se había quedado, apenas, a una treintena de cuentas para formar el collar. Atenea lloró inconsolablemente, pero Zeus que siempre se había mostrado comprensivo con ella, la abrazó y le pidió que mirara en su cajita de madera. Atenea le obedeció y, para su sorpresa, multitud de perlas empezaron a brotar, envolviendo su afligido corazón. Zeus le explicó que el verdadero significado de la labor que había llevado a cabo durante estos años, era que entendiera que sólo había sido posible gracias a la ayuda de los habitantes del Reino que estaban a su alrededor. De esta forma, cada vez que alguien mostraba interés y afecto por ella, una perla se alojaba en lo más profundo del corazón de Atenea y permanecería ahí para siempre. En cuanto a las cuentas que había conseguido por su trabajo, no eran más que valores aprendidos que ella debía transmitir, intentando colocar sus perlas en la cajita del corazón de otras personas. Atenea sintió una gran felicidad cuando comprendió que su corazón estaba ahora enriquecido de sabiduría y valores que otros le habian inculcado, y estuvo eternamente agradecida por ello, principalmente rebosaba gratitud por Zeus, por haberle permitido formar parte de su Reino, por su cariño y dedicación. 
A Elvira. 



\section{Abreviaturas, acrónimos y siglas}

$\Delta$ : Deleción (Deletion)

$\lambda$-PPasa: $\lambda$-Fosfatasa ( $\lambda$-PPase: $\lambda$-PhosPhatase)

aa: Aminoácido (Amino Acid)

ADH: Alcohol deshidrogenasa (Alcohol DeHydrogenase)

AGC: Grupo de kinasas denominadas así por sus miembros fundadores, las proteín kinasas A, G y C (Protein kinase group known by protein kinase $A, G$, and $C$ families)

AMR: Anillo contráctil de actomiosina (ActoMyosin Ring)

APC/C: Complejo Promotor de Anafase/ciclosoma (Anaphase Promoting Complex/Cyclosome)

BSA: Albumina de suero bovino (Bovine Serum Albumin)

cAMP: Adenosín mono-fosfato cíclico (cyclic Adenosine MonoPhosphate)

CAPS: Ácido 3-(Ciclohexilamino)-1-propanosulfónico ( $N$-Cyclohexyl-3-AminoPropaneSulfonic acid)

Cdc: Ciclo de división celular (Cell Division Cycle)

CDK: Kinasa depeniente de Ciclina (Cyclin-Dependent Kinase)

cDNA: DNA copia (copy DNA)

CF: Calcoflúor (CalcoFluor)

CHAPS: 3-[(3-Colamidopropil)dimetil amonio]-1-propano sulfonato (3-[(3-Cholamidopropyl) dimethylammonio]-1-propanesulfonate)

ClonNAt: Nourserotricina (Nourseothricin)

CTE: Extensión C-terminal (C-Terminal Extension)

C-terminal: Carboxiterminal (Carboxyterminal)

DAPI: 4',6-diamino-2-fenilindol (4',6-DiAmidino-2-Phenyllndole)

DIC: Microscopía diferencial de contraste de interferencia (Differential Interference Contrast)

DNA: Ácido desoxirribonucleico (DeoxyriboNucleic Acid)

DTT: Ditiotreitol (DiThioThreitol)

EDTA: Ácido etilendiaminotetra-acético (EthyleneDiamineTetraacetic Acid)

EGTA: Ácido etilen glicol bis tetra-acético (Ethylene Glycol Tetraacetic Acid)

FEAR: Liberación temprana de Cdc14 (cdc Fourteen Early Anaphase Release)

FRAP: Recuperación de la fluorescencia después del quemado (Fluorescence Recovery After Photobleaching)

FRET: Transferencia de energía de resonancia de Förster (Förster Resonance Energy Transfer)

GAP: Proteína activadora de la actividad GTPasa (GTPase Activating Protein)

GCK: Kinasas de centro germinal (Germinal Center Kinase)

GDI: Inhibidor de la disociación de GDP (GDP Dissociation Inhibitor)

GEF: Factor intercambiador de nucleótidos de guanina (Guanine nucleotide Exchange Factor)

GFP: Proteína Fluorescente Verde (Green Fluorescent Protein)

GIcNAc: N-acetil-D-glucosamina (N-Acetyl-D-Glucosamine)

GTPasa: Guanosina trifosfatasa (GTPase: Guanosine TriPhosphatase)

HEPES: Ácido 4-2-hidroxietil-1-piperazinil-etansulfónico

(4-(2-hydroxyethyl)-1-piperazineethanesulfonic acid)

HSG: Genes específicos de hifas (Hyphae-Specific Genes)

HSS: Estado específico de hifas (Hyphae-Specific State)

IPG: Gradiente de pH inmovilizado (Immobilized PH Gradient) 
kDa: Kilodalton (KiloDalton)

kV: kilovoltio (KiloVolt)

LB: Medio rico para E. coli (Luria-Bertani)

LiAc: Acetato de litio (Lithium Acetate)

MAPK: Proteín kinasa activada por mitógeno (Mitogen-Activated Protein Kinase)

MEN: Ruta de salida de mitosis (Mitotic Exit Network)

mRNA: RNA mensajero (Messenger RNA)

N-terminal: Aminoterminal (Amine-terminal)

NDR: Kinasa nuclear relacionada con Dbf2 (Nuclear Dbf2-Related kinase)

OD: Densidad óptica (Optical Density)

ORF: Fase de lectura abierta (Open Reading Frame)

pb: Pares de bases (bp: base pair)

PBS: Tampón fosfato salino (Phosphate-Buffered Saline)

PBS-T: Buffer fosfato salino más Tween al 1\% (Phosphate-Buffered Saline +Tween 1\%)

PCR: Reacción en cadena de la polimerasa (Polymerase Chain Reaction)

PEG: Polietilen Glicol (PolyEthylene Glycol)

PH: Homología con Pleckstrinas (Pleckstrin Homology)

PIP2A: Fosfatidil inositol 4,5-bisfosfato (Phosphatidyllnositol 4,5-BisPhosphate)

PMSF: Fluoruro de ortometil fenil sulfonilo (Phenyl Methyl Sulfonyl Fluoride)

PP1: Proteín fosfatasa tipo 1 (Protein Phosphatase 1)

PP2: Proteín fosfatasa tipo 2A (Protein Phosphatase 2A)

PVDF: Fluoruro de polivinilideno (PolyVinyliDene Fluoride)

qRT-PCR: PCR cuantitativa a tiempo real (quatitative Real Time PCR)

RAM: Ruta de regulacion de Ace2 y morfogénesis (Regulation of Ace2 and Morphogenesis)

rDNA: DNA ribosómico (ribosomal DNA)

RNA: Ácido Ribonucleico (RiboNucleic Acid)

RNAasa: Ribonucleasa (RNase: RiboNuclease)

rpm: Revoluciones por minuto (Revolutions Per Minute)

S: Coeficiente de Sedimentación (Sedimentation coefficient)

SAC: Punto de control del ensamblaje del huso mitótico (Spindle Assembly Checkpoint)

SD: Desviacion estándar (Standard Deviation)

SDS: Dodecil Sulfato Sódico (Sodium Dodecyl Sulfate)

SDS-PAGE: Electroforesis en gel de poliacrilamida en condiciones desnaturalizantes

(PolyAcrilamide Gel Electrophoresis)

SEM: Error estándar de la media (Standard Error of the Mean)

SPB: Cuerpo Polar del huso (Spindle Pole Body)

SPOC: Punto de control de la orientación del huso mitótico (Spindle POsition Checkpoint)

SUE: Elemento único de septinas (Septine Unique Element)

SUMO: Pequeño modificador relacionado con Ubiquitina (Small Ubiquitin-Related Modifier)

TCA: Ácido tricloroacético (Trichloroacetic Acid)

TGN: Trans-Golgi (Trans-Golgi Network)

UV: Ultravioleta (UltraViolet)

YEPD: Medio rico para Candida (Yeast Extract Peptone Dextrose)

YNB: Nitrógeno base (Yeast Nitrogen Base) 


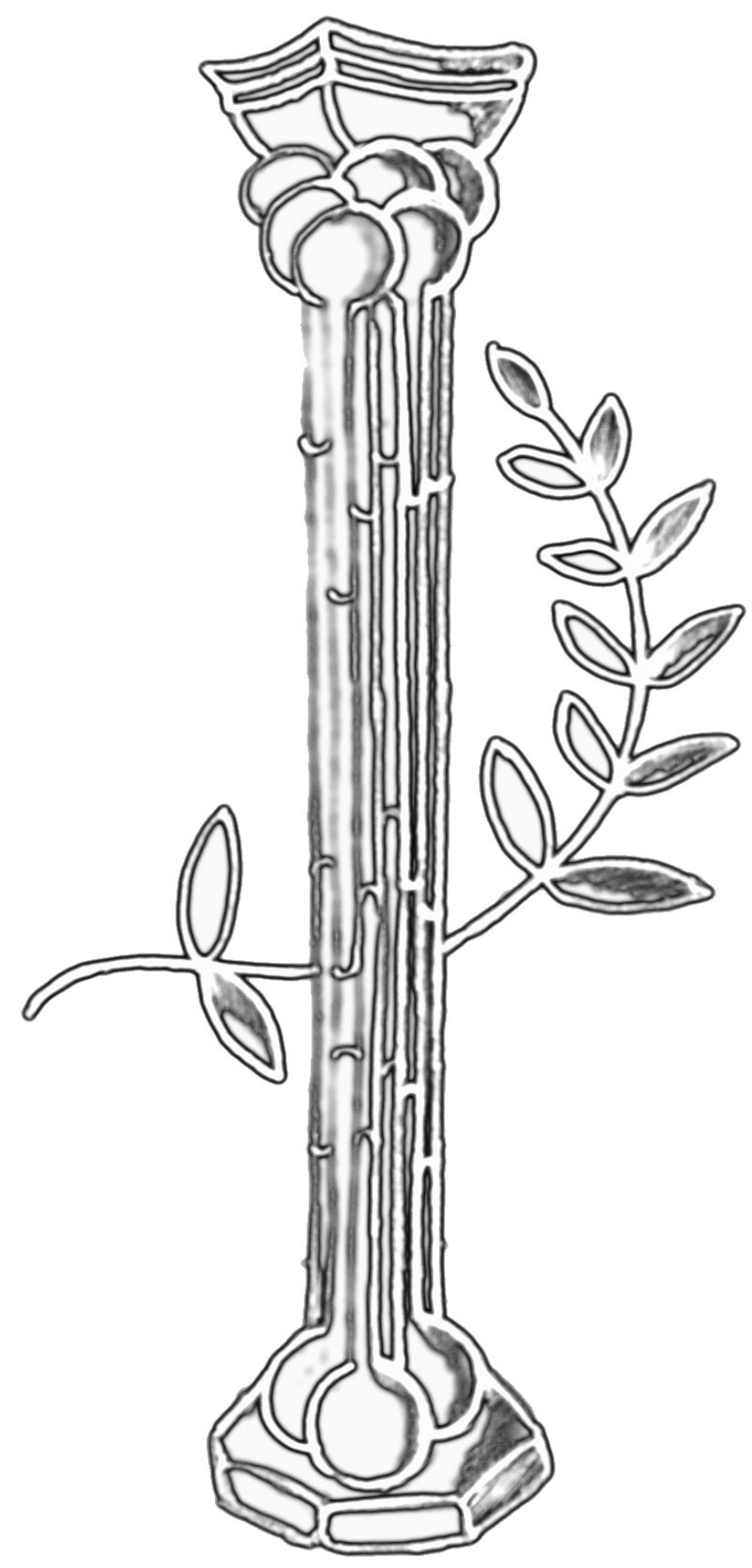

\section{Índice}



1. Candida albicans: infección fúngica y su importancia en salud pública $\ldots \ldots \ldots \ldots \ldots \ldots \ldots \ldots$

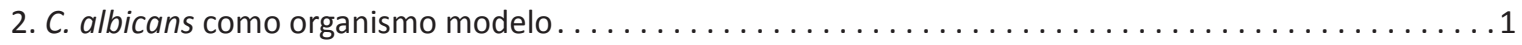

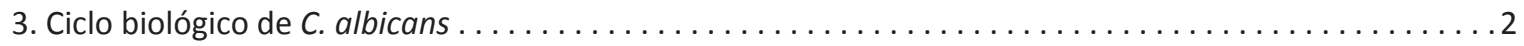

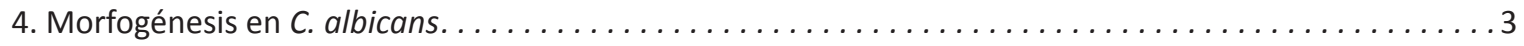

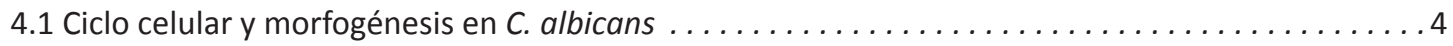

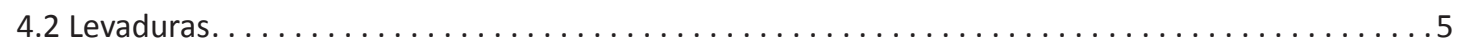

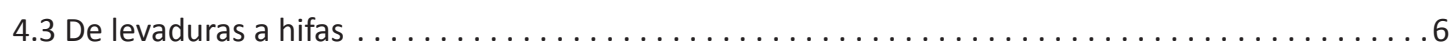

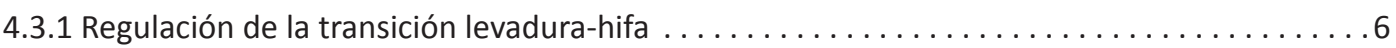

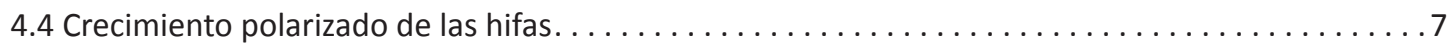

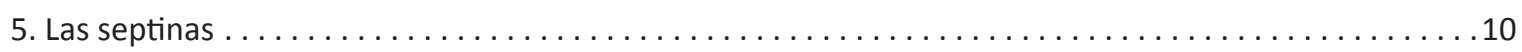

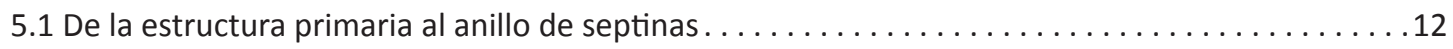

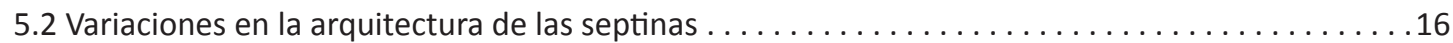

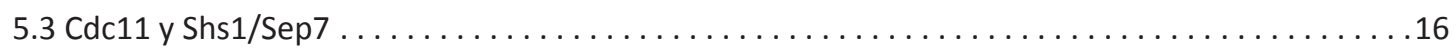

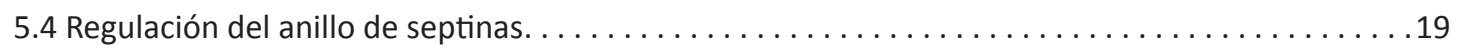

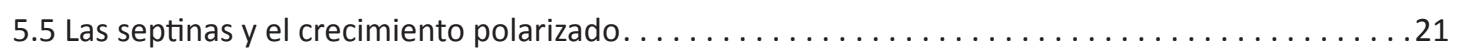

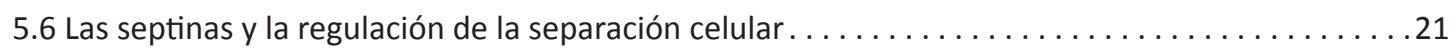

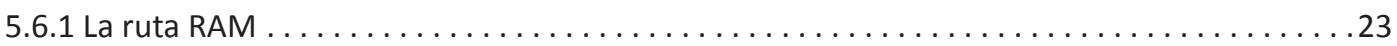

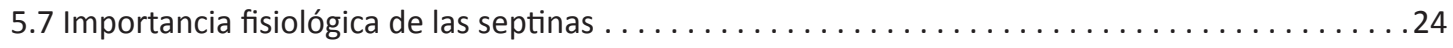

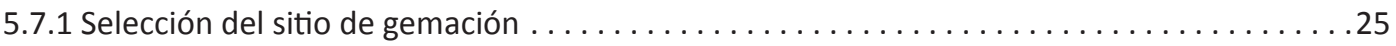

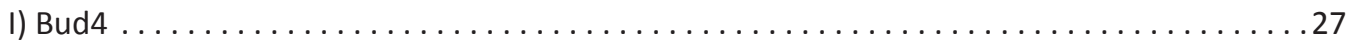

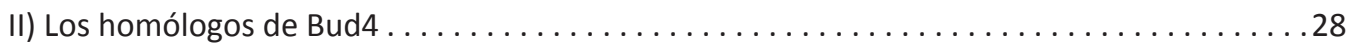

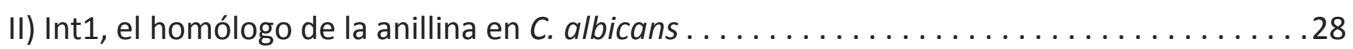

5.7 .2 Orientación del huso mitótico y segregación de cromosomas . . . . . . . . . . . . 29

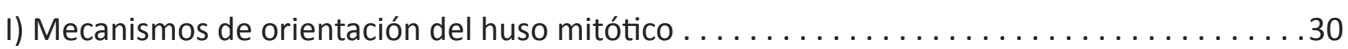

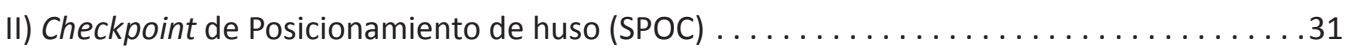

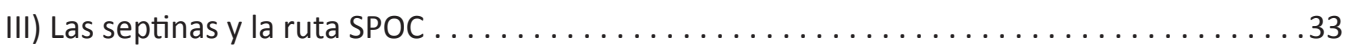

CAPÍTULO I: La dosis génica de las septinas juega un papel fundamental en la inhibición de la separación celular

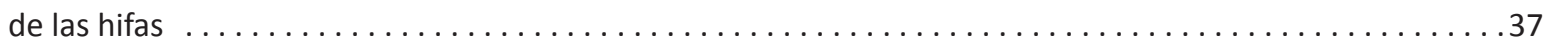

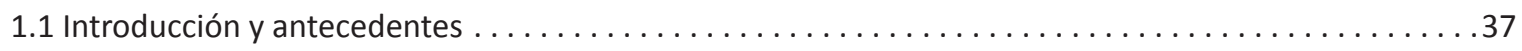

$1.2 \operatorname{sep} 7 \Delta \Delta$, a diferencia de otros mutantes nulos de septinas ( $c d c 11 \Delta \Delta$ y $c d c 10 \Delta \Delta)$, presenta

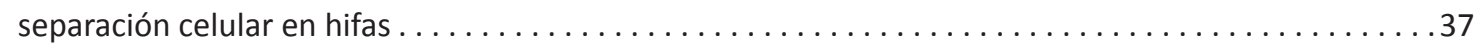

1.3 La dosis génica de SEP7 es importante para inhibir la separación celular de las hifas . . . . . . . . . .40

1.4 La dosis génica de $C D C 11$ también contribuye a inhibir la separación celular en hifas. . . . . . . . . 44

1.5 Las proporciones relativas de Sep7, Cdc11 y Cdc10 son importantes para mantener la inhibición de

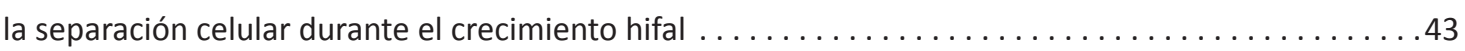

1.6 No existe una correlación directa entre el estado específico de hifas del anillo de septinas y la

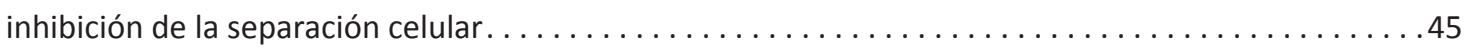

1.7 Los octámeros de levaduras e hifas presentan diferentes propiedades bioquímicas . . . . . . . .46 
Índice

CAPÍTULO II: Regulación de Sep7 por fosforilación en las distintas morfologías de C. albicans ....

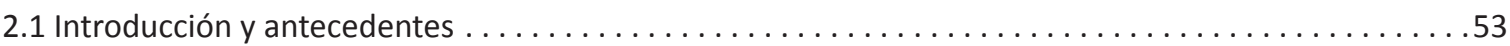

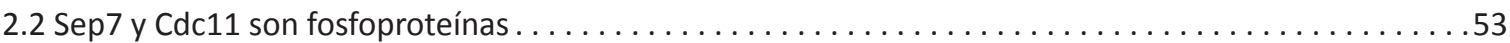

2.3 La región comprendida entre los aminoácidos 394 y 552 de Sep7 es necesaria para inhibir la

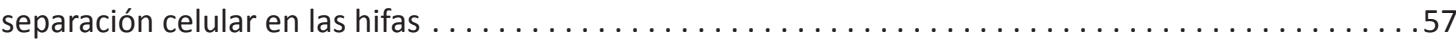

2.4 Los sitios de fosforilación del Grupo / de Sep7 son necesarios para inhibir la separación celular en

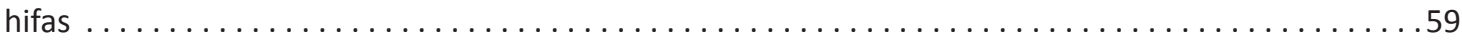

2.5 La fosforilación en el extremo del C-terminal de Sep7 regula la división del anillo de septinas en hifas 61

2.6 El extremo C-terminal de Sep7 no es suficiente para inhibir la separación celular de las hifas ... .63

2.7 La fosforilación de Ser14 y Ser22 en extremo amino es necesaria para el ensamblaje de los anillos

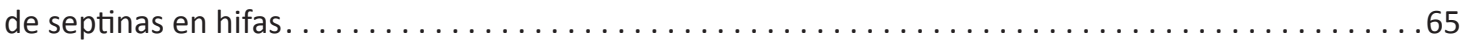

2.8 Sep7 no es necesaria para la correcta localización de Sec3 y Gin4 . . . . . . . . . . . . . . .67

CAPÍTULO III: La fosforilación de Cdc12 está implicada en la correcta septación. . . . . . . . . . . . . .71

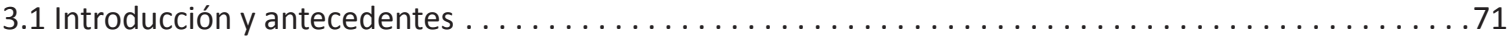

3.2 Cdc12 sufre modificaciones post-traduccionales específicas del tipo de crecimiento . . . . . . . . 73

3.3 Cdc12 interacciona con el complejo Cbk1-Mob2 y la kinasa Cdc28 . . . . . . . . . . . . . . . . .74

3.4 La defosforilación de Cdc12 es necesaria para que la septación en hifas se lleve a cabo correctamente75

CAPÍTULO IV: La anillina Int1 y la estabilidad del anillo de septinas $\ldots \ldots \ldots \ldots \ldots \ldots \ldots \ldots \ldots \ldots$

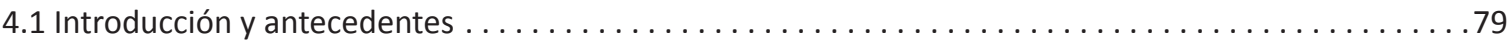

4.2 Int1 colocaliza con las septinas en el presumible sitio de gemación y en el cuello entre la célula

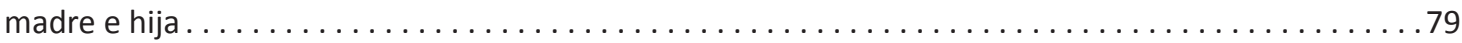

4.3 Los anillos de septinas son inestables tras su duplicación en el mutante int $1 \Delta \Delta \ldots \ldots \ldots \ldots \ldots 1$

4.4 La composición de los anillos de septinas no se altera en el mutante $i n t 1 \Delta \Delta \ldots \ldots \ldots \ldots \ldots \ldots 4$

4.5 El mutante int1 $\Delta \Delta$ presenta una contracción normal del AMR (Mlc1), así como una localización silvestre del polarisoma (Spa2), el exocisto $(\mathrm{Sec} 3)$ y la kinasa Gin4 $\ldots \ldots \ldots \ldots \ldots \ldots \ldots \ldots \ldots$

4.6 La funcionalidad de Int1 reside mayoritariamente en el extremo C-terminal . . . . . . . . . . . . 88

4.7 La fosforilación de los sitios consenso para la kinasa Cbk1 en Int1 está implicada en su funcionalidad 90

$4.8 \mathrm{El}$ mutante doble $i n t 1 \Delta \Delta \operatorname{sep} 7 \Delta \Delta$ presenta un aumento en la ploidía celular . . . . . . . . . . . 992

4. 9 El mutante int $1 \Delta \Delta \operatorname{sep} 7 \Delta \Delta$ presenta fallos en mitosis y en orientación del huso mitótico . . . . . . . 96

$4.10 \mathrm{El}$ mutante $\operatorname{int} 1 \Delta \Delta \operatorname{sep} 7 \Delta \Delta$ presenta defectos en la localización de proteínas implicadas en el

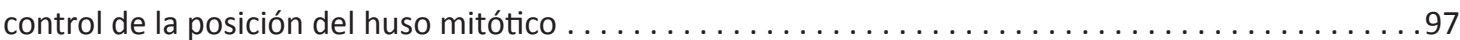

DISCUSIÓN 103

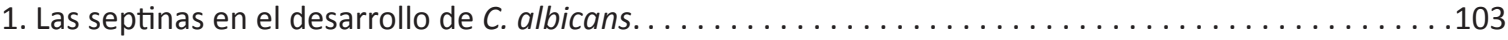

1.1 Las estructuras de septinas en levaduras e hifas y su relación con la separación celular. . . . . . .103

1.2. Regulación de las septinas por modificaciones post-traduccionales. . . . . . . . . . . . . 108

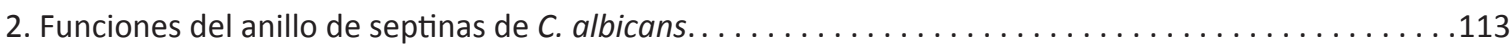




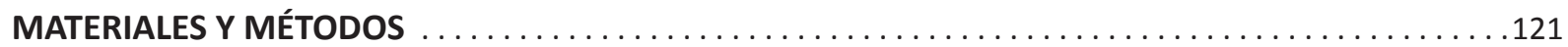

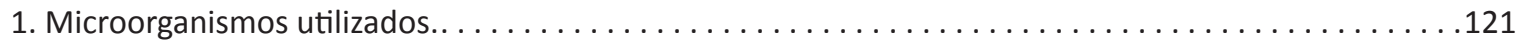

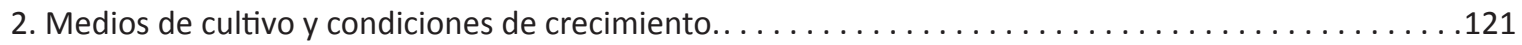

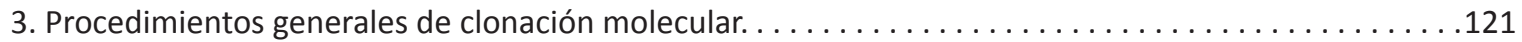

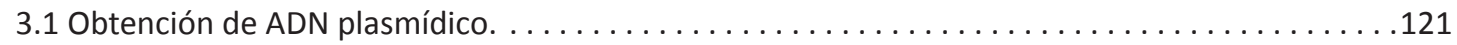

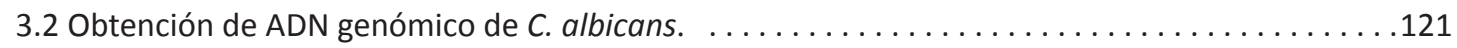

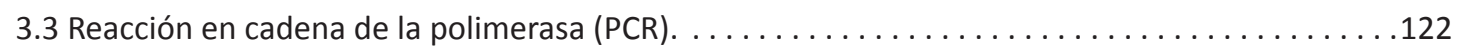

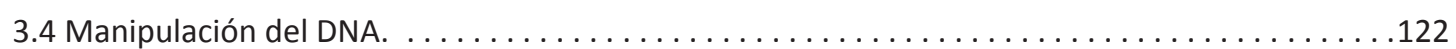

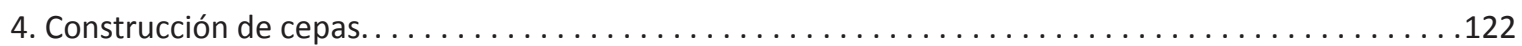

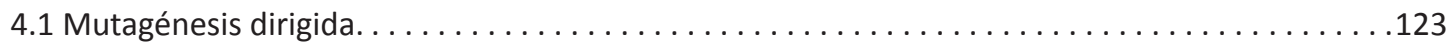

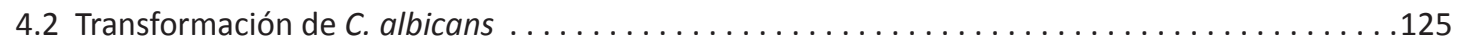

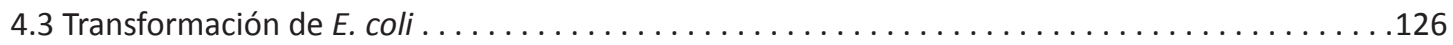

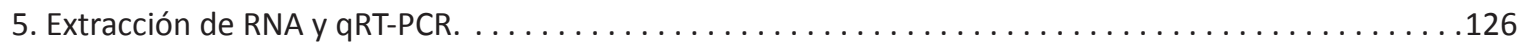

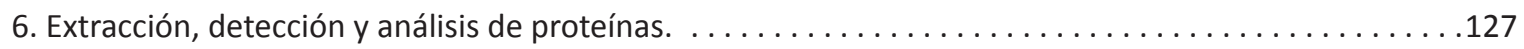

6.1 Extracción. . . . . . . . . . . . . . . . . . . . . . . . . . . . . . . . . . . . 127

6.2 Separación electroforética e inmunodetección de proteínas (Western Blot). . . . . . . . . . . 127

6.3 Western Blot con geles Phos-Tag. . . . . . . . . . . . . . . . . . . . . . . . . . . . . . 128

6.4 Electroforesis 2D. . . . . . . . . . . . . . . . . . . . . . . . . . . . . . . . 128

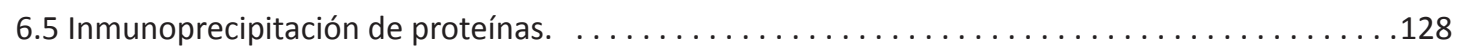

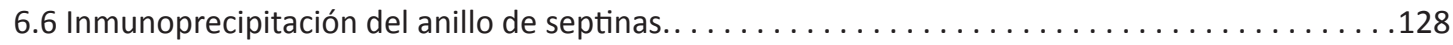

7. Gradientes de sacarosa. . . . . . . . . . . . . . . . . . . . . . . . . . . . . . . . . . . 129

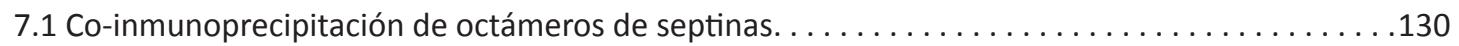

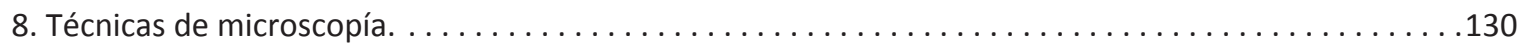

8.1 Microscopía óptica. . . . . . . . . . . . . . . . . . . . . . . . . . . . . . . . . . . . . . . . 130

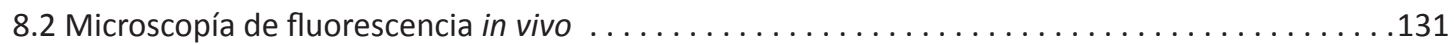

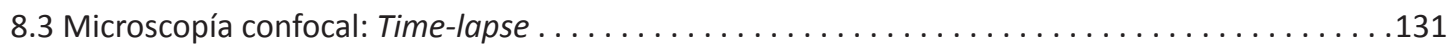

8.4 Microscopía confocal: Recuperación de fluorescencia después de photobleaching (FRAP). . . . .131

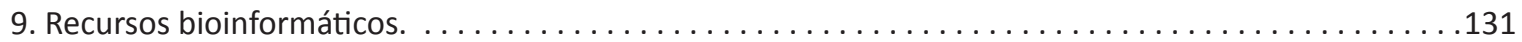

SUMMARY: Importance of the septin ring plasticity in the biology of C. albicans . . . . . . . . 137

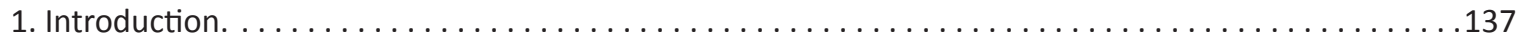

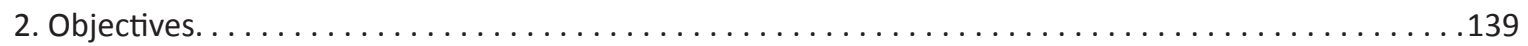

3. Results and Discussion. . . . . . . . . . . . . . . . . . . . . . . . . . . . . . . . . . . . . 139

3.1 Septin gene dosage play a fundamental role in the inhibition of hyphal cell separation. . . . . .139

3.2. Regulation of Sep7, Cdc11 and Cdc12 by phosphorylation in the different morphologies of $C$.

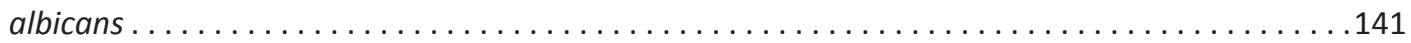

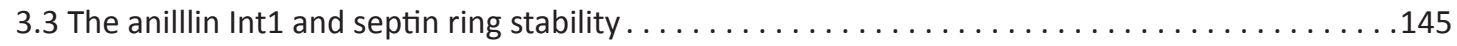





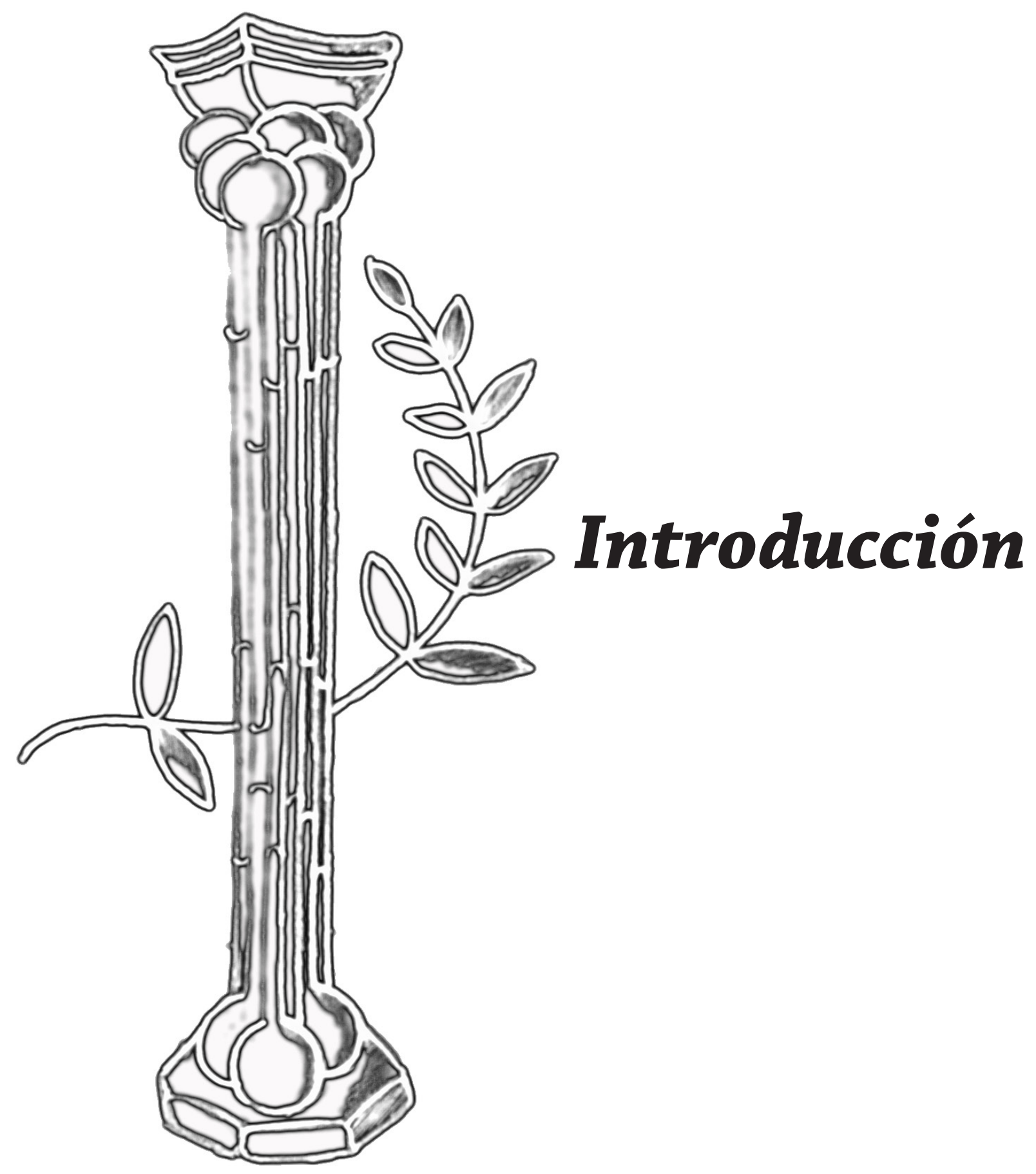





\section{Candida albicans: infección fúngica y su importancia en salud pública.}

Desde la década de los 80, los hongos han surgido como los mayores agentes causales de infecciones humanas, especialmente en pacientes con el sistema inmune comprometido y hospitalizados con enfermedades graves subyacentes. Varios estudios epidemiológicos sobre las sepsis causadas por hongos demuestran que el número de casos de esta enfermedad en EEUU se ha incrementado en un $207 \%$ entre 1979 y 2000 . Además, se han descrito altos porcentajes de morbilidad y mortalidad asociada a estas infecciones, por lo que está claro que las enfermedades causadas por hongos se pueden considerar como un importante problema de salud pública (Pfaller y Diekema, 2007).

Dentro de los hongos patógenos, C. albicans es un microorganismo oportunista del ser humano, que en condiciones normales forma parte de la microbiota habitual del organismo, principalmente de las membranas mucosas de los tractos gastrointestinal y genitourinario. Estudios estadísticos indican que alrededor del $70 \%$ de los hombres y del $75 \%$ de las mujeres sufrirán esta infección al menos una vez en su vida (Schulze y Sonnenborn, 2009). La infección de C. albicans es conocida como candidiasis y generalmente afecta a las células epiteliales gastrointestinales o vaginales. Sin embargo, puede generar infecciones sistémicas o candidemias con una mortalidad del 30\% (McCarty y Pappas, 2016). C. albicans es en la actualidad el hongo patógeno más frecuentemente aislado en hospitales, llegando a constituir más del 48\% de los aislados clínicos de candidemias en la Unión Europea (Tortorano et al., 2006; De Luca et al., 2012). En menor medida, aparecen otras especies del género Candida, como C. glabrata, C. krusei, C. dubliniensis, C. parapsilosis, y C. tropicalis en pacientes infectados (Gozalbo et al., 2004).

El diagnóstico y tratamiento apropiados, así como la prevención y el conocimiento general de la biología de las especies de Candida spp., suponen un gran reto para los médicos y microbiólogos alrededor del mundo, por lo que el estudio del género resulta una cuestión de gran importancia para la salud pública mundial.

\section{C. albicans como organismo modelo.}

Saccharomyces cerevisiae ha sido el organismo modelo por excelencia dentro de las levaduras de gemación. Probablemente, la contribución más importante de esta levadura modelo a la comunidad científica haya sido establecer la conexión de genes y proteínas con las funciones que desempeñan en la célula. Además, los métodos para introducir mutaciones dirigidas por el investigador en el genoma de la levadura han hecho particularmente fácil el estudio no solamente de las funciones bioquímicas, sino también las consecuencias biológicas de la falta de la función de un gen (Botstein y Fink, 2011).

Aunque C. albicans había sido descubierta hace mucho tiempo, no captó la atención de la comunidad científica hasta finales de 1960 y no se ha estudiado con vigor hasta 1990. Al parecer, la razón podría ser el aumento repentino de infecciones en pacientes inmunocomprometidos debido al cambio en las técnicas médicas modernas en los años 1970 y 1980. Estos pacientes fueron infectados por una variedad de microbios, y el género Candida pasó a ser uno de los principales patógenos (Odds, 1987). Desde entonces, un objetivo importante de las investigaciones con modelos patógenos como $C$. albicans reside en el hecho de identificar dianas apropiadas para las terapias antifúngicas (Berman y Sudbery, 2002). Para su estudio, la mayoría de las técnicas usadas en C. albicans han sido transferidas de S. cerevisiae. En un principio, la investigación en Candida fue difícil, debido a la falta de disponibilidad de una versión haploide (hasta hace poco tiempo) que permitiera el uso de técnicas 
genéticas convencionales. Sin embargo, en las últimas décadas, se han desarrollado y aplicado técnicas importantes para la manipulación genética y estudios proteómicos (Kabir et al., 2012).

Una de las características más importantes del genoma de $C$. albicans es la enorme cantidad de variaciones que sufre en la estructura y número de sus cromosomas, las cuales le garantizan una importante diversidad genética como consecuencia de procesos como polimorfismos de los cromosomas, translocaciones recíprocas, pérdida de cromosomas o ganancia de uno de ellos (trisomías). Todas estas alteraciones le permiten realizar cambios fenotípicos que constituyen una importante estrategia adaptativa para su supervivencia en diferentes nichos.

\section{Ciclo biológico de C. albicans.}

C. albicans es un comensal humano diploide que tiene un ciclo parasexual particular recientemente descrito (revisado en Bennett, 2015; Zhang et al., 2015; Schmid et al., 2016)(Fig. 1). La conjugación está regulada por la transición white-opaque, ya que las células opaque son más eficientes que las white para conjugar y formar un tetraploide. Los tetraploides pueden dividirse establemente o generar de nuevo células diploides y aneuploides mediante un programa de pérdida de cromosomas en lugar de una meiosis convencional.
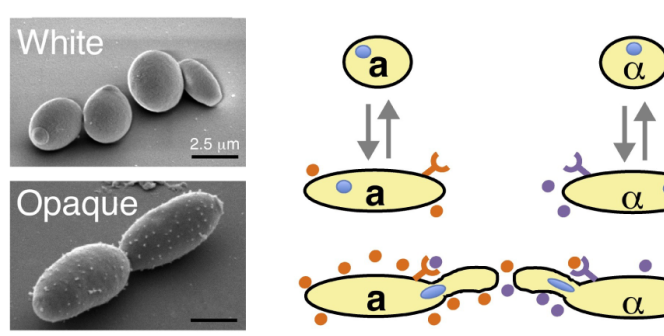

White (2n)

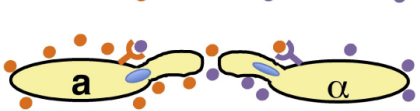

Opaque (2n)

Formación proyecciones de conjugación
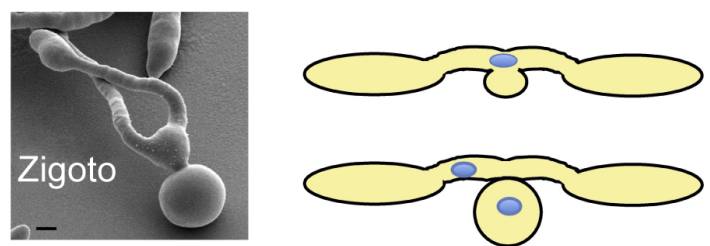

Fusión nuclear en el zigoto (4n)

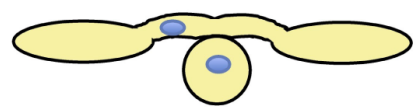

Segregación del núcleo tetraploide (4n)
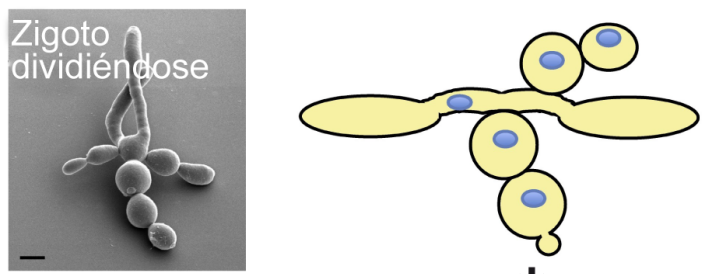

División de los tetraploides
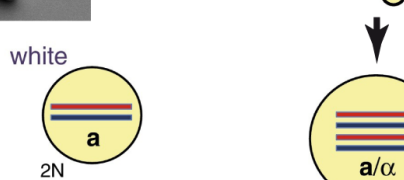

$2 \mathrm{~N}$
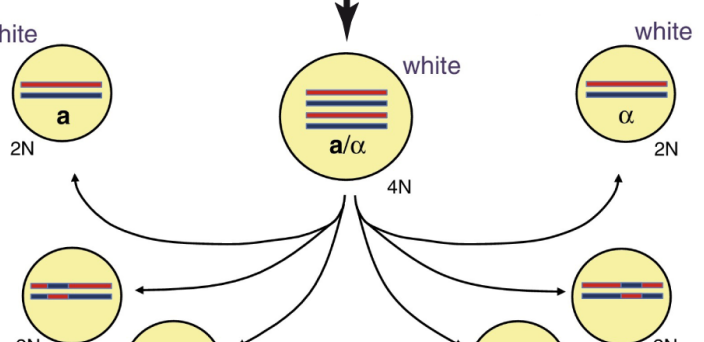

${ }_{4 \mathrm{~N}}$
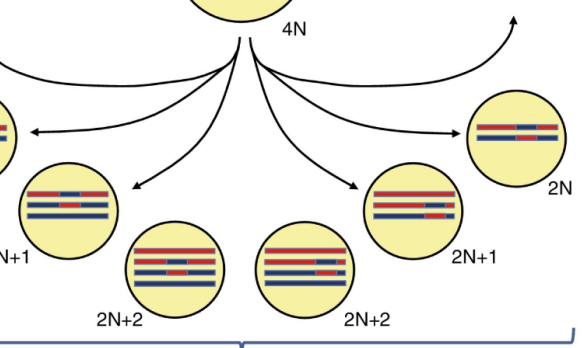

$2 \mathrm{~N}+2$

Productos parasexuales de la recombinación (mezcla a, $\alpha$ y a/ $\alpha$ )
Durante el transcurso de su evolución, C. albicans y S. cerevisiae divergieron de un ancestro común hace 200 millones de años, y desde entonces han sido capaces de adaptarse a diferentes hábitats. Así, mientras que S. cerevisiae vive en nichos con altas concentraciones de azúcares, C. albicans se ha adaptado a vivir en animales de sangre caliente llegando a ser

Figura 1. Ciclo parasexual de C. albicans. Las células white cambian a la forma opaque competente para el apareamiento, y tras recibir la señalización de las feromonas de las células del tipo sexual opuesto forman proyecciones de conjugación. Las proyecciones se fusionan formando un zigoto en el que ocurre la cariogamia, generando núcleo tetraploide que se replica. Las células tetraploides pueden dividirse establemente o sufrir pérdida de cromosomas, produciendo células diploides $a, \alpha$ o $a / \alpha$. La pérdida de cromosomas puede generar diversas combinaciones de células aneuploides $(2 \mathrm{~N}+1$ o $2 \mathrm{~N}+2)$, así como diploides con diferentes configuraciones MTL. Sólo se muestra uno de los ocho cromosomas. Modificado de Bennett, 2015. 


\section{Pseudohifas}

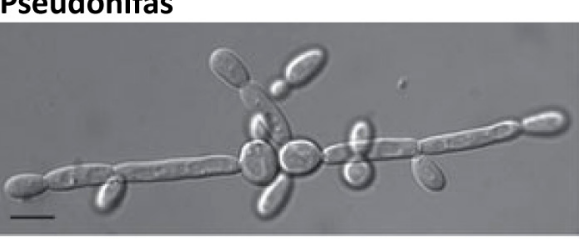

Levaduras

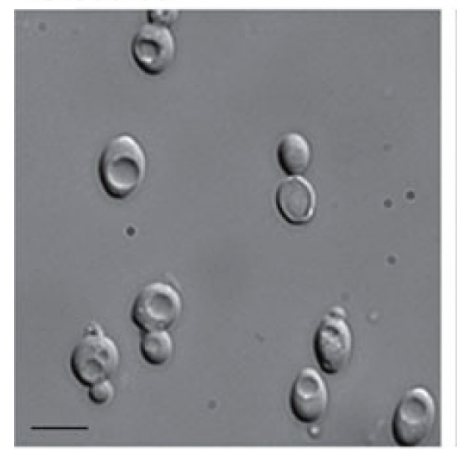

Hifas

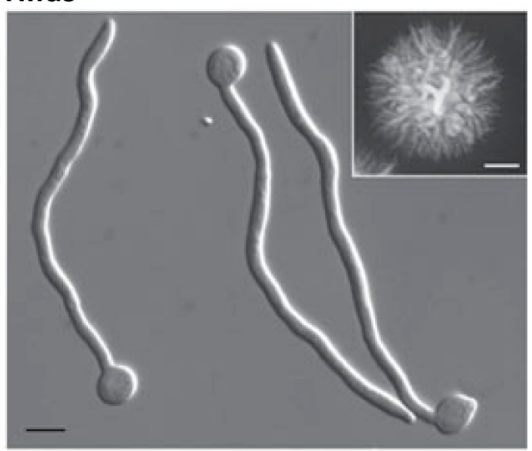

Figura 2. Distintas morfologías de $\boldsymbol{C}$. albicans. Microscopía en campo claro de diferentes formas de $C$. albicans. El panel inferior derecho muestra las hifas después de 5 días creciendo en medio Spider y su respectiva colonia. Modificado de Sudbery, 2011b. parte de la microbiota normal de sus hospedadores. Esta trayectoria evolutiva como organismo comensal le ha permitido desarrollar una serie de características que le confieren la capacidad de adaptarse rápidamente a los estímulos ambientales $(\mathrm{pH}$, presión de oxígeno, $\mathrm{CO}_{2}$, temperatura o suero sanguíneo) a los que está sujeto durante la colonización de nuevos nichos en el hospedador (Biswas et al., 2007). Esta habilidad adaptativa le permite realizar numerosas transiciones morfológicas (levadura-hifa, células white-células opaque, etc), en las que la célula cambia de forma reversible su morfología y fisiología. De esta

manera, a diferencia de la mayoría de los hongos patógenos que proliferan como levadura de gemación (p.ej., Cryptococcus neoformans) o filamentos (p.ej., Aspergillus spp.), C. albicans tiene la habilidad de crecer en tres formas diferentes, levaduras, hifas y pseudohifas, lo que se ha interpretado como una importante adaptación para sobrevivir en diferentes condiciones (Fig. 2)(Berman y Sudbery, 2002). Las levaduras son formas redondeadas unicelulares que se dividen por gemación y se separan al finalizar la citoquinesis. Las hifas son estructuras multicelulares que presentan un crecimiento hiperpolarizado dando lugar a filamentos en los que las paredes laterales del filamento se mantienen paralelas a nivel del septo. Las pseudohifas se presentan como una forma intermedia entre levaduras e hifas y se caracterizan por presentar constricciones en el plano de división de los diferentes compartimentos celulares y por crecer de forma ramificada. En cada uno de los tres tipos celulares se observa un núcleo por célula (Sudbery et al., 2004).

\section{Morfogénesis en C. albicans.}

Los procesos morfogenéticos resultan como consecuencia de la polaridad celular, la cual puede ser definida como la distribución asimétrica de diferentes orgánulos y proteínas en un lugar concreto de la célula, que le permiten crecer de forma asimétrica (Fig. 3). Debido a que las distintas proteínas que definen y regulan el crecimiento polarizado se encuentran conservadas en diferentes organismos, existe la posibilidad de que los mecanismos que regulan la polaridad celular se encuentren también conservados en eucariotas, y de ahí la importancia de su estudio.

Como se comentó antes, $C$. albicans tiene la habilidad de crecer en diferentes morfologías (Sudbery et al., 2004). La transición del crecimiento en forma de levaduras al crecimiento como hifas es inducida por estímulos ambientales que reflejan las condiciones existentes en el hospedador (temperatura de $37^{\circ} \mathrm{C}, \mathrm{pH}$ neutro ó alcalino y/o presencia de suero sanguíneo), los cuales se transmiten al interior de la célula a través de una compleja red de vías de señalización. A pesar de que en estudios recientes se ha demostrado que la transición de levadura a hifa no siempre es necesaria para la virulencia en 

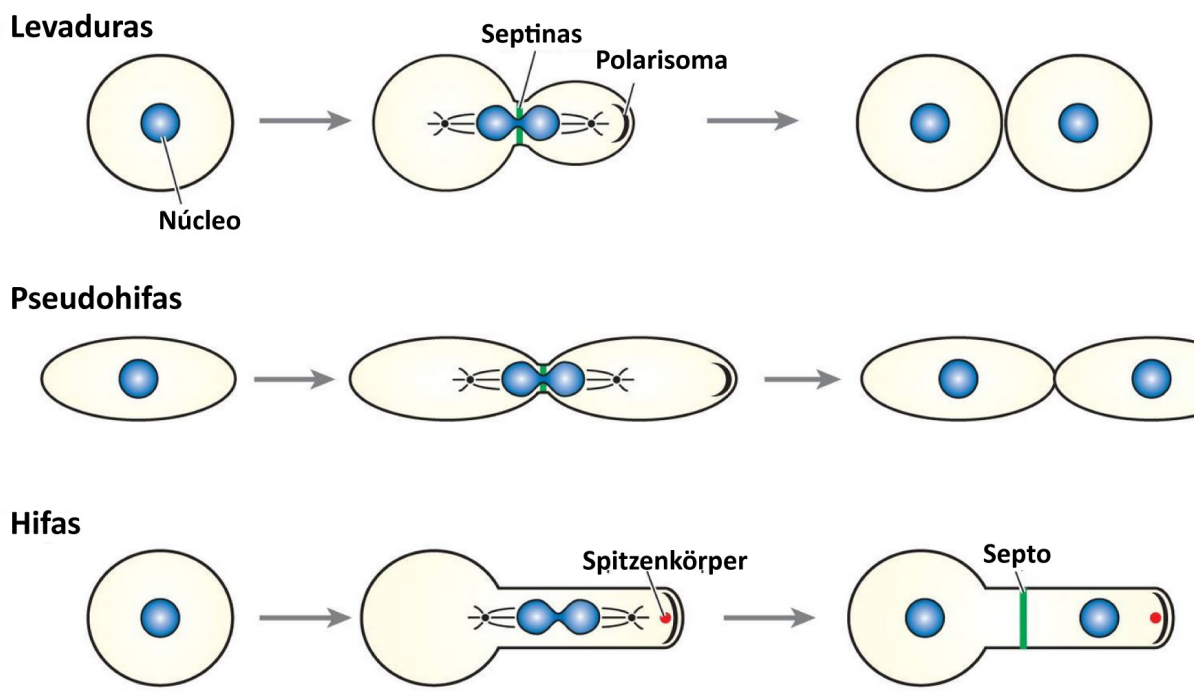

Figura 3. Crecimiento de las diferentes morfologías de C. albicans. En levaduras el ciclo comienza con la formación de una nueva yema a partir de una célula madre. Cuando la yema alcanza un tamaño adecuado, los cuerpos polares del huso (SPBs) forman el huso mitótico que separará los cromosomas a través del cuello madre-hija, lugar donde se localiza el anillo de septinas (verde). En las pseudohifas, la división nuclear también ocurre en el cuello. Las células son más alargadas y permanecen unidas después de la citoquinesis. En ambos casos, el crecimiento polarizado lo determina el polarisoma. En hifas, depende tanto del polarisoma como del "Spitzenkörper", localizados en la punta de la hifa. El núcleo se divide dentro del tubo germinativo, en la posición donde se localizará el futuro septo. Tras la mitosis, uno de los núcleos regresa a la célula madre y el otro migra hacia la punta del tubo germinativo. Modificado de Whiteway y Bachewich, 2007.

candidiasis sistémicas (Noble et al., 2010), la morfogénesis aún es considerada como un factor de virulencia importante, como lo demuestra el hecho de que cepas deficientes en la transición dimórfica presenten una virulencia reducida en candidiasis invasivas (Zacchi et al., 2010). Además, el desarrollo de hifas es importante para evadir a los fagocitos (Lorenz et al., 2004), escapar de los vasos sanguíneos (Phan et al., 2000) y para colonizar instrumental médico mediante la formación de biofilms (Nobile y Mitchell, 2006). A pesar de que una de las principales formas virulentas del hongo es la fase filamentosa, las levaduras también han sido aisladas de órganos infectados. Por tanto, los procesos morfogenéticos de $C$. albicans contribuyen de forma importante a la virulencia del hongo.

\subsection{Ciclo celular y morfogénesis en C. albicans.}

El ciclo celular de $C$. albicans está dirigido por la proteín kinasa dependiente de ciclinas Cdc28 (también conocida como Cdk1), homóloga a la del mismo nombre de $S$. cerevisiae, que desempeña un papel esencial en la morfogénesis de levaduras e hifas. Este hongo posee dos ciclinas de G1 (Ccn1 y Cln3) y dos ciclinas de $\mathrm{G} 2$ ( $\mathrm{Clb} 2$ y Clb4) para regular la progresión del ciclo (revisado en Berman, 2006; Wang, 2009). Ccn1 está presente en las fases $G 1$ y $S$ temprana y es necesaria para el mantenimiento del crecimiento polarizado, pero no para su iniciación (Loeb et al., 1999). Cln3 es la única ciclina de G1 esencial, y su pérdida produce defectos en morfogénesis: las células aumentan de diámetro y crecen en forma de hifa (Bachewich y Whiteway, 2005; Chapa y Lazo et al., 2005), por lo que parece ser importante para el control del tamaño en la fase G1. De las dos ciclinas de tipo B, sólo Clb2 es esencial (Bensen et al., 2005; Ofir y Kornitzer, 2010). Clb2 y Clb4 regulan negativamente el crecimiento polarizado, aunque en diferente medida y su ausencia produce diferentes fenotipos. Las células carentes de Clb4 crecen lentamente en forma de hifas de manera constitutiva, mientras que la eliminación de Clb2 produce un bloqueo en anafase tardía con células alargadas y núcleos divididos conectados por husos mitóticos alargados. 
Además, existe otra ciclina de G1 específica de hifas, denominada Hgc1 (Zheng et al., 2004; Li et al., 2007). A diferencia del resto de los genes de ciclinas, cuya expresión está regulada a lo largo del ciclo celular, la expresión de HGC1 se activa por las señales que inducen la filamentación, lo que permite que la elongación de las hifas sea completamente independiente del ciclo celular.

\subsection{Levaduras.}

Las levaduras de gemación mantienen un pronunciado crecimiento polarizado gracias a la GTPasa Cdc42, que regula la polarización del citoesqueleto y la exocitosis (Fig. 4)(revisado en Park y Bi, 2007; Bi y Park, 2012). Las células de S. cerevisiae crecen hacia un solo sitio cortical de forma dependiente del ciclo celular, lo que lleva a la emergencia de la yema y su crecimiento hasta telofase. A partir de ese momento, la maquinaria de crecimiento se redirige al cuello para promover la citoquinesis y la separación. En primer lugar, existe un "crecimiento apical" (desde finales de G1 hasta la fase G2) que impulsa el alargamiento celular y, a continuación, un "crecimiento isotrópico" que favorece la expansión de la yema uniformemente (revisado en Howell y Lew, 2012). De esta forma, la duración relativa de los dos tipos de crecimiento determina la forma de la yema, que normalmente es ovoide. El interruptor apical-isotrópico depende de los complejos ciclina-Cdc28.

Durante el ciclo celular de levaduras, hay tres sistemas citoesqueléticos que están polarizados: actina, septinas y microtúbulos citoplasmáticos (revisado en Oh y Bi, 2011; Bi y Park, 2012). En respuesta a señales temporales y espaciales, en $S$. cerevisiae, Cdc42 comienza a acumularse de forma polarizada durante la determinación del sitio cortical que conducirá al crecimiento de la yema (Fig. 4A)(Park y $\mathrm{Bi}, 2007)$. Cdc42 cicla entre su estado inactivo (unido a GDP) y activo (unido a GTP). Su activación es catalizada por el factor de intercambio de nucleótidos de guanina (GEF) Cdc24 y la inactivación por hidrólisis de GTP es estimulada por las proteínas activadoras de GTPasa (GAP) Bem2, Bem3, Rga1, y

A

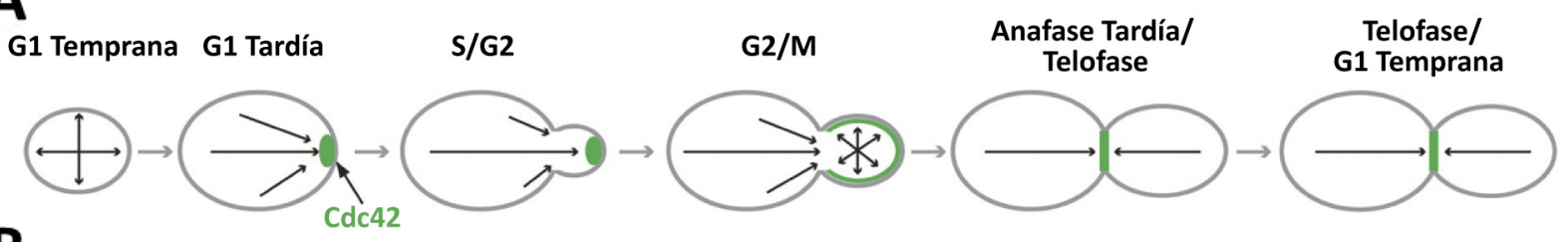

B
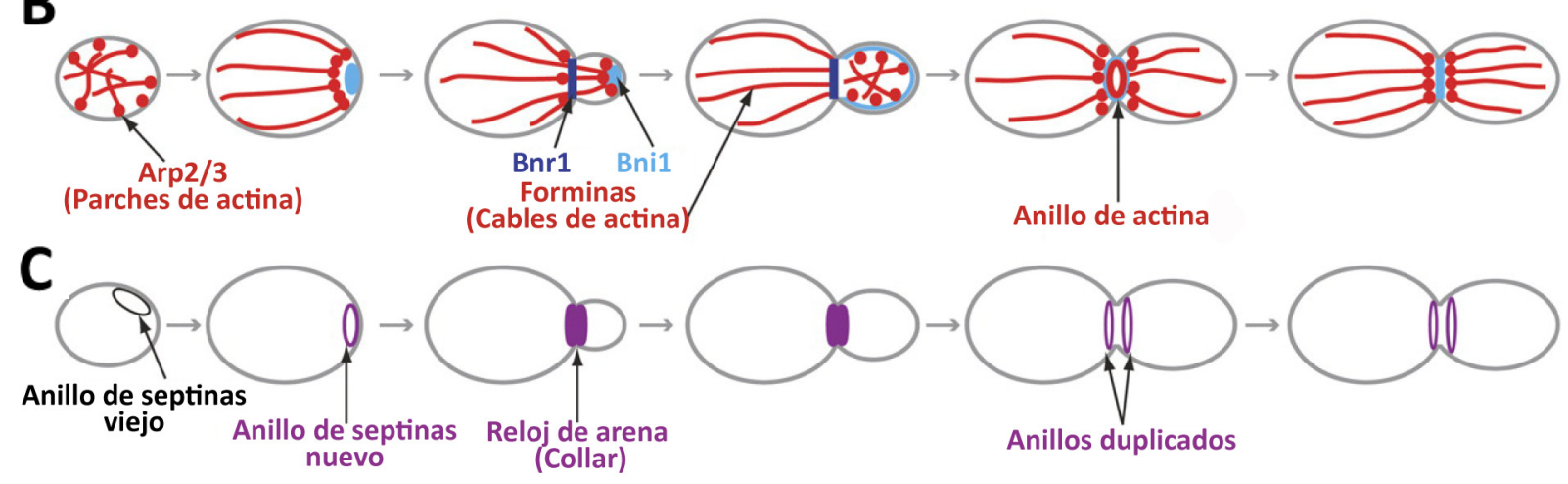

Figura 4. Cdc42, crecimiento celular y polarización del citoesqueleto durante el ciclo celular. (A). Localización de Cdc42 y dirección del crecimiento celular. (B). Organización de la actina durante el ciclo celular. Los parches de actina, formados por el complejo Arp2/3, son los sitios de endocitosis. A partir de ellos, las forminas Bni1 y Bnr1 nuclean los cables de actina que guían la exocitosis polarizada. El anillo de actina, nucleado por las forminas (principalmente Bni1), está implicado en citoquinesis. (C). Organización de septinas durante el ciclo celular. Cdc42 dirige el reclutamiento de las septinas al sitio de gemación hasta la formación del anillo cortical. Tras la emergencia de la yema, el anillo de septinas se expande adquiriendo una forma de reloj de arena en el cuello. Antes de citoquinesis, se divide en dos anillos independientes. Modificado de Bi y Park, 2012. 
Rga2. Cdc42 también está regulada por el inhibidor de la disociación de nucleótidos de guanina (GDI) Rdi1. Se cree que Cdc42 controla la exocitosis mediada por cables de actina regulando la localización y/o actividad de los forminas (Bni1 y Bnr1)(Fig. 4B). Los cables de actina actúan como "pistas" para guiar la entrega de vesículas secretoras hacia el sitio de crecimiento. Por otro lado, Cdc42 controla el ensamblaje del anillo septinas en el incipiente sitio de gemación (Fig. 4C). Como resultado, las septinas aparecen como un anillo cortical en el sitio de gemación que se expande en una estructura en forma de reloj de arena durante la emergencia de la yema. Al inicio de la citoquinesis, el reloj de arena se divide en dos anillos corticales que intercalan la maquinaria de la citoquinesis (esto se describirá más detalladamente en el Apartado 5).

Finalmente, los microtúbulos citoplasmáticos, que emanan del cinetocoro (el homólogo en levaduras del centrosoma animal), también están polarizados durante el inicio de la gemación y el crecimiento de las yemas, aunque no son necesarios para el crecimiento polarizado (Moore et al., 2009).

\subsection{De levaduras a hifas.}

C. albicans es un microorganismo exquisitamente adaptado para crecer en su hospedador humano; es capaz de desarrollar hifas en respuesta a una amplia variedad de condiciones ambientales las cuales reflejan la diversidad de microambientes presentes en el hospedador. Por ejemplo, las hifas se forman en respuesta a la presencia de suero, $\mathrm{pH}$ neutro, $\mathrm{CO}_{2}$ al $5 \%$ (la presión parcial del oxígeno en el torrente sanguíneo), N-acetil-D-glucosamina (GlcNAc) y temperatura de $37^{\circ} \mathrm{C}$. La filamentación se induce también durante el crecimiento en determinados medios sólidos, como el medio Lee o el medio Spider.

El cambio morfológico entre levaduras e hifas está también regulado por la interacción con la microflora acompañante. En este sentido, se han descrito algunos mecanismos sofisticados que resultan no sólo de la comunicación entre las células de $C$. albicans sino también de la comunicación con células bacterianas (revisado en Shareck y Belhumeur, 2011). Así, Candida es capaz de sentir la densidad de las poblaciones bacterianas aledañas mediante un mecanismo denominado quorum sensing basado en la inhibición de la filamentación mediada por el sesquiterpeno farnesol, secretado por otras células de la población (Hornby et al., 2001). En contraste, el alcohol aromático tirosol induce la formación de tubos germinativos e hifas en levaduras quiescentes (Chen et al., 2004).

\subsubsection{Regulación de la transición levadura-hifa.}

La expresión de genes específicos de hifas (HSG) está regulada negativamente por un complejo que incluye al corepresor transcripcional Tup1 en asociación con Nrg1 o Rfg1. Estos complejos son necesarios para mantener reprimida la expresión de los genes específicos de hifas durante el crecimiento levaduriforme, de tal manera que los mutantes carentes de cualquiera de ellos crecen constitutivamente como pseudohifas en las que los HSGs están desreprimidos.

La regulación de la expresión de los HSGs es llevada a cabo por un grupo de factores de transcripción que incluyen a Efg1, Cph1, Cph2, Tec1, Flo8, Czf1, Rim101 y Ndt80 (revisado en Sudbery, 2011b). Efg1 es necesaria para la formación de hifas en respuesta a estímulos como el suero, $\mathrm{CO}_{2}$, $\mathrm{pH}$ neutro o presencia de GlcNAc en medios líquidos y también en medios sólidos. Por otro lado, Cph1 y su vía de activación sólo son necesarias para la formación de filamentos en medio Spider pero no en medio líquido, por lo que Efg1 puede ser considerado el principal regulador de la formación de hifas en respuesta a múltiples 
condiciones. Además, se sabe que Efg1 y Cph1 son activados por distintas vías de señalización, siendo la ruta del AMP cíclico (cAMP) la activadora de Efg1, mientras que Cph1 depende de la ruta de las MAPK kinasas. Estas dos vías son a su vez activadas mediante estimulación por parte de la proteína Ras1 (Fig. 5).

C. albicans posee una única forma de la adenilato ciclasa, Cyr1, que integra una serie de estímulos ambientales, siendo esencial para el crecimiento filamentoso pero no para el crecimiento en forma de levaduras. Un requisito necesario en todas las condiciones que inducen filamentación es la incubación a temperaturas elevadas. El sensor de la temperatura es la proteína Hsp90 (implicada en la respuesta a estrés térmico), que se inactiva a $37^{\circ} \mathrm{C}$ y libera la inhibición que mantiene sobre Ras1 durante el crecimiento a temperaturas inferiores. La señalización por parte de Hsp90 requiere una vía del cAMP intacta, pues mutaciones en cualquiera de los componentes que se encuentran por encima de Efg1 bloquean la inducción de hifas mediada por la inhibición de Hsp90 (Shapiro et al., 2009).

\subsection{Crecimiento polarizado de las hifas.}

Al contrario de lo que sucede en levaduras y pseudohifas, el crecimiento polarizado en hifas es continuo durante todo el ciclo celular, por lo que el citoesqueleto de actina permanece continuamente polarizado. El crecimiento de las hifas está mediado por una exocitosis polarizada dependiente del

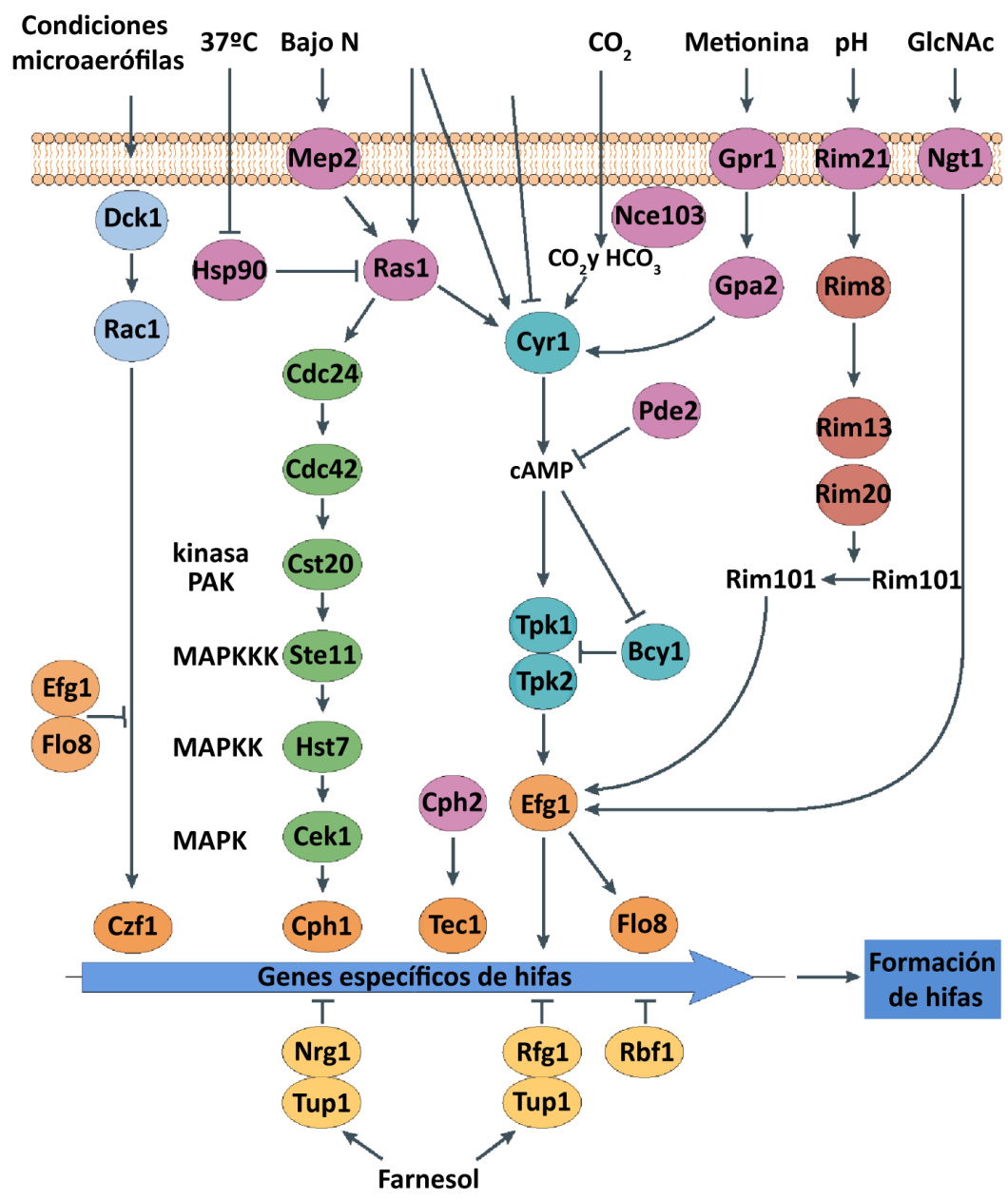

Figura 5. Rutas de transducción de señales que activan la expresión de los genes específicos de hifas. Varias señales ambientales activan la transcripción de genes implicados en la formación de filamentos, a través de múltiples rutas de señalización. También se muestran los reguladores negativos como Tup1, Rfg1, Nrg1 y Rbf1. Modificado de Sudbery, 2011 b. 
citoesqueleto hacia la punta de la hifa y por fuerzas de expansión citoplasmáticas que empujan el citoplasma contra la pared apical flexible (revisado en Riquelme, 2013). Las vesículas de secreción aportan el material para la expansión de la membrana plasmática y las enzimas implicadas en la síntesis de la nueva pared celular. Estas vesículas viajan a lo largo de los cables de actina, que se polarizan hacia la punta. La formina Bni1 y proteínas asociadas a vesículas, como Sec4, Mlc1 y Sec2, se acumulan en un orgánulo específico cerca de la punta de la hifa que ha sido denominado Spitzenkörper (Crampin et al., 2005; Bishop et al., 2010; Jones y Sudbery, 2010), similar al de hongos filamentosos (Fig. 6)(Virag y Harris, 2006). El Spitzenkörper es una región subapical rica en vesículas tanto exocíticas como endocíticas importante para el crecimiento de las hifas, y su posición en la hifa determina la direccionalidad de crecimiento (revisado en Steinberg, 2007; Sudbery, 2011a; Riquelme y Sánchez-León, 2014). Puede considerarse como un centro de suministro de vesículas, que recibe vesículas liberadas desde el aparato de Golgi y genera vesículas exocíticas hacia la punta de la hifa. Tanto la localización de proteínas como los estudios de su dinámica sugieren que el Spitzenkörper es distinto del exocisto y del polarisoma. El exocisto es un complejo octamérico que regula el anclaje de las vesículas a la membrana plasmática (Chen et al., 2015; Chavez-Dozal et al., 2016). Los componentes del exocisto y del polarisoma se localizan en forma de media luna en la punta de la hifa (Jones y Sudbery, 2010), y determinan la región de la hifa donde se fusionan las vesículas de secreción, contribuyendo a la forma de la hifa (Caballero-Lima et al., 2013). Los mutantes del exocisto en C. albicans muestran distintos fenotipos, incluyendo defectos en la formación de biofilms, filamentación y secreción (Li et al., 2007; Luo et al., 2014; Chavez-Dozal et al., 2016).

La formación de hifas es el resultado de un crecimiento apical sostenido en el tiempo, y esto necesita de la activación de la GTPasa Cdc42 en la punta de la hifa. De hecho, cepas que expresan niveles reducidos de Cdc42 o de su activador Cdc24 son viables pero incapaces de responder al suero (Bassilana et al., 2003; Bassilana et al., 2005). Además, durante la inducción de la filamentación Cdc42 y

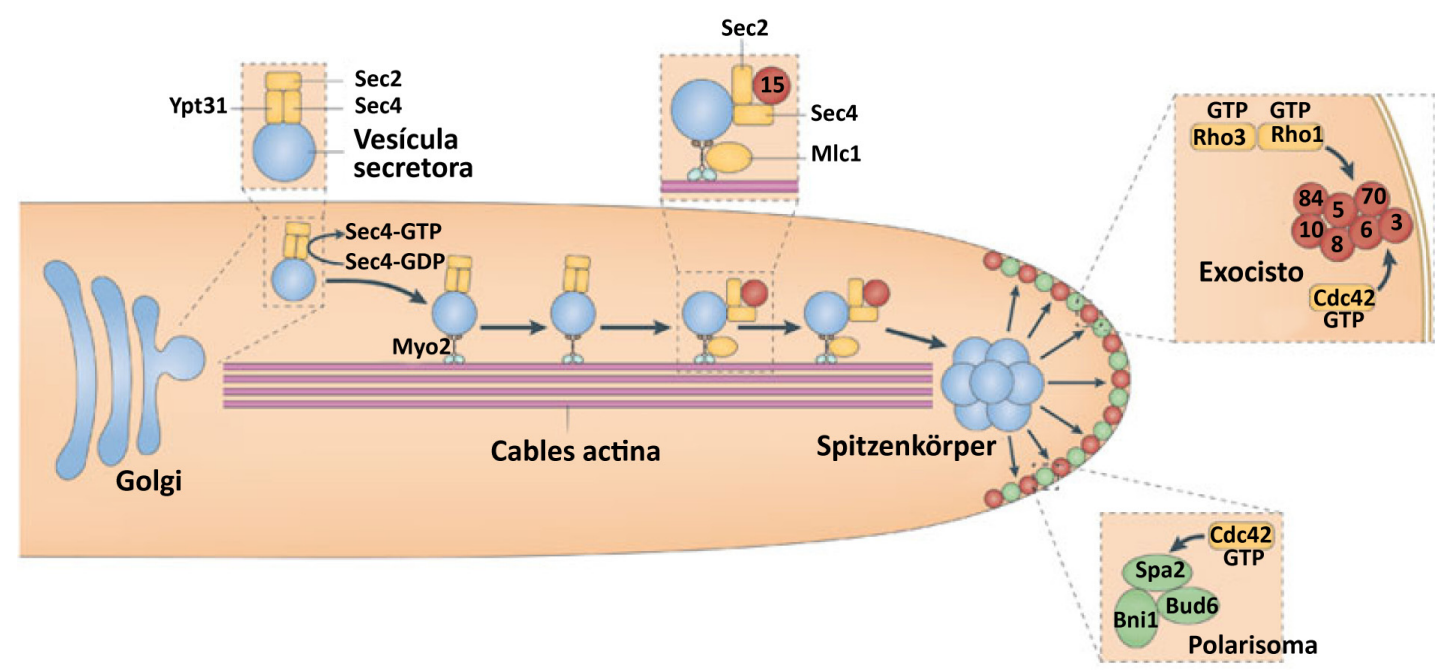

Figura 6. Modelo de liberación de vesículas secretoras en la punta de la hifa basados en el crecimiento polarizado de S. cerevisiae. Desde el trans-Golgi network (TGN), la GTPasa Ypt31 recluta a Sec2 en la superficie de las vesículas nacientes. Sec2 activa la Rab GTPasa Sec4, y la vesícula puede dejar el TGN. El componente del exocisto Ypt31 es sustituido por Sec15, el cual físicamente interactúa con Sec2 y Sec4. Las vesículas son transportadas juntas hacia la punta a través de los cables de actina. Estos cables están formados por la formina Bni1 ayudada por el polarisoma, el cual se localiza en la superficie celular y está formado por Spa2 y Bud6. La miosina Myo2, forma un complejo con la cadena ligera de la miosina (Mlc1), proporcionando la fuerza para el transporte de vesículas. Las vesículas se acumulan en una región subapical llamada Spitzenkörper antes de la unión con el exocisto, el cual está compuesto por Sec3, Sec5, Sec6, Sec8, Sec10, Sec15, Exo70 y Exo84 . El contacto inicial antes de la fusión se cree que es entre Sec15 y Sec10. La fusión con la membrana plasmática está mediada por el v-SNARE Sec9 en la vesícula y las SNAREs Sec9 y Sso2 en la membrana plasmática. Modificado de Sudbery, 2011b. 
Cdc24 se localizan en la punta de la hifa (Hazan et al., 2002; Bassilana et al., 2005), donde se acumula Cdc42 activo (Corvest et al., 2013). Existen dos GAPs para Cdc42 en C. albicans, codificados por los genes $B E M 3$ y RGA2. Un mutante carente de ambos forma hifas en condiciones que normalmente sólo permiten la formación de pseudohifas (Court y Sudbery, 2007).

Resultados de los últimos años están poniendo de manifiesto que las proteín kinasas, y en particular Cdc28, desempeñan un papel crucial en el establecimiento y mantenimiento del crecimiento polarizado de las hifas, habiéndose identificado un conjunto de dianas importantes en este proceso (revisado en Sudbery, 2011b; Vázquez de Aldana y Correa-Bordes, 2012; Wang, 2016). La actividad CDK es esencial para el crecimiento polarizado, ya que la formación de hifas se interrumpe en las células en las que la expresión de Cdc28 está reprimida o se inhibe y las células que carecen de la ciclina Hgc1 inician los tubos germinales, pero rápidamente se despolarizan (Zheng et al., 2004). En los últimos años se ha demostrado que Hgc1-Cdc28 tiene la capacidad de fosforilar directamente y regular de manera coordinada múltiples maquinarias celulares responsables de diferentes aspectos del desarrollo de las hifas. Así, la inducción de hifas causa la fosforilación de Rga2 de forma dependiente de Hgc1-Cdc28, produciendo su separación de Cdc42 en la punta de las hifas y su acumulación en el citoplasma. La mutación de los sitios de fosforilación en Rga2 reveló que la fosforilación por Hgc1-Cdc28 impide la localización de Rga2 en la punta de las hifas (Zheng et al., 2007). Hgc1-Cdc28 también regula la secreción polariza al menos a dos niveles. Primero, fosforilando a Sec2, el GEF que activa a la GTPasa Rab Sec4, y regulando su localización (Bishop et al., 2010). El bloqueo de esta fosforilación provoca el desarrollo anormal de las hifas. Segundo, a través de la subunidad del exocisto Exo84, que tras su fosforilación por Hgc1-Cdc28 cambia su afinidad por fosfatidilserina, y se separa de la membrana plasmática (Caballero-Lima y Sudbery, 2014). Esta fosforilación es necesaria para la extensión eficiente de las hifas. Otra de las dianas del complejo Hgc1-Cdc28 recientemente identificada es el componente del polarisoma Spa2, que durante el crecimiento hifal es fosforilado por los complejos Hgc1-Cdc28 y Clb2-Cdc28 para mantener su localización en la punta de la hifa (Wang et al., 2016). El bloqueo de esta fosforilación provoca que Spa2 se localice en el septo, alterando la morfología de las hifas. La localización de Spa2 en la punta de la hifa también depende de la kinasa Cbk1-Mob2, cuya subunidad reguladora Mob2 también es sustrato de Hgc1-Cdc28 (Gutiérrez-Escribano et al., 2011). Los mutantes de Mob2 que no pueden ser fosforilados presentan defectos en el mantenimiento del crecimiento polarizado. Finalmente, los filamentos son cadenas de células alargadas cuya formación requiere la supresión de la separación celular después de la citoquinesis. El factor de transcripción Ace2 activa los genes que codifican enzimas tales como quitinasas y glucanasas necesarias para la degradación del septo, lo que lleva a la separación de las células al final del ciclo celular (Weiss, 2012; Calderón-Noreña et al., 2015). Se ha descrito la existencia de un mecanismo que impide que Ace2 active sus genes diana en las hifas. Efg1 es un factor de transcripción necesario para la activación de la expresión de los HSG. Curiosamente, Hgc1-Cdc28 fosforila a Efg1 en un único sitio, y esta fosforilación le confiere especificidad para unirse a los promotores normalmente ocupados por Ace2, bloqueando así la expresión de genes de separación e impidiendo la degradación del septo (Wang et al., 2009).

Ccn1-Cdc28 también desempeña un papel importante en el desarrollo de las hifas, actuando junto con la kinasa Gin4 en la fosforilación y regulación de la septina Cdc11 (Sinha et al., 2007)(se desarrollará en el Apartado 5.4) y al mismo tiempo el complejo Clb2-Cdc28 regula directamente la actividad de Gin4 fosforilándola en sitios localizados cerca de su dominio kinasa (Li et al., 2012a). 


\section{Las septinas.}

Las septinas pertenecen a una familia de proteínas altamente conservadas en eucariotas superiores que están presentes en animales, hongos, y algas, pero, curiosamente, están ausentes en plantas (revisado en Weirich et al., 2008; Oh y Bi, 2011; Spiliotis y Gladfelter, 2012; Fung et al., 2014). El número de genes de septinas oscila entre un mínimo de dos en Caenorhabditis elegans (UNC-59 y UNC-61) y un máximo de 14 en los seres humanos (SEPT1 a SEPT14), y en muchos organismos existen formas alternativas de procesamiento (Lindsey y Momany, 2006; Cao et al., 2007; Pan et al., 2007). Por ejemplo, a partir del gen SEPT9 se producen 18 mRNAs diferentes y un total de 15 polipéptidos (Mcllhatton et al., 2001). Todas ellas son proteínas de unión a GTP capaces de ensamblarse formando complejos hetero-oligoméricos y estructuras altamente ordenadas que incluyen filamentos y anillos.

Inicialmente, las septinas fueron descubiertas hace 40 años por Lee Hartwell en S. cerevisiae cuando realizaba la búsqueda de genes reguladores del ciclo de división celular $(C D C)$. Estos estudios permitieron identificar 4 genes (CDC3, CDC10, CDC11 y CDC12) cuya mutación producía defectos en citoquinesis en las células (Hartwell, 1971). Posteriormente se descubrieron las septinas específicas de esporulación (SPR3 y SPR28) y una séptima proteína con homología con septinas, SHS1 (Seventh Homolog of Septin). La utilización de técnicas de inmuno-microscopía mostró que las proteínas codificadas por estos genes se disponen en forma de anillos en el cuello de septación, razón por la cual el científico estadounidense John Pringle las denominó septinas (Haarer y Pringle, 1987).

La organización de las estructuras supramoleculares comienza al inicio de la fase G1, cuando la GTPasa Cdc42 define el sitio de crecimiento polarizado, formando un foco único en la corteza celular asociado a la proteína de andamiaje Bem1 y a su GEF Cdc24. Las septinas son reclutadas a este punto y se asocian con la membrana plasmática gracias a la interacción de los motivos poli-básicos de las septinas con los fosfolípidos de membrana (Zhang et al., 1999; Casamayor y Snyder, 2003; Bertin et al., 2010). Entonces sufren un cambio en la organización y pasan a formar un anillo de aproximadamente $1 \mu \mathrm{m}$ de diámetro, cambio que requiere la hidrólisis del GTP unido a Cdc42 y sus factores GAP (Gladfelter et al., 2002; Caviston et al., 2003; Kadota et al., 2004). Un estudio reciente ha demostrado que la acumulación de las septinas inhibe la actividad de $\mathrm{Cdc} 42$, formando un bucle de retroalimentación negativa, y que la exocitosis dirigida hacia el centro del acúmulo de Cdc42 y septinas contribuye a crear un agujero en la densidad de septinas que alivia la inhibición de Cdc42. Este aporte continuo de membrana contribuye a crear el anillo incipiente de septinas, lo que al mismo tiempo genera un borde claro que limita la actividad Cdc42 y la exocitosis a su interior, y por lo tanto claramente delinea la identidad de célula hija (Okada et al., 2013). En este proceso, Cdc42 no sólo es necesario para activar la exocitosis polarizada, sino que también desempeña un papel activo en el reclutamiento de las septinas y su ensamblaje en filamentos de forma directa y a través de su efector Gic1 (Sadian et al., 2013). Tras la emergencia de la yema, el anillo de septinas se convierte en una estructura estable en forma de reloj de arena en el cuello entre la célula madre y la hija que ha sido denominada collar. Finalmente, antes de la citoquinesis el collar se divide dando lugar a dos anillos que flanquean la región donde se va a formar el septo de división. Cuando la formación del septo se completa y las células comienzan una nueva fase G1, los dos anillos se desensamblan para volver a formarse en el futuro sitio de gemación (Fig. 7A).

Un nivel adicional de complejidad se estableció al estudiar la dinámica de las septinas mediante análisis de FRAP (Fluorescence Recovery After Photobleaching). Durante los estados iniciales del 
ensamblaje del collar, las septinas son móviles (estado fluid) en el incipiente sitio de gemación, basados en la rápida recuperación de la fluorescencia en esta región de las células que contienen las septinas marcadas con GFP (Caviston et al., 2003; Dobbelaere et al., 2003). Una vez la yema ha emergido, las septinas se encuentran en un estado congelado (frozen) en el cuello (pues la zona quemada en el collar no recupera su fluorescencia). Posteriormente, cuando el collar se duplica para permitir la ingresión de la membrana plasmática durante la contracción del anillo de actomiosina (AMR), las septinas son de nuevo dinámicas.

En C. albicans, existen 7 genes codificantes de septinas, los cuales muestran un alto grado de conservación con sus homólogos en $S$. cerevisiae, por lo que fueron denominados de la misma forma (excepto SHS1, que en C. albicans se conoce como SEP7). De ellos, solamente CDC3 y CDC12 son esenciales para el crecimiento de las células. Los genes CDC10 y CDC11 no son esenciales en C. albicans, aunque las células carentes de cualquiera de ellos presentan defectos morfológicos durante el crecimiento en forma de levaduras y dan lugar a filamentos más curvados que las cepas silvestres cuando se induce la filamentación, lo que indica que las septinas son necesarias para mantener la estabilidad del eje longitudinal del crecimiento polarizado (Warenda y Konopka, 2002). Así mismo, se demostró que los genes SPR3 y SPR28, ortólogos a los genes que codifican las septinas específicas de

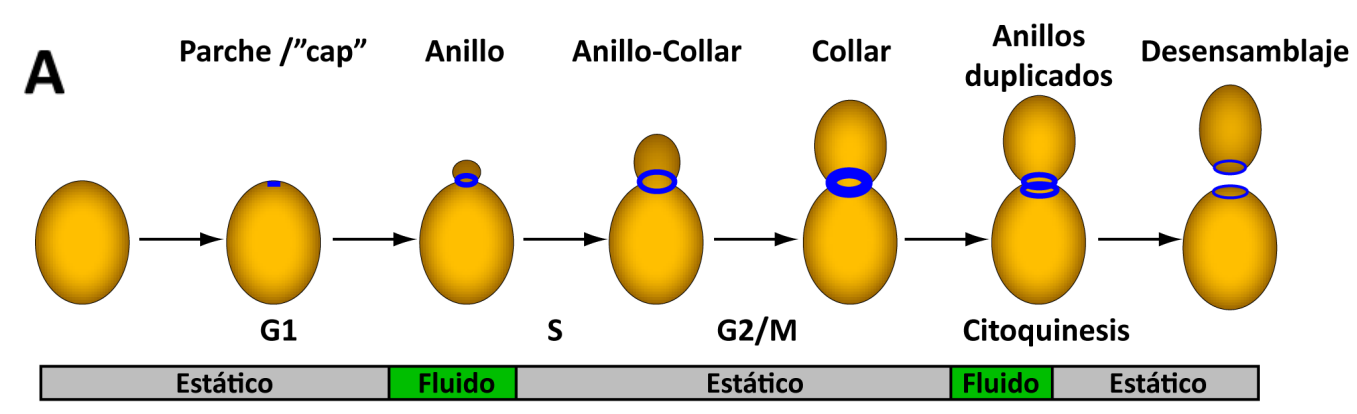

B

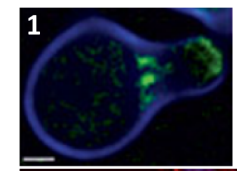

4

$=$ Anillo de septinas

InIl Banda basal de septinas

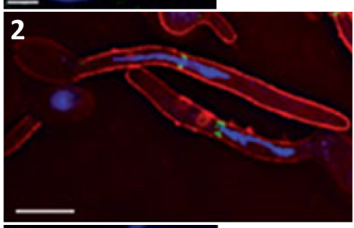

3
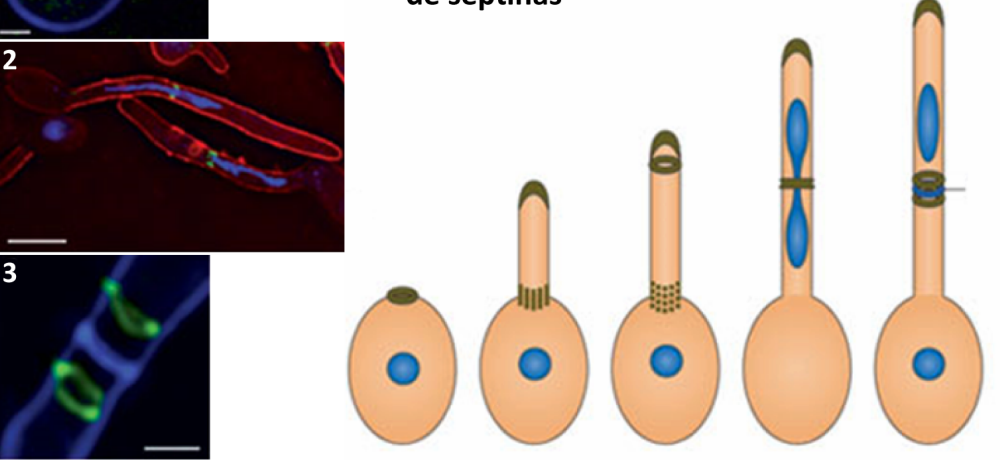

"Cap"de septinas

Núcleo

Figura 7. Dinámica de las septinas. (A). En levaduras, la dinámica del anillo de septinas depende del ciclo celular. Los momentos de fluidez coinciden con cambios en la topología de la membrana plasmática, emergencia de la yema y citoquinesis. La barra representa la distribución de los estados estático (gris) y fluido (verde) a lo largo del ciclo celular. (B). Las septinas en el desarrollo hifal de $C$. albicans. 1. Al inicio de la evaginación del tubo germinal, una banda basal de septinas se hace visible en la base y en la punta. Se muestra la septina Cdc10 marcada con la YFP. El contorno de la hifa (azul) ha sido teñido con Concavalina-Alexaflúor. 2. El crecimiento del tubo germinativo da lugar a que la banda basal desaparezca para formar un anillo de septinas en el interior de la hifa en crecimiento. En ese momento, el núcleo (teñido con DAPI; color azul) migra fuera del cuerpo de la hifa para realizar la mitosis en el tubo germinativo. La tinción con Concavalina-Texas Red marca el contorno de las hifas. 3. El anillo de septinas se divide en dos, permitiendo la formación del septo en medio de las dos estructuras. Tinción como en la imagen 1. 4. Esquema del primer ciclo celular durante el desarrollo hifal. Modificado de Sudbery, 2011b. 
esporulación, no se expresan durante el crecimiento levaduriforme o hifal. Mediante purificación de los complejos de septinas en levaduras e hifas y análisis por espectrometría de masas, se ha comprobado que la composición de los anillos es similar en ambas morfologías y presenta una estequiometría de 2 moléculas de Cdc3, 2 de Cdc12, 1-2 de Cdc10, 1 de Cdc11, y $\leq 1$ de Sep7 (Kaneko et al., 2004).

Durante el crecimiento en forma de levaduras, la distribución y dinámica del citoesqueleto de septinas es similar al descrito en S. cerevisiae (Fig. 7A). Durante la inducción del crecimiento hifal se producen cambios en la organización y en la dinámica de las estructuras de septinas (Fig. 7B)(Sudbery et al., 2004; González-Novo et al., 2008). En las hifas se han descrito tres tipos de estructuras diferentes de septinas. La primera se localiza en la base del tubo germinativo cuando éste comienza a emerger y se ha denominado banda basal. Las septinas se organizan como barras paralelas al eje de crecimiento polarizado, con un patrón similar al que ocurre en los shmoos de $S$. cerevisiae. A medida que el tubo germinativo crece para formar la hifa, las septinas se localizan en el ápice, formando una estructura conocida como cap. Finalmente, cuando la hifa adquiere una longitud determinada, parte de las septinas del cap quedan en las paredes laterales de la hifa y forman un anillo similar al de levaduras, que determina el plano de división donde se ensamblará el septo que divide el cuerpo del primer compartimento hifal (Warenda y Konopka, 2002; Sudbery et al., 2004).

\subsection{De la estructura primaria al anillo de septinas.}

Todas las septinas presentan una organización y estructura primaria común, con un dominio de unión a GTP central altamente conservado (GTPasa), seguido por una región común a todas las septinas que ha sido denominada "elemento único de septinas" (Septin Unique Element o SUE), una secuencia altamente conservada que es importante para la asociación de los monómeros (Fig. 8A)(revisado en Douglas et al., 2005; Versele y Thorner, 2005; Pan et al., 2007; Weirich et al., 2008; Estey et al., 2011; Fung et al., 2014). Este dominio central está flanqueado por dos regiones más variables a los extremos. En el extremo amino existe una región rica en aminoácidos básicos que es necesaria para su interacción con los fosfoinositoles de membrana, mientras que con algunas excepciones en el extremo C-terminal (CTE) poseen una hélice superenrollada (coiled-coil). A diferencia de otras proteínas que unen GTP de tipo Ras, las septinas son capaces de polimerizar y formar complejos oligoméricos básicos.

En los últimos años se han obtenido grandes avances en el conocimiento de la estructura y organización de los filamentos gracias a estudios de microscopía electrónica en C. elegans y S. cerevisiae y a la resolución de la estructura cristalográfica del complejo humano formado por Sept2, Sept6, Sept7 (John et al., 2007; Sirajuddin et al., 2007; Barral y Kinoshita, 2008; Bertin et al., 2008; Weirich et al., 2008). Estos estudios estructurales confirmaron que la formación de complejos y filamentos depende del dominio GTPasa en lugar de los coiled-coils, como se pensaba anteriormente.

La microscopía electrónica del complejo de septinas de C. elegans demostró que las dos septinas están alineadas en un patrón lineal de cuatro densidades, y mediante marcaje de las distintas subunidades con la proteína fluorescente verde (GFP) se comprobó que el orden de las subunidades era UNC-59/ UNC-61/UNC-61/UNC-59, por lo que es no polar. La polimerización de estos tetrámeros en estructuras de orden superior se produce por interacción entre dos subunidades UNC-59, por lo que los filamentos resultantes también son no polares (John et al., 2007). Por otro lado, la resolución de la estructura cristalográfica del complejo de septinas humanas reveló que las distintas subunidades interactúan entre ellas mediante dos interfaces diferentes: una a través del dominio de unión a nucleótidos que 

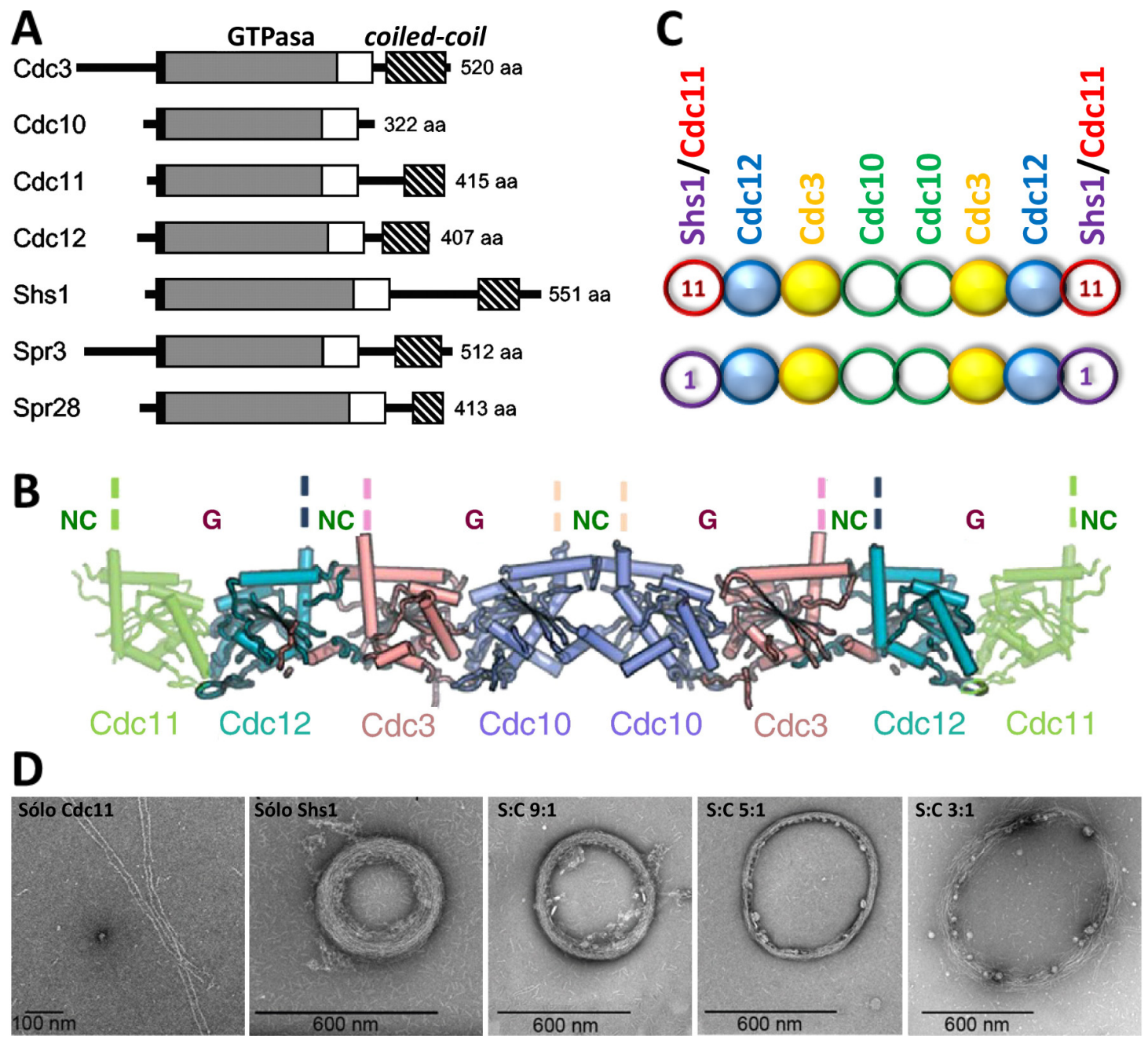

Figura 8. Complejos de septinas y el ensamblaje de sus filamentos. (A). Comparación de las septinas de S. cerevisiae. Se muestran diagramas de sus estructuras. Negro, región rica en aminoácidos básicos implicada en la unión a los fosfoinosítidos de las membranas ; gris, dominio GTPasa ; blanco, dominio conservado característico de las septinas (SUE); rayado, coiled-coil. La longitud de cada septina se indica tras el diagrama de la proteína. (B). Representación esquemática de la disposición de los monómeros de septinas en complejos octaméricos de S. cerevisiae basado en la estructura de las septinas humanas. Los tetrámeros se unen cabeza con cabeza a través de $\mathrm{Cdc10}$. Las distintas subunidades se unen a través de interfaces G (unión de GTP o GDP) y NC (extremos N- y C-terminal) alternantes. Las líneas discontinuas indican el CTE, no incluido en la estructura cristalográfica (C). Representación esquemática de los octámeros homodiméricos caracterizados in vitro al expresar las septinas de S. cerevisiae en bacterias. (D) Polimerización de octámeros con Cdc11 o con Shs1 en condiciones de baja salinidad. Los complejos de Cdc11 forman filamentos lineales pareados, mientras que los de Shs1 polimerizan en forma de anillos. La relación entre Shs1 y Cdc11 (S:C) modula el diámetro de los anillos: al aumentar la proporción de Cdc11, aumenta el diámetro del anillo. Imágenes modificadas de Douglas et al., 2005 (A), Bertin et al., 2010 (B) y García et al., 2011 (D).

ha sido denominada interfaz $\mathrm{G}$ y otra que implica interacciones entre los extremos $\mathrm{N}$ y $\mathrm{C}$ terminal, llamada interfaz NC (Fig. 8B); los coiled-coils se extienden de forma perpendicular a la dirección del filamento. Aunque la estructura básica de los filamentos de septinas humanas descrita inicialmente fue un hexámero lineal no polar Sept7-Sept6-Sept2-Sept2-Sept6-Sept7, en el que las distintas subunidades se unen mediante interfaces G y NC que alternan (Sirajuddin et al., 2007), posteriormente se describió que son octámeros que contienen Sept9 en los extremos (Kim et al., 2011; Sellin et al., 2011). En S. cerevisiae, al igual que en humanos, se forman hetero-tetrámeros compuestos por una molécula de cada una de las septinas $\mathrm{Cdc3}, \mathrm{Cdc10}, \mathrm{Cdc11}$ y Cdc12 con el orden Cdc11-Cdc12-Cdc3-Cdc10. Dos de estos hetero-tetrámeros se asocian a su vez a través de $\mathrm{Cdc10}$, dando lugar a la unidad básica de polimerización de los filamentos, que es el octámero no polar Cdc11-Cdc12-Cdc3-Cdc10-Cdc10-Cdc3- 
Cdc12-Cdc11 (Bertin et al., 2008)(Fig. 8B). Finalmente, la unión de varios octámeros a través de la subunidad Cdc11 conduce a la formación de estructuras de orden superior, como los filamentos.

Estudios bioquímicos indican que las cinco septinas mitóticas en $S$. cerevisiae forman al menos dos hetero-octámeros palindrómicos distintos (Cdc11-Cdc12-Cdc3-Cdc10-Cdc10-Cdc3-Cdc12-Cdc11 o Shs1-Cdc12-Cdc3-Cdc10-Cdc10-Cdc3-Cdc12-Shs1)(Fig.8C)(Bertin et al., 2008; Garcia et al., 2011), pero no existen evidencias de la existencia de hetero-octámeros con Cdc11 en un extremo y Shs1 en el otro, ni in vitro (Garcia et al., 2011) ni in vivo (Iwase et al., 2007; Garcia et al., 2011; McMurray et al., 2011; Finnigan et al., 2015b). Cada octámero tiene un diámetro de 4-5 nm y 25-32 nm de longitud. Mediante experimentos in vitro se demostró que la incorporación de Cdc11 o Shs1 en los octámeros cambia drásticamente sus propiedades de polimerización. Así, cuando los octámeros con Cdc11 en los extremos purificados en bacterias se diluyen en un tampón de baja fuerza iónica ( $\mathrm{NaCl} 10 \mathrm{mM}$ ) son capaces de polimerizar a través de sus extremos formando largos filamentos rectos pareados, mientras que los octámeros que contienen Shs1 forman estructuras similares a anillos grandes, de varias capas en los que los octámeros interactúan tanto por ambos extremos como lateralmente, a menudo en forma escalonada, lo que permite una mayor extensión longitudinal. Además, se comprobó que cuando se mezclaban octámeros Shs1 con cantidades crecientes de octámeros Cdc11 se producía un aumento en el diámetro (y una reducción en el grosor) de los anillos resultantes (Garcia et al., 2011) (Fig. 8D). Más recientemente, mediante ensayos FRET (Förster Resonance Energy Transfer), Booth y colaboradores han demostrado que los octámeros Cdc11 tienen capacidad para formar filamentos mediante uniones homotípicas Cdc11-Cdc11 estables, mientras que los octámeros Shs1 son incapaces de hacerlo. Sin embargo, los octámeros Shs1 si son capaces de formar filamentos mediante uniones heterotípicas Shs1-Cdc11 estables (Booth et al., 2015). A pesar de que estos estudios bioquímicos aportan gran información sobre las reglas que gobiernan la polimerización en estructuras de orden superior, también se ha descrito que la arquitectura supramolecular está influenciada por la interacción con monocapas lipídicas que contienen fosfatidilinositol-4,5-bisfosfato (PIP2)(Bertin et al., 2010). La superficie lipídica favorece la asociación lateral de los dominios globulares, lo que hace que los filamentos tengan tendencia a formar láminas de filamentos asociados lateralmente que a menudo contienen otros filamentos ortogonales espaciados periódicamente, formando una red.

Una cuestión biológica importante es entender cómo se ensamblan los octámeros in vivo para dar lugar a las distintas estructuras de orden superior que forman las septinas, como los anillos, espirales u otras estructuras corticales, ya que desempeñan importantes funciones celulares (revisado en McMurray y Thorner, 2009; Bertin y Nogales, 2012), y en los últimos años ha habido cierta controversia sobre este asunto. Los trabajos iniciales sobre la estructura y función septinas en $S$. cerevisiae están basados en estudios descriptivos mediante microscopía de fluorescencia y condujeron a un debate sobre la orientación de los filamentos en el reloj de arena y el mecanismo de cambio de orientación del filamento durante la transición de reloj de arena a doble anillo. Mediante el uso de microscopía de fluorescencia polarizada, Vrabioiu y Mitchison propusieron que la estructura en forma de reloj de arena estaba formada por filamentos alineados a lo largo del eje madre-yema y que durante la citoquinesis experimentan un giro de $90^{\circ}$, disponiéndose de forma circunferencial y perpendiculares al eje mayor (Vrabioiu y Mitchison, 2006; Vrabioiu y Mitchison, 2007). Posteriormente, usando la misma técnica con anisotropía fluorescente, De May y colaboradores mostraron que los filamentos se organizan por pares in vivo en S. cerevisiae, Ashbya gossypii y células epiteliales de mamíferos y que el cambio de orientación 
del filamento de $90^{\circ}$ incluye el desmontaje y montaje de los filamentos (DeMay et al., 2011). Mediante microscopía electrónica y reconstrucción tomográfica 3D, Bertin y colaboradores propusieron que la arquitectura del collar o reloj de arena estaría formada por pares de filamentos unidos estrechamente dispuestos de forma circunferencial y con los que se entrecruzan filamentos axiales individuales. Los filamentos axiales se cruzan con los circunferenciales a un intervalo regular y definen la distancia que separa unos filamentos circunferenciales de otros, que corresponde a la longitud de un octámero, $30 \mathrm{~nm}$ (Bertin et al., 2012)(Fig. 9A).

El modelo actual de la arquitectura de las septinas a lo largo del ciclo celular se basa en el trabajo de Ong y colaboradores, que visualizaron las estructuras de septinas en esferoplastos (células que han perdido su pared celular pero siguen vivas) usando microscopía electrónica de réplicas de platino (Fig. 9B)(Ong et al., 2014). Según este modelo, coincidiendo con la emergencia de la yema, el anillo de septinas naciente consiste en filamentos dobles de septinas organizados paralelamente al eje madrehija (Fig.9B, 1). En su maduración, el reloj de arena adquiere filamentos sencillos ortogonales al eje madre-hija (azul en la Fig. 9B) que se cruzan con los filamentos dobles a intervalos regulares, por lo que al final de anafase, el collar maduro consta de dos conjuntos simétricos de filamentos dobles conectados por filamentos individuales (Fig. 9B, 2). Estos autores hipotetizaron que los filamentos ortogonales contienen Shs1, ya que los octámeros purificados con Cdc11 polimerizan como filamentos dobles, mientras que los octámeros con Shs1 forman filamentos sencillos. Finalmente, durante citoquinesis, los filamentos dobles del reloj de arena se desensamblan y se reorganizan en filamentos
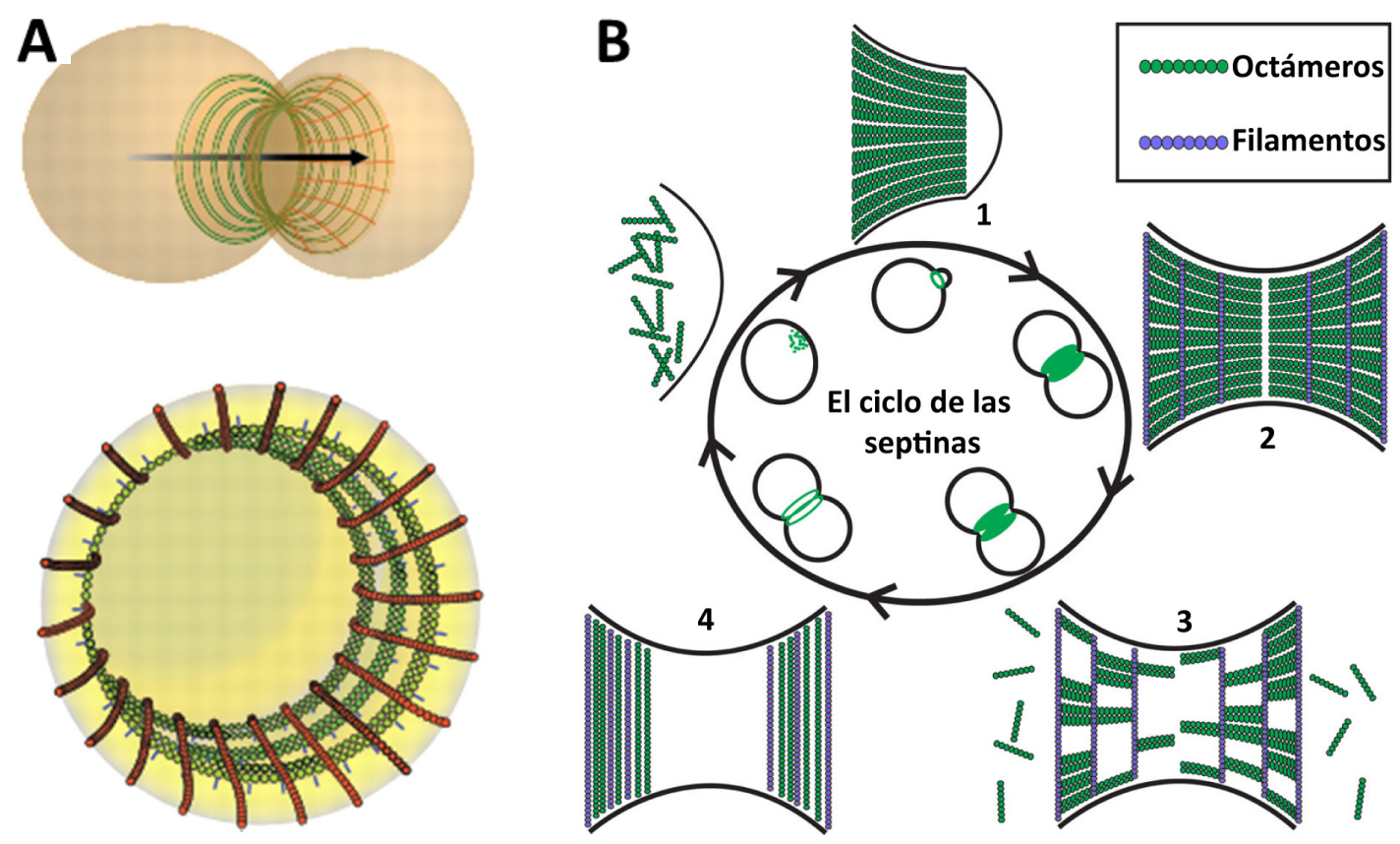

Figura 9. Ensamblaje de las septinas en el cuello de S. cerevisiae. (A). Estructura tridimensional de los filamentos de septinas en S. cerevisiae propuesta por Bertin y colaboradores. Representación esquemática de la disposición de filamentos de septinas en el cuello de la yema. Arriba, orientación del collar de septinas con respecto al eje madre-yema (flecha negra). Abajo, vista ampliada que representa los filamentos circulares de $10 \mathrm{~nm}$ compuestos por un par de filamentos de septinas fuertemente asociados (verde) con pequeños conectores (azul) que los conectan a la cara interna de la membrana plasmática y filamentos axiales (rojo) compuestos de un filamento de septinas que se cruzan con los circunferenciales con una separación de $30 \mathrm{~nm}$ que corresponde a la longitud de un octámero de los filamentos axiales. Tomado de Bertin et al., 2012 (B). El ciclo de las septinas. Remodelamiento de anillo de septinas durante el ciclo celular en S. cerevisiae de acuerdo con el modelo de Ong y colaboradores. Modificado de Ong et al., 2014. 
circunferenciales, acompañado por un cambio de $90^{\circ}$ en la orientación de los filamentos (Fig. 9B, 3). Algunas subunidades se pierden y otras se reensamblan, de tal manera que en el anillo duplicado existen filamentos sencillos y dobles, aunque ambos tipos son ortogonales al eje madre-hija (Fig. 9B, 4).

\subsection{Variaciones en la arquitectura de las septinas.}

Estudios en levaduras y mamíferos indican que una propiedad universal conservada de las septinas es su plasticidad para formar complejos. Aunque el orden en el octámero parece fijo (Cdc11-Cdc12Cdc3-Cdc10-Cdc10-Cdc3-Cdc12-Cdc11), un estudio reciente demostró la plasticidad de los complejos de septinas in vivo (McMurray et al., 2011), ya que algunos mutantes de septinas pueden sobrevivir debido a que son capaces de formar filamentos diferentes. Estos autores demostraron que los complejos de septinas carentes de ciertas subunidades tienen la habilidad de formar filamentos porque la pérdida de ciertas subunidades desenmascara la capacidad de autoasociación de otras subunidades. Por ejemplo, en ausencia de Cdc10 las células muestran defectos en proliferación y morfología, pero son capaces de crecer debido a que las restantes subunidades forman trímeros Cdc11-Cdc12-Cdc3 que dimerizan a través de Cdc3 vía "interfaz G", formando hexámeros Cdc11-Cdc12-Cdc3-Cdc3-Cdc12Cdc11. Del mismo modo, la supervivencia de los mutantes $c d c 11 \Delta$ depende de la homodimerización de las subunidades de Cdc12 vía "interfaz G". Aunque no son óptimas, en ambos casos las septinas restantes pueden formar uniones alternativas y permitir la viabilidad de la levadura. Del mismo modo, en mamíferos las septinas también son capaces de formar anillos cuando se elimina SEPT9, la septina más externa (Kim et al., 2011).

En contraste, la eliminación de las septinas internas, Cdc3 o Cdc12, no es compatible con la formación de filamentos in vitro o con la viabilidad. También resultan en inviabilidad las alteraciones que anulan la capacidad de los octámeros para formar filamentos, como la eliminación de la hélice $\alpha 0$ en Cdc10 o Cdc11. Según la estructura cristalográfica de las septinas humanas, el extremo $\mathrm{N}$-terminal de SEPT2 se organiza como una corta hélice $\alpha(\alpha 0)$ (Sirajuddin et al., 2007) que contiene un grupo de aminoácidos cargados positivamente y se ha propuesto que estos residuos son importantes para la interacción con el PIP2 de las membranas (Bertin et al., 2010). El mutante $c d c 10(\Delta \alpha 0)$ es letal porque es incapaz de formar octámeros o filamentos, mientras que el mutante $c d c 11(\Delta \alpha 0)$ impide la interacción Cdc11-Cdc11 y la formación de filamentos. Por tanto, las células $c d c 10 \Delta$ y $c d c 11 \Delta$ sobreviven porque las septinas son capaces de formar un anillo en el cuello mediante uniones subóptimas, pero los mutantes $c d c 10(\Delta \alpha 0)$ y $c d c 11(\Delta \alpha 0)$ son inviables al no poder formar el anillo. Todo esto demuestra que la capacidad de formar filamentos, la localización cortical de septinas y la supervivencia de la célula están unidas, ya que el complejo de septinas debe polimerizar en filamentos en el cuello para ejecutar al menos una función esencial (McMurray et al., 2011).

\subsection{Cdc11 y Shs1/Sep7.}

Mediante análisis filogenéticos se ha comprobado que Cdc11 y Shs1 comparten un mayor de grado de similitud que cualquier otro par de septinas, por lo que pertenecen al mismo grupo filogenético, habiendo divergido de un antecesor común (Pan et al., 2007)(Fig. 10A). Esta duplicación se ha mantenido en algunos grupos de hongos, porque a pesar de ocupar la misma posición terminal en el octámero han divergido en su función. Se ha propuesto que la presencia de varias subunidades relacionadas proporciona plasticidad fisiológica, ya que la incorporación de subunidades alternativas supone un mecanismo para lograr la diversidad ultraestructural al aportar nuevas formas de interacción 
entre subunidades o con diferentes conjuntos de proteínas asociadas (Garcia et al., 2011). Shs1 es a menudo considerada como una septina accesoria porque los mutantes nulos (shs1 $\Delta$ ) tienen un fenotipo leve (Mino et al., 1998; Iwase et al., 2007; Garcia et al., 2011) y debido a que es recuperada en cantidades subestequiométricas en complejos nativos de septinas bajo determinadas condiciones (Mortensen et al., 2002). Sin embargo, Shs1 es la septina mitótica más fuertemente modificada por fosforilación y SUMOilación (Johnson y Blobel, 1999; Smolka et al., 2006; Egelhofer et al., 2008) y esto está correlacionado con el comportamiento dinámico de los filamentos de septinas en el cuello (Dobbelaere et al., 2003), por lo que se empieza a considerar a Shs1 como una subunidad reguladora del anillo de septinas. Aunque esta septina no sea esencial para la viabilidad, los octámeros con Shs1 deben generar in vivo filamentos con características especiales o con la habilidad de reclutar proteínas únicas que regulen de forma fina la morfogénesis celular (Iwase et al., 2007).

En contraste con la pérdida de Shs1, las células cdc11 son, dependiendo del fondo genético, inviables (Versele et al., 2004) o exhiben un crecimiento extremadamente lento y una morfología alargada (Frazier et al., 1998). Sin embargo, en los fondos donde las células cdc11 $\Delta$ mueren, el doble mutante $c d c 11 \Delta \operatorname{sep} 7 \Delta$ es viable y sobrevive, debido a polimerización de los octámeros a través de la interacción no natural Cdc12-Cdc12 (McMurray et al., 2011). Por el contrario, en los fondos genéticos donde $c d c 11 \triangle$ es viable, la sobreexpresión de Shs1 produce letalidad, lo que no sucede con células CDC11 (Iwase et al., 2007). Esto indica que los hetero-octámeros de Shs1 no son suficientes para la viabilidad,
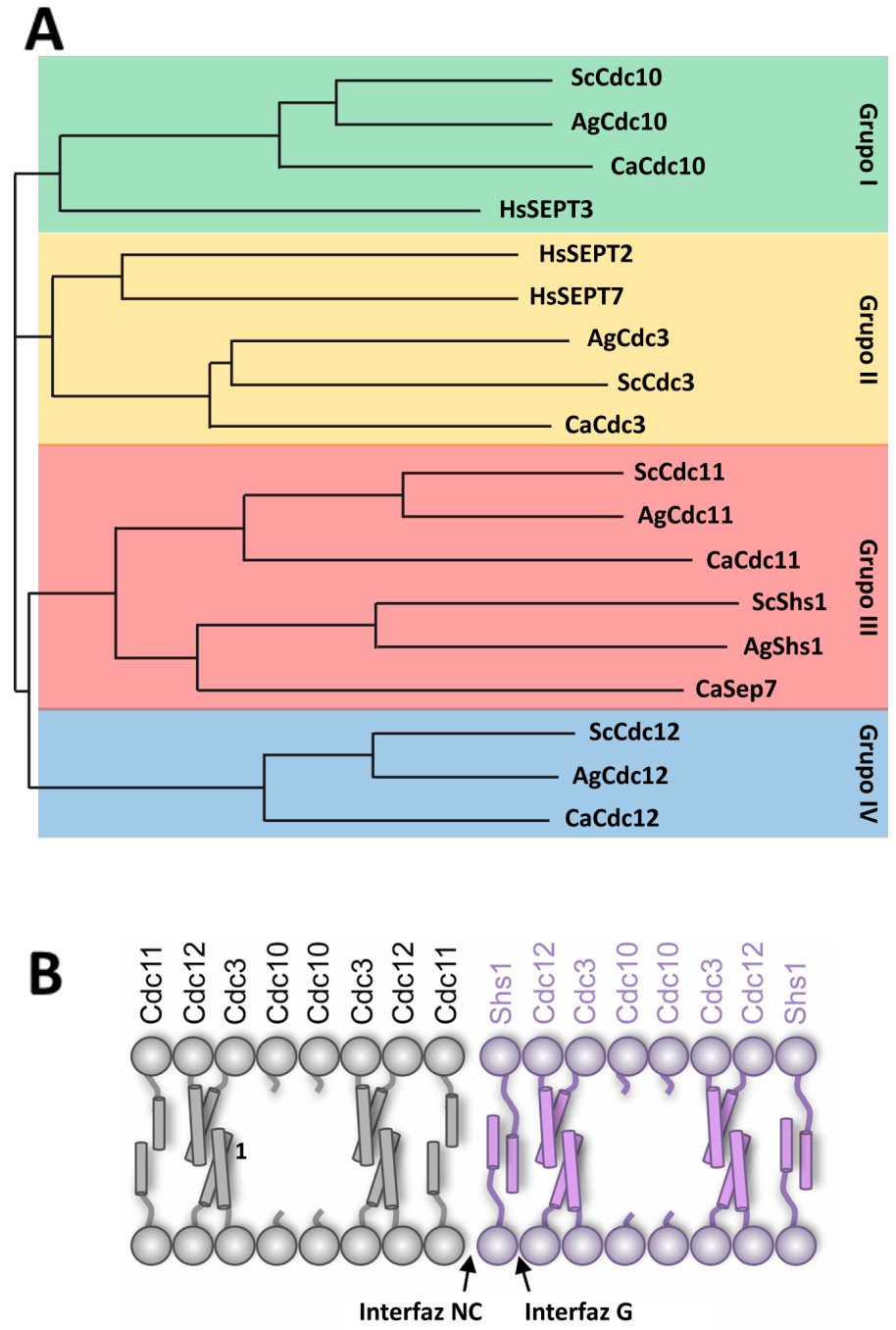

y cuando Cdc11 no está presente, Shs1 se une a Cdc12 y previene la polimerización de los hexámeros Cdc12-Cdc3-Cdc10Cdc10-Cdc3-Cdc12.

Las dos zonas más divergentes entre Cdc11 y Shs1 son el extremo N-terminal y la extensión C-terminal que contiene el coiled-coil, que es mayor en el caso de Shs1 (Fig. 8A), por lo que se supone que son las regiones que deberían determinar sus propiedades diferenciales. En cuanto a sus extremos C-terminales (CTEs), se ha descrito que no son esenciales ni en Cdc11

Figura 10. (A). Filogenia de las septinas. Dendrograma que muestra las relaciones evolutivas de las septinas de S. cerevisiae (Sc), A. gossypii (Ag), C. albicans (Ca) y humanos (Hs) construido por alineamiento múltiple con Clustal Omega. Los grupos están basados en la clasificación descrita por Pan y colaboradores (2007). (B). Papel de los CTEs en la organización de los filamentos de septinas. Los CTES de dos monómeros de $\mathrm{Cdc} 3$ y dos monómeros de $\mathrm{Cdc} 12$ adyacentes se asocian formando un haz de cuatro hélices (four-helix bundle, 1) que es esencial para posicionar los octámeros enfrentados y formar filamentos pareados. Los CTEs de Cdc11 y Shs1 están implicados en la interacción con otras proteínas que se localizan en el cuello. Modificado de Finnigan et al., 2015b. 
ni en Shs1 para la formación de hetero-octámeros o filamentos in vitro (Bertin et al., 2008; Garcia et al., 2011; Booth et al., 2015) ni para el ensamblaje de la estructura de septinas en el cuello in vivo (Versele et al., 2004; Finnigan et al., 2015b). Sin embargo, la eliminación de ambos CTEs simultáneamente o la mutación de los coiled-coils causa severos fenotipos en el crecimiento y una morfología elongada, indicativo de un fallo en citoquinesis emparejado a la función de las septinas (McMurray et al., 2011; Finnigan et al., 2015b). Aunque los CTEs puedan contribuir a la organización supramolecular y/o la dinámica de las estructuras de septinas en el cuello, su función principal en Cdc11 y Shs1 es el reclutamiento de otras proteínas a través de la interacción con sus coiled-coils (Finnigan et al., 2015a). Los elementos coiled-coil de los CTEs de Shs1 y Cdc11 pueden tener múltiples papeles, tales como ayudar en la polimerización de filamentos, en la organización 3D de las estructuras de septinas y/o conducir cambios conformacionales que dirijan transiciones geométricas en la arquitectura supramolecular de la estructura de las septinas. Así, también puede servir para el reclutamiento al cuello de factores necesarios para otros procesos celulares. De hecho, se ha demostrado que existe interacción física o genética de Shs1 (y/o Cdc11) con otras proteínas del cuello tales como componentes del polarisoma Spa2 (Mino et al., 1998), las proteín kinasas Elm1 (Bouquin et al., 2000), Gin4 (Okuzaki et al., 1997; Mortensen et al., 2002), Hsl1 (Shulewitz et al., 1999) y Kcc4 (Barral et al., 1999), la formina Bnr1 (Gao et al., 2010), la proteína de asociación al ER Scs2 (Chao et al., 2014), la proteína F-BAR Hof1 (Meitinger et al., 2011), la IQGAP Iqg1 (Iwase et al., 2007), y las proteínas Nis1 (Iwase y Toh-e, 2001) y Bni5 (factor de unión a Myo1)(Lee et al., 2002; Finnigan et al., 2015a). Esta función de los CTEs de Cdc11 y Shs1 en el reclutamiento de otras proteínas que desempeñan su función en el anillo es completamente distinta de la que se ha atribuido a los CTEs de Cdc3 y Cdc12 (Fig. 10B). Estos últimos son esenciales para el ensamblaje de los filamentos de las septinas, ya que los de dos subunidades adyacentes del octámero se asocian formando un coiled-coil paralelo. A su vez, esta estructura se combina con otra similar correspondiente a un filamento adyacente para formar un haz de cuatro hélices (four-helix bundle) que posiciona a los hetero-octámeros paralelos en registro y constituye la base para la formación de filamentos pareados (Versele et al., 2004; Bertin et al., 2008; Bertin et al., 2010).

Mediante mutagénesis dirigida de los residuos básicos o deleción de la hélice $\alpha 0$ se ha comprobado que esta hélice no es esencial en la interacción Cdc11-Cdc11 o Shs1-Cdc11, aunque su eliminación desestabiliza ligeramente ambas proteínas (Booth et al., 2015; Finnigan et al., 2015b). Sin embargo, los residuos básicos de la hélice $\alpha 0$ de Cdc11 y Sep7 son esenciales para concentrar los complejos de septinas en la membrana plasmática, incrementando la incorporación en polímeros (McMurray et al., 2011; Finnigan et al., 2015b), y esta función es compartida también por Cdc10 (Bertin et al., 2010).

En referencia a la estequiometría de los filamentos, se sabe que los complejos de Shs1 y Cdc11 tienen la misma longitud, cuando son coexpresadas con distintas combinaciones de septinas en bacterias. La mayoría de los complejos de Cdc11 son hetero-octámeros, mientras que los complejos de Shs1 también tienen una proporción significativa de hexámeros y heptámeros, sugiriendo que Shs1 tiene menos afinidad que Cdc11 para unirse a Cdc12. Además, los mutantes shs1- $\Delta C T E$ forman más octámeros que los complejos de Shs1, lo que sugiere que el CTE puede desestabilizar la unión Shs1Cdc12 a través de la interfaz G (Garcia et al., 2011). Estos estudios también concluyeron que hay 3 niveles de fosforilación que podrían regular el ensamblaje de septinas, 1) la fosforilación en el CTE de Shs1 que evitaría la formación de filamentos, 2) la fosforilación en una interfaz específica podría debilitar la interacción septina-septina y con ello potenciar el desmontaje del complejo y/o la disociación de una 
subunidad individual y su sustitución por otra subunidad alternativa y 3) la fosforilación podría inducir cambios estructurales que impulsen nuevas interacciones cruzadas y con ello la adquisición de una ultraestructura marcadamente diferente (Garcia et al., 2011).

\subsection{Regulación del anillo de septinas.}

Durante los últimos años se ha puesto de manifiesto que las septinas sufren una serie de modificaciones post-traduccionales, que a menudo tienen importantes efectos en el ensamblaje y función de las mismas. Los tres tipos de modificaciones más comunes son la fosforilación, acetilación y SUMOilación (revisado en Hernández-Rodríguez y Momany, 2012). La primera modificación que se identificó en las septinas de S. cerevisiae fue la adición de SUMO (Small Ubiquitin-related MOdifier). Las septinas Cdc3, Cdc11 y Shs1 de S. cerevisiae sufren esta modificación en la transición G2/M, que se elimina posteriormente en citoquinesis (Johnson y Blobel, 1999; Takahashi et al., 1999). Sin embargo, no se ha detectado esta modificación ni en hifas ni en levaduras de $C$. albicans, aunque existe un homólogo de SUMO (Smt3), que se localiza preferentemente en el lado de la célula madre del anillo de septinas, y algunas proteínas que contienen Smt3 inmunoprecipitan con Cdc11 (Martin y Konopka, 2004). Por tanto, en C. albicans son las proteínas asociadas a las septinas, y no las propias septinas, las que se modifican por SUMO de forma asimétrica. La acetilación también se ha detectado en Cdc11 de C. albicans, tanto en hifas como en levaduras, aunque ocurre en una metionina en lugar de lisina y su función no está clara (Sinha et al., 2007).

La modificación más abundante y mejor caracterizada de las septinas es la fosforilación, y muchas mutaciones que afectan a estos sitios de fosforilación producen defectos en morfogénesis y citoquinesis (revisado en Hernández-Rodríguez y Momany, 2012). Al menos cuatro proteín kinasas desempeñan un papel importante en la regulación de las septinas. Cla4, un miembro de la familia de las kinasas PAK, interacciona con las septinas y fosforila a $\mathrm{Cdc} 3$ y $\mathrm{Cdc} 10$ in vitro y posiblemente a otras septinas in vivo (Versele y Thorner, 2004). La fosforilación por Cla4 parece desempeñar un papel en la estabilización de los filamentos de septinas, ya que coincide con el cambio al estado congelado y porque las septinas permanecen en el estado fluido en el mutante cla4 $\Delta$. Otras dos kinasas que regulan las septinas son Elm1 y Gin4 (Bouquin et al., 2000; Longtine et al., 2000; Mortensen et al., 2002; Gladfelter et al., 2004; Asano et al., 2006). La kinasa Gin4 se localiza en el cuello y regula la función de las septinas fosforilando al menos a Shs1 (Longtine et al., 1998; Dobbelaere et al., 2003). Los mutantes gin4 $\Delta$ no forman anillos de septinas, sino que las septinas se disponen en el cuello en forma de barras paralelas al eje madre-hija, lo que sugiere que Gin4 podría estabilizar el anillo promoviendo la asociación lateral de los filamentos de septinas. Finalmente, las septinas también son fosforiladas por la kinasa Cdc28 para promover el desensamblaje del anillo tras la citoquinesis. La fosforilación de Cdc3 por el complejo Cln-Cdc28 en G1 parece ser necesaria para el desensamblaje del anillo, ya que un mutante $c d c 3$ que carece de los sitios de fosforilación presenta un retraso en el desensamblaje del anillo de septinas (Tang y Reed, 2002).

Normalmente la fosforilación ocurre en las regiones $\mathrm{N}$ - y C-terminal de las septinas, en las que el estado de fosforilación parece regular el ensamblaje y desensamblaje del anillo. Los únicos ejemplos de fosforilación dentro del dominio $\mathrm{G}$ descritos son $\mathrm{Cdc10}$, la septina central del hetero-octámero que se fosforila en una región importante para la formación de la interfaz G (la mayoría de las septinas de hongos posee una Gly en esta posición) y Shs1, cuya fosforilación en Ser259 puede actuar como un 
interruptor que determina el tipo de estructura que se ensambla (Garcia et al., 2011). La septina no esencial Shs1 es la que más modificaciones por fosforilación sufre, ya que es fosforilada en un aminoácido localizado en el extremo $\mathrm{N}$-terminal, en algunos residuos cerca de la interfaz $\mathrm{G}$ y fundamentalmente en el extremo C-terminal (Egelhofer et al., 2008; Garcia et al., 2011). Recientemente, mediante experimentos de análisis masivos, se han identificado hasta $28 \mathrm{Ser} / \mathrm{Thr}$ que se encuentran fosforiladas en Shs1 (Swaney et al., 2013).

Por otro lado, la fosfatasa PP2A unida a Rts1, subunidad reguladora de tipo B, está implicada en la defosforilación de las septinas. PP2A-Rts1 se localiza en el cuello tras la división del anillo de septinas, y los anillos de septinas en el mutante rts1 $\Delta$ son más estables (Dobbelaere et al., 2003).

En C. albicans, la kinasa Gin4 también parece estar implicada en la transmisión de la señal que desencadena la formación del anillo de septinas en las hifas, ya que los mutantes gin $4 \Delta \Delta$ no forman anillos estables en las hifas, aunque si son capaces de localizarse en el ápice de la hifa (Wightman et al., 2004). En este organismo, Gin4 fosforila a Cdc11 en un único residuo que permite su posterior fosforilación en un residuo adyacente por el complejo Ccn1-Cdc28 (Sinha et al., 2007). Estas fosforilaciones son necesarias para mantener un crecimiento polarizado robusto, pero mutantes no fosforilables de Cdc11 son capaces de ensamblar anillos de septinas normales, lo que indica que deben existir otras dianas de Gin4 que son críticas para la organización y asociación de las septinas a la membrana plasmática. De hecho, recientemente se ha demostrado que Gin4 se asocia con Sep7 y lo fosforila, estabilizando la unión entre estas dos proteínas (Li et al., 2012a). Gin4 contiene un grupo de sitios CDK localizados cerca de su dominio kinasa (Vázquez de Aldana y Correa-Bordes, 2012) que son fosforilados por Cdc28, activando su actividad kinasa (Li et al., 2012a). La mutación de estos sitios a Ala impide la activación de Gin4, debilita su asociación con Sep7, altera la dinámica de Sep7 y produce defectos morfológicos. Es interesante que Gin4 se une a Sep7 mediante un mecanismo que es independiente del que implica su asociación con el resto de las septinas, y que podría mediar el control de la organización del anillo de septinas por Cdc28. Además, Gin4 tiene otra función en la organización del anillo de septinas en G1 que es independiente de su actividad catalítica.

La kinasa Cla4 también regula el ensamblaje del anillo de septinas en $C$. albicans. A pesar de que las septinas se localizan en el punto de gemación, el mutante cla $4 \Delta \Delta$ es incapaz de formar un anillo en el cuello y las septinas permanecen en la punta de la yema, produciendo una morfología alargada (Huang et al., 2014). Estos autores también identificaron a la proteína Nap1 como otra de las dianas de las kinasas Gin4 y Cla4. Nap1 es una proteína asociada al anillo de septinas necesaria para la correcta organización de las septinas en el cuello. Es interesante que su defosforilación depende de las fosfatasas Rts1 y Cdc14, que se localizan en el cuello en algún momento del ciclo celular (Clemente-Blanco et al., 2006; Huang et al., 2014). El mutante $r t s 1 \Delta \Delta$ también presenta defectos en la organización del anillo de septinas (Tesis Doctoral de Caballero-Lima, 2009), lo que podría indicar que esta fosfatasa regula la dinámica del anillo de septinas defosforilando las septinas o sus proteínas reguladoras asociadas. Finalmente, también se ha demostrado que la subunidad estructural de las fosfatasas PP2A Tpd3 y la subunidad catalítica Pph21 defosforilan Sep7 (Liu et al., 2016). Los mutantes tpd3 $\Delta \Delta$ o pph $21 \Delta \Delta$ tienen defectos en la organización de las septinas y en el crecimiento hifal, y crecen como pseudohifas en condiciones de crecimiento levaduriforme. Una de las dianas de esta fosfatasa es Sep7, que se encuentra hiperfosforilada en estos mutantes. 


\subsection{Las septinas y el crecimiento polarizado.}

El hecho de que las células de C. albicans posean la habilidad de polarizar rápidamente su crecimiento en respuesta a factores inductores sugiere que, además de la inducción del programa transcripcional especifico de hifas, la modificación post-traduccional de proteínas previamente existentes en las levaduras es importante para la transición levadura-hifa (revisado en González-Novo et al., 2009). Además de los ejemplos comentados en el Apartado 4.4, la septina Cdc11 es fosforilada inmediatamente después de la inducción de las hifas y esta fosforilación se mantiene durante todo crecimiento filamentoso. En levaduras, Cdc11 es fosforilada en Ser395 por Gin4 y esto es necesario para que tenga lugar la fosforilación en la serina contigua (Ser394) por la kinasa Cdc28 asociada a Ccn1. Esta modificación ocurre en los 5 minutos posteriores a la inducción de las hifas y es esencial para el inicio y mantenimiento del crecimiento hifal (Fig. 11)(Sinha et al., 2007). Así, las células deficientes en la proteína Ccn1 o mutantes que contienen un alelo fosfodeficiente de Cdc11 (cdc11-S394A) emiten tubos germinales normales pero son incapaces de mantener el crecimiento polarizado una vez formado el primer septo. En el mutante $\operatorname{ccn} 1 \Delta$, este fenotipo se suprime al introducir un alelo fosfomimético de Cdc11 (cdc11-SS394,395DD). Puesto que Ccn1 se degrada durante el crecimiento hifal, el mantenimiento de la fosforilación de Cdc11 en etapas posteriores depende de Hgc1-Cdc28. Estos resultados ponen de manifiesto que el estado de fosforilación de Cdc11 es importante para mantener un crecimiento

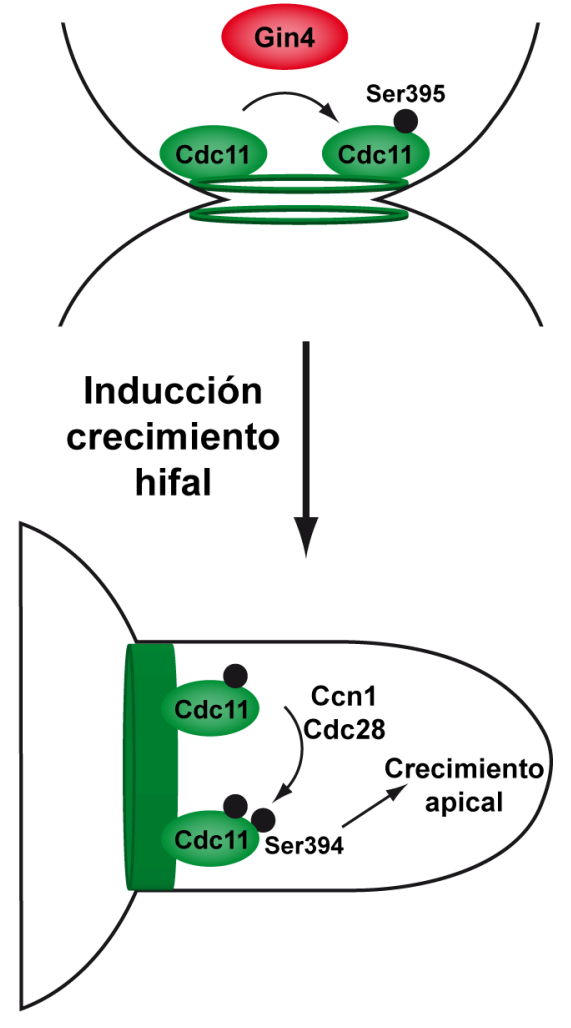

Figura 11. Las septinas son esenciales para el desarrollo de las hifas de C. albicans. Durante el crecimiento en forma de levaduras, Cdc11 es fosforilado por Gin4 en Ser395 al final del ciclo celular previo. Durante la inducción de la filamentación, el complejo Ccn1 -Cdc28 rápidamente fosforila a Cdc11 en la Ser394, lo que permite el correcto desarrollo de las hifas después de ensamblaje del primer anillo de septinas. polarizado sostenido en el tiempo. Una posibilidad es que la fosforilación en Ser394 regule la interacción del anillo con otras proteínas implicadas en el crecimiento polarizado, ya que una de sus funciones es actuar como andamiaje para otros factores celulares. Uno de ellos podría ser el exocisto, pues células carentes de Sec3 (componente del exocisto) muestran un fenotipo similar al del mutante $\operatorname{ccn} 1 \Delta \Delta$, fenotipo que se suprime al delecionar CDC11 (Li et al., 2007).

Recientemente se ha demostrado que las septinas son necesarias para mantener el crecimiento polarizado en las hifas (Li et al., 2012b). Mediante el uso del mutante termosensible cdc12-6, que elimina los últimos 13 aminoácidos de la proteína, se ha demostrado que es capaz de responder al suero e iniciar la formación de filamentos, pero a tiempos más largos forma cadenas de compartimentos elongados sin anillos de septinas y con defectos en la formación de septos. Al mismo tiempo, estas células frecuentemente forman una segunda hifa en las proximidades de la primera, un fenotipo que no se observa en la cepa silvestre y además, son incapaces de formar la banda basal de septinas.

\subsection{Las septinas y la regulación de la separación celular.}

El ciclo de división celular en levaduras llega a su fin cuando los dos citoplasmas de las células resultantes se separan mediante la síntesis de una barrera física denominada septo. 
Es una estructura muy similar en C. albicans y S. cerevisiae, presentándose en ambos casos como una estructura trilaminar. La capa central se denomina septo primario y está compuesta principalmente por quitina, sintetizada por la quitín sintasa II (Chs2 en S. cerevisiae y Chs1 en C. albicans), mientras que a ambos lados se encuentran los llamados septos secundarios, cuya composición química es similar al resto de la pared, compuestos principalmente de $\beta$-1,3-glucano y $\beta$-1,6-glucano (Klis et al., 2001). El último paso del ciclo celular es la separación física de las dos células por hidrólisis del septo primario (Fig. 12). En S. cerevisiae la separación ocurre cuando el septo primario es degradado por la quitinasa Cts1 y la endoglucanasa Eng1, permitiendo la separación de las células madre e hija (Kuranda y Robbins, 1987; Baladrón et al., 2002). La expresión de estos genes es específica de la célula hija y está regulada por el factor de transcripción Ace2, el cual se acumula de forma asimétrica en el núcleo de la célula hija por acción de la kinasa Cbk1 y su subunidad reguladora Mob2 (Colman-Lerner et al., 2001).

En C. albicans, la separación de las dos células durante el crecimiento en forma de levadura también depende de enzimas hidrolíticas como la endoglucanasa Eng1 y las quitinasas Cht1, Cht2 y Cht3 (McCreath et al., 1995; McCreath et al., 1996; Dunkler et al., 2005; Esteban et al., 2005), cuya expresión está regulada por un mecanismo similar al de S. cerevisiae dependiente de Ace2 y Cbk1Mob2 (Kelly et al., 2004; Song et al., 2008)(Fig. 12). Una diferencia crucial entre el crecimiento en forma de levaduras e hifas es que mientras que en las primeras la separación ocurre inmediatamente tras la citoquinesis permitiendo que la célula madre e hija se conviertan en entidades independientes, en las hifas la separación de los compartimentos está inhibida, posibilitando que se formen las estructuras filamentosas típicas del crecimiento hifal. El fenotipo de los mutantes $\operatorname{sep} 7 \Delta \Delta$ en hifas es que activan la separación, de tal manera que los distintos compartimentos de la hifa se independizan en lugar de permanecer unidos. Esto se correlaciona con un cambio en las propiedades dinámicas del anillo de septinas en hifas, ya que mediante FRAP se demostró que poseen un comportamiento dinámico
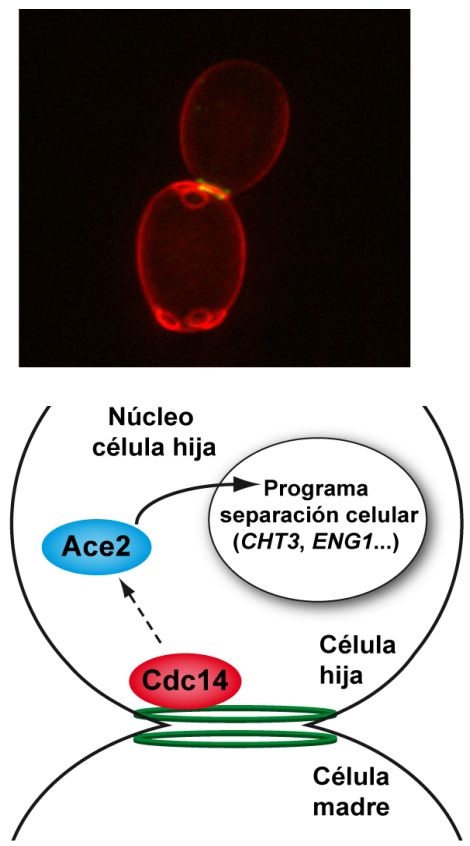

Inducción filamentación
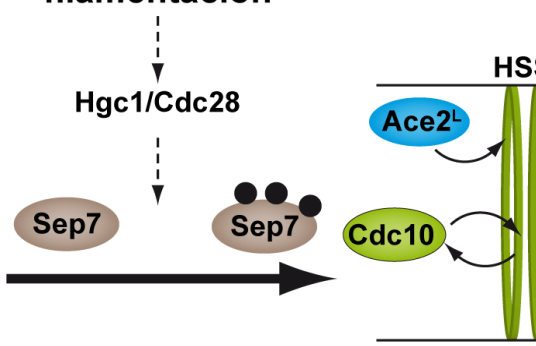

HSS

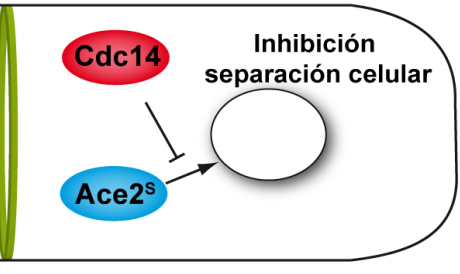

Figura 12. Regulación de la separación celular en C. albicans. En levaduras, las septinas sirven como andamio para la llegada de Cdc14 al plano de división, lo que activa la maquinaria de separación celular dependiente de Ace2. Con la inducción de la filamentación, las septinas cambian su dinámica al estado específico de hifas (HSS) que se caracteriza por el intercambio de Cdc10 entre el citoplasma y el anillo. Este cambio en la dinámica depende de una forma de Ace2 que carece de actividad transcripcional (Ace2 $2^{L}$ ) e impide la localización de Cdc14 en el septo de la hifa con lo que el programa de separación celular permanece inhibido. Este proceso es dependiente de Sep7 y de Hgc1. 
diferente de los estados estático y fluido de levaduras, y que ha sido denominado estado específico de hifas (HSS o Hypha-Specific State)(González-Novo et al., 2008; González-Novo et al., 2009). Este estado se caracteriza porque las distintas septinas presentan una dinámica diferente: así, mientras que $\mathrm{Cdc} 3$, Cdc12 y Sep7 permanecen incorporadas de forma estable en el anillo, la septina Cdc10 es altamente dinámica y presenta una alta tasa de intercambio entre el anillo y el citoplasma. Este comportamiento dinámico de Cdc10 es dependiente de Sep7 y de su fosforilación por parte de la ciclina Hgc1, ya que tanto en los mutantes $\operatorname{sep} 7 \Delta \Delta$ como en los $h g c 1 \Delta \Delta$ el intercambio de Cdc10 con el citoplasma se pierde. En este proceso también está implicada la fosfatasa $\mathrm{Cdc14}$, que en levaduras se localiza en la región del septo durante la citoquinesis, mientras que en hifas se mantiene excluida de él por acción del complejo Hgc1-Cdc28 y por el cambio en la dinámica del anillo de septinas (Clemente-Blanco et al., 2006; González-Novo et al., 2008). Así, se ha comprobado que en el mutante sep7 $\Delta \Delta$ la fosfatasa Cdc14 se localiza en el septo de las hifas y esto es suficiente para activar la separación, ya que en el doble mutante $\operatorname{sep} 7 \Delta \Delta c d c 14 \Delta \Delta$ los compartimentos de las hifas permanecen unidos a pesar de que la dinámica del anillo de septinas es similar a la del mutante $\operatorname{sep} 7 \Delta \Delta$. Más recientemente se ha demostrado que Ace2 también regula la dinámica del anillo de septinas, ya que en $C$. albicans existen dos formas, una de las cuales (Ace $2^{5}$ ) actúa como factor de transcripción (Fig. 12). La segunda forma, Ace $2^{L}$, contiene una extensión en el extremo $\mathrm{N}$-terminal con un posible dominio transmembrana y no tiene actividad transcripcional, pero es necesaria para la conversión de los anillos de hifas al HSS. Además, Cbk1-Mob2 también son necesarios para esta conversión, aunque no se conoce si es a través de Ace $2^{\llcorner}$o de otra diana (Calderón-Noreña et al., 2015).

\subsubsection{La ruta RAM.}

La ruta de regulación de Ace2 y morfogénesis (conocida como ruta RAM por Regulation of Ace2 and Morphogenesis) es una ruta de señalización mediada por kinasas conservada en eucariotas, desde levaduras hasta humanos, la cual ha sido ampliamente estudiada en $S$. cerevisiae donde regula procesos como la separación celular y el crecimiento polarizado (revisado en Maerz y Seiler, 2010; Saputo et al., 2012). Esta ruta es homóloga de la ruta Hippo de células eucariotas superiores, en las que regula el crecimiento tisular y controla otra serie de procesos como la determinación del destino celular, mitosis o pluripotencia (Lin et al., 2013; Yu et al., 2015). Esta Introducción se centrará fundamentalmente en la función de la ruta RAM en hongos y levaduras. Para más información sobre esta ruta en eucariotas superiores, consultar algunas revisiones recientes (Avruch et al., 2012; Harvey y Hariharan, 2012; Ramos y Camargo, 2012; Yu y Guan, 2013; Meng et al., 2016).

La estructura de esta ruta es similar en todos los organismos en los que están presentes, existiendo una proteín kinasa del grupo de las kinasas de centro germinal o GCK (la kinasa Mst/Hippo) que controla directamente la actividad de otra kinasa del grupo AGC (la kinasa NDR/LATS) que se encuentra unida a una subunidad coactivadora de tipo "Mob" (Hergovich, 2011; Hergovich, 2012). Las kinasas NDR/LATS son el componente final de la ruta y controlan polarización celular, expresión génica y morfogénesis.

En levaduras, la ruta RAM controla el crecimiento polarizado y la separación celular, por lo que mutantes carentes de cualquiera de los componentes de esta ruta presentan dos fenotipos principales: defectos en separación celular lo que genera grupos de células, e incapacidad de mantener el crecimiento polarizado, por lo que las células son redondeadas (revisado en Maerz y Seiler, 2010; Saputo et al., 2012). El primero de estos fenotipos es debido al papel que Cbk1-Mob2 desempeñan en 
la regulación del factor de transcripción Ace2, que regula a los genes necesarios para degradar el septo (Bidlingmaier et al., 2001; Colman-Lerner et al., 2001). En cuanto al segundo fenotipo, aunque el papel de la ruta RAM en el crecimiento polarizado no ha sido bien caracterizado, se sabe que Cbk1 interviene en la regulación de procesos de secreción dependientes del aparato de Golgi y de las proteínas Sec2 y Sec4, implicadas en exocitosis (Fig. 13)(Kurischko et al., 2008).

La ruta RAM en C. albicans se compone de las mismas proteínas que en S. cerevisiae, Cbk1, Mob2, Kic1, Hym1, Tao3/Pag1 y Sog2 (Fig. 13), siendo la NDR Kinasa Cbk1 y su proteína reguladora Mob2 los efectores finales de la ruta (McNemar y Fonzi, 2002; Song et al., 2008). Los mutantes $c b k 1 \Delta \Delta$ son incapaces de separarse cuando crecen en forma de levaduras y de formar filamentos, indicando que en este organismo la ruta RAM también regula separación y crecimiento polarizado. Consistente con esta idea, se ha comprobado que los mutantes $\operatorname{mob} 2 \Delta \Delta, \operatorname{kic} 1 \Delta \Delta$, pag $1 \Delta \Delta$, hym $1 \Delta \Delta$ y $\operatorname{sog} 2 \Delta \Delta$ presentan los mismos defectos que los mutantes $c b k 1 \Delta \Delta$ y que la expresión de los genes regulados por Ace2 y de un grupo de genes específicos de hifas está reducida en el mutante mob2 $\Delta \Delta$ (Song et al., 2008). Similar a lo que ocurre en $S$. cerevisiae, los mutantes ace $2 \Delta \Delta$ exhiben importantes defectos de la separación celular y en la expresión del gen CHT3 (Clemente-Blanco et al., 2006; Song et al., 2008). Consistente con su papel en la regulación de genes implicados en separación celular, Ace2 se localiza tanto en el núcleo de las células hijas de levaduras como en el núcleo de las hifas (Kelly et al., 2004; Wang, 2009).

En Candida, el complejo Cbk1-Mob2 desempeña un papel esencial en la regulación del crecimiento polarizado durante la filamentación, siendo necesario para el mantenimiento de la organización del polarisoma durante el crecimiento hifal y se ha propuesto que Spa2 podría ser una diana de este complejo (Gutiérrez-Escribano et al., 2011). A su vez, se ha demostrado que Cdc28 regula directamente a la ruta RAM a través de la fosforilación directa de Mob2 en cuatro sitios consenso en las fases tempranas del desarrollo hifal. También se ha demostrado que Cbk1-Mob2 regula el desarrollo de biofilms a través de la fosforilación del factor de transcripción Bcr1 (Gutiérrez-Escribano et al., 2012).

\subsection{Importancia fisiológica de las septinas.}

En la mayoría de los casos, las septinas se asocian a membranas celulares y a los citoesqueletos de actina y microtúbulos para regular una gran variedad de procesos celulares esenciales (revisado en Spiliotis y Nelson, 2006; Gilden y Krummel, 2010; Gladfelter, 2010; Saarikangas y Barral, 2011; Bridges et al., 2014; Bridges y Gladfelter, 2015). Los estudios estructurales, junto con análisis funcionales en distintos organismos, han permitido determinar que las septinas desempeñan dos funciones principales.

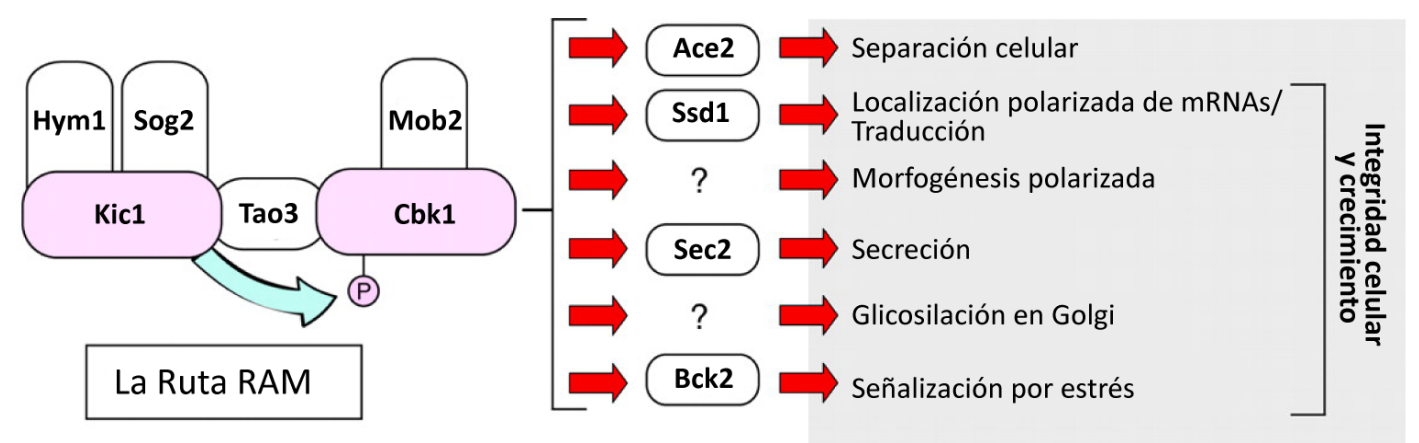

Figura 13. La Ruta RAM en S. cerevisiae. Esquema de los componentes de la ruta. La flecha azul indica la fosforilación de Cbk1 por parte de Kic1, clave para su regulación. También se indican las funciones de esta ruta y los sustratos identificados que median cada una ellas. Modificado de Saputo et al., 2012. 
En las células, las septinas forman estructuras en forma de anillo en la base de cilios, flagelos, espinas dendríticas y yemas de levaduras, donde se asocian fuertemente a la membrana y forman una barrera de difusión. De esta manera, compartimentalizan la membrana en dos dominios definidos. En levaduras se ha demostrado que las septinas son esenciales para establecer un compartimiento específico en el cuello donde se concentran factores difusibles importantes para la citoquinesis, como la proteína Spa2, la quitín sintasa Chs2 o la proteína del exocisto Sec3 (Dobbelaere y Barral, 2004). También se ha descrito que las septinas impiden la difusión de las proteínas de la membrana del retículo endoplásmico a la célula hija, y que esta función depende del reclutamiento de Bud6 al cuello por parte de las septinas (Luedeke et al., 2005). Finalmente, las septinas también intervienen en el control del envejecimiento gracias a su comportamiento como barrera de difusión que impide la translocación de las proteínas del poro nuclear y del retículo endoplásmico a la yema (Shcheprova et al., 2008; Caudron y Barral, 2009; Clay et al., 2014).

Al mismo tiempo, los anillos de septinas actúan como organizadores corticales de los citoesqueletos de actina y microtúbulos, al reclutar a diferentes proteínas al anillo y actuar como andamios moleculares (revisado en Spiliotis y Nelson, 2006; Barral y Kinoshita, 2008; Weirich et al., 2008; Gilden y Krummel, 2010; Gladfelter, 2010; Spiliotis, 2010). Además, las septinas también han sido implicadas en el control del ciclo celular, en la coordinación de la respuesta al daño en DNA y en el denominado checkpoint de morfogénesis (revisado en Lew, 2003; Keaton y Lew, 2006; Howell y Lew, 2012). También juegan un papel clave en la selección del sitio de gemación con el reclutamiento de un complejo de proteínas (axial landmark)(revisado en Chang y Peter, 2003; Park y Bi, 2007; Bi y Park, 2012; Howell y Lew, 2012) y en el posicionamiento del huso mitótico durante la mitosis (revisado en Moore y Cooper, 2010; Merlini y Piatti, 2011; Markus et al., 2012). De este modo, el anillo de septinas es el lugar perfecto para coordinar el posicionamiento del huso mitótico y la división celular. En caso de que el huso mitótico esté mal posicionado, un mecanismo de supervivencia llamado Spindle POsition Checkpoint (SPOC) bloquea la salida de mitosis y la citoquinesis para dar tiempo para el realineamiento del huso mitótico e impedir la formación de células anucleadas y poliploides. Parte de la maquinaria del SPOC se localiza en el anillo de septinas. Esta Introducción se centra fundamentalmente en las funciones que desempeñan las septinas en levaduras. Existen revisiones más detalladas recientes sobre la función de las septinas en células eucariotas superiores (Spiliotis y Gladfelter, 2012; Bezanilla et al., 2015).

\subsubsection{Selección del sitio de gemación.}

El correcto posicionamiento del eje de polaridad en respuesta a la señal espacial es importante en una variedad de funciones celulares tales como la transmisión neuronal, la determinación del destino celular y la migración celular direccional (Nelson, 2003; Witte y Bradke, 2008; Neukirchen y Bradke, 2011; Williams y Fuchs, 2013; Coles y Bradke, 2015). En S. cerevisiae, el control espacial de la polarización celular se manifiesta por la selección del sitio de gemación, un proceso que tiene lugar al final de G1 (Fig. 14A)(revisado en Chant y Pringle, 1995; Pringle et al., 1995; Casamayor y Snyder, 2002; Park y Bi, 2007; Seiler y Justa-Schuch, 2010). Hay dos patrones de gemación dependiendo del tipo de célula. Las células haploides (MATa o MATa) eligen un nuevo sitio de gemación cercano al sitio previo de división (patrón axial), por lo que las cicatrices de gemación están conectadas en una cadena. Sin embargo, las células diploides MATa/MATa geman en un patrón bipolar en el cual las células hijas eligen el nuevo sitio de gemación exclusivamente en el polo distal al sitio previo de división mientras la célula madre puede seleccionar el sitio de gemación adyacente u opuesto al sitio previo de división. 
Como resultado, las cicatrices de gemación se distribuyen en los dos polos de la célula (Chant, 1999; Casamayor y Snyder, 2002; Park y Bi, 2007; Bi y Park, 2012).

Tres grupos de genes, llamados colectivamente "genes $B U D$ ", están involucrados en la generación de estos patrones. El primer grupo incluye $B U D 3, B U D 4, A X L 1$, y $A X L 2 / B U D 10$, que son necesarios específicamente para el patrón axial. El segundo grupo incluye $B U D 7-B U D 9, R A X 1$, y $R A X 2$, que son necesarios para el patrón bipolar. El tercer grupo, que incluye RSR1/BUD1, BUD2, y $B U D 5$, participan en ambos patrones, por lo que se piensa que codifica la "maquinaria general de selección del sitio de gemación". Estas proteínas transmiten información específica del tipo celular a la maquinaria de establecimiento polaridad (Fig. 14B)(revisado en Park y Bi, 2007; Bi y Park, 2012; Howell y Lew, 2012). Las mutaciones en $B U D 3, B U D 4, A X L 1$, o $A X L 2$ eliminan el patrón axial en células haploides, lo que resulta en gemación bipolar, pero no afectan la gemación en diploides. Las septinas también juegan un papel importante en la gemación axial, ya que algunos mutantes de septinas pierden el patrón axial (Chant y Pringle, 1995). Las proteínas codificadas por estos genes funcionan como un marcador cortical (axial landmark) transitorio para el patrón axial. Los datos genéticos y de localización apoyan la idea de que el ciclo de montaje y desmontaje de un complejo de proteínas en el cuello proporciona una memoria espacial de un ciclo celular al siguiente. Del mismo modo, Bud8, Bud9, Rax1 y Rax2, constituyen la marca espacial del crecimiento bipolar. Mutaciones en cualquiera de estos genes eliminan el patrón bipolar pero no afectan a la gemación axial. Se piensa que BUD8 y BUD9 codifican componentes que marcan los polos distal y proximal al polo de nacimiento de la célula hija, respectivamente (revisado en Park y Bi, 2007; Bi y Park, 2012; Howell y Lew, 2012).

Muchas de estas proteínas son integrales de la membrana plasmática, cuyos dominios extracelulares pueden interactuar con la pared celular para restringir su movilidad, preservando así su localización.

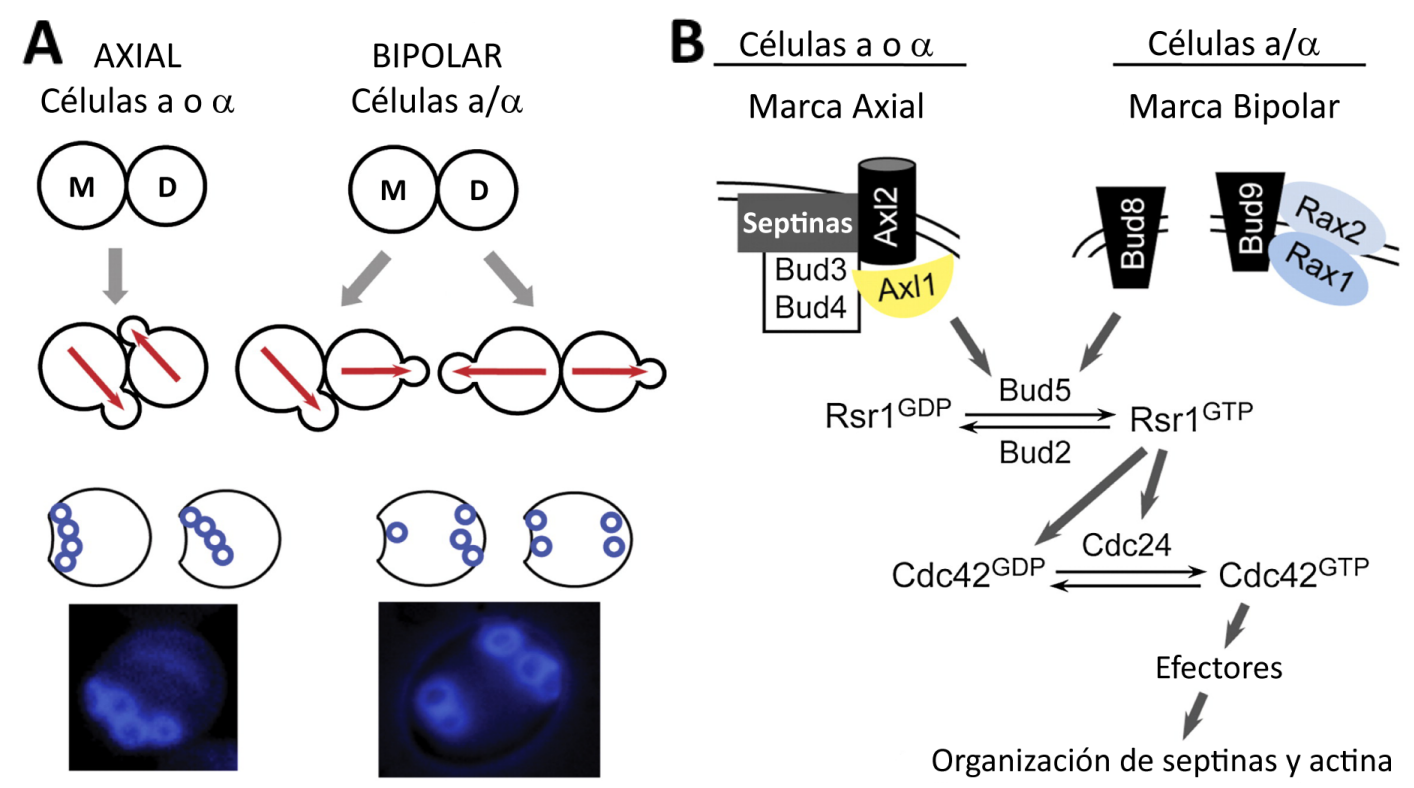

Figura 14. Selección del sitio de gemación en S. cerevisiae. (A). Patrones axial y bipolar. En la parte inferior se muestran las cicatrices de gemación en la superficie de la célula resultantes de los dos modos de gemación. En cada célula una sola cicatriz de nacimiento marca el lugar de donde se ha separado de la madre. Las cicatrices se muestran como anillos azules, por estar teñidas con Calcoflúor. En el patrón axial, las cicatrices forman cadenas. En el patrón bipolar, las cicatrices están en el polo proximal y en el distal. (B). Marcas corticales de los patrones de crecimiento axial y bipolar. Aunque la interacción física se ha demostrado en algunos casos, las interacciones se basan fundamentalmente en datos genéticos y de localización. No todas las proteínas interaccionan al mismo tiempo necesariamente. Modificados de Bi y Park, 2012. 


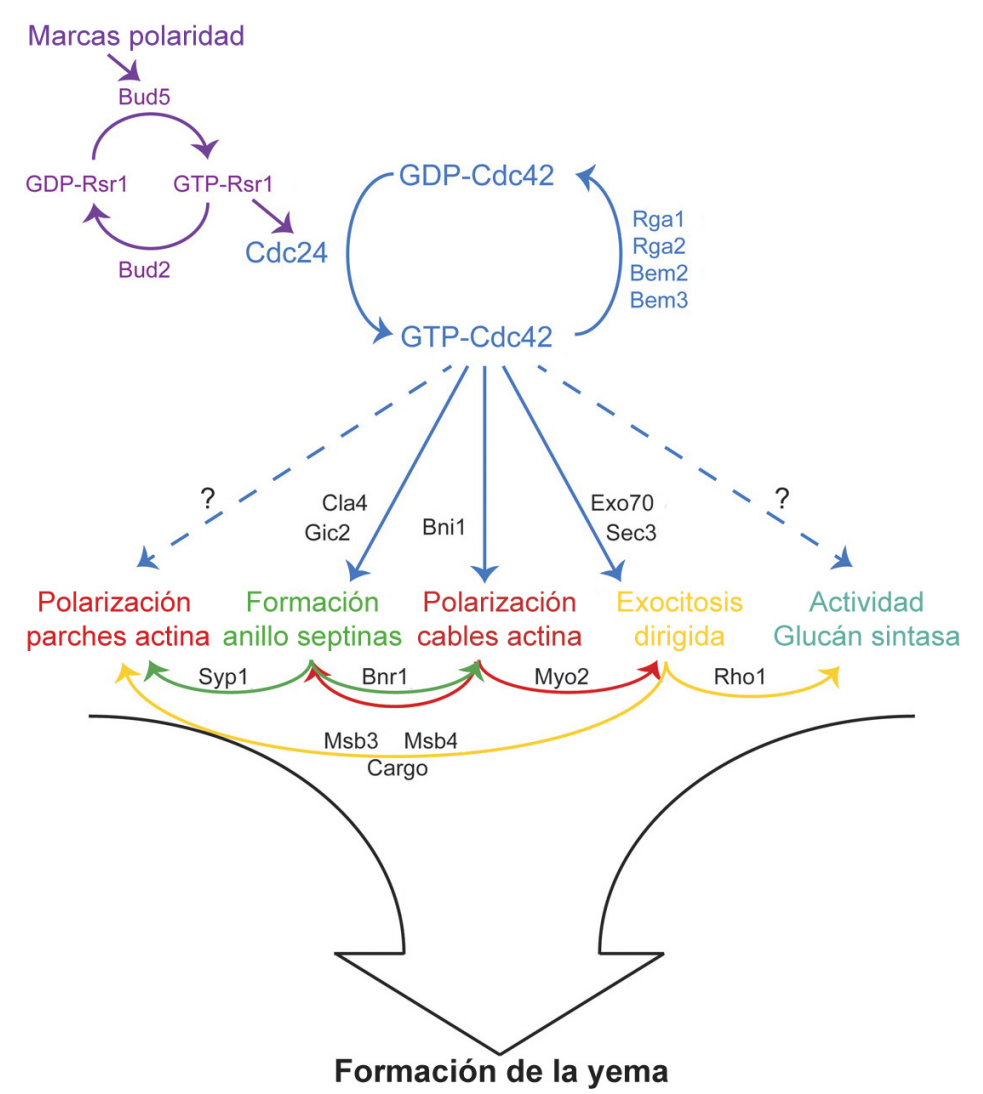

Figura 15. Establecimiento de la polaridad. Selección del sitio de gemación (violeta): la localización de las marcas de polaridad promueve la carga de GTP en Rsr1, el cual recluta a Cdc24. En el establecimiento de polaridad (azul), Cdc24 localiza y activa a Cdc42, generando una retroalimentación positiva que mantiene a GTP-Cdc42 en el córtex celular. Durante los eventos posteriores, la localización de GTP-Cdc42 promueve el ensamblaje del anillo de septinas (verde), la polarización de los cables de actina (rojo), la exocitosis (amarillo), y posiblemente también la síntesis de glucano y la acumulación de parches de actina. Modificado de Howell y Lew, 2012.

Los dominios intracelulares de las marcas corticales pueden interactuar con el GEF de Rsr1 (GTPasa de la familia Ras), y esto resulta en la acumulación localizada de GTP-Rsr1 cerca del marcador cortical. GTP-Rsr1 activa a Cdc42 (GTPasa de la familia Rho), poniendo en marcha toda la maquinaria necesaria para el ensamblaje de una nueva yema en la

localización de las marcas corticales, como la polarización del citoesqueleto de actina, el ensamblaje del anillo de septinas, la exocitosis dirigida y posiblemente la síntesis de glucano (revisado en Howell y Lew, 2012)(Fig. 15).

\section{I) Bud4.}

Bud4 es una proteína necesaria para la normal formación de la marca axial, que permanece asociada al anillo de septinas durante todo el ciclo. Presenta similitud con las anillinas animales y contiene un dominio PH (Pleckstrin Homology) cerca del extremo el C-terminal (aa 1304-1412) precedido por un dominio anilina o DUF1709 (aa 1174-1276)(Kang et al., 2013). Además, se ha descrito recientemente que posee capacidad para unir GTP, aunque no está claro qué papel desempeña (Kang et al., 2012). Aparte de su función en la selección del sitio de gemación, Bud4 es necesario para mantener la organización de las septinas tras la citoquinesis, ya que en los mutantes bud4 $\Delta$ el doble anillo de septinas se desensambla (Wloka et al., 2011; Eluere et al., 2012; Kang et al., 2013), mientras que la sobreexpresión de Bud4 causa el ensamblaje de estructuras extras de septinas (Kang et al., 2013).

Bud4 también se necesita para una citoquinesis normal en ausencia de las kinasas Gin4 o Cla4 (Wloka et al., 2011), por lo que las células defectivas en la organización de septinas son especialmente sensibles a los efectos del exceso de Bud4. La deleción de Bud4 no deslocaliza a Gin4 ni Cla4 en ningún momento del ciclo celular. Esta proteína no participa directamente en la regulación de Gin4, pero la deleción de Bud4 en células gin $4 \Delta$ incrementa dramáticamente el porcentaje de células con estructuras aberrantes (Eluere et al., 2012). Esto sugiere que Bud4 desempeña un papel en la organización de las septinas y en la estabilización del anillo. 
Mediante truncamientos de diferentes regiones se ha comprobado la función de los diferentes dominios. El dominio PH interacciona con los fosfoinosítidos cargados negativamente. La función de Bud4 en la organización de las septinas reside en el extremo carboxilo (regiones PH y DUF1709), mientras que su papel tras la duplicación del anillo de septinas durante citoquinesis requiere tanto el extremo amino como el carboxilo. Esto sugiere que ambos extremos pueden cooperar para promover una fuerte interacción con los filamentos de septinas, lo que ayuda a prevenir la pérdida de subunidades de septinas durante y después de la transición collar-doble anillo (Wu et al., 2015).

Al igual que en los mutantes bud4 $\Delta$, los anillos de septinas se desensamblan en las células $c d c 10 \Delta$. Sorprendentemente, en ambos casos el AMR se forma y se cierra eficientemente, y tanto la maquinaria de secreción (la miosina tipo V Myo2 o Exo84) como Chs2 se localizan eficientemente en el sitio de división en ambos casos. Por tanto, la barrera de difusión del doble anillo de septinas no parece ser indispensable para la citoquinesis (Wloka et al., 2011). Bud4 también está implicado en la organización de septinas durante el crecimiento de la yema, ya que las células bud $4 \Delta$ shs $1 \Delta$ tienen yemas elongadas y son defectivas en la organización de septinas a $18^{\circ} \mathrm{C}$, y la sobreexpresión de Bud4 afecta a la organización de septinas durante el crecimiento de la yema en células shs $1 \Delta$ a $30^{\circ} \mathrm{C}$ (Wu et al., 2015).

En cuanto a las modificaciones post-traduccionales de Bud4 en S. cerevisiae, se sabe que es sustrato de $\mathrm{Clb2}$-Cdc28 in vivo. Clb2 se localiza en el cuello antes y durante anafase y en mutantes bud3 $\Delta$, Clb2 no se localiza en el cuello y la fosforilación de Bud4 desciende (Eluere et al., 2012). Bud4 tiene 18 posibles sitios de fosforilación por CDK, de los cuales 13 están concentrados en dos grupos. Esta fosforilación de Bud4 dependiente de CDK regula la citoquinesis, ya que la sustitución a alaninas de los sitios de fosforilación por CDK causa defectos en citoquinesis en células gin $4 \Delta$ similares a la deleción completa de BUD4 (Eluere et al., 2012).

\section{II) Los homólogos de Bud4.}

Bud4 presenta un bajo grado de similitud en la secuencia de aminoácidos (18\%) con las anillinas animales (Oegema et al., 2000), y presenta homología con otras proteínas de otros microorganismos, como Int1 en C. albicans y Mid1 y Mid2 en S. pombe. La función común de la anillina y de las proteínas de hongos relacionadas con la anillina parece ser regular la citoquinesis (Piekny y Maddox, 2010), y en la mayoría de los casos, la función implica la interacción con septinas. Por ejemplo, las anillinas de vertebrados interaccionan directamente con las septinas a través de la región C-terminal que contiene el dominio Anillina y PH (Kinoshita et al., 2002). Mid2, uno de los dos homólogos en S. pombe, actúa para estabilizar el anillo de septinas durante citoquinesis (Berlin et al., 2003; Tasto et al., 2003). Int1, el homólogo en C. albicans, puede interaccionar con las septinas de S. cerevisiae (Gale et al., 2001). Por el contrario, unas pocas proteínas relacionadas con anillina regulan la citoquinesis in interaccionar con las septinas, tales como Mid1 en levaduras de fisión, la cual juega un papel en el posicionamiento del sitio de citoquinesis (Paoletti y Chang, 2000). No se conoce si el homólogo de Bud4 en los hongos filamentosos Neurospora crassa y Aspergillus nidulans, que son cruciales en citoquinesis, interactúan con septinas (Justa-Schuch et al., 2010; Si et al., 2012).

\section{II) Int1, el homólogo de la anillina en C. albicans.}

No existen muchos datos acerca de la función de Int1 en C. albicans. Se ha descrito que se localiza en el sitio de gemación antes que las septinas y colocaliza con ellas durante todo el ciclo celular. También 
podría desempeñar un papel en la selección del sitio de gemación. En C. albicans, las células son diploides y siguen el patrón de $S$. cerevisiae, aunque se ve afectado por la temperatura. A temperaturas inferiores a $30^{\circ} \mathrm{C}$ el patrón de gemación es predominantemente bipolar, aumentando la gemación axial a medida que aumenta la temperatura. Para la cepa silvestre, se ha descrito que sobre el $58 \%$ de las células geman axialmente y el $42 \%$ de forma bipolar, y esta relación se altera en el fondo int $1 \Delta \Delta$, reduciéndose el porcentaje de células axiales hasta el 26\% (Gale et al., 2001). El gen INT1 también es importante para la morfogénesis hifal, adherencia y virulencia (Gale et al., 1998) y en hifas se localiza en anillos sencillos y dobles que colocalizan con la septina Cdc3. Los mutantes int $1 \Delta \Delta$ tienen reducida la capacidad de formar hifas en medio Milk-Tween y Spider, pero forman hifas aparentemente normales en presencia de suero (Gale et al., 1998). Además, las cepas int $1 \Delta \Delta$ atenúan la virulencia de candidiasis sistémicas en modelos de ratón (Gale et al., 1998).

Cuando INT1 se expresa en S. cerevisiae, genera células que crecen con morfología filamentosa, cuya distribución de actina está altamente polarizada y con defectos en citoquinesis, presentando una media de tres núcleos por filamento (Asleson et al., 2001). En estas células de S. cerevisiae, la organización del anillo de septinas se altera tras la expresión de Int1 y se forman espirales en las que colocalizan Int1 y septinas que impiden la correcta localización de Myo1, Gin4 y Hsl1 (Gale et al., 2001). Por el contrario, la sobreexpresión de Bud4 en S. cerevisiae raramente genera estructuras elongadas y los anillos de septinas son normales (Gale et al., 2001). Además, INT1 no complementa el defecto de las cepas bud4 $\Delta$ en la selección del sitio de gemación, lo que indica que Int1 y Bud4 no son funcionalmente homólogas en su totalidad.

\subsubsection{Orientación del huso mitótico y segregación de cromosomas.}

Cuando una célula inicia el ciclo celular, se ponen marcha los procesos que resultan en la replicación del DNA, duplicación de los cuerpos polares del huso (SPBs, Spindle Pole Bodies, equivalente al centrómero en las células animales) y la formación de la célula hija. El material genético duplicado debe ser físicamente transportado desde el interior de la célula madre al compartimento de la célula hija de una manera fiable y estrechamente regulada. Errores en este proceso resultan en la exclusión de los cromosomas de la célula hija, y en un incremento del material genético en la madre (de $1 \mathrm{n}$ a 2n). Este último evento (la poliploidía) puede suponer un incremento en la demanda de replicación del DNA y en la maquinaria de mantenimiento de los cromosomas, causando cambios en la dosis génica, lo cual puede alterar la estequiometría de las proteínas, y puede tener severas consecuencias para su estado físico (Torres et al., 2008).

La correcta separación del genoma durante mitosis requiere la precisa regulación de la conexión entre los cromosomas y el huso mitótico, la orientación del huso hacia la zona del córtex donde está la yema y, finalmente, la separación fiel de los cromosomas (revisado en Winey y Bloom, 2012; Marston, 2014), y en este proceso también están implicadas las septinas al marcar la posición donde se localiza la yema hija. Existen dos puntos de control o checkpoints que son cruciales para la fidelidad de la segregación cromosómica y el mantenimiento de la ploidía, el Spindle Assembly Checkpoint (SAC) y el Spindle POsition Checkpoint (SPOC). La interacción entre los cromosomas y el huso mitótico está mediada por el cinetocoro, un complejo proteico especializado que ensambla el DNA centromérico y facilita su captura por los dinámicos microtúbulos del huso mitótico (Chan et al., 2005; Yamagishi et al., 2014). Este es el proceso que vigila el SAC, actuando en la transición metafase-anafase y previniendo la 
separación de las cromátidas hermanas hasta que todos los cinetocoros están bi-orientados (revisado en Musacchio y Salmon, 2007; London y Biggins, 2014). El SPOC actúa en anafase e impide la salida de mitosis hasta que el huso mitótico se alinea en el eje madre-hija (revisado en Caydasi et al., 2010a; Caydasi y Pereira, 2012).

EI SAC, que está conservado en eucariotas, incluye las kinasas Mps1 y Bub1, así como las proteínas Mad1, Mad2, Mad3 y Bub3. Estas proteínas se localizan en cinetocoro y retrasan la segregación a través de la inactivación del complejo APC/C, la ubiquitin ligasa que promueve la segregación de las cromátidas hermanas y la salida de mitosis (revisado en Foley y Kapoor, 2013; London y Biggins, 2014). El modelo actual es que el SAC monitoriza la tensión de los cinetocoros unidos al huso mitótico, siendo el sensor de la tensión la Aurora kinasa B (revisado en Lampson y Cheeseman, 2011; Krenn y Musacchio, 2015). Ipl1/Aurora B fosforila sustratos del cinetocoro en ausencia de tensión, lo que desestabiliza las uniones incorrectas y permite la reorientación. EI SAC está activo en los cinetocoros no unidos al huso, bloqueando la transición metafase-anafase. Solamente cuando todos los cromosomas están perfectamente bi-orientados, se produce la inactivación del SAC y la mitosis continúa. Estudios recientes revelan que la proteín fosfatasa PP1 antagoniza la función de Aurora B e induce el silenciamiento del SAC (revisado en Lesage et al., 2011; Rebelo et al., 2015). La tensión generada por la bi-orientación de los cromosomas separa espacialmente los cinetocoros de la región centromérica donde se localiza Aurora B alejándola de sus sustratos, que comprende varias proteínas que interaccionan con PP1. La defosforilación de estas proteínas crea sitios de unión para PP1 en los cinetocoros.

En S. cerevisiae, la subunidad catalítica de PP1, Glc7, funciona en asociación con diversas subunidades reguladoras tales como Sla1, Red1, Scd5, Bud14 y Bni4. Las subunidades regulatorias dan especificidad a Glc7 que puede regular un amplio rango de procesos incluyendo metabolismo de glucógeno, meiosis, traducción, segregación de cromosomas, polaridad celular, y progresión de G2/M en el ciclo celular (revisado en Cannon, 2010). Glc7 se encuentra en el núcleo durante la mayor parte del ciclo celular y es más abundante en el nucleolo. Al inicio de anafase, Glc7 se acumula en los SPBs o cinetocoros y transitoriamente aparece en el anillo de actomiosina en citoquinesis. Esta proteína también se acumula en un anillo en el presumible sitio de gemación antes de la emergencia de la yema y permanece durante largo tiempo en el lado de la madre cuando está gemando hasta el final del ciclo (Kozubowski et al., 2003).

\section{I) Mecanismos de orientación del huso mitótico.}

Estudios iniciales de la orientación del huso mitótico en S. cerevisiae revelan que los mecanismos responsables de su orientación en fases tempranas del ciclo son distintos a los de las fases tardías, ya que los mecanismos tempranos requieren cables de actina mientras que los tardíos no los necesitan (revisado en Merlini y Piatti, 2011; Markus et al., 2012). Durante las fases tempranas (células con yema pequeña o mediana), la célula madre contiene cables de actina cortical convergiendo en la punta de la yema o en el cuello. El mecanismo temprano dependiente de actina, conocido como vía Kar9 (Fig. 16A), usa la miosina de tipo V, Myo2, para guiar a los extremos de los microtúbulos astrales a lo largo de los cables de actina cortical en el cuello o en el ápice del córtex de la yema. Clb4-Cdc28 fosforila a Kar9 y se acumula en el polo de destino de la célula madre. Las mutaciones que bloquean la fosforilación de los sitios consenso de Cdc28 resultan en la localización de Kar9 en ambos polos. Clb4-Cdc28 mantiene a Kar9 en la célula madre, y esta distribución asimétrica asegura que sólo una de los polos se oriente 
hacia la yema. Myo2 es reclutado en los extremos de los microtúbulos a través de Kar9. A su vez, Kar9 se une a Bim1, el cual interactúa con los extremos de los microtúbulos astrales. Cuando Myo2 es transportado por los cables de actina, lleva a Kar9, Bim1, y los microtúbulos asociados (como cargo) a través del cuello hacia la punta celular. De esta manera, Kar9 puede ser vista como un adaptador que promueve la interacción entre los microtúbulos astrales y los cables de actina cortical, permitiendo la penetración o el mantenimiento de los microtúbulos en la yema (Markus et al., 2012).

En contraste con la vía temprana Kar9, la vía de la dineína (Fig. 16B) opera más tarde en el ciclo celular y emplea a la dineína anclada corticalmente como motor para que el huso se mueva a través del cuello. Debido a que el motor está anclado, este movimiento genera una fuerza de tracción que se origina desde el córtex de la célula hija. Finalmente, cuando el huso está correctamente orientado por las vías Kar9 y dineína, la anafase termina y el huso rápidamente se desensambla al inicio de la citoquinesis (Markus et al., 2012).

\section{II) Checkpoint de Posicionamiento de huso (SPOC).}

Con el fin de impedir que la salida de mitosis ocurra antes del correcto posicionamiento del huso, existe un mecanismo de control que monitoriza su orientación y comunica esta información a la ruta de salida de mitosis (MEN). El Spindle POsition Checkpoint (SPOC) actúa inhibiendo la ruta MEN, que está formada por una cascada de transducción de señales que en último lugar inician el desensamblaje del huso y la citoquinesis (revisado en Merlini y Piatti, 2011; Caydasi y Pereira, 2012). La salida de mitosis en S. cerevisiae depende de la fosfatasa Cdc14, que permanece secuestrada en el nucleolo durante la mayoría del ciclo celular a través de la interacción con la proteína nucleolar Net1 (revisado en

Figura 16. Dinámica del huso mitótico en S. cerevisiae. (A). La vía de Kar9. Los microtúbulos que emanan del SPB próximo a la célula hija son guiados hacia el cuello por Myo2-Kar9-Bim1. Una vez en el cuello, la captura de los microtúbulos es dependiente de Bud6. (B). La vía tardía, mediada por dineína y sus proteínas accesorias, posicionan al huso entre la célula madre e hija. La dineína actúa como andamio en los extremos de los microtúbulos para que se unan al receptor Num1, que parece regular el anclaje al córtex celular. El anclaje de los microtúbulos por la dineínadinactina resulta en el movimiento del núcleo y del huso mitótico a través del cuello. Modificado de Markus et al., 2012.

\section{A Ruta Kar9 (captura y contracción)}

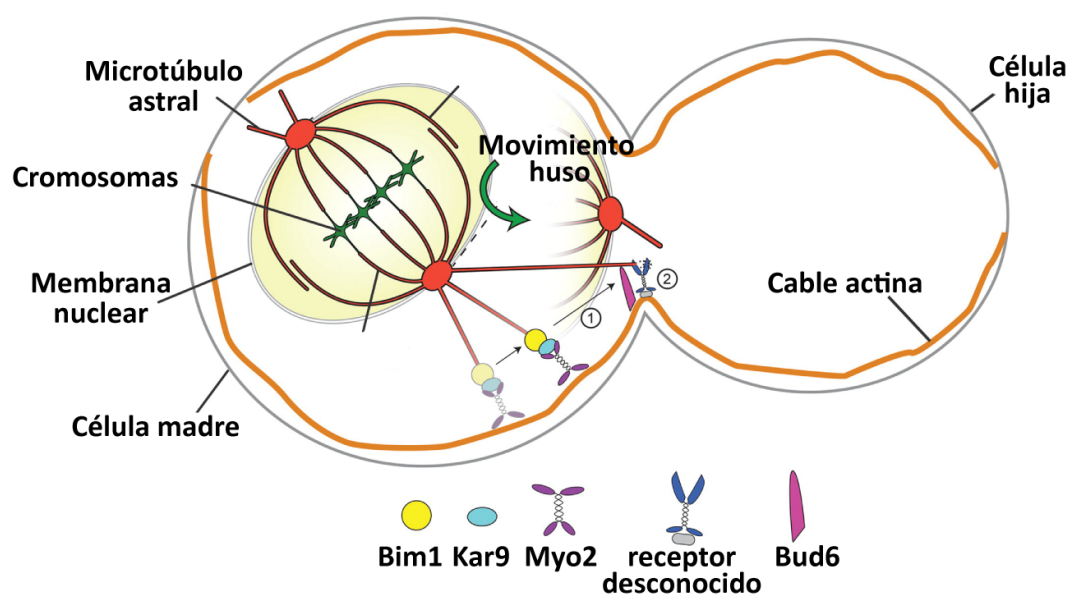

\section{B Ruta Dineína}

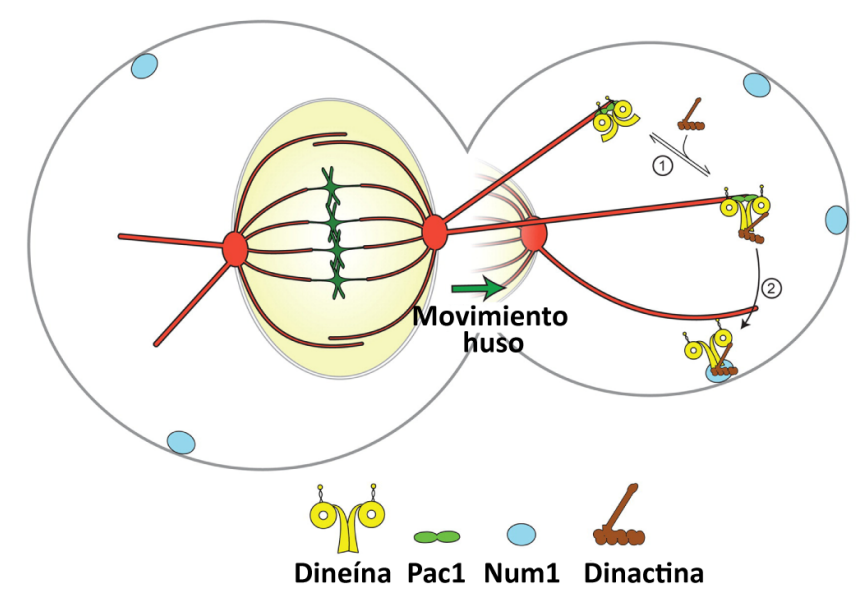


Segal, 2011; Meitinger et al., 2012). Durante anafase, Cdc14 es gradualmente liberada del nucleolo en dos pasos. El primero es mediado por la ruta cdc Fourteen Early Anaphase Release (FEAR) y tiene lugar poco después de la transición metafase-anafase. Cdc14 parcialmente liberado defosforila a las dianas de CDK incluyendo Ask1, Sil15, Fin1 y Ase1 para completar las funciones relacionadas con anafase, tales como segregación del rDNA y estabilización del huso en anafase. La liberación completa de Cdc14 ocurre después en la anafase y activa la ruta MEN, una cascada de señalización controlada por la GTPasa Tem1. Tem1 activo promueve la activación secuencial de las kinasas Cdc15 y Dbf2. Dbf2, en complejo con su regulador Mob1, fosforila a Cdc14 obstaculizando su señal de localización nuclear y facilitando su localización en el citoplasma.

Cuando se producen fallos en la orientación del huso, la supervivencia de las células sólo es posible si son capaces de parar el ciclo hasta que el huso esté bien orientado (Fig. 17)(revisado en Merlini y Piatti, 2011; Caydasi y Pereira, 2012). En esta situación, el SPOC mantiene la ruta MEN inactiva por inhibición de la GTPasa Tem1. Componentes del SPOC son el complejo Bfa1-Bub2, la Polo kinasa Cdc5 y la kinasa Kin4, junto con las proteínas implicadas en la regulación de Kin4. Bfa1 y Bub2 forman un complejo GAP que acelera la hidrólisis de GTP de Tem1, manteniéndolo en su forma inactiva unida a GDP. La Polo kinasa Cdc5 fosforila a Bfa1 e inhibe la actividad GAP del complejo, mientras que la fosforilación de Bfa1 por Kin4 protege al complejo de la acción inhibitoria de Cdc5. El primer interruptor de MEN es la GTPasa Tem1, la cual parece ser activada por Lte1. Sin embargo, el mecanismo por el que Lte1 activa a Tem1 no parece ser directo, ya que Lte1 no es una GEF de Tem1, pero contribuye a la salida de mitosis por la regulación negativa de Kin4. Antes de la elongación del huso, Tem1 se localiza en el SPB más próximo a la célula hija, donde activa a Cdc15, una proteín kinasa que promueve directamente la salida de mitosis. De esta manera, el SPOC puede evaluar la posición del huso usando al SPB como un sensor que responde a las señales espaciales entre la madre y la hija: la zona "activadora" de la ruta MEN está localizada en la yema como resultado de la localización de Lte1, mientras que la célula madre es la zona "inhibitoria" debido a la presencia de Kin4, la kinasa que mantiene el complejo GAP Bfa1-Bub2 en un estado activo. Bfa1-Bub2 activo inhibe a Tem1, y consecuentemente previene la iniciación de MEN. Así, el SPB que contiene Tem1 debe no solo entrar en la yema para señalizar la salida de mitosis, sino también para escapar de la inhibición de Kin4 en la célula madre.

Kin4 es una pieza clave en la regulación del SPOC, en parte por el establecimiento de la zona de inhibición de MEN en la célula madre. Durante la salida de mitosis, Kin4 se acumula en el cuello y en el nuevo sitio de gemación en G1. Sin embargo, cuando una nueva yema emerge, Kin4 es excluida del córtex de la yema, donde está Lte1. Durante un corto periodo de tiempo en anafase, Kin4 se localiza en el SPB de la célula madre, pero si el huso está desalineado, Kin4 se localiza en ambos SPBs. La actividad de Kin4 está directamente regulada por fosforilación por la kinasa Elm1 en un residuo de treonina en el T-loop activador. Se sabe que la función de Elm1 en el SPOC depende de su localización en el cuello, ya que una truncación de Elm1 que no es capaz de asociarse al cuello es deficiente en el SPOC. Kin4 está hipofosforilada durante los estados del ciclo celular cuando su actividad tiene que estar inhibida, para inhibir a MEN, y es rápidamente fosforilada durante la salida de mitosis. Estudios recientes han mostrado que la fosfatasa PP2A es importante para mantener a Kin4 en su estado hipofosforilado, y esta desfosforilación por PP2A es necesaria para que Kin4 se una al SPB. Por tanto, PP2A es el mayor factor en la localización selectiva de Kin4 en el córtex de la madre y es el factor clave en el mantenimiento del SPOC. Rts1, una de las subunidades reguladoras de PP2A, está implicada en la regulación de Kin4. 


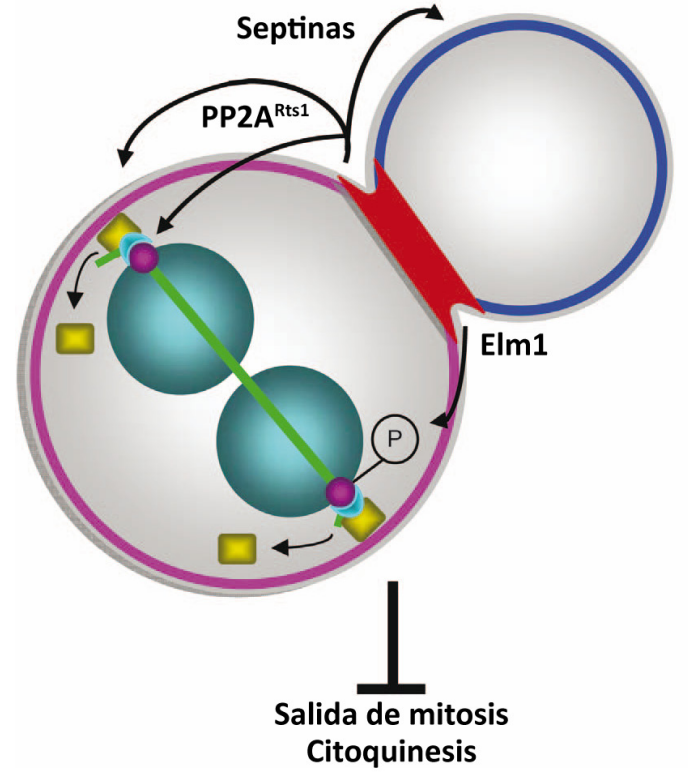

Figura 17. Contribución de las proteínas del cuello al SPOC. Las septinas contribuyen a mantener a Lte1 (activador de MEN) en la yema y previenen su difusión a la célula madre. La fosfatasa PP2A-Rts1, que se localiza en el cuello en anafase tardía y regula la dinámica de las septinas, es necesaria para la localización de Kin4 (inhibidor de MEN) en la célula madre. La kinasa Elm1 se localiza en el cuello y fosforila a Kin4 en T209, lo que la activa. Kin4 promueve la activación de Bub2-Bfa1, el complejo GTPasa que inhibe a Tem1. La compartimentalización espacial de Kin4 y Lte1 es importante para prevenir la salida de mitosis cuando el huso mitótico está mal orientado. Modificado de Merlini y Piatti, 2011.

Aunque no se conoce si PP2A-Rts1 defosforila directamente a Kin4, está claro que la deleción de RTS1 causa acumulación de formas hipofosforiladas de Kin4 que no pueden localizarse correctamente en los SPBs y en el córtex.

\section{III) Las septinas y la ruta SPOC.}

El cuello donde se localizan las septinas es una plataforma de señalización crucial para la transmisión adecuada de los cromosomas y la regulación de la salida de mitosis (Fig. 17). La integridad del cuello y del anillo de septinas contribuye a la segregación cromosómica en varios niveles : (i) al participar en el posicionamiento del huso, mediante la regulación de la dinámica de los microtúbulos astrales a través de las rutas de Kar9 y la dineína, y (ii) a través del SPOC, participando en la compartimentación de algunos factores críticos y en la localización en el cuello de algunas de las proteín kinasas claves en esta ruta. Algunas evidencias indican que la interacción entre los microtúbulos astrales y el cuello de gemación juega un importante papel en el SPOC. Inicialmente, Castillon y colaboradores describieron que los mutantes de septinas sep7 $\triangle$ y $c d c 10 \Delta$ son defectivos en el SPOC, de forma que las células salen inapropiadamente de mitosis aunque el huso esté mal orientado, dando lugar a células madre con dos núcleos (Castillon et al., 2003). Además, en estos mutantes Lte1 está deslocalizado hacia la célula madre, lo mismo sucede en un mutante $c d c 12-6$. Estos resultados sugieren que las septinas sirven como barrera de difusión para Lte1. Además, la mayoría de estas células con defectos en septinas fallan en la localización del núcleo en el cuello. Este defectivo posicionamiento es similar al de las células mutantes carentes de Kar9 o dineína, dos proteínas que han sido implicadas en el posicionamiento nuclear. Por tanto, se puede decir que las septinas son necesarias para el correcto posicionamiento del huso relativo al plano de división (Kusch et al., 2002). 



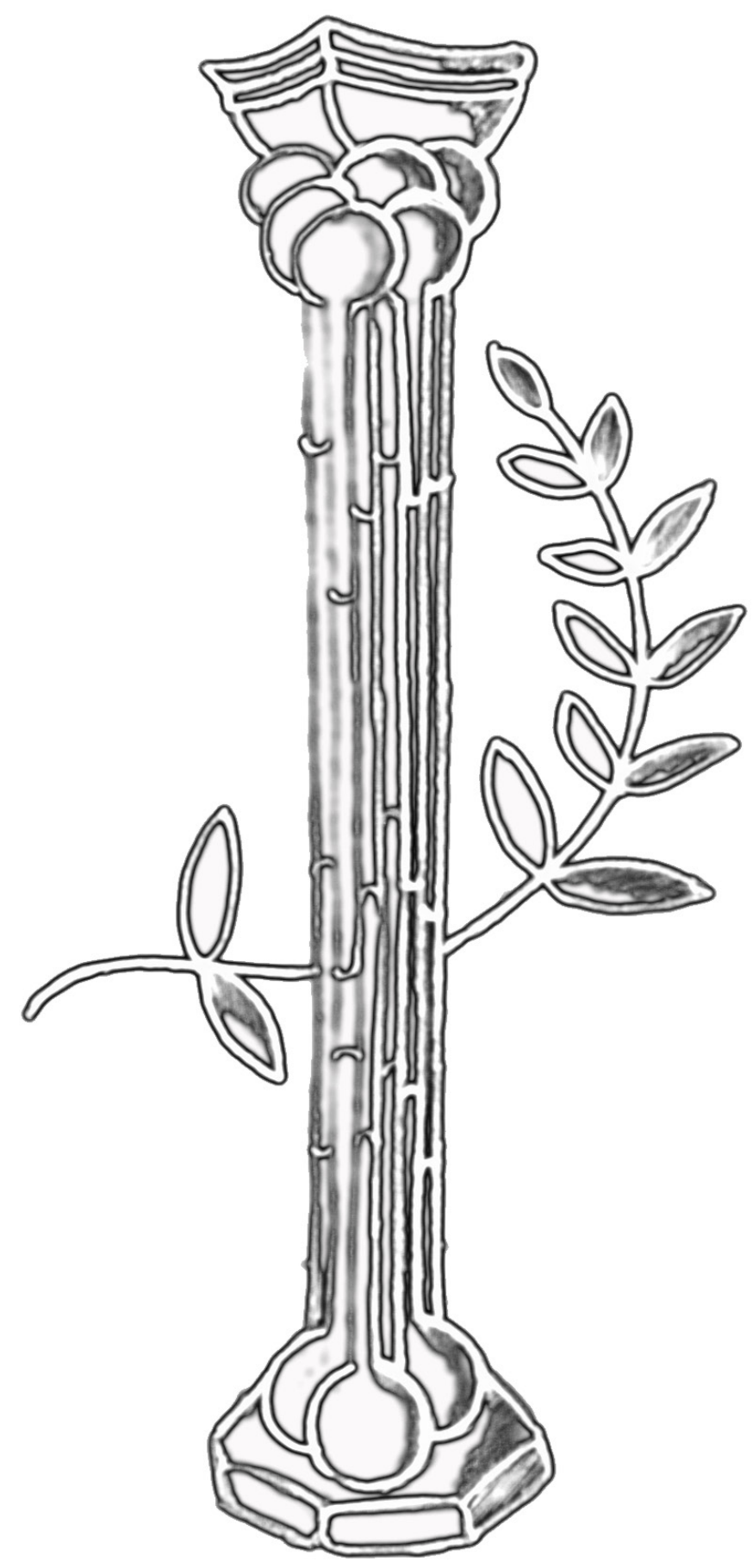

Objetivos 

El trabajo descrito en esta Memoria se enmarca dentro de un proyecto más amplio que tiene como objetivo el estudiar los procesos que regulan temporal y espacialmente la separación celular en hongos y levaduras.

El objetivo general es el estudio de diversos aspectos de la regulación del anillo de septinas y su relación con la morfogénesis en el patógeno oportunista $C$. albicans. Para ello se plantearon los siguientes objetivos específicos:

1. Estudiar la composición del anillo de septinas en los distintos estadíos morfológicos, mediante técnicas in vitro para la caracterización bioquímica de los complejos de septinas.

2. Estudiar la importancia de la dosis génica de cada una de las septinas en el control de la separación celular de las hifas.

3. Analizar el papel de la septina Sep7 como regulador de la separación celular de las hifas y determinar las regiones de la proteína importantes para esta función.

4. Estudiar la función que desempeñan las modificaciones post-traduccionales de distintas septinas en el control de la separación celular.

5. Caracterizar la función de otras proteínas reguladoras del anillo de septinas, como Int1, y su importancia en la dinámica de esta estructura. 



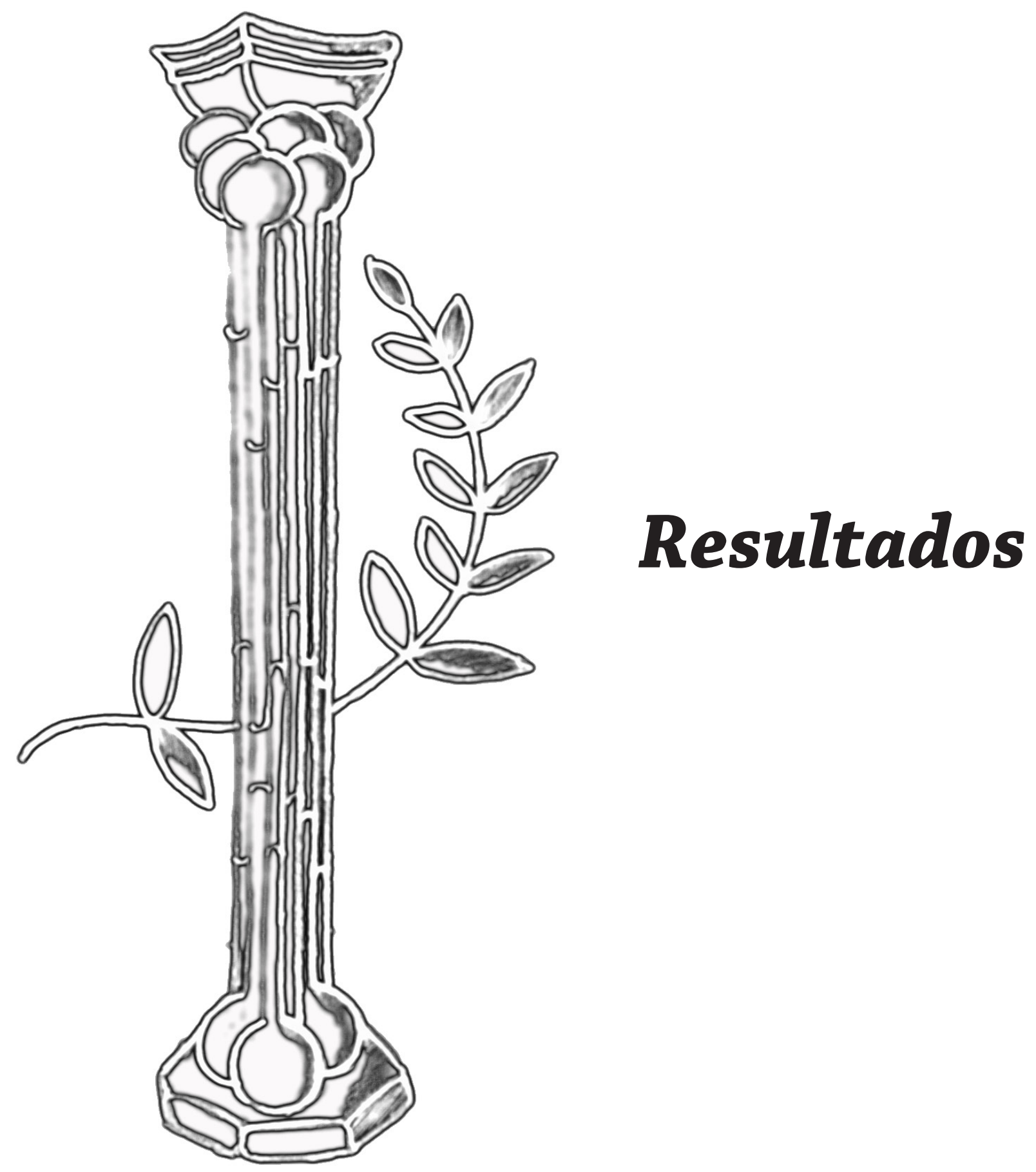





\section{CAPÍTULO I: La dosis génica de las septinas juega un papel fundamental en la inhibición de la} separación celular de las hifas.

\subsection{Introducción y antecedentes.}

Históricamente, C. albicans ha sido considerado como un organismo diploide obligado sin estado haploide (Jones et al., 2004; Noble y Johnson, 2007), aunque recientemente Hickman y colaboradores (2013) han descubierto cepas haploides. Estas nuevas cepas haploides desenmascararon mutaciones recesivas, generando un fondo genético diferente al de sus progenitores diploides. Esto evidenció que los juegos de cromosomas de un organismo diploide son altamente heterocigóticos y se planteó la importancia de mantener las dos copias intactas de cada gen para poder llevar a cabo su función correctamente.

Como se ha comentado en la Introducción, resultados previos del laboratorio indicaban que la inhibición de la separación celular en hifas depende de la modificación de la dinámica del anillo de septinas, el cual es convertido a una forma específica de hifas (González-Novo et al., 2008). Este estado se caracteriza porque dos de las septinas, Cdc10 y Cdc11, presentan un alto intercambio entre el citoplasma y el anillo, mientras que las otras tres septinas (Cdc3, Cdc12 y Sep7) se mantienen estables. El cambio al estado específico de hifas y la inhibición de la separación celular son dependientes de Sep7, pues las hifas del mutante $\operatorname{sep} 7 \Delta \Delta$ poseen una dinámica similar a la de levaduras y al mismo tiempo activan la maquinaria de separación celular. Estas observaciones sugerían que podría existir una correlación directa entre la dinámica del anillo de septinas y la inhibición de la separación celular.

Por otro lado, estudios filogenéticos entre las distintas septinas han demostrado la existencia de cinco grupos evolutivos que se conservan en todos los organismos eucariotas (Pan et al., 2007). Cdc11 y Shs1 son las septinas más directamente relacionadas, perteneciendo al mismo grupo, lo que probablemente indica que hayan surgido de una duplicación génica (Fig. 10A)(Pan et al., 2007). Estudios bioquímicos han demostrado esta relación, ya que Cdc11 y Shs1 compiten por ocupar la posición terminal en los octámeros de septinas in vivo (Bertin et al., 2008; Garcia et al., 2011). Sin embargo, Finnigan y colaboradores proponen que los octámeros Shs1-Cdc12-Cdc3-Cdc10-Cdc10-Cdc3-Cdc12-Shs1 son incapaces de formar filamentos, al menos in vitro (Garcia et al., 2011; Finnigan et al., 2015b), y que por este motivo los mutantes $c d c 11 \Delta$ son inviables a altas temperaturas.

En este Capítulo se mostrarán los resultados que evidencian la importancia de mantener intacta la dosis génica de SEP7, así como la relación 1:1 de las septinas Sep7 y Cdc11, para inhibir la separación celular durante el crecimiento hifal; además, se expondrán los datos que demuestran que no existe una correlación directa entre la dinámica del anillo de septinas y la inhibición de la separación celular.

\section{$1.2 \operatorname{sep} 7 \Delta \Delta$, a diferencia de otros mutantes nulos de septinas $(\operatorname{cdc} 11 \Delta \Delta$ y $\operatorname{cdc} 10 \Delta \Delta)$, presenta separación celular en hifas.}

Ya se conocía en S. cerevisiae que las septinas cooperaban en la formación del septo, las proyecciones de conjugación y las esporas, cuando Warenda y Konopka (2002) estudiaron sus homólogos en C. albicans. Estos autores comprobaron que, al igual que en S. cerevisiae, CDC3 y CDC12 son esenciales para la viabilidad. En contraste, los mutantes $c d c 10 \Delta \Delta$ y $c d c 11 \Delta \Delta$ son viables pero tienen defectos en citoquinesis, localización de la quitina en la pared celular y morfología de la yema (Fig. 18A). Así, la 
mayoría de las células $c d c 10 \Delta \Delta$ tienen una apariencia silvestre a $30^{\circ} \mathrm{C}$, pero a $37^{\circ} \mathrm{C}$ el $34 \%$ de sus células son elongadas y muchas de ellas muestran un patrón muy similar a las pseudohifas. A $42^{\circ} \mathrm{C}$, el $94 \%$ de las células $c d c 10 \Delta \Delta$ son elongadas y forman grupos que no se separan. Por otro lado, el mutante $c d c 11 \Delta \Delta$ exhibe un fenotipo independiente de la temperatura, con colonias arrugadas y asimétricas durante su crecimiento en placa, y un $91 \%$ de células anormales en medio líquido. A diferencia de las células $c d c 10 \Delta \Delta$, el mutante $c d c 11 \Delta \Delta$ no muestra yemas elongadas a $42^{\circ} \mathrm{C}$. Sin embargo, $c d c 10 \Delta \Delta$ y $c d c 11 \Delta \Delta$ tienen en común que forman células encadenadas con múltiples núcleos, lo que indica defectos en citoquinesis. Por su parte, la deleción de SEP7 causa defectos leves en citoquinesis durante el crecimiento levaduriforme (Warenda y Konopka, 2002). En cuanto al crecimiento filamentoso, los mutantes $c d c 10 \Delta \Delta$ y $c d c 11 \Delta \Delta$ responden a estímulos de inducción hifal y forman hifas, pero presentan una curvatura anormal y un crecimiento más lento que una cepa silvestre. Además, los mutantes $\operatorname{cdc} 11 \Delta \Delta$ son defectivos en el crecimiento invasivo en medio sólido. En cuanto a Sep7, los mutantes de esta septina son capaces de formar hifas indistinguibles de las de un silvestre, con respecto a su tamaño y morfología (Warenda y Konopka, 2002).

No obstante, estudios más recientes demostraron que la pérdida de Sep7 resulta en la separación celular de las hifas, ya que a tiempos largos de filamentación comienzan a degradarse los septos más antiguos (los más cercanos al cuerpo celular) y se observan cuerpos celulares aislados y fragmentos de hifas sin cuerpo celular (González-Novo et al., 2008)(Fig. 18B). Para cuantificar este defecto, se construyó la cepa sep $7 \Delta \Delta$ reemplazando la región codificante completa del gen en cada uno de los alelos por las secuencias de los genes HIS1 y SAT1 (que confiere resistencia a ClonNat) en la cepa BWP17 (todas las cepas construidas durante este trabajo fueron comprobadas por PCR y/o secuenciación). Posteriormente, se fijaron muestras de hifas silvestres y mutantes $\operatorname{sep} 7 \Delta \Delta$ tras 2,$5 ; 3,5$ y $4,5 \mathrm{~h}$ de inducción de la filamentación y se determinó el porcentaje de hifas en las que se había activado la separación contando el número de cuerpos celulares aislados frente a los que todavía se mantenían unidos a la hifa (salvo que se indique lo contrario, el resto de experimentos de esta Memoria se realizaron en las mismas condiciones). Los resultados mostraron que tras $2,5 \mathrm{~h}$ de filamentación el mutante $\operatorname{sep} 7 \Delta \Delta$ presentaba un $15 \%$ de separación, a diferencia de la cepa silvestre que apenas tenía cuerpos separados (Fig. 18B). Esta diferencia se mantuvo en el siguiente punto (3,5 h de filamentación), debido a que el porcentaje de hifas separadas aumentaba desde el $10 \%$ observado en el silvestre a cerca del $30 \%$ en el mutante $\operatorname{sep} 7 \Delta \Delta$. A 4,5 h de filamentación, tanto la cepa silvestre como el mutante sep $7 \Delta \Delta$ presentaban un alto porcentaje de cuerpos separados (en torno al $35 \%$ en un silvestre y a un $45 \%$ en el mutante). Dado que a 2,5 h de filamentación una cepa silvestre prácticamente permanece intacta y a 4,5 h los porcentajes de separación son más parecidos se determinó tomar un tiempo intermedio (3,5 h de filamentación) para posteriores contajes de separación celular.

Figura 18. Los mutantes de septinas alteran la morfología celular. (A). Los mutantes nulos de las septinas Cdc10 y Cdc11 presentan una morfología elongada. Las cepas de C. albicans analizadas incluyen BWP17 (A-C) y los mutantes $c d c 10 \Delta \Delta$ (D-F) y $c d c 11 \Delta \Delta(\mathrm{J}-\mathrm{L})$. Además las cepas $c d c 10 \Delta \Delta$ y $c d c 11 \Delta \Delta$ con una copia del gen silvestre integrado bajo su promotor endógeno (G-I y $\mathrm{M}-\mathrm{O}$ ) fueron analizadas para confirmar que el fenotipo era debido a la deleción del gen indicado. Barra de escala, $10 \mu \mathrm{m}$. Tomada de Warenda y Konopka (2002). (B). Los mutantes sep $7 \Delta \Delta$ forman filamentos que se separan después de citoquinesis. Izquierda: Imágenes de hifas silvestres y $\operatorname{sep} 7 \Delta \Delta$ tras $3 \mathrm{~h}$ en condiciones de filamentación. Las regiones indicadas con números están ampliadas en los paneles inferiores. Barra de escala, $5 \mu \mathrm{m}$. Tomada de González-Novo et al., (2008) Derecha: Cuantificación del número de cuerpos celulares separados a las 2,$5 ; 3,5$ y 4,5 h de filamentación. El gráfico muestra el porcentaje promedio en la cepa silvestre (negro) y en el mutante $\operatorname{sep} 7 \Delta \Delta$ (rojo) (4 experimentos, $n>200$ células), con la desviación estándar. (C). Las septinas se unen formando octámeros no polares. Representación esquemática de los octámeros de una cepa silvestre y los mutantes $\operatorname{sep} 7 \Delta \Delta, \operatorname{cdc} 11 \Delta \Delta$ y $c d c 10 \Delta \Delta$. (D). No todos los mutantes de septinas presentan separación celular de las hifas. El gráfico muestra el porcentaje promedio de cuerpos separados en la cepa silvestre (negro) y en los mutantes $\operatorname{sep} 7 \Delta \Delta, c d c 11 \Delta \Delta$ y $c d c 10 \Delta \Delta$ (blanco), con la SEM, a 3,5 h de filamentación. Los asteriscos indican el nivel de significación (****: p<0,0001; t test). WT (OL1417), sep7 $\Delta \Delta$ (OL2138), cdc11 $\Delta \Delta$ (OL1365) y cdc10 $\Delta \Delta$ (OL2213). 


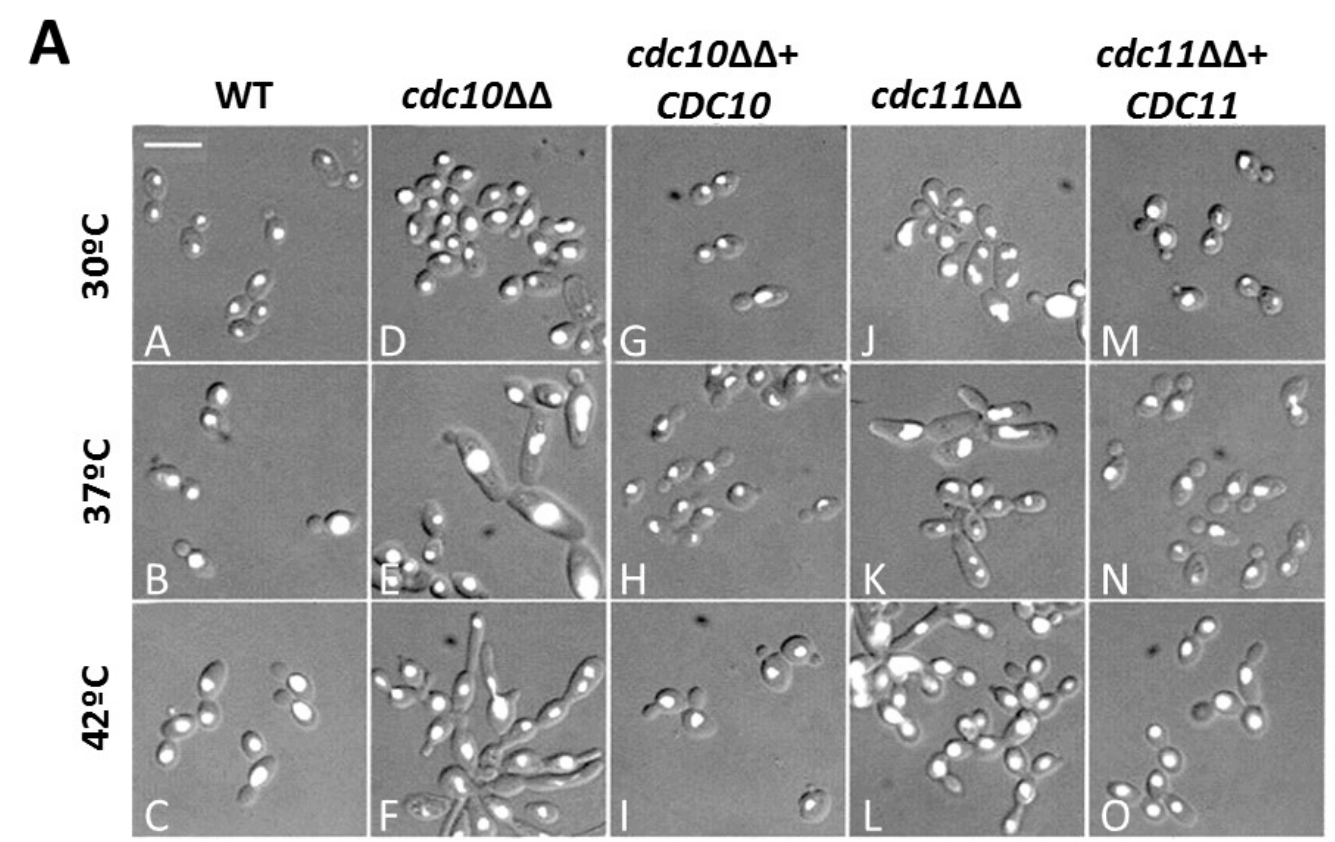

B
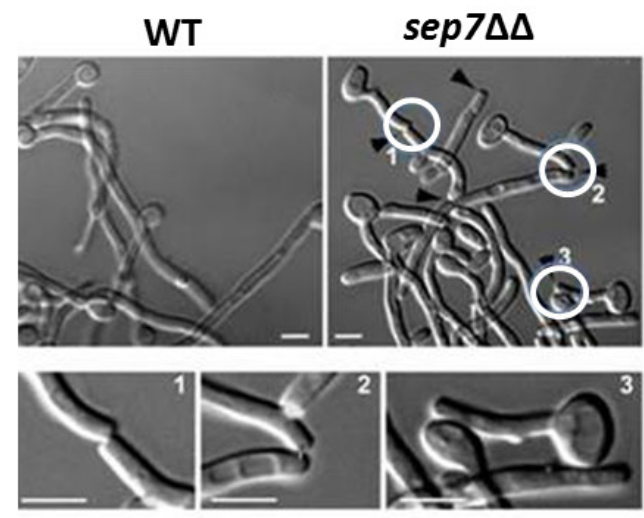

$-\mathrm{WT} \rightarrow \operatorname{sep} 7 \Delta \Delta$

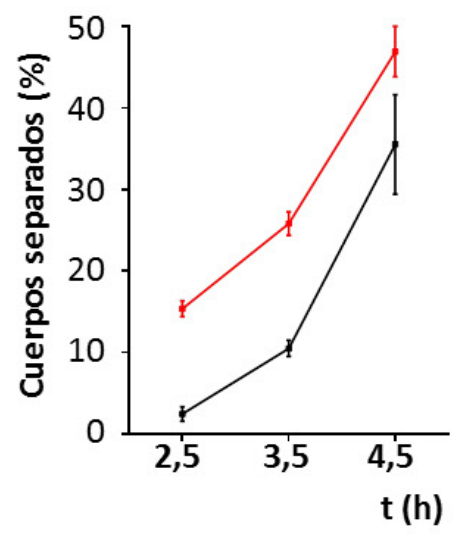

C

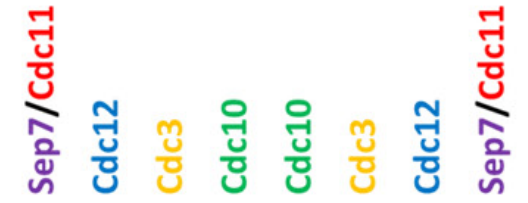

100000000 wr

290000000 sepras

${ }_{3}, 000000000$ adtans

4 Q0000000 actoos

Septinas 0 Septinas no Septinas

esenciales 0 esenciales delecionadas

D

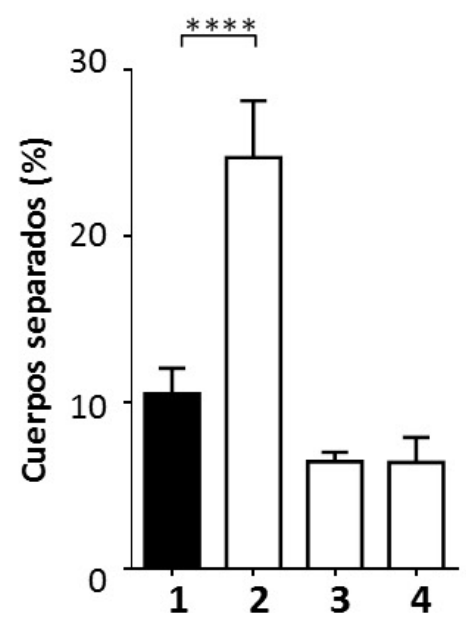


A continuación, para estudiar si este defecto era específico de mutantes $\operatorname{sep} 7 \Delta \Delta$ o el resto de las septinas también estaban implicadas en la regulación de la separación en hifas, se construyeron los mutantes nulos en el resto de las septinas viables, $c d c 11 \Delta \Delta$ y $c d c 10 \Delta \Delta$ (Fig. 18C). En estos mutantes de deleción, al igual que en el mutante $\operatorname{sep} 7 \Delta \Delta$, la región codificante completa del gen en cada uno de los alelos se sustituyó por los genes HIS1 y SAT1 en la cepa BWP17. Una vez construidas, se estudió cómo afectaba la pérdida de cada gen a la separación de las hifas y se comprobó que presentaban un porcentaje similar a la cepa silvestre (5-10\%) a 3,5 h de filamentación, a diferencia del mutante $\operatorname{sep} 7 \Delta \Delta$ cuyo porcentaje de separación celular era superior y la diferencia con respecto al silvestre era estadísticamente significativa (Fig. 18D). Sin embargo, es difícil comparar las condiciones de filamentación del silvestre y de los mutantes $c d c 11 \Delta \Delta$ y $c d c 10 \Delta \Delta$, pues en estos últimos el desarrollo hifal está retrasado en comparación con el silvestre, presentando unas hifas abombadas que pierden ligeramente la secreción polarizada y filamentos curvos que crecen más lentamente. Por tanto, estos resultados indican que Sep7 tiene una función específica en la regulación de la separación celular de hifas que no es compartida por Cdc10 o Cdc11.

\subsection{La dosis génica de SEP7 es importante para inhibir la separación celular de las hifas.}

Dado que Sep7 parecía desempeñar un papel regulador de la separación de las hifas, lo primero que se comprobó fue cómo afectaba la reducción de la dosis génica de SEP7 a este proceso. Para ello, se construyó un mutante heterocigótico para SEP7 (que denominaremos SEP7+/-), en el que la región codificante completa de un alelo fue reemplazada por el gen SAT1 en la cepa BWP17, manteniendo el otro alelo intacto (Fig. 19A). En esta cepa cabría esperar que la cantidad del mRNA de SEP7, y por tanto de la septina Sep7, fuera la mitad de la observada en la cepa silvestre, sin alterar las cantidades de las otras cuatro septinas.

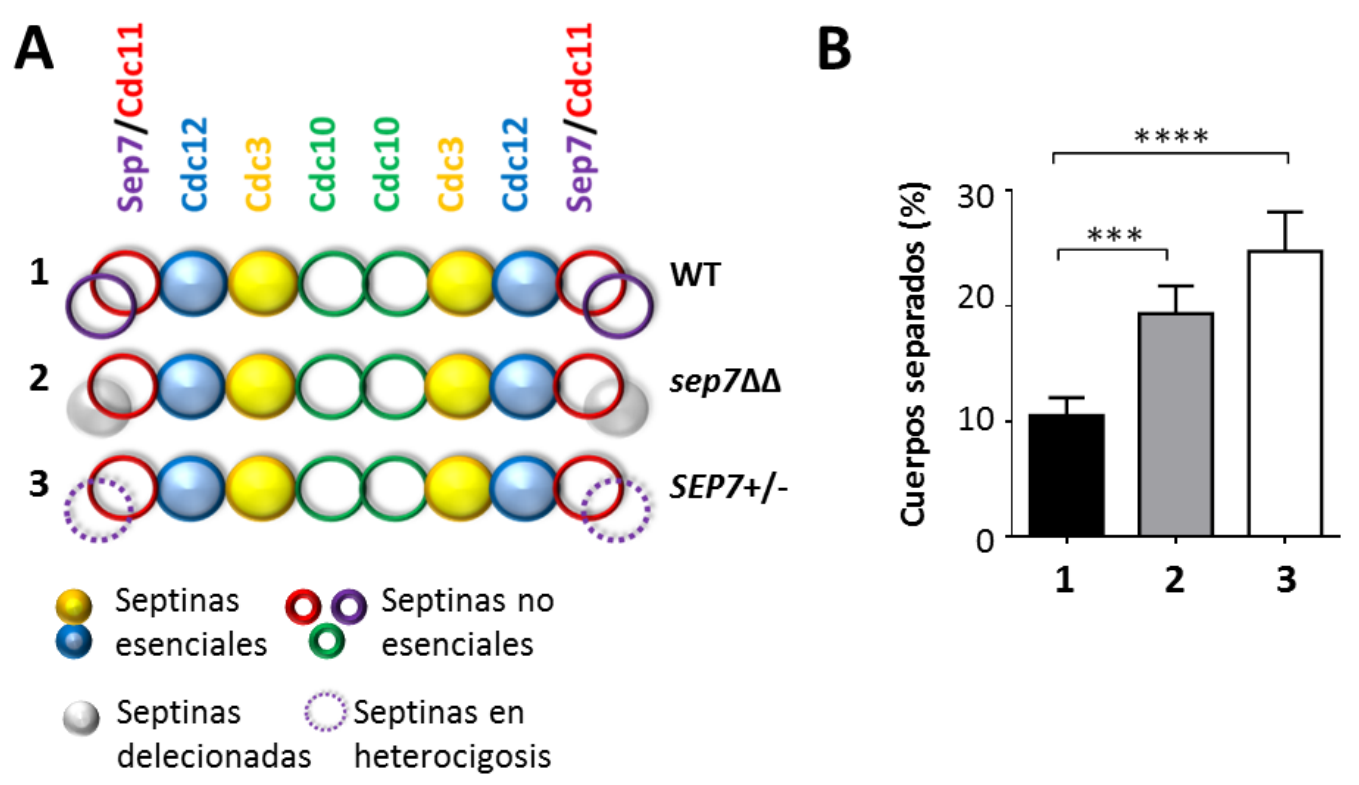

Figura 19. La dosis génica de SEP7 es importante para inhibir la separación celular de las hifas. (A). Representación esquemática de los octámeros de una cepa silvestre, el mutante $\operatorname{sep} 7 \Delta \triangle$ y el heterocigótico $S E P 7+/-$. (B). El mutante heterocigótico SEP7+/presenta separación celular, pero en un menor porcentaje que el mutante nulo sep $7 \Delta \Delta$. El gráfico muestra el porcentaje promedio de cuerpos separados en la cepa silvestre (negro), el mutante $\operatorname{sep} 7 \Delta \Delta$ (blanco) y el heterocigótico $S E P 7+/-$ (gris), con la SEM, a 3,5 h de filamentación. Los asteriscos indican el nivel de significación ( ${ }^{* * *}: p=0,0001 ; * * * * p<0,0001 ; t$ test). WT (OL1417), sep7 $\triangle$ (OL2138) y SEP7+/- (OL2049). 
Este mutante se analizó mediante técnicas de microscopía óptica y se observó que no poseía ningún defecto en el crecimiento ni en medio mínimo YNB ni en medio rico YEPD durante el desarrollo levaduriforme comparado con la cepa silvestre. Además, cuando se indujo la filamentación de la cepa silvestre y del mutante heterocigótico SEP7+/- se comprobó que el mutante era capaz de formar hifas similares a las de la cepa silvestre cuando se observaron en el microscopio óptico. A pesar de ello, el mutante heterocigótico activaba la separación celular durante el crecimiento hifal, presentando un porcentaje de separación intermedio (en torno al 20\%) entre una cepa silvestre y un mutante nulo (10\% y $30 \%$, respectivamente), después de 3,5 h de filamentación (Fig. 19B). Este resultado indica que la cantidad de Sep7 en relación con el resto de las septinas es importante para mantener unidos los compartimentos hifales.

\subsection{La dosis génica de CDC11 también contribuye a inhibir la separación celular en hifas.}

Dado que el mutante heterocigótico SEP7+/- presentaba defectos en la inhibición de la separación celular, se planteó la posibilidad de que la dosis alélica del resto de septinas también pudiera participar en la regulación de este proceso. De esta forma, se construyeron los mutantes heterocigóticos para el resto de los genes de septinas, es decir, $C D C 11+/-, C D C 10+/-, C D C 3+/-$ y $C D C 12+/-$ (Fig. 20A). Al igual que el mutante $S E P 7+/-$, estas nuevas cepas se construyeron reemplazando una de las dos copias del gen correspondiente por el gen SAT1, y manteniendo la otra copia sin modificar.

Una vez construidas y comprobadas, se usó la técnica de PCR cuantitativa a tiempo real (qRT-PCR) para confirmar que en todos los mutantes heterocigóticos (SEP7+/-, CDC11+/-, CDC10+/-, CDC3+/- y $C D C 12+/-)$ existía una bajada de la expresión del gen que codificaba para la septina que se encontraba en heterocigosis. Para ello, se diseñaron cinco parejas de oligonucleótidos, de forma que cada una de ellas amplificaba específicamente una región de cada gen de septinas (CDC3, CDC12, CDC11, CDC10 y SEP7). Para el estudio de cada mutante heterocigótico se usaron dos parejas, una que amplificaba la región del gen en heterocigosis ( $C D C 3$ en el mutante $C D C 3+/-, C D C 12$ en el mutante $C D C 12+/-$, y así sucesivamente) y otra que se usaba como control, que en la mayoría de los casos fue el gen CDC3. Obviamente, en el mutante $C D C 3+/$ - se usó como control otra pareja de oligonucleótidos alternativa, en este caso la que amplificaba la región de CDC12.

Con esta finalidad, se purificó el mRNA de las cepas heterocigóticas en crecimiento exponencial, se usó la retrotranscriptasa para obtener el cDNA y se determinó la cantidad del mRNA de las septinas por qRT-PCR. Los resultados cuantitativos obtenidos en este experimento mostraron que, efectivamente, en todos los casos la expresión del gen que se encontraba en heterocigosis era aproximadamente la mitad de la del gen usado como control (Fig. 20B). Aunque no se comprobó que la cantidad de las distintas septinas estaba también reducida a la mitad (ya que estas cepas carecían de epítopos que permitieran analizar su abundancia), estos resultados sugerían que se disponía de un conjunto de cepas en las que la cantidad de una de las subunidades era limitante en comparación con las otras cuatro.

Al igual que en el caso del mutante $S E P 7+/-$, estos nuevos mutantes crecían en medio YEPD o YNB de forma similar a un silvestre en estado levaduriforme. Además, a diferencia de los mutantes $c d c 10 \Delta \Delta$ y $c d c 11 \Delta \Delta$, todas las cepas heterocigóticas presentaban hifas idénticas al silvestre, ya que no se observaron diferencias en el tamaño de los filamentos y/o morfología. No obstante, cuando se estudió la separación celular tras 3,5 h de filamentación, se observó que únicamente el mutante heterocigótico CDC11+/- presentaba un alto porcentaje de hifas separadas (en torno al 35\%), incluso mayor al del 
heterocigótico SEP7+/- ( 20\%). El resto de mutantes, CDC3+/-, CDC10+/- y CDC12+/-, mantenían un porcentaje similar al de la cepa silvestre en ese tiempo de filamentación (alrededor del 10\%)(Fig. 20C).

Por tanto, estos resultados indican que no todas las septinas contribuyen de forma similar a inhibir de la separación de las hifas, y apuntan a que la dosis alélica de los genes que codifican para las septinas que se encuentran en los extremos de los octámeros debe mantenerse estable para que los compartimentos hifales se mantengan unidos a tiempos largos de filamentación.
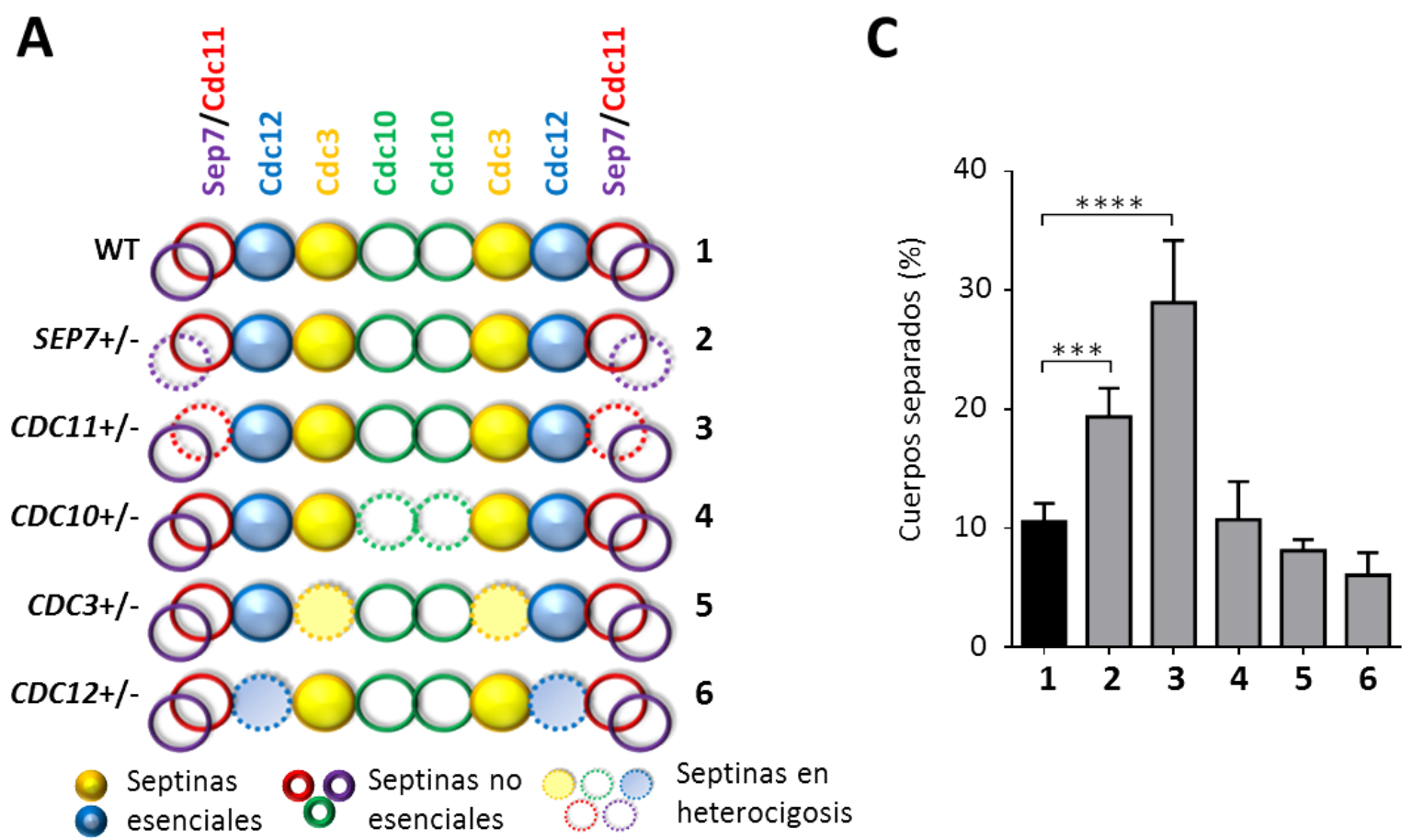

\section{B}

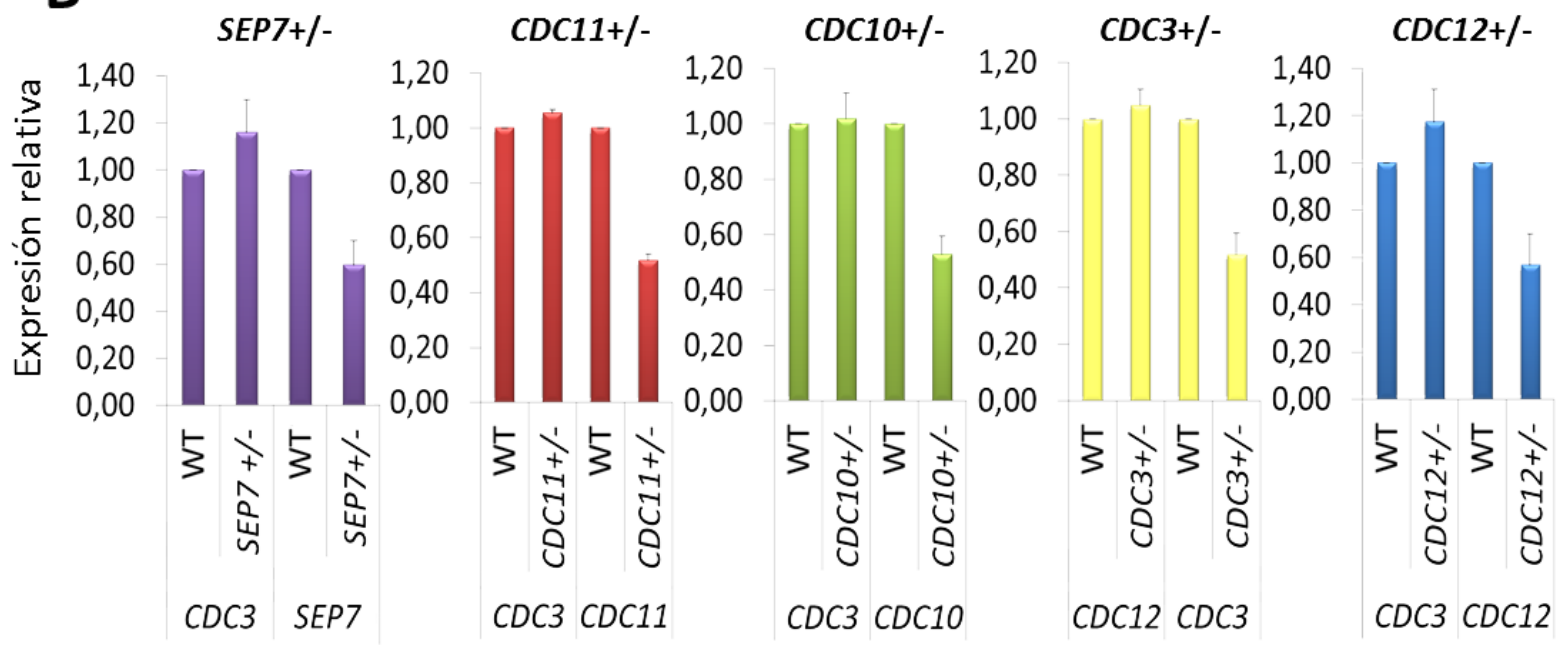

Figura 20. La dosis génica de CDC11 también contribuye a inhibir la separación celular en hifas. (A). Representación esquemática de los octámeros de una cepa silvestre y los mutantes heterocigóticos SEP7+/-, CDC11+/-, CDC10+/-, CDC3+/- y CDC12+/-. (B). Los niveles de expresión de las septinas en heterocigosis se reducen a la mitad. Se analizó la cantidad de mRNA presente en células creciendo exponencialmente mediante qRT-PCR. Los valores fueron normalizados con los obtenidos para el gen $A D E 2$. (C). El mutante $C D C 11+/$ - presenta un alto porcentaje de separación celular de las hifas. El gráfico muestra el porcentaje promedio de cuerpos separados en la cepa silvestre (negro) y en los mutantes heterocigóticos (gris) a 3,5 h de filamentación, y son la media \pm SEM de, al menos, tres experimentos independientes. Los números corresponden a las cepas indicadas en (A). Los asteriscos indican el nivel de significación $(* * *: p=0,0001 ; * * * *: p<0,0001 ; t$ test). WT (OL1417), SEP7+/(OL2049), CDC11+/- (OL2050), CDC10+/- (OL2136), CDC3+/- (OL2134) y CDC12+/- (OL1184). 


\subsection{Las proporciones relativas de Sep7, Cdc11 y Cdc10 son importantes para mantener la} inhibición de la separación celular durante el crecimiento hifal.

Los resultados anteriores indican que los únicos mutantes heterocigóticos que activan la separación celular en hifas son SEP7+/-y CDC11+/-, y precisamente son estas dos proteínas las que "compiten" para unirse a los extremos de los octámeros de septinas. De hecho, en $S$. cerevisiae se ha demostrado que los octámeros tienen diferentes propiedades de polimerización in vitro dependiendo de si contienen Shs1 o Cdc11 en los extremos (Booth et al., 2015; Finnigan et al., 2015b) y que Cdc11 puede sustituir in vivo a Shs1, pero Shs1 es necesaria para un ensamblaje eficiente de los polímeros, así como para controlar la longitud, localización y organización de los filamentos y arquitectura del collar (Ong et al., 2014). Una hipótesis interesante para explicar estos resultados podría ser que la proporción relativa de bastones (con la misma proteína a ambos lados del octámero, Sep7-Sep7 o Cdc11-Cdc11, o mixtos Sep7-Cdc11, con Sep7 a un lado del bastón y Cdc11 al otro) que se forman durante el crecimiento en forma de levaduras o hifas fuera diferente, y que esto condicionara la estructura y/o propiedades de los anillos de septinas en ambas morfologías. De esta manera, la reducción en la dosis génica de SEP7 y CDC11 cambiaría estas proporciones y estaría alterando la funcionalidad del anillo. Una predicción

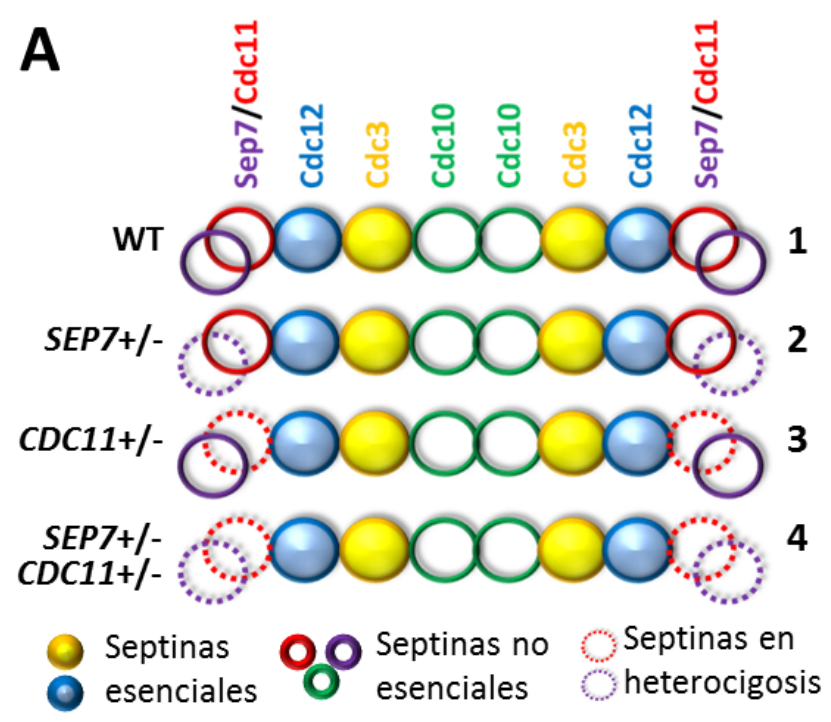

B

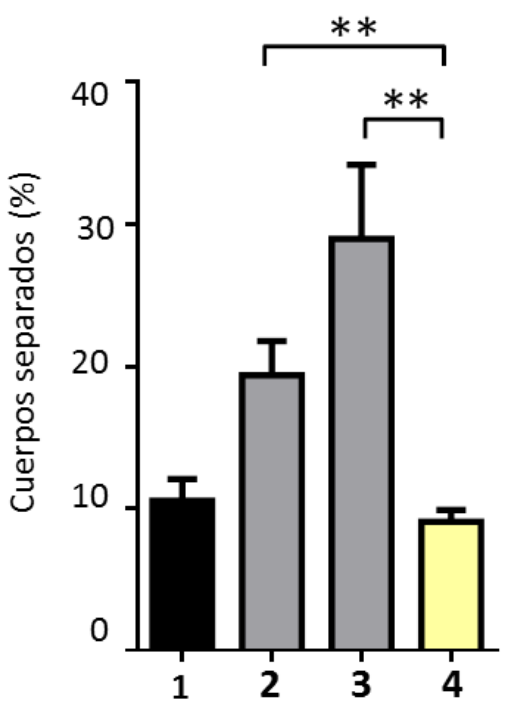

de esta hipótesis es que si se restaura la proporción 1:1 de Sep7 y Cdc11 en un mutante heterocigótico se debería corregir el fenotipo de separación de las hifas.

Para comprobar si esta hipótesis era cierta, la primera aproximación fue construir una cepa en la que se restablecía la relación 1:1 entre Sep7 y Cdc11, es decir, un mutante heterocigótico doble SEP7+/- CDC11+/(Fig. 21A) (este mutante se construyó partiendo del heterocigótico SEP7+/- que contenía el gen de resistencia SAT1, al que se le reemplazó una de las copias del gen CDC11 por el gen HIS1). Este nuevo mutante no tenía defectos ni en morfología ni en crecimiento durante su estado levaduriforme;

Figura 21. Las proporciones relativas entre las septinas son importantes para mantener la inhibición de la separación celular en hifas. (A). Representación de los octámeros de una cepa silvestre, los mutantes heterocigóticos SEP7+/- y CDC11+/- y el doble SEP7+/CDC11+/-. (B). El heterocigótico doble SEP7+/-CDC11+/restaura los niveles silvestres de separación celular. El gráfico muestra el porcentaje promedio de cuerpos separados en la cepa silvestre (negro), los mutantes heterocigóticos sencillos (gris) y el heterocigótico doble (amarillo) a 3,5 h de filamentación y son la media con la SEM de, al menos, cinco experimentos independientes. Los números corresponden a las cepas indicadas en (A). Los asteriscos indican el nivel de significación (**: $\mathrm{p}=0,0059 ; \mathrm{t}$ test). WT (OL1417), SEP7+/- (OL2049), CDC11+/- (OL2050), SEP7+/- CDC11+/- (OL2106/ OL2109). 
además respondía a la inducción hifal de forma similar al silvestre. Cuando se analizó la separación celular de las hifas, se comprobó que en esta cepa se restablecía la inhibición de la separación celular, presentando un porcentaje similar al de la cepa silvestre, alrededor del 10\% (Fig. 21B). Este resultado confirma la hipótesis de que los genes SEP7 y CDC11 tienen que estar en relación 1:1 para mantener unidos los compartimentos hifales.

En vista de este resultado, se decidió comprobar si la reducción de la dosis génica de alguna de las otras tres septinas también era capaz de suprimir el fenotipo del mutante SEP7+/- o este efecto era específico de la pareja Sep7-Cdc11. Para ello, se construyeron los mutantes heterocigóticos dobles, SEP7+/- CDC3+/-, SEP7+/- CDC12+/- y SEP7+/- CDC10+/- (Fig. 22A). Como en los casos anteriores, se comprobó que estos mutantes eran capaces de crecer en forma de levaduras tanto en medio YEPD como YNB de forma similar al silvestre, y que formaban hifas de tamaño y morfología adecuada tras la inducción de la filamentación. En cuanto a la separación celular de las hifas, los recuentos de cuerpos separados a 3,5 h de filamentación determinaron que tanto SEP7+/- CDC3+/- como SEP7+/- CDC12+/presentaban unos porcentajes similares a los del mutante sencillo SEP7+/-, indicando que, a diferencia de lo que sucede en SEP7+/- CDC11+/-, estos mutantes no recuperan el fenotipo silvestre. Contrariamente, el mutante SEP7+/- CDC10+/- era capaz de revertir el fenotipo de SEP7+/-, ya que mostraba un porcentaje de separación similar al silvestre y a SEP7+/- CDC11+/- (Fig. 22B).

Este resultado introduce un nuevo gen, $C D C 10$, cuya dosis alélica, al igual que SEP7 y $C D C 11$, también es importante para regular la separación celular de las hifas. Por tanto, serían las septinas de los extremos de los tetrámeros las involucradas en la inhibición de la separación celular durante el desarrollo hifal.
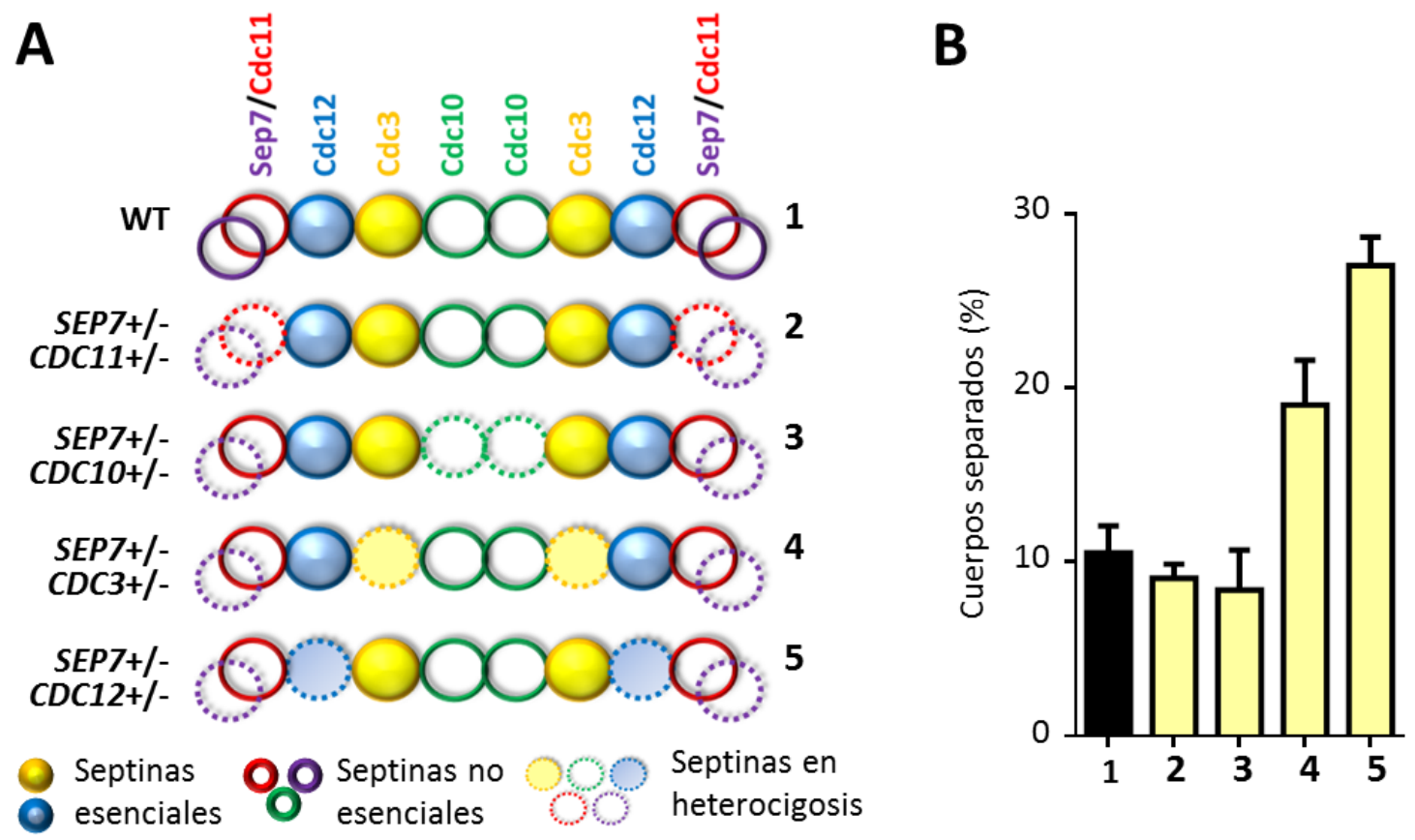

Figura 22. CDC10 tiene un papel regulador de la separación celular cuando la cantidad de Sep7 es limitante. (A). Esquema de los octámeros de una cepa silvestre y de los mutantes heterocigóticos dobles SEP7+/- CDC11+/-, SEP7+/- CDC10+/-, SEP7+/- CDC3+/- y SEP7+/- CDC12+/-.(B). Los heterocigóticos dobles SEP7+/- CDC11+/- y SEP7+/- CDC10+/- presentan un porcentaje de separación celular similar al silvestre. El gráfico muestra el porcentaje promedio de cuerpos separados de, al menos, tres experimentos, en la cepa silvestre (negro) y los mutantes heterocigóticos dobles (amarillo), con la SEM, a 3,5 h de filamentación. Los números corresponden a las cepas indicadas en (A). WT (OL1417), SEP7+/- CDC11+/- (OL2109), SEP7+/CDC10+/- (OL2151), SEP7+/- CDC3+/- (OL2241) y SEP7+/- CDC12+/- (OL2131). 
Finalmente, también se construyeron cepas que contenían todas las posibles combinaciones de dos septinas en heterocigosis (Tabla I), para así poder estudiar los efectos de la reducción de la dosis génica de dos de las septinas. En primer lugar, se confirmó que todas estas nuevas cepas eran capaces de crecer en forma de levadura en diferentes tipos de medio (YEPD e YNB) de forma similar a un silvestre. De igual modo, cuando se estudió su capacidad para filamentar, se observó que todas ellas eran capaces de formar hifas como las de la cepa silvestre. Posteriormente, se cuantificó el número de hifas separadas tras 3,5 h de filamentación y se concluyó que las combinaciones entre las septinas que en heterocigosis no presentaban fenotipo de separación (CDC12+/-, CDC3+/- y CDC10+/-) no variaban el porcentaje de cuerpos separados al combinar las dos heterocigosis. Dicho de otra manera, las cepas $C D C 12+/-C D C 3+/-, C D C 12+/-C D C 10+/-$ y $C D C 3+/-C D C 10+/-$, al igual que un silvestre, tenían sobre un $10 \%$ de sus hifas separadas (datos no mostrados). Por otro lado, las restantes combinaciones con CDC11+/- (CDC11+/- CDC12+/-, CDC11+/- CDC3+/- y CDC11+/- CDC10+/-), no corregían el defecto y mantenían un porcentaje de separación en torno al 30\% (datos no mostrados). En conjunto, todos los resultados mostrados indican que la regulación de la separación de las hifas depende fundamentalmente de la dosis génica de SEP7 y CDC11, aunque CDC10 también parece desempeñar un papel regulador cuando la cantidad de Sep7 es limitante.

\begin{tabular}{|c|c|c|c|c|c|c|}
\hline & WT & $C D C 3+/-$ & CDC12+/- & CDC11+/- & CDC10+/- & SEP7+/- \\
\hline WT & WT & |-- & - & -- & 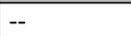 & -- \\
\hline$C D C 3+/-$ & $C D C 3+/-$ & LETAL & -- & -- & -- & -- \\
\hline CDC12+/- & $C D C 12+/-$ & $\begin{array}{l}C D C 3+/- \\
C D C 12+/-\end{array}$ & LETAL & -- & -- & -- \\
\hline CDC11+/- & CDC11+/- & $\begin{array}{l}C D C 3+/- \\
C D C 11+/-\end{array}$ & $\begin{array}{l}\text { CDC12+/ } \\
\text { CDC11+/- }\end{array}$ & $\operatorname{cdc} 11 \Delta \Delta$ & -- & -- \\
\hline CDC10+/- & CDC10+/- & $\begin{array}{l}C D C 3+/- \\
C D C 10+/-\end{array}$ & $\begin{array}{l}C D C 12+/ \\
C D C 10+/-\end{array}$ & $\begin{array}{l}\text { CDC11+/ } \\
\text { CDC10+/- }\end{array}$ & $\operatorname{cdc} 10 \Delta \Delta$ & -- \\
\hline SEP7+/- & SEP7+/- & $\begin{array}{l}\text { SEP7+/- } \\
\text { CDC3+/ }\end{array}$ & $\begin{array}{l}\text { SEP7+/- } \\
\text { CDC12+/ }\end{array}$ & $\begin{array}{l}\text { SEP7+/- } \\
\text { CDC11+/ }\end{array}$ & $\begin{array}{l}\text { SEP7+/- } \\
\text { CDC10+/ }\end{array}$ & $\operatorname{sep} 7 \Delta \Delta$ \\
\hline
\end{tabular}

Tabla I. Combinaciones de mutantes de septinas en heterocigosis. Se representan todas las combinaciones posibles de mutantes heterocigóticos sencillos y dobles. Se han clasificado en mutantes sin separación celular (azul), con separación celular (naranja) y letales (rojo). En azul oscuro se muestran los que tienen un porcentaje de separación similar al silvestre, pero que tienen problemas en el mantenimiento del crecimiento polarizado de las hifas y manifiestan un crecimiento lento. El resto de mutantes que no se separan (azul claro) filamentan de forma similar al silvestre. WT (OL1417), CDC3+/(OL2134), CDC12+/- (OL1184), CDC11+/- (OL2050), CDC10+/- (OL2136), SEP7+/- (OL2049), CDC3+/- CDC12+/- (OL2260), $C D C 3+/-C D C 11+/-(\mathrm{OL2258}), C D C 3+/-C D C 10+/-(\mathrm{OL2256}), S E P 7+/-C D C 3+/-(\mathrm{OL2241}), C D C 12+/-C D C 11+/-(\mathrm{OL2171})$, CDC12+/-CDC10+/- (OL2209), SEP7+/-CDC12+/- (OL2131), CDC11+/-CDC10+/- (OL2211), SEP7+/-CDC11+/- (OL2109), $S E P 7+/-C D C 10+/-(\mathrm{OL} 2151), c d c 11 \Delta \Delta$ (OL1365), $c d c 10 \Delta \Delta$ (OL2213) y sep7 $\Delta$ (OL2138).

1.6 No existe una correlación directa entre el estado específico de hifas del anillo de septinas y la inhibición de la separación celular.

Como se ha descrito previamente, un mutante $\operatorname{sep} 7 \Delta \Delta$ presenta una reducida recuperación de la fluorescencia de Cdc10 una vez que ha sido eliminada, comparado con un silvestre, lo que llevó a proponer la existencia de una correlación entre la dinámica del anillo de septinas y la inhibición de la separación celular (González-Novo et al., 2008). Para comprobar si esta hipótesis era correcta, se marcó CDC10 con la proteína fluorescente verde (Cdc10-GFP) en los mutantes heterocigóticos que activaban la separación celular (SEP7+/- y CDC11+/-) así como en el heterocigótico doble SEP7+/- CDC11+/- que suprimía este defecto y se analizó la tasa de intercambio de Cdc10-GFP entre el anillo de septinas 
y el citoplasma mediante experimentos de FRAP (Fluorescence Recovery After Photobleaching) comparado con un silvestre. El ensayo consistía en eliminar la fluorescencia del anillo completo de las hifas mediante iluminación con el láser del microscopio confocal y analizar su recuperación a lo largo del tiempo, de tal manera que la recuperación de la fluorescencia en el área quemada indicaba la incorporación de nuevas moléculas provenientes del citoplasma. De forma similar a lo descrito, en la cepa silvestre se observó recuperación de la fluorescencia en los anillos, que entre 200 y $300 \mathrm{~s}$ alcanzaban un valor en torno al $50 \%$ de la fluorescencia inicial (Fig. 23). Por el contrario, en el mutante $\operatorname{sep} 7 \Delta \Delta$ la recuperación de la fluorescencia de Cdc10 era menor, y nunca superaba el $40 \%$ del valor inicial. Cuando se analizó la recuperación de la fluorescencia de Cdc10-GFP en los mutantes heterocigóticos sencillos SEP7+/- y CDC11+/-, se comprobó que era más baja que en el silvestre y similar a la del mutante $\operatorname{sep} 7 \Delta \Delta$ (Fig. 23). Sin embargo, la dinámica de los anillos de septinas del mutante heterocigótico doble SEP7+/- CDC11+/- no volvía a ser similar a la de la cepa silvestre, de acuerdo con lo esperado. Estos resultados indican que el estado específico de hifas, por sí sólo, no determina la inhibición de la separación celular.

\subsection{Los octámeros de levaduras e hifas presentan diferentes propiedades bioquímicas.}

Los resultados mostrados en los apartados anteriores sugieren que la composición y/o estructura de los anillos de septinas de levaduras e hifas de $C$. albicans son diferentes y que esta diferencia puede ser debida en gran parte a las proporciones relativas de Sep7 y Cdc11 que se incorporen en los extremos de los bastones en ambas morfologías. Además, el mutante sep $7 \Delta \Delta$ presenta un leve defecto morfológico en levaduras pero tiene un fenotipo acusado de separación celular de las hifas (Warenda y Konopka, 2002; González-Novo et al., 2008), lo que podría indicar que la pérdida de función de Sep7 compromete más el crecimiento hifal que el levaduriforme.

En S. cerevisiae se han realizado estudios bioquímicos in vitro sobre la organización molecular de las septinas y se ha demostrado que Shs1 y Cdc11 condicionan las propiedades de ensamblaje de las septinas. Así, en condiciones de alta salinidad (superiores a $200 \mathrm{mM}$ ), el complejo de septinas mitóticas compuesto por Cdc3, Cdc10, Cdc12, y Cdc11 se encuentra formando octámeros simétricos de $32 \mathrm{~nm}$ con el orden Cdc11-Cdc12-Cdc3-Cdc10-Cdc10-Cdc3-Cdc12-Cdc11, mientras que en condiciones de menor fuerza iónica estos bastones se autoensamblan formando largos filamentos apareados que recuerdan las vías de tren (Fig. 8D)(Bertin et al., 2008). La sustitución de Cdc11 por Shs1 induce la formación de una estructura en forma de anillo a baja concentración salina, mientras que en alta salinidad los complejos formados por Shs1 tienen una mayor proporción de hexámeros y heptámeros, indicando 
que Shs1 tiene menos afinidad que Cdc11 para unirse a Cdc12 (Garcia et al., 2011). Es interesante que no se ha descrito hasta la fecha ni in vitro ni in vivo la existencia de octámeros mixtos que contengan Cdc11 en un extremo y Shs1 en el otro.

Todas estas observaciones conducen a pensar que la organización de las septinas es altamente variable y plástica, y que Cdc11 y Shs1 pueden desempeñar un papel esencial en la regulación de la función fisiológica de las estructuras de septinas in vivo. En el caso de C. albicans, podría existir una diferencia en la composición de los octámeros que conforman las estructuras supramoleculares de las septinas en levaduras e hifas. Además, teniendo en cuenta que la cantidad de Sep7 aumenta durante la inducción hifal (Tesis Doctoral de González-Novo, 2005), una hipótesis para explicar estos resultados podría ser que durante el crecimiento levaduriforme exista un mayor número de bastones con Cdc11 en ambos extremos mientras que en hifas sean los octámeros Sep7 los más abundantes (Fig. 24A). Además, podría ocurrir también que en hifas se formaran octámeros mixtos (con Sep7 en un extremo y Cdc11 en el otro). Por consiguiente, se decidió realizar una caracterización bioquímica de la composición de los octámeros según el tipo de crecimiento. Para llevar a cabo este experimento, se marcaron las septinas Sep7 y Cdc11 con epítopos que permitieran analizarlas por Western Blot. Se construyó una cepa en la que las dos copias de SEP7 estaban marcadas con la proteína fluorescente roja (Cherry, Ch) y las dos copias de CDC11 con la GFP (SEP7-Ch/SEP7-Ch CDC11-GFP/CDC11-GFP, que a partir de

A

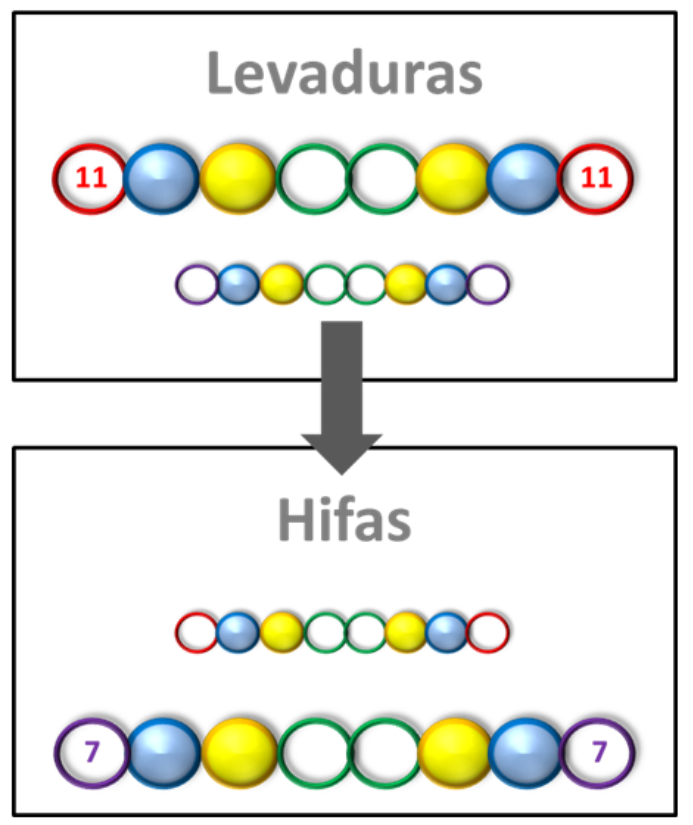

B

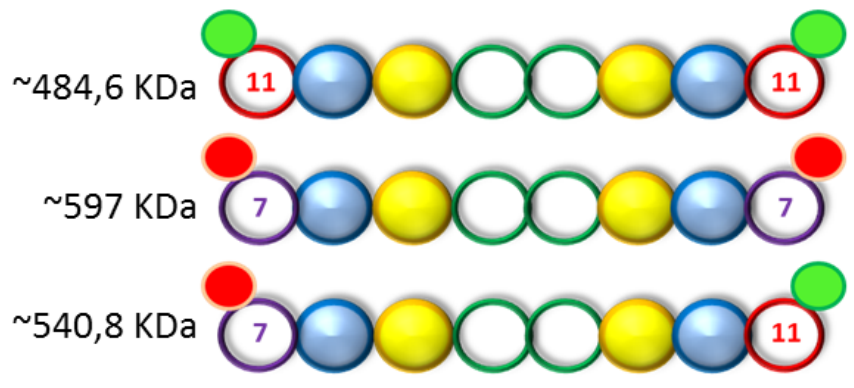

GFP
Cherry $\begin{aligned} & \text { Septinas } \\ & \text { esenciales }\end{aligned}\left(\begin{array}{l}\text { Septinas no } \\ \text { esenciales }\end{array}\right.$ ahora se denominará SEP7-Ch CDC11-GFP). De esta forma, los octámeros constituidos únicamente por Cdc11-GFP (Cdc11-GFPCdc12-Cdc3-Cdc10-Cdc10-Cdc3-Cdc12Cdc11-GFP) tendrían un peso molecular esperado de $\sim 484,6 \mathrm{kDa}$, mientras que los compuestos exclusivamente por Sep7-Ch (Sep7-Ch-Cdc12-Cdc3-Cdc10-Cdc10-Cdc3Cdc12-Sep7-Ch) tendrían un peso molecular esperado de $\sim 597 \mathrm{kDa}$. Finalmente, en el caso de que existieran octámeros mixtos (Cdc11GFP-Cdc12-Cdc3-Cdc10-Cdc10-Cdc3-Cdc12Sep7-Ch), éstos tendrían un peso molecular intermedio, 540,8 kDa (Fig. 24B).

En primer lugar, fue necesario poner a punto en el laboratorio el sistema de separación de octámeros de septinas por centrifugación en gradientes de sacarosa utilizado previamente para caracterizar las

Figura 24. Modelos para explicar las distintas propiedades de los anillos de septinas de hifas y levaduras. (A). Modelo de las poblaciones de octámeros según el tipo de crecimiento. En levaduras, habría una mayor abundancia de octámeros con $\mathrm{Cdc11}$ en ambos extremos, mientras que en hifas, abundarían los octámeros con Sep7 en los extremos. (B). Peso molecular calculado de los diferentes octámeros marcados con Cdc11-GFP y Sep7-Cherry. 
septinas humanas (Sellin et al., 2011; Sellin et al., 2012). Este sistema usa gradientes continuos de sacarosa (entre el $10 \%$ y el $30 \%$ ) en un tampón que contiene $0,3 \mathrm{M} \mathrm{NaCl}$ para mantener los octámeros de septinas separados y evitar su polimerización en filamentos. Inicialmente, los gradientes se calibraron usando proteínas de tamaño molecular y coeficiente de sedimentación conocidos. Se usaron los siguientes marcadores: albúmina de suero bovino (BSA), alcohol deshidrogenasa (ADH), catalasa y ureasa (Fig. 25). Durante la centrifugación, los marcadores se distribuían a lo largo del gradiente hasta alcanzar el punto que igualara su coeficiente de sedimentación. Tras la centrifugación, con ayuda de un fraccionador de gradientes, se recogían 18 fracciones (siendo la 1 la más ligera y la 18 la más pesada). Las proteínas de cada fracción eran separadas en geles de acrilamida y teñidas con azul de Coomassie para analizar su distribución en el gradiente. Con estos datos se generó una recta patrón (Peso molecular/fracción) que nos permitía determinar el coeficiente de sedimentación de las septinas (Fig. 25). De acuerdo con los pesos moleculares esperados mencionados anteriormente, los octámeros de septinas deberían migrar en las fracciones 12-14.

\begin{tabular}{lcr} 
& Pm (kDa) & \multicolumn{1}{c}{$\mathrm{S}$} \\
\hline BSA & 67 & 4,6 \\
ADH & 150 & 7,3 \\
Catalasa & 250 & 11,3 \\
Ureasa & 545 & 18,3 \\
\hline
\end{tabular}

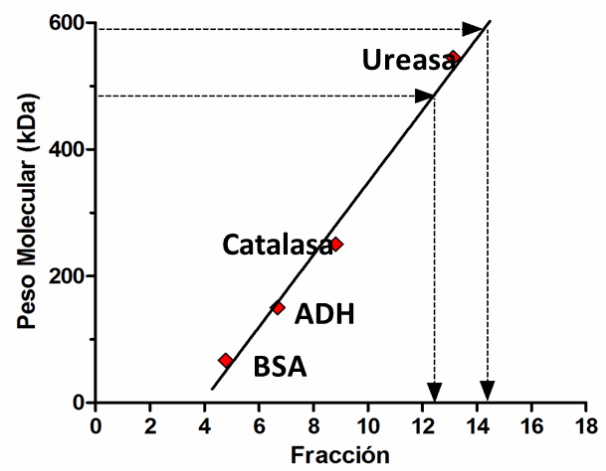

Figura 25. Calibración de los gradientes de sacarosa. Composición del gradiente: Tampón fosfato $10 \mathrm{mM} \mathrm{pH} \mathrm{7,5;0,3} \mathrm{M} \mathrm{NaCl,} \mathrm{Sacarosa}$ 10-30\%. Arriba: Peso molecular (Pm) en kDa y Coeficiente de sedimentación ( $\mathrm{S}$ ) de las proteínas usadas para la calibración (BSA, ADH, Catalasa y Ureasa). Abajo: Representación gráfica del Pm de cada proteína frente al número de fracción del gradiente donde sedimenta el pico después de la centrifugación. La región del gradiente donde deberían sedimentar los octámeros de septinas según su Pm es la comprendida entre las flechas discontinuas.

Una vez que los gradientes habían sido calibrados, se comenzó con el estudio de la composición de los octámeros en $C$. albicans durante el crecimiento levaduriforme e hifal. Para ello, se obtuvieron extractos proteicos de la cepa SEP7-Ch CDC11-GFP creciendo en forma de levaduras o hifas (después de $3 \mathrm{~h}$ de inducción de la filamentación) usando un tampón de rotura con 0,3 $\mathrm{M}$ de $\mathrm{NaCl}$ (para separar las estructuras de septinas en octámeros) y se usaron gradientes de sacarosa del 10 al 30\% para separar los bastones según su coeficiente de sedimentación. De esta forma, esperaríamos que si los gradientes tuvieran resolución suficiente, los octámeros compuestos por Cdc11-GFP/Cdc11-GFP deberían sedimentar en una fracción más ligera que los octámeros compuestos Sep7-Ch/Sep7-Ch, que por ser más pesados se desplazarían hacia una zona más densa del gradiente. Cada uno de los gradientes se recogió en 18 fracciones y las proteínas presentes en cada fracción se precipitaron con TCA, se separaron en geles de acrilamida y se analizaron con anticuerpos anti-GFP o anti-Cherry mediante Western Blot.

Los resultados indicaron que el pico de sedimentación de Cdc11-GFP y Sep7-Ch coincidía en la misma fracción, la número diez para el caso de las levaduras y la número nueve durante el crecimiento hifal (Fig. 26A). Es posible que esta técnica no tenga resolución suficiente para separar claramente los octámeros con Cdc11 (484,6 kDa) de los que contienen Sep7-Ch (597 kDa), ya que la diferencia en peso molecular no es muy grande o que las ligeras diferencias se hayan perdido al recoger las fracciones. Dos hechos llamaron la atención. En primer lugar que los picos de Cdc11-GFP y Sep7-Ch aparecieran en las fracciones 9-10, cuando se esperaba que sedimentaran en las fracciones 12-14. Esto podría deberse a que las proteínas usadas para la calibración presentan una estructura globular mientras que los 

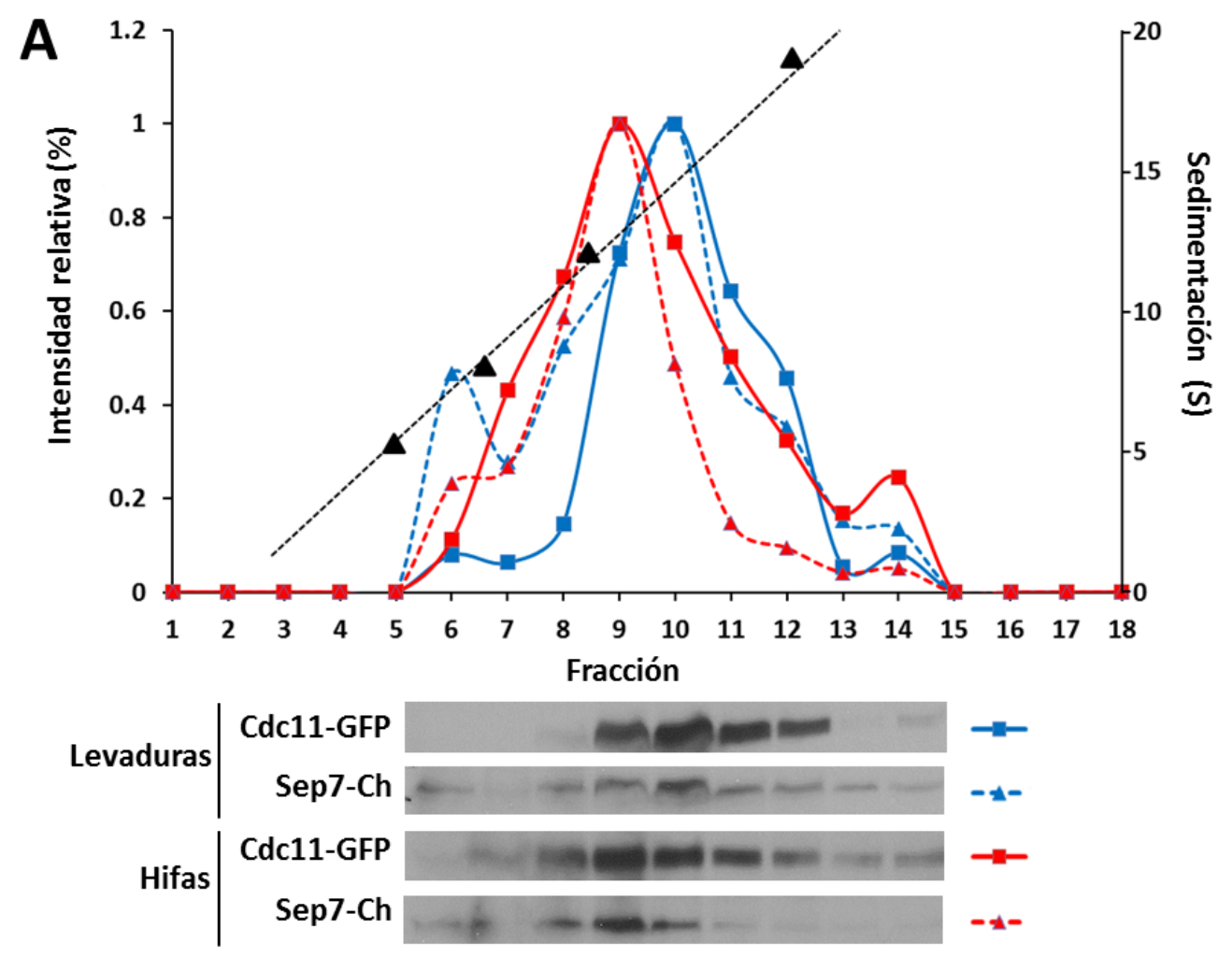

B
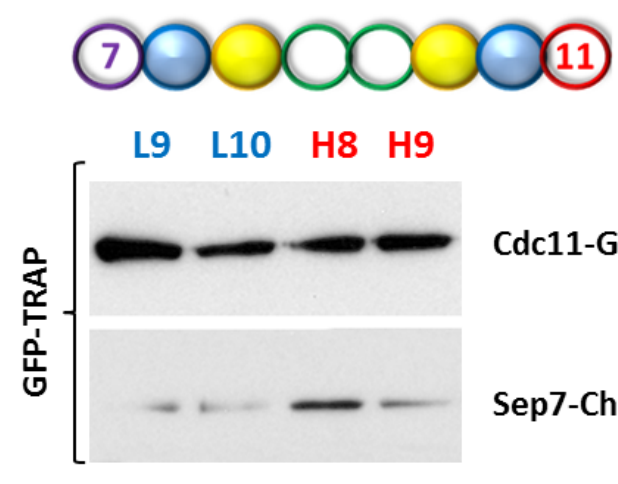

Sep7-Ch
C

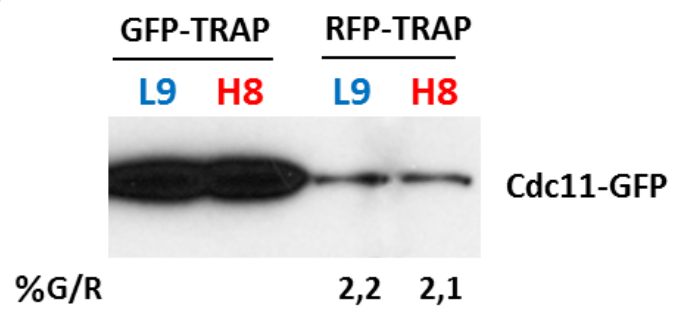

Ratio $11 / 7 \quad 0,9 \quad 0,7 \quad 0,6 \quad 0,8$

Figura 26. Composición de los octámeros según el tipo de crecimiento. (A). Extractos proteicos de levaduras e hifas tras $3 \mathrm{~h}$ de filamentación de la cepa SEP7-Ch CDC11-GFP (OL2538) se centrifugaron en un gradiente sacarosa (10-30\%) con 0,3 M $\mathrm{NaCl}$. Se fraccionó el gradiente en 18 tubos y se analizó la distribución de Sep7 y Cdc11 con anticuerpos anti-GFP y anti-RFP. En la gráfica se representa la distribución de Cdc11 (línea continua) y Sep7 (línea discontinua) en levaduras (azul) o hifas (rojo). La línea negra discontinua es la recta de calibración usando las proteínas BSA, ADH, Catalasa y Ureasa; se representa el coeficiente de sedimentación (S) frente a la fracción. (B). Los octámeros mixtos aparecen en la misma proporción en levaduras e hifas. La fracción del pico y la inmediatamente anterior fueron inmunoprecipitadas usando GFP-Trap. Las muestras fueron analizadas con anticuerpos anti-GFP y anti-RFP. Se indica la relación Cdc11-GFP/Sep7-Ch en cada fracción. (C). Las fracciones L9 y H8 fueron inmunoprecipitadas usando GFP-Trap o RFP-Trap y analizadas con anti-GFP. Se indica la relación de Cdc11-GFP que precipita con Sep7-Ch frente al total de Cdc11-GFP.

octámeros de septinas son bastones lineales de $32 \mathrm{~nm}$ de longitud, por lo que su sedimentación puede verse alterada por la forma, y algo similar ha sido descrito para las septinas humanas (Sellin et al., 2011; Sellin et al., 2012). En segundo lugar, aunque tanto en levaduras como en hifas, Cdc11-GFP y Sep7-Ch sedimentaban en la misma fracción, los bastones de hifas siempre quedaban retenidos en fracciones más ligeras que los octámeros de levaduras en todos los gradientes analizados. Esta observación indica que los octámeros de hifas tienen diferentes propiedades bioquímicas y/o estructurales que los de levaduras, lo que modifica su sedimentación. 
Una posibilidad para explicar estas diferencias es que en alguna de las morfologías existieran octámeros mixtos, formados por Cdc11-GFP en un extremo y Sep7-Ch en el otro, y que estos bastones, por su asimetría estructural migraran de forma diferente en los gradientes. Para comprobar si esta hipótesis era correcta y si existían octámeros mixtos, se hicieron ensayos de inmunoprecipitación a partir de las fracciones separadas en el gradiente. La idea se basa en que, asumiendo que con la centrifugación se ha conseguido separar la fracción de octámeros de las estructuras de orden superior, si al inmunoprecipitar Cdc11-GFP con GFP-Trap, se detectara Sep7-Ch en el inmunoprecipitado, esto indicaría que el octámero estaba formado por Cdc11-GFP en un extremo y Sep7-Ch en el otro. Para ello, se purificó Cdc11 con GFP-Trap de dos fracciones del gradiente, la correspondiente al pico donde se concentraba Cdc11-GFP y la fracción inmediatamente anterior, y posteriormente se analizó por Western Blot la presencia tanto de Sep7 como de Cdc11 en el precipitado. Los resultados mostraron que en las cuatro fracciones analizadas existía una interacción entre Sep7-Ch y Cdc11-GFP (Fig. 26B). Sin embargo, cuando se determinó la relación Cdc11/Sep7 en cada una de las fracciones se comprobó que no variaba significativamente de una morfología a la otra. Para tratar de determinar el porcentaje de octámeros mixtos, se repitió la inmunoprecipitación de las fracciones L9 y H8, esta vez usando tanto GFP-Trap como RFP-Trap y analizando la abundancia de Cdc11-GFP en cada inmunoprecipitado por Western Blot. Como se observa en la Figura 26C, la cantidad de Cdc11-GFP que precipita asociada a Sep7-Ch (con RFP-Trap) es muy inferior a la cantidad total que se precipita con GFP-Trap. A pesar de que los carriles correspondientes al GFP-Trap están claramente saturados, se cuantificó la relación de Cdc11 en ambas muestras. Los resultados indicaron que el porcentaje de octámeros mixtos sería inferior al $2 \%$. Estos resultados indican que, si las fracciones del gradiente analizadas contienen octámeros, existiría una población de bastones mixtos, con Sep7-Ch en un extremo y Cdc11-GFP en el otro, aunque es un porcentaje muy pequeño y no se modifica significativamente durante el crecimiento levaduriforme o hifal. Por tanto, parece que la divergencia en la sedimentación de los octámeros no es debida a una

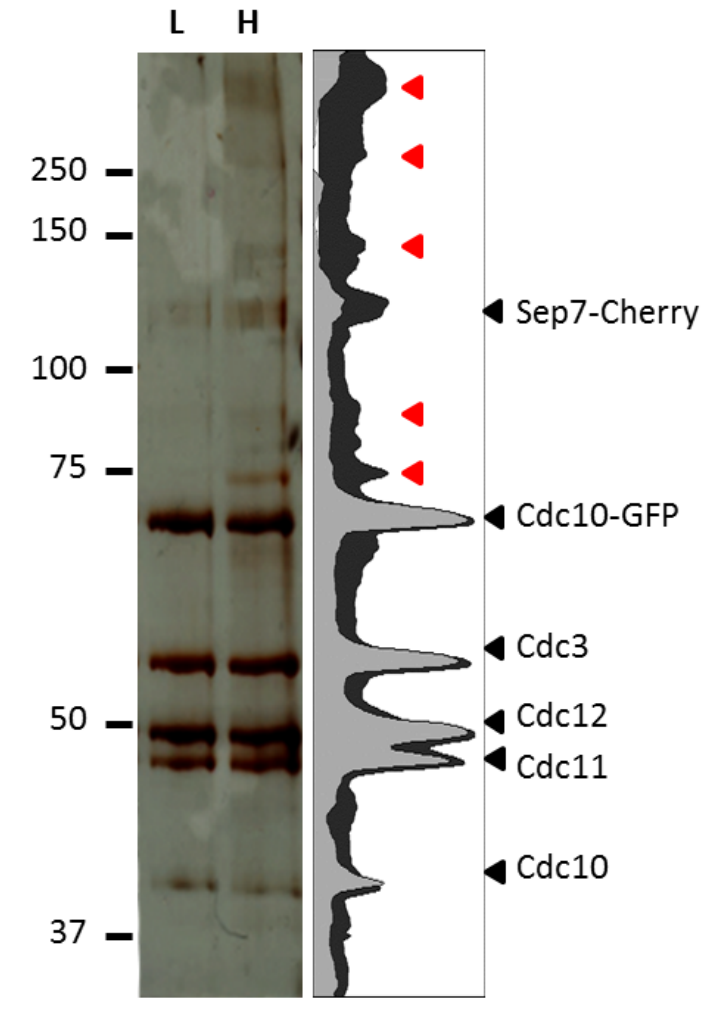
mayor abundancia de octámeros mixtos en una de las formas de crecimiento de C. albicans.

Otra explicación alternativa sería que la diferencia en la migración de los octámeros no se deba únicamente a la presencia de Cdc11-GFP o Sep7-Ch en sus extremos, si no a la interacción con otras proteínas específicas de cada morfología. Para estudiar esta posibilidad, se purificaron los complejos de septinas de una cepa silvestre (marcada con Cdc10-GFP) durante su crecimiento como levaduras y como hifas después de $3 \mathrm{~h}$ de filamentación. Para ello se extrajeron las proteínas usando un tampón de

Figura 27. Interacciones del anillo de septinas. Se extrajeron las proteínas de una cepa silvestre CDC10-GFP (OL2243) durante su crecimiento levaduriforme (L) y en forma de hifas tras $3 \mathrm{~h}$ de filamentación $(\mathrm{H})$ y se purificaron las septinas usando bolas magnéticas con anticuerpo anti-GFP. Las muestras se separaron mediante SDS-PAGE y se revelaron por tinción con nitrato de plata. A la derecha se muestra la densitometría del carril de levaduras (claro) e hifas (oscuro). Las bandas comunes en ambos tipos de crecimiento corresponden a las septinas (triángulo negro). Las exclusivas de hifas se representan con triángulo rojo. 
lisis con una concentración salina ligeramente superior al usado para hacer los gradientes $(400 \mathrm{mM}$ $\mathrm{KCl}$ ) y se utilizaron bolas magnéticas con anticuerpo anti-GFP para purificar los complejos de septinas. Después se lavaron las bolas con un tampón menos salino que el anterior (200 mM KCl) y finalmente se separaron las proteínas en un gel de acrilamida que se tiñó con nitrato de plata. Lo más significativo fue la aparición de algunas bandas en el estado de hifas que no aparecían en levaduras (Fig. 27). Por tanto, es probable que la diferencia de sedimentación se deba a que existen proteínas específicas que se asocian al anillo de septinas durante el crecimiento hifal. 



\section{CAPÍTULO II: Regulación de Sep7 por fosforilación en las distintas morfologías de C. albicans.}

\section{1 Introducción y antecedentes.}

Los resultados del Capítulo I indican que las propiedades bioquímicas de los octámeros de septinas podrían ser distintas según el tipo de crecimiento. Al mismo tiempo, resultados previos han demostrado que Sep7 es esencial para regular la dinámica y función de los anillos de septinas de hifas (GonzálezNovo et al., 2008). Dado que la cantidad de Sep7 aumenta durante la inducción hifal (Tesis Doctoral de González-Novo, 2005), esto podría condicionar la existencia de un mayor número de octámeros compuestos únicamente por Sep7 en ambos extremos cuando $C$. albicans crece en forma de hifas. Como se ha demostrado en el Capítulo anterior, la cantidad de Sep7 es importante para inhibir la separación en condiciones de filamentación, pero también cabe la posibilidad de que las distintas modificaciones post-traduccionales que sufren las septinas, según el tipo de crecimiento, les cambie la afinidad para unirse al resto del complejo y/o que afecten a la estabilidad de esa unión, modificando su función.

La fosforilación es la modificación post-traduccional mejor caracterizada en las septinas y más abundante en levaduras de gemación. En S. cerevisiae, las kinasas Cdc28, Cla4 y Gin4 afectan al ensamblaje y desensamblaje del anillo de septinas, concretamente por modificación de Cdc3, Cdc11 y Shs1. De ellas, Shs1 es en la que se han descrito más fosforilaciones. De los cincuenta y nueve sitios de fosforilación mapeados en septinas, treinta y nueve pertenecen a Shs1 (Hernández-Rodríguez y Momany, 2012). Además, se sabe que la fosforilación del extremo C-terminal regula negativamente la formación del anillo de septinas (Hernández-Rodríguez y Momany, 2012). En C. albicans, Martin y Konopka (2004) comprobaron que Sep7-HA migraba 40 kDa más arriba de lo que debería según su peso molecular. Más tarde, González-Novo y colaboradores (2008) comprobaron mediante tratamiento con fosfatasa que Sep7 es una fosfoproteína. Todos estos resultados permiten concluir que Sep7 es modificada por fosforilación.

En este Capítulo se analizan las regiones de Sep7 necesarias para su función en hifas y sus modificaciones post-traduccionales por fosforilación y cómo éstas condicionan su funcionalidad, según crezcan las células en forma de levaduras o como hifas.

\subsection{Sep7 y Cdc11 son fosfoproteínas.}

En S. cerevisiae, Shs1 es una de las proteínas más fosforiladas, y los aminoácidos que son fosfomodificados se distribuyen a lo largo de toda su secuencia (Holt et al., 2009; Swaney et al., 2013). No obstante, en Shs1 aparecen dos grandes grupos donde se concentran los sitios de fosforilación, el primero entre el elemento único de las septinas (SUE) y el coiled-coil y el segundo comprendido entre el coiled-coil y el extremo C- terminal (Fig. 28).

Al inicio del presente trabajo, en $C$. albicans no se había realizado un análisis similar, por lo que en primer lugar se estudió el grado de conservación de la secuencia de aminoácidos en ambos microorganismos (S. cerevisiae y C. albicans). Para ello se realizó un alineamiento de Sep7 (C. albicans) con su homólogo Shs1 (S. cerevisiae) con el programa Align. Este alineamiento mostró que Sep7 y Shs1 presentan un $34,4 \%$ de identidad global. Si se estudia más detalladamente, se puede comprobar que ambas proteínas muestran un mayor porcentaje de identidad en el dominio GTPasa+SUE $(42,8 \%)$ y en 

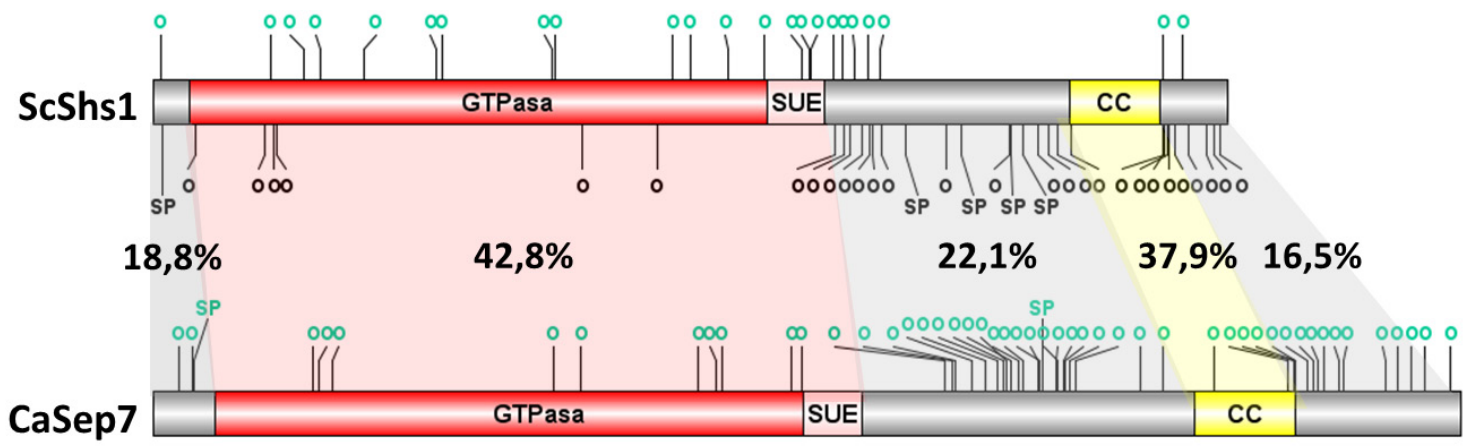

Figura 28. Shs1 y Sep7 presentan zonas altamente conservadas. Esquema de las proteínas Shs1 (S. cerevisiae) y Sep7 (C. albicans). Se indican las regiones GTPasa, el SUE (Septin Unique Element) y el coiled-coil (CC). Encima de las proteínas: Sitios de fosforilación predichos bioinformáticamente (programa KinasePhos, SVM score $>90 \%$ ) (verde). Debajo: Sitios de fosforilación comprobados in vitro o in vivo (negro). Los sitios consenso para CDK se indican como SP, el resto con "o".

el coiled-coil (37,9\%), seguido de la región comprendida entre los dominios SUE y coiled-coil $(22,1 \%)$, siendo las regiones más divergentes las del extremo amino y carboxilo, donde la identidad baja hasta el $18,8 \%$ y $16,5 \%$ respectivamente (Fig. 28 ).

Para profundizar más en el conocimiento de la proteína Sep7, se analizó su secuencia comparándola con las distintas bases de datos de dominios y motivos, y programas de predicción de sitios de fosforilación (Pfam, SMART, InterPro, KinasePhos, etc). Estos análisis bioinformáticos indicaron la existencia de hasta cincuenta posibles sitios de fosforilación (Fig. 28), dos de los cuales podrían ser fosfomodificados por las CDKs, ya que se ajustaban al consenso S/T-P (Holmes y Solomon, 1996). Fundamentalmente, estos posibles sitios de fosforilación estaban englobados en dos grupos que seguían un patrón de distribución parecido al de Shs1, es decir, uno entre la región SUE y el coiled-coil y el otro entre el coiled-coil y el final de la proteína. Esta conservación en la distribución espacial de las regiones fosforilables a pesar de la baja identidad de secuencia podría ser tomada como una indicación de que desempeñan un importante papel regulador, integrando diversas señales.

Estas observaciones, junto con el hecho de que Sep7 es una fosfoproteína in vivo (González-Novo et al., 2008), nos llevaron a analizar si existía una fosforilación diferencial de Sep7 en hifas y levaduras. En colaboración con el Dr. Jaime Correa (Universidad de Extremadura), se analizó el comportamiento electroforético de Sep7 durante la inducción hifal usando geles que contenían Phos-Tag. El Phos-Tag es un reactivo que se une a los fosfatos de las proteínas durante la electroforesis, retardando su migración de forma proporcional al número de fosfatos que posea. Por tanto, este tipo de geles aumenta la resolución a la hora de analizar las distintas isoformas fosforiladas de una proteína presente en extractos celulares. Tras varias pruebas preliminares, se determinó que las condiciones óptimas de resolución para separar las diferentes isoformas de Sep7 eran geles de acrilamida al 6\% con $40 \mu \mathrm{M}$ de Phos-Tag. Para analizar la movilidad electroforética de Sep7, se insertó el epítopo HA en el extremo 3'del gen SEP7. Las células SEP7-HA se crecieron en medio YEPD hasta alcanzar la fase estacionaria. Después fueron sometidas a condiciones de inducción de la filamentación (medio rico YEPD + suero y $37^{\circ} \mathrm{C}$ ) y se recogieron muestras a distintos tiempos (el tiempo cero es el momento de la inducción hifal). Se extrajeron las proteínas y se precipitaron con TCA. Finalmente, se separaron en geles Phos-Tag y se reveló Sep7-HA usando anticuerpos específicos. 
Los resultados mostraron que la cantidad de la proteína Sep7 se incrementaba a medida que avanzaba la inducción hifal. Además, también variaba el patrón de bandas (Fig. 29). Así, en los primeros momentos de la inducción hifal (15 min) aparecía una banda con menor movilidad electroforética no presente en levaduras, indicando que la filamentación conlleva una defosforilación parcial de Sep7. Sin embargo, a tiempos posteriores volvía a aumentar la fosforilación. Estos cambios de movilidad podrían ser el reflejo de modificaciones post-traduccionales específicas de la transición levadura-hifa.

Como ocurre en otros organismos, Cdc11 es la septina que más se parece a Sep7 en C. albicans, presentando un $23,1 \%$ de identidad. En S. cerevisiae, se ha propuesto que Cdc11 y Shs 1 son parálogos que han divergido de un antecesor común y esto se mantiene en otros grupos de hongos, presumiblemente porque tienen diversidad en su función (Hernández-Rodríguez y Momany, 2012; Finnigan et al., 2015a). La diferencia más llamativa entre Shs1 y Cdc11 de S. cerevisiae es que la región CTE está pobremente conservada y es mucho más larga en Shs1 que en Cdc11. Cuando se comparan estas proteínas en C. albicans, también Sep7 es una proteína mucho mayor (670 aa) que Cdc11 (402 aa), siendo las regiones más conservadas el dominio GTPasa+SUE y el coiled-coil (con un porcentaje de identidad del 35,3 y $19,6 \%$ respectivamente)(Fig. 30A). Sin duda, la zona más divergente es la comprendida entre las regiones SUE y coiled-coil, que es mucho mayor en Sep7 y contiene multitud de posibles sitios de fosforilación. Las predicciones bioinformáticas indican la existencia de veintiún posibles sitios de fosforilación en Cdc11 en C. albicans.

Para comprobar si los sitios de fosforilación predichos mediante estudios informáticos se encontraban realmente fosforilados in vivo y tratar de identificar aquellos que eran específicos de una de las morfologías, se analizaron las proteínas Sep7 y Cdc11 en una cepa silvestre mediante espectrometría de masas. Para ello se construyó una cepa en la que CDC12 se estaba marcado con el epítopo TAP-TAG para poder purificar los complejos de septinas fácilmente y se obtuvieron extractos proteicos de cultivos de levaduras y de $3 \mathrm{~h}$ de filamentación. A continuación se purificaron las septinas usando Dynabeads acopladas a IgG que reconocían al epítopo TAP-TAG. Los complejos de septinas purificados se separaron en un gel de acrilamida, se tiñeron con azul de Coomassie y se cortaron las bandas correspondientes a Sep7 y Cdc11 (Fig. 30B). El análisis de los residuos fosforilados por espectrometría de masas se llevó a cabo en la Universidad de Harvard. El mapa de fosforilación resultante se muestra en la Figura 30A (la cobertura del análisis fue distinta en ambas proteínas, siendo alrededor del $40 \%$ para Sep7 y del $85 \%$ para Cdc11) y éste indicó que ambas proteínas eran fosforiladas, aunque sólo en el caso de Sep7 se detectaron diferencias en las modificaciones post-traduccionales dependiendo del modo de crecimiento. En Sep7 se identificaron veintitrés sitios de fosforilación (tres eran sitios $\mathrm{S} / \mathrm{T}-\mathrm{P}$ ). De todos ellos, un $17,4 \%$ eran específicos del estado de levadura (azul en la Fig. 30A), un $21,7 \%$ del estado de hifas (rojo) y el $60,9 \%$ de las fosforilaciones restantes se producían en ambos tipos de crecimiento (naranja). Por el contrario, Cdc11 se encuentra menos fosforilada, habiéndose detectado únicamente cinco sitios, que además eran comunes en ambos tipos de crecimiento.

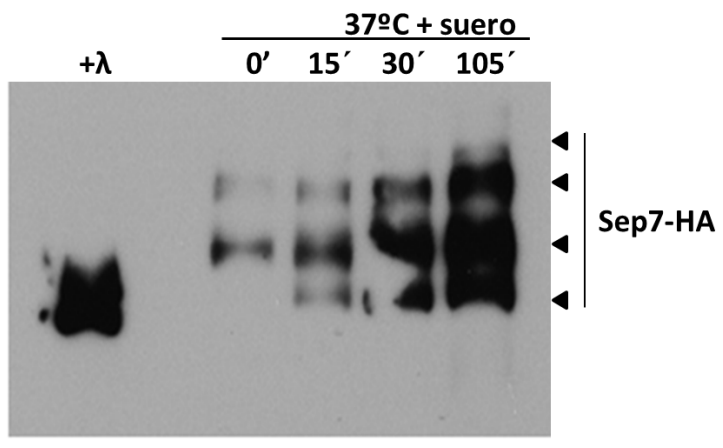

Figura 29. Sep7 es una fosfoproteína que incrementa su expresión tras de la inducción hifal. Análisis de extractos celulares de la cepa SEP7-HA (OL1405) crecida en YEPD $+10 \%$ suero a $37^{\circ} \mathrm{C}$. Se incubaron en presencia $(+\lambda)$ o ausencia de $\lambda$-fosfatasa antes de su separación mediante SDS-PAGE con $40 \mu \mathrm{M}$ Phos-Tag y revelado con anticuerpos anti-HA. Imagen cortesía del Dr. J.Correa. 
Por tanto, se puede concluir que aunque Sep7 y Cdc11 son proteínas parálogas con una cierta similitud, son modificadas post-traduccionalmente de forma diferente, siendo Sep7 la más fosforilada, lo que podría ser importante para la regulación de su función. Es interesante que durante el transcurso de este trabajo se ha publicado un análisis del fosfoproteoma de $C$. albicans durante el crecimiento filamentoso (Willger et al., 2015). El 53,3\% de los sitios de Sep7 identificados en el citado trabajo coinciden con nuestro análisis, salvo que Willger y colaboradores detectan diez aminoácidos extras que bajo nuestras condiciones no aparecen como fosfomodificados (o que detectamos únicamente durante el estado de levadura); a su vez, nuestros resultados incluyen tres aminoácidos que no aparecen en el estudio del fosfoproteoma de C. albicans. Por su parte, tres de los cinco aminoácidos de Cdc11 identificados coinciden en ambos estudios (Fig. 30A, en negro encima de las proteínas).
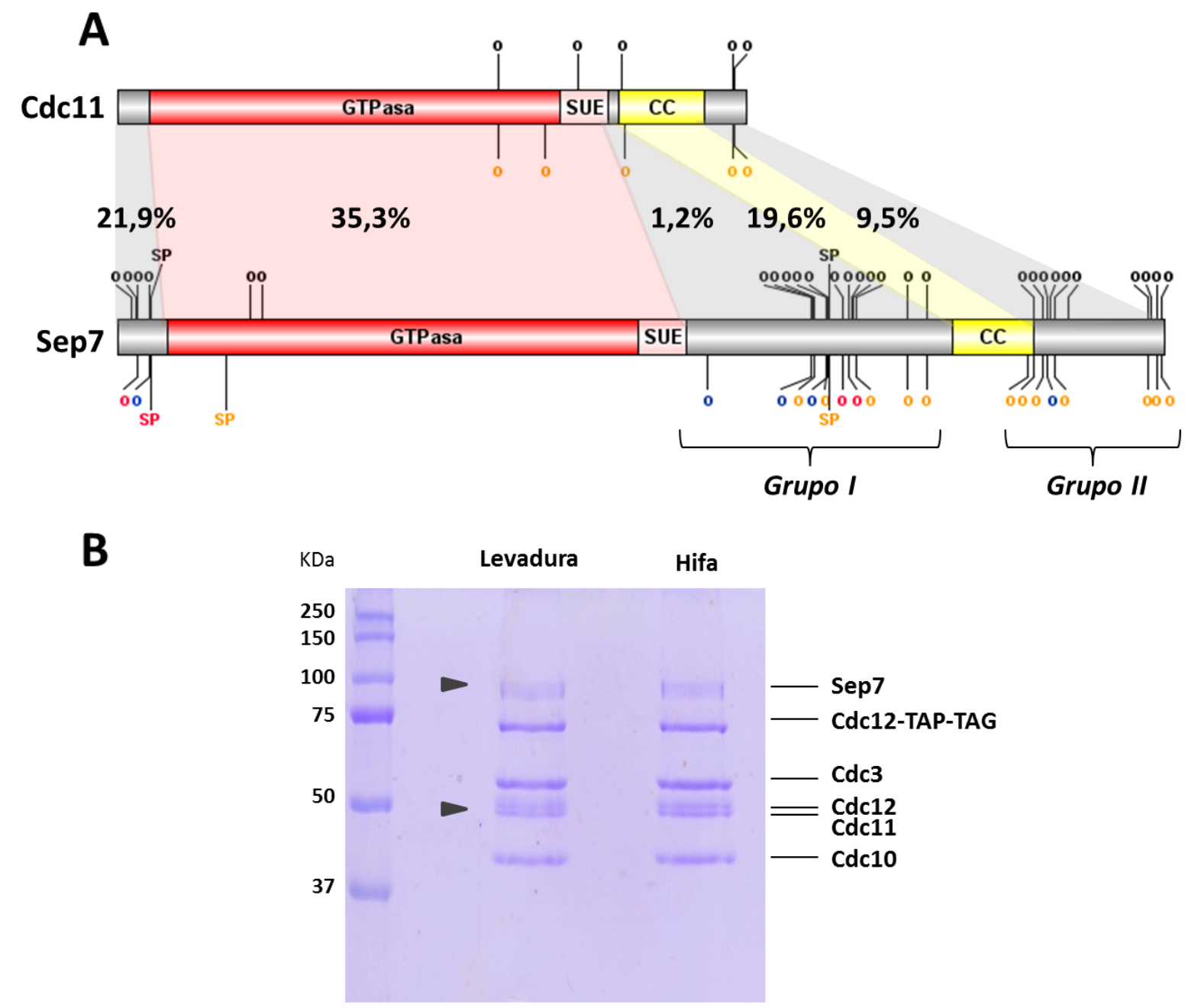

Figura 30. Cdc11 y Sep7 difieren fundamentalmente en su extremo carboxilo. (A). Representación esquemática de las proteínas Cdc11 y Sep7. Encima de las proteínas: Sitios identificados en el fosfoproteoma de C. albicans en hifas (negro) (Willger et al., 2015). Debajo de las proteínas: Sitios de fosforilación identificados por espectrometría de masas en este trabajo en levaduras (azul), en hifas (rojo) o en ambos tipos de crecimiento (naranja). Los sitios de fosforilación identificados en Sep7 se agrupan en dos regiones denominadas Grupo / y II. Sitios SP (consenso para CDK) y S/T(o). (B). Purificación del complejo de septinas. Los extractos de levaduras y de hifas de la cepa CDC12-TAP-TAG (OL2368) fueron purificados mediante anticuerpos anti-IgG. Posteriormente los extractos se separaron por SDS-PAGE, se tiñieron con azul de Coomassie y se cortaron las bandas correspondientes a Sep7 y Cdc11 para analizarlas por espectrometría de masas. 
El análisis de los mapas de fosforilación evidenció aún más las diferencias entre Sep7 y Cdc11, que divergen fundamentalmente en el extremo C-terminal donde existen dos grupos de fosforilación en Sep7 que no aparecen en Cdc11, y que a partir de ahora se denominarán como Grupo I (zona comprendida entre SUE y coiled-coil) y Grupo II (sitios entre el coiled-coil y el extremo C-terminal) (Fig. 30A). Pero también, ambas proteínas difieren en su extremo amino, ya que existen sitios de fosforilación en Sep7 que no están presentes en Cdc11, uno de los cuales es específico de levaduras y los otros dos de hifas. En Apartados posteriores se describirá el análisis de estos sitios y su importancia en la regulación de Sep7.

\subsection{La región comprendida entre los aminoácidos 394 y 552 de Sep7 es necesaria para} inhibir la separación celular en las hifas.

Uno de los elementos críticos para la funcionalidad de Cdc11 y Shs1 tanto in vivo como in vitro en S. cerevisiae es el CTE que se encuentra después del dominio de unión a GTP y que contiene el coiled-coil (Bertin et al., 2008; Finnigan et al., 2015b). Como se ha explicado anteriormente, una de las funciones de Sep7 durante la formación de hifas es mantener los compartimentos hifales unidos. Para tratar de profundizar en los mecanismos por los que Sep7 regula este proceso, se decidió hacer un análisis de las regiones de esta proteína, especialmente del CTE donde se localizan gran cantidad de los sitios de fosforilación identificados. Para ello, se construyeron distintos truncamientos de Sep7 en los que se eliminaban progresivamente distintas regiones de la proteína (Fig. 31A). Estos truncamientos se hicieron teniendo en cuenta los análisis bioinformáticos y de fosfoproteómica que identificaban sitios de fosforilación, basándonos en la posibilidad de que alguna de esas modificaciones post-traduccionales fueran necesarias para la función de Sep7 durante el crecimiento filamentoso. De esta forma, se construyeron cuatro cepas mutantes que contenían versiones de Sep7 truncadas en las posiciones 629 (que perdía cuarenta y un aminoácido del extremo carboxilo pero mantenía parte del Grupo /l de fosforilación), 580 (que eliminaba la región comprendida entre el coiled-coil y el final de la proteína, y por tanto el Grupo II), 522 (carente del coiled-coil y del Grupo I/ de fosforilación) y la más severa en la posición 394 (que perdía todo el CTE, incluidos el Grupo / y II). Todas estas construcciones se hicieron introduciendo la proteína Cherry en fase después del aminoácido indicado, por lo que las distintas versiones de Sep7 (Sep7t-394; Sep7t-522; Sep7t-580 y Sep7t-629) quedaban marcadas con esta proteína fluorescente para poder analizar su localización. Estos truncamientos se hicieron en los dos alelos de SEP7, para descartar del análisis los efectos relacionados con la dosis génica. Posteriormente, todas estas cepas fueron marcadas también con GFP en el extremo 3'del gen CDC10.

Una vez comprobado por Western Blot que las distintas versiones de la proteína Sep7 se expresaban correctamente tanto en crecimiento levaduriforme como hifal (Fig. 31B), se estudió la morfología de las levaduras y la localización de las septinas, tanto de la versión truncada de Sep7 (marcada con Cherry), como Cdc10-GFP (Fig. 31C). Se comprobó que todas las versiones truncadas de Sep7-Ch colocalizaban con Cdc10-GFP y que su posición en el presumible sitio de gemación y los cuellos era similar al silvestre. Así, la morfología de estas cepas no se diferenciaba de la de un WT. Para su estudio durante el crecimiento hifal, se incubaron en condiciones de inducción de la filamentación durante $2,5 \mathrm{~h}$, se tiñeron con calcoflúor y se observaron al microscopio. Al igual que en levaduras, los truncamientos de Sep7 aparecían en una localización silvestre y todas las cepas fueron capaces de formar hifas con aspecto similar al de la cepa silvestre (Fig. 31E). A continuación, se determinó si los distintos truncamientos afectaban a la separación de las hifas después de 3,5 h de filamentación, 

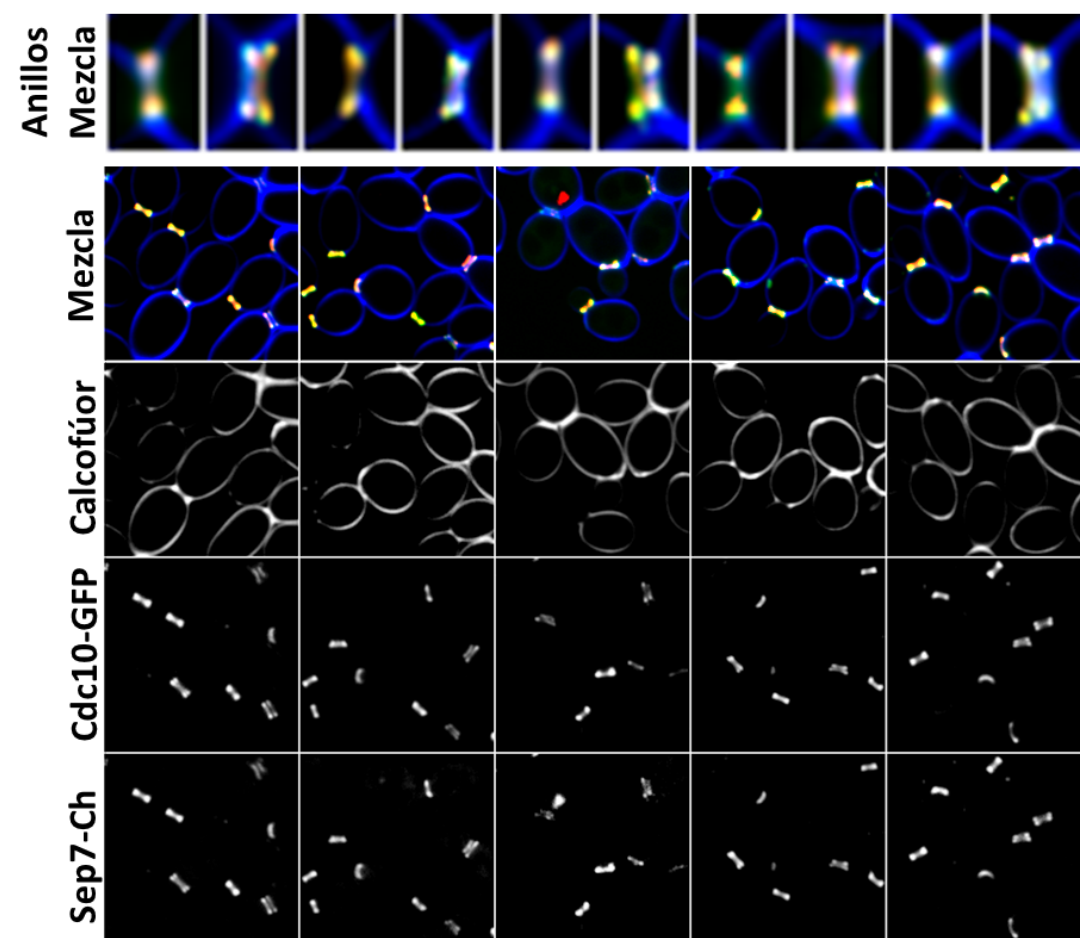

늠

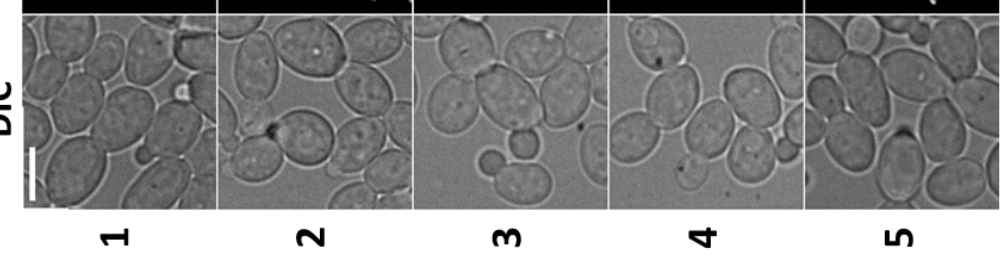

ט

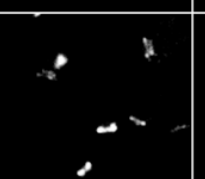

H

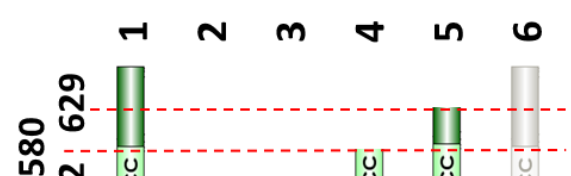

요

N
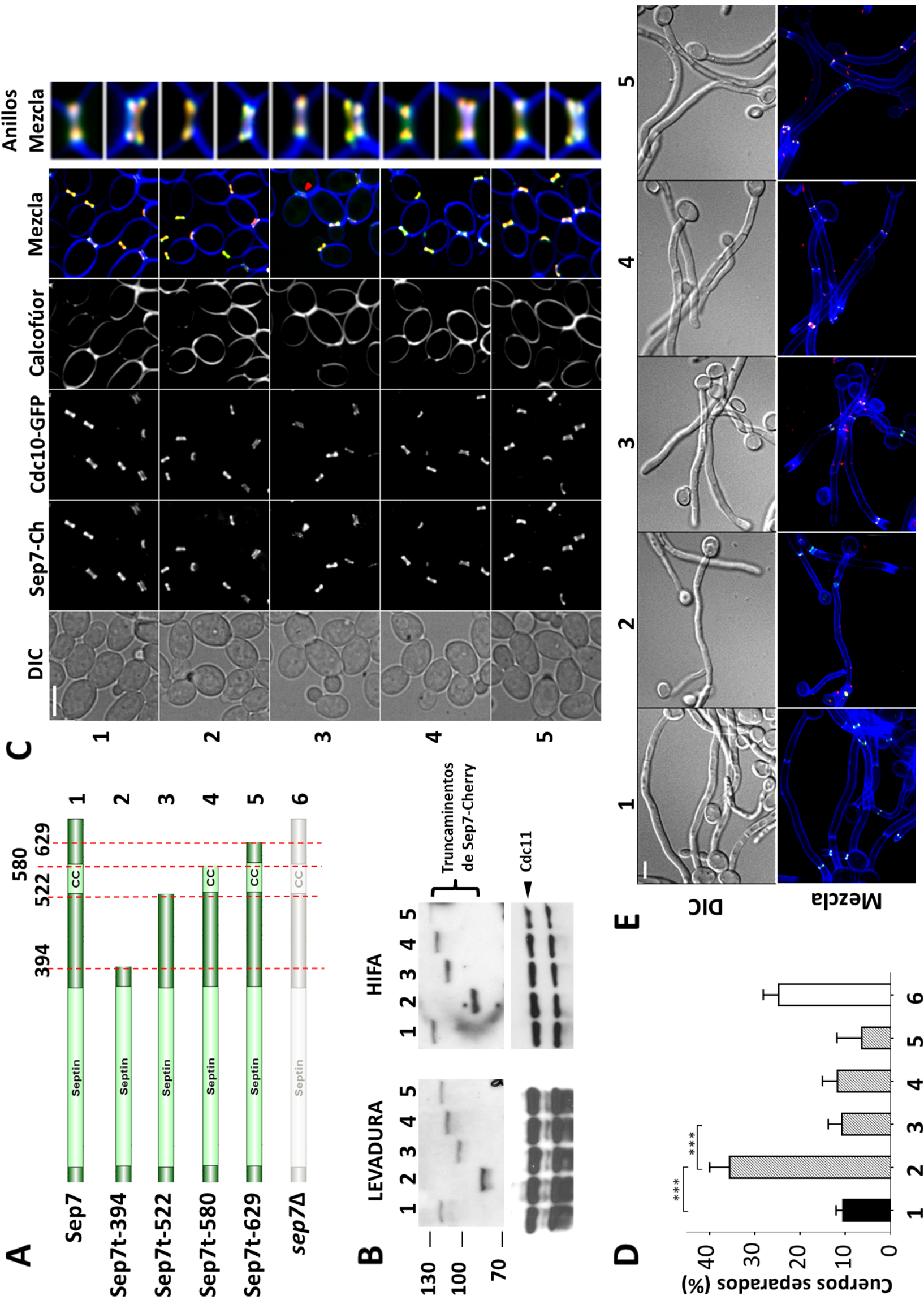
determinando el porcentaje de cuerpos separados en cada caso y los resultados obtenidos mostraron que el único de los mutantes que producía separación de los compartimentos hifales era sep7t-394, que presentaba un $\sim 35 \%$ de cuerpos separados (Fig. 31D). Sin embargo, el resto de cepas, incluida la del truncamiento en 522, que contenía el Grupo I de fosforilación pero perdía desde el coiled-coil hasta el final de la proteína, mantenían un porcentaje de separación parecido al de la cepa silvestre tras 3,5 h de filamentación ( 10\%). Estos resultados demuestran que la región de Sep7 comprendida entre las posiciones 394 y 522 es necesaria para inhibir la separación celular en hifas.

Adicionalmente, se analizó la dinámica de Cdc10-GFP en los mutantes que contenían truncamientos de Sep7 y se comprobó que la recuperación de la fluorescencia de la septina era similar a la del silvestre (datos no mostrados), lo que de nuevo indica que el estado específico de hifas no está directamente relacionado con la separación celular durante el crecimiento hifal.

\subsection{Los sitios de fosforilación del Grupo I de Sep7 son necesarios para inhibir la separación celular en hifas.}

El hecho de que la región 394-522 de Sep7 fuera necesaria para inhibir la separación celular en las hifas resultó interesante, pues esta zona contiene múltiples sitios de fosforilación (Grupo I) identificados por espectrometría de masas. Estos resultados indican que Sep7 contribuye significativamente a la función óptima de las septinas durante la filamentación, y que contiene dominios específicos y/o residuos que le permiten desempeñar su papel fisiológico de inhibir la separación celular durante el crecimiento hifal. Sin embargo, no está claro cómo puede esta región ejercer su función. Una hipótesis para explicarlo es que esta región sea necesaria para interaccionar con otras proteínas reguladoras de la separación (en hifas o levaduras), y que sean las modificaciones post-traduccionales de esta región las que modulen la capacidad de Sep7 para interaccionar con dichos reguladores.

Para comprobar si las fosforilaciones del Grupo I de la región 394-522 eran necesarias para inhibir la separación celular en las hifas, se construyó por mutagénesis dirigida una cepa fosfodeficiente sep7-10A (en los que se intercambiaron los aminoácidos fosforilados, Ser444, Thr445, Ser446, Ser454, Ser455, Ser456, Ser468, Ser470, Thr471 y Ser473, por Alanina, aminoácido sin carga)(Fig. 32A). Se escogieron estas posiciones porque los aminoácidos 444, 446, 454, 455, 456, 468 y 473 habían sido identificados en el estudio de espectrometría de masas y el resto habían sido publicados en el estudio del fosfoproteoma de hifas de Willger y colaboradores (2015). De nuevo, estas modificaciones se introdujeron en los dos alelos de SEP7 para eliminar los efectos de la dosis génica. Tras construir la cepa, se secuenció el genoma de los mutantes obtenidos para comprobar que los dos alelos tenían

Figura 31. Análisis del CTE de Sep7. (A). Esquema de Sep7 (1) y las proteínas truncadas Sep7t-394 (2), Sep7t-522 (3), Sep7t-580 (4) y Sep7t-629 (5) construidas. (B). Estabilidad de las proteínas en ambos tipos de crecimiento. Muestras recogidas en fase exponencial (levadura) y tras 2,5 h de filamentación (hifas) se analizaron mediante Western Blot con anti-RFP. Como control de carga se utilizó anti-Cdc11. (C). Fenotipo de las distintas cepas en levaduras. Imágenes de contraste interferencial (DIC), fluorescencia de Sep7-Cherry, Cdc10-GFP y tinción con calcoflúor (proyección máxima de 10 planos cada 0,4 $\mu \mathrm{m}$ ) de las distintas cepas. Mezcla: Sep7-Cherry+Cdc10-GFP+calcoflúor. En la parte derecha se muestran detalles de anillos simples y duplicados. Barra de escala, $5 \mu \mathrm{m}$. (D). El mutante sep7t-394 presenta un alto porcentaje de separación celular de las hifas. El gráfico muestra el porcentaje promedio de cuerpos separados de, al menos, tres experimentos en la cepa silvestre (negro), en los mutantes de Sep7 (gris rayado) y en el mutante $\operatorname{sep} 7 \Delta \Delta$ (blanco), con la SEM, a 3,5 h de filamentación. Los asteriscos indican el nivel de significación (***: $p=0,0001 ; t$ test). (E). Fenotipo durante el crecimiento en forma de hifas. Las cepas se incubaron en condiciones de inducción de filamentación durante $2,5 \mathrm{~h}$ antes de teñirlas con calcoflúor. Imágenes de contraste diferencial (DIC) y proyección máxima de 10 planos adquiridos cada $0,4 \mu \mathrm{m}$ que muestran la fluorescencia de Sep7-Cherry, Cdc10-GFP (Cdc11-GFP para el caso 1) y calcoflúor. Los números de los paneles hacen referencia a los mostrados en (A). Barra de escala, 5 um. SEP7-Ch (OL2217), sep7t-394 (OL2185), sep7t-522 (OL2252), sep7t-580 (OL2187), sep7t-629 (OL2189), SEP7-Ch CDC11-GFP (OL2538), sep7t-394 CDC10-GFP (OL2233), sep7t-522 CDC10-GFP (OL2271), sep7t-580 CDC10-GFP (OL2235) sep7t-629 CDC10-GFP (OL2237). 
las 10 mutaciones deseadas. Posteriormente, uno de los alelos fue marcado con la proteína Cherry en su extremo C-terminal. Después de comprobar que su localización era correcta y que la proteína mutante era capaz de incorporarse al anillo de septinas de forma similar a la silvestre tanto en levaduras como hifas (datos no mostrados), se contabilizó el número de cuerpos que habían degradado el septo primario del primer compartimento y se habían separado del resto de la hifa. Los resultados mostraron que el porcentaje de separación era similar al del mutante $\operatorname{sep} 7 \Delta \Delta$ (Fig. 32B). Esto indica que son las modificaciones por fosforilación en estas posiciones las que confieren a Sep7 la capacidad para inhibir la separación celular durante el crecimiento filamentoso.

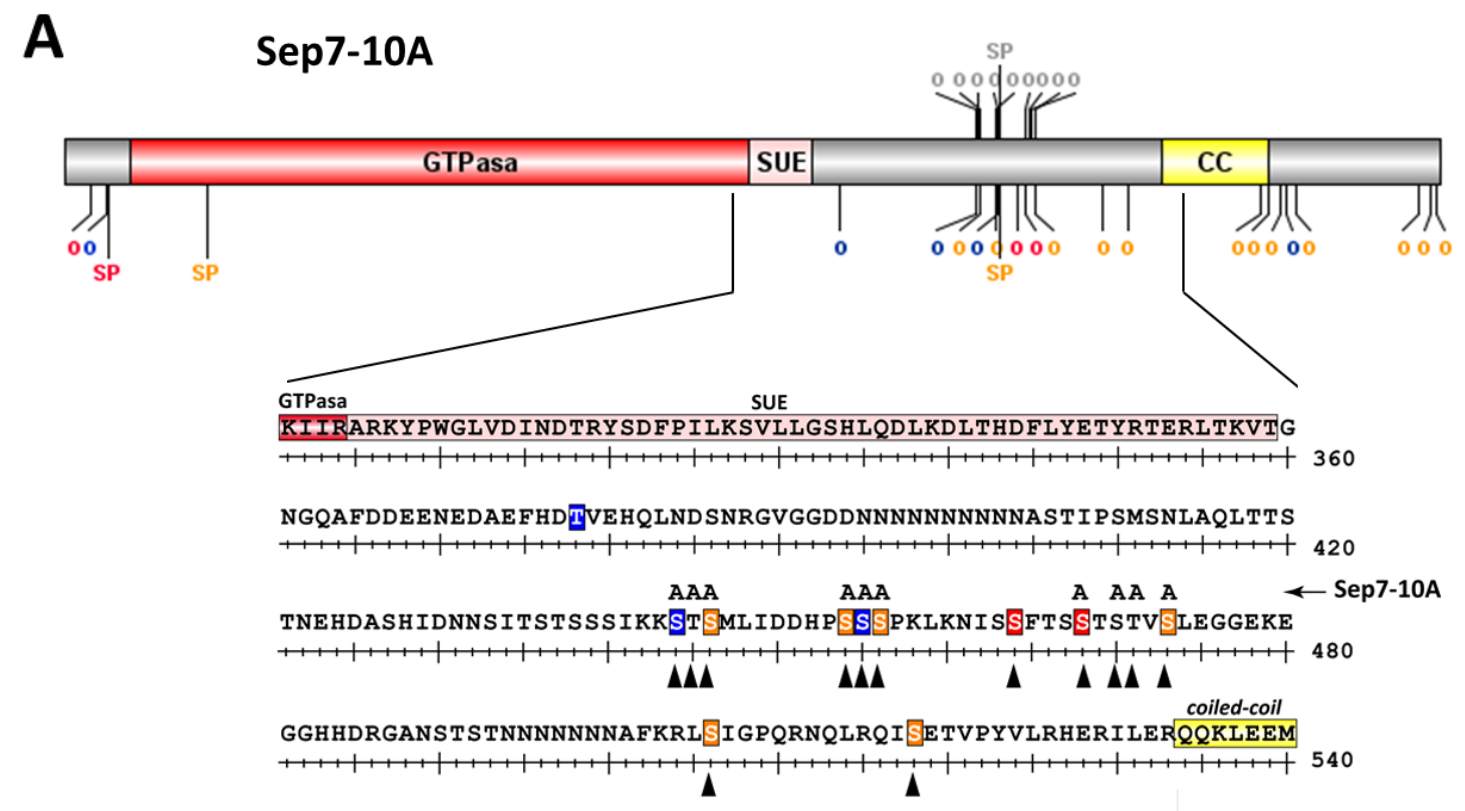

B

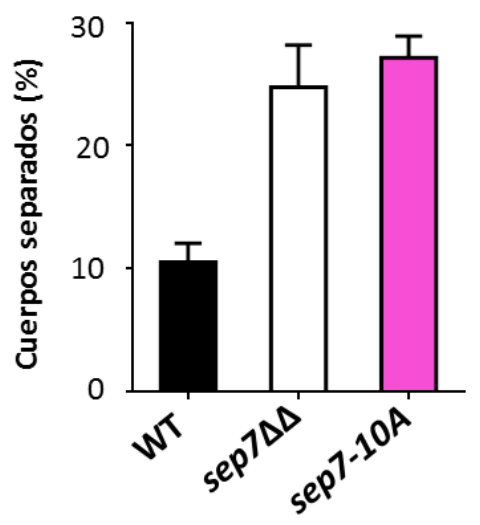

Figura 32. La fosforilación del Grupo I es importante para la función de Sep7 en hifas. (A). Representación esquemática de la proteína Sep7-10A. Encima de la proteína: Sitios modificados a Alanina en el mutante sep7-10A. Debajo: Sitios de fosforilación detectados por espectrometría de masas en levaduras (azul), hifas (rojo) o en ambos tipos de crecimiento (naranja). En la parte de abajo se muestra la secuencia de la zona de interés con el mismo código de colores. Los triángulos negros indican los sitios identificados en el análisis del fosfoproteoma de hifas (Willger et al., 2015). Sitios SP (consenso para CDKs) y S/T(O). (B). EI mutante sep7-10A presenta un alto porcentaje de separación celular de las hifas. El gráfico muestra el porcentaje promedio de cuerpos separados de, al menos, tres experimentos en la cepa silvestre (negro), en el mutante $\operatorname{sep} 7 \Delta \Delta$ (blanco) y en el mutante sep7-10A (rosa), con la SEM, a 3,5 h de filamentación. WT (OL1417), sep7 $\Delta \Delta$ (OL2138), sep7-10A (OL2636). 


\subsection{La fosforilación del extremo del C-terminal de Sep7 regula la división del anillo de septinas en hifas.}

Parece claro que los CTEs en aquellas septinas que los poseen les otorgan estabilidad y son responsables de algunas de sus funciones, como la organización supramolecular y/o la dinámica de las estructuras de septinas o del reclutamiento de otras proteínas por interacción con los coiled-coils (Versele et al., 2004; Finnigan et al., 2015a). En C. albicans, se ha mostrado anteriormente que la fosforilación de la zona central del CTE de Sep7 le confiere especificidad para inhibir la separación celular en las hifas. En el extremo C-terminal de la proteína existe otro grupo de fosforilación (Grupo II), por lo que se decidió analizar si las modificaciones post-traduccionales en esta región desempeñaban alguna función concreta en la regulación de los anillos de septinas.

Con el fin de comprobar esta hipótesis, se construyeron mutantes fosfodeficientes en los sitios $\mathrm{S} / \mathrm{T}$ más próximos al extremo carboxilo. Se generaron los mutantes sep7-3A (T659A, S665A y S668A), que son sitios identificados en el análisis de espectrometría de masas y que también aparecían en el estudio de Willger y colaboradores (2015) y sep7-8A (S645A, T646A, T651A, S652A, T659A, T661A, $S 665 A$ y $S 668 A$ ), que incluye un cuarto sitio identificado en el fosfoproteoma de hifas de Willger y cuatro aminoácidos adicionales que englobaban todas las $S / T$ desde la posición 645 , ya que aunque no había indicios previos de que fueran fosforilados in vivo, uno de ellos era un sitio S/T-P, consenso para CDKs (Fig. 33A). Estas modificaciones se hicieron por mutagénesis dirigida introduciendo la proteína GFP en el extremo C-terminal. Así, se generaron versiones fosfodeficientes de Sep7 marcadas con GFP.

De igual forma que el mutante sep7-10A, estas nuevas mutaciones se hicieron en las dos copias del gen SEP7 y fueron comprobadas por secuenciación. Cuando se analizó el crecimiento y la morfología del mutante sep7-3A en el microscopio no se observó ningún fenotipo relevante, ni en levaduras ni en hifas. Además, la localización de la proteína Sep7-3A-GFP y la estructura de los anillos de septinas en ambas formas de crecimiento eran similares a los de la cepa silvestre (datos no mostrados). Por el contrario, el mutante sep7-8A era normal en forma de levaduras, pero en hifas presentaba un mayor número de anillos aberrantes (en forma de "v")(Fig. 33B) que un silvestre en el momento de la duplicación. Posteriormente, estudios más detallados a lo largo del tiempo corroboraron esta dificultad para dividir el anillo, ya que un mutante sep7-8A formaba el anillo sencillo de Sep7-8A-GFP muy parecido al del silvestre (Sep7-GFP)(Fig. 33C). Sin embargo, aunque no se ha hecho un análisis estadístico, en muchos casos permanecía más tiempo desde su formación hasta que conseguía duplicarse, lo que suponía un retraso en la formación del septo, que en algunos casos llegaba hasta los 120 min en comparación con los 30 min de la cepa silvestre (Fig. 33C). En vista de estos resultados que parecían denotar un defecto en la duplicación de los anillos de septinas de la cepa sep7-8A, se marcó el anillo contráctil (Mlc1) con Cherry para tener un patrón de referencia temporal del momento de ensamblaje del AMR y analizar si había retrasos en el ensamblaje del anillo de actomiosina o en su contracción. Los estudios de time-lapse concluyeron que, aún habiendo defectos en la morfología del anillo de septinas y en su duplicación, la cepa sep7-8A era capaz de ensamblar el AMR y llevar a cabo la citoquinesis satisfactoriamente, y el tiempo desde que se formaba el AMR hasta su contracción no variaba significativamente con respecto al silvestre (Fig. 33D). Por tanto, los anillos con Sep7-8A-GFP consiguen, aunque retrasados, duplicarse con éxito y confinar un espacio para que la citoquinesis ocurra espacial y temporalmente igual que en un silvestre. 
A

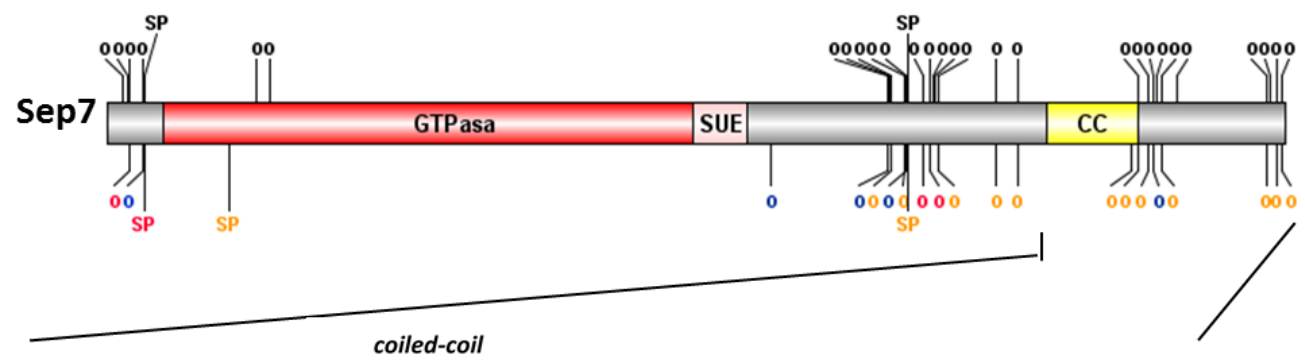

RAALLEKKAAQLKAKEKALRQLELNRQKQEESATSSLHRKDSDISGSVQSGGVDDGKSES
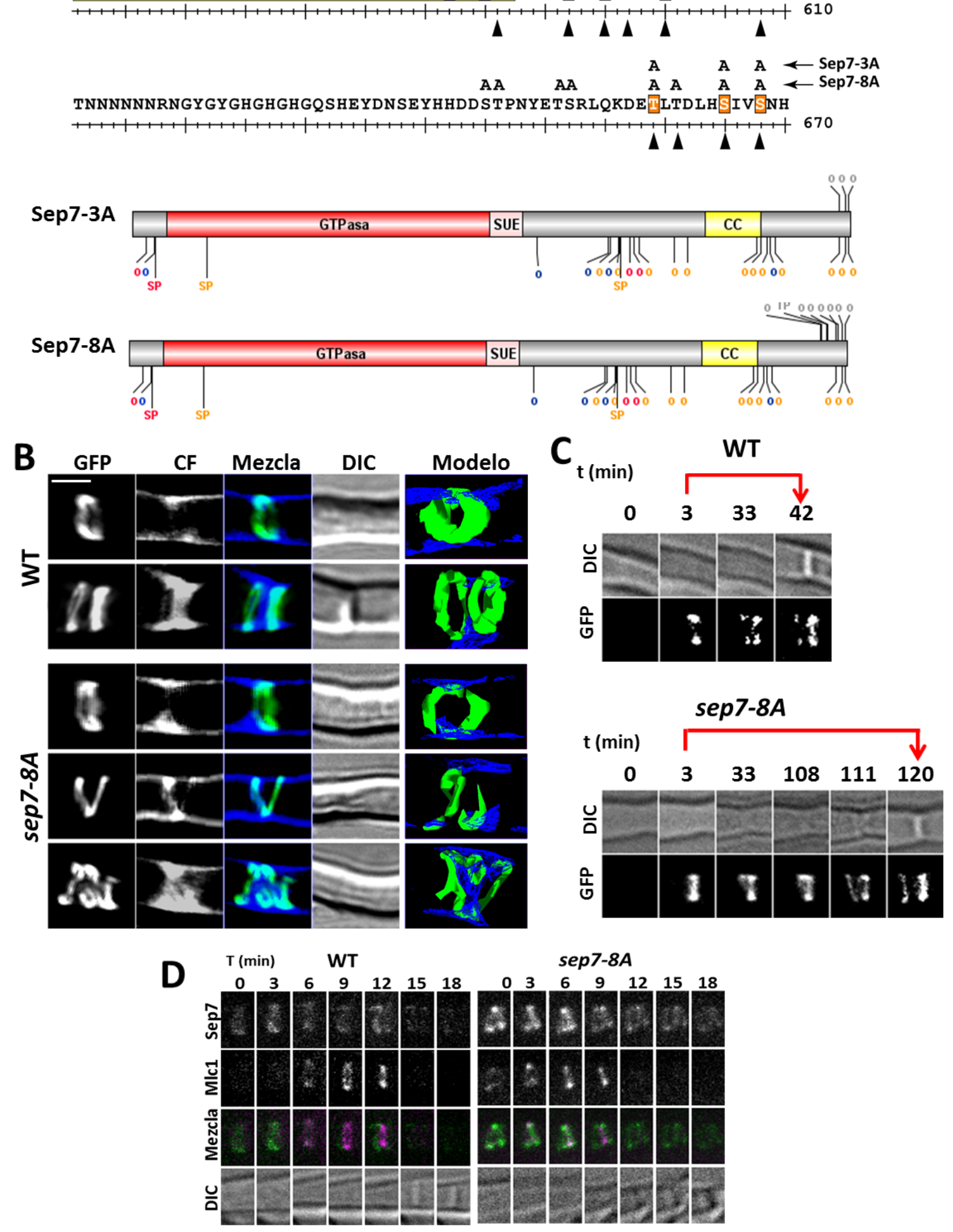


\section{6 El extremo C-terminal de Sep7 no es suficiente para inhibir la separación celular de} las hifas.

Los resultados presentados anteriormente indican que la región CTE de Sep7 desempeña una importante función en la inhibición de la separación celular de los compartimentos hifales. En el Capítulo I se mostró que Sep7 y Cdc11 compiten por unirse a los extremos finales de los octámeros, y que la proporción entre bastones con Sep7 o Cdc11 en ambos extremos parece ser crucial para esta función. Se planteó entonces la posibilidad de que la diferencia en la funcionalidad de los octámeros con Sep7 o Cdc11 se basara principalmente en el diferente CTE presente en cada tipo de octámero, que es mucho más largo y fosforilado en Sep7 que en Cdc11. Si esto fuera relevante para inhibir la separación celular en las hifas, entonces una quimera de Cdc11 que tuviera fusionado el CTE de Sep7 podría ser capaz de mimetizar a Sep7 en el extremo del octámero y desempeñar su función (Fig. 34A).

Para comprobar esta posibilidad, se construyeron dos cepas que contenían quimeras de CDC11. En la primera se truncaba Cdc11 en la posición 380 (justo después de su coiled-coil) y se sustituía por el extremo carboxilo de Sep7 (desde el coiled-coil hasta el final, posiciones 580-670). En la segunda se cortaba a Cdc11 en la posición 303 (en la región SUE), tras la que se fusionaba la secuencia del CTE completo de Sep7 (posiciones 354-670), que contenían los sitios de fosforilación del Grupo I y II (Fig. 34B). Estas construcciones se hicieron en un fondo genético de $\operatorname{sep} 7 \Delta \Delta$, generando la secuencia quimérica en una de las copias de $C D C 11$ y manteniendo el otro alelo de $C D C 11$ sin alterar. Estas quimeras con la versión corta de Sep7, sep7 $\triangle C D C 11 / C D C 11$ (CTEC-SEP7) o la versión larga, sep7 $\triangle C D C 11 / C D C 11$ (CTEI-SEP7), se denominarán a partir de ahora $C D C 11^{\text {CTEC-Sep7 }}$ y $C D C 11^{\text {CTE-Sep7. }}$.

Al haber modificado un alelo de $C D C 11$, manteniendo el otro silvestre, se pretendía ver si la relación 1:1 del CTE de Sep7 y el de Cdc11 en el extremo de los octámeros presentaba un fenotipo similar al del mutante heterocigótico $C D C 11+/-S E P 7+/$-. La idea se fundamentaba en que, en ausencia de moléculas de Sep7, una de las copias de CDC11 (la que no ha sido modificada) codificaría para la proteína Cdc11, mientras que la quimera $C D C 11^{C T E-S e p 7}$ debería generar una proteína que podría imitar a Sep7.

Cuando se analizó la separación de las hifas, se comprobó que ninguno de los mutantes, ni $C D C 11^{\text {CTEC-Sep } 7}$ ni $C D C 11^{\text {CTE-Sep7 }}$, era capaz de revertir el defecto de separación celular que se produce en el fondo genético $\operatorname{sep} 7 \Delta \Delta$ (Fig. 34C), ya que los porcentajes de cuerpos separados observados eran similares a los de los mutantes CDC11+/-y SEP7+/-. Esto demuestra que el extremo C-terminal de Sep7 no es el único responsable de la función desempeñada por esta septina. Alternativamente, es posible que las proteínas quimeras no sean funcionales o no se incorporen a los anillos y, por tanto, estén mimetizando el fenotipo de un mutante $C D C 11+/-$.

Figura 33. La fosforilación del extremo C-terminal es importante para la correcta duplicación del anillo de septinas en hifas. (A). Representación esquemática de las proteínas Sep7, Sep7-3A y Sep7-8A. Para Sep7, encima de la proteína: sitios identificados en el análisis de fosfoproteoma de C. albicans (negro)(Willger et al., 2015); debajo: sitios de fosforilación detectados por espectrometría de masas en levaduras (azul), en hifas (rojo) o en ambos tipos de crecimiento (naranja). Debajo se muestra la secuencia de la región con el mismo código de colores. Los triángulos negros indican los sitios identificados por Willger y colaboradores. Para Sep7-3A y Sep7-8A, encima: Sitios modificados a Ala; debajo: sitios de fosforilación detectados por espectrometría de masas, con el mismo código de colores. Sitios SP (consenso para CDKs) y S/T(o). (B). Estructura de los anillos de septinas sencillos y dobles durante la filamentación de las cepas silvestre y sep7-8A. Las imágenes muestran la fluorescencia de Sep7-GFP (GFP, verde) y la tinción con calcofúor (CF, azul) y el modelo 3D de cada anillo. Barra de escala, $2 \mu \mathrm{m}$. (C). Time-lapse de las cepas silvestre y sep7-8A. Las imágenes muestran la fluorescencia de Sep7-GFP y DIC. (D). Time- lapse de las septinas y del anillo de actomiosina de las cepas silvestre y sep7-8A. Las imágenes muestran la fluorescencia de Sep7-GFP (verde), Mlc1-Cherry (magenta) y DIC. SEP7-GFP (OL1456), sep7-3A (OL2399), sep7-8A (OL2119), SEP7-GFP MLC1-Ch (OL2231) y sep7-8A MLC1-Ch (OL2184). 

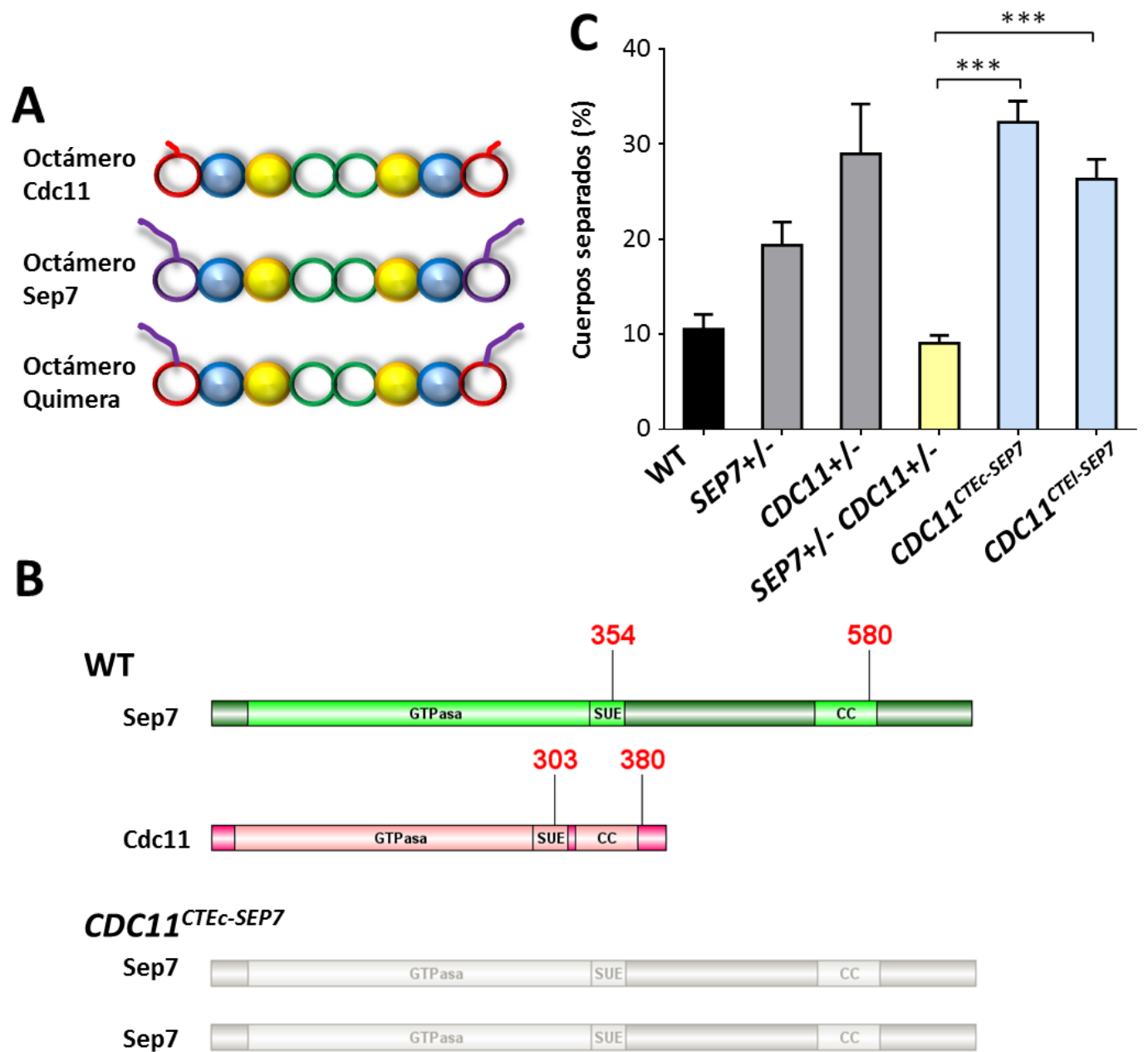

Cdc11 GTPasa $\quad$ SUE $\|$ CC $\square$

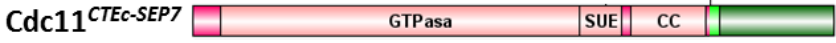

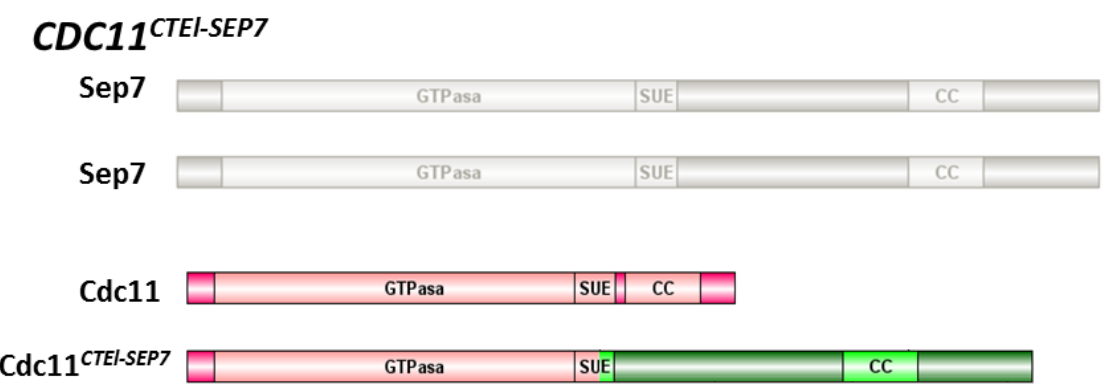

Figura 34. Relevancia del extremo carboxilo de Sep7. (A). Representación esquemática de los octámeros compuestos por Cdc11, Sep7 y la quimera Cdc11-Sep7. (B). Esquema de los mutantes CDC11 CTEC-SEP7 y CDC11 ${ }^{\text {CTE-SEP7. }}$ (C). Los mutantes CDC11 ${ }^{\text {CTEC-SEP7 }}$ y CDC11 ${ }^{\text {CTE-SEP7 }}$ presentan un alto porcentaje de separación celular de las hifas. El gráfico muestra el porcentaje promedio de cuerpos separados de, al menos, tres experimentos en la cepa silvestre (negro), los mutantes heterocigóticos sencillos SEP7+/- y CDC11+/- (gris), el mutante heterocigótico doble SEP7+/- CDC11+/- (amarillo) y los mutantes CDC11 CTEC-SEP7 y CDC11 CTEL-SEP7 (azul), con la SEM, a 3,5 h de filamentación. Los asteriscos indican el nivel de significación (***: $\mathrm{p}=0,0001$; $\mathrm{t}$ test). WT (OL1417), SEP7+/- (OL2049), CDC11+/- (OL2050), SEP7+/-CDC11+/- (OL2109), CDC11 ${ }^{\text {CTE-SEP7 }}$ (OL2169) y CDC11 $1^{\text {CTEL-SEPP }}$ (OL2166). 


\subsection{La fosforilación de Ser14 y Ser22 en el extremo amino es necesaria para el ensamblaje de los anillos de septinas en hifas.}

Como se ha comentado previamente, cuando se estudió el mapa de fosforilación obtenido en el análisis de espectrometría de masas, una de las cosas llamativas fue la existencia de tres sitios de fosforilación en el extremo N-terminal de Sep7, uno específico del crecimiento levaduriforme (Ser21) y otros dos que aparecían únicamente en las muestras de hifas (Ser14 y Ser22)(Fig. 35A). Estos sitios no están conservados en otras septinas de C. albicans, ni en las de S. cerevisiae (incluido Shs1), ni mamíferos. Además están localizados en la región inmediatamente anterior a la hélice $\alpha 0$ (Fig. 35A).

Se ha propuesto que la hélice $\alpha 0$ es importante para la asociación de las septinas con los fosfolípidos acídicos de la membrana plasmática, al contener una serie de residuos básicos (Zhang et al., 1999; Bertin et al., 2010). Cuando se determinó la estructura cristalográfica del complejo de septinas de ratón, se comprobó que la hélice $\alpha 0$ desempeña también un papel crucial en el establecimiento de las uniones NC al interaccionar con la septina adyacente (Sirajuddin et al., 2007). Además, debido a la unión cabeza con cabeza de los tetrámeros básicos a través de SEPT2 (Cdc10) y a la alternancia de uniones NC y G, las septinas que ocupan los extremos quedan orientadas con la hélice $\alpha 0$ hacia el exterior (Fig. 35B). Por tanto, la introducción de cargas negativas por fosforilación en esta zona de Sep7 podría modular la interacción de un octámero con los adyacentes o con las membranas, determinando así el tipo de estructuras de orden superior que se forman. Por ello se decidió analizar si estos aminoácidos desempeñaban algún papel en el ensamblaje de las estructuras de septinas en levaduras o hifas. Se construyó por mutagénesis dirigida un mutante fosfodeficiente sep7-2A y otro fosfomimético sep7-2E modificando los sitios que se encontraban fosforilados específicamente en hifas (posiciones Ser14 y Ser22). En estas construcciones se sustituyeron los aminoácidos correspondientes por Alanina o Ácido Glutámico y al igual que en los casos anteriores, se modificaron las dos copias de SEP7.

En primer lugar se estudió la morfología de las levaduras y su capacidad para filamentar. Aunque son estudios preliminares que deberán ser comprobados con más detalle, los resultados mostraron que las levaduras del mutante sep7-2A eran de un tamaño ligeramente mayor a la cepa silvestre y sep7-2E (Fig. 36), aunque este resultado no ha sido todavía cuantificado. Por otro lado, las hifas del silvestre y de ambos mutantes eran similares en apariencia. Sin embargo, cuando se contabilizó el porcentaje de células separadas tras 3,5 h de filamentación, se comprobó que el mutante fosfomimético se comportaba como un silvestre, pero el mutante fosfodeficiente tenía un porcentaje de separación extremadamente bajo. Incluso a tiempos de 4,5 h de filamentación, cuando el silvestre alcanza un 40\% de separación, el mutante fosfodeficiente sep7-2A mantenía unidas casi el 100\% de las hifas (Fig. 35C). Esto podría evidenciar la necesidad de fosforilar estos sitios para que se active de la separación celular a tiempos largos de filamentación y que las hifas empiecen a separar sus compartimentos y a gemar lateralmente, para revertir a un estado levaduriforme.

Para obtener más información sobre el fenotipo de sep7-2A y sep7-2E, las proteínas mutantes fueron marcadas con la proteína Cherry en su extremo C-terminal. Inicialmente, se comprobó que la localización de estas proteínas era similar a Sep7 silvestre en levaduras (Fig. 36), y que Sep7-2A y Sep7-2E se incorporaban normalmente a los anillos de septinas, que presentaban una morfología similar a la de la cepa silvestre. Durante la filamentación, las hifas del mutante sep7-2A presentaban una disposición normal de las septinas tras 40 min de inducción, pero a tiempos más largos comenzaba 

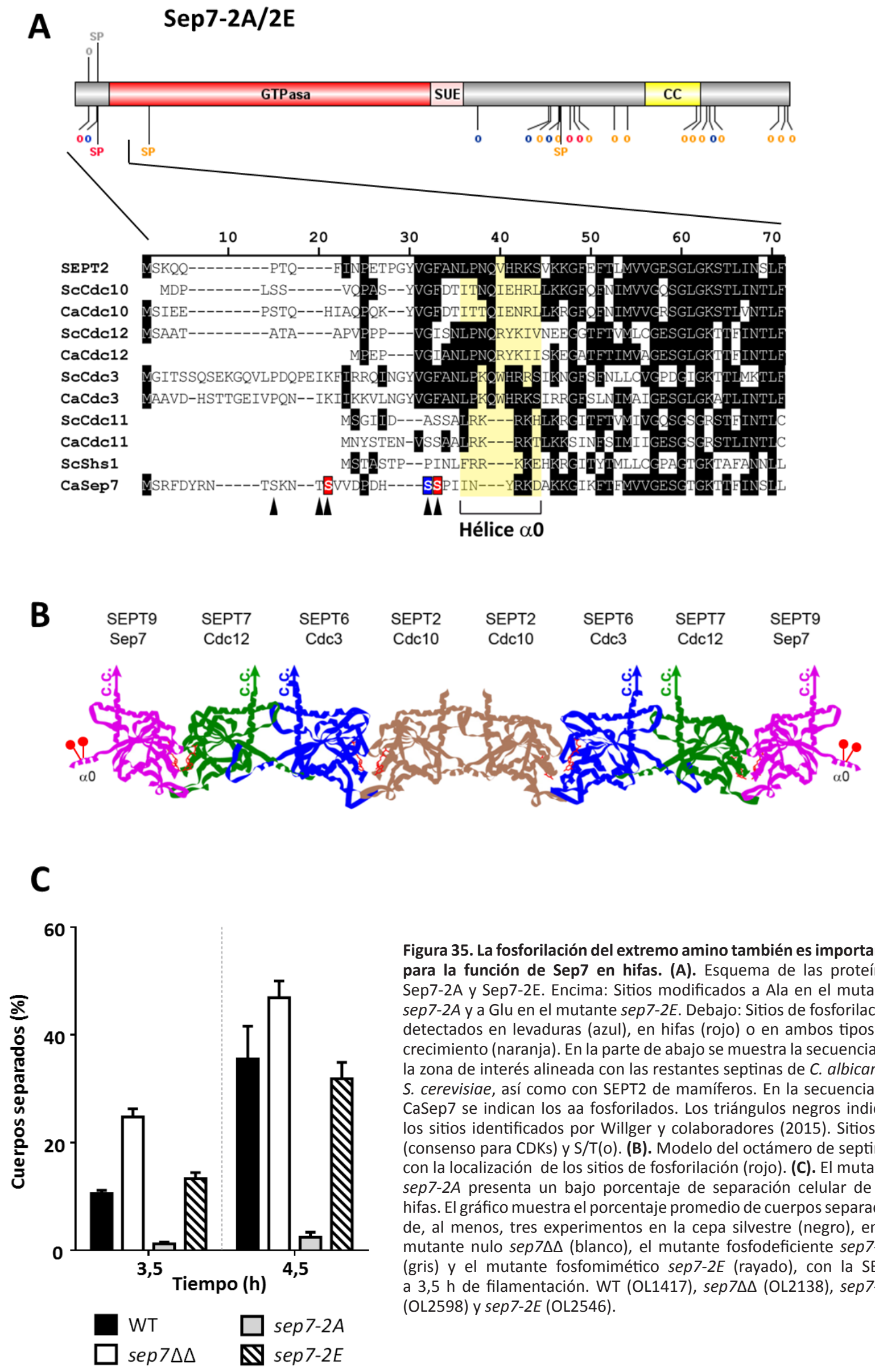

Figura 35. La fosforilación del extremo amino también es importante para la función de Sep7 en hifas. (A). Esquema de las proteínas Sep7-2A y Sep7-2E. Encima: Sitios modificados a Ala en el mutante sep7-2A y a Glu en el mutante sep7-2E. Debajo: Sitios de fosforilación detectados en levaduras (azul), en hifas (rojo) o en ambos tipos de crecimiento (naranja). En la parte de abajo se muestra la secuencia de la zona de interés alineada con las restantes septinas de $C$. albicans y S. cerevisiae, así como con SEPT2 de mamíferos. En la secuencia de CaSep7 se indican los aa fosforilados. Los triángulos negros indican los sitios identificados por Willger y colaboradores (2015). Sitios SP (consenso para CDKs) y S/T(O). (B). Modelo del octámero de septinas con la localización de los sitios de fosforilación (rojo). (C). El mutante sep7-2A presenta un bajo porcentaje de separación celular de las hifas. El gráfico muestra el porcentaje promedio de cuerpos separados de, al menos, tres experimentos en la cepa silvestre (negro), en el mutante nulo sep $7 \Delta \Delta$ (blanco), el mutante fosfodeficiente sep7-2A (gris) y el mutante fosfomimético sep7-2E (rayado), con la SEM, a 3,5 h de filamentación. WT (OL1417), sep7 $\Delta$ (OL2138), sep7-2A (OL2598) y sep7-2E (OL2546). 


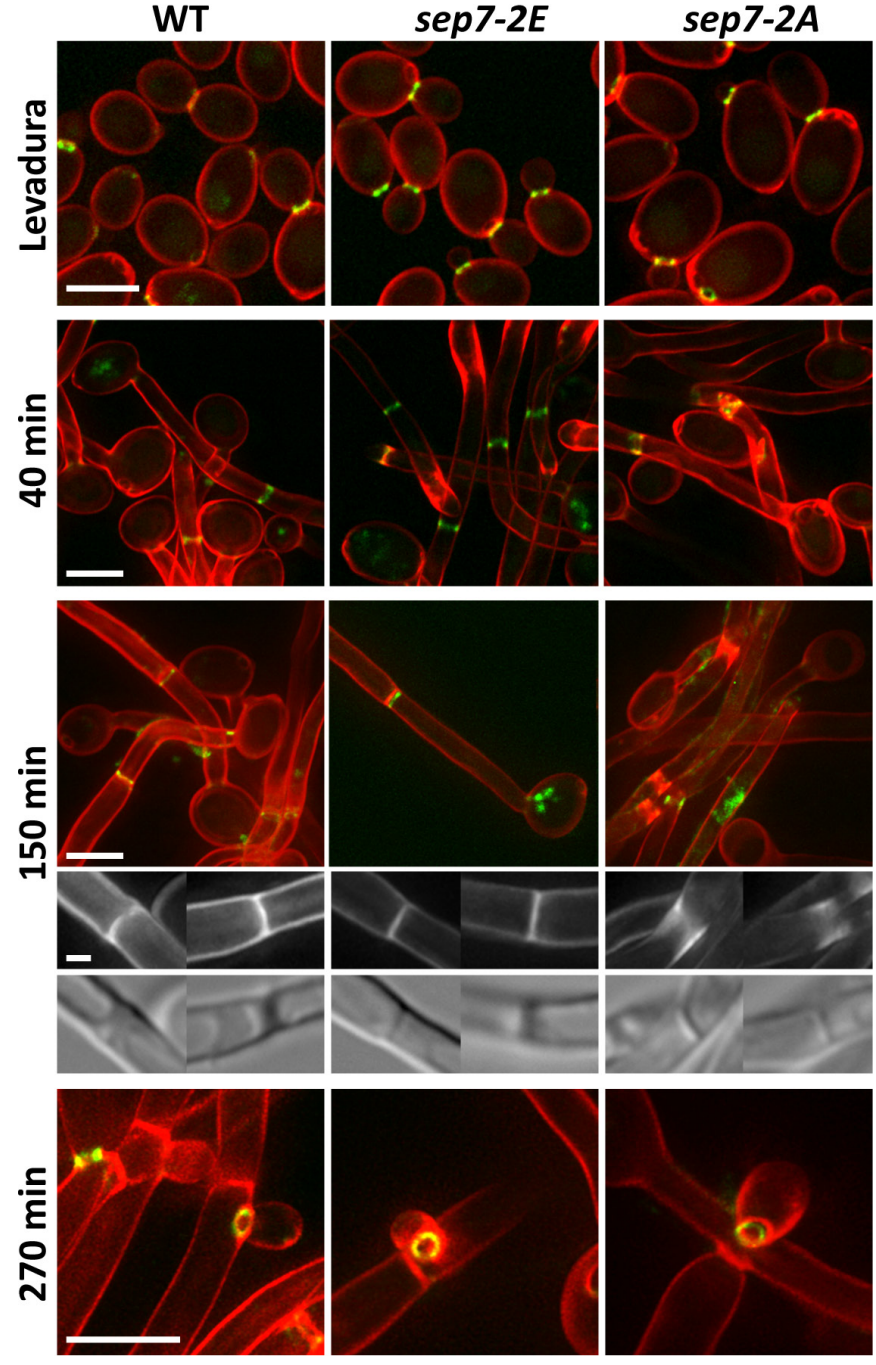

Figura 36. Los mutantes sep7-2A presentan defectos en levaduras e hifas. Localización de Sep7 en las cepas WT, sep7-2E y sep7-2A en levaduras e hifas. Las cepas fueron teñidas con calcoflúor antes de su visualización. Las imágenes son la proyección máxima de 10 planos adquiridos cada $0,4 \mu \mathrm{m}$ y muestran la fluorescencia de Sep7-Ch (verde) y la tinción de calcoflúor (rojo). A los 150 min se muestran detalles de los septos teñidos con calcofúor (arriba) y la imagen DIC (abajo). Barra de escala: $5 \mu \mathrm{m}$. SEP7-Ch (OL2217), sep7-2A-Ch (OL2632) y sep7-2E-Ch (OL2634). a ser aberrante. Así, por ejemplo, a los 150 min Sep7-2A no parecía ser capaz de formar anillos de septinas compactos $y$ aparecían puntos sueltos en el citoplasma y anillos de septinas difusos que se extendían por la membrana. De la misma forma, la señal del calcoflúor estaba dispersa en la zona de citoquinesis y no se observaba la señal correspondiente al septo primario, a pesar de que imágenes de microscopía de contraste interferencial mostraran un septo aparentemente bien formado (Fig. 36).

Por su parte, la localización en las puntas y los sitios de septación eran indistinguible entre Sep7-Ch y Sep7-2E-Ch a 40 y 150 min de inducción de la filamentación. Por tanto, es posible que la inhibición de la separación celular a tiempos largos de filamentación de la cepa sep7-2A se deba a que estos mutantes no forman correctamente el septo, y por tanto las quitinasas y endoglucanasas no pueden degradarlo posteriormente. Es interesante que, a pesar del defecto de separación de las hifas, a tiempos largos de filamentación el mutante sep7-2A era capaz de emitir yemas laterales de forma similar a la cepa silvestre y al mutante sep7-2E (Fig. 36), formando anillos de septinas en la base de la yema de apariencia normal. El hecho de que los anillos de levaduras y de las yemas laterales sean normales pero los de hifas no, parece indicar que Sep7-2A afecta específicamente a los anillos de hifas.

\subsection{Sep7 no es necesaria para la correcta localización de Sec3 y Gin4.}

Como se ha demostrado en este Capítulo, la región 394-522 de Sep7 es importante para regular el anillo de septinas en hifas y podría hacerlo por interacción con una o varias proteínas que regularan la separación celular de las hifas de C. albicans. De hecho, en S. cerevisiae se ha demostrado que Shs1 interacciona con otras proteínas que se localizan en el cuello, como el componente del polarisoma Spa2 (Mino et al., 1998), las proteín kinasas Elm1 (Bouquin et al., 2000), Gin4 (Okuzaki et al., 1997; Mortensen et al., 2002), Hsl1 (Shulewitz et al., 1999) y Kcc4 (Barral et al., 1999) y otras proteínas como Nis1 (Iwase y Toh-e, 2001), Bni5 (factor de unión a Myo1)(Lee et al., 2002; Finnigan et al., 2015a), la IQGAP Iqg1 (Iwase et al., 2007), la formina Bnr1 (Gao et al., 2010) o la proteína F-BAR Hof1 (Meitinger et 
al., 2011). Con la intención de averiguar si la interacción de alguna de estas proteínas estaba implicada en la regulación de la separación celular de las hifas en C. albicans, se propuso estudiar la localización de Gin4, ya que se ha descrito que esta kinasa fosforila a Sep7 y que su deleción provoca la desorganización
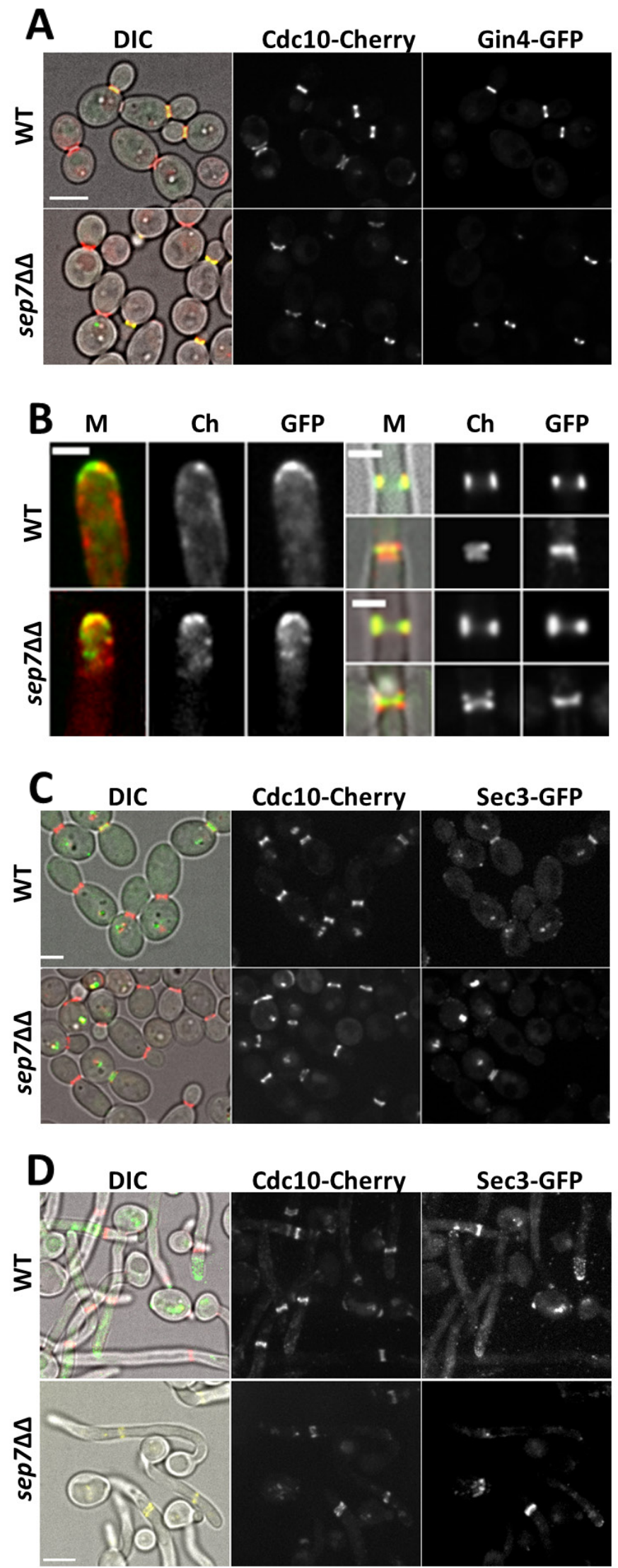

del anillo de septinas, la elongación celular y fallo en la citoquinesis, así como pérdida de localización en el cuello de otras proteínas como Spa2 (polarisoma), lqg1 (actomiosina) y $\mathrm{Sec} 3$ (exocisto) (Li et al., 2012). Para ello, se fusionó la secuencia de la GFP al extremo 3' del gen GIN4 tanto en un fondo silvestre como en el mutante carente del gen SEP7, ambos conteniendo Cdc10-Cherry para marcar la localización de los anillos de septinas. Una vez comprobada la correcta integración de la GFP, se analizó la localización de la proteína Gin4-GFP en levaduras e hifas. Como puede observarse en la Figura 37A, la regulación espacial de Gin4 no parece estar alterada en la cepa carente de Sep7.

Figura 37. Gin 4 y Sec3 se localizan correctamente en el mutante $\operatorname{sep} 7 \Delta \Delta$. (A). Análisis por microscopía de contraste interferencial (DIC) y de fluorescencia de Cdc10 y Gin4 en levaduras de las cepas WT y $\operatorname{sep} 7 \Delta \Delta$. Las imágenes son la proyección máxima de 10 planos adquiridos cada $0,4 \mu \mathrm{m}$ y muestran la fluorescencia Cdc10-Cherry (rojo) y Gin4-GFP (verde). Escala: $5 \mu \mathrm{m}$. (B). Mismo análisis que en (A) durante el desarrollo hifal, después de $3 \mathrm{~h}$ de filamentación. Escala: $2 \mu \mathrm{m}$. (C). Análisis por microscopía de contraste interferencial (DIC) y de fluorescencia de la septina Cdc10 y el componente del exocisto Sec3 en las cepas WT y $\operatorname{sep} 7 \Delta \Delta$ durante su estado de levadura. Las imágenes son la proyección máxima de 10 planos adquiridos cada $0,4 \mu \mathrm{m}$ y muestran la fluorescencia Cdc10-Cherry (rojo) y Sec3-GFP (verde). Escala: $5 \mu \mathrm{m}$. (D). Mismo análisis que en (C) durante el desarrollo hifal, tras 45 min de filamentación. Barra de escala: $5 \mu \mathrm{m}$. GIN4-GFP CDC10-Ch (OL2393), sep7 $\triangle$ GIN4-GFP CDC10-Ch (OL2421), SEC3-GFP CDC10-Ch (OL2391), sep7 $\triangle \Delta$ SEC3-GFP CDC10-Ch (OL2417). 
La kinasa se localizaba en los cuellos de gemación hasta el momento de la duplicación del anillo de septinas en ambos fondos genéticos en levaduras (Fig. 37A). Así mismo, Gin4 aparecía de manera indistinguible entre silvestre y mutante $\operatorname{sep} 7 \Delta \Delta$ en las puntas de las hifas y formando un anillo que colocalizaba con las septinas, en este caso permaneciendo en la zona de citoquinesis después de la duplicación del anillo de septinas (Fig. 37B). Por tanto, estos resultados preliminares indican que la proteína Sep7 no es necesaria para la localización de la kinasa Gin4 en cuellos de septación, aunque será necesario comprobar si la actividad kinasa es la misma en ambas cepas.

De igual manera, se estudió la localización de uno de los componentes del exocisto (Sec3) en el mutante nulo de SEP7 en comparación con una cepa silvestre, ya que este complejo tiene un papel esencial en el crecimiento polarizado de las células, por el transporte de moléculas requeridas para la construcción de nuevas estructuras en los sitios de crecimiento. En C. albicans, las células $\sec 3 \Delta \Delta$ pueden formar el tubo germinal, pero no son capaces de mantener el crecimiento en la punta tras la formación del primer septo, resultando en la expansión isotrópica de la misma (Li et al., 2007). Se comprobó que en las levaduras del mutante $\operatorname{sep} 7 \Delta \Delta$, Sec3-GFP (al que se había fusionado la secuencia de la GFP al extremo 3' del gen) se localizaba en los sitios de crecimiento, de manera similar a un silvestre, salvo que la señal de Sec3-GFP estaba parcialmente deslocalizada del cuello hacia la célula hija en levaduras, probablemente porque en este mutante, el anillo de septinas aparece frecuentemente con una disposición asimétrica hacia la yema (Fig. 37C). En hifas, Sec3-GFP se localizó correctamente en puntas y zonas de septación (Fig. 37D).

Por tanto, la localización de Gin4 o Sec3 en el septo es independiente de Sep7. 



\section{CAPÍTULO III: La fosforilación de Cdc12 está implicada en la correcta septación.}

\subsection{Introducción y antecedentes.}

Como se ha descrito en el Capítulo II, las modificaciones post-traduccionales de las septinas, entre ellas la fosforilación, pueden determinar su correcta funcionalidad. En C. albicans son varias las septinas que sufren este tipo de modificación. Así, Sep7 es fosforilada por Gin4 y Cdc11 y Cdc3 por las CDKs (Longtine et al., 1998; Tang y Reed, 2002; Dobbelaere et al., 2003; Sinha et al., 2007). Por otro lado, entre las proteínas que pueden estar regulando la dinámica del anillo de septinas se encuentra el complejo Cbk1-Mob2, implicado en el control del crecimiento polarizado. Esto se basa en la observación de que los mutantes mob2 $\Delta \Delta$ presentan unos cuellos mucho más anchos y engrosados que los de la cepa silvestre (Gutiérrez-Escribano et al., 2011), lo que indica la existencia de un defecto en las etapas iniciales de ensamblaje del anillo de septinas. Además, recientemente se ha descrito que el mutante hipomorfo mob2-4A tiene alterada la dinámica del anillo de septinas en hifas, de forma similar al mutante $\operatorname{sep} 7 \Delta \Delta$ (Calderón-Noreña et al., 2015). Por ello, es posible que el complejo Cbk1-Mob2 también esté implicado en la regulación de las septinas en determinados momentos del ciclo de vida, bien de forma directa o indirecta.

Con el fin de estudiar las posibles modificaciones post-traduccionales en otras septinas, se hizo un análisis buscando sitios consenso de fosforilación por Cbk1 (H-X-X-R/K-X-S/T o H-X-R/K-X-X-S/T) o por CDKs (S/T-P-X-K/R)(usando el programa KinasePhos 2.0) en el resto de septinas. Según las predicciones bioinformáticas, Cdc12 es la segunda septina con mayor número de posibles fosforilaciones para estas kinasas (y la única de las cinco septinas que contiene una secuencia consenso de reconocimiento por Cbk1, Fig. 38A). Así, en Cdc12 se predicen cuatro sitios de fosforilación: Ser64 (sitio consenso para Cbk1, pero que también forma parte de un sitio SP, posible diana de CDKs), Thr92, Ser178 y Thr202 (tres sitios S/T-P consenso para CDKs).

\begin{tabular}{|c|c|c|c|}
\hline Septina & Secuencia & Posición & Total \\
\hline Cdc3 & TP & 259 & 1 \\
\hline \multirow[t]{2}{*}{ Cdc10 } & SP & 70 & \multirow[t]{2}{*}{2} \\
\hline & TP & 102 & \\
\hline \multirow[t]{2}{*}{ Cdc11 } & TP & 90 & \multirow[t]{2}{*}{2} \\
\hline & TP & 177 & \\
\hline \multirow[t]{5}{*}{ Cdc12 } & HNKFTS & $59-65$ & \multirow[t]{5}{*}{5} \\
\hline & SP & 64 & \\
\hline & TP & 92 & \\
\hline & SP & 178 & \\
\hline & TP & 202 & \\
\hline \multirow[t]{6}{*}{ Sep7 } & SP & 22 & \multirow[t]{6}{*}{6} \\
\hline & SP & 70 & \\
\hline & TP & 135 & \\
\hline & TP & 188 & \\
\hline & SP & 456 & \\
\hline & TP & 646 & \\
\hline
\end{tabular}

\section{B Cdc12}
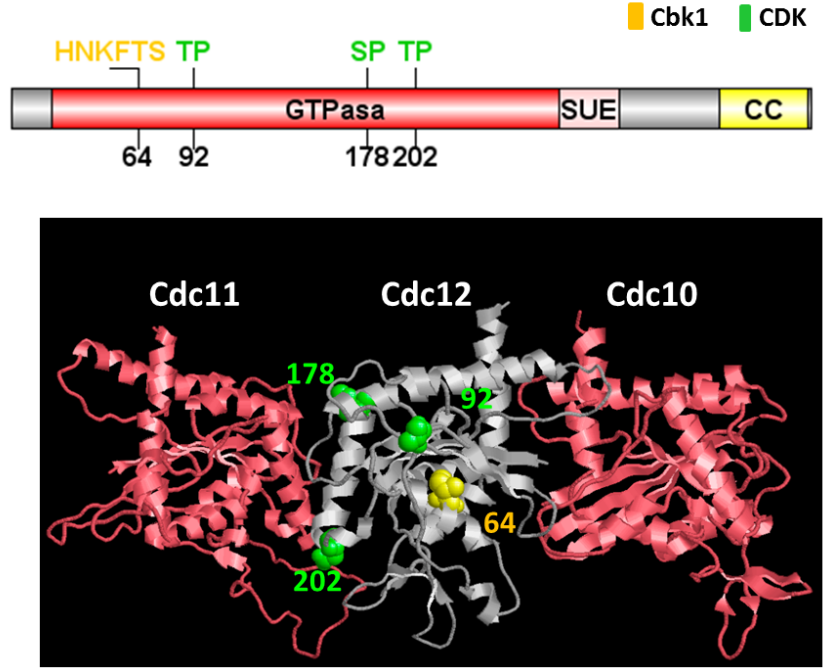

Figura 38. Las septinas pueden ser sustrato de diversas kinasas. (A). En la tabla se recogen los posibles sitios de fosforilación por Cbk1 (H-X-X-R/K-X-S/T o H-X-R/K-X-X-S/T) o CDKs (S/T-P) para cada una de las septinas. (B). Representación esquemática de los posibles sitios de fosforilación en Cdc12 (Amarillo: sitio H-X-X-R/K-X-S/T; Verde: sitios S/T-P). Predicción de la localización de los posibles sitios de fosforilación de Cdc12 basada en la estructura cristalográfica de la septina SEPT7 de mamíferos (Sirajuddin et al., 2007). 
A<smiles>CCCCCCCCCCCCCCCCCCC(C)(C)C</smiles>
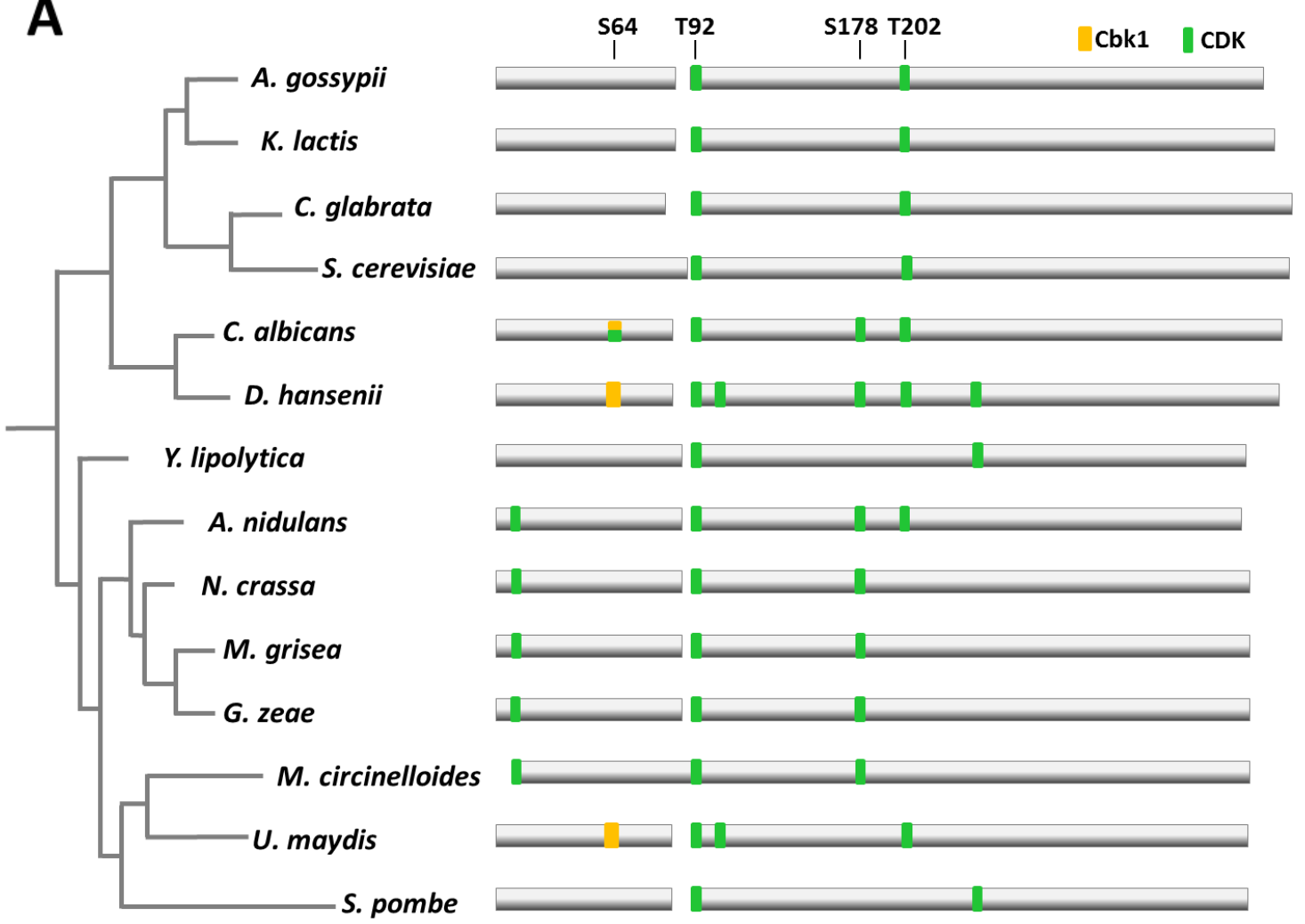

B
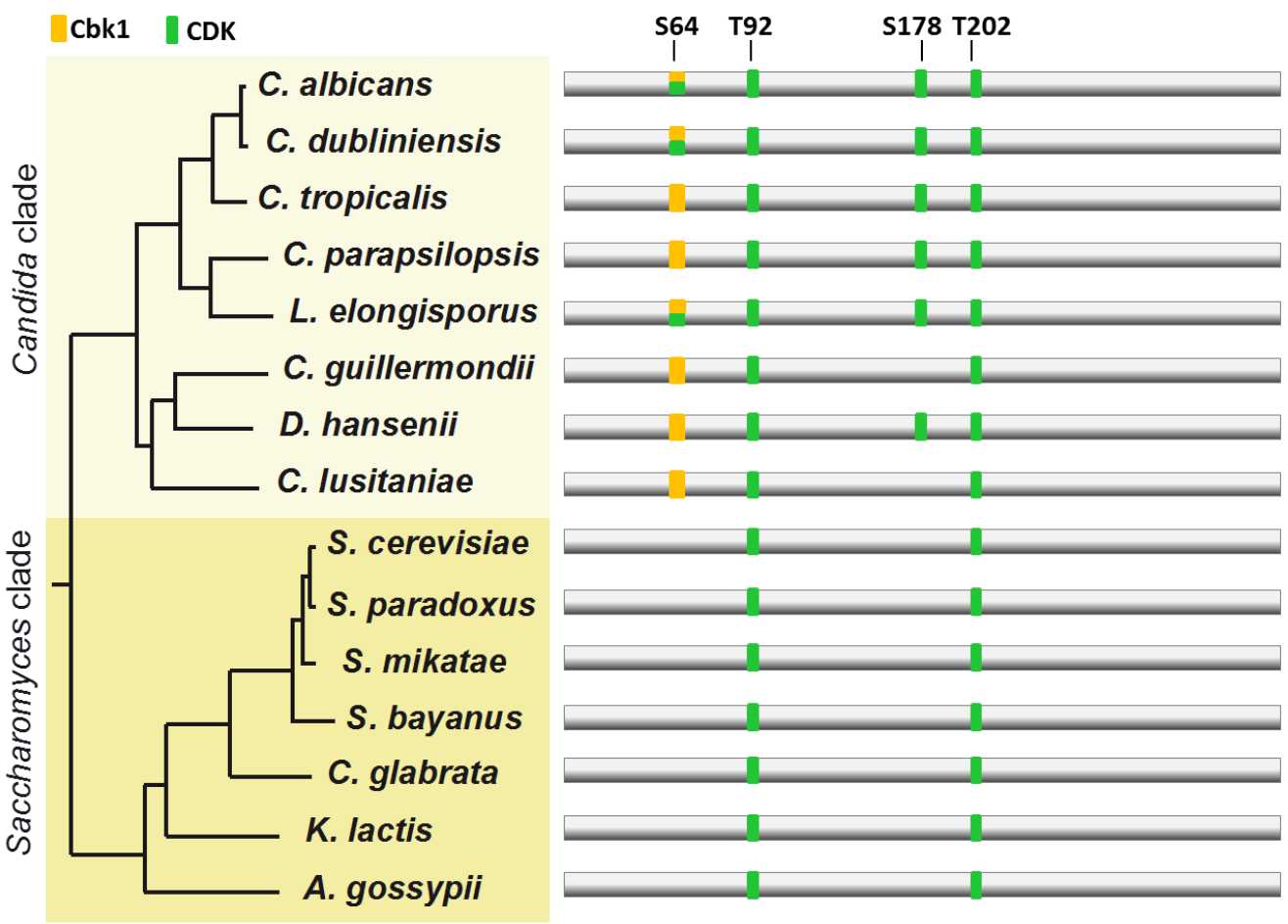

Figura 39. Los posibles sitios de fosforilación de Cdc12 presentan diferente grado de conservación. (A). Dendrograma de diversos hongos y levaduras. A la derecha, esquema de la secuencia de Cdc12 y los posibles sitios de fosforilacion. (B). Dendrograma de distintas especies de los clades Candida (Clade CTG) y Saccharomyces. Amarillo: sitios H-X-X-R/K-X-S/T o H-X-R/K-X-X-S/T; Verde: sitios S/T-P. 
Para comprobar el grado de conservación de estos sitios, se hizo un análisis filogenético y se comprobó que, dentro de los grandes grupos de levaduras, los sitios Thr92, Ser178 y Thr202 están más o menos conservados (Fig. 39A), no así el sitio consenso para Cbk1/CDKs (Ser64), que sólo se conserva en $D$. hansenii y $U$. maydis. Para analizar con más detalle en qué grupos estaba presente el posible sitio de fosforilación de Cbk1, se alinearon diversas levaduras de los grupos de Candida (el denominado Clade (TG) y Saccharomyces y se comprobó que los sitios Thr92 y Thr202 están conservados en todas las especies analizadas, mientras que la Ser64 (consenso para Cbk1/CDK) y la Ser178 aparecen exclusivamente en el Clade CTG (Fig. 39B). Por tanto, esto podría ser una indicación de que los posibles sitios de fosforilación que se conservan en la mayoría de las especies desempeñan un papel estructural común a todas ellas, mientras que los específicos del Clade CTG podrían haber surgido para regular algunas funciones específicas de este grupo.

Para completar este estudio, basándonos en la estructura cristalográfica de las septinas de mamíferos (Sirajuddin et al., 2007), se realizó un modelo de la localización de los posibles sitios de fosforilación en Cdc12 (Fig. 38B). Según este modelo, los aminoácidos Ser64, Thr92, Ser178 y Thr202 se dispondrían hacia la parte externa de la proteína plegada, posibilitando la interacción con hipotéticas kinasas. Tres de ellos, Ser64, Thr92 y Ser178, se localizan en las caras laterales del eje longitudinal del octámero, por lo que a priori no parecerían influenciar en su polimerización. La Thr202 se localizaría en un lazo entre las hélices $\alpha 6$ y $\alpha 7$ de $C d c 12$ que se sitúa próximo a Cdc11, y esto podría ser importante a la hora de ensamblar los filamentos. Por tanto, la fosforilación de estos sitios podría modular la interacción con otros filamentos de septinas adyacentes o con otras proteínas asociadas al anillo de septinas.

Existen pocos estudios de CDC12 porque es un gen esencial (Warenda y Konopka, 2002). Ante la imposibilidad de trabajar con un mutante nulo, se ha generado un mutante termosensible, $c d c 12-6$, que crece bien a temperatura ambiente pero no lo hace a $37^{\circ} \mathrm{C}$. A temperatura restrictiva muestra defectos en septación y en la morfogénesis de la yema, similar a lo que se había descrito en el mutante análogo en S. cerevisiae (Li et al., 2012b). En hifas, cdc12-6 tiene problemas en el mantenimiento del crecimiento polarizado y frecuentemente forma un segundo tubo germinativo muy cerca del primero. Al margen de este mutante, no había nada descrito hasta la fecha en cuanto a las modificaciones post-traduccionales por fosforilación de Cdc12. En este Capítulo se demostrará que Cdc12 se fosforila, y que la mutación de los sitios CDK produce defectos en la septación durante el desarrollo hifal.

\subsection{Cdc12 sufre modificaciones post-traduccionales específicas del tipo de crecimiento.}

Debido a que en geles de acrilamida no se observaban diferencias aparentes en la movilidad electroforética que indicaran si Cdc12 estaba fosforilada (Fig. 30B), se decidió analizar esta proteína mediante geles bidimensionales en los que se separan las distintas formas de una proteína según su punto isoeléctrico y su peso molecular. De esta forma, si Cdc12 sufriera fosforilaciones, las distintas versiones de la proteína migrarían hacia un punto isoeléctrico diferente. Para ello, se marcó a Cdc12 con el epítopo HA en su extremo C-terminal. El resultado de este experimento, realizado en colaboración con el Dr. Jaime Correa, mostró una sutil diferencia en el patrón de puntos de Cdc12 en levaduras e hifas, ya que en los filamentos aparecía una pequeña fracción en la región más ácida no presente en levaduras (Fig. 40). Este resultado indica que Cdc12 sufre modificaciones post-traduccionales distintas en levaduras e hifas. 


\subsection{Cdc12 interacciona con el complejo Cbk1-Mob2 y la kinasa Cdc28.}

Aunque los resultados indicaban que $\mathrm{Cdc} 12$ era una fosfoproteína, al menos en las hifas, no se sabía cuáles podrían ser las kinasas implicadas en su fosforilación. Los análisis bioinformáticos habían determinado que Cdc12 era la única septina de C. albicans que tenía una secuencia consenso de reconocimiento por Cbk1, en la posición Ser64. Si Cdc12 fuera un sustrato in vivo de Cbk1-Mob2, cabría esperar que existiera una interacción física entre ambos complejos. Para comprobarlo, se realizaron ensayos de co-inmunoprecipitación. Para ello, se etiquetó a Mob2 con el epítopo myc en una cepa CDC12-HA (marcada en su locus nativo y con su promotor). Como control del experimento, se usó una cepa que contenía únicamente $C D C 12-H A$. Las distintas cepas se incubaron en condiciones de crecimiento como levaduras o hifas, se prepararon extractos proteicos y se inmunoprecipitaron con anticuerpos anti-myc. Las proteínas inmunoprecipitadas fueron separadas en geles de acrilamida y analizadas mediante Western Blot con anticuerpos anti-HA y anti-myc. Cuando se analizó la presencia de Cdc12 en los inmunoprecipitados, se comprobó que existía interacción entre Mob2 y Cdc12 (Fig. 41A). A pesar de que en el control negativo también se observó una tenue banda correspondiente a Cdc12 (especialmente en levaduras), la intensidad en los carriles que coexpresaban ambas proteínas marcadas era muy superior. Estas observaciones parecen indicar que Cdc12 interacciona con el complejo Cbk1-Mob2 en las condiciones ensayadas.
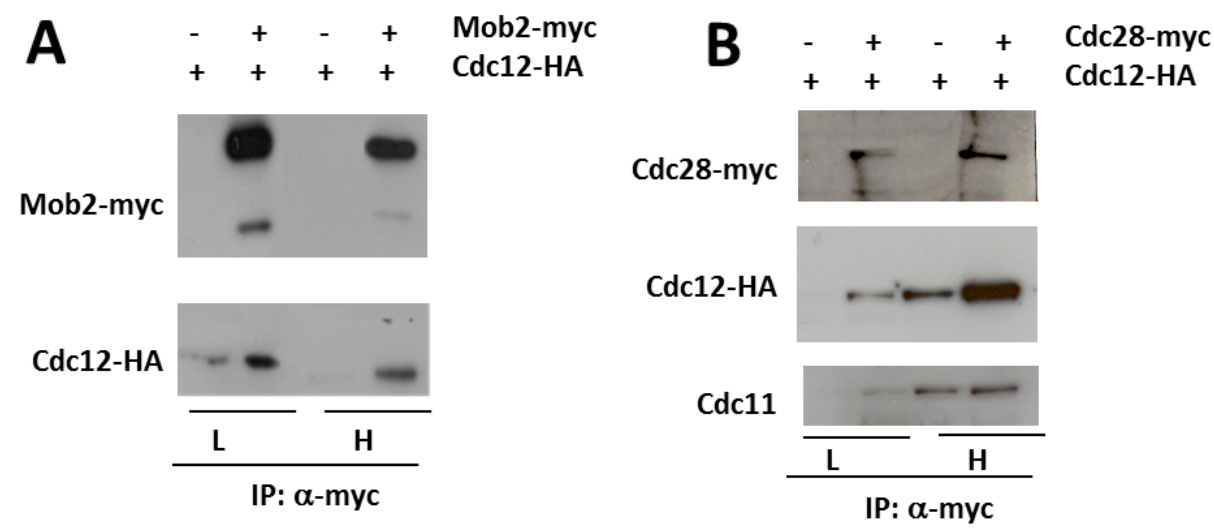

Figura 41. Cdc12 interacciona con Mob2 y Cdc28. (A). Co-inmunoprecipitación de Mob2-Cdc12. (B). Co-inmunoprecipitación de $\mathrm{Cdc} 28-\mathrm{Cdc} 12 / \mathrm{Cdc} 11$. Los extractos proteicos fueron inmunoprecipitados usando bolas magnéticas con anticuerpos anti-myc. Las muestras fueron separadas por SDS-PAGE y analizadas con anticuerpos anti-myc, anti-HA y anti-Cdc11. CDC12-HA (OL1419), MOB2-myc CDC12-HA (OL2100) y CDC28-myc CDC12-HA (OL2102). 
Como también existían sitios consenso para CDKs (S/T-P), se decidió hacer un ensayo de co-inmunoprecipitación para ver si Cdc12 interaccionaba con Cdc28. Para ello, se marcó Cdc28 con el epítopo myc en una cepa CDC12-HA y como control negativo se usó una cepa CDC12-HA. Al igual que antes, las distintas cepas se pusieron a crecer en forma de levaduras e hifas y se analizó la presencia de Cdc12 en los inmunoprecipitados obtenidos con anti-myc (que purificaban Cdc28-myc). Se comprobó que Cdc12 precipitaba asociada a Cdc28, siendo más acusada esta interacción durante el crecimiento hifal que en el levaduriforme (Fig. 41B). Además, también se analizó la presencia de Cdc11 (revelando con anticuerpos anti-Cdc11) en los inmunoprecipitados y se pudo observar que también hay interacción de Cdc28 con Cdc11, en levaduras e hifas, pero en este caso es una interacción mucho más leve y que no se incrementa durante el desarrollo hifal. Estas observaciones apoyarían la idea de que Cdc12 podría ser fosforilado por Cbk1 y CDK.

\subsection{La defosforilación de Cdc12 es necesaria para que la septación en hifas se lleve a cabo correctamente.}

Para comprobar si los posibles sitios de fosforilación por Cbk1 y/o CDKs de Cdc12 desempeñaban algún papel en su función, se construyeron una serie de mutantes fosfomiméticos y fosfodeficientes en un fondo CDC12+/- (al cual se le había sustituido una de las copias de CDC12 por el gen URA3 o SAT1, según la cepa). De esta manera, cada mutante sólo expresaría la forma modificada genéticamente. Las construcciones que se hicieron por mutagénesis dirigida se detallan a continuación (Fig. 42A):

- Mutantes fosfodeficiente y fosfomimético en Ser64 (sitio consenso para Cbk1), en los que se sustituyó este aminoácido por Alanina o Ácido glutámico, respectivamente. Estos mutantes recibieron los nombres de cdc12-S64A y cdc12-S64E.

- Mutantes fosfodeficiente y fosfomimético en Ser64 y Ser178 (ya que eran los específicos del Clade CTG). Estas mutaciones cambiaban las posibles serinas fosfoaceptoras (Ser64 y Ser178) por Alanina o Ácido glutámico (cdc12-2A y cdc12-2E).

- Mutantes fosfodeficiente y fosfomimético en Ser64, Thr92 y Ser178, que intercambiaban esas posiciones por Alanina o Ácido glutámico (cdc12-3A y cdc12-3E).

- Los últimos mutantes cambiaban las cuatro posiciones predichas (Ser64, Thr92, Ser178 y Thr202) por Alanina o Ácido glutámico (cdc12-4A y cdc12-4E).

Cuando se analizaron estos mutantes al microscopio, ninguno de ellos presentaba defectos morfológicos en su estado de levadura, ni siquiera los mutantes más severos cdc12-4A o $c d c 12-4 E$ (Fig. 42B). Además, todos eran capaces de responder a suero y mantener el crecimiento polarizado de las hifas de forma similar al silvestre. Sin embargo, los mutantes fosfomiméticos $c d c 12-3 E$ y $c d c 12-4 E$ presentaban un fenotipo similar, con hifas largas después de 2,5 h de filamentación que aún no habían sintetizado el primer septo y en las que el citoplasma se distribuía en un único compartimento. Para analizar con más detalle este defecto, se marcó con GFP las proteínas Cdc12-3E y Cdc12-4E, lo que permitía estudiar su incorporación al anillo de septinas. Además, estas cepas se tiñeron con calcoflúor para analizar al mismo tiempo la distribución de quitina y la estructura de los septos. Los resultados mostraron que en muchos de los septos, las proteínas Cdc12-3E-GFP y Cdc12-4E-GFP no se incorporaban correctamente al anillo de septinas, estando claramente desorganizadas en comparación con el silvestre (Fig. 42C). 


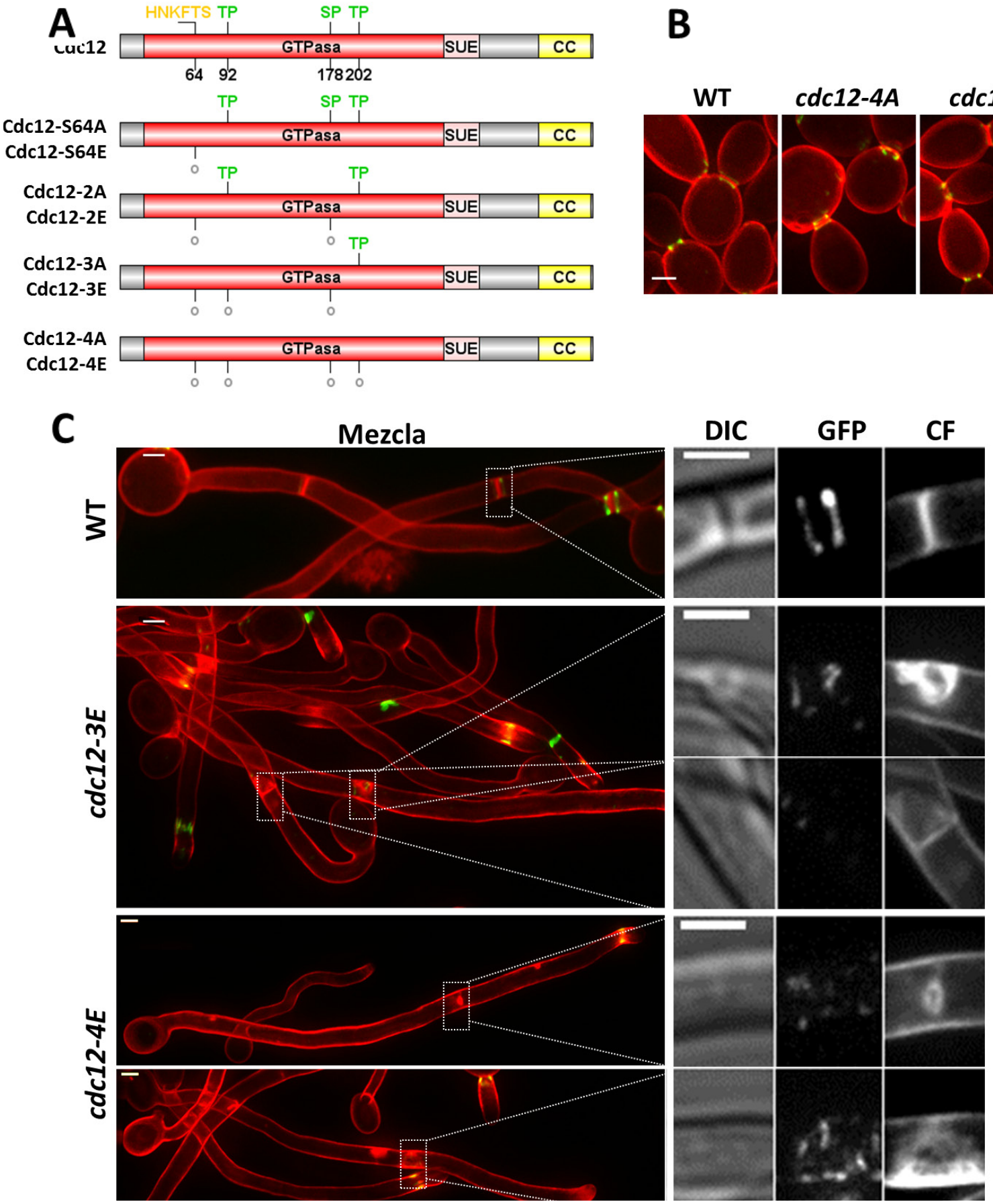

Figura 42. Análisis de los posibles sitios de fosforilación de Cdc12. (A). Esquema de las versiones fosfodeficientes y fosfomiméticas de la proteína Cdc12. (B). Fenotipo de las cepas $c d c 12-4 A$ y $c d c 12-4 E$ durante el crecimiento en forma de levaduras. Imágenes de fluorescencia de Cdc12-GFP (verde) y calcoflúor (rojo) de las cepas silvestre, cdc12-4A y cdc12-4E. Las imágenes son la proyección máxima de 10 planos adquiridos cada 0,4 $\mu \mathrm{m}$. Barra de escala, $2 \mu \mathrm{m}$. (C). Fenotipo de las cepas cdc12-3E y cdc12-4E durante el crecimiento en forma de hifas. Se muestran imágenes con la fluorescencia de Cdc12-GFP (verde) y calcoflúor (rojo) de las tres cepas. A la derecha, detalles de los septos: contraste interferencial (DIC), fluorescencia de Cdc12-GFP (GFP) y calcoflúor (CF). Las imágenes son la proyección máxima de 10 planos adquiridos cada 0,4 $\mu \mathrm{m}$. Barra de escala, 2 um. CDC12-GFP (OL1446), cdc12-3E (OL2221), cdc12-4A (OL2220), cdc12-4E (OL2222). 
Además, esta desorganización de los anillos de septinas coincidía con defectos en la síntesis del septo primario. Por tanto, la defosforilación de alguno de estos sitios (Ser64, Thr92 o Ser178) parece ser importante para la correcta formación del doble anillo de septinas durante el crecimiento hifal que confine la maquinaria de síntesis del septo y para que la citoquinesis se lleve a cabo correctamente. 



\section{CAPÍTULO IV: La anillina Int1 y la estabilidad del anillo de septinas.}

\subsection{Introducción y antecedentes.}

La anillina fue inicialmente identificada como una proteína de unión a F-actina en Drosophila melanogaster (Field y Alberts, 1995). Estudios posteriores demostraron que también se une a las septinas y a las miosinas de tipo II independientemente de la F-actina (Oegema et al., 2000; Kinoshita et al., 2002) y juega un papel en la coordinanción del ensamblaje de septinas y organización del anillo contráctil (revisado en Piekny y Maddox, 2010). En S. cerevisiae existe un homólogo de la anillina que se conoce como Bud4, aunque muestra un bajo grado de similitud de la secuencia de aminoácidos con ella (18\%). En C. albicans y en la levadura de fisión S. pombe también existen homólogos, denominados Int1 y Mid2 respectivamente (Fig. 43). Bud4, Int1 y Mid2 poseen en común un dominio PH (pleckstrin homology) en el extremo C-terminal y un dominio anillina (también llamado DUF1709)(Oegema et al., 2000). Si se comparan las proteínas de levaduras de gemación, Bud4 e Int1 tienen un $22 \%$ de identidad global, aunque el extremo C-terminal es más parecido ( $28 \%$ de identidad)(Fig. 43).

Se ha descrito que la función común de la anillina y de las proteínas de hongos relacionadas parece ser regular la citoquinesis (Piekny y Maddox, 2010), y en la mayoría de los casos, la función conlleva interacción con las septinas (Kinoshita et al., 2002). Por otro lado, Mid2 actúa para estabilizar el anillo de septinas durante citoquinesis (Berlin et al., 2003; Tasto et al., 2003) e Int1, el homólogo en C. albicans, puede interaccionar con septinas en S. cerevisiae (Gale et al., 2001).

En este Capítulo se describe la caracterización de la función de Int1 en el ensamblaje del anillo de septinas en C. albicans. Los resultados obtenidos demuestran que Int1 y Sep7 desempeñan una función aditiva en el mantenimiento de la integridad del cuello y en la segregación nuclear.

\subsection{Int1 colocaliza con las septinas en el presumible sitio de gemación y en el cuello entre} la célula madre e hija.

En primer lugar, se quiso estudiar la dinámica de Int1 y su localización durante el ciclo celular y para ello se llevaron a cabo ensayos de time-lapse en el microscopio. Con este fin, se marcó INT1 con GFP en el extremo 3' del gen y CDC10 con Cherry en un fondo silvestre. Las células incubaron en medio rico YEPD de forma asincrónica y se analizó la localización de ambas proteínas a lo largo del tiempo. Los resultados mostraron que Int1-GFP y Cdc10-Cherry colocalizaban durante todo el ciclo

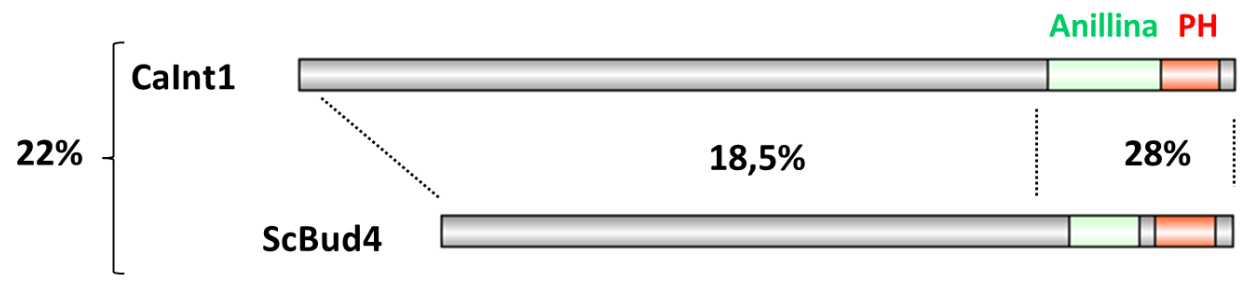

SpMid2

Figura 43. Int1, Bud4 y Mid2 presentan baja identidad. Representación esquemática de las proteínas Int1 (C. albicans), Bud4 (S. cerevisiae) y Mid2 (S. pombe). Regiones anillina (verde) y PH (rojo). Se indica el porcentaje de identidad (\%). 
celular, apareciendo primero en el presumible sitio de gemación y en el cuello como anillos sencillos que se duplican antes de la citoquinesis dando lugar a dos anillos independientes (Fig. 44). Cuando se estudió con más detalle este proceso, se observó que Int1 aparecía en el punto de gemación casi al mismo tiempo que las septinas (Fig. 44A) y que la duplicación de ambos anillos en citoquinesis era casi simultánea o había una ligera diferencia temporal, siendo la aparición del doble anillo de septinas inmediatamente posterior a la duplicación del anillo de Int1 (Fig. 44B-C). Además, la cuantificación de la intensidad media de los anillos sencillos y dobles de Cdc10-Cherry e Int1-GFP mostró que, tras la duplicación del anillo del homólogo de la anillina, la intensidad se mantenía bastante constate, mientras que las septinas comienzan a perder intensidad tras la remodelación del anillo (Fig. 44D).

Como Int1 y septinas colocalizaban durante todo el ciclo celular, se analizó si la localización de Int1 en el cuello dependía de las septinas. Para abordar esta idea, se estudió la localización de Int1 en mutantes de septinas como $c d c 10 \Delta \Delta$ y $\operatorname{sep} 7 \Delta \Delta$. Se marcó a INT1 en su extremo 3' con GFP tanto en la cepa silvestre como en las cepas $c d c 10 \Delta \Delta$ y $\operatorname{sep} 7 \Delta \Delta$. Cuando analizó la localización de Int1-GFP, se observó que seguía posicionándose en el cuello de las células $c d c 10 \Delta \Delta$ y sep $7 \Delta \Delta$ (Fig. 45A).

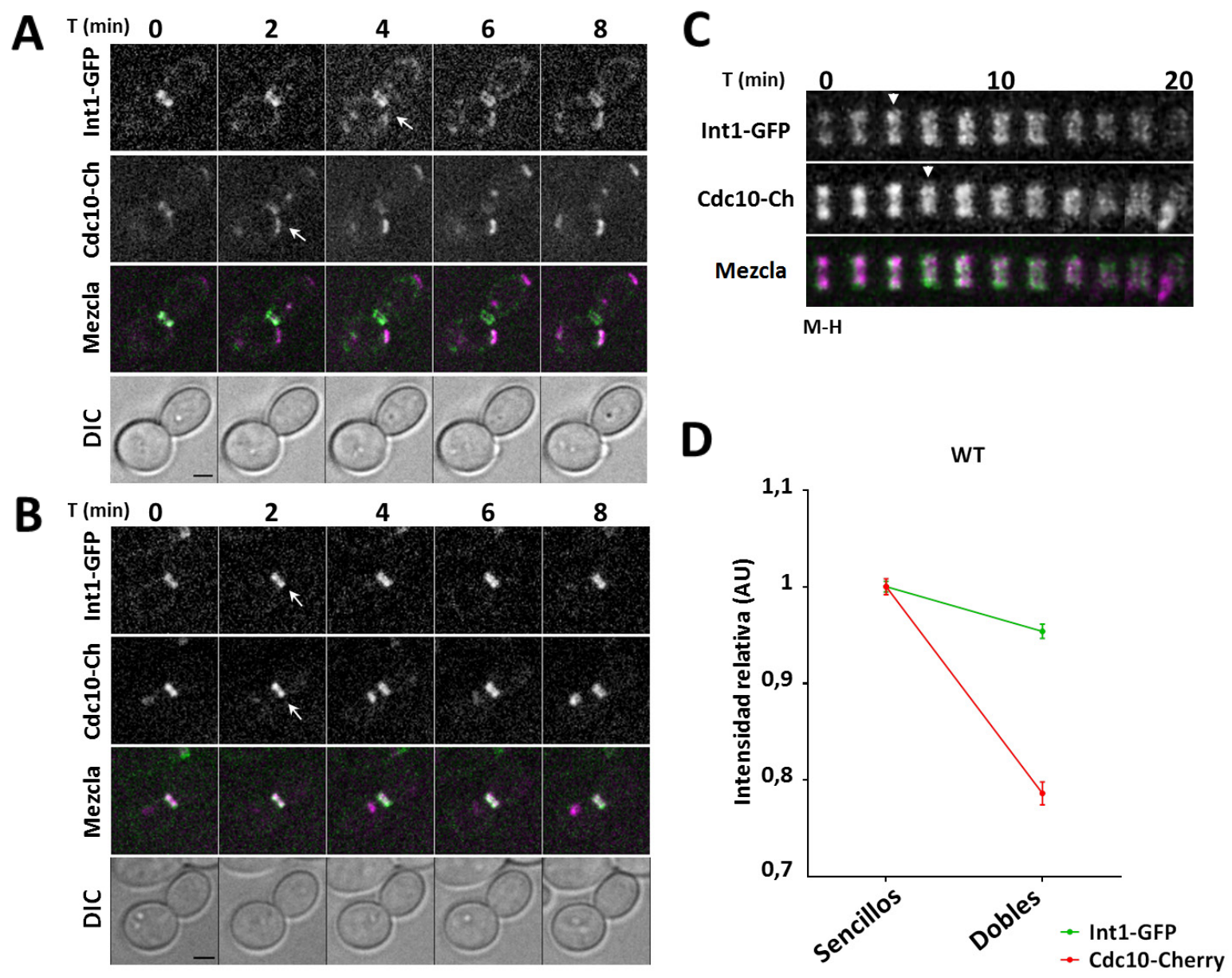

Figura 44. Int1 y Cdc10 colocalizan durante la mayor parte del ciclo celular. (A). Análisis por microscopía de contraste interferencial (DIC) y de fluorescencia en la cepa INT1-GFP CDC10-Ch (OL2262) durante la emergencia de la yema. Las imágenes son la proyección máxima de 3 planos adquiridos cada 0,4 $\mu \mathrm{m}$. Imágenes de contraste interferencial (DIC) y de fluorescencia de Int1-GFP y Cdc10-Cherry. Mezcla: Int1-GFP (verde) + Cdc10-Cherry (magenta). Las flechas señalan el momento de aparición de la proteína en el sitio de gemación. Barra de escala: $2 \mu \mathrm{m}$. (B). Localización durante la duplicación del anillo. Las flechas señalan el momento de la duplicación de los anillos. Barra de escala: 2 mm. (C). Detalle de los cuellos de gemación de las células mostradas en (B). M-H: Madre-Hija. Los triángulos señalan el momento de la duplicación de los anillos (D). La bajada de intensidad de Cdc10-Cherry es mayor que la de Int1-GFP tras la duplicación de los anillos. El gráfico muestra la intensidad media relativa de, al menos, cincuenta anillos en la cepa silvestre, con la SEM. Int1-GFP (verde), Cdc10-Cherry (rojo). 

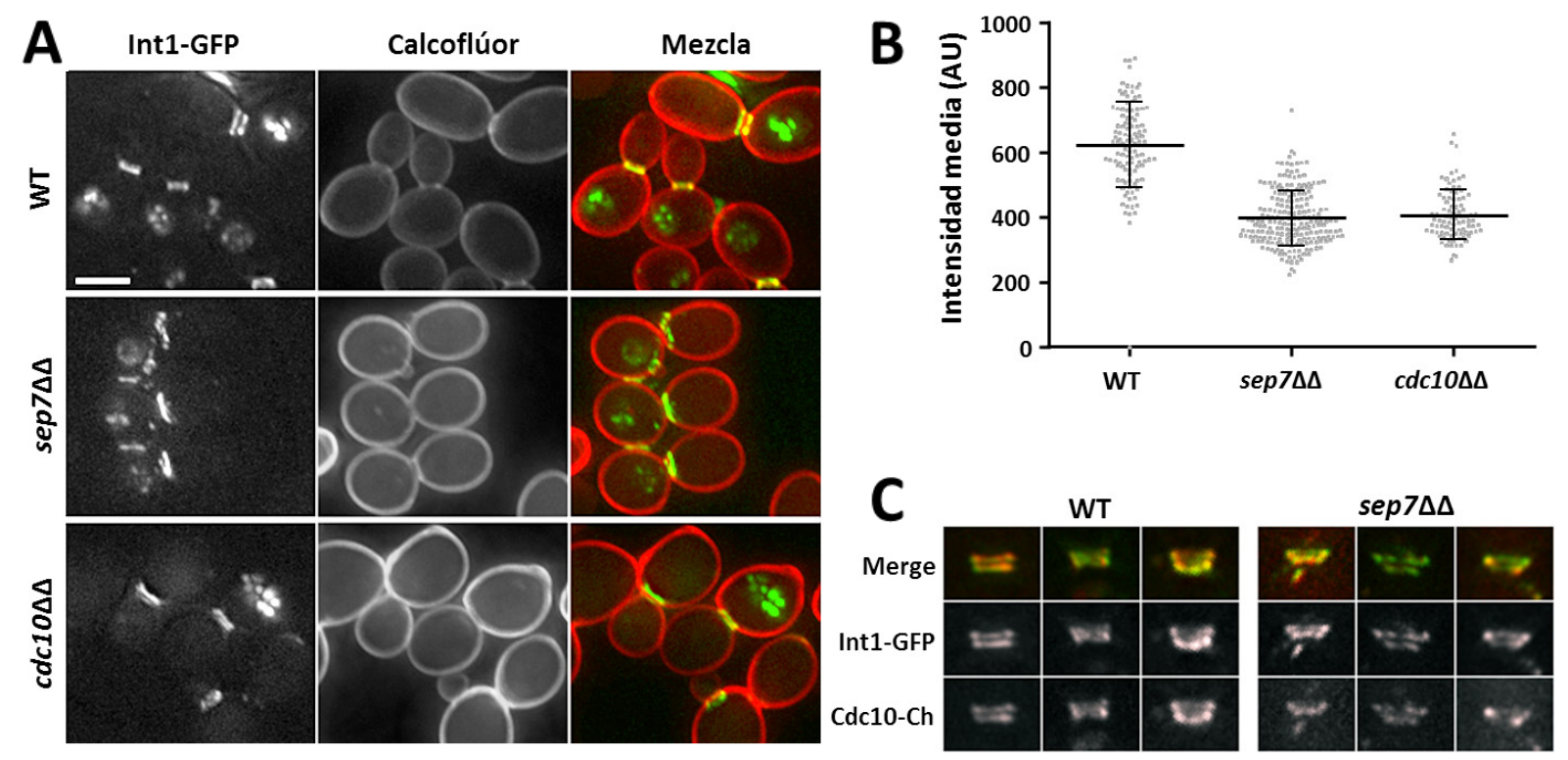

Figura 45. Localización de Int1 en mutantes de septinas. (A). Imágenes de fluorescencia de Int1-GFP y tinción con calcoflúor de las cepas silvestre (WT), sep7 $\Delta$ y $c d c 10 \Delta \Delta$. Mezcla: Int1-GFP (verde) + calcoflúor (rojo). Las imágenes son la proyección máxima de 10 planos adquiridos cada $0,4 \mu \mathrm{m}$. Barra de escala, $2 \mu \mathrm{m}$. (B). Int1 se localiza más pobremente en $\operatorname{sep} 7 \Delta \Delta$ y $c d c 10 \Delta \Delta$ que en el silvestre. El gráfico muestra la intensidad media de, al menos, noventa anillos en las tres cepas, con la desviación típica (SD). (C). Detalle de anillos duplicados de Int1-GFP y Cdc10-Cherry en WT y sep7 $\Delta \Delta$. Mezcla: Int1-GFP (verde)+Cdc10-Cherry (rojo). INT1-GFP (OL1611), INT1-GFP CDC10-Ch (OL2262), sep7D INT1-GFP CDC10-Ch (OL2310) y cdc10 $\triangle$ INT1-GFP (OL1644).

Sin embargo, cuando se cuantificó la intensidad de Int1-GFP en el cuello, se comprobó que había menos cantidad del homólogo de la anillina si faltaba alguna de las septinas estudiadas (Fig. 45B). Análisis más detallados de los anillos dobles de las septinas (Cdc10-Cherry) y de Int1 (Int1-GFP) en el mutante $\operatorname{sep} 7 \Delta \Delta$ revelaron que ambas proteínas colocalizaban en el cuello, pero se encontraban ligeramente desplazados hacia la célula hija en muchos casos (Fig. 45C).

\subsection{Los anillos de septinas son inestables tras su duplicación en el mutante int1 $\Delta \Delta$.}

Para analizar el fenotipo del mutante $\operatorname{int} 1 \Delta \Delta$ en $C$. albicans, se construyó una cepa en la que se sustituyeron las dos copias del gen INT1 por marcadores auxotróficos. En primer lugar, se comprobó que la cepa int $1 \Delta \Delta$ crecía normalmente como levadura en medio rico y medio mínimo, y que era capaz de responder a condiciones de filamentación y mantener el crecimiento polarizado de las hifas de forma similar a un silvestre. A continuación, se estudió la localización de las septinas en el mutante int1 $\triangle \triangle$ marcando el gen CDC10 con GFP. Las observaciones al microscopio tanto de levaduras como de hifas revelaron que, en ambos casos, no se observaban anillos dobles de Cdc10-GFP en el mutante int1 $\Delta \Delta$ (levaduras: Fig. 46A). Debido a que no parecía haber diferencias en ambos tipos de crecimiento, a partir de este momento todos los experimentos se centraron en el estado de levaduras.

Para caracterizar con más detalle este defecto, se usó la cepa int1 $\triangle$ CDC10-GFP para cuantificar los diferentes tipos de células (células sin anillo de septinas, con anillo sencillo y con anillo doble) en comparación con la cepa silvestre CDC10-GFP. Los resultados confirmaron que no existían células con anillos dobles de septinas en el mutante $\operatorname{int} 1 \Delta \Delta$, aunque el porcentaje de células con septo (determinado mediante la tinción de calcoflúor) era similar en el silvestre y en el mutante int1 $\Delta \Delta$ (Fig. 46B). Estos datos muestran que, a pesar de que los anillos de septinas desaparecen durante la citoquinesis, el mutante int $1 \Delta \Delta$ es capaz de formar el septo entre la célula madre e hija de forma similar al silvestre. 

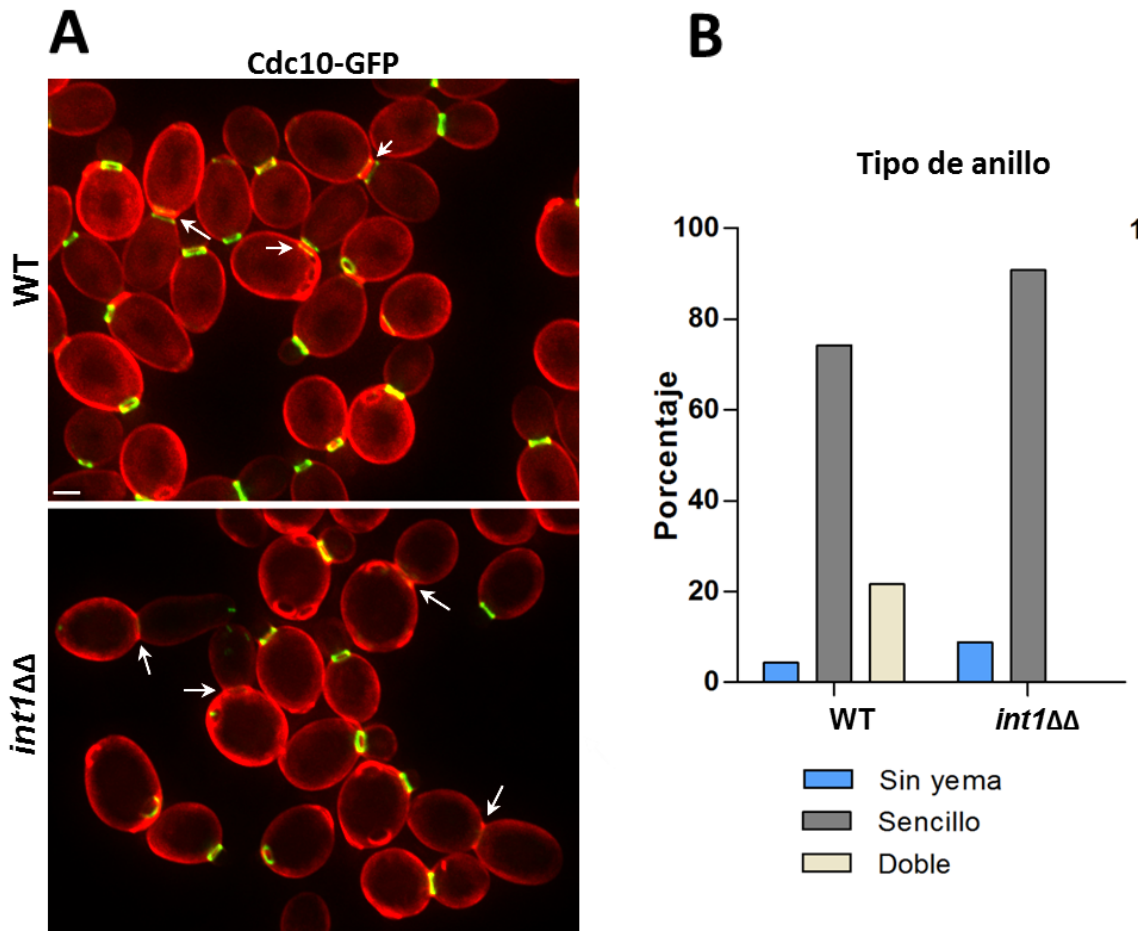

Septos

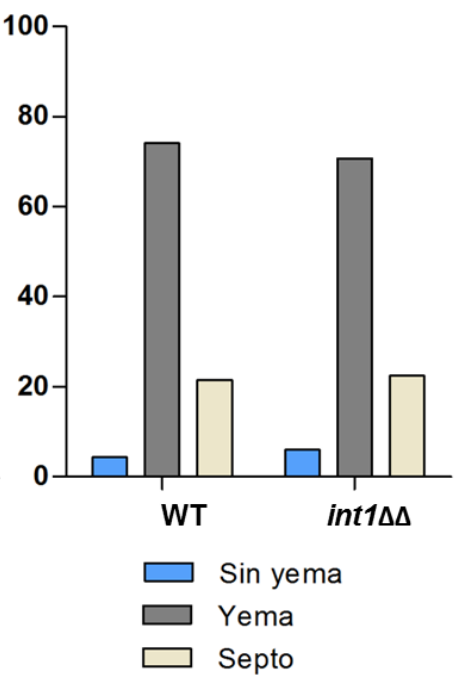

Figura 46. El mutante int1 $\Delta \Delta$ no presenta anillos dobles de septinas pero realiza la citoquinesis correctamente. (A). Fenotipo de las cepas WT e int1 $\Delta \Delta$ durante el crecimiento en forma de levaduras. Proyección máxima de 10 planos (cada 0,4 $\mu \mathrm{m}$ ) mostrando la fluorescencia de Cdc10-GFP (verde) y la tinción con calcoflúor (rojo). Barra de escala, $2 \mu \mathrm{m}$. Las flechas indican células con septo visible (según calcoflúor). (B). El mutante int1 $\Delta \Delta$ no presenta anillos dobles de septinas pero tiene un porcentaje de células con septo similar al silvestre. Los gráficos muestran: Izquierda, porcentaje promedio de células sin yema (azul), con anillo de septinas sencillo (gris oscuro) y con anillo doble (beis). Derecha, media de células sin yema (azul), con yema pequeña (gris oscuro) y con yema y septo (beis), según la tinción con calcoflúor. CDC10-GFP (OL2243) e int1 $\Delta \Delta$ CDC10-GFP (OL2316).

Mediante un análisis más exhaustivo, se comprobó que los anillos sencillos eran prácticamente indistinguibles entre la cepa silvestre y el mutante int1 $\Delta \Delta$ en cuanto a su estructura (Fig. 47A), aunque el diámetro era ligeramente mayor en células con yema grande (Fig. 47B). En cuanto a los anillos dobles, a pesar de que aparentemente no estaban presentes en el mutante int $1 \Delta \Delta$, cuando se forzaba el histograma de la señal de las septinas (Cdc10-GFP), era posible apreciar restos de fluorescencia a ambos lados del cuello (Fig. 47C), que en ningún caso formaban un verdadero anillo doble (Fig. 47D).

Para analizar con más detalle el momento en que se producía la desaparición del anillo de septinas, se realizaron experimentos de microscopía a lo largo del tiempo (time-lapse), mediante los que se siguieron los cambios del anillo de septinas (Cdc10-GFP) durante su duplicación en el mutante int1 $\Delta \Delta$, en comparación con un silvestre. Con estos experimentos se comprobó que en la cepa silvestre la duplicación del anillo de septinas precede ligeramente a la formación del septo y que, tras la duplicación, la intensidad de la señal de Cdc10-GFP comienza a decaer lentamente (Fig. 48, arriba). En el caso del mutante int $1 \Delta \Delta$, la intensidad de la señal decae más rápidamente, coincidiendo con el momento esperado de la duplicación, y los anillos se desorganizan, no llegando a observarse el anillo doble completamente formado (Fig. 48, abajo).

Durante estos experimentos también se observó que en algunas células, especialmente en células pequeñas sin yema, existían unos anillos de septinas, de un diámetro mucho menor que el anillo que se forma en el cuello, sueltos en el citoplasma (Fig. 49A), y que recuerdan a los descritos en A. gossypii (DeMay et al., 2009; Meseroll et al., 2013). Mediante microscopía a lo largo del tiempo se comprobó 

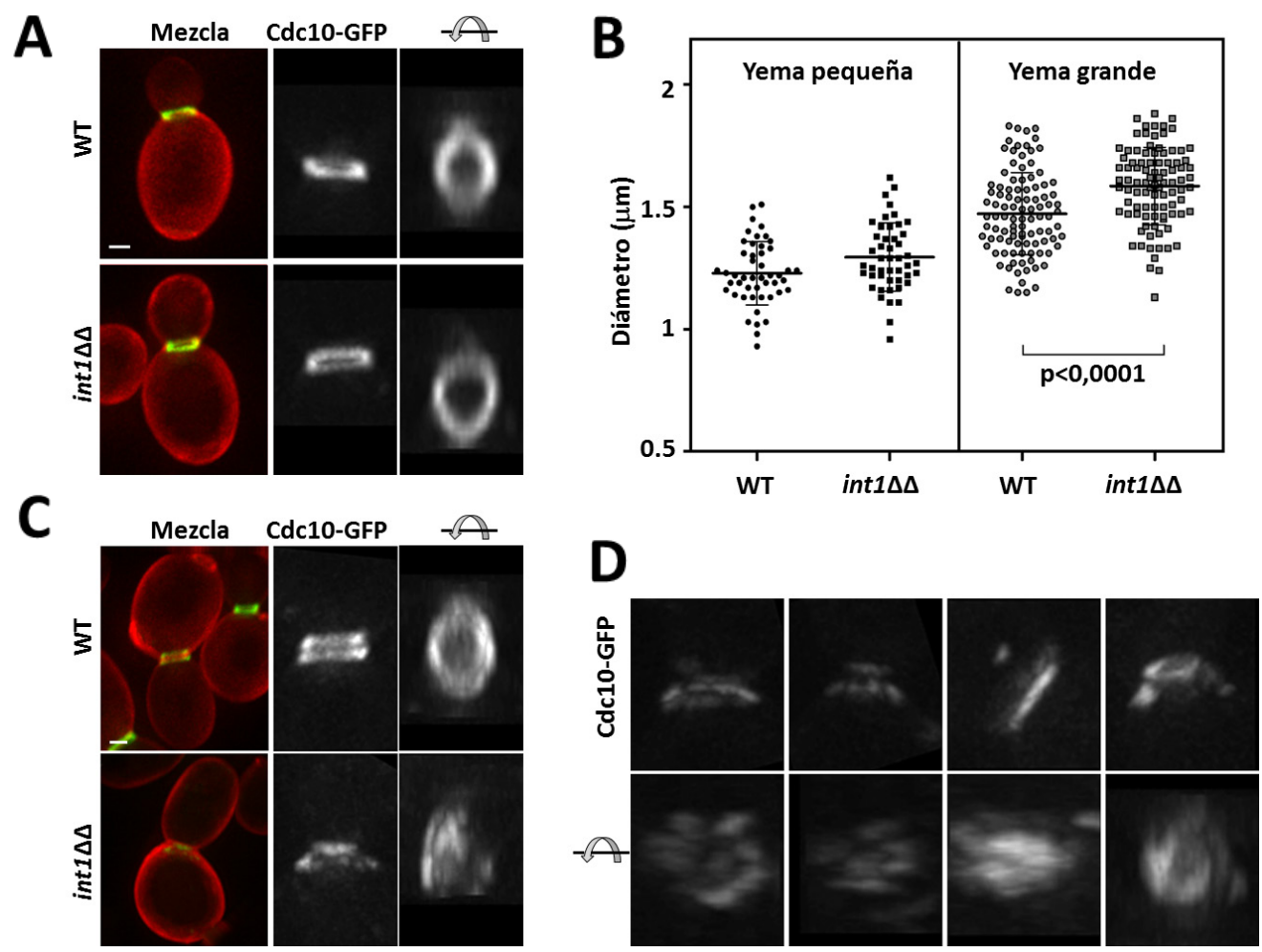

Figura 47. Anillos de septinas sencillos y dobles en el mutante int1 $\Delta \Delta$. (A). Anillos sencillos de septinas en las cepas CDC10-GFP (OL2243) e int1 $\triangle \triangle$ CDC10-GFP (OL2316) durante el crecimiento en forma de levaduras. Imágenes de fluorescencia de Cdc10-GFP (verde) y tinción con calcoflúor (rojo). (B). El mutante int1 $\Delta \Delta$ presenta anillos de septinas sencillos ligeramente más anchos que el silvestre. Los gráficos muestran el diámetro de los anillos sencillos de septinas en células de yema pequeña (izquierda) y de yema grande (derecha). (C). Anillos dobles de septinas en las mismas cepas. Imágenes de fluorescencia de Cdc10-GFP (verde) y tinción con calcoflúor (rojo). (D). Detalles de anillos dobles de septinas en int1 $\Delta \Delta$, con la proyección máxima (arriba) y girados $90^{\circ}$ (abajo). Se ha ajustado el histograma de las imágenes para permitir su visualización. En todos los paneles, las imágenes son la proyección máxima de 10 planos adquiridos cada 0,4 $\mu \mathrm{m}$. Barra de escala, $2 \mu \mathrm{m}$. .

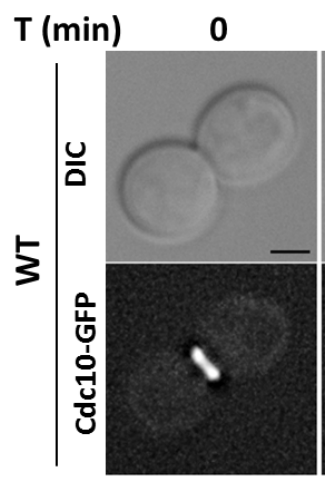

6
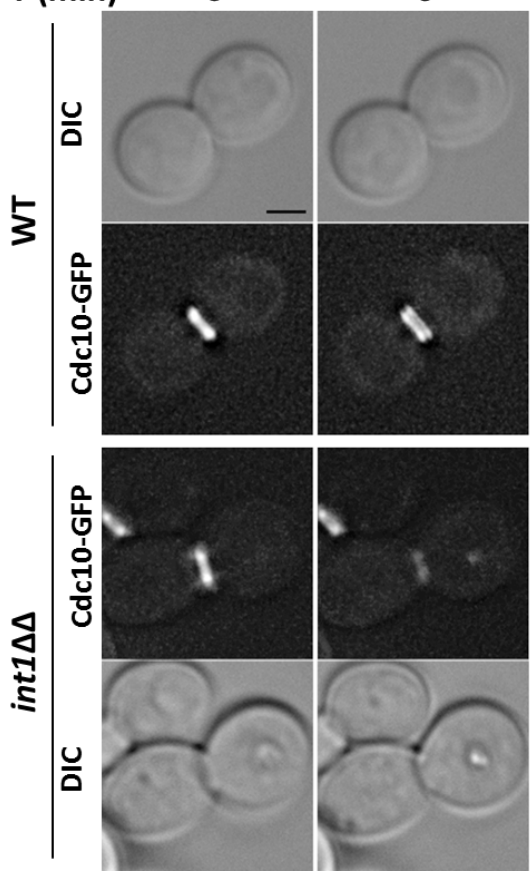

12
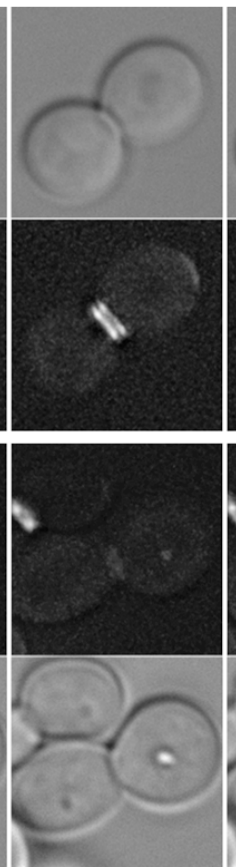

18
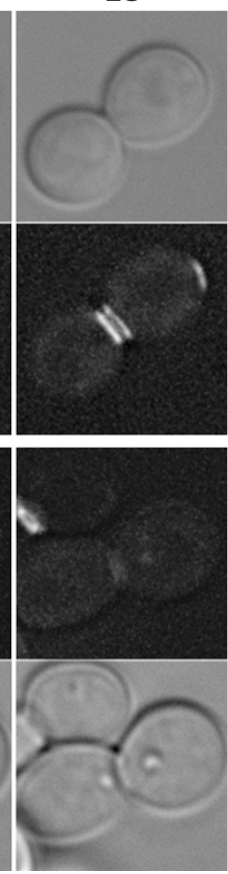

24
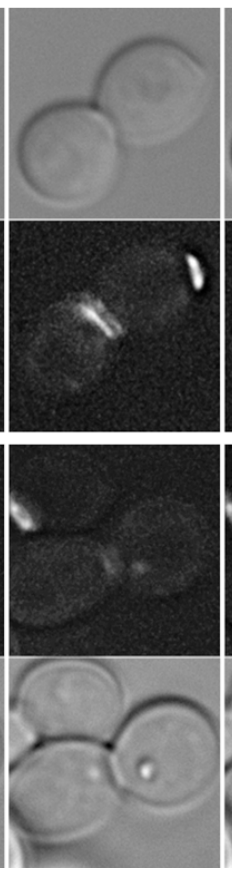

30
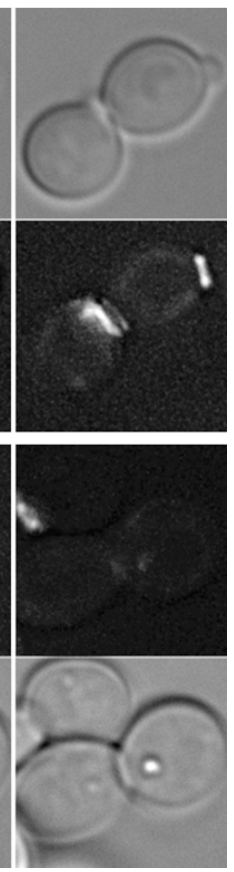

Figura 48. El anillo de septinas es inestable tras la duplicación en int1 $\Delta \Delta$. Transición anillo sencillo-duplicado en las cepas silvestre (WT) e int1 $\Delta \Delta$ en levaduras. Imágenes de contraste interferencial (DIC) y fluorescencia de Cdc10-GFP. Las imágenes son la proyección máxima de 10 planos adquiridos cada 0,4 $\mu \mathrm{m}$. Barra de escala, $2 \mu \mathrm{m}$. CDC10-GFP (OL2243) e int1 $\Delta \Delta$ CDC10-GFP (OL2316). 
A

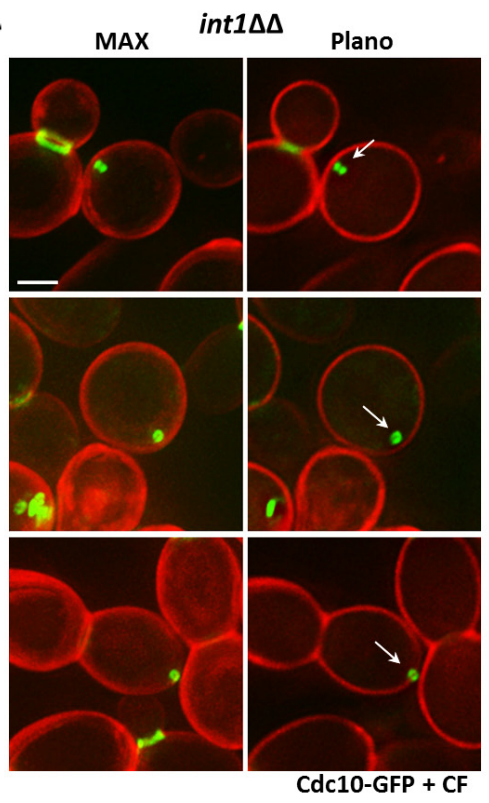

B
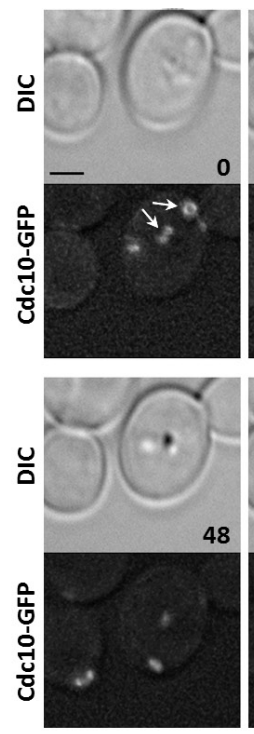

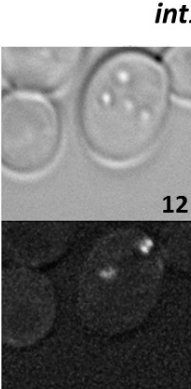

$\operatorname{int1\Delta \Delta }$

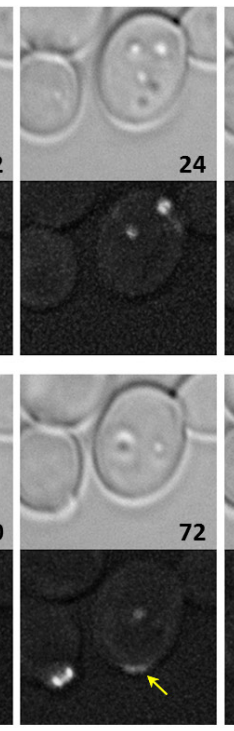

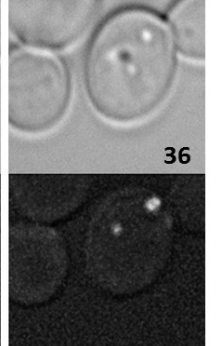

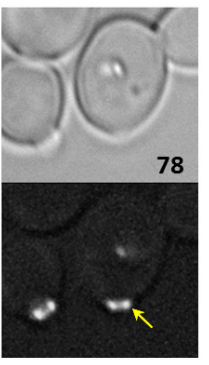

Figura 49. Anillos citoplásmicos de septinas en las células int1 $\Delta \Delta$. (A). Pequeños anillos citoplásmicos de septinas en células sin yema de int1 $\Delta \Delta$. Imágenes de fluorescencia de Cdc10-GFP (verde) y tinción con calcoflúor (rojo). Se muestra la proyección máxima (MAX) y el plano central. Las flechas blancas señalan los anillos citoplásmicos. Barra de escala, $2 \mu \mathrm{m}$. (B). El mutante int1 $\Delta \Delta$ presenta dificultad para localizar las septinas en el sitio de gemación. Imágenes de contraste interferencial (DIC) y fluorescencia de Cdc10-GFP (proyección máxima) a los tiempos indicados. Las flechas blancas señalan los anillos citoplásmicos y las amarillas indican los anillos de septinas en el sitio de gemación. Barra de escala, $2 \mu \mathrm{m}$. CDC10-GFP (OL2243) e int1 $\Delta \Delta$ CDC10-GFP (OL2316).

que estos anillos permanecían en el citoplasma por tiempo variable hasta que conseguían asociarse a la membrana y ensamblar un anillo de proporciones normales, dando lugar a una nueva yema (Fig. 49B). Esta observación podría explicar el aumento en el número de células sin yema que presenta el mutante int $1 \Delta \Delta$ respecto a la cepa silvestre ( $8,8 \%$ frente a $4,4 \%$, respectivamente, Fig. $46 \mathrm{~B})$. Estos

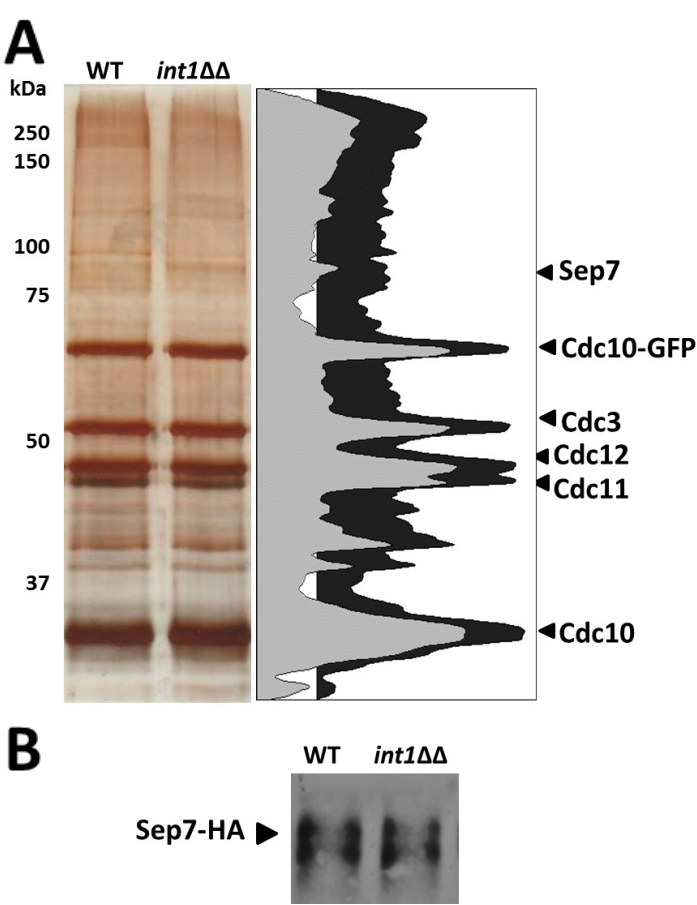

datos no hacen más que evidenciar que Int1 desempeña un papel en la estabilización del anillo de septinas tras su duplicación y que también contribuye al anclaje de las septinas en el nuevo punto de gemación.

\subsection{La composición de los anillos de septinas no se altera en el mutante int $1 \Delta \Delta$.}

Dado que la estabilidad de los anillos de septinas tras la duplicación estaba reducida en el mutante int $1 \Delta \Delta$ y que la localización de Int1-GFP en el cuello se veía reducida cuando faltaban algunos componentes del anillo de septinas (Cdc10 o Sep7), se estudió la composición de los anillos de septinas en el mutante int $1 \Delta \Delta$. Para ello, se purificaron los anillos de septinas usando anticuerpos anti-GFP en fondos silvestre e int1 $\Delta \Delta$ que contenían Cdc10-GFP. Posteriormente, los extractos proteicos

Figura 50. Composición de los anillos de septinas en el mutante int1 $\Delta \Delta$. (A). Extractos de proteínas de las cepas silvestre (WT) e int1 $\Delta \Delta$ con Cdc10-GFP se inmunoprecipitaron con anticuerpos anti-GFP, se separaron por SDS-PAGE y se tiñeron con nitrato de plata. A la derecha, densitograma de la cepa silvestre (gris claro) e int1 $\Delta \Delta$ (gris oscuro). (B). Sep7 es fosforilada en ambas cepas. Análisis de extractos celulares de levaduras de la cepas WT e int1 $\Delta \Delta$ marcadas con Sep7-HA. Los extractos se separaron por SDS-PAGE con $40 \mu \mathrm{M}$ Phos-Tag y se analizaron con anticuerpos anti-HA. INT1-HA CDC1O-GFP (OL2317), int1 $\Delta \Delta$ CDC10-GFP (OL2316), SEP7-HA (OL2507), int1 $\triangle$ SEP7-HA (OL2506). 
purificados se separaron en un gel de acrilamida que se reveló con la tinción de plata. Este gel mostró una ligera diferencia en el patrón de bandas en la región donde debería migrar Sep7 entre ambas cepas (Fig. 50A). Para analizar esta diferencia con mayor resolución y especificidad, se usaron geles de Phos-Tag para separar extractos de células con Sep7-HA (tanto silvestre como int $1 \Delta \Delta$ ). Sin embargo, los resultados obtenidos no mostraron cambios de movilidad en las bandas de dicha septina (Fig. 50B).

\subsection{El mutante int1 $\Delta \Delta$ presenta una contracción normal del AMR (Mlc1), así como una} localización silvestre del polarisoma (Spa2), el exocisto (Sec3) y la kinasa Gin4.

Dado que en las células del mutante $\operatorname{int} 1 \Delta \Delta$ no se observaban anillos de septinas duplicados, se quiso estudiar si esto condicionaba el ensamblaje del anillo contráctil de actomiosina (AMR). En otros organismos se ha descrito que el collar de septinas funciona como una plataforma para el ensamblaje del AMR (Bi et al., 1998; Lippincott y Li, 1998; Gladfelter et al., 2001) y tras la duplicación, el doble anillo de septinas lo encierra a modo sándwich.

Para estudiar el AMR, se marcó la cadena ligera de la miosina Mlc1 con Cherry en el extremo C-terminal en fondos silvestre e int1 $\Delta \Delta$ (que ya contenían Cdc10-GFP). Las cepas se fijaron al fondo de cámaras iBIDI para poder estudiarlas a lo largo del tiempo con el microscopio confocal. En el silvestre se observó que el AMR se ensamblaba sobre el anillo de septinas sencillo, y el tiempo medio del ensamblaje era de 11,8 \pm 0,6 min. Una vez ensamblado, comenzaba su contracción, coincidiendo casi simultáneamente con la duplicación del anillo de septinas. El tiempo medio de contracción fue estimado en $4,1 \pm 0,2 \mathrm{~min}$ (Fig. 51A). Cuando se analizaron células del mutante int $1 \Delta \Delta$, se comprobó que el AMR también se ensamblaba sobre el anillo de septinas sencillo, aunque el tiempo medio de ensamblaje fue ligeramente superior, unos 15,4 $\pm 0,6 \mathrm{~min}$. A pesar de este ligero retraso, una vez que se iniciaba su contracción, ésta se producía de forma similar a la de la cepa silvestre $(5,1 \pm 0,2 \mathrm{~min})$, indicando que la ausencia de Int1 no altera sustancialmente la dinámica de contracción del AMR. También se comprobó que la intensidad de la señal de Cdc10-GFP comenzaba a disminuir durante el tiempo de ensamblaje del anillo (entre -5 y 0 min), desapareciendo casi completamente al inicio de la contracción. Estas observaciones quedan perfectamente reflejadas en la gráfica mostrada en la Figura 51A. Estos resultados indican que, a pesar de la ausencia de anillos de septinas dobles, las células int $1 \Delta \Delta$ son capaces de contraer el AMR de forma similar a la cepa silvestre, aunque se produce un ligero aumento en su tiempo de ensamblaje.

Cuando se utilizó el microscopio Deltavision para aumentar la resolución espacial, se comprobó que no existían graves defectos en el AMR del mutante int1 $\Delta \Delta$ (Fig. 51B). De hecho, reconstrucciones $3 D$ de los cuellos de células int $1 \Delta \Delta$ muestran un AMR bien formado, aunque está adherido a los restos del anillo de septinas que quedan después de su duplicación. Por tanto, parece que en células int1 $\Delta \Delta$ el anillo sencillo de septinas es suficiente para que se ensamble un AMR completamente funcional, que se contrae a pesar de la desaparición del anillo de septinas, por lo que la citoquinesis termina satisfactoriamente. Estos resultados están en consonancia con los recuentos del número de septos en la cepa silvestre y en int1 $\Delta \Delta$ (Fig. 46B), que ya indicaban que la citoquinesis se llevaba a cabo en el mutante de forma indistinguible de un silvestre.

Teniendo en cuenta que las septinas constituyen un andamio para la localización en el cuello de otras proteínas (Wloka et al., 2011) y que en S. cerevisiae se ha descrito que durante la citoquinesis los anillos de septinas a ambos lados del AMR actúan como barreras que definen un compartimento 


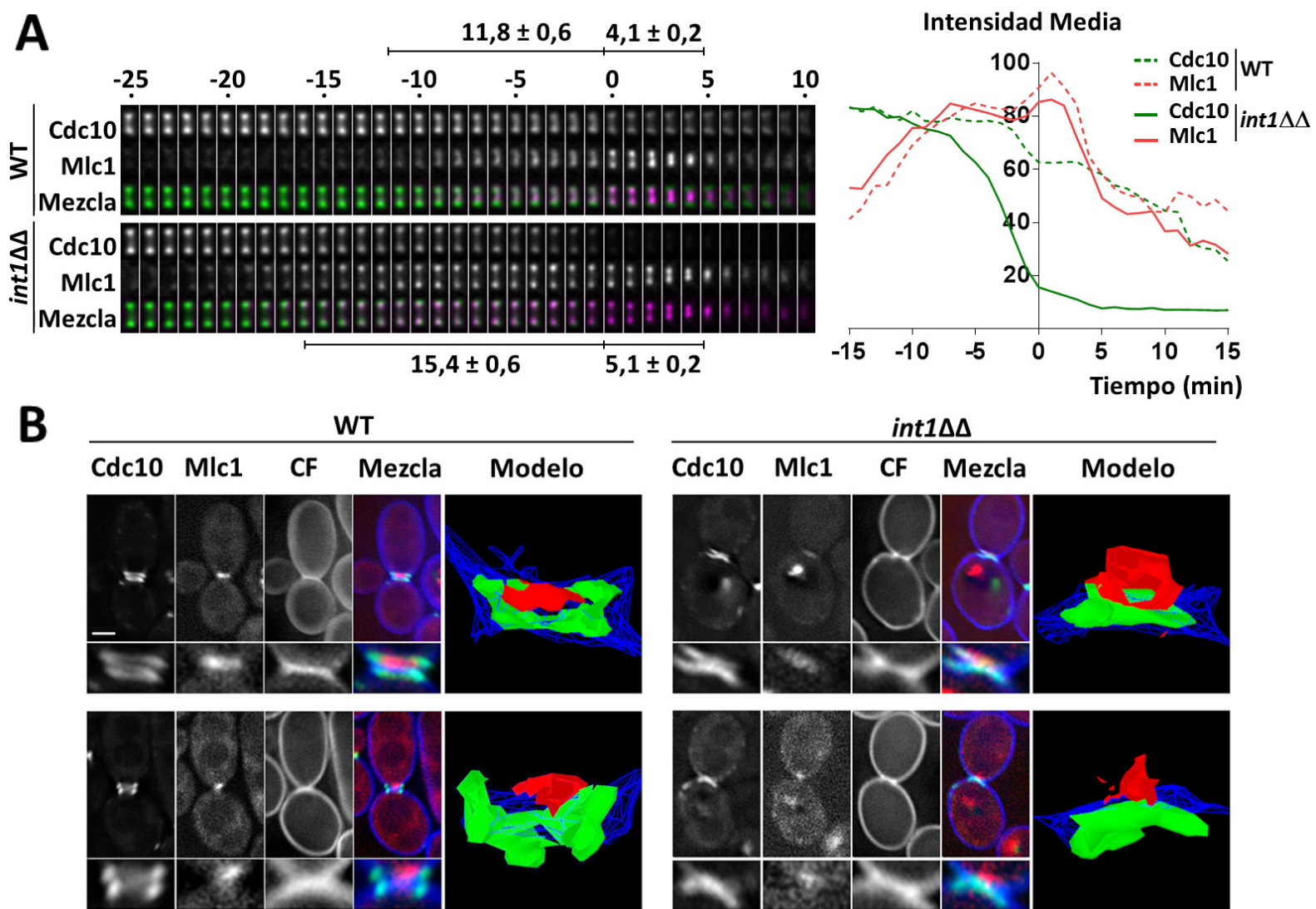

Figura 51. El mutante int1 $\Delta \Delta$ lleva a cabo una correcta citoquinesis. (A). La dinámica de contracción del AMR es similar en el silvestre e int1 $\Delta \Delta$. Imágenes de fluorescencia (proyección máxima de 10 planos cada 0,4 $\mu \mathrm{m}$ ) de Cdc10-GFP (verde) y Mlc1-Cherry (magenta). Mezcla: Cdc10-GFP+Mlc1-Cherry. Derecha: Intensidad media de los anillos de Cdc10-GFP (verde) y Mlc1-Cherry (rojo) en el WT (línea discontinua) e int1 $\Delta \Delta$ (línea continua). El tiempo cero es el inicio de la contracción del AMR. (B). Detalle de la zona del cuello. Imágenes de fluorescencia de Cdc10-GFP (verde), Mlc1-Cherry (rojo) y calcoflúor (azul). Mezcla: Cdc10-GFP+Mlc1-Cherry+calcoflúor. Barra de escala, $2 \mu \mathrm{m}$. CDC10-GFP MLC1-Ch (OL2338) e int1 $\triangle \triangle$ CDC10-GFP MLC1-Ch (OL2328).

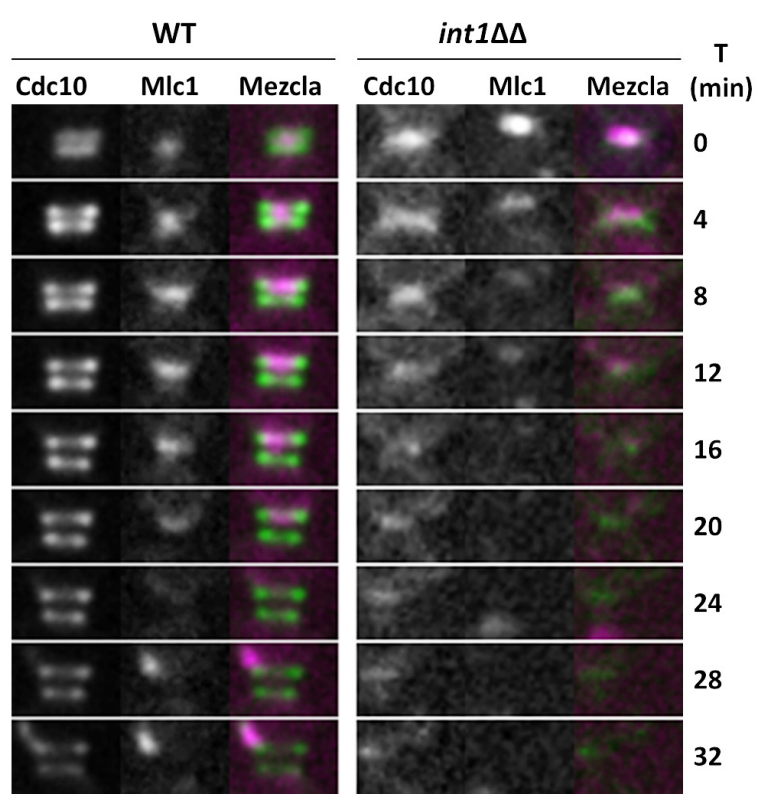

Figura 52. El polarisoma no queda confinado en la zona del cuello en el mutante int1 $\Delta \Delta$. Imágenes de fluorescencia de Cdc10-GFP y Mlc1-Cherry. Mezcla: Cdc10-GFP (verde)+Mlc1-Cherry (magenta). Las imágenes son la proyección máxima de 10 planos adquiridos cada $0,4 \mu \mathrm{m}$. La célula hija se dispone arriba y la madre, abajo. CDC10-GFP MLC1-Ch (OL2338) e int1 $\triangle A$ CDC10-GFP MLC1-Ch (OL2328). especializado de la célula alrededor del sitio de citoquinesis (Dobbelaere y Barral, 2004), se analizó qué ocurría en el cuello del mutante int $1 \Delta \Delta$ tras la contracción del AMR. Además de ser un componente del AMR, Mlc1 forma parte del polarisoma, asociándose con este complejo en las zonas de crecimiento polarizado (Crampin et al., 2005). En la cepa silvestre, tras la desaparición del AMR (T0 en la Fig. 52), Mlc1 se localiza durante un cierto tiempo entre los anillos de septinas (T4-20), desplazado asimétricamente hacia el lado de la célula hija. Posteriormente, desaparece de esta región y comienza a acumularse en el nuevo punto de gemación (T28-32). A diferencia de lo que ocurre en el silvestre, en las células int $1 \Delta \Delta$ no se observa esta dinámica, apareciendo Mlc1 de forma difusa (Fig. 52). Por tanto, la ausencia de Int1 produce defectos en la localización del polarisoma en el cuello tras la citoquinesis. 


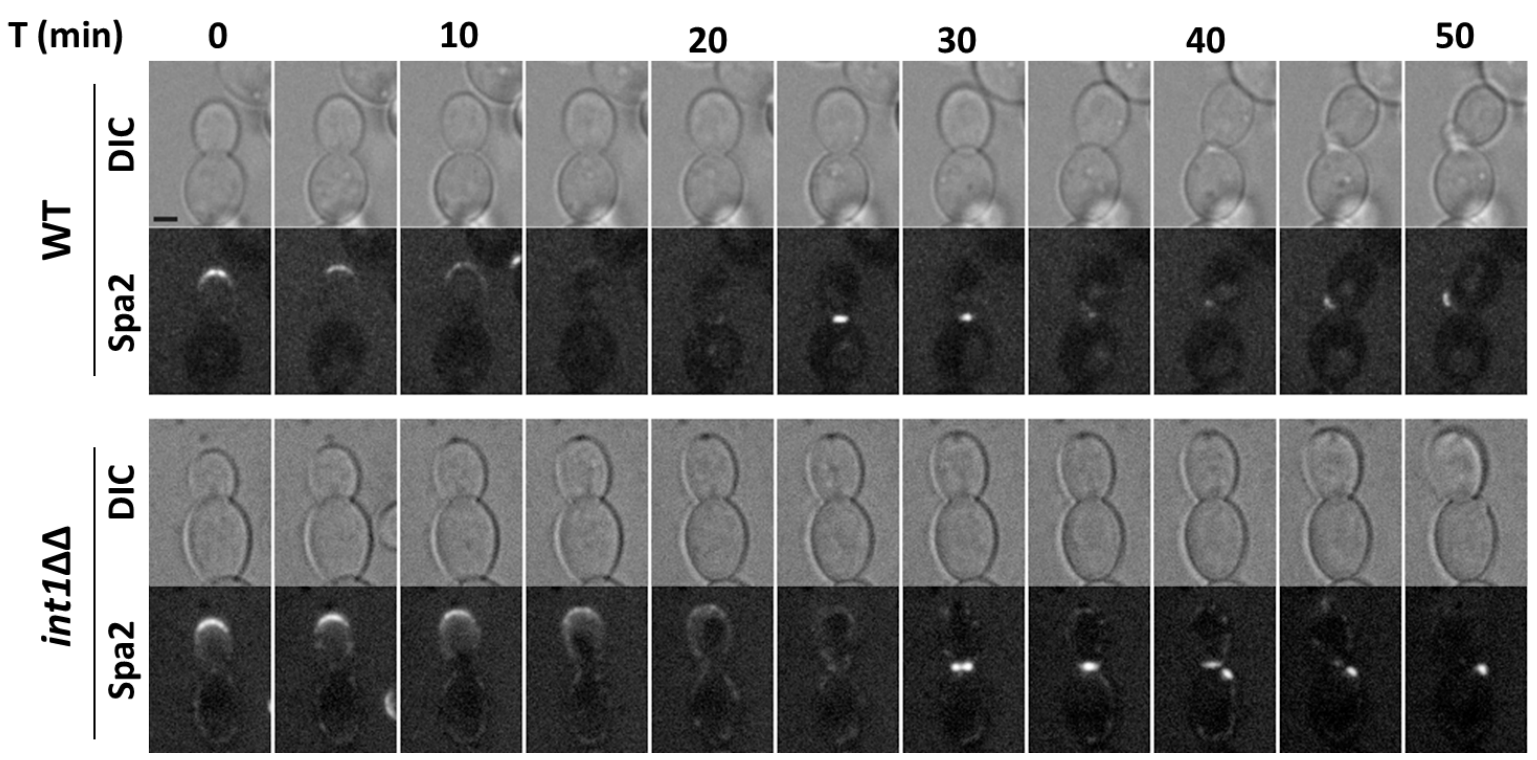

Figura 53. Spa2 se localiza correctamente en el mutante int1 $\Delta \Delta$. Análisis por microscopía (time-lapse) de contraste interferencial (DIC) y de fluorescencia de Spa2-GFP en células de levaduras de las cepas silvestre (WT) e int1 $\Delta \Delta$. Las imágenes de fluorescencia son la proyección máxima de 10 planos adquiridos cada 0,4 $\mu \mathrm{m}$ Barra de escala: $2 \mu \mathrm{m}$. SPA2-GFP (OL2349) e int1 $\triangle$ SPA2-GFP (OL2354).

Para corroborar estos resultados y comprobar si la localización del polarisoma estaba alterada en otros momentos del ciclo celular, se marcó la proteína Spa2, otro de los componentes del polarisoma con GFP. Los resultados mostraron que Spa2 presentaba una localización normal en el mutante int $1 \Delta \Delta$, apareciendo en el córtex de las yemas pequeñas/medianas, localizándose posteriormente en el cuello y finalmente en el nuevo punto de gemación (Fig. 53).

Finalmente, también se estudiaron otras proteínas cuya localización depende de las septinas, como Sec3, uno de los componentes del exocisto (Li et al., 2007) y la kinasa Gin4. No se observaron defectos aparentes en la localización de $\operatorname{Sec} 3$ en la cepa int1 $\Delta \Delta$ (datos no mostrados). En el caso de Gin4-GFP, la proteína se localizaba en el anillo de septinas sencillo y desaparecía de la zona del cuello en el momento de la duplicación del anillo de septinas en la cepa silvestre (Fig. 54). En el mutante int1 $\Delta \Delta$, también desaparecía en el mismo momento, coincidiendo con el momento en que se desensamblan las septinas del cuello en este mutante.

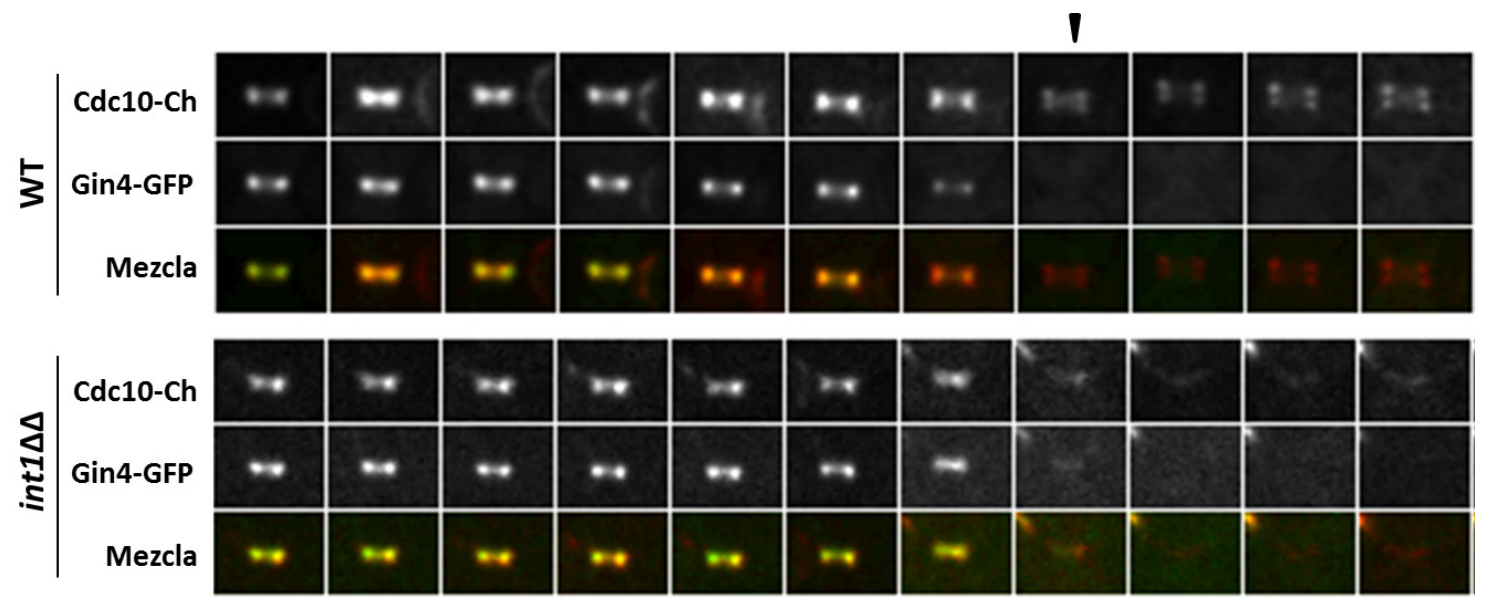

Figura 54. Gin4 se localiza correctamente en el mutante int1 $\Delta \Delta$. Análisis por microscopía (time-lapse) de fluorescencia de la septina Cdc10-Cherry (rojo) y la kinasa Gin4-GFP (verde) en levaduras de las cepas WT e int1 $\Delta \Delta$. Mezcla: Cdc10-Cherry+Gin4-GFP. Las imágenes son la proyección máxima de 10 planos adquiridos cada $0,4 \mu \mathrm{m}$. El triángulo señala la división del anillo de septinas. Barra de escala: $2 \mu \mathrm{m}$. GIN4-GFP CDC10-Ch (OL2393) e int1 $\triangle \triangle$ GIN4-GFP CDC10-Ch (OL2389). 


\subsection{La funcionalidad de Int1 reside mayoritariamente en el extremo C-terminal.}

Estudios previos en S. cerevisiae demostraron que la parte de Bud4 necesaria para asociarse con las septinas se localiza en la región central mientras que la región C-terminal relacionada con anillina no está implicada en esta interacción (Wu et al., 2015). Para tratar de identificar qué dominios de Int1 eran necesarios para su función se construyeron dos versiones de la proteína, una a la que se le eliminaba la región N-terminal (aa 1- 1134) y otra a la cual se le suprimía el extremo C-terminal (aa 1134-1711) que contenía los dominios conservados anillina y $\mathrm{PH}$. Estas construcciones se denominaron int1- $\Delta N$ e int1- $\Delta C$ respectivamente (Fig. 55A). Una vez comprobado por Western Blot que estas versiones de Int1 se expresaban correctamente (datos no mostrados), se hicieron ensayos de gota para analizar la viabilidad de las nuevas cepas. Sorprendentemente, después de 2 días de incubación en medio rico, el mutante int1- $\Delta C$ presentaba colonias rugosas a $37^{\circ} \mathrm{C}$ (no así a temperaturas más bajas), a diferencia del mutante nulo y del int1- $\Delta N$. Además, tanto el mutante int1 $\Delta \Delta$ como int1- $\Delta N$ presentaban un ligero defecto en el crecimiento a $21^{\circ} \mathrm{C}$ (Fig. 55B).

Para comprobar la localización de las versiones mutantes de Int1, se marcaron con GFP en el extremo C-terminal y se comprobó que ambas versiones aparecían en el cuello de gemación y colocalizaban con
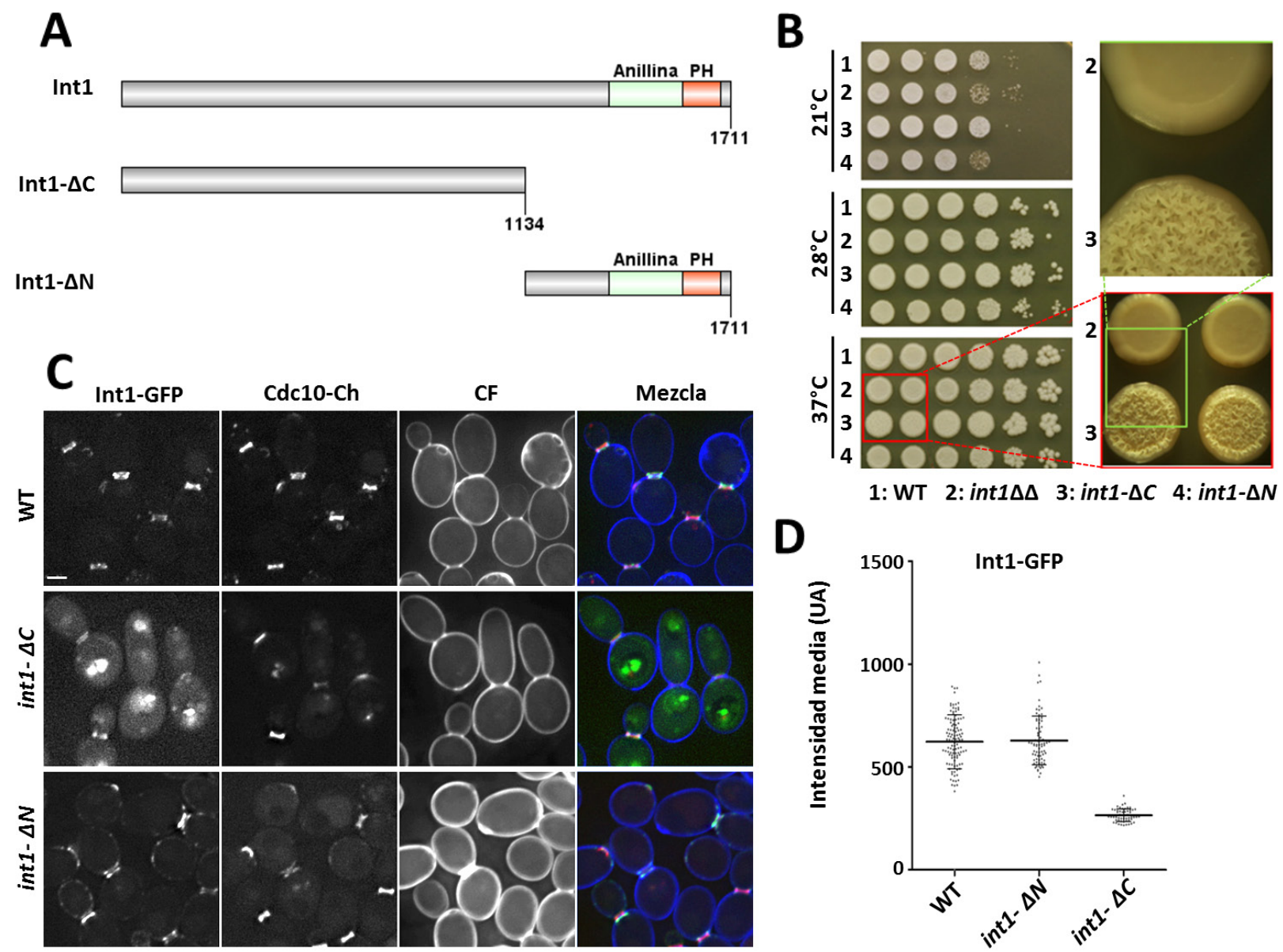

Figura 55. Truncamientos de Int1. (A). Esquema de las proteínas Int1, Int1- $\Delta \mathrm{C}$ e Int1- $\Delta N$. Regiones anillina (verde) y PH (rojo). (B). Crecimiento de las cepas WT (1), int1 $\Delta \Delta$ (2), int1- $\Delta C$ (3) e int1- $\Delta N$ (4) a diferentes temperaturas. (C). Localización de Int1-GFP (verde), Cdc10-Cherry (rojo) y calcoflúor (azul) en las cepas silvestre (WT), int1- $\Delta \mathrm{C}$ e int1- $\Delta \mathrm{N}$ (proyección máxima de 3 planos separados 0,4 $\mu \mathrm{m}$ ). Mezcla: Int1-GFP+Cdc10-Cherry+calcoflúor. Barra de escala: $2 \mu \mathrm{m}$. (D). Int1- $\Delta C$ se localiza más pobremente en el cuello que Int1 o Int1- $\Delta N$. Intensidad media de, al menos, cincuenta anillos en las mismas cepas con la desviación típica (SD). int1 $\Delta \Delta$ (OL2314), int1- $\Delta C$ (OL2162), int1- $\Delta N$ (OL2164), INT1-GFP (OL1611), int1- $\Delta C-$ GFP (OL2273), int1- $\triangle N$-GFP (OL2274), INT1-GFP CDC10-Ch (OL2262), int1- $\triangle$ C-GFP CDC10-Ch (OL2278), int1- $\triangle N$-GFP CDC10-Ch (OL2280). 
las septinas (Fig. 55C), pero la intensidad de Int1- $\triangle$ C-GFP en el cuello era significativamente inferior a la de Int1- $\Delta$ N-GFP o Int1-GFP (Fig. 55D). Por tanto, la región C-terminal de Int1 parece necesaria para su correcta localización en el cuello.

A continuación, para estudiar la duplicación del anillo de septinas en los fondos genéticos int1- $\Delta N$ e int1- $\Delta C$, se marcó la septina Cdc10 con GFP en el extremo carboxilo y se observaron las células al microscopio (Fig. 56A). Al igual que en el mutante int $1 \Delta \Delta$, se hicieron recuentos de células según el tipo de anillo de septinas (sin anillo, con anillo sencillo o con anillo doble) y según si presentaban o no septo. Se comprobó que el mutante int1- $\Delta C$ era similar al mutante nulo int1 $\Delta \Delta$, ya que no se observaban células con anillos dobles de septinas (sólo restos), aunque el número de células septadas era parecido al del silvestre (Fig. 56B). Por su parte, en el mutante int1- $\Delta N$ era posible observar anillos dobles de septinas, pero de menor intensidad que en el silvestre. Además, presenta un porcentaje ligeramente superior de células sin yema (Fig. 56B). Adicionalmente, se hizo un recuento del número de anillos de septinas dobles bien formados frente a los que habían quedado como restos mal ensamblados o carecían de él en las cuatro cepas. Se comprobó que en las células int $1 \Delta \Delta$ e int1- $\Delta C$ no existían anillos

A

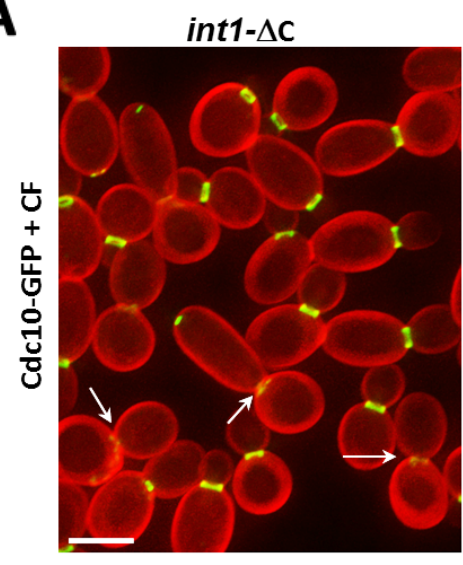

B

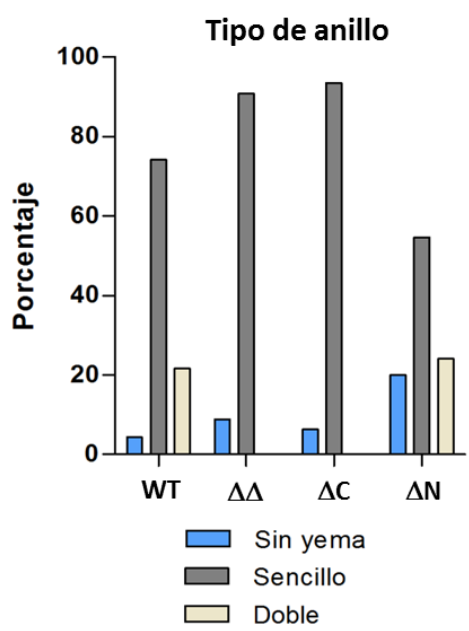

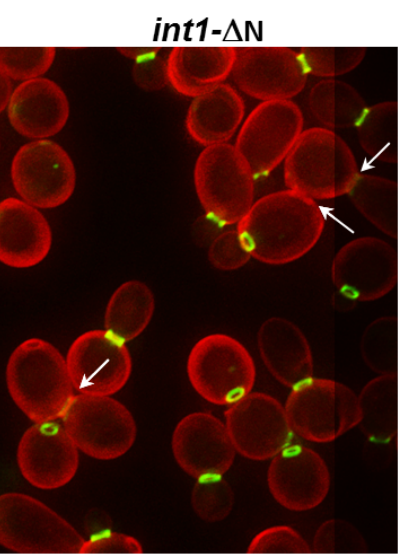

Septos

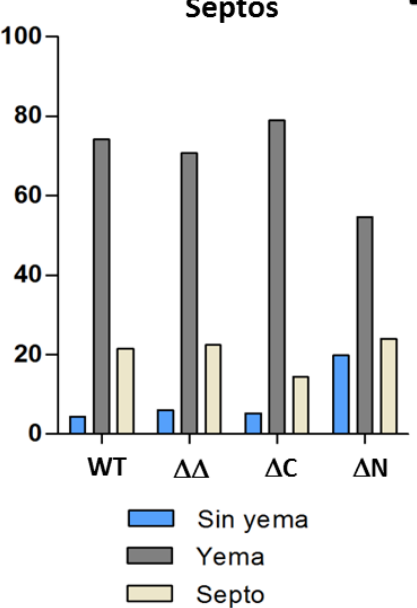

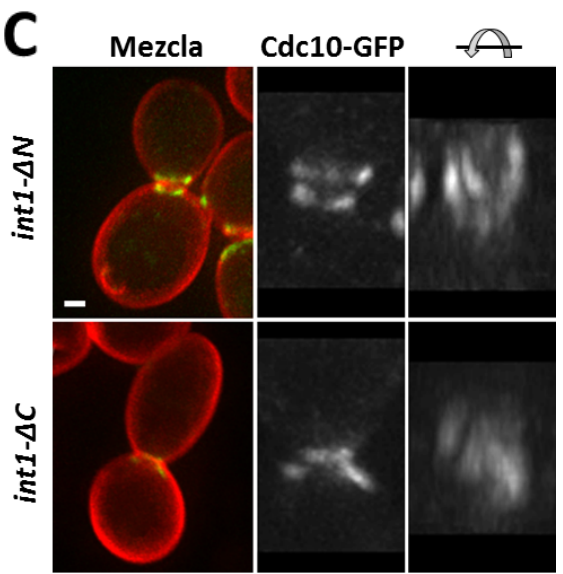

D

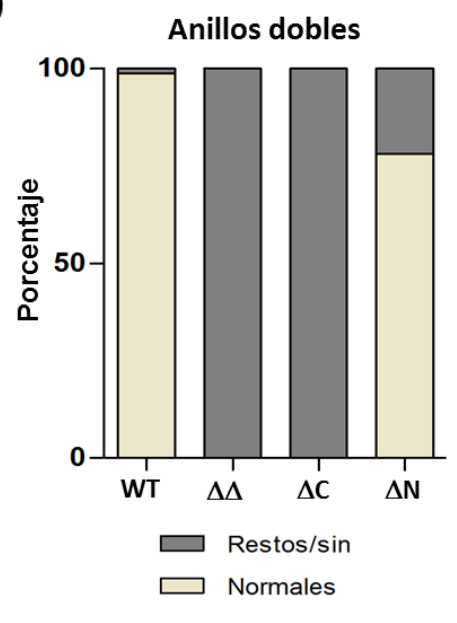

Figura 56. El mutante int1- $\Delta \mathrm{C}$ tiene un fenotipo similar a int1 $\Delta \Delta$. (A). Fenotipo de levaduras de int1- $\Delta C$ e int1- $\Delta N$. Proyección máxima de 10 planos de Cdc10-GFP (verde) y tinción con calcoflúor (rojo). Las flechas indican células con septo visible (según calcoflúor). Escala, $5 \mu \mathrm{m}$. (B). El mutante int1- $\Delta C$ no tiene anillos de septinas dobles, pero forma septos. Los gráficos muestran la media de anillos en células sin yema (azul), con anillo sencillo (gris oscuro) y con anillo doble (beis)(izquierda) y la media de células sin yema (azul), con yema pequeña (gris oscuro) y con septo (beis)(derecha). (C). Detalles de anillos dobles de septinas en int1- $\Delta C$ e int1- $\Delta N$. Izquierda, Mezcla: Cdc10-GFP+calcoflúor. Centro: proyección máxima de Cdc10-GFP. Derecha, anillos girados $90^{\circ}$. Las imágenes de Cdc10-GFP tienen el histograma ajustado. Barra de escala: $2 \mu \mathrm{m}$. (D). El mutante int1- $\Delta N$ presenta un mayor porcentaje de restos de anillos dobles que un WT. Porcentaje promedio de anillos dobles normales y los que están en forma de restos, en una cepa WT, int1 $\Delta \Delta$, int1- $\triangle C$ e int1- $\triangle N$. CDC10-GFP (OL2243), int1 $\Delta \triangle$ CDC10-GFP (OL2316), int1- $\triangle C$ CDC10-GFP (OL2193), int1- $\triangle$ N CDC10-GFP (OL2304). 


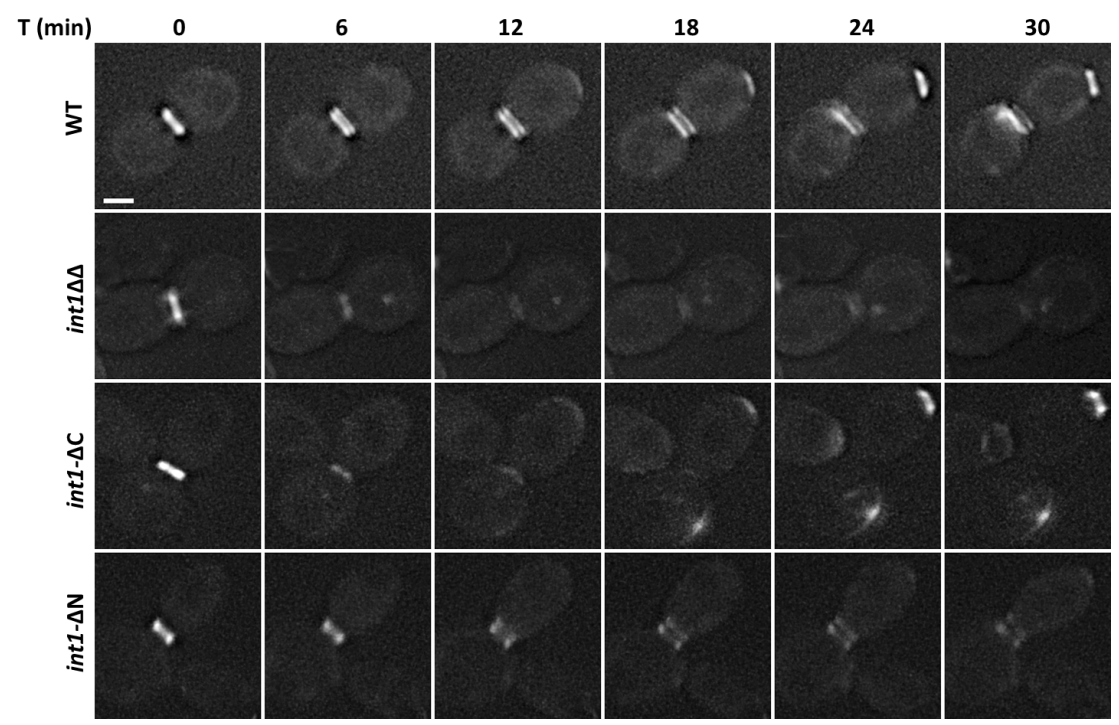

Figura 57. Duplicación del anillo de septinas en int1 $\Delta \Delta$, int1- $\Delta C$ e int1- $\Delta \boldsymbol{N}$. Transición anillo sencilloduplicado en las cepas WT, int $1 \Delta \Delta$, int1- $\Delta C$ e int1- $\Delta N$ durante el crecimiento en forma de levaduras. Imágenes de fluorescencia de Cdc10-GFP (proyección máxima de 10 planos cada $0,4 \mu \mathrm{m}$ ). Barra de escala: $2 \mu \mathrm{m}$. CDC10-GFP (OL2243), int1 $\triangle \triangle$ CDC10-GFP (OL2316), int1- $\triangle C \quad C D C 10-G F P \quad(\mathrm{OL} 2193)$, int1- $\triangle N$ CDC10-GFP (OL2304).

dobles normales, mientras que en las células int $1-\Delta N$, aproximadamente un $20 \%$ de los anillos dobles estaban mal ensamblados (Fig. 56B), ya que aunque parecían normales estaban incompletos cuando se hacían reconstrucciones tridimensionales (Fig. 56C).

Para confirmar estas observaciones, se hicieron experimentos de microscopía a lo largo del tiempo con las cepas int1- $\Delta N$ e int1- $\Delta C$ (Fig. 57). Los resultados confirmaron que la cepa int1- $\Delta C$ presentaba un defecto similar al del mutante nulo, desapareciendo los anillos de septinas en el momento de la duplicación, mientras que en el mutante int1- $\Delta N$ se producía una disminución de la intensidad de los anillos dobles.

Todos estos resultados indican que el extremo carboxilo de la proteína Int1 que contiene los dominios anillina y $\mathrm{PH}$ es esencial para el mantenimiento de la estabilidad de los anillos de septinas dobles, aunque la región $\mathrm{N}$-terminal también desempeña un papel minoritario en este proceso.

\subsection{La fosforilación de los sitios consenso para la kinasa Cbk1 en Int1 está implicada en su funcionalidad.}

En S. cerevisiae, Bud4 tiene 18 posibles sitios de fosforilación por CDKs, de los cuales 13 están concentrados en dos grupos, y se ha demostrado que Bud4 es un sustrato de Clb2-Cdc28 in vivo (Eluere et al., 2012). Cuando se analizó la secuencia de Int1 buscando posibles sitios de fosforilación, se comprobó que existen 10 sitios completos susceptibles de ser reconocidos por CDKs y otros 11 incompletos (Fig. 58A). A pesar de la baja identidad de secuencia entre Bud4 e Int1, se mantiene la distribución espacial de los sitios CDK, concentrándose en dos grupos, uno cerca del extremo amino y otro antes del dominio anillina. Sin embargo, existen cuatro sitios consenso para Cbk1 en Int1, que no están conservados en su homólogo Bud4. Tres de ellos se disponen en el extremo carboxilo muy próximos entre sí, y el cuarto en el extremo amino (Fig. 58A). Estos posibles sitios de fosforilación por Cbk1 están más o menos conservados en otras especies del clade CTG, especialmente dentro de las especies del género Candida (Fig. 58B), lo que sugiere una posible función reguladora específica de este grupo de microorganismos.

En base a esto, se decidió construir los mutantes fosfodeficiente y fosfomimético de los sitios consenso para Cbk1 que se agrupan en el extremo C-terminal (en este caso se partió de una cepa 
Figura 58. Int1 es una fosfoproteína. (A). Esquema de los sitios de fosforilación de Int1 (C. albicans) y Bud4 (S. cerevisiae). Se indican los sitios consenso completos e incompletos para CDK (azul y verde, respectivamente) y los sitios consenso para Cbk1 (rojo). (B). Alineamiento de Int1 en las especies del clade CTG. Se indican los sitios consenso completos e incompletos para CDK (azul $y$ verde, respectivamente) y los sitios consenso para Cbk1 (rojo).

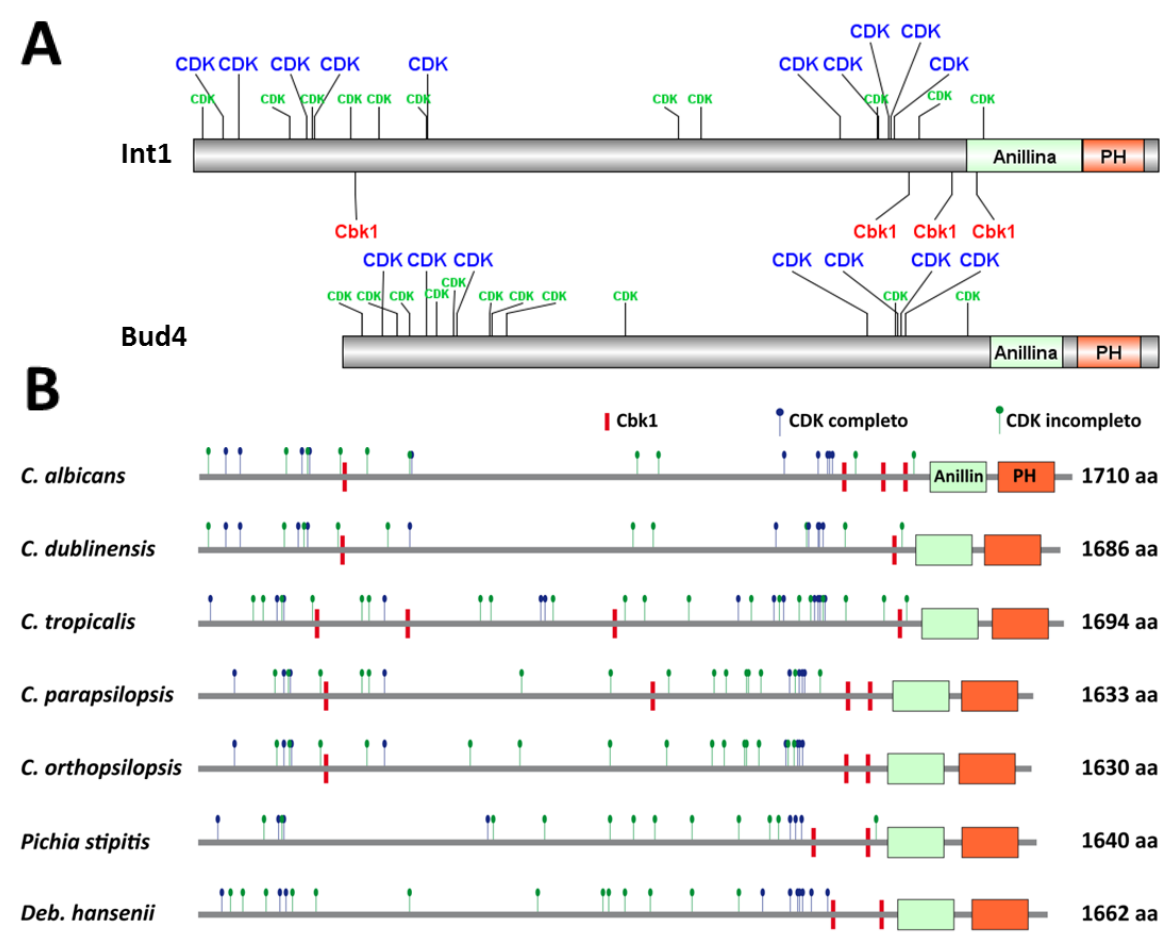

A Int1

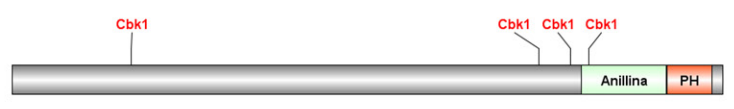

Int1-3A

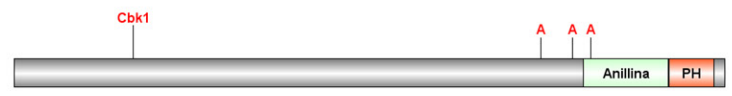

Int1-3E

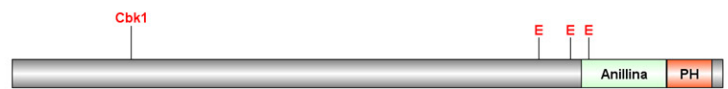

B
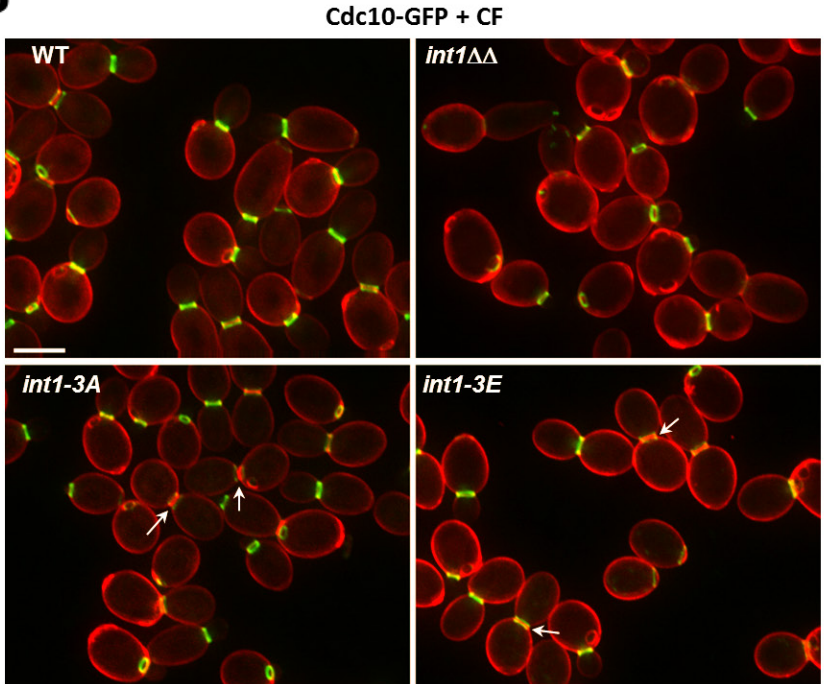

C
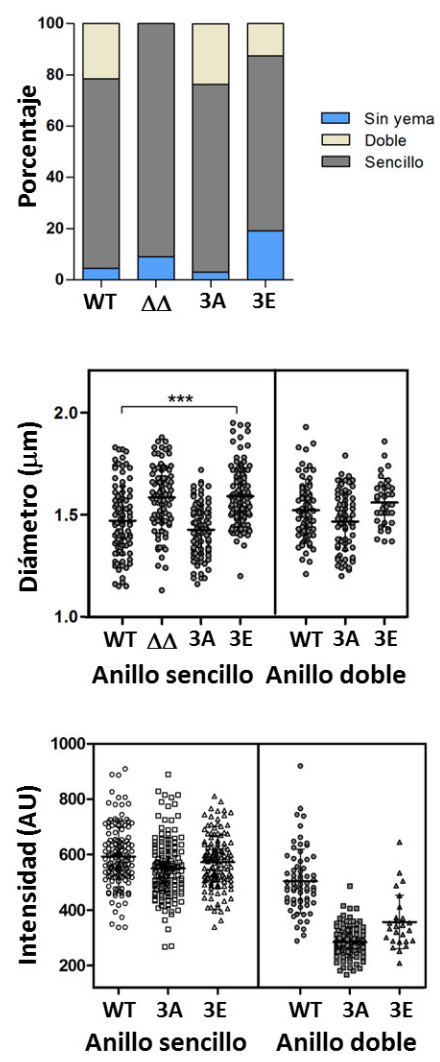

Figura 59. Fosforilación de Int1. (A). Esquema de las proteínas Int1, Int1-3A e Int1-3E. Regiones anillina (verde) y PH (rojo). Los sitios consenso para Cbk1 están marcados en rojo. Modificación a Ala (A) o Glu (E). (B). Localización de Cdc10-GFP (verde) y calcoflúor (rojo) en levaduras de la cepa WT, int1 $\Delta \Delta$, int1-3A e int1-3E (proyección máxima de 10 planos cada 0,4 $\mu \mathrm{m}$ ). Las flechas señalan anillos duplicados de septinas. Barra de escala: 5 Hm. (C). Análisis de los anillos de septinas. Arriba, el mutante int1-3E tiene un mayor porcentaje de células sin yema. Porcentaje promedio de células sin yema (azul), con anillo sencillo (gris oscuro) y con anillo doble (beis) en cada cepa. Centro, las cepas int $1 \Delta \Delta$ y int1-3E presentan un anillo sencillo de septinas más ancho. Diámetro de, al menos, cincuenta anillos de septinas (izquierda: sencillos; derecha: dobles) de las mismas cepas. Los asteriscos indican el nivel de significación (***: $p=0,0001$; test). Abajo, la intensidad de los anillos dobles es menor en int1-3A e int1-3E. Intensidad de Cdc10-GFP en, al menos, cincuenta células de las mismas cepas. CDC10-GFP (OL2243), int1 $\Delta \Delta$ CDC10-GFP (OL2316), int1-3A CDC10-GFP (OL2195) e int1-3E CDC10-GFP (OL2197). 
INT1+/- y las sustituciones de Ser por Ala o Glu se incorporaron en el único alelo funcional). A estas cepas se las denominó int1-3A e int1-3E (Fig. 59A). Posteriormente, para estudiar los efectos sobre la localización de las septinas en estos mutantes, se marcó Cdc10-GFP en cada una de las cepas (Fig. 59B). El recuento de células en función del tipo de anillo de septinas (sin anillo, sencillo o doble) indicó que los mutantes int1-3A e int1-3E presentan proporciones de células con anillos dobles similares al silvestre (Fig. 59C, gráfica superior), aunque en el mutante int1-3E se observó un incremento en el porcentaje de células sin yema. Cuando se analizó el diámetro de los anillos de septinas en estas cepas, las células del mutante int1-3E tenían un anillo sencillo de tamaño significativamente superior al de la cepa silvestre y similar a las del mutante nulo, aunque esta diferencia se reducía tras la duplicación (Fig. 59C, gráfica media). Finalmente, cuando se midió la intensidad de la fluorescencia de los anillos de septinas, se concluyó que los sencillos eran indistinguibles entre silvestre y los dos mutantes, pero la intensidad se reducía mucho más en las cepas int1-3A e int1-3E que en la cepa silvestre después de la duplicación, siendo más acusada esta diferencia en el mutante int1-3A (Fig. 59C, gráfica inferior).

\subsection{El mutante doble int $1 \Delta \Delta \operatorname{sep} 7 \Delta \Delta$ presenta un aumento en la ploidía celular.}

En vista de que los resultados anteriores ponen de manifiesto una relación entre el homólogo de la anillina Int1 y las septinas, se decidió construir mutantes dobles que combinaran la deleción de INT1 con la de algunas de las proteínas que componen el anillo de septinas. En los Capítulos anteriores se ha mostrado que Sep7 desempeña un importante papel regulador del anillo de septinas, por lo que inicialmente se planteó el estudio del mutante int $1 \Delta \Delta \operatorname{sep} 7 \Delta \Delta$ para comprobar si existían interacciones entre estas dos proteínas. Para construir este mutante, se delecionaron las dos copias de SEP7 en un fondo int1 $\Delta \Delta$. Además, para estudiar la localización de las septinas, se marcó CDC10 con GFP. La comparación de los anillos de septinas del doble mutante con los de las cepas int $1 \Delta \Delta$ y $\operatorname{sep} 7 \Delta \Delta$ mediante microscopía y reconstrucciones 3D muestran que los sencillos son muy parecidos en todas las cepas estudiadas. Respecto a los anillos dobles, en el mutante $i n t 1 \Delta \Delta \operatorname{sep} 7 \Delta \Delta$ se suman los fenotipos de asimetría del anillo $(\operatorname{sep} 7 \Delta \Delta$ ) y desensamblaje tras la duplicación (int1 $\Delta \Delta$ )(Fig. 60A).

Durante el análisis de los anillos de septinas del mutante doble int1 $\Delta \Delta$ sep7 $\Delta \Delta$ se observó que existían células de mayor tamaño que las de la cepa silvestre. Para caracterizar este defecto con más detalle, las células int $1 \Delta \Delta \operatorname{sep} 7 \Delta \Delta$ se incubaron en medio rico a $28^{\circ} \mathrm{C}$ y fueron teñidas con DAPI y calcoflúor antes de visualizarlas al microscopio. Este mutante presentaba una población de células de mayor tamaño y muchas de ellas eran polinucleadas (Fig. 60B). Para discernir si era un fenotipo específico de la interacción entre Int1 y Sep7 o si, por el contrario, la eliminación de cualquiera de los componentes del anillo de septinas junto con la deleción de INT1 mostraría el mismo fenotipo, se construyó el mutante doble int $1 \Delta \Delta c d c 10 \Delta \Delta$ (de forma análoga a la anterior). Cuando se analizó este mutante, se comprobó que no presentaba células con morfología aberrante ni polinucleadas al teñirlas con DAPI (Fig. 60B). Por tanto, este resultado indica que el defecto en la ploidía es producido específicamente por la ausencia de Int1 y Sep7, y no es general debido a un defecto en el ensamblaje del anillo de septinas.

Un fenotipo similar al de las células int $1 \Delta \Delta \operatorname{sep} 7 \Delta \Delta$, con aberrante morfología celular y poliploidía, se ha descrito para el mutante rts1 $\Delta \Delta$ (Tesis Doctoral de Caballero-Lima, 2009)(Fig. 61A). Rts1 es la subunidad reguladora de la fosfatasa PP2A y se localiza en el núcleo y cuello de la célula. Para profundizar en el estudio de este defecto, se realizó una cuantificación de los tipos de células en función de su 
A
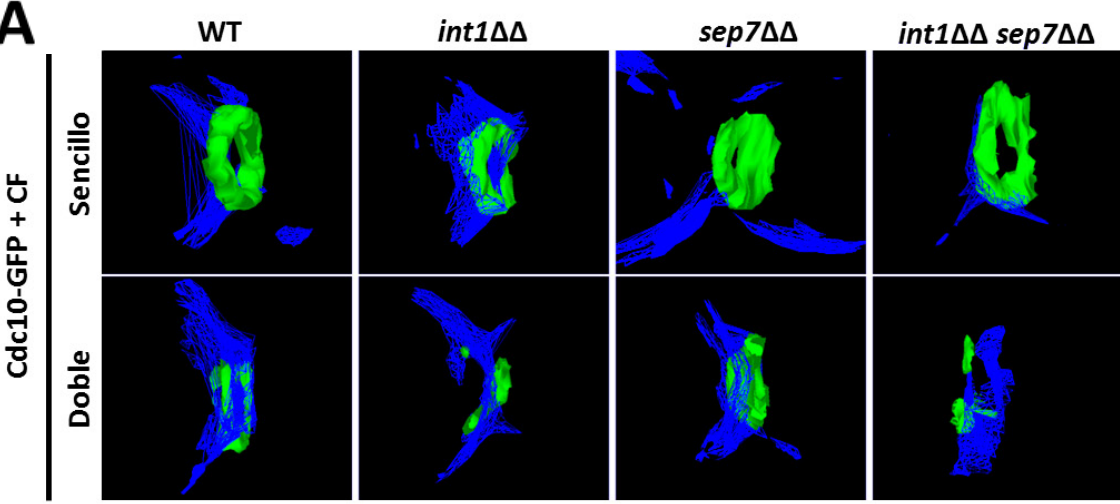

B

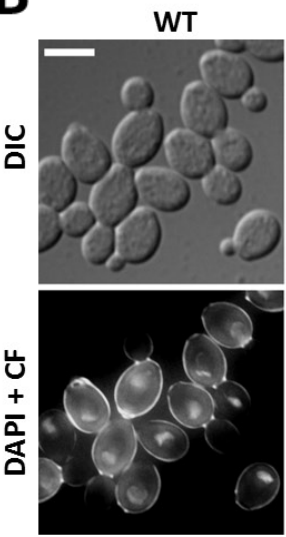

$\operatorname{int} 1 \Delta \Delta$
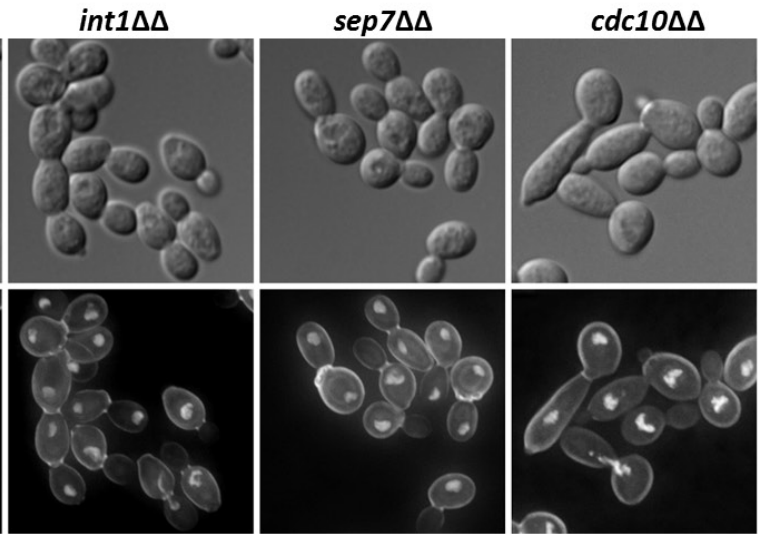

$\operatorname{int} 1 \Delta \Delta \operatorname{sep} 7 \Delta \Delta$
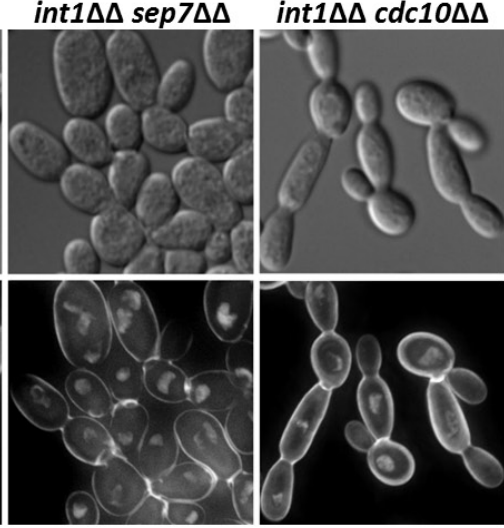

Figura 60. Fenotipos del mutante int1 $\Delta \Delta$ en combinación con la deleción de algunas septinas. (A). Reconstrucción 3D de anillos sencillos y dobles de Cdc10-GFP en las cepas silvestre (WT), int1 $\Delta \Delta$, sep7 $\Delta \Delta$ e int1 $\Delta \Delta \operatorname{sep} 7 \Delta \Delta$ (B). Fenotipo de las levaduras de las cepas silvestre (WT), int $1 \Delta \Delta$, sep $7 \Delta \Delta, c d c 10 \Delta \Delta$, int $1 \Delta \Delta \operatorname{sep} 7 \Delta \Delta$ e int $1 \Delta \Delta \operatorname{cdc} 10 \Delta \Delta$ crecidas a $28^{\circ} \mathrm{C}$. Imágenes de contraste interferencial (DIC) y proyección máxima de 3 planos que muestran la tinción de DAPI y calcoflúor. Barra de escala: $5 \mu \mathrm{m}$. CDC10-GFP (OL2243), int1 $\triangle \triangle$ CDC10-GFP (OL2316), sep7 $\triangle$ CDC10-GFP (OL1431), int1 $\triangle \Delta$ sep7 $\triangle$ CDC10-GFP (OL2513), BWP17 (WT, OL1417), int1 $\Delta \Delta$ (OL2314), sep7 $\Delta$ (OL2138), cdc10 $\Delta \Delta$ (OL2213), int1 $\Delta \Delta$ sep7 $\Delta \Delta$ (OL2509) e int1 $\Delta \Delta$ $c d c 10 \Delta \Delta(\mathrm{OL} 2532)$.

morfología (tamaño) y del número de núcleos en los distintos mutantes sencillos y dobles. Los mutantes sencillos int $1 \Delta \Delta$, sep $7 \Delta \Delta$ y $c d c 10 \Delta \Delta$ presentaban un porcentaje de células de tamaño normal y un sólo núcleo superiores al 90\%, similar al de la cepa silvestre (Fig. 61B). El porcentaje de células grandes con más de un núcleo aumentaba en el mutante $r t s 1 \Delta \Delta$ y en int $1 \Delta \Delta$ sep $7 \Delta \Delta$ hasta proporciones parecidas, aunque la cepa rts $1 \Delta \Delta$ tenía un mayor número de células de morfología silvestre y un solo núcleo. De nuevo el mutante int $1 \Delta \Delta c d c 10 \Delta \Delta$ era similar al mutante $c d c 10 \Delta \Delta$, mostrando un porcentaje de células anormales ligeramente superior al silvestre. Para completar el análisis, se construyeron las otras dos combinaciones posibles, el mutante int $1 \Delta \Delta$ rts $1 \Delta \Delta$ y el $r t s 1 \Delta \Delta \operatorname{sep} 7 \Delta \Delta$. Los porcentajes obtenidos al analizar la cepa int $1 \Delta \Delta \operatorname{rts} 1 \Delta \Delta$ fueron casi idénticos a los de int $1 \Delta \Delta \operatorname{sep} 7 \Delta \Delta$, lo que podría sugerir que Rts1 y Sep7 son integrantes de una misma ruta funcional. Sin embargo, el fenotipo del mutante $r t s 1 \Delta \Delta$ sep $7 \Delta \Delta$ era más severo, y en él se observaban muchas células de tamaño normal pero que contenían más de un núcleo (Fig. 61B). Por tanto, estos resultados parecen indicar que Int1 y Sep7 son necesarios para mantener la ploidía de las células, aunque funcionan en una ruta diferente de Rts1.

Dado que Rts1 se localiza en el núcleo de las células y en el cuello durante la citoquinesis, una posible explicación del defecto del mutante int $1 \Delta \Delta \operatorname{sep} 7 \Delta \Delta$ es que, por defectos en la estructura del anillo de septinas, Rts1 no pudiera asociarse a otras proteínas del cuello. Para comprobar esto, se insertó la GFP en el extremo $3^{\prime}$ del gen RTS1 en los mutantes int1 $\Delta \Delta$, sep7 $\Delta \Delta$ e int $1 \Delta \Delta \operatorname{sep} 7 \Delta \Delta$. Cuando se analizó la 

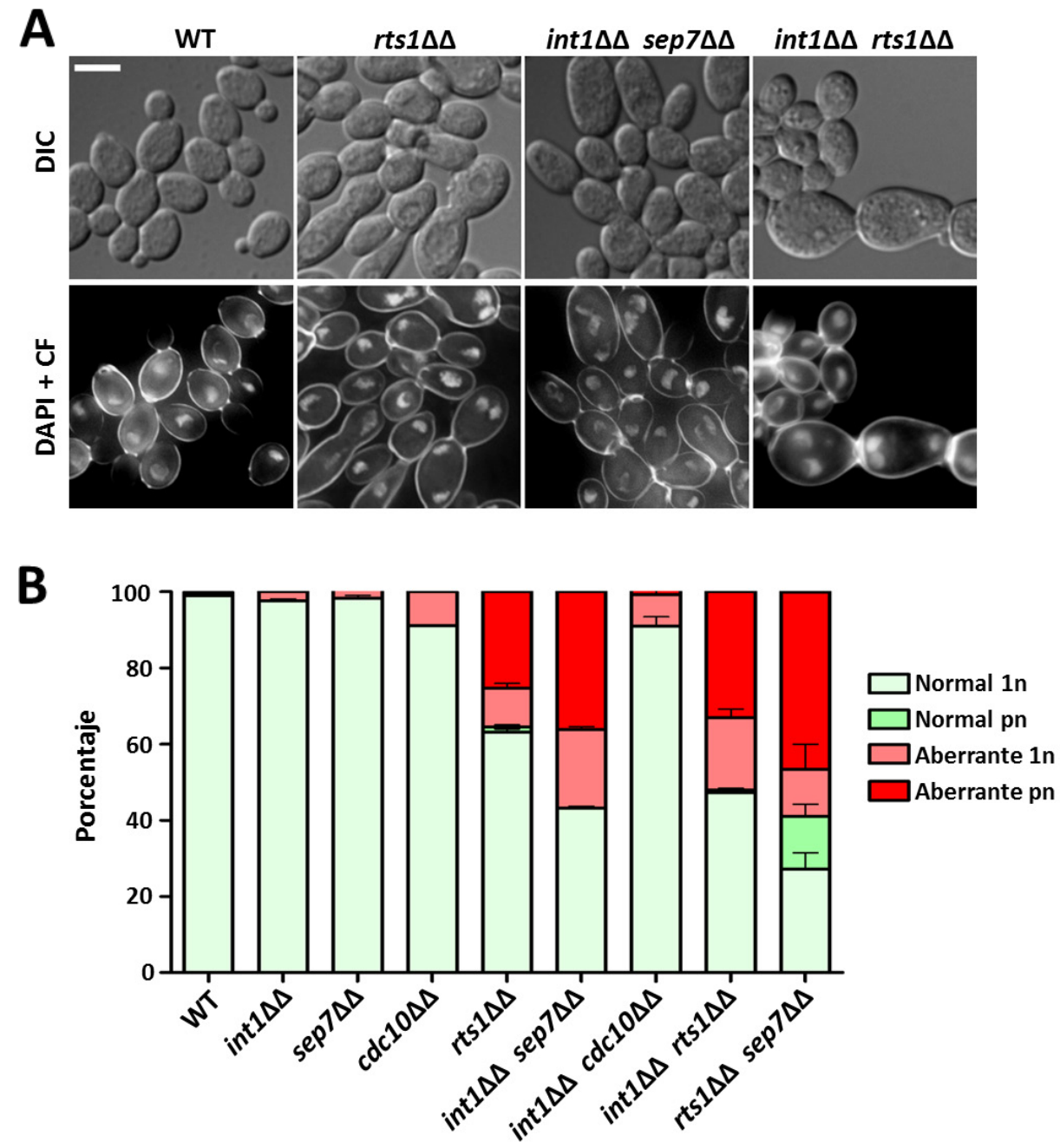

Figura 61. Similitud de los fenotipos de las células int1 $\Delta \Delta \operatorname{sep} 7 \Delta \Delta$ y rts1 $\Delta \Delta$. (A). Fenotipo de las cepas WT, rts $1 \Delta \Delta$, int $1 \Delta \Delta$ sep $7 \Delta \Delta$ e int $1 \Delta \Delta$ rts $1 \Delta \Delta$ en estado levaduriforme. Imágenes de contraste interferencial (DIC) y proyección máxima de 3 planos adquiridos cada 0,4 $\mu \mathrm{m}$ que muestran la tinción de DAPI y calcoflúor. Barra de escala, $5 \mu \mathrm{m}$. (B). Representación gráfica del porcentaje promedio de células normales (verde) y aberrantes (rojo), uni- (1n) o polinucleadas (pn) de las cepas silvestre (WT, OL1417), int1 $\Delta \Delta$ (OL2314), sep7 $\Delta \Delta$ (OL2138), $c d c 10 \Delta \Delta$ (OL2213), rts1 $\Delta \Delta$ (OL2526), int1 $\Delta \Delta \operatorname{sep} 7 \Delta \Delta$ (OL2509), int1 $\Delta \Delta c d c 10 \Delta \Delta$ (OL2532), int $1 \Delta \Delta$ rts $1 \Delta \Delta$ (OL2520) y rts $1 \Delta \Delta$ sep $7 \Delta \Delta$ (OL2530) con la desviación típica (SD).

localización de Rts1-GFP, se comprobó que en las tres cepas se localizaba en el núcleo y el cuello durante citoquinesis, de forma similar a la cepa silvestre (Fig. 62A). Además, la cuantificación de la intensidad media de la señal de GFP tanto en núcleo como en el cuello no mostró diferencias significativas entre las tres cepas y el silvestre (Fig. 62B). Por tanto, los defectos del mutante int $1 \Delta \Delta \operatorname{sep} 7 \Delta \Delta$ no se deben a una deslocalización de la fosfatasa Rts1.

Ya que las tinciones DAPI sólo aportan información sobre el número de masas nucleares pero no sobre el contenido en DNA, se analizaron las distintas cepas mediante citometría de flujo. Para ello, las células en crecimiento asincrónico de las distintas cepas se fijaron con formaldehído, se marcaron con una sonda intercalante de DNA y se analizó la composición del cultivo mediante citometría. Los resultados obtenidos indicaron que las células de los mutantes $c d c 10 \Delta \Delta$, int1 $\Delta \Delta$ y $\operatorname{sep} 7 \Delta \Delta$, así como el mutante doble int $1 \Delta \Delta c d c 10 \Delta \Delta$ presentaban unos picos de poblaciones celulares con un contenido en DNA 2C, 4C y >8C muy parecidos a los de la cepa silvestre (Fig. 63). Por el contrario, en las cepas $r t s 1 \Delta \Delta$, int $1 \Delta \Delta$ rts $1 \Delta \Delta$ e int $1 \Delta \Delta \operatorname{sep} 7 \Delta \Delta$ se incrementaba significativamente la población de células con 
contenido en DNA >8C. Por su parte, en el mutante doble $r t s 1 \Delta \Delta \operatorname{sep} 7 \Delta \Delta$, el pico de células con un contenido en DNA >8C aparecía aún más incrementado. Estos resultados indican que las células con varias masas nucleares observadas con las tinciones de DAPI corresponden realmente a células poliploides y no a fragmentación nuclear. Además, confirman la observación de que la combinación de la ausencia de Int1 con Sep7 o Rts1 es diferente a la combinación $r t s 1 \Delta \Delta \operatorname{sep} 7 \Delta \Delta$.

Figura 62. Localización de Rts1 en los mutantes anillina/septinas. (A). Análisis por microscopía de contraste interferencial (DIC) y de fluorescencia de Rts1-GFP y calcoflúor. Mezcla: DIC (rojo)+Rts1-GFP (verde). Las imágenes de fluorescencia son la proyección máxima de 3 planos adquiridos cada 0,4 $\mu \mathrm{m}$. Barra de escala: $2 \mu \mathrm{m}$. (B). La señal de Rts1-GFP es similar en todos las cepas. El gráfico muestra la intensidad media de, al menos, veinte cuellos y núcleos de la cepas WT, int $1 \Delta \Delta$, sep $7 \Delta \Delta$ e int $1 \Delta \Delta$ sep $7 \Delta \Delta$, con la SEM. RTS1-GFP (OL2550), int $1 \Delta \Delta$ RTS1-GFP (OL2553), sep7 $\triangle$ RTS1-GFP (OL2552) e int $1 \Delta \Delta$ sep7 $\Delta \triangle R T S 1-G F P$ (OL2555).
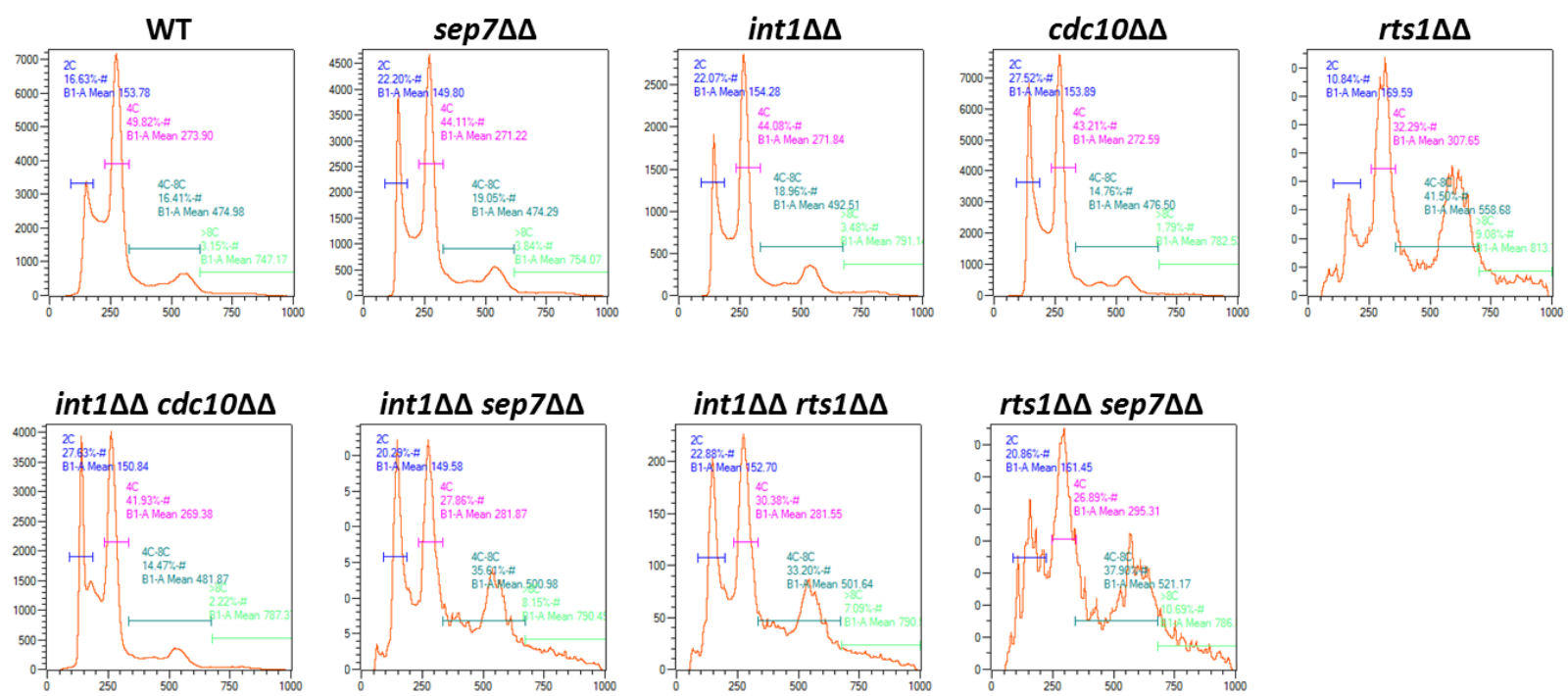

Figura 63. Los combinaciones de deleciones en INT1, SEP7 y RTS1 generan células con alto contenido en DNA. Análisis de citometría de flujo de las cepas silvestre (WT, OL1417), sep7 $\Delta \Delta$ (OL2138), int1 $\Delta \Delta$ (OL2314), cdc10 $\Delta \Delta$ (OL2213), rts1 $\Delta \Delta$ (OL2526), int1 $\Delta \Delta c d c 10 \Delta \Delta$ (OL2532), int1 $\Delta \Delta \operatorname{sep} 7 \Delta \Delta$ (OL2509), int1 $\Delta \Delta \operatorname{rts} 1 \Delta \Delta(\mathrm{OL} 2520)$ y rts $1 \Delta \Delta \operatorname{sep} 7 \Delta \Delta(\mathrm{OL} 2530)$. 


\section{9 El mutante int1 $\Delta \Delta$ sep $7 \Delta \Delta$ presenta fallos en mitosis y en orientación del huso} mitótico.

Para que el material genético se reparta de manera fiel entre las células hijas, la célula debe coordinar de forma correcta una serie de eventos que incluyen la replicación del DNA, la duplicación del SPB y la formación de la yema. Una vez duplicado, el material genético debe ser físicamente transportado desde el interior de la célula madre al compartimento de la célula hija de una manera fiable y precisa, ya que de lo contrario se generarían células poliploides (Torres et al., 2008). Para profundizar en el estudio del fenotipo de poliploidía del mutante int $1 \Delta \Delta \operatorname{sep} 7 \Delta \Delta$, se marcó el gen NOP1 (que codifica para una

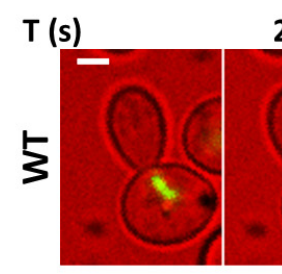

$20 \quad 40$

60

$60 \quad 80$ 120

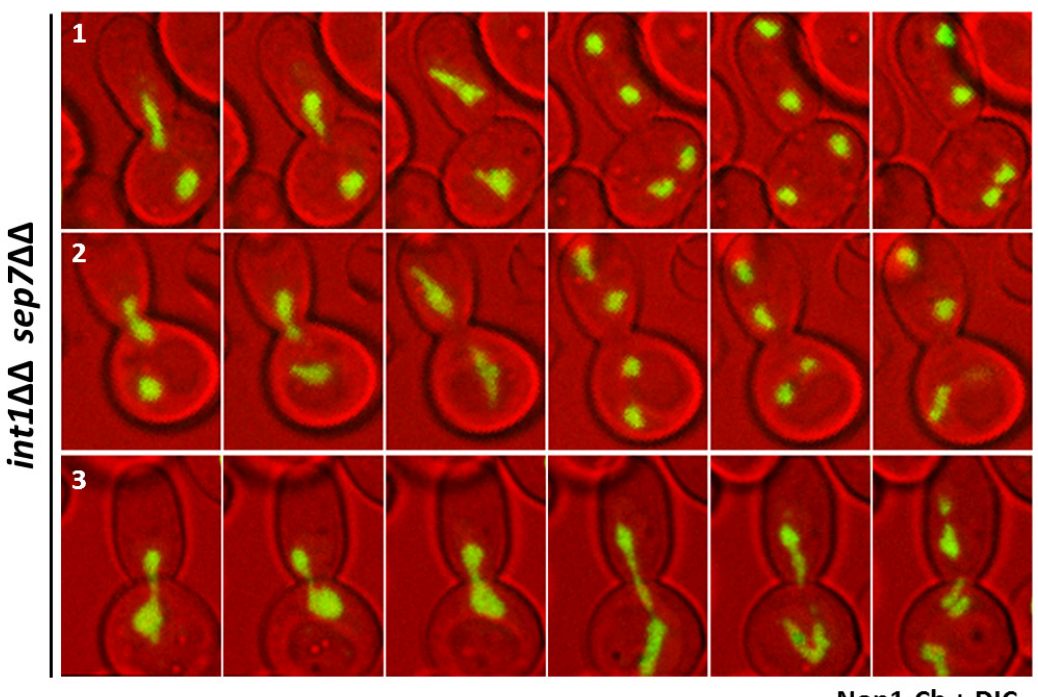

Nop1-Ch + DIC

Figura 64. Segregación del nucleolo en la cepa $\operatorname{int} 1 \Delta \Delta \operatorname{sep} 7 \Delta \Delta$. Análisis de microscopía (time-lapse) de contraste interferencial (DIC, rojo) y fluorescencia de Nop1-Cherry (verde) en las cepas NOP1-Ch (WT, OL2347) e int1 $\Delta \Delta \operatorname{sep} 7 \Delta \Delta$ NOP1-Ch (OL2514) (Células: 1, 2 y 3 en int1 $\Delta \Delta \operatorname{sep} 7 \Delta \Delta$ ). Las imágenes son la proyección máxima de 3 planos adquiridos cada 0,4 $\mu \mathrm{m}$. Barra de escala: $2 \mu \mathrm{m}$. proteína integrante del nucleolo) con Cherry en el extremo 3' del gen y se estudió la dinámica de segregación de los núcleos mediante microscopía a lo largo del tiempo. Mediante estos experimentos se comprobó que en la cepa silvestre el nucleolo se alargaba en el eje longitudinal de las células y uno de los extremos penetraba en la célula hija, generando finalmente dos nucleolos independientes (Fig. 64). En el mutante int1 $\Delta \Delta \operatorname{sep} 7 \Delta \Delta$ se observó que en la mayoría de los casos, en la célula madre existían dos nucleolos independientes producto de la mitosis anterior, uno de ellos pasaba a la célula hija y se producía la duplicación de ambos nucleolos, cada uno en un compartimento celular antes de que se completara la citoquinesis (Fig. 64, células 1 y 2). En algunos casos, a partir de lo que parecía un único nucleolo se producía la mitosis en el cuello de forma aparentemente normal, pero posteriormente era posible observar varias masas de Nop1-Cherry independientes (Fig. 64, célula 3).

Para analizar con más detalle la progresión de la mitosis en el mutante $\operatorname{int} 1 \Delta \Delta \operatorname{sep} 7 \Delta \Delta$, se marcó el gen TUB1, componente del citoesqueleto de tubulina, con GFP. En una cepa silvestre, Tub1-GFP se localiza en los SPBs, en el huso mitótico y en los microtúbulos astrales, permitiendo identificar la fase del ciclo celular en la que se encuentran las células. Cuando se utilizó el microscopio Deltavision, en la cepa control se observaron células en todos los estadíos del ciclo (Fig. 65). En el mutante int1 $\Delta \Delta \operatorname{sep} 7 \Delta \Delta$ también se observaron células en diferentes momentos del ciclo. Sin embargo, en muchas de las células de tamaño grande era posible observar numerosos microtúbulos astrales, algunos sueltos en el citoplasma y separados del huso mitótico. Esto sugiere que en las células grandes podría existir un defecto en el ensamble de citoesqueleto de tubulina. 


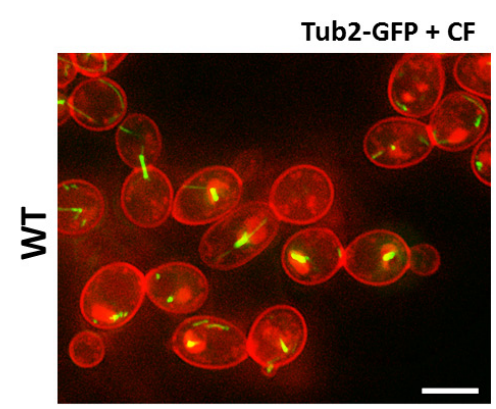

Figura 65. Disposición aberrante de los microtúbulos astrales en la cepa int1 $\Delta \Delta$ $\operatorname{sep} 7 \Delta \Delta$. Imágenes de fluorescencia de Tub2-GFP (verde) y calcoflúor (rojo). Las imágenes son la proyección máxima de 6 planos adquiridos cada 0,4 $\mu \mathrm{m}$. Barra de escala, $5 \mu \mathrm{m}$. TUB2-GFP (OL2477) e int1 $\triangle \triangle$ sep7 $\triangle \triangle$ TUB2-GFP (OL2536).

El análisis de la progresión de la mitosis en las células con varios núcleos del mutante int $1 \Delta \Delta \operatorname{sep} 7 \Delta \Delta$ se realizó mediante microscopía a lo largo del tiempo. En la cepa silvestre, al inicio de la

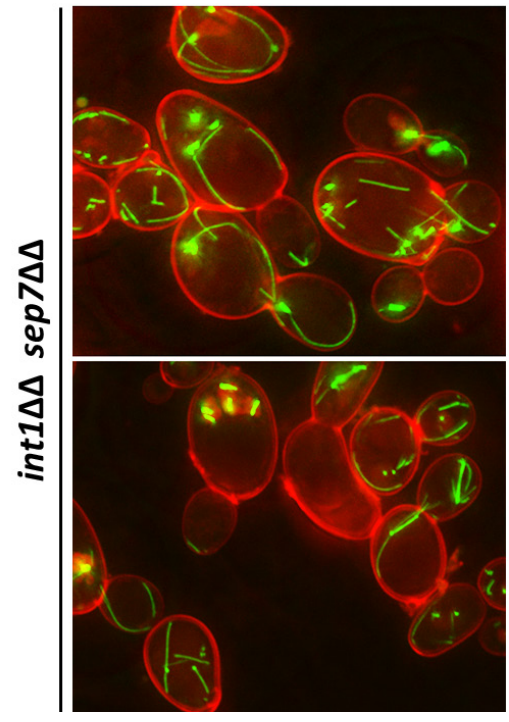
mitosis se forma el huso mitótico (Fig. 66A, arriba, T=0:30) del que parten los microtúbulos astrales, algunos de los cuales consiguen entrar en la célula y orientan el huso en el eje longitudinal madrehija ( $T=6: 00)$. Una vez orientado, comienza la telofase y el huso se alarga, separando los núcleos hijos ( $T=12: 00$ a 19:00). Tras el desensamblaje del huso y citoquinesis ( $T=21: 00)$, Tub1-GFP se localiza en los SPBs hasta que comienza una nueva mitosis ( $T=58: 00)$. En el mutante int $1 \Delta \Delta \operatorname{sep} 7 \Delta \Delta$, en la mayoría de las células con dos núcleos, se observó que se paraban con el huso típico de células en anafase, que emitían microtúbulos astrales (Fig. 66A, abajo, $\mathrm{T}=0: 00)$. Esta situación se mantenía por un tiempo variable hasta que uno de los núcleos conseguía colocarse en el cuello y acababa migrando a la célula hija ( $T=8: 00$ a 20:00). A partir de ese momento se producía la telofase, en la mayoría de los casos de forma coordinada, y orientando los husos mitóticos perpendiculares al eje longitudinal madre-hija ( $T=24: 00$ a 44:00). Tras completar la separación nuclear, se producía el desensamblaje del huso y la citoquinesis ( $T=48: 00$ a 56:00), resultando dos células con dos núcleos cada una ( $T=68: 00)$. A pesar de que este parecía ser el comportamiento mayoritario, también se observaron casos en los que los dos núcleos en anafase emitían microtúbulos astrales que atravesaban el cuello y se alargaban, pero no conseguían arrastrar el núcleo y posicionarlo en el cuello (Fig. 66B, célula superior). En otras ocasiones, uno de los núcleos conseguía orientarse en el eje longitudinal y segregaba normalmente mientras que el otro lo hacía de forma transversal en una célula, generando una segregación 3:1 (Fig. 66B, célula intermedia). Las células con tres núcleos segregaban también de forma aleatoria (Fig. 66B, célula inferior), generando de esta manera una diversidad en la ploidía de la población. Estas observaciones indican que en el mutante int $1 \Delta \Delta \operatorname{sep} 7 \Delta \Delta$ existen defectos en el anclaje de los núcleos en anafase al cuello de la célula y en la orientación del huso mitótico que conducen a problemas en la segregación nuclear.

\subsection{El mutante int $1 \Delta \Delta \operatorname{sep} 7 \Delta \Delta$ presenta defectos en la localización de proteínas implicadas en el control de la posición del huso mitótico.}

En S. cerevisiae, el anillo de septinas es esencial para posicionar el huso mitótico a lo largo del eje madre-hija y permitir una segregación cromosómica a la célula hija (Kusch et al., 2002). Se han descrito checkpoints que detienen el ciclo cuando ocurren defectos en este proceso. Así, el Spindle Assembly Checkpoint (SAC) controla que todos los cromosomas estén unidos al huso mitótico de forma correcta, mientras que el Spindle POsition Checkpoint (SPOC) actúa inhibiendo la salida de mitosis cuando el huso mitótico no tiene la orientación correcta (revisado en Caydasi y Pereira, 2009; Markus et al., 2012). 
A
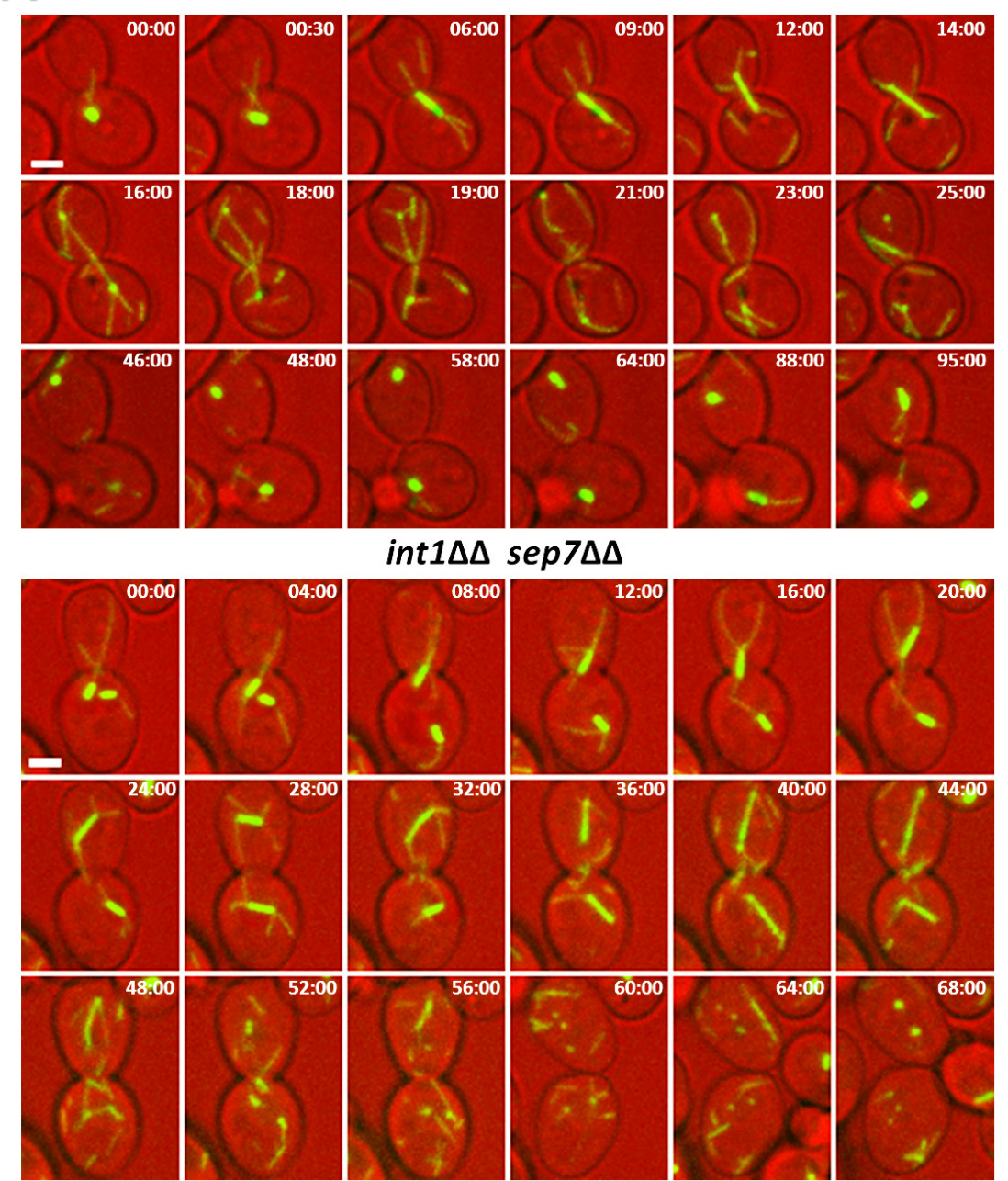

B
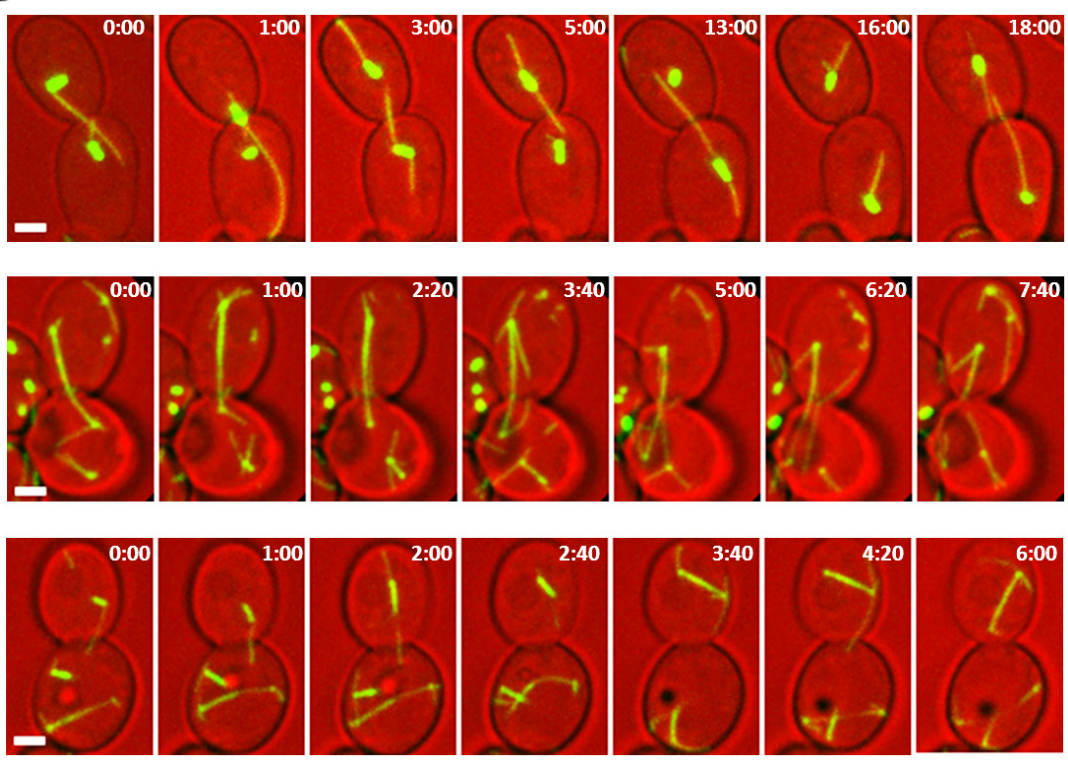

Figura 66. Desorientación del huso mitótico en la cepa int1 $\Delta \Delta \operatorname{sep} 7 \Delta \Delta$. (A) Análisis de microscopía (time-lapse) de contraste interferencial (DIC, rojo) y fluorescencia de Tub2-GFP (verde) en las cepas silvestre (WT) e int $1 \Delta \Delta \operatorname{sep} 7 \Delta \Delta$. Las imágenes son la proyección máxima de 3 planos adquiridos cada 0,4 $\mu \mathrm{m}$. (B) Ejemplos de segregación anormal en el mutante int $1 \Delta \Delta \operatorname{sep} 7 \Delta \Delta$. En ambos casos se indica el tiempo (min:s). Barra de escala: $2 \mu \mathrm{m}$. TUB2-GFP (OL2477) e int1 $\triangle$ sep7 $\triangle$ TUB2-GFP (OL2536).
Aunque en C. albicans no se conoce si existe un control similar que regule este proceso, el hecho de que en el mutante int $1 \Delta \Delta \operatorname{sep} 7 \Delta \Delta$ se generen células poliploides plantea la hipótesis de que la ruta SPOC no se activara en este mutante, permitiendo la salida de mitosis aunque el huso mitótico estuviera mal orientado. Son muchas las proteínas implicadas en esta regulación las descritas en $S$. cerevisiae, pero entre ellas existen varias kinasas y fosfatasas que se localizan en el cuello entre la célula madre e hija, como la kinasa Elm1 y las fosfatasas Glc7, Rts1 y Cdc14. Puesto que cabe esperar que el defecto primario del mutante int $1 \Delta \Delta \operatorname{sep} 7 \Delta \Delta$ sea la organización del anillo de septinas, se decidió analizar la localización de estas proteínas en este mutante.

En S. cerevisiae, la kinasa Elm1 fosforila a Kin4 activándola, y su función en el SPOC está ligada a su localización en el cuello, la cual es dependiente de las septinas (Caydasi et al., 2010b). Para estudiar la localización de Elm1 en C. albicans, se marcó el gen ELM1 en el extremo 3'con GFP en los fondos genéticos silvestre, int $1 \Delta \Delta, \operatorname{sep} 7 \Delta \Delta$, $r t s 1 \Delta \Delta$ e int $1 \Delta \Delta \operatorname{sep} 7 \Delta \Delta$. 


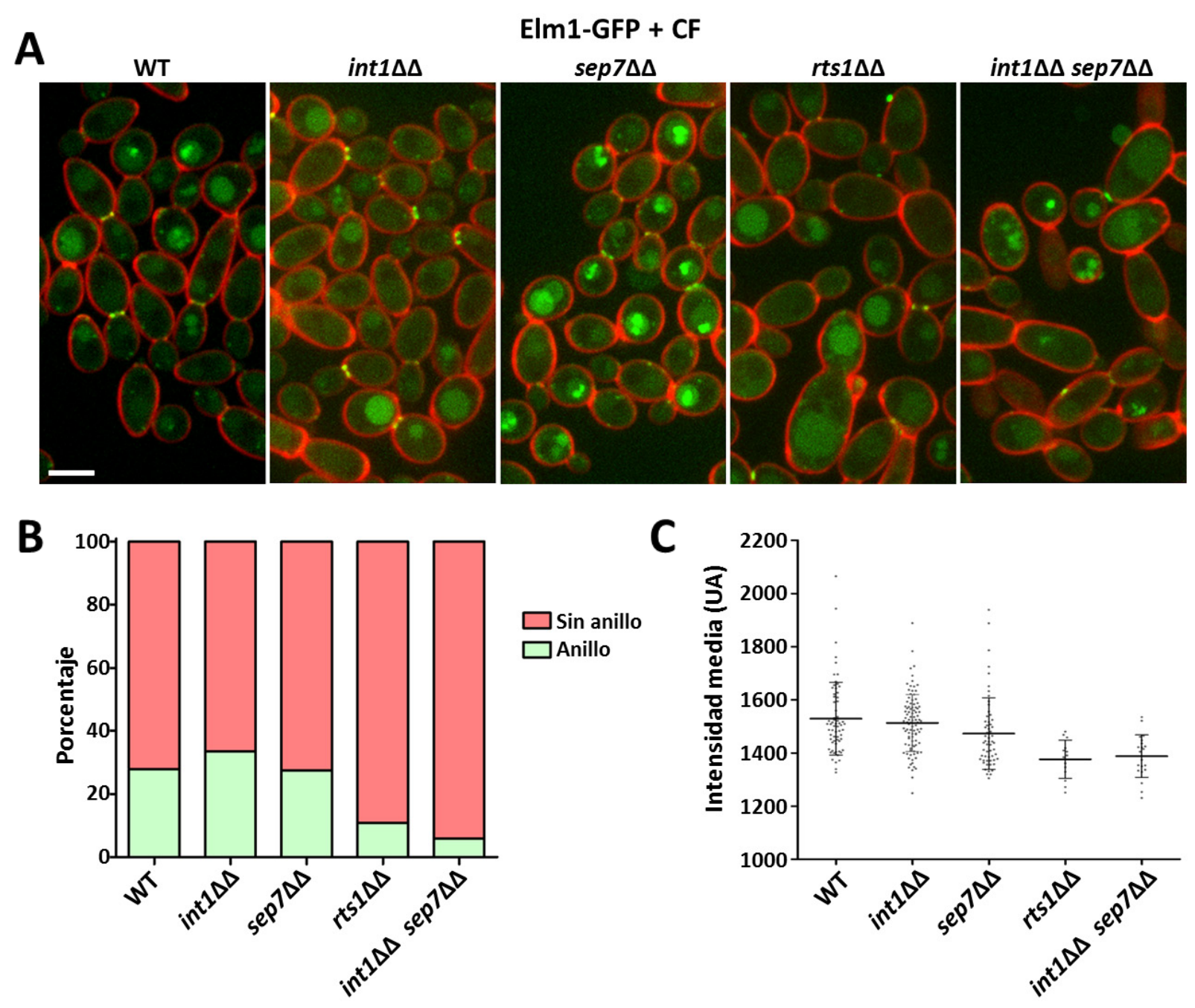

Figura 67. Localización de Elm1 en los mutantes anillina/septinas. (A). Análisis por microscopía de fluorescencia de Elm1-GFP (verde) y calcoflúor (rojo) en levaduras de la cepa silvestre (WT), int $1 \Delta \Delta, \operatorname{sep} 7 \Delta \Delta, r t s 1 \Delta \Delta$ e int $1 \Delta \Delta \operatorname{sep} 7 \Delta \Delta$. Las imágenes son la proyección máxima de 3 planos adquiridos cada 0,4 $\mu \mathrm{m}$. Barra de escala: $5 \mu \mathrm{m}$. (B). Representación gráfica del porcentaje de células con/sin anillo de Elm1-GFP en las mismas cepas. (C). Intensidad media de, al menos, veinte anillos de Elm1-GFP en

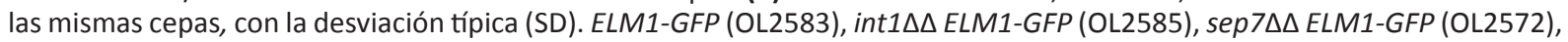
rts1 $\triangle \triangle E L M 1-G F P(O L 2575)$ e int1 $\Delta \Delta \operatorname{sep} 7 \Delta \triangle E L M 1-G F P(O L 2576)$.

Cuando se analizaron al microscopio estas cepas, se comprobó que en la cepa silvestre Elm1GFP se localizaba en el cuello de las células con yema grande y desaparecía tras la formación del septo (Fig. 67A). Un patrón similar ocurría en los mutantes int $1 \Delta \Delta$ y sep $7 \Delta \Delta$. En los mutantes rts $1 \Delta \Delta$ e int1 $\Delta \Delta \operatorname{sep} 7 \Delta \Delta$ también se observaban células con Elm1-GFP en el cuello, aunque su abundancia parecía menor. Cuando se cuantificó el porcentaje de células con Elm1-GFP en el cuello, se comprobó que era menor en estos dos mutantes que en la cepa silvestre (Fig. 67B). Además, en aquellas células en las que era posible observar el anillo de Elm1-GFP en el cuello, la intensidad media era más baja que en los mutantes int $1 \Delta \Delta$ y $\operatorname{sep} 7 \Delta \Delta$ y en el silvestre (Fig. 67C).

La subunidad catalítica de la fosfatasa PP1, Glc7, regula la unión de microtúbulos y cinetocoros en S. cerevisiae, lo cual es sumamente importante para la correcta segregación cromosómica (Sassoon et al., 1999). Glc7 se localiza en diversos compartimentos y estructuras, incluyendo citoplasma, núcleo, SPBs y sitios de crecimiento polarizado (Bloecher y Tatchell, 2000). Al igual que para el estudio de Elm1, se marcó GLC7 en su extremo 3' con GFP en las cepas silvestre, int $1 \Delta \Delta$, sep $7 \Delta \Delta, r t s 1 \Delta \Delta$ e int $1 \Delta \Delta \operatorname{sep} 7 \Delta \Delta$. 
A

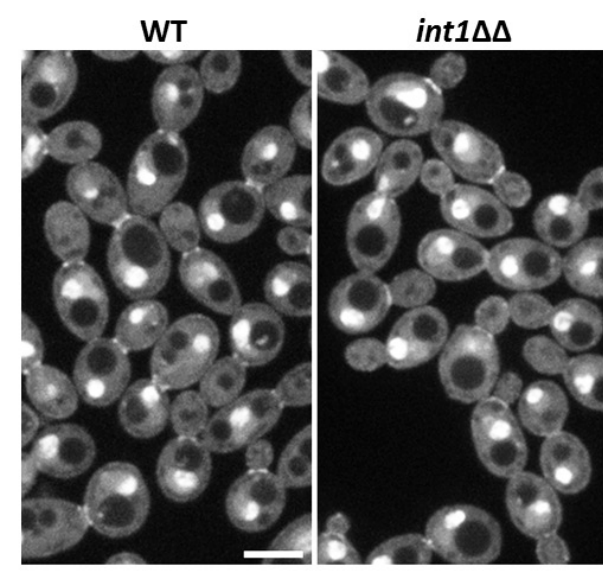

B

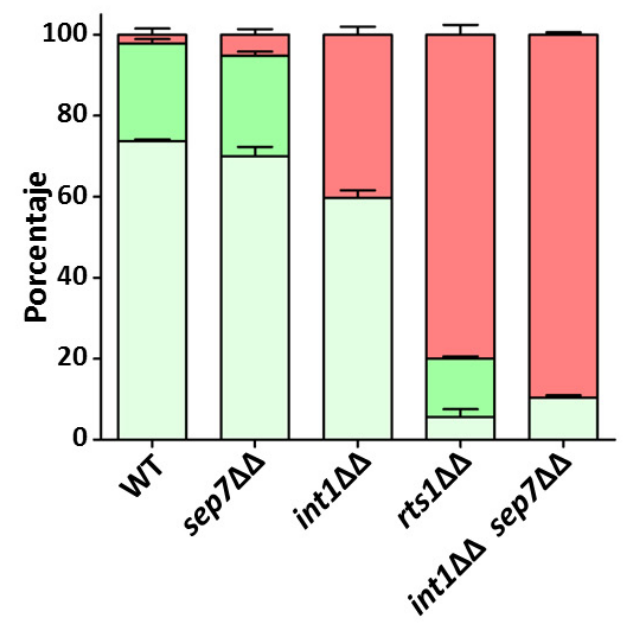

\section{GIc7-GFP}

$\operatorname{sep} 7 \Delta \Delta$

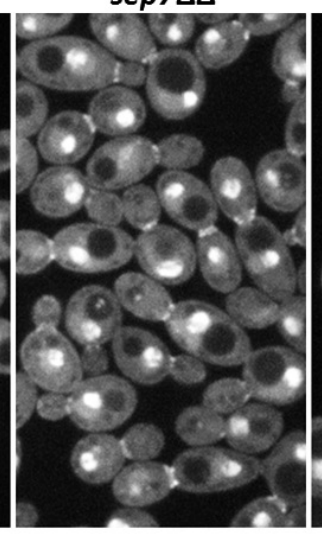

$r t s 1 \Delta \Delta$

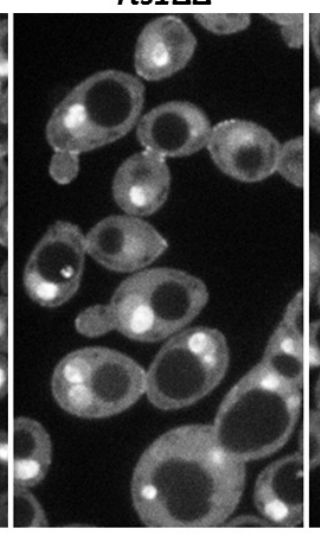

$\operatorname{int} 1 \Delta \Delta \operatorname{sep} 7 \Delta \Delta$
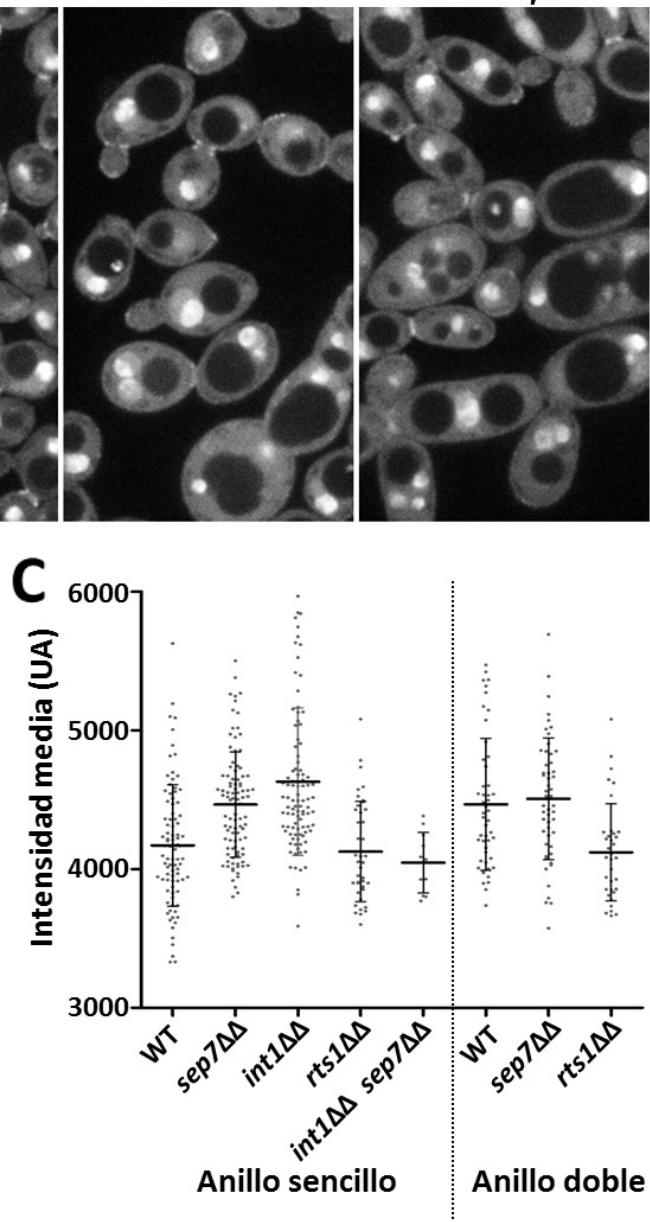

Figura 68. Localización de Glc7 en los mutantes anillina/septinas. (A). Análisis por microscopía de fluorescencia de Glc7-GFP en las cepas silvestre (WT), int $1 \Delta \Delta$, sep $7 \Delta \Delta, \operatorname{rts} 1 \Delta \Delta$ e int $1 \Delta \Delta \operatorname{sep} 7 \Delta \Delta$ en su estado de levadura. Las imágenes son la proyección máxima de 3 planos adquiridos cada 0,4 $\mu \mathrm{m}$. Barra de escala: $5 \mu \mathrm{m}$. (B). Representación gráfica del porcentaje de células con/ sin anillo (sencillo o doble) de Glc7-GFP en las mismas cepas. (C). Intensidad media de, al menos, cincuenta anillos de Glc7GFP en las mismas cepas, con la desviación típica (SD). GLC7-GFP (OL2556), int1 $\Delta \triangle$ GLC7-GFP (OL2586), sep7D $\triangle$ GLC7-GFP (OL2558), rts1 $\triangle$ GLC7-GFP (OL2561) e int1 $\Delta \Delta \operatorname{sep} 7 \Delta \Delta$ GLC7-GFP (OL2563).

En la cepa silvestre de Candida, Glc7-GFP también presentaba una localización en distintos compartimentos celulares, estando presente de forma difusa en el citoplasma y acumulándose en el núcleo y en el cuello. Además era posible observar anillos dobles en el cuello, indicando que permanecía en esa región tras la citoquinesis (Fig. 68A). De nuevo, en los mutantes int1 $1 \Delta \Delta$ y sep $7 \Delta \Delta$ la localización de Glc7 era muy similar a la del silvestre. En el mutante $r t s 1 \Delta \Delta$ también se observaban anillos de Glc7, tanto sencillos como dobles. En el mutante int $1 \Delta \Delta \operatorname{sep} 7 \Delta \Delta$ aparecían células con anillos sencillos de Glc7, aunque nunca se observaron anillos dobles, quizás debido a que los anillos de septinas desaparecen en este mutante tras su duplicación. Cuando se contabilizó el número de células con anillo de Glc7, se comprobó que en torno al $80 \%$ de las células de rts $1 \Delta \Delta$ y un porcentaje ligeramente inferior en el mutante int $1 \Delta \Delta \operatorname{sep} 7 \Delta \Delta$ no presentaban señal de Glc7 en el cuello (Fig. 68B). Sin embargo, en este caso la intensidad media de la señal de Glc7-GFP en aquellas células que lo tenían era bastante similar a la del silvestre (Fig. 68C). 
Finalmente, se analizó la localización de la fosfatasa $\mathrm{Cdc} 14$, que en $\mathrm{S}$. cerevisiae es el efector final de la ruta MEN, aunque en C.albicans no es necesaria para la salida de mitosis (Clemente-Blanco et al., 2006). Para ello se contruyeron cepas derivadas del silvestre y de los mutantes int $1 \Delta \Delta, \operatorname{sep} 7 \Delta \Delta, r t s 1 \Delta \Delta$ e int $1 \Delta \Delta \operatorname{sep} 7 \Delta \Delta$ que contenían Cdc14-GFP y se comprobó que no existían diferencias significativas en su localización (datos no mostrados).

Por tanto, todos estos resultados muestran que algunos de los componentes del SPOC presentan defectos en su localización en el cuello de la célula, lo que sugiere que la estructura del anillo de septinas y la función del SPOC están también íntimamente ligadas en C. albicans y apoyan la idea de que la integridad del cuello es crucial para la señalización del SPOC. 



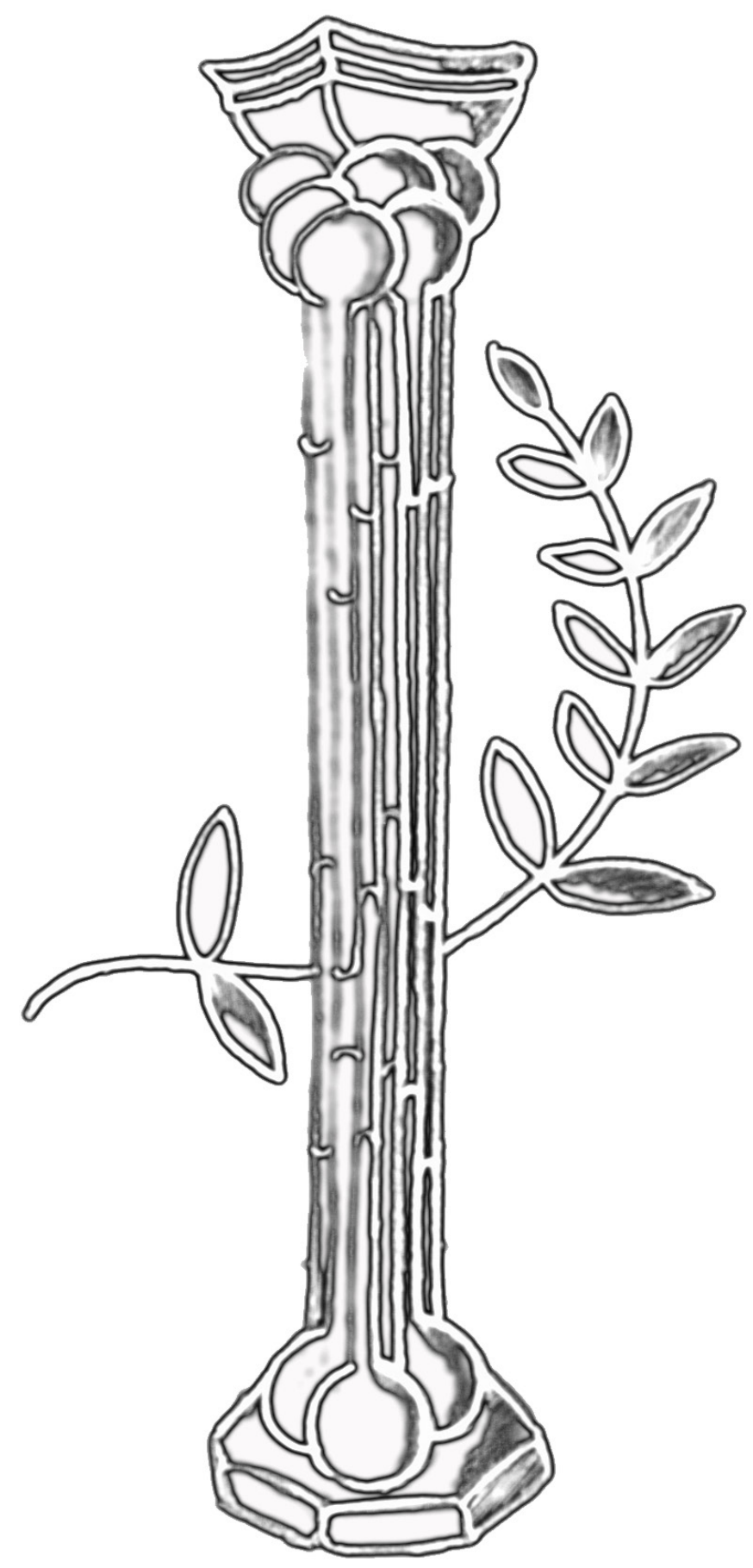

Discusión 



\section{Las septinas en el desarrollo de $C$. albicans.}

Las septinas son una familia de proteínas conservada en células eucariotas (con la excepción de plantas) que desempeñan funciones esenciales en los procesos de morfogénesis y citoquinesis. Esta familia de proteínas ha sido ampliamente estudiada en la levadura S. cerevisiae, donde son necesarias para la septación y citoquinesis, entre otras funciones de gran importancia para las células. De hecho, en los últimos años el conocimiento de la estructura y organización de los complejos supramoleculares de septinas ha sufrido un espectacular avance en S. cerevisiae gracias a la combinación de estudios in vivo e in vitro. A pesar de que $S$. cerevisiae y $C$. albicans son similares morfológicamente, divergieron de un ancestro común hace 200 millones de años, adaptándose a nichos diferentes, por lo que el estudio de las septinas en $C$. albicans resulta interesante por varios motivos. Primero, poco es lo que se sabe de la funcionalidad de este importante elemento del citoesqueleto en C. albicans. Segundo, C. albicans es un patógeno oportunista con transiciones morfológicas que contribuyen a la virulencia, lo que permite estudiar cómo responden las células a estímulos extracelulares y modifican los componentes del citoesqueleto para crecer con una morfología diferente. Además, desde el punto de vista aplicado, puede ayudar a entender la importancia de las septinas en la virulencia. Todo esto, unido a que el interés del grupo de trabajo en los últimos años se ha centrado en el estudio de los mecanismos que regulan la separación celular en levaduras, incluyendo S. cerevisiae, S. pombe y C. albicans, y a que estudios previos del laboratorio mostraron que la separación celular de las hifas es dependiente de Sep7 (González-Novo et al., 2008), nos condujo a profundizar en el estudio de las septinas en C. albicans.

1.1 Las estructuras de septinas en levaduras e hifas y su relación con la separación celular.

En C. albicans, el complejo de septinas está constituido por las proteínas Cdc3, Cdc12, Cdc10, Cdc11 y Sep7. De ellas, sólo Cdc3 y Cdc12 son esenciales para el crecimiento de las células, aunque la eliminación de Cdc10 y Cdc11 genera células con defectos morfológicos (Warenda y Konopka, 2002). Aunque todas las septinas se incorporan al anillo en levaduras e hifas, éste tiene características específicas de cada tipo de crecimiento. Una propiedad que los diferencia es la dinámica, ya que los anillos de levaduras están en estado congelado la mayor parte del tiempo y las septinas sólo son móviles durante G1 y en citoquinesis; sin embargo, en hifas se produce un cambio al denominado "estado específico de hifas" (HSS), en el que Cdc10 y Cdc11 son dinámicas, mientras que el resto de septinas permanecen estáticas (González-Novo et al., 2008). Otra de las características diferentes entre ambas morfologías es la separación celular. En levaduras, las dos células se separan después de la citoquinesis, mientras que en hifas permanecen unidas para formar los filamentos típicos. Los datos existentes indicaban que la dinámica del anillo y la separación celular están relacionadas, ya que el mutante $\operatorname{sep} 7 \Delta \Delta$ presenta un reducido intercambio de Cdc10 en hifas y una prematura separación de los compartimentos hifales. La ausencia de Sep7 permite que Cdc14, que en C. albicans regula la separación, se una a los anillos de hifas cuando no lo hace en el silvestre (Clemente-Blanco et al., 2006; González-Novo et al., 2008).

A priori, las diferentes propiedades del anillo en levaduras e hifas podrían ser debidas a varias causas: (i) los anillos de septinas de las hifas tienen algún componente estructural diferente o no presente en levaduras, como podrían ser los octámeros mixtos Sep7-Cdc11; (ii) las proporciones relativas de los monómeros cambian de levaduras a hifas, alterando de esta manera las estructuras supramoleculares; (iii) la unión de proteínas reguladoras específicas de una morfología que controlen la estructura del anillo, lo que podría ser dependiente de modificaciones post-traduccionales de alguna septina. 
- En cuanto a la primera posibilidad, la existencia de octámeros mixtos en C. albicans es una hipótesis atractiva. El análisis de los complejos de septinas en $S$. cerevisiae ha demostrado que se unen en filamentos lineales con Cdc11 o Shs1 en los extremos (Bertin et al., 2008), pero no hay evidencias de la existencia de octámeros mixtos con Cdc11 en un extremo y Shs1 en el otro ni in vitro (Garcia et al., 2011) ni in vivo (Finnigan et al., 2015b; Garcia et al., 2011; Iwase et al., 2007; McMurray et al., 2011). A pesar de ello, en C. albicans podría ocurrir que el cambio en el patrón de crecimiento en respuesta a señales que inducen la filamentación produjera la aparición o aumento de estos octámeros. Para comprobar esta hipótesis se realizaron experimentos de sedimentación e inmunoprecipitación en condiciones de alta salinidad, en las que los filamentos se disocian en octámeros (Garcia et al., 2011; Sellin et al., 2011). Este análisis mostró que existe una diferencia reproducible en la sedimentación de los octámeros de levaduras e hifas, lo que puede indicar unas propiedades bioquímicas distintas. En las condiciones usadas (300 mM KCl), cabe suponer que los filamentos estén disociados en sus componentes básicos, por lo que no deben ser producidas por distinto grado de polimerización (en algunos gradientes se observó que una ligera fracción de Sep7 y/o Cdc11 sedimentaba en las fracciones más densas, que podrían corresponder con octámeros no disociados). En todos los casos, las septinas aparecían en fracciones con un coeficiente de sedimentación menor al esperado (el coeficiente $S$ esperado era 16-21S, pero aparecían en las fracciones correspondientes a 11-15S, Fig. 26). Esto podría deberse a que los octámeros son bastones lineales de $32 \mathrm{~nm}$ de longitud, lo que puede alterar su sedimentación en comparación con una proteína globular. Otra evidencia que apoya que las estructuras se han separado en octámeros es que el coeficiente de sedimentación de los picos de nuestro análisis coincide con el descrito para los octámeros de mamíferos (Sellin et al., 2011; Sellin et al., 2012).

Para comprobar si en C. albicans existían octámeros mixtos, se realizaron experimentos de inmunoprecipitación en las fracciones del gradiente, precipitando $\mathrm{Cdc} 11$ y analizando si en el precipitado también aparecía Sep7. Este experimento se basa en la asunción de que en las fracciones del gradiente existe una población de octámeros aislados, de tal manera que al precipitar una de las septinas del extremo estamos preguntando si en el otro está la misma septina u otra diferente. Además, no se pueden realizar en extractos totales porque si en ellos quedan restos de filamentos, siempre aparecerían Sep7 y Cdc11 en los inmunoprecipitados, como se muestra en otros experimentos (Figs. 27 y 30B). Los resultados indicaron la existencia de una fracción de octámeros que podrían ser mixtos, pero la abundancia relativa no variaba de levaduras a hifas (Fig. 26). En ambos casos era similar y representaba un porcentaje muy minoritario frente al total de octámeros presentes en cada condición (no supone más del 1-2\%). No obstante, no podemos descartar rotundamente que esta pequeña fracción sea debida a filamentos no separados, puesto que no se han analizado las fracciones por microscopía electrónica para comprobar su grado de disociación. Por tanto, como ocurre en S. cerevisiae (Garcia et al., 2011), no parece haber evidencias de la existencia de hetero-octámeros Cdc11-Sep7 y el pequeño porcentaje observado no está regulado en el desarrollo.

- La segunda posibilidad planteada es que las diferencias entre levaduras e hifas se deban a la variación de las proporciones relativas de los monómeros de septinas en función del tipo de crecimiento, alterando de esta manera las estructuras supramoleculares. Esta hipótesis se basa en las observaciones realizadas en $S$. cerevisiae, donde recientemente se ha propuesto un modelo de organización de los filamentos en el cuello (Ong et al., 2014). Según estos autores, el collar de septinas está formado por filamentos dobles organizados paralelamente al eje madre-hija y filamentos sencillos ortogonales que 
se cruzan con los dobles (Fig. 9B). Estos autores postularon que los filamentos dobles contendrían Cdc11 mientras que Shs1 formaría los filamentos ortogonales. Puesto que en Candida no existen datos sobre la organización de las septinas in vivo ni en levaduras ni en hifas, es necesario asumir que la arquitectura podría ser similar a la de $S$. cerevisiae. Esto se apoya en estudios recientes que han demostrado que los filamentos se organizan por pares in vivo y que cambian de orientación $90^{\circ}$ tras la duplicación en S. cerevisiae, A. gossypii y células epiteliales de mamíferos (DeMay et al., 2010). Por tanto, podemos pensar que en $C$. albicans también existirían filamentos dobles paralelos al eje mayor que estarían formados por Cdc11 y filamentos ortogonales con octámeros Sep7 y octámeros Cdc11.

En S. cerevisiae se ha comprobado que la sustitución de Cdc11 por Shs1 afecta dramáticamente a la disposición supramolecular de las septinas y se ha sugerido que esto podría ser un mecanismo para producir complejos con diferentes propiedades estructurales $y$, por tanto, diferente especificidad funcional (Garcia et al., 2011). La presencia de múltiples subunidades relacionadas proporciona plasticidad fisiológica en vez de redundancia, porque aporta nuevas superficies para interacciones alternativas entre subunidades $y$, potencialmente, para interacciones con diferentes conjuntos de proteínas asociadas. Esta podría ser la base estructural de las diferencias entre los anillos de hifas y levaduras en $C$. albicans. sep $7 \Delta \Delta$ es el único mutante de septinas que presenta un leve defecto en levaduras (Warenda y Konopka, 2002), pero tiene un fenotipo de separación celular de las hifas (González-Novo et al., 2008), por lo que cabría pensar que la pérdida de la función de Sep7 compromete más el crecimiento hifal que el levaduriforme. Por tanto, esto sugiere que la incorporación de octámeros Sep7 confiere unas propiedades especiales a las estructuras de las septinas en hifas. Esta dependencia de Sep7 podría ser debida a causas físicas que diferencian ambos anillos: los de levaduras tienen un diámetro medio de 1,4-1,5 $\mu \mathrm{m}$ y se ensamblan en el cuello, una región donde la membrana tiene una gran curvatura. Por el contrario, el crecimiento apical de las hifas condiciona la formación de los anillos, pues en este caso se posicionan en las paredes laterales de un filamento con un diámetro fijado, por lo que debe adaptarse a las características del tubo germinativo existente. Por ello, el diámetro corresponde con el diámetro de las hifas (media de 1,8 $\mu \mathrm{m}$ ). Además, como las paredes de las hifas son paralelas, no existe curvatura de membrana en esta región. Si asumimos que la arquitectura en hifas es similar a la de levaduras, esta diferencia en el diámetro no debería afectar al ensamblaje de los filamentos dobles paralelos al eje mayor. Sin embargo, los filamentos ortogonales (con octámeros Sep7 y octámeros Cdc11) sí que deben variar su longitud y curvatura para adaptarse a la nueva longitud de la circunferencia de las hifas. Aunque la ausencia de Sep7 no parece alterar la incorporación de las demás septinas en anillos (Cdc10-GFP se localiza en el cuello en el mutante $\operatorname{sep} 7 \Delta \Delta$ ), se aprecian sutiles diferencias en la estructura en levaduras (asimetría), similares a las descritas en S. cerevisiae (Garcia et al., 2011). Mediante estudios de microscopía electrónica, se comprobó que la ausencia de Shs1 altera la arquitectura de las septinas en la transición collar a doble anillo, ya que las uniones de los filamentos eran menos frecuentes. Por tanto, Shs1 es necesaria para controlar la longitud, localización y organización de los filamentos y arquitectura del collar (Ong et al., 2014). Además, se ha demostrado que en A. gossypii la ausencia del coiled-coil de Shs1 hace que las estructuras de septinas se formen en áreas convexas, lo que sugiere que regula la curvatura de las estructuras de septinas (Meseroll et al., 2012). Podríamos pensar entonces que en $C$. albicans los defectos de asimetría del anillo de septinas en levaduras y la separación celular de los compartimentos hifales durante el crecimiento filamentoso del mutante $\operatorname{sep} 7 \Delta \Delta$ se deban a que la mayoría de los filamentos ortogonales están ausentes o son aberrantes, como pasa en el mutante shs1 $\Delta$ en $S$. cerevisiae. 
Según este modelo, la formación de los filamentos ortogonales condiciona la estructura del anillo, por lo que sería sensible a los cambios en la cantidad de octámeros formados por Shs1/Sep7 o Cdc11. Mediante los análisis de sedimentación de los octámeros de $C$. albicans desarrollados en esta Memoria no se ha podido diferenciar si existen un mayor o menor número de octámeros homo-diméricos de Cdc11 o Sep7 según el tipo de crecimiento, aunque sí se comprobó que existen diferencias de sedimentación en ambas morfologías (Fig. 26). Sin embargo, varias evidencias genéticas obtenidas del análisis de mutantes heterocigóticos apuntan a que esta posibilidad puede ser correcta, y que mantener una proporción adecuada entre los octámeros Cdc11 y octámeros Sep7 es crítica durante el crecimiento hifal, al menos para mantener los compartimentos unidos. Primero, de todos los heterocigóticos sencillos, únicamente en los mutantes SEP7+/- y CDC11+/- se activa la separación de las hifas. Segundo, el mutante heterocigótico doble SEP7+/- CDC11+/- corrige el defecto de la separación celular. El hecho de que la dosis génica de las septinas que se encuentran en los extremos de los octámeros (Sep7 o Cdc11) condicione la separación celular en hifas puede indicar que cuando se reduce la cantidad de una de ellas, la proporción de filamentos paralelos vs. ortogonales se ve alterada. Se podría pensar que en el mutante $S E P 7+/$ la proporción de filamentos ortogonales formados por Sep7 fuera menor, alterando su curvatura. Del mismo modo, en el mutante de CDC11+/- disminuiría el número de filamentos dobles paralelos y ortogonales formados por Cdc11. Consecuente con esta idea, el mutante heterocigótico SEP7+/- CDC11+/- recupera la inhibición de la separación, ya que las proporciones relativas de filamentos paralelos y ortogonales serían similares a las de un silvestre.

Para el caso del mutante $C D C 10+/-$, es posible que además de los octámeros Cdc11 o Sep7, también se generen hexámeros por unión de Cdc3 (Sep7/Cdc11-Cdc12-Cdc3-Cdc3-Cdc12-Sep7/Cdc11)(McMurray et al., 2011). Esto afectaría por igual a los filamentos paralelos y ortogonales, y de ahí la ausencia de fenotipo de separación celular. Sin embargo, es llamativo que la combinación de CDC10+/- con SEP7+/- o CDC11+/- tenga fenotipos opuestos (CDC10+/- SEP7+/- suprime el fenotipo de separación mientras que $C D C 10+/-C D C 11+/-$ presenta un alto porcentaje de cuerpos separados). Se sabe que Shs1 tiene menos afinidad para unirse a Cdc12 que Cdc11, ya que la expresión de Shs1 con otras septinas en bacterias produce una proporción significativa de hexámeros y heptámeros además de octámeros (Garcia et al., 2011). La diferente afinidad de Sep7 o Cdc11 para unirse a los extremos podría condicionar la cantidad o estabilidad de los hexámeros ( $\sin \mathrm{Cdc} 10$ ) que se forman, y por tanto explicar la diferencia de los mutantes SEP7+/- y CDC11+/- ante la bajada de la dosis de CDC10. Esto podría sugerir que los hexámeros formados por Cdc11 o Sep7 podrían tener una diferente afinidad para unirse a las estructuras supramoleculares de septinas. Como un mecanismo adicional, las proporciones de Sep7, Cdc11 y Cdc10 podrían ser críticas para determinar la polimerización de filamentos y su asociación a las membranas, ya que se ha demostrado en S. cerevisiae que los residuos básicos del extremo $\mathrm{N}$-terminal de Cdc10, Cdc11 y Shs1 son esenciales para la interacción de los filamentos de septinas con el fosfatidilinositol 4,5-bisfosfato de las membranas (Bertin et al., 2010; Finnigan et al., 2015b; McMurray et al., 2011). Si asumimos que esta función está conservada en C. albicans, podría ocurrir que la alteración de las proporciones de estas tres subunidades afecte a la interacción de los filamentos con la membrana, y esto tenga mayor efecto en hifas debido a la diferente curvatura de membrana.

Otro resultado sorprendente de este trabajo es que no parece existir una correlación clara entre la inhibición de la separación celular y el estado específico de hifas del anillo de septinas. El análisis de su dinámica en hifas en las cepas SEP7+/, CDC11+/- y SEP7+/-CDC11+/- mostró que era similar a 
la del mutante $\operatorname{sep} 7 \Delta \Delta$, ya que existía un menor intercambio de Cdc10 con el citoplasma que en la cepa silvestre. Esto no se correlaciona con el fenotipo, ya que las hifas SEP7+/- y CDC11+/- activan prematuramente la separación (porcentaje superior al 20\%)(Figs. 19-20), mientras que el mutante SEP7+/- CDC11+/- es similar al silvestre (Fig. 21). Por lo tanto, al contrario de lo pensado inicialmente (González-Novo et al., 2008), el estado específico de hifas, por sí sólo, no regula la inhibición de la separación celular, por lo que deben existir factores adicionales que contribuyan a regular este proceso.

- Además de la estequiometría de las distintas subunidades, la tercera posibilidad planteada es que la unión de proteínas reguladoras específicas de una única morfología controlen la estructura y/o propiedades de los anillos. Estudios de microscopía electrónica sugieren que los coiled-coils de las septinas juegan un papel importante en la asociación de los filamentos y su interacción con las membranas (Bertin et al., 2008). En los últimos años se ha descrito que el CTE de las septinas desempeña un papel importante en la organización de los anillos, aunque hay notables diferencias funcionales (Booth et al., 2015; Finnigan et al., 2015b). Los CTEs de Cdc3 y Cdc12 son esenciales para la formación de filamentos, ya que los de cuatro subunidades se asocian formando un haz de cuatro hélices (four-helix bundle) que posiciona a los octámeros de dos filamentos en registro (Fig. 10B) (Bertin et al., 2008; Bertin et al., 2010; Versele y Thorner, 2004). Por el contrario, los CTEs de Cdc11 y Shs1 contribuyen a la organización supramolecular y/o la dinámica de las estructuras de septinas por reclutamiento de otras proteínas a través de la interacción con sus coiled-coils (Finnigan et al., 2015a). En S. cerevisiae, se ha demostrado que Shs1 interacciona físicamente con proteínas del cuello, como componentes del polarisoma (Mino et al., 1998), proteín kinasas (Bouquin et al., 2000; Mortensen et al., 2002; Okuzaki et al., 1997; Shulewitz et al., 1999) y otras proteínas como Bni5 (Finnigan et al., 2015a). El reclutamiento de proteínas específicas podría explicar las diferencias de sedimentación observadas entre los octámeros de hifas y levaduras (Fig. 26). Aunque las interacciones iónicas entre proteínas deben ser pocas a la molaridad usada $(0,3 \mathrm{M} \mathrm{NaCl})$, mediante inmunoprecipitación a partir de extractos totales, se ha observado la presencia de proteínas específicas en los anillos de hifas (Fig. 27). En C. albicans, un buen candidato es la kinasa Gin4, que interacciona con las septinas y fosforila a Sep7 (Li et al., 2012a). Además, su actividad kinasa es necesaria para la reorganización de las septinas desde el cap a anillos, por lo que la modificación de la dinámica del anillo de septinas dependiente de Sep7 podría estar mediada por Gin4. Sin embargo, nuestros datos indican que Sep7 no es necesario para la localización de Gin4 en el cuello ni en levaduras ni en hifas. A pesar de ello, Sep7 podría regular o modular la actividad kinasa de Gin4 o la función de Gin4 independiente de su actividad kinasa, y este defecto podría estar relacionado con la separación celular.

El defecto de separación de las hifas del mutante $\operatorname{sep} 7 \Delta \Delta$ podría ser debido a que el CTE de Sep7 fuera necesario para el reclutamiento de alguna proteína reguladora desconocida y que no se asocie a las septinas en ausencia de Sep7. Para comprobar si esta posibilidad era correcta, se construyeron las cepas $C D C 11^{\text {CTEC-Sep7 }}$ y $C D C 11^{\text {CTE-Sep7 }}$, en las que se reemplazaron distintas regiones del CTE de Cdc11 por el de Sep7. Sin embargo, ninguna de las dos construcciones fue capaz de complementar el defecto del mutante sep $7 \Delta \Delta$ (Fig. 34). Aunque en S. cerevisiae los CTEs de Shs1 y Cdc11 son intercambiables y comparten funciones en el ensamblaje de los anillos de levaduras (Finnigan et al., 2015b), nuestros análisis del CTE de Sep7 y Cdc11 en C. albicans parecen indicar que en este organismo no son completamente intercambiables y tienen funciones específicas durante la inducción hifal. Aunque las cepas con estas quimeras no tienen defectos morfológicos en levaduras, no cabe descartar que las 
quimeras de Cdc11 presenten defectos en su incorporación al anillo, ya que no se ha analizado ni su localización in vivo ni su asociación a otras septinas por inmunoprecipitación.

El análisis de los fenotipos de los mutantes con truncamientos de Sep7 (sep7t-394, sep7t-522, sep7t-580 y sep7t-629, Fig. 31) aporta algunas conclusiones interesantes sobre la funcionalidad de esta región en $C$. albicans. En primer lugar, el coiled-coil no parece ser determinante para la inhibición de la separación de las hifas, ya que los mutantes sep7t-522 y sep $7 t-580$ presentan un porcentaje de cuerpos separados similar al de la cepa silvestre aunque Sep7t-580 contiene el coiled-coil y Sep7t-522 no. Esto está en controversia con recientes estudios en $S$. cerevisiae y A. gossypii, en los que se ha demostrado que el coiled-coil es la región importante para el desempeño de sus funciones (Finnigan et al., 2015b; Meseroll et al., 2012; Meseroll et al., 2013). En segundo lugar, la región comprendida entre las posiciones 394 y 522 es esencial para la inhibición de la separación mediada por Sep7. Aunque las proteínas Sep7t-394 y Sep7t-522 se incorporan de forma similar al anillo en los dos tipos de crecimiento, las hifas del mutante sep $7 t-394$ tienen un alto porcentaje de separación mientras que sep7t-522 es similar al silvestre. Por tanto, en el CTE de Sep7 puede existir una región necesaria para la regulación de la separación de las hifas, proceso morfogenético específico de Candida que no ocurre en los otros dos organismos. Finalmente, cabe destacar que en esta región se concentra uno de los grupos de sitios fosforilados identificados en los análisis de espectrometría de masas (Grupo I, Fig. 30), por lo que cabe la posibilidad de que la función de Sep7 durante el crecimiento filamentoso sea regulada por la fosforilación de esta región.

\subsection{Regulación de las septinas por modificaciones post-traduccionales.}

Las septinas sufren modificaciones post-traduccionales que a menudo tienen importantes efectos en el ensamblaje de las estructuras supramoleculares y en su función, siendo los tipos más comunes la fosforilación, acetilación y SUMOilación (revisado en Hernández-Rodríguez y Momany, 2012). La diferencia en la sedimentación de los octámeros de hifas y levaduras podría ser debida a alguna modificación post-traduccional específica de una de las morfologías. En principio, la fosforilación no debería alterar drásticamente la sedimentación ya que los fosfatos son moléculas de reducido tamaño, pero las ubiquitinaciones o SUMOilaciones añaden moléculas más voluminosas a las proteínas que las sufren. Sin embargo, las septinas de $C$. albicans no son SUMOiladas ni en levaduras ni en hifas (Martin y Konopka, 2004). Algunas de las septinas de C. albicans, como Cdc11, se acetilan, y existen estudios en S. cerevisiae y A. gossypii que sugieren que la acetilación puede influenciar el ensamblaje y la estabilidad de los polímeros (Hernández-Rodríguez y Momany, 2012).

Sin duda alguna, la fosforilación es la modificación post-traduccional que más contribuye a regular la función de las septinas, inhibiendo o alterando el ensamblaje y, por tanto, la función de las estructuras de septinas. Se ha propuesto que la fosforilación podría regular esta estructura debilitando la interacción septina-septina y con ello potenciando el desmontaje del anillo o la disociación de una subunidad individual y permitiendo su sustitución por otra subunidad alternativa (Garcia et al., 2011). En S. cerevisiae, existen numerosos datos que indican que la fosforilación-defosforilación de algunas subunidades es importante para su función. Por ejemplo, se ha descrito que la fosforilación de Cdc3 por Cdc28 favorece la disolución del anillo (Tang y Reed, 2002) y que la fosforilación de Cdc10 por Cla4 promueve la formación de filamentos (Schmidt et al., 2003; Versele y Thorner, 2004). Para Shs1, su defosforilación por la fosfatasa PP2A unida a Rts1 es necesaria para el desmontaje del anillo duplicado 
al final de la citoquinesis (Dobbelaere et al., 2003). Sin embargo, recientemente se ha comprobado que la sustitución de los sitios de fosforilación del CTE de Shs1 por Ala no afecta de forma detectable a la función Shs1 in vivo, a excepción de en el fondo cdc10 (Finnigan et al., 2015b).

En C. albicans también hay datos sobre la regulación de las septinas por fosforilación. Así, Gin4 fosforila a Cdc11 durante el ciclo celular permitiendo que, tras recibir la señal de la inducción del desarrollo hifal, el complejo Ccn1-Cdc28 la fosforile en un residuo adyacente necesario para el inicio y manteniendo el crecimiento polarizado (Fig. 11)(Sinha et al., 2007). Hasta la fecha, únicamente se ha descrito un mutante que durante la filamentación es incapaz de ensamblar los anillos de septinas, y es el mutante gin $4 \Delta \Delta$. En este mutante, las septinas se localizan normalmente en la banda basal y en el cap, pero no forman anillos (Sinha et al., 2007; Wightman et al., 2004). Por tanto, la actividad kinasa de Gin4 es necesaria para la formación de los anillos. También se ha comprobado que Gin4 fosforila y se asocia con Sep7, aunque no se han identificado los residuos de Sep7 que son modificados (Li et al., 2012a; Wightman et al., 2004). Además, se demostró que Gin4 tiene funciones independientes de su actividad kinasa que son esenciales para el ensamblaje del anillo de septinas (Li et al., 2012a). Finalmente, la kinasa Cla4 también regula el ensamblaje del anillo de septinas en C. albicans (Huang et al., 2014). Es interesante que la defosforilación de proteínas que se localizan en el cuello junto con Sep7 depende de las fosfatasas Rts1 y Cdc14 (Tesis Doctoral de Caballero-Lima, 2009; Clemente-Blanco et al., 2006; Huang et al., 2014).

Nuestros resultados muestran que Sep7 sufre un incremento en los niveles de proteína cuando se induce filamentación, así como un cambio en el patrón de fosforilación (Fig. 29). Este comportamiento de Sep7 en filamentación no es un fenómeno generalizado en las septinas (González-Novo, 2005), por lo que podría ser una indicación de que la modificación del patrón morfogenético en $C$. albicans viene acompañada por una modificación específica de Sep7. Para analizar la importancia de la fosforilación en las septinas y su posible implicación en la regulación de la transición levadura-hifa se analizaron los sitios fosforilados in vivo en levaduras e hifas por espectrometría de masas en Sep7 y Cdc11, las dos subunidades terminales de los octámeros. Los resultados indicaron que Cdc11 estaba menos fosforilada y sufría las mismas modificaciones en levaduras e hifas mientras que en Sep7 había una mayor abundancia de sitios fosforilados, existiendo algunos específicos de cada morfología. Esto podría indicar que las modificaciones específicas de un tipo de crecimiento confieren funciones distintas a los anillos de levaduras o hifas. Recientemente se ha publicado el fosfoproteoma completo de Candida durante el crecimiento hifal (Willger et al., 2015), y nuestros datos coinciden sustancialmente con los de este trabajo, aunque hay algunos sitios que estos autores describen que no han aparecido en nuestro análisis (o la probabilidad asignada al péptido fosforilado era muy baja y no se consideraron positivos). Este es el caso, por ejemplo, de los sitios S295 y S323 de Cdc11 que se encontrarían fosforilados en hifas y no aparecieron en nuestro análisis. En la Figura 69 se han representado los datos combinados de ambos estudios.

La comparación de los sitios fosforilados en C. albicans con los descritos en S. cerevisiae y A. gossypii muestra algunas diferencias interesantes entre los tres microorganismos (Fig. 69). En primer lugar, la conservación de los sitios de fosforilación en Cdc11 es pobre. Es interesante que la región comprendida entre el dominio GTPasa y el coiled-coil en S. cerevisiae y A. gossypii es mayor (42 y 36 aa, respectivamente) que en $C$. albicans y en ella se localizan la mayoría de los sitios identificados en estos organismos. En C. albicans, los sitios identificados se localizan al final del dominio GTPasa, al inicio 
del coiled-coil (que coinciden posicionalmente con uno de los descritos en S. cerevisiae) y en la región C-terminal, que es ligeramente más larga (17 aa) y contiene los dos sitios de fosforilación esenciales para la filamentación (Ser394 y Ser395)(Sinha et al., 2007). Estos dos sitios se encuentran en una secuencia acídica (EEESSENE), por lo que su fosforilación generaría un extremo altamente negativo. A pesar de que se ha descrito que Ser395 se fosforila por Ccn1-Cdc28 en respuesta a la inducción hifal (Sinha et al., 2007), en nuestro análisis ha aparecido fosforilada también en levaduras. Esto podría ser debido a una diferencia cuantitativa, es decir, es probable que exista un nivel basal de fosforilación durante el crecimiento levaduriforme y que se incremente durante la transición a hifas, por lo que se detecta esta modificación en ambos tipos de crecimiento. En este trabajo no se ha analizado la importancia de los sitios de Cdc11 en el ensamblaje del anillo o en la regulación de la separación celular, aunque en el futuro será interesante comprobar por mutagénesis dirigida si alguno de ellos es relevante.

Para el caso de Shs1/Sep7, esta septina es una de las proteínas más fosforiladas de todo el genoma, y los aminoácidos fosforilados se concentran fundamentalmente en dos regiones, una entre el dominio GTPasa y el coiled-coil y otra entre el coiled-coil y el final de la proteína (Fig. 69). A pesar de la poca conservación de la secuencia de estas regiones, el patrón global de fosforilación parece conservado, lo que podría indicar que existe cierta conservación en la función de estas modificaciones. Para su estudio, los grupos de fosforilación conservados en Sep7/Shs1 fueron denominados Grupo I (región 394-522) y Grupo I/ (580-extremo carboxilo). Los resultados obtenidos indican que el Grupo I de Sep7 es necesario para inhibir la separación celular en hifas, ya que el mutante sep7-10A presenta un porcentaje de separación celular similar a sep $7 \Delta \Delta$ (Fig. 32). Este resultado concuerda con el hecho de que en esta región se encuentran varios residuos cuya fosforilación parece específica de hifas (Fig. 69) y coincide con la región de Sep7 necesaria para mantener los compartimentos hifales unidos identificada mediante truncamientos (Fig. 31). Dado que la proteína Sep7-10A tiene una localización silvestre tanto en hifas como levaduras, pero el mutante fosfodeficiente se comporta como el mutante $\operatorname{sep} 7 \Delta \Delta$ en condiciones de filamentación, podemos pensar que la fosforilación del Grupo I no es importante para que Sep7 se una al anillo, pero sí para otorgarle funciones específicas relacionadas con la separación, bien sea porque esta versión fosforilada de Sep7 active o bloquee la unión de otras proteínas al anillo o porque la fosforilación sea necesaria para que Sep7 forme parte de alguna ruta de señalización. Una posibilidad interesante es que en el mutante sep7-10A la fosfatasa Cdc14 sea capaz de unirse al anillo de septinas de hifas, activando la separación celular de forma prematura. En todo caso, la región 394-552 de Sep7 y su fosforilación parece haber surgido como una adpatación para regular una función específica de la biología de $C$. albicans, como es la inhibición de la separación celular durante el crecimiento filamentoso, no presente ni en S. cerevisiae ni en A. gossypii.

Por otro lado, la fosforilación del extremo C-terminal de Sep7 parece controlar procesos estructurales de la organización del anillo de septinas durante su duplicación en hifas, ya que los anillos del mutante sep7-8A tienen problemas para duplicarlo. Este dato está en contradicción con lo observado en el mutante sep7t-629 (que elimina 41 aa del extremo C-terminal, incluidos los ocho sitios modificados en sep7-8A). Aunque en ambos casos el anillo se duplica, en el mutante sep7-8A se observan defectos o retrasos en la duplicación. Esta diferencia podría ser debida a que el extremo sin fosforilar de Sep7-8A actúe como un regulador negativo e impida que Sep7 ejerza su función correctamente. De esta forma, la versión truncada de Sep7 carecería de los sitios de regulación negativa, actuando como una proteína silvestre. Sin embargo, Sep7-8A contiene cambios a Ala en los cuatro sitios identificados 

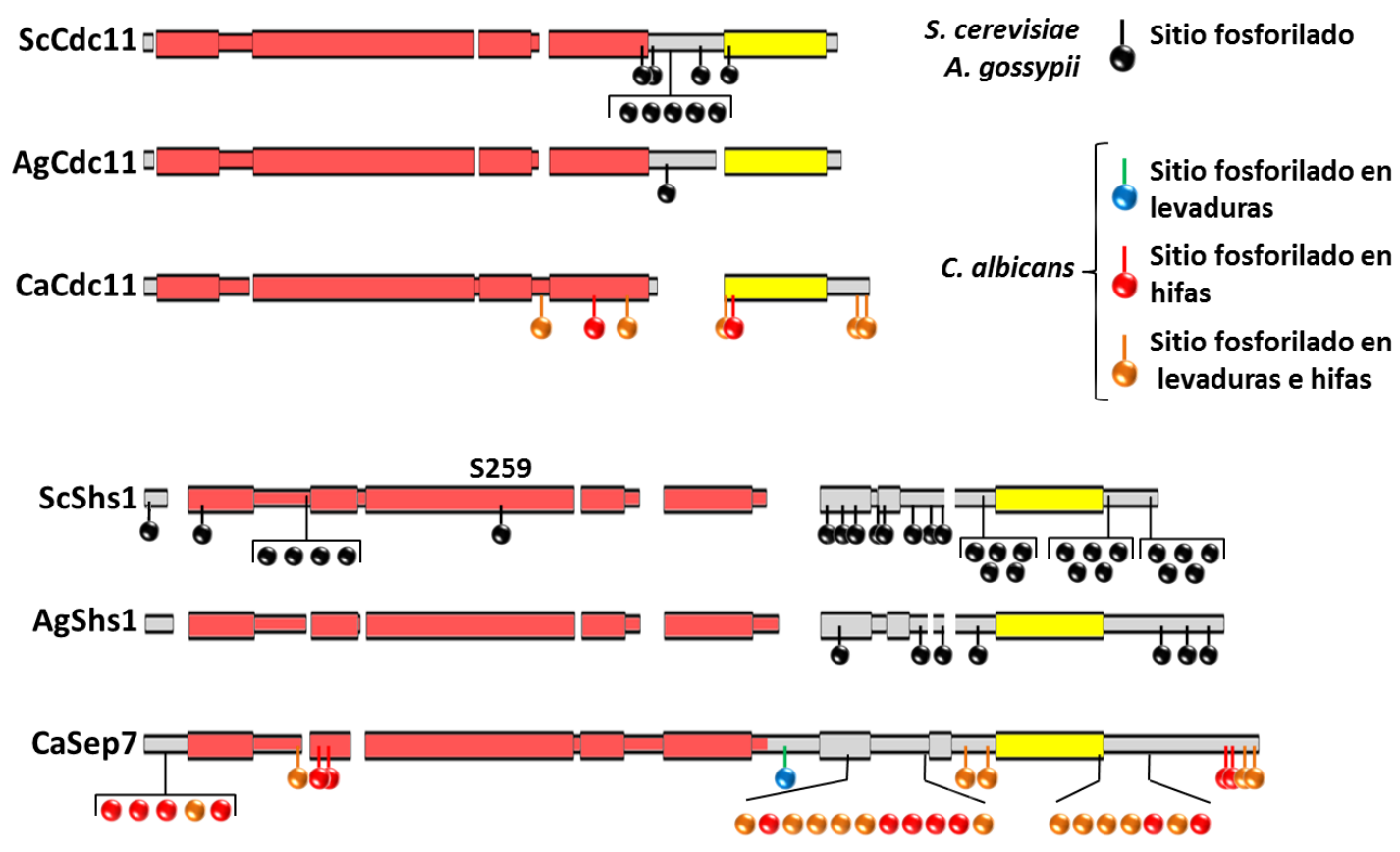

Figura 69. Regulación de Cdc11 y Shs1/Sep7 por fosforilación. Representación esquemática de Cdc11 y Shs1/Sep7 de S. cerevisiae, A. gossypii y C. albicans y los sitios de fosforilación identificados in vitro/in vivo. Están indicados los dominios GTPasa (rojo) y coiled-coil (amarillo). Los huecos representan regiones que no están presentes en la proteína. Los datos de Shs1 y Cdc11 en S. cerevisiae han sido tomado de SGD y los de A. gossypii de DeMay et al. (2009) y Meseroll et al. (2013). En C. albicans se han representado los datos obtenidos del estudio de Cdc11 y Sep7 por espectrometría de masas llevado a cabo en esta Memoria y los sitios adicionales que se han descrito en Willger et al. (2015).

como fosforilados (tres de los cuales también se han cambiado en Sep7-3A) y en otras cuatro Ser/Thr adyacentes y dado que Sep7-3A no parece afectar a la duplicación de los anillos de hifas, no podemos descartar que la sustitución de las $8 \mathrm{Ser} /$ Thr por Ala esté modificando la estructura tridimensional de esta región y afectando el correcto funcionamiento del anillo de septinas, especialmente el de las hifas por sus peculiaridades.

Entre los sitios de fosforilación no conservados posicionalmente cabe destacar, en primer lugar, la Ser259 de S. cerevisiae, cuya fosforilación puede permitir el ensamblaje de septinas al promover la forma de "gasa" en el anillo (Garcia et al., 2011), que no está presente en A. gossypii y C. albicans. En segundo lugar, la divergencia en el número de sitios de fosforilación del extremo amino en los tres microorganismos. Aunque en S. cerevisiae se ha descrito que Shs1 está fosforilado in vivo en Thr6 (Egelhofer et al., 2008), la mutación de este residuo a Ala no tiene efectos fenotípicos (Garcia et al., 2001). Sin embargo en C. albicans, en esta región se localizan 5 sitios fosforilados, 4 de los cuales son específicos de hifas (Ser10, Thr13, Ser14 y Ser22) y el $5^{\circ}$ (Ser21) aparece en ambas morfologías. Esto sugiere que la fosforilación de esta región de Sep7 podría conferirle una función específica en hifas. De hecho, nuestros datos apuntan a que la fosforilación de al menos dos de ellos (Ser14 y Ser22) es necesaria para la correcta función de Sep7 en hifas. El mutante sep7-2A tiene graves defectos en la separación celular de las hifas, ya que a diferencia de un silvestre y del mutante fosfomimético sep7-2E, los compartimentos hifales permanecían unidos tras $4,5 \mathrm{~h}$ de filamentación. Sin embargo, cuando se analizó la localización de Sep7-2A-GFP y la estructura de los septos, se comprobó que en muchos casos los anillos de septinas en hifas presentaban defectos en el ensamblaje y no se observaba un septo primario (por tinción con calcoflúor) a pesar de que los septos parecían haberse ensamblado (DIC) (Fig. 36). Esto explicaría la ausencia casi total de separación observada en el mutante sep7-2A, ya que 
si el septo primario no se ha formado correctamente las quitinasas y glucanasas encargadas de su disolución no pueden ejercer su función. Por el contrario, tanto la localización de Sep7-2A-GFP como los septos parecían normales en levaduras. También cuando las hifas comenzaban a gemar lateralmente y revertir al crecimiento levaduriforme, la estructura de los anillos de septinas en la base de las yemas parecía normal. Será necesario comprobar mediante microscopía electrónica la estructura de los septos de este mutante, tanto de hifas como de levaduras, para determinar si esta mutación afecta específicamente al ensamblaje de los septos de hifas. Hay que destacar que los sitios fosforilados del extremo amino se encuentran cerca de la hélice $\alpha 0$, que contiene una serie de residuos básicos importantes para su asociación con los fosfolípidos de la membrana plasmática (Bertin et al., 2010; Zhang et al., 1999). Recientemente se ha descrito que los residuos básicos de la hélice $\alpha 0$ de Cdc11 y Shs1 son importantes para concentrar los octámeros en la membrana e incrementar su incorporación en las estructuras de orden superior (Finnigan et al., 2015b). Es posible que en Sep7-2A, al alterarse el balance de cargas positivas/negativas de esta región, se condicione la unión de esta versión de Sep7 a otros octámeros y/o a los lípidos de membrana, y de ahí la dificultad de compactar los anillos de las hifas. Alternativamente, también es posible que la fosforilación de esta región condicione o module las interacciones de unos octámeros con otros, ya que la hélice $\alpha 0$ es esencial en la formación de las interfaces NC (Fig. 35), y que esto sea determinante para el ensamblaje de los anillos de las hifas.

El defecto en el ensamblaje de los anillos de septinas del mutante sep7-2A podría ayudar a explicar por qué la cepa $C D C 11^{\text {CTEl-Sep7 }}$ sigue activando la separación en hifas a pesar de haber restablecido artificialmente la relación 1:1 entre Cdc11 y un "falso Sep7" que conserva la región más relevante de esta proteína para inhibir la separación celular. El hecho de que las modificaciones del extremo amino de Sep7 en hifas determinen unas características especiales para unirse al anillo podría ser la causa

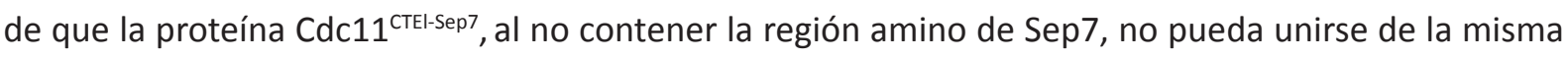
forma al complejo de septinas de hifas y el fenotipo sea parecido al del mutante $\operatorname{sep} 7 \Delta \Delta$.

Además de los estudios sobre la regulación de Sep7 y su implicación en la separación de los compartimentos hifales, también se analizó la importancia de la fosforilación en Cdc12. Se eligió esta septina porque contiene varios posibles sitios de fosforilación por CDK y uno de ellos, Ser64, también puede ser diana de Cbk1-Mob2, pues forma parte de la secuencia HNKFTSP. Dado que recientemente se ha descrito que el mutante hipomorfo mob2-4A (que elimina los 4 sitios consenso de fosforilación por Cdc28) tiene alterada la dinámica del anillo de septinas en hifas de forma similar al mutante $\operatorname{sep} 7 \Delta \Delta$ (Calderón-Noreña et al., 2015), se decidió analizar si esta regulación dependía de la fosforilación de Ser64 en Cdc12. El complejo Cbk1-Mob2 también regula el desarrollo hifal, ya que mob2-4A tiene graves defectos en la morfogénesis de la hifa y activa la separación celular (Gutiérrez-Escribano et al., 2011). Sin embargo, los mutantes $c d c 12-1 A$ y $c d c 12-1 E$ (que modifican la posible diana de Cbk1-Mob2) no tienen ningún fenotipo aparente en levaduras ni en hifas, lo que sugiere que, a pesar de la interacción detectada entre Cbk1 y Cdc12, o bien Cdc12 no es fosforilado por el complejo Cbk1-Mob2 directamente, o si lo hace no tiene ningún efecto la dinámica del anillo de septinas. Por el contrario, los mutantes cdc12-3E y cdc12-4E tienen un fenotipo similar al silvestre en levaduras, pero presentan un porcentaje elevado de hifas con septos incompletos o ausentes a tiempos en los que un silvestre ya ha delimitado, al menos, el primer compartimento. El hecho de que la localización de Cdc12-3E-GFP y Cdc12-4E-GFP en levaduras sea normal y no se observen defectos en el ensamblaje del septo descartaría que estas mutaciones estén alterando sustancialmente la estructura de $\mathrm{Cdc} 12$ y generando una proteína no 
funcional. El defecto observado en los mutantes $c d c 12-3 E$ y $c d c 12-4 E$ sugiere que $C d c 12$ podría estar fosforilado en Thr92 (es el sitio adicional mutado en $c d c 12-3 E$ respecto a $c d c 12-2 E$, que no presenta defectos aparentes, Fig. 42) en levaduras, y que debe ser defosforilado en la transición a hifas. Es precisamente este sitio el único que está conservado en todos los hongos analizados (Fig. 39). Será necesario analizar la fosforilación de Cdc12 en levaduras e hifas para comprobar si esta hipótesis es cierta, ya que en el análisis del fosfoproteoma de hifas publicado Cdc12 es la única septina que no aparece en la lista (Willger et al., 2015). El fallo en citoquinesis podría ser debido a un retraso temporal del ensamblaje del anillo de septinas. La presencia de versiones fosfomiméticas de Cdc12 afecta claramente a la organización de las septinas en hifas, que son incapaces de compactarse en un anillo a pesar de que los filamentos siguen creciendo. El defecto más evidente es que la unión de las septinas en el sitio de citoquinesis no es correcto (muchas veces se disponen en forma de nubes o espirales), lo que produce defectos en el septo naciente, que no se completa y está más engrosado en algunos puntos o la quitina está difusa en la pared lateral de la hifa (Fig. 42). Las septinas en S. cerevisiae son necesarias para delimitar un compartimento especializado en citoquinesis (donde se localizaría el polarisoma, el exocisto y la maquinaria biosintética del septo) e impedir su difusión a la célula madre o hija (Dobbelaere y Barral, 2004). Es posible que en C. albicans las septinas desempeñen un papel similar, y que en ausencia de un anillo de septinas normal la maquinaria biosintética del septo difunda hacia la pared lateral de las hifas, produciendo una deposición anormal de quitina.

En resumen, todo lo expuesto anteriormente demuestra que las septinas han evolucionado tras la separación evolutiva de $S$. cerevisiae y $C$. albicans, adaptándose a la condición pleomórfica de este hongo. Los resultados aportados en esta Memoria claramente indican que los anillos de levaduras e hifas presentan propiedades diferentes, quizás como resultado de la adaptación del ensamblaje de esta estructura citoesquelética a las características propias de cada forma de crecimiento. Durante el crecimiento en forma de hifas, las proporciones relativas de Sep7, Cdc11 y Cdc10 parecen desempeñar un papel relevante en la regulación de la separación de los compartimentos hifales. Específicamente, Sep7 parece haber adaptado su papel regulador del anillo de septinas descrito en otros organismos a controlar la separación de las hifas, conteniendo una región antes del coiled-coil esencial para esta función. El estudio de sitios de fosforilación de las septinas ha permitido determinar que existen algunos que desempeñan un papel estructural y cuya mutación afecta al ensamblaje del anillo y del septo (como ocurre con Sep7-8A, Sep-2A y Cdc12-3E y Cdc12-4E) mientras que otros parecen haberse adaptado a la regulación de la separación de las hifas (Sep7-10A).

\section{Funciones del anillo de septinas de C. albicans.}

Dentro de las funciones que se han descrito para el anillo de septinas en S. cerevisiae están: (a) selección del sitio de gemación, (b) formación de barreras de difusión permitiendo la localización asimétrica de proteínas entre madre-hija, (c) andamio de otras proteínas durante citoquinesis, (d) participar en mecanismos de control, coordinando la morfogénesis celular (o gemación) con la progresión del ciclo celular (checkpoint de morfogénesis), sirviendo de guía en la orientación del huso mitótico en la segregación de cromosomas y colaborando para impedir que las células entren en mitosis hasta que el núcleo esté correctamente orientado (checkpoint de posicionamiento del huso mitótico, SPOC). Mediante el estudio de determinados mutantes en $C$. albicans de esta Memoria, se ha podido comprobar el nivel de conservación de estas funciones con otras levaduras y mamíferos. 
- En primer lugar, (a) la selección del sitio de gemación viene determinada por las septinas y por el homólogo de la anillina, Int1 (ortóloga de Bud4 de S. cerevisiae). Las septinas y la anillina están relacionadas en prácticamente todos los microorganismos estudiados. En S. cerevisiae, Bud4 se localiza en el anillo de septinas y es necesaria para su duplicación (Eluere et al., 2012). En S. pombe, los mutantes mid $2 \Delta$ presentan defectos en la organización y estabilidad del anillo de septinas, que son unas treinta veces más dinámicos que en el silvestre (Berlin et al., 2003; Tasto et al., 2003). En C. albicans, Int1 es importante para la morfogénesis de la hifa, adherencia y virulencia (Gale et al., 1998). Los mutantes int1 $\Delta \Delta$ tienen defectos en el ensamblaje de los anillos de septinas de levaduras e hifas (Gale et al., 2001). Además, la localización de Int1 depende de las septinas, ya que los mutantes sep $7 \Delta \Delta$ o $c d c 10 \Delta \Delta$ presentan un menor número de moléculas de Int1 en el cuello (Fig. 45). Por tanto, en Candida la localización de Int1 en el cuello también es dependiente de las septinas, al menos de Sep7 y Cdc10.

El análisis del fenotipo del mutante int1 $\Delta \Delta$ mostró que presentaba un mayor porcentaje de células sin gemar con anillos de septinas de tamaño reducido "flotando" en el citoplasma (Fig. 49). Esto podría indicar que Int1 está actuando de señalizador y/o marca espacial en el presumible sitio de gemación necesario para el anclaje del anillo de septinas, y que la ausencia del homólogo de la anillina produce un retraso en la localización cortical de las septinas y la posterior emergencia de la yema. De hecho, el mutante int $1 \Delta \Delta$ presenta un mayor número de células sin yema que el silvestre (Fig. 46), que podría ser debido a este retraso, aunque mediante microscopía a lo largo del tiempo se ha comprobado que Int1 se localiza en el nuevo punto de gemación ligeramente después que las septinas (Fig. 44).

- En cuanto a las barreras de difusión (b), se ha descrito en S. cerevisiae que algunas proteínas, como la proteína integral de membrana Ist2, el regulador de la ruta MEN Lte1 y los parches de actina cortical, se localizan exclusiva o preferentemente en la célula hija antes de la transición G2-M, de manera dependiente de las septinas del cuello (revisado en Longtine y $\mathrm{Bi}, 2003$ ). En esta Memoria, el análisis del mutante int $1 \Delta \Delta$ en $C$. albicans permitió estudiar la función de barrera de las septinas, ya que en estas células las septinas se desensamblan en citoquinesis y no se forman anillos dobles normales (Fig. 47). La morfología de las células int $1 \Delta \Delta$ es silvestre y no presenta fallos en crecimiento ni en polaridad (Fig. 46), lo que sugiere que el anillo sencillo de septinas es funcional y actuaría como barrera de difusión impidiendo que los marcadores de polaridad localizados en la célula hija penetren en la madre. Sin embargo, para que la duplicación del anillo de septinas se lleve a cabo correctamente es necesaria la presencia de Int1 en el cuello. De hecho, el análisis por microscopía revela que Int1 y septinas colocalizan durante todo el ciclo celular y que la duplicación del anillo de Int1 precede a la de las septinas (Fig. 44). Se podría pensar que Int1 es necesario para que se reorganicen los octámeros de septinas durante su duplicación o que sirve de andamio para estabilizar el doble anillo una vez formado. Esta función sería similar a la descrita para Bud4 en S. cerevisiae, donde los anillos de septinas también se desensamblan tras la duplicación (Kang et al., 2013). En cualquier caso, Int1 es fundamental para este proceso y por ello se decidió hacer un análisis más exhaustivo de cómo podría controlar la duplicación del anillo de septinas. El análisis de los mutantes int1- $\Delta C$ e int1- $\Delta N$ determinó que el extremo C-terminal (la zona más conservada) es la región más relevante para que Int1 estabilice el anillo de septinas. Consecuentemente, Int1- $\Delta C$ se localiza más pobremente en el cuello y este mutante presenta el mismo defecto que int $1 \Delta \Delta$ (Figs. 55 y 56 ). Sin embargo, el extremo amino también participa en este proceso, ya que la proteína Int1- $\Delta \mathrm{N}$ se localiza bien en el cuello, pero tiene los anillos dobles de septinas menos intensos (Fig. 56). En S. cerevisiae se ha descrito que la deleción del extremo carboxilo 


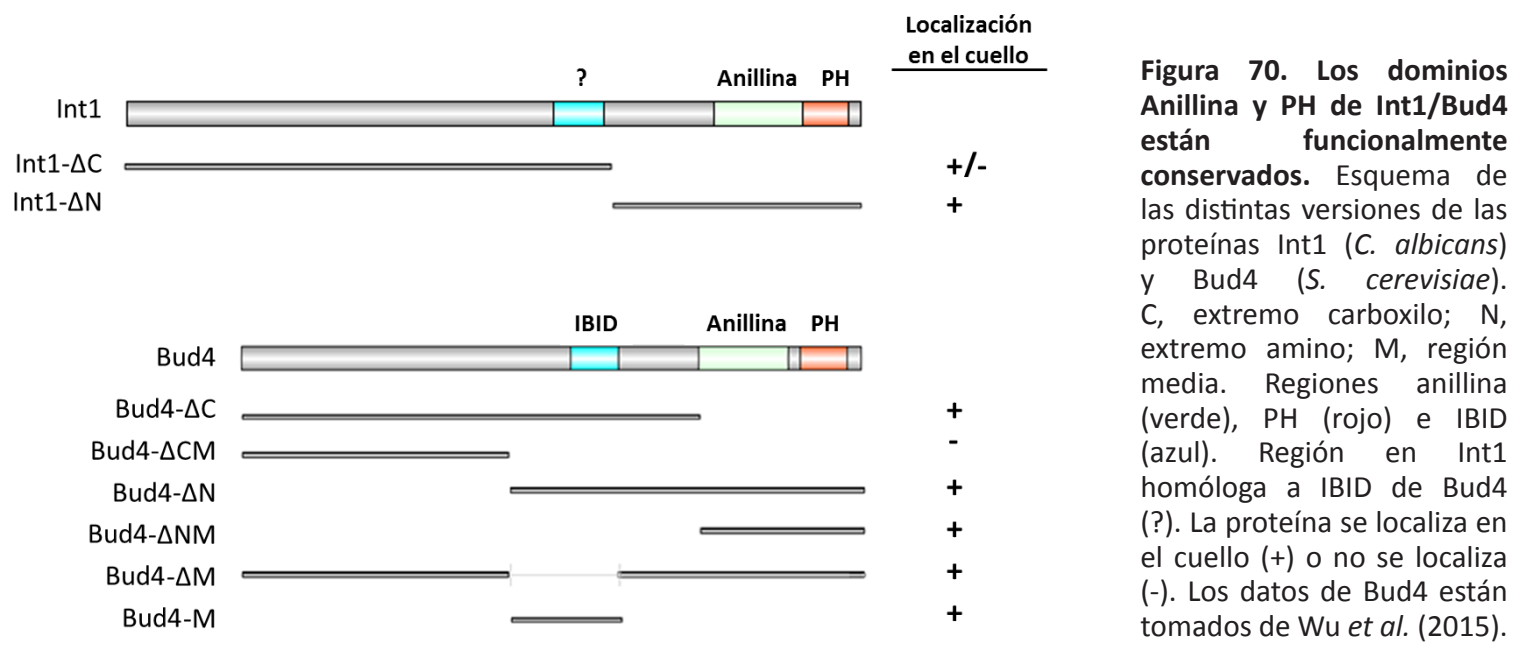

(regiones Anillina y PH) o del extremo amino no deslocalizan a Bud4 del cuello, pero la eliminación de la zona central (que contiene un dominio IBID, de interacción con Iqg1) y el extremo C-terminal impide que se localice en el cuello (Bud4- $\Delta C M$, Fig. 70)(Wu et al., 2015). Por tanto, en Bud4 la región anillina coopera con la región central para su asociación al cuello. Aunque, a priori los truncamientos equiparables de ambas proteínas parecen seguir un patrón parecido, la región C-terminal en Int1 parece ser más importante para su localización en el cuello que en Bud4 (no se puede descartar que la zona central también tenga alguna función en Int1, ya que no se ha generado un truncamiento similar). En cualquier caso, la región más conservada en ambas proteínas (dominios Anillina y PH) parece desempeñar un papel relevante en su localización en el cuello, probablemente porque el dominio $\mathrm{PH}$ interaccione con los fosfoinosítidos cargados negativamente de la membrana plasmática.

- Las septinas funcionan como andamio (c) para el anclaje de numerosos factores al cuello en distintos momentos del ciclo. Entre ellos se encuentran el polarisoma, el exocisto y la quitín sintasa II (Chs2, responsable de la síntesis del septo primario) durante la citoquinesis (Dobbelaere y Barral, 2004). En esta Memoria, el estudio de alguno de estos factores, como el componente del polarisoma Spa2, el exocisto (Sec3) o kinasas (Gin4) mostró que el anillo de septinas sencillo funciona correctamente para el anclaje de estas proteínas. Además, el collar funciona como andamio sobre el que se ensambla el AMR, aunque una vez que comienza su contracción las septinas son dispensables.

Sin embargo, cuando el mutante int $1 \Delta \Delta$ se combina que la deleción de otros genes, como SEP7 o RTS1 (int1 $\Delta \Delta \operatorname{sep} 7 \Delta \Delta$ e int $1 \Delta \Delta$ rts $1 \Delta \Delta$ ), aparecen problemas en separación en un porcentaje elevado de células (Fig. 61). La hipótesis más razonable para explicar este defecto es que la maquinaria implicada en la separación tenga problemas para degradar el septo, que es anormal (bien porque presente un cambio en la estructura o en la composición química del mismo). Además, dado que las septinas son necesarias para el reclutamiento del exocisto en esta zona durante la citoquinesis (Dobbelaere y Barral, 2004), es posible que la actuación de quitinasas y glucanasas esté comprometida en estos mutantes, por lo que el defecto en separación podría deberse a una combinación de una estructura anormal del septo y una reducida presencia de enzimas hidrolíticos en esta región.

Finalmente, otra posibilidad sería que algún elemento regulador del proceso de separación no fuera capaz de localizarse correctamente en el cuello, provocando (o aumentando) los defectos en separación. En este sentido, es interesante destacar que la proteína Cdc14 desempeña un papel crucial 
en la separación de $C$. albicans. Esta fosfatasa se localiza de forma transitoria en el cuello al final de mitosis en la cepa silvestre, pero también en los mutantes $\operatorname{int} 1 \Delta \Delta \operatorname{sep} 7 \Delta \Delta$ y int $1 \Delta \Delta$ rts $1 \Delta \Delta$, por lo que los defectos de separación no pueden ser atribuidos a la ausencia de Cdc14 del cuello.

- Otra función en la que participan las septinas es (d) la orientación del huso mitótico y el SPOC, que permite la correcta segregación de los cromosomas. Como en otros hongos, $S$. cerevisiae sufre una mitosis cerrada y los SPBs se localizan en la membrana nuclear. Tras la replicación del DNA y la duplicación del SPB, uno de ellos se dirige a la célula hija por interacción entre los microtúbulos astrales y proteínas localizadas en el cuello, como Bud6 (Fig. 16)(revisado en Markus et al., 2012; Merlini y Piatti, 2011). Se sabe que las conexiones de los microtúbulos descienden significativamente cuando la organización de las septinas se altera, sugiriendo que hay un sitio de captación de microtúbulos en el cuello dependiente de las septinas. El ciclo celular de las levaduras de $C$. albicans se parece al de S. cerevisiae, el crecimiento de la yema, la replicación del DNA y el ensamblaje de los husos mitóticos están coordinados con el ciclo celular. La segregación de cromosomas se produce después de que la replicación del DNA se haya completado, cuando las yemas han alcanzado un tamaño adecuado para recibir un núcleo (Hazan et al., 2002), aunque no existen datos sobre los mecanismos que controlan la orientación del huso. El análisis de los fenotipos del doble mutante int1 $\Delta \Delta \operatorname{sep} 7 \Delta \Delta$ aporta algunos datos sobre estos procesos, ya que presenta cambios en el contenido en DNA y en la morfología celular, además de otros defectos. Primero, existen fallos en la orientación del huso mitótico en muchas células. Segundo, estos defectos en la orientación conducen a que los núcleos a menudo no se segreguen equitativamente, produciendo células con una amplia gama de contenido en DNA. Tercero, en algunos casos la citoquinesis falla, formando varios compartimentos celulares que comparten un citoplasma. Cuarto, una gran parte de las células tienen contenido en DNA 4C, 8C o 16C y varios husos mal orientados. Estas observaciones indican que Int1 y Sep7 colaboran en una función que permite la correcta orientación del huso durante la mitosis, y que es específica de Int1 y Sep7, ya que no se observan los mismos defectos en el mutante int $1 \Delta \Delta c d c 10 \Delta \Delta$. Puesto que ambas proteínas se localizan en el cuello, la hipótesis más razonable es que la estructura del anillo de septinas esté alterada en este mutante, dificultando el reclutamiento de alguna proteína esencial para que los microtúbulos astrales reconozcan el punto del córtex donde se localiza la yema. Esto parece ser diferente a lo descrito en S. cerevisiae, donde Shs1 y Cdc10 son necesarios para el SPOC, aunque parece que actúan en rutas diferentes, ya que tanto Sep 7 como Cdc10 son necesarios para mantener a Lte1 en el córtex de la yema mientras que Cdc10 parece funcionar también como andamio para el reclutamiento de un posible sensor de microtúbulos (Castillon et al., 2003).

Un candidato claro es la fosfatasa PP2A Rts1, que participa en el SPOC en S. cerevisiae (revisado en Caydasi et al., 2010; Caydasi y Pereira, 2012), ya que el mutante $r t s 1 \Delta \Delta$ presenta un fenotipo similar (pero no tan acusado). En el mutante $r t s 1 \Delta \Delta$ existe también una población mixta de células de tamaño normal que contiene generalmente un núcleo y células de gran tamaño con más de un núcleo (Tesis Doctoral de Caballero-Lima, 2009)(Fig. 61). Este parecido en el fenotipo podría sugerir que la localización de Rts1 en el cuello en el mutante int $1 \Delta \Delta \operatorname{sep} 7 \Delta \Delta$ está fallando, pero no es el caso (Fig. 62). Además, el fenotipo del mutante int $1 \Delta \Delta \operatorname{rts} 1 \Delta \Delta$ es parecido al de int $1 \Delta \Delta \operatorname{sep} 7 \Delta \Delta$, mientras que en el mutante rts $1 \Delta \Delta \operatorname{sep} 7 \Delta \Delta$ es más severo, presentando, además de células grandes con varios núcleos, un porcentaje de células de tamaño normal y polinucleadas. Por tanto podemos pensar que Int1, Sep7 y Rts1 tienen algunas funciones en común en la señalización del cuello, pero que actúan en vías distintas. 
El análisis de la segregación nuclear en cepas con Tub2-GFP (Fig. 66) puso de manifiesto que muchas de las células con más de un núcleo se bloqueaban con husos típicos de anafase que emitían microtúbulos astrales. Sin embargo, los microtúbulos astrales eran incapaces de orientar los núcleos, que permanecían en la célula madre un tiempo variable hasta que uno de ellos migraba a la célula hija. En ese momento, la mitosis continuaba en ambas células, generando dos células con dos núcleos cada una. En S. cerevisiae el SPOC coordina la segregación cromosómica con la salida de mitosis, parando el ciclo celular hasta que el huso está bien orientado (revisado en Caydasi et al., 2010; Caydasi y Pereira, 2012). Aunque no se ha descrito un mecanismo similar en C. albicans, en el doble mutante int $1 \Delta \Delta \operatorname{sep} 7 \Delta \Delta$ parece que los núcleos se bloquean en anafase por un tiempo indefinido, lo que sugiere que podría existir un mecanismo que monitoriza la orientación del huso. Sin embargo, hemos comprobado que algunas de las proteínas implicadas en el SPOC, como Glc7 y Elm1, no se localizan correctamente en el cuello, lo que indica que el ensamblaje del anillo de septinas es necesario para que este checkpoint actúe correctamente, y podría explicar por qué la mitosis continúa una vez que uno de los núcleos ha entrado en la célula hija.

Una pregunta interesante es cómo se generan las células polinucleadas a partir de una célula con un único núcleo. Una posibilidad es que el defecto en la orientación del huso unido a un SPOC no completamente funcional permita que la mitosis continúe aunque el huso esté orientado perpendicularmente al eje madre-hija, generando una célula con dos núcleos y un compartimento vacío. Si la citoquinesis falla y se emite una nueva yema se generan tres compartimentos celulares que comparten el citoplasma y dos núcleos. Cuando se produce la mitosis en estas células, una de ellas heredará dos núcleos (Fig. 71). La progenie de los mutantes $r t s 1 \Delta \Delta$, int1 $\Delta \Delta \operatorname{sep} 7 \Delta \Delta$, int1 $\Delta \Delta \operatorname{rts} 1 \Delta \Delta$ y $r t s 1 \Delta \Delta \operatorname{sep} 7 \Delta \Delta$ contiene una mezcla de células normales y células grandes con más de un núcleo. Sin embargo, las cepas son viables y no se observan defectos en el crecimiento de los cultivos líquidos. Mediante micromanipulación de células grandes poliploides y normales del mutante int $1 \Delta \Delta \operatorname{sep} 7 \Delta \Delta$, hemos comprobado que la progenie de ambos tipos celulares es siempre una mezcla de células poliploides y células normales, lo que indica que las células con más de un núcleo también son capaces de generar células con uno sólo. Esta reversión se produciría cuando uno de los núcleos se orienta paralelo al eje madre-hija y segrega normalmente mientras que el otro lo hace de forma perpendicular, produciendo una segregación 3:1 (Fig. 66).

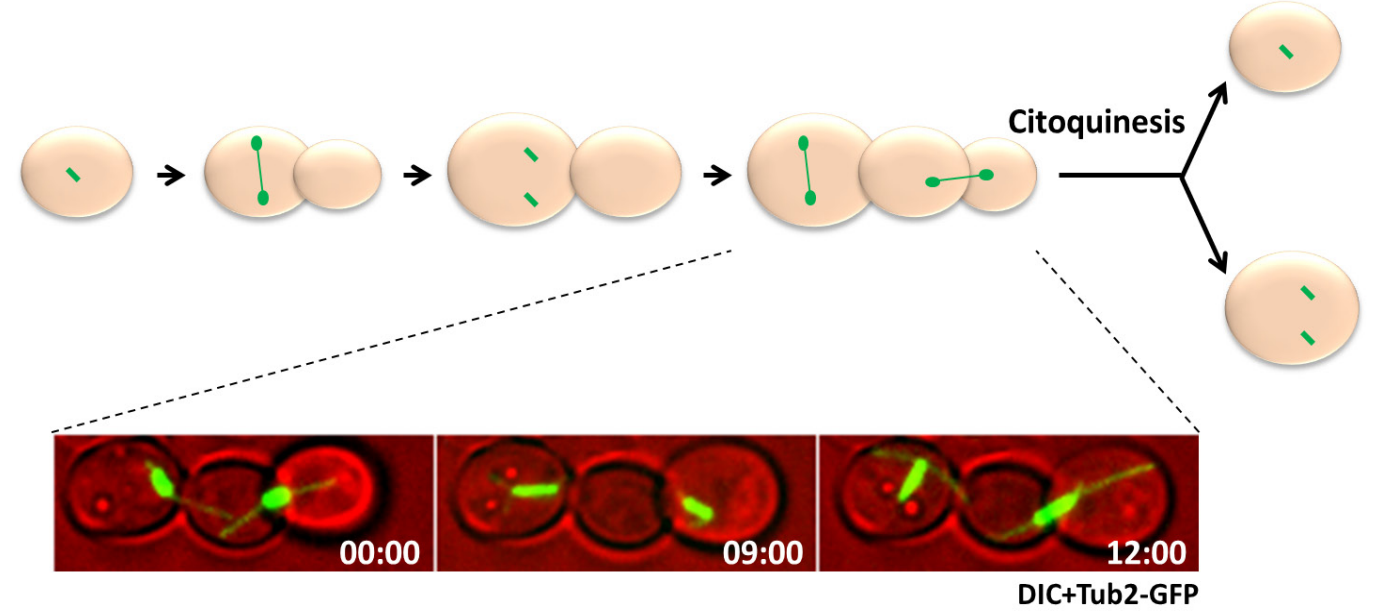

Figura 71. Formación de células poliploides en $\operatorname{int} 1 \Delta \Delta \operatorname{sep} 7 \Delta \Delta$. Arriba: Representación de un hipotético fallo en segregación que genera dos poblaciones de células distintas: con un solo núcleo y polinucleadas. Abajo: "Time-lapse" que muestra tres compartimentos celulares que comparten citoplasma y dos núcleos en anafase, con el posterior alargamiento de los husos. Imágenes de contraste interferencial (DIC) y Tub2-GFP (verde). Tiempo (min:s). 
Podemos pensar que Sep7 en C. albicans, en combinación con otros elementos del cuello como Int1, o la fosfatasa Rts1, participa en la orientación del huso mitótico en el eje madre-hija durante la mitosis y en el punto de control que monitoriza este proceso y que la integridad del anillo de septinas es esencial para una correcta segregación nuclear.

Por tanto, el análisis de los dobles mutantes septinas/anillina Int1 permite confirmar que en C. albicans las septinas desempeñan las mismas funciones que en otros organismos y que, hasta ahora, no habían sido descritas en este organismo dimórfico. Es el caso del confinamiento del polarisoma entre los dos anillos de septinas, la correcta segregación de cromosomas o el checkpoint de posicionamiento del huso mitótico (SPOC). 


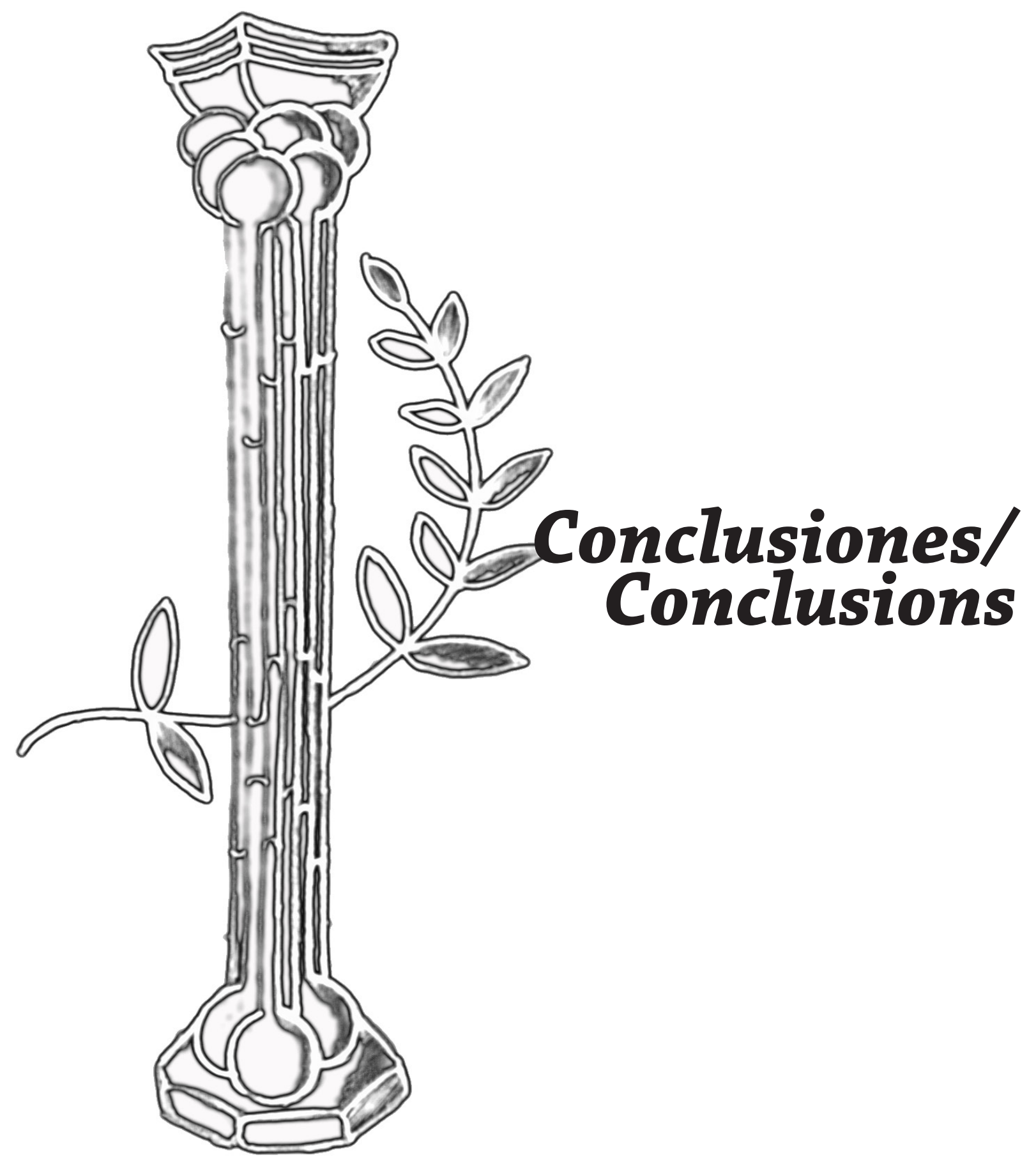



1. El mantenimiento de la dosis génica de $S E P 7, C D C 11$ y $C D C 10$ es fundamental para que los compartimentos celulares permanezcan unidos durante la filamentación, aunque esto no afecte a la capacidad de crecer en forma de levaduras ni al desarrollo de las hifas.

2. El anillo de septinas presenta propiedades bioquímicas diferentes en función del tipo de morfología, aunque éstas no se deben a la existencia de octámeros mixtos con Sep7 en un extremo y Cdc11 en el otro.

3. Sep7 desempeña un papel determinante en la inhibición de la separación celular de las hifas a través del dominio C-terminal. La región comprendida entre el SUE y el coiled-coil (394-522) es esencial para esta función y en ella se localizan 10 sitios cuya fosforilación durante el desarrollo hifal es esencial para mantener unidos los compartimentos hifales.

4. Sep7 contiene dos regiones cuya fosforilación regula la formación de anillos de septinas en las hifas. Una de ellas se localiza antes de la hélice $\alpha 0$ y su fosforilación es necesaria para la síntesis del septo primario en hifas. La segunda es el extremo C-terminal, cuya fosforilación se necesita durante el desarrollo hifal para la correcta duplicación de los anillos.

5. Cdc12 contiene 4 posibles sitios de fosforilación por CDKs. El estudio de mutantes fosfodeficientes y fosfomiméticos sugiere que uno de ellos (Thr92) debe ser defosforilado durante el desarrollo hifal para el correcto ensamblaje del anillo de septinas.

6. La anillina Int1 desempeña varias funciones en la regulación del anillo de septinas en C. albicans, participando en el reclutamiento de las septinas al punto de gemación y estabilizando los anillos tras su duplicación en citoquinesis. Esta función depende esencialmente del extremo C-terminal donde se localizan los dominios Anillina y PH conservados en sus homólogos.

7. En C. albicans, el anillo de septinas, y en concreto Sep7, es importante para la orientación del huso mitótico en anafase y para asegurar el reparto equitativo del material nuclear. Las proteínas Sep7, Int1 y Rts1 colaboran en una función necesaria para adecuada la segregación de los núcleos. 
1. The maintenance of SEP7, CDC11 and CDC10 gene dosage is essential for inhibition of hyphal cell separation, although this does not affect the yeast morphology nor the development of hyphal filaments.

2. The septin ring has different biochemical properties depending on the type of morphology, but this is not due to the presence of mixed octamers capped with Sep7 and Cdc11 at the ends.

3. Sep7 plays key role in the inhibition of hyphal cell separation through the CTE domain. A region between the SUE and the coiled-coil (394-522) is essential for this function, and contains 10 residues whose phosphorylation during hyphal development is essential to maintain the hyphal compartments attached.

4. Sep7 contains two regions whose phosphorylation regulates septin ring formation in hyphae. One is located before the $\alpha 0$ helix and its phosphorylation is required for primary septum synthesis in hyphae. The second is the C-terminus, whose phosphorylation is needed during hyphal development for proper septin ring duplication.

5. Cdc12 contains 4 putative CDK phosphorylation sites. The analysis of the phenotypes of phosphomimetic and phosphodeficient mutants suggests that one of them (Thr92) must be dephosphorylated during hyphal development for correct septin ring assembly.

6. The homolog of anillin Int1 performs several functions in the regulation of septin rings in C. albicans, being required for the recruitment of septins to the bud emergence site and for stabilization of duplicated septin rings after cytokinesis. This latter function essentially depends on the C-terminus, where the conserved anillin and PH domains are located.

7. In C. albicans, the septins rings, and specifically Sep7, play an important role in the orientation of the mitotic spindle in anaphase and to ensure the proper distribution of the nuclear material. Sep7, Int1 and Rts1 collaborate in a function necessary for proper segregation of nuclei. 


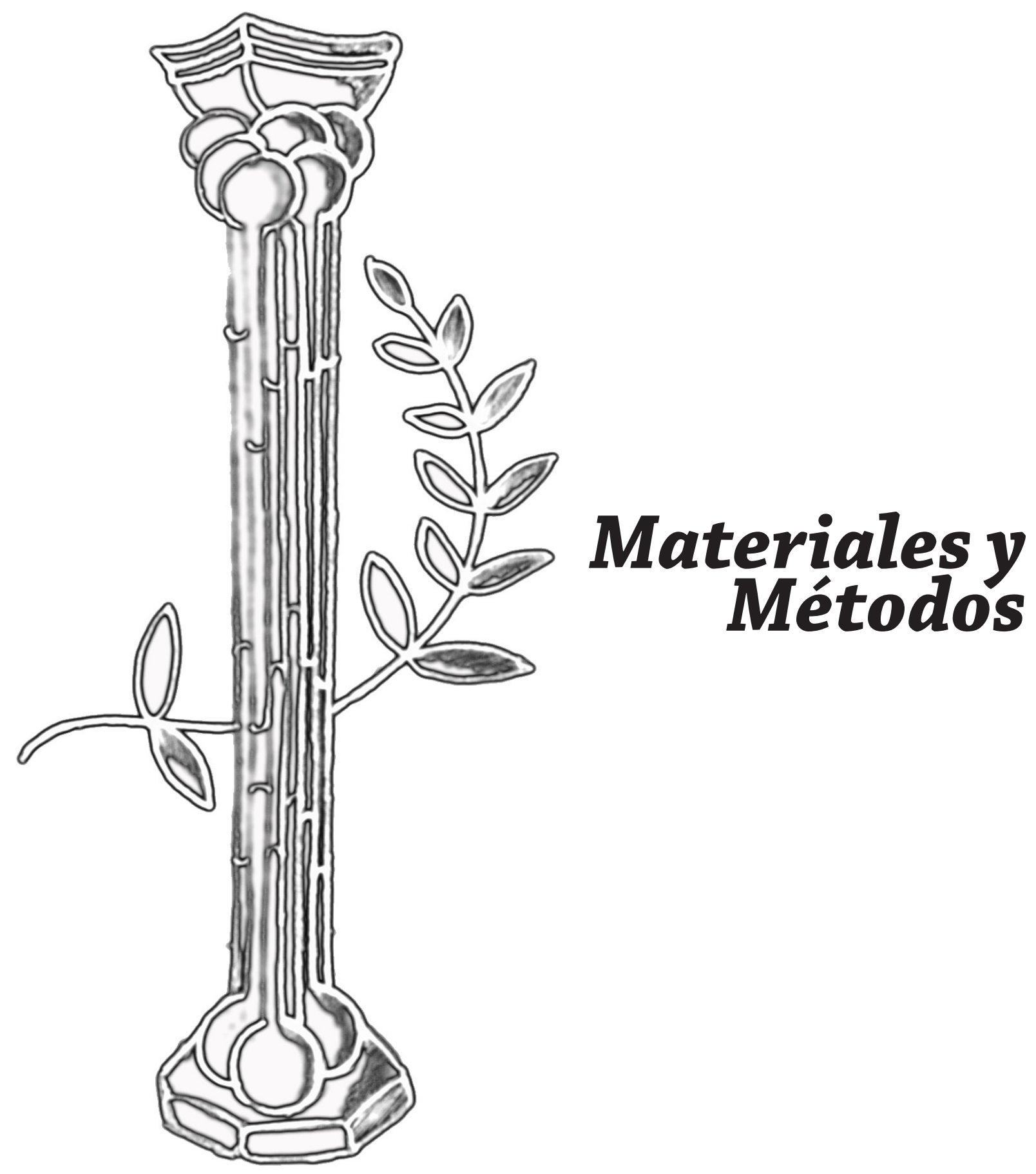





\section{Microorganismos utilizados.}

Para el desarrollo de este trabajo de investigación se utilizaron diferentes estirpes de la bacteria Escherichia coli y del hongo ascomycota Candida albicans; sus características genéticas así como su procedencia se detallan en la Tabla 2. C. albicans fue el microorganismo elegido como modelo para estudiar los procesos de morfogénesis, crecimiento y división celular descritos en este trabajo; las cepas construidas de este microorganismo derivan del fondo genético BWP17 (Wilson et al., 1999) y CAI4 (Fonzi y Irwin, 1993). La cepa DH5a de E. coli fue empleada para los experimentos rutinarios de clonación molecular y como hospedador de los plásmidos utilizados.

La conservación de las cepas de levaduras se realizó a $-80^{\circ} \mathrm{C}$ en crioviales con glicerol al $15 \%$, mientras que las cepas bacterianas fueron conservadas en glicerol al $50 \%$.

\section{Medios de cultivo y condiciones de crecimiento.}

Los medios de cultivo se prepararon con agua milli-Rho y se esterilizaron en autoclave. Así mismo, los medios sólidos se hicieron agregando agar al $2 \%$ a los medios líquidos correspondientes.

- Crecimiento de C. albicans. C. albicans fue cultivada rutinariamente a $28^{\circ} \mathrm{C}$ en YEPD (Bacto Peptona $2 \%$, dextrosa $2 \%$ y extracto de levaduras $1 \%$ ) o medio mínimo YNB (dextrosa $2 \%$ y $6,7 \%$ de YNB), suplementado con aminoácidos según los requerimientos de cada cepa, a concentraciones finales de $40 \mathrm{mg} / \mathrm{L}$ para arginina e histidina y de $80 \mathrm{mg} / \mathrm{L}$ para uridina. El crecimiento hifal de C. albicans se indujo en medio YEPD con suero fetal bovino al $10 \%$ a $37^{\circ} \mathrm{C}$.

- Crecimiento de E. coli. Las estirpes bacterianas de E. coli crecieron a $37^{\circ} \mathrm{C}$ en medio Luria Bertani (LB), compuesto por bactotriptona al $1 \%$, extracto de levadura al $0,5 \%$ y cloruro de sodio al $1 \%$. La selección de clones se realizó mediante siembra en LB suplementado con 100 mg/ml de ampicilina.

\section{Procedimientos generales de clonación molecular.}

\subsection{Obtención de ADN plasmídico.}

Para la extracción rápida y a pequeña escala de DNA plasmídico de $E$. coli se empleó el método de lisis alcalina (Sambrook y Russell, 2001). Cuando se necesitó de una alta pureza y mayor concentración del DNA, se recurrió al uso de columna de intercambio iónico Quantum Prep ${ }^{\circledR}$ Plasmid Miniprep Kit (Bio-Rad) según las indicaciones del fabricante.

\subsection{Obtención de ADN genómico de C. albicans.}

Para aislar el DNA de alto peso molecular se usó el método de extracción fenólica con lisis mecánica. Para ello se inocularon $5 \mathrm{ml}$ de YEPD con la levadura y se incubó toda la noche a $28^{\circ} \mathrm{C}$. Tras recuperar las células por centrifugación, se resuspendieron en 0,2 ml de Tampón de rotura (Tritón X-100 2\%, SDS 1\%, $\mathrm{NaCl} 100 \mathrm{mM}$, Tris-HCl pH 8,0 $10 \mathrm{mM}$ y EDTA $1 \mathrm{mM}$ ), 0,2 ml fenol-cloroformo-isoamílico (25:24:1) y $0,3 \mathrm{~g}$ de bolitas de vidrio $(0,4 \mathrm{~mm}$; Sigma-Aldrich); esta mezcla se agitó $4 \mathrm{~min}$ en vórtex a máxima potencia. Al finalizar la ruptura, se añadieron $0,2 \mathrm{ml}$ de TE $1 \mathrm{X}$ a las células rotas y se separó la fase acuosa de la fenólica centrifugando $5 \mathrm{~min}$ a $13000 \mathrm{rpm}$. La fase acuosa fue transferida a un nuevo tubo que contenía $1 \mathrm{ml}$ de etanol al 100\% para después centrifugar $2 \mathrm{~min}$ a $13000 \mathrm{rpm}$. El precipitado se resuspendió en $400 \mathrm{ml}$ de TE $1 \mathrm{X}$ y fue tratado con $30 \mu \mathrm{g}$ de RNAasa, $15 \mathrm{~min}$ a $37^{\circ} \mathrm{C}$. A continuación, se 
añadieron $10 \mu \mathrm{l}$ de acetato de amonio 2,5 M y $1 \mathrm{ml}$ de etanol al 100\% y se mezclaron por inversión para precipitar el DNA que fue concentrado por centrifugación a $13000 \mathrm{rpm}$ durante 2 minutos y secado a temperatura ambiente hasta la total evaporación del etanol, para ser resuspendido finalmente en $0,1 \mathrm{ml}$ de TE $1 \mathrm{X}$.

\subsection{Reacción en cadena de la polimerasa (PCR).}

La amplificación de fragmentos de DNA se hizo mediante reacción en cadena de la polimerasa en un termociclador MiniciclerTM (MJ Reasearch), usando diferentes polimerasas como KAPA HIFI, KAPA $2 G^{T M}$ Robust HotStart (Nippon Genetics) y Go Taq (Promega) según la fidelidad requerida. Para todas las enzimas, la reacción se realizó según se indicaba en las instrucciones de la casa comercial. Por lo general, el DNA fue desnaturalizado durante $5 \mathrm{~min}$ a $95^{\circ} \mathrm{C}$ seguido de $30-35$ ciclos con los siguientes pasos: $30 \mathrm{~s}$ a $95^{\circ} \mathrm{C}, 30 \mathrm{~s}$ a la temperatura de anillamiento específica del oligonucleótido empleado, 1 min a $72^{\circ} \mathrm{C}$ de extensión por cada kilobase de DNA a amplificar, y para finalizar la reacción 10 min de extensión a $72^{\circ} \mathrm{C}$.

\subsection{Manipulación del DNA.}

Los procedimientos generales de manipulación del DNA se encuentran recogidos en el manual de laboratorio de Sambrook y Russell (2001), excepto en aquellas ocasiones en las que se utilizaron kits comerciales para las que se siguieron las indicaciones de la casa comercial. Todos los fragmentos de DNA obtenidos por PCR o por tratamiento con enzimas de restricción se analizaron en geles de agarosa (SeaKem ${ }^{\circledR}$ ME Agarose, FMC Bio Products) teñidos con bromuro de etidio $(0,5 \mathrm{mg} / \mathrm{ml}$ ) o Midori Green Advance DNA Stain (Nippon Genetics) $(0,05 \mu \mathrm{l} / \mathrm{ml})$ preparados en tampón TAE (Tris-acetato $40 \mathrm{mM}$, EDTA $1 \mathrm{mM}, \mathrm{pH}$ 7,5-7,8) a concentraciones que oscilaban entre 0,8 y 1,5\%, según el tamaño de los fragmentos a separar. El aislamiento y purificación de los fragmentos específicos de DNA obtenidos por PCR o por restricción con enzimas, se realizó con el kit NucleoSpin ${ }^{\circledR}$ Extract II (Macherey-Nagel). Para la clonación de fragmentos de DNA se usaron enzimas de restricción así como la ligasa del fago T4 de la casa comercial Roche. La fosfatasa alcalina fue proporcionada por Roche.

\section{Construcción de cepas.}

La deleción de genes de $C$. albicans así como los truncamientos y el marcaje con proteínas fluorescentes y epítopos se realizaron con el método mediado por PCR usando los módulos pFA (Gola et al., 2003; Schaub et al., 2006; Reijnst et al., 2011). Los transformantes se seleccionaron en medio YNB suplementado con los aminoácidos necesarios según sus auxotrofías, o en YEPD con clonNAT a una concentración final de $200 \mathrm{\mu g} / \mathrm{ml}$ (Werner BioAgents) para seleccionar cepas SAT1. Las cepas que contenían proteínas marcadas con proteínas fluorescentes o epítopos se consideraban funcionales en tanto que se observase un crecimiento normal en un fondo heterocigoto. Todas las cepas se confirmaron por PCR usando oligonucleótidos obtenidos de la casa comercial Biomers o Sigma-Aldrich y/o por secuenciación.

- Mutantes de deleción. La construcción de cepas carentes de un gen determinado se llevó a cabo usando la técnica de reemplazamiento genético (Rothstein, 1991), la cual se basa en la transformación integrativa de las moléculas lineales de DNA. Esta estrategia consiste en el uso de un casete de transformación obtenido mediante PCR (a partir de DNA plasmídico de alguno de los módulos pFA), el 
cual contiene un marcador de selección flanqueado por las regiones no codificantes $5^{\prime}$ y $3^{\prime}$ del gen para dirigir la integración, regiones que provenían de oligonucleótidos de 100 pb. Estas regiones homólogas permiten la recombinación del fragmento con uno de los alelos del gen a delecionar, sustituyendo el ORF del mismo por el marcador de selección.

- int1- $\Delta N$. Se amplificó la región $5^{\prime}$ de INT1 a partir de DNA genómico de Candida y se clonó en pFA-ARG4 mediante los sitios Pvull-Bg/ll (pFA-5'INT1-ARG4). La ligación de los distintos fragmentos en los plásmidos pFA se llevó a cabo usando el kit de ligación Rapid DNA Dephos \& Ligation Kit (Roche) (este procoloco se seguirá siempre que se requiera ligación en las construcciones posteriores). Después se amplificó la zona del promotor de INT1 mediante PCRs independientes que luego se unificaron mediante PCR de fusión y se clonó en pFA-5'INT1-ARG4 usando Pmel-Sall/ Spel (pFA-5'INT1-ARG4-PINT1). Posteriormente, se amplificó parte de la región codificante de INT1 (G1127-Q1711) y se clonó en el plásmido anterior a través de los extremos Sall-Spel. El plásmido resultante se denominó pFA-5'INT1-ARG4-PINT1-INT1 ORF (G1127-Q1711), cuyo número de la colección es $p C 1165$. La construcción de este plásmido se representa en la Figura 72. Finalmente, se amplificó el inserto de $p C 1165$ y se transformó Candida (en un fondo INT1/int1A) para conseguir la versión INT1- $\triangle N$-HA. Para posteriores ensayos, se marcó esa construcción con GFP amplificando el DNA de pFA-GFP-HIS1 usando oligonucleótidos que recombinaran justo después del truncamiento. Así se obtuvo la versión INT1- $\triangle N-G F P$.

- int1- $\Delta C$. Se amplificó un casete por PCR partiendo del DNA de pFA-GFP-HIS1 usando oligonucleótidos que recombinaran entre las posiciones 1134 y el final de la región codificante de INT1 y se transformó Candida. Así se obtuvo la versión INT1- $\triangle C$-GFP. Para la versión INT1- $\triangle C$-HA se siguieron los mismos pasos anteriores amplificando el DNA del plásmido pFA-HA-URA3.

- Truncamientos de SEP7. Se amplificaron varios casetes por PCR partiendo del DNA de los pFA-yEmCherry-HIS1/URA3 usando oligonucleótidos que recombinaran en las posiciones 394, 522, 580 o 629 y en el extremo 3' no codificante de SEP7 y se transformó Candida.

- Quimeras CDC11-SEP7. Se amplificó el extremo C-terminal de Sep7 desde Glu580 (para $C D C 11^{\text {CTE-Sep7) }}$ o desde Arg354 (para $C D C 11^{\text {CTEC-Sep7) }}$ usando como molde DNA genómico de BWP17. Se clonó en vectores pFA-ARG4 usando Pvull-BamHI (se generaron los plásmidos pFA-Sep7E580-ARG4 y pFA-Sep7R354-ARG4, pC1292 y pC1294 respectivamente). A continuación, se amplificaron los casetes a partir de los plásmidos anteriores con los oligonucleótidos correspondientes para que recombinaran en CDC11 en la posición 303 (CDC11 $1^{\text {CTE-Sep7 }}$ ) o $380\left(\right.$ (CDC11 $\left.{ }^{\text {CTEC-Sep7 }}\right)$ y se transformó la cepa sep7 $\Delta$.

\subsection{Mutagénesis dirigida.}

- Cepa sep7-10A. La mutagénesis dirigida de los sitios de fosforilación de Sep7 se realizó a partir del DNA del plásmido pFA-Sep7R354-ARG4 ( $p$ C1294, que contenía la secuencia de Sep7 desde R354) usando dos oligonucleótidos que contenían cinco mutaciones a Alanina cada uno y usando el kit Quik Change Lightning Multi Site (Agilent Technologies). Al plásmido resultante se le denominó pFA-Sep7-10A-ARG4 ( $p C 1346)$. Una vez generadas las mutaciones y confirmadas por secuenciación, se creó un fragmento de sep7-10A fusionado a Cherry (amplificando por un lado el fragmento de SEP7 con las mutaciones a partir de pFA-Sep7-10A-ARG4 y por el otro la secuencia codificante para la proteína Cherry a partir de pFA-yEm-Cherry-URA3, $p$ C1256); finalmente ambos fragmentos se fusionaron por 

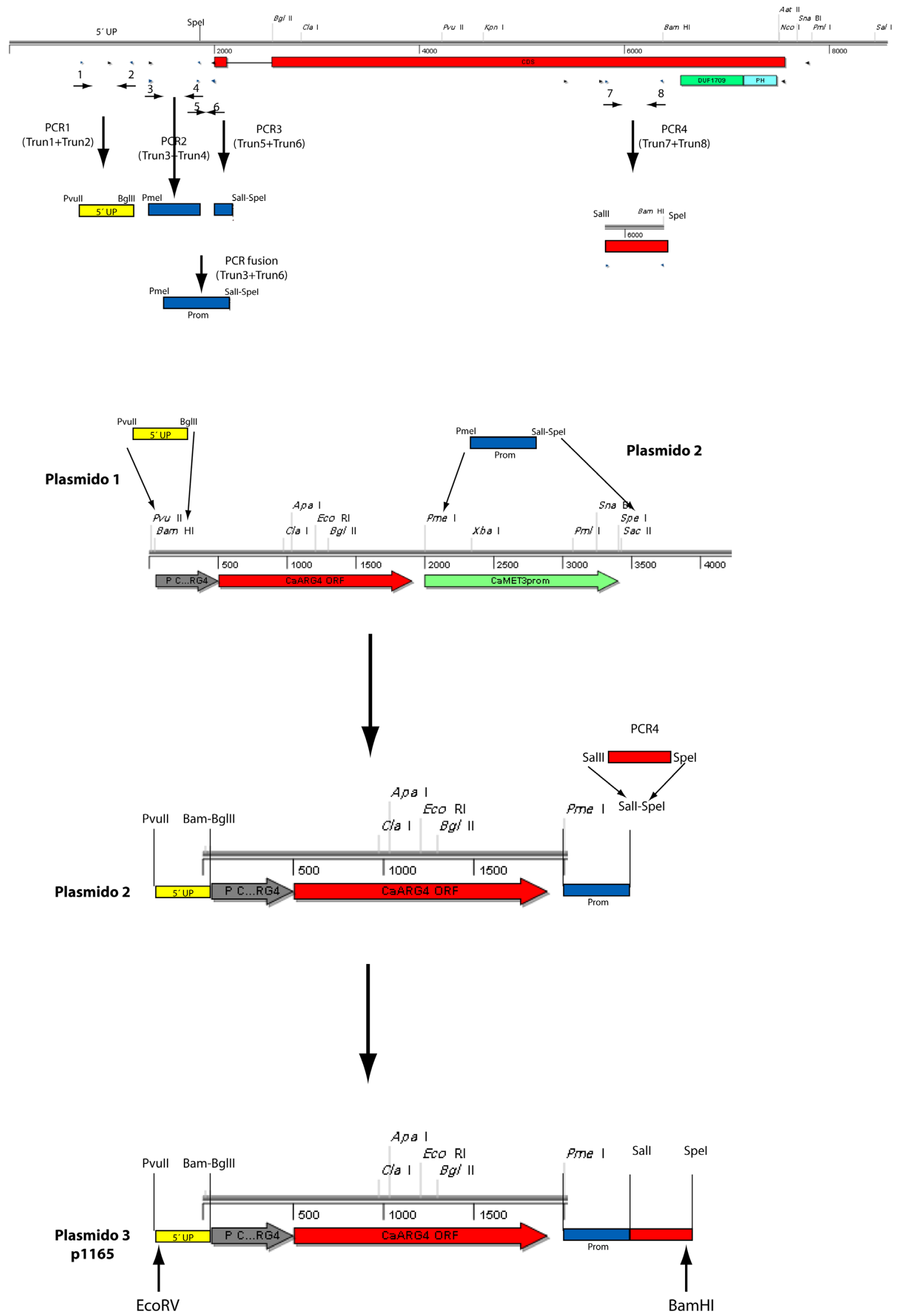

Figura 72. Esquema de la estrategia de construcción del plasmido para generar int1- $\Delta N$. 
PCR recombinante. Dicho fragmento se clonó en los plásmidos pFA-ARG4/HIS1 usando los sitios Sall-BamHI (pFA-SEP710A-Cherry-ARG4/HIS1, pC1352/pC1353). Finalmente, para transformar Candida, se amplificó el casete desde pFA-Sep710A-Cherry-ARG4/HIS1 que contenía las mutaciones en SEP7, la secuencia de la Cherry y un marcador auxotrófico. Para esta amplificación se usaron oligonucleótidos que recombinaban en la zona deseada (entre Arg354 y el final de la secuencia codificante de SEP7).

- Cepas sep7-2A y sep7-2E. En primer lugar se clonó la región 5' del gen de SEP7 en vectores pFA-ARG4/HIS1. Para ello se amplificó dicha región por PCR a partir de DNA genómico y se clonó en los plásmidos cortando con Sall y BamHI (pFA-5'SEP7-ARG4/HIS1, pC1331/pC1333). Posteriormente se clonó en esos mismos vectores el extremo N-terminal de SEP7 con promotor (desde-689 hasta +128), amplificando dicha región por PCR a partir de DNA genómico. Los oligonucleótidos para esta PCR introducían las mutaciones S14A-S22A y S14E-S22E. La clonación se hizo cortando inserto y vector con Pmel y Clal. Una vez clonados se secuenció para confirmar las mutaciones y a estos plásmidos se les denominó pFA-5'SEP7-2A/2E-ARG4/HIS1 (pC1339, pC1340, pC1342 y pC1344). Para la transformación de Candida se amplificó el casete de los vectores resultantes usando oligonucleótidos que recombinaran en la zona deseada (entre la región 5' del gen y el inicio de la región codificante de SEP7).

- $\quad$ sep7-3A y sep7-8A. Se amplificó un casete para transformar Candida que insertaba la GFP detrás del extremo C-terminal de Sep7 y al mismo tiempo generaba las mutaciones en el extremo C-terminal de SEP7. El casete se amplificó por PCR a partir de pFA-CaGFP-ARG4/HIS1 usando oligonucleótidos que recombinaban al final de la región codificante del gen introduciendo las mutaciones. Se utilizaron oligonucleótidos específicos que introducían 3 u 8 mutaciones.

- int-3A e int-3E. Se amplificó la región de 3' del gen INT1 a partir de DNA genómico de BWP17 por PCR y se clonó en el vector pFA-HA-ARG4 usando los sitios Pmel-Spel (pFA-HA-ARG4-3'INT1, pC1291). Se confirmaron las mutaciones por secuenciación. A continuación, se clonó la región codificante de INT1 (amplificada a partir de DNA genómico de BWP17) en el plásmido construido anteriormente, usando los sitios Pvull-Sall (pFA-ORFINT1-HA-ARG4-3'INT1, pC1302). Después se generaron dos versiones del plásmido anterior con las mutaciones int1-3A e int1-3E usando el Kit Quik Change Lightning Multi Site (Agilent Technologies). Estos plásmidos fueron denominados pFA-ORFINT1(3A)-HA-ARG4-3'INT1 y pFA-ORFINT1(3E)-HA-ARG4-3'INT1 ( plásmido con Pvull-Spel, se separó la banda deseada en gel agarosa y se transformó Candida en un fondo genético int1 $\triangle /$ INT1. Así se construyeron las versiones de int1-3A-HA e int1-3E-HA. Posteriormente se clonó el gen GFP a continuación de las mutaciones, amplificando el DNA de pFA-GFP-URA3 con oligonucleótidos que recombinaran en esa zona y transformando Candida (int1-3A-GFP e int1-3E-GFP).

\subsection{Transformación de C. albicans.}

Dos metodologías fueron usadas para introducir DNA en las diferentes cepas del hongo:

- Transformación con Acetato de litio. La transformación química se realizó como ha sido previamente descrito por Walther y Wendland (2003), con algunas modificaciones. Los cultivos celulares de las cepas a transformar que habían crecido durante toda la noche se diluyeron en $25 \mathrm{ml}$ de medio fresco a una densidad óptica a $600 \mathrm{~nm}\left(\mathrm{OD}_{600}\right)$ de 0,3 e incubadas con agitación a $28^{\circ} \mathrm{C}$ durante 3-4 h hasta alcanzar una $\mathrm{OD}_{600}$ de 1,4-1,8. Las células se recogieron, se lavaron con $25 \mathrm{ml}$ de agua destilada estéril y se resuspendieron en 1,5 ml de solución de acetato de litio (acetato de litio $100 \mathrm{mM}$, 
Tris-HCl 10 mM, EDTA $1 \mathrm{mM}$ ). La mezcla de transformación se hizo agregando $100 \mu$ l de células, $100 \mu \mathrm{g}$ de DNA monocatenario ( $2 \mathrm{mg} / \mathrm{ml}$ ), 1-5 $\mu \mathrm{g}$ de DNA a insertar en el genoma y $600 \mu \mathrm{l}$ de solución PEG-LiAc (PEG 4000 al $50 \%$ en solución de acetato de litio). Esta mezcla se incubó toda la noche en agitación a $28^{\circ} \mathrm{C}$ antes de someterla a un choque térmico a $44^{\circ} \mathrm{C}$ durante $15 \mathrm{~min}$. Las células se lavaron y se sembraron en medios selectivos.

- Transformación por electroporación. El protocolo de electroporación para C. albicans fue el descrito por Reuss y colaboradores (2004). A partir de un pre-cultivo en YEPD de C. albicans, se realizó una dilución a $\mathrm{OD}_{600}=0,4$ en $25 \mathrm{ml}$ de medio fresco y se incubó con agitación a $28^{\circ} \mathrm{C}$ hasta llegar a 1,4-1,6 $\mathrm{OD}_{600}$. Las células se recogieron por centrifugación y se resuspendieron en $25 \mathrm{ml}$ de solución de acetato de litio (acetato de litio 0,1 M pH 7,5, Tris-HCl 10 mM, EDTA 1 mM pH 7,5 y DTT 10 mM). Después se incubaron $1 \mathrm{~h}$ a temperatura ambiente. Después, las células se lavaron 3 veces con agua estéril fría y una vez con sorbitol $1 \mathrm{M}$. Estas células competentes se recogieron por centrifugación y se resuspendieron en $160 \mu \mathrm{l}$ de sorbitol $1 \mathrm{M}$. La mezcla de electroporación, que contenía $50 \mu \mathrm{l}$ de la suspensión de células competentes y 1-5 $\mu \mathrm{g}$ de DNA, se mantuvo durante 5 min en hielo. Entonces, se llevó a cabo la electroporación de las células competentes en un electroporador Gene pulser ${ }^{\circledast}$ de Bio-Rad (cubetas de 0,2 cm a 1,5 kV). Después de la electroporación, las células se lavaron con $1 \mathrm{ml}$ de sorbitol y se sembraron en medios selectivos.

Para los dos tipos de transformaciones, cuando se usaba como selección el marcador SAT1, las células se incubaban en $1 \mathrm{ml}$ de YEPD a $28^{\circ} \mathrm{C}$ en agitación con el fin de permitir su recuperación antes de ser sembradas en el medio con la nourseotricina.

\subsection{Transformación de E. coli.}

La transformación de la cepa bacteriana $\mathrm{DH} 5 \alpha$ se realizó según el procedimiento descrito por Kushner (1978), basado en el choque térmico y mediante el uso del kit StrataClone Blunt PCR Cloning ${ }^{\circledR}$ (Agilent Technologies) siguiendo las instrucciones de la casa comercial.

\section{Extracción de RNA y qRT-PCR.}

Para la extracción del RNA se recogió un cultivo celular en fase logarítmica y se almacenó a $-80^{\circ} \mathrm{C}$. Un total de $50 \mathrm{mg}$ de células fueron lisadas con $0,3 \mathrm{~g}$ de bolitas de vidrio $(0,4 \mathrm{~mm}$; Sigma-Aldrich) en una FastPrep FR120 (Savant, Bio101) en presencia de $50 \mu \mathrm{l}$ de TRIzo/ ${ }^{\circledR}$ Reagent (Invitrogen). El RNA total fue extraído siguiendo las instrucciones de la casa fabricante. La cantidad, calidad e integridad del RNA fueron analizados en Bioanalizador 2100 (Agilent Technologies). La síntesis del cDNA fue realizada con el sistema SupersScript II First-Strand Synthesis (Invitrogen) usando oligo-(dT), partiendo de $3 \mu \mathrm{g}$ de RNA total previamente tratado con DNAasa I (Invitrogen). Los ensayos de PCR cuantitativa se realizaron usando SYBR ${ }^{\circledR}$ Premix Ex Taq (Takara bio Inc.). Para cada reacción se usó $1 \mu$ de cDNA. Los ensayos de qPCR fueron hechos por duplicado llevando a cabo 40 ciclos (desnaturalización inicial de $45 \mathrm{~s}$ a $95^{\circ} \mathrm{C}$, 40 ciclos de $5 \mathrm{~s}$ a $95^{\circ} \mathrm{C}, 31 \mathrm{~s}$ a $60^{\circ} \mathrm{C}$, un paso de disociación de $15 \mathrm{~s}$ a $95^{\circ} \mathrm{C}, 1 \mathrm{~min}$ a $60^{\circ} \mathrm{C}$ y $15 \mathrm{~s} \mathrm{a} 95^{\circ} \mathrm{C}$ ).

Se usó un termociclador Applied Biosystems 7300 Real-Time PCR System (Applied Biosystems). La cuantificación de la expresión se realizó usando el método de la curva estándar. 


\section{Extracción, detección y análisis de proteínas.}

\subsection{Extracción.}

Se prepararon los extractos proteicos a partir de cultivos celulares en fase exponencial de crecimiento en medio líquido apropiado según el experimento a realizar. Se recogieron $1,6 \times 10^{6}$ de células y se lavaron con agua estéril fría. La extracción de proteínas se hizo de dos formas:

- Ruptura en tampón de lisis. Las células se resuspendieron en $200 \mu \mathrm{l}$ de tampón de lisis $B 70$ (HEPES 50 mM, AcK 70 mM NaF 1 mM, $\beta$-glicerolfosfato 20 mM, AcMg 5 mM, Triton X-100 0,1\%, glicerol 10\%, PMSF $1 \mathrm{mM}$, DTT $1 \mathrm{mM}$ ) el cual contenía el cóctel inhibidor de proteasas libre de EDTA de Roche, y se añadieron $200 \mu \mathrm{l}$ de bolitas de vidrio $(0,4 \mathrm{~mm}$; Sigma-Aldrich). La rotura de las células se realizó en una FastPrep FR120 (Savant, Bio101), empleando tres pulsos de $20 \mathrm{~s}$ a una potencia de 5,5, dejando los tubos durante 3 min en hielo durante pulso y pulso. Se recuperaron los extractos proteicos agujereando la base del eppendorf y centrifugando sobre otro eppendorf limpio. Los extractos se clarificaron centrifugando a $5000 \mathrm{rpm}$ durante $10 \mathrm{~min}$ a $4^{\circ} \mathrm{C}$. La determinación de la concentración de proteína se realizó con el kit Bio-Rad Dc Protein Assay, cuantificado cada muestra por duplicado y tomando como referencia una recta patrón de BSA $(0-1 \mu \mathrm{g} / \mu \mathrm{l})$.

- Precipitación de proteínas con TCA. La recogida de células se realizó de la misma forma que en el apartado anterior, una vez que las células fueron lavadas con agua fría se procedió a la precipitación de proteínas con TCA. Para ello se lavaron con $1 \mathrm{ml}$ de TCA al 20\% y transfirieron a tubos de tapón de rosca, los cuales habían sido numerados y pesados. Se centrifugaron $1 \mathrm{~min}$, se eliminó todo el sobrenadante y se volvió a pesar el tubo. La diferencia entre ambos pesos era el peso húmedo de células de la muestra.

Después de pesar los tubos, las células se resuspendieron en $100 \mu \mathrm{l}$ de TCA al $20 \%$ y se dejaron al menos $1 \mathrm{~h}$ a $-80^{\circ} \mathrm{C}$. A continuación, se añadían $200 \mu \mathrm{l}$ de bolas de vidrio $(0,4 \mathrm{~mm}$; Sigma-Aldrich) y se rompían las células en una FastPrep FR120 mediante 3 pulsos de $20 \mathrm{~s}$, a una velocidad de 5,5, dejando los tubos $3 \mathrm{~min}$ en hielo entre pulso y pulso. Posteriormente se realizaron agujeros en la base de los tubos, se colocaron sobre tubos nuevos y se centrifugaron $1 \mathrm{~min}$ a $2000 \mathrm{rpm}$. Luego se lavaron las bolas con $200 \mu \mathrm{l}$ de TCA al 5\% y se volvieron a centrifugar $5 \mathrm{~min}$ a $3000 \mathrm{rpm}$, se eliminó el sobrenadante y las proteínas precipitadas se resuspendieron en Sample Buffer ( $10 \mu \mathrm{l}$ por cada $\mu \mathrm{g}$ de peso húmedo) y

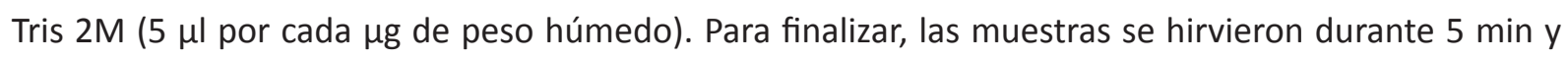
seguidamente se centrifugaron a $13200 \mathrm{rpm}$ durante $5 \mathrm{~min}$. El sobrenadante se transfirió a eppendorf nuevos y de aquí se cogieron $10 \mu$ para cargar en el gel.

\subsection{Separación electroforética e inmunodetección de proteínas (Western Blot).}

Las proteínas fueron separadas mediante electroforesis en geles de poliacrilamida, usando el sistema Mini Proteanll (Bio-Rad). Se cargaron entre 50 y $100 \mu \mathrm{g}$ de cada extracto proteico en condiciones desnaturalizantes, en geles del 10\% Bis-Tris Acrilamida (Bio-Rad). Se utilizó un tampón de electroforesis Tris-Glicina (Tris base $3 \mathrm{~g} / \mathrm{l}$, Glicina 14,4 g/l y SDS $1 \mathrm{~g} / \mathrm{l}$ ).

Una vez separadas las proteínas, se transfirieron a una membrana de PVDF P-Hybond (GE Healthcare), usando el sistema de transferencia Mini-Trans-Blot (Bio-Rad) a $100 \mathrm{v}$ constantes durante 60-90 min en un tampón CAPs-Metanol (CAPS 0,01M pH 11, metanol 10\%). Después de la transferencia, 
las membranas fueron lavadas 10 min con solución PBS 1 X-Tween $0,1 \%$ (PBS-T) y posteriormente bloqueadas durante al menos $1 \mathrm{~h}$ en solución de bloqueo (leche desnatada en polvo al 5\% en PBS-T). Los anticuerpos primario y secundario fueron incubados en solución de bloqueo durante al menos $1 \mathrm{~h}$, según condiciones que fueron estandarizadas para cada uno de ellos y las recomendaciones de la casa comercial. La detección de los complejos antígenos-anticuerpo se realizó usando la detección de la actividad peroxidasa ligada al anticuerpo secundario mediante quimioluminiscencia ( $E C L$ detection de GE Helthcare ó Supersignal West Femto kit de Pierce Biotechnologies), la cual impresiona las películas fotosensibles (Hyperfilm ${ }^{T M}$ MP, GE Healthcare). Los anticuerpos usados en este trabajo se describen en la Tabla 3.

\subsection{Western Blot con geles Phos-Tag.}

Para el análisis mediante Western Blot se cargaron $10 \mu \mathrm{l}$ de los extractos desnaturalizados y se separaron en un gel SDS-poliacrilamida al $6 \%$ con Phos-Tag a una concentración de $40 \mu \mathrm{M}$. Se corrieron a un voltaje constante de $100 \mathrm{v} /$ gel durante $5 \mathrm{~h}$. El sistema de electroforesis utilizado fue el de Bio-Rad utilizando tampón de electroforesis especial (Tris base 25 mM, Glicina 192 mM y SDS 0,1\%). Después de la electroforesis, el gel se incubó con tampón de transferencia (Tris base 25 mM, Glicina $192 \mathrm{mM}$ y metanol 20\%) más EDTA $1 \mathrm{mM}$ durante 10 min en agitación. Seguidamente, se lavó otros $10 \mathrm{~min}$ con tampón de transferencia sin EDTA. La transferencia a una membrana Hybond-P (GE Healthcare), previamente activada con metanol, se realizó usando el sistema Mini-Trans-Blot (Bio-Rad) durante $1 \mathrm{~h}$ a $100 \mathrm{v}$ en tampón de transferencia. El resto del procedimiento fue el mismo que se ha mencionado en el apartado 6.2.

\subsection{Electroforesis 2D.}

Se precipitaron los extractos de células usando metanol-cloroformo y se resuspendieron en Buffer de hidratación (urea 8M, tiourea 2M, CHAPS 4\%, DTT 1 mM, Buffer IPG 0,5\% y Reactivo DeStreak $1,2 \%$, GE Healthcare) a una concentración final de $2 \mathrm{mg} / \mathrm{ml}$ e incubado durante $20 \mathrm{~min}$. Se separaron aproximadamente $10 \mu \mathrm{g}$ de proteínas usando tiras de $7 \mathrm{~cm}$ (Inmobiline Drystrip pH 6-11, GE Healthcare) en el aparato Isolectric Focusing System (Ettan IPG phor 3 IEF System, GE Healthcare). A continuación, la técnica del Western Blot se llevó a cabo como se ha descrito previamente.

\subsection{Inmunoprecipitación de proteínas.}

La preparación de extractos celulares para inmunoprecipitación se llevó a cabo siguiendo el protocolo de extracción de proteínas antes descrito, seguido de la incubación de los lisados con bolas magnéticas que llevan unidos los anticuerpos correspondientes ( $\mu$ MACS $^{\circledR} \mathrm{HA}$, myc o GFP, Tagged Protein Isolation kit, Miltenyi Biotec), durante $30 \mathrm{~min}$ a $4^{\circ} \mathrm{C}$ en agitación. Esta mezcla fue cargada en las columnas de separación (MACS ${ }^{\circledR}$ Separation Columns, Miltenyi Biotec), seguido de 4 lavados con el tampón B70 y un lavado final con el tampón de lavado. Las proteínas retenidas en las columnas fueron eluídas con el tampón de elución proporcionado en el kit. El Western Blot se realizó siguiendo el protocolo anteriormente descrito. En caso de ser necesario, tras el revelado con el primer anticuerpo se realizaba una limpieza de la membrana con Glicina 200 mM pH 2,3.

\subsection{Inmunoprecipitación del anillo de septinas.}

Cuando una de las septinas estaba marcada con GFP se utilizó la resina GFP TRAP ${ }^{\circledR}$ Magnetic 
(Chromotek). Para ello, se crecieron $25 \mathrm{ml}$ de células O/N en YEPD y se refrescaron y se dejaron crecer hasta $\mathrm{DO}_{600}=1$ en $200 \mathrm{ml}$ de cultivo. Se recuperaron las células por centrifugación y se lavaron. Después se repartió el cultivo en tubos de tapón de rosca ( $500 \mu \mathrm{l}$ por tubo), se añadió el doble de la masa $(\mu \mathrm{g})$ en volumen $(\mu \mathrm{l})$ del Buffer de lisis con inhibidores de proteasas (HEPES-KOH, pH 7,6 $50 \mathrm{mM}$, $\mathrm{KCl} 1 \mathrm{M}, \mathrm{MgCl}_{2} 1 \mathrm{mM}$, EGTA $1 \mathrm{mM}$, Tween-20 0,1\%, glicerol 5\%, Inhibitores de proteasas Roche 1X-2X) y 150-200 $\mu \mathrm{l}$ de bolas Zirconia/Silica (BioSpec) y se rompieron las células en la FastPrep FR120 como se ha descrito previamente. Los extractos celulares se pasaron a un tubo limpio agujereando el tubo de tapón de rosca. Se añadió $15 \mu \mathrm{l}$ de bolas GFP TRAP ${ }^{\circledR}$ Magnetic (Chromotek) y se incubaron durante $2 \mathrm{~h}$ a $4^{\circ} \mathrm{C}$ en rotación. Después, con la ayuda de un imán, se lavaron las bolas siete veces con el tampón HEPES-KOH, pH 7,6 50 mM, KCl 200 mM, MgCl 1 mM, EGTA 1 mM, Tween-20 0,1\%, glicerol 5\%. Finalmente, se resuspendieron las bolas en $20 \mu$ de Sample Buffer y se analizó por Western Blot.

En el caso de que una de las septinas estuviera marcada con TAP-TAG, el anillo se purificó siguiendo los mismos pasos que en el caso anterior usando bolas magnéticas con IgG (Dynal Biotech, Invitrogen). Para separar las bolas de las proteínas se añadió Sample Buffer $\sin \beta$-mercaptoetanol y se calentaron a $65^{\circ} \mathrm{C}$ durante $10 \mathrm{~min}$. Después se llevó el líquido a un tubo nuevo y se añadió $\beta$-mercaptoetanol en una concentración final de $200 \mathrm{mM}$.

\section{Gradientes de sacarosa.}

- Montaje del equipo. Se colocó el formador de gradientes (que consta de dos depósitos) sobre un agitador magnético, de forma que el depósito más cercano a una bomba peristáltica (Microtube Pump, MP-3, Eyela) estuviera en constante agitación y después éste se conectó a una bomba peristáltica a través de un tubo de teflón. Finalmente, el tubo (cónico para ultracentrifugación de 9/16 x $3 \frac{1}{2}$ pulgadas, Beckman Coulter) donde se iba a formar el gradiente se puso en una gradilla en el otro extremo del capilar de la bomba (se dispuso ligeramente inclinado para evitar la perturbación del gradiente con la caída brusca de las gotas de la solución).

- Formación de los gradientes. Con los grifos del formador de gradiente cerrados y el capilar

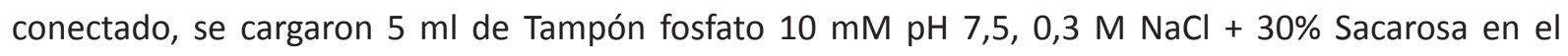

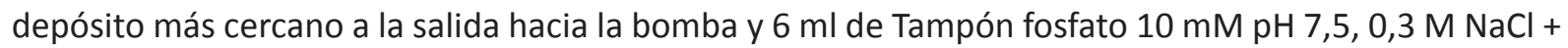
$10 \%$ Sacarosa en el depósito más alejado de la bomba. Se encendió el agitador magnético, se abrieron secuencialmente el grifo que conecta los dos depósitos y el que conecta el formador y la bomba y se encendió la bomba a una velocidad de 3 . Una vez que se formó el gradiente se almacenó a $4^{\circ} \mathrm{C}$.

- Calibrado de los gradientes. Se usaron las proteínas BSA, ADH, Catalasa y Ureasa. Se cargaron $100 \mu \mathrm{g}$ de cada proteína en la parte superior del gradiente y se centrifugó en el rotor SW40 Ti (Beckman) durante $14 \mathrm{~h}$ a $38000 \mathrm{rpm}$ y 4 ํㅡ. Cuando la centrifugación había acabado se recogieron fracciones de $650 \mu \mathrm{l}$ con ayuda de un fraccionador de gradientes en un total de 18 eppendorf. Se precipitaron las proteínas añadiendo $440 \mu \mathrm{l}$ de TCA al $50 \%$ y se congelaron las fracciones a $-80^{\circ} \mathrm{C}$ al menos durante $1 \mathrm{~h}$. A continuación, se centrifugaron a $13000 \mathrm{rpm}$ durante $5 \mathrm{~min}$ y a $4^{\circ} \mathrm{C}$ y se retiró el sobrenadante. Se lavó con $500 \mu \mathrm{l}$ de etanol (que estaba conservado a $-20^{\circ} \mathrm{C}$ ) y después de centrifugar y retirar el etanol, se dejó $5 \mathrm{~min}$ a temperatura ambiente con las tapas de los eppendorf abiertas para que se evaporaran los restos de etanol. Finalmente se resuspendió el pellet en $40 \mu \mathrm{l}$ de Sample Buffer y se hirvieron las muestras 5 min. 
Las muestras se separaron en geles SDS-PAGE al $10 \%$ de acrilamida durante $1,5 \mathrm{~h}$ a $140 \mathrm{v}$ y se tiñó el gel con azul de Coomassie para revelar las proteínas.

- Extracción de proteínas y separación por centrifugación del gradiente. Se recogieron las células (300 ml de levaduras o de $3 \mathrm{~h}$ de filamentación, $\mathrm{DO}_{600}=1$ ) y se lavaron con agua estéril fría. Se repartió el cultivo en epperdorf ( $500 \mu \mathrm{l}$ por tubo). Se centrifugaron las células y se eliminó el sobrenadante. Se añadieron $200 \mu \mathrm{l}$ de bolas de vidrio $(0,4 \mathrm{~mm}$, Sigma-Aldrich) y $200 \mu \mathrm{l}$ de Tampón fosfato $10 \mathrm{mM}$ $\mathrm{pH} 7,5,0,3 \mathrm{M} \mathrm{NaCl}$. Se procedió a la rotura de las células mediante 3 pulsos de $20 \mathrm{~s}$ en un equipo Ribolyser (Hybaid Inc.) a una velocidad de 5,5, dejando los tubos 3 min en hielo entre pulso y pulso. Posteriormente se realizaron agujeros en la base de los tubos, se colocaron sobre eppendorf nuevos y se centrifugaron $1 \mathrm{~min}$ a $2000 \mathrm{rpm}$. Se lavaron las bolas con $100 \mu \mathrm{l}$ de Tampón fosfato $10 \mathrm{mM} \mathrm{pH} \mathrm{7,5,}$ $0,3 \mathrm{M} \mathrm{NaCl}$ y se centrifugó a $9000 \mathrm{rpm}$ durante $10 \mathrm{~min}$ (los extractos de hifas fueron posteriormente concentrados con tubos Amicon de $5 \mathrm{ml}$ centrifugando a $4000 \mathrm{~g}$ durante $40 \mathrm{~min}$ ).

Se cuantificaron las proteínas midiendo en el espectrofotómetro con cubetas de cuarzo a $260 \mathrm{~nm}$. Se ajustó la muestra a $\mathrm{DO}_{260}=100$ en $1 \mathrm{ml}$ y se cargó sobre el tubo del gradiente. La centrifugación del gradiente y la recogida de las fracciones se llevó a cabo igual que se ha descrito previamente para las proteínas de calibración. Una vez que finalizó la electroforesis en SDS-PAGE al 10\% de acrilamida durante $1,5 \mathrm{~h}$ a $140 \mathrm{v}$, se transfirieron las proteínas a una membrana Hybond-P (GE Healthcare) previamente activada con metanol. Para ello se realizó usando el sistema Mini-Trans-Blot (Bio-Rad) durante $1 \mathrm{~h}$ a $100 \mathrm{v}$ en tampón de transferencia. Finalmente, se revelaron las proteínas usando los anticuerpos apropiados.

\subsection{Co-inmunoprecipitación de octámeros de septinas.}

Una vez que los extractos proteicos habían sido centrifugados en un gradiente continuo de sacarosa (10-30\%) y fraccionados en 18 eppendorf con $650 \mu \mathrm{l}$ de volumen, estos extractos se dividían en dos: Tubo A, $300 \mu \mathrm{l}$ que eran precipitados con $200 \mu \mathrm{l} \mathrm{TCA}$ al $50 \%$ y congelados a $-80^{\circ} \mathrm{C}$ y Tubo B, $300 \mu \mathrm{l}$ que directamente eran congelados a $-80^{\circ} \mathrm{C}$ sin tratar con TCA. Una vez analizados los picos del gradiente usando los tubos $\mathrm{A}$, se seleccionaban las fracciones para hacer los ensayos de co-inmunoprecipitación de los tubos B. Cada uno de esos tubos, a su vez, se repartió en dos alícuotas de $150 \mu \mathrm{l}$ y se llevó a

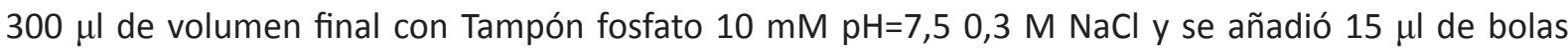
GFP-TRAP o RFP-TRAP. Se incubó durante $2 \mathrm{~h}$ en roller a $4^{\circ} \mathrm{C}$. Se lavó cuatro veces con Tampón fosfato $10 \mathrm{mM} \mathrm{pH}=7,50,2 \mathrm{M} \mathrm{NaCl}$ con ayuda de un imán. Posteriormente, las bolas libres de tampón de lavado, se resuspendieron en $20 \mu \mathrm{l}$ de Sample Buffer y se hirvieron a $100^{\circ} \mathrm{C}$ durante $5 \mathrm{~min}$. Finalmente, las muestras se separaron en SDS-PAGE al $10 \%$ de acrilamida y se transfirieron a membrana como los extractos totales analizados anteriormente. Se reveló usando anticuerpos anti-GFP y anti-RFP.

\section{Técnicas de microscopía.}

\subsection{Microscopía óptica.}

Los microorganismos fueron observados en preparación húmeda en los microscopios: Personal Deltavision (Applied Precision, LLC) controlado mediante el software SoftWoRx Resolve 3D y Olympus IX81 equipado con un sistema confocal Yokogawa Spinning Disk (Roper Scientific) controlado por MetaMorph (MDS Analytical Technologies). Las imágenes fueron capturadas con una cámara CoolSNAP 
HQ2 (Photometrics) en el Personal Deltavision o EMCCD Evolve (Photometrics) en el Olympus-Spinning Disk, y procesadas con los programas MetaMorph (MDS Analytical Technologies), ImageJ 1.37 y Adobe Photoshop CS6 (Adobe System, Inc).

- Tinción con calcoflúor. El calcoflúor es un fluorocromo que en C. albicans tiñe las zonas de la pared celular ricas en quitina. Se excita al recibir luz con una longitud de onda de $372 \mathrm{~nm}$ emitiendo fluorescencia azul. El calcoflúor (Blankophor BBH, Bayer Corporation) se preparó a una concentración de $10 \mathrm{mg} / \mathrm{ml}$ en agua con unas gotas de $\mathrm{KOH} 10 \mathrm{~N}$ para permitir su total disolución. Se filtró y se almacenó a $4^{\circ} \mathrm{C}$ protegido de la luz. Las tinciones con este fluoróforo se realizaron a partir de cultivos creciendo en fase logarítmica, añadiendo $1 \mu \mathrm{l}$ de solución de calcoflúor por cada mililitro de muestra a observar al microscopio.

\subsection{Microscopía de fluorescencia in vivo.}

La observación se realizó en los microscopios Personal Deltavision y Olympus-Spinning Disk. Para la observación de cepas que contenían la proteína fluorescente verde (GFP) o roja (RFP, Cherry), se recogieron cepas en crecimiento exponencial en medio líquido. En función del objetivo del experimento, se tomó una foto del plano central de la célula o bien de a 8 a 12 imágenes de secciones transversales del todo el volumen celular (series en Z) con una separación de 0,3-0,4 $\mu$ m cada una.

\subsection{Microscopía confocal: Time-lapse.}

Para los ensayos de time-lapse se utilizaron cámaras de ocho pocillos (iBIDI u-slide). Previamente, se cubrió el fondo del pocillo con $10 \mu$ de lectina $1 \mathrm{mg} / \mathrm{ml}$ (Soybean L1395, Sigma-Aldrich) y se dejó secar durante 20 min. Después se inoculó el pocillo con $300 \mu$ del cultivo, se dejó fijar durante 5 min y se lavó dos veces con el medio que se fuera a utilizar. Finalmente, se añadieron $300 \mu$ l de medio limpio sobre las células pegadas al fondo del pocillo.

\subsection{Microscopía confocal: Recuperación de fluorescencia después de photobleaching (FRAP).}

Se utilizó el microscopio confocal Olympus-Spinning Disk. El quemado de la fluorescencia se realizó con el módulo láser iLAS (Roper Scientific) del microscopio a máxima potencia hasta que no se observaba ninguna señal de fluorescencia. Las fotos posteriores fueron tomada cada 20-40 s durante 4-6 min. La intensidad de la fluorescencia fue cuantificada con el programa Metamorph, normalizando mediante la resta del fondo y la corrección de la fluorescencia perdida por muestras que no habían sido quemadas.

\section{Recursos bioinformáticos.}

Los programas y recursos bioinformáticos empleados para la realización de este trabajo se encuentran recogidos en la Tabla 4. 
Tabla 2: Estirpes de microorganismos utilizados en este trabajo.

\begin{tabular}{|c|c|c|c|}
\hline Estirpe & Nombre & Genotipo & Procedencia \\
\hline \multicolumn{4}{|l|}{ C. albicans } \\
\hline OL29 & CAI4 & ura3s::imm434/ura3s::imm434 & Fonzi e Irwin 1993 \\
\hline OL1417 & BWP17 & 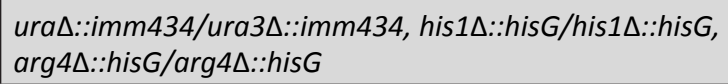 & Enloe et al., 2000 \\
\hline OL1326 & CDC14-GFP & CAI4 CDC14/CDC14-GFP::URA3 & Stock del laboratorio \\
\hline OL1365 & $\operatorname{cdc} 11 \Delta \Delta$ & BWP17 cdc11 $:: A R G 4 / c d c 11 \Delta:: H I S 1$ & Stock del laboratorio \\
\hline OL1405 & SEP7-HA & CAI4 SEP7/SEP7-HA-URA3 & Stock del laboratorio \\
\hline OL1419 & CDC12-HA & CAI4 CDC12/CDC12-HA::URA3 & Stock del laboratorio \\
\hline OL1431 & $\operatorname{sep} 7 \triangle \triangle C D C 10-G F P$ & $\begin{array}{l}\text { BWP17 sep7D::HIS1/sep7D::URA3, } \\
\text { CDC10/CDC10-GFP::ARG4 }\end{array}$ & $\begin{array}{l}\text { González-Novo et al. } \\
\text { (2008) }\end{array}$ \\
\hline OL1446 & CDC12-GFP & BWP17 CDC12/CDC12-GFP::URA3 & Stock del laboratorio \\
\hline OL1456 & SEP7-GFP & BWP17 SEP7/SEP7-GFP::ARG4 & Stock del laboratorio \\
\hline OL1611 & INT1-GFP & BWP17 INT1/INT1-GFP::HIS1 & Stock del laboratorio \\
\hline OL1644 & $c d c 10 \Delta \triangle I N T 1-G F P$ & $B W P 17 c d c 10 \Delta \Delta$, INT1-GFP & Stock del laboratorio \\
\hline OL2349 & SPA2-GFP & CAI4 SPA2/SPA2-GFP::URA3 & Dr. Jaime Correa \\
\hline OL2477 & TUB2-GFP & BWP17 TUB2/TUB2-GFP::URA3 & Dr. Jaime Correa \\
\hline \multicolumn{4}{|l|}{ E. coli } \\
\hline & $D H 5 \alpha$ & $\begin{array}{l}\text { supE44 } \Delta \text { lacU } 169 \text { ( } \Theta 80 \text { lacZ } \triangle M 15 \text { ) hsdR17 recA1 } \\
\text { endA1 gyrA96 thi-1 relA1 }\end{array}$ & Stock del laboratorio \\
\hline
\end{tabular}

Estirpes de C.albicans construídas para este trabajo (todas derivan del fondo genético BWP17):

\begin{tabular}{|c|c|c|}
\hline Estirpe & Nombre & Genotipo \\
\hline OL1184 & $C D C 12+/-$ & CDC12/cdc12 $\triangle:: S A T 1$ \\
\hline OL2001 & $c d c 12-S 64 E$ & CDC12 (S64A)::HIS1-GFP::ARG4/cdc12A::URA3 \\
\hline OL2007 & $c d c 12-S 64 E$ & CDC12 (S64E)::HIS1-GFP::ARG4/cdc12A::URA3 \\
\hline OL2025 & $c d c 12-2 E$ & CDC12 (S64E;S178E)::HIS1/cdc12A::SAT1 \\
\hline OL2049 & $S E P 7+/-$ & SEP7/sep7D::SAT1 \\
\hline OL2050 & $C D C 11+/-$ & CDC11/cdc11 $1:: S A T 1$ \\
\hline OL2082 & SEP7+/- CDC10-GFP & SEP7/sep7D::SAT1 CDC10/CDC10-GFP::URA3 \\
\hline OL2084 & CDC11+/-CDC10-GFP & CDC11/cdc11 $::$ SAT1 CDC10/CDC10-GFP::URA3 \\
\hline OL2100 & MOB2-mус CDC12-HA & MOB2/MOB2-myc::HIS1 CDC12/CDC12-HA::ARG4 \\
\hline OL2102 & $C D C 28-m y c$ CDC12-HA & CDC28/CDC28-myc::ARG4 CDC12/CDC12-HA::HIS1 \\
\hline OL2106 & $C D C 11+/-S E P 7+/-$ & CDC11/cdc11 $::$ SAT1 SEP7/sep7D::HIS1 \\
\hline OL2109 & $S E P 7+/-C D C 11+/-$ & SEP7/sep7D::SAT1, CDC11/cdc11A::HIS1 \\
\hline OL2119 & sep7-8A & $\begin{array}{l}\text { SEP7 (S645A;T646A;T651A;S652A;T659A;T661A;S665A;S668A)-GFP::ARG4/ } \\
\text { SEP7 (S645A;T646A;T651A;S652A;T659A;T661A;S665A;S668A)-GFP::HIS1 }\end{array}$ \\
\hline OL2131 & $S E P 7+/-C D C 12+/-$ & SEP7/sep7D::SAT1 CDC12/cdc12A::HIS1 \\
\hline OL2134 & $C D C 3+/-$ & $C D C 3 / c d c 3 \Delta:: S A T 1$ \\
\hline OL2136 & $C D C 10+/-$ & CDC10/cdc10D::SAT1 \\
\hline OL2138 & $\operatorname{sep} 7 \Delta \Delta$ & sep7D::SAT1/sep7D::HIS1 \\
\hline OL2140 & $\begin{array}{l}\text { SEP7+/-CDC11+/- } \\
\text { CDC10-GFP }\end{array}$ & SEP7/sep7D::HIS1, CDC11/cdc11 ::SAT1 CDC10/CDC10-GFP::URA3 \\
\hline OL2151 & $S E P 7+/-C D C 10+/-$ & SEP7/sep7D::SAT1 CDC10/cdc10 $:: H I S 1$ \\
\hline OL2162 & int1- $\Delta C$ & int1- $\triangle C(1135-1712)-H A:: U R A 3 /$ int1 $\Delta:: S A T 1$ \\
\hline OL2164 & int1- $\Delta N$ & ARG4::int1- $\Delta N(1-1126) /$ int1D::SAT1 \\
\hline OL2166 & CDC11 $11^{\text {CTEL-SEP7n }}$ & sep7D::SAT1/sep7D::HIS1 CDC11/Cdc11 (1-380)+Sep7 (580-670)::ARG4 \\
\hline
\end{tabular}




\begin{tabular}{|c|c|c|}
\hline Estirpe & Nombre & Genotipo \\
\hline OL2169 & CDC11 $11^{\text {CTEC-SEP7 }}$ & 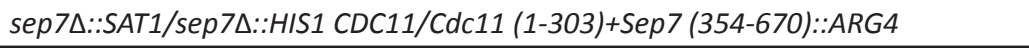 \\
\hline OL2171 & $C D C 12+/-C D C 11+/-$ & 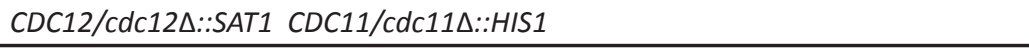 \\
\hline OL2183 & $\operatorname{cdc} 12-3 A$ & CDC12 (S64A; T92A; S178A)::HIS1-GFP::ARG4/cdc12A::SAT1 \\
\hline OL2184 & SEP7-8A MLC1-Ch & $\begin{array}{l}\text { SEP7(S645A;T646A;T651A;S652A;T659A;T661A;S665A;S668A)-GFP::ARG4/ } \\
\text { SEP7(S645A;T646A;T651A;S652A;T659A;T661A;S665A;S668A)-GFP::HIS1, } \\
\text { MLC1/MLC1-Cherry::URA3 }\end{array}$ \\
\hline OL2185 & sep7t-394 & SEP7t-394-Cherry::URA3/SEP7t-394-Cherry::HIS1 \\
\hline OL2187 & sep $7 t-580$ & SEP7t-580-Cherry::URA3/SEP7t-580-Cherry::HIS1 \\
\hline OL2189 & sep7t-629 & SEP7t-629-Cherry::URA3/SEP7t-629-Cherry::HIS1 \\
\hline OL2193 & int1- $\triangle C$ CDC10-GFP & int1- $\triangle C(1135-1712)-H A:: U R A 3 /$ int1A::SAT1 CDC10/CDC10-GFP::HIS1 \\
\hline OL2195 & int1-3A CDC10-GFP & INT1-(S1270A;T1345A;T1389A)-HA::ARG4/int1D::SAT1 CDC10/CDC10-GFP::HIS1 \\
\hline OL2197 & int1-3E CDC10-GFP & INT1-(S1270E;T1345E;T1389E)-HA::ARG4/int1D::SAT1 CDC10/CDC10-GFP::HIS1 \\
\hline OL2209 & $C D C 12+/-C D C 10+/-$ & 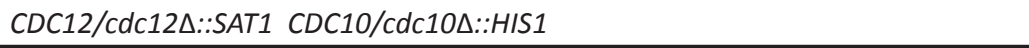 \\
\hline OL2211 & $C D C 11+/-C D C 10+/-$ & 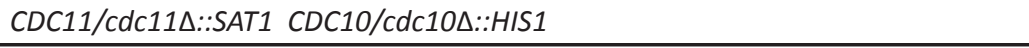 \\
\hline OL2213 & $\operatorname{cdc} 10 \Delta \Delta$ & 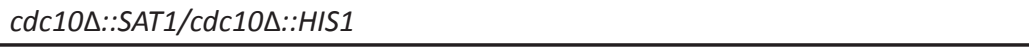 \\
\hline OL2217 & SEP7-Ch & SEP7/SEP7-Cherry::URA3 \\
\hline OL2220 & $\operatorname{cdc} 12-4 A$ & CDC12(S64A; T92A; S178A; T202A)::HIS1-GFP::ARG4/cdc12A::SAT1 \\
\hline OL2221 & $c d c 12-3 E$ & CDC12(S64E; T92E; S178E)::HIS1-GFP::ARG4/cdc12A::SAT1 \\
\hline OL2222 & $c d c 12-4 E$ & CDC12(S64E; T92E; S178E; T202E)::HIS1-GFP::ARG4/cdc12A::SAT1 \\
\hline OL2231 & SEP7-GFP MLC1-Ch & SEP7/SEP7-GFP::ARG4 MLC1/MLC1-Cherry::URA3 \\
\hline OL2233 & sep7t-394 CDC10-GFP & SEP7t-394-Cherry::URA3/SEP7t-394-Cherry::HIS1 CDC10/CDC10-GFP::ARG4 \\
\hline OL2235 & sep7t-580 CDC10-GFP & SEP7t-580-Cherry::URA3/SEP7t-580-Cherry::HIS1 CDC10/CDC10-GFP::ARG4 \\
\hline OL2237 & sep7t-629 CDC10-GFP & SEP7t-629-Cherry::URA3/SEP7t-629-Cherry::HIS1 CDC10/CDC10-GFP::ARG4 \\
\hline OL2241 & SEP7+/-CDC3+/- & 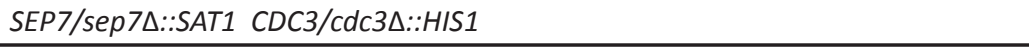 \\
\hline OL2243 & CDC10-GFP & CDC10/CDC10-GFP::ARG4 \\
\hline OL2252 & sep $7 t-522$ & SEP7t-522-Cherry::URA3/SEP7t-522-Cherry::HIS1 \\
\hline OL2256 & $C D C 3+/-C D C 10+/-$ & 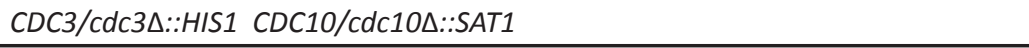 \\
\hline OL2258 & $C D C 3+/-C D C 11+/-$ & CDC3/cdc3A::HIS1 CDC11/cdc11A::SAT1 \\
\hline OL2260 & $C D C 3+/-C D C 12+/-$ & CDC3/cdc3A::HIS1 CDC12/cdc12A::SAT1 \\
\hline OL2262 & INT1-GFP CDC10-Ch & INT1/INT1-GFP::HIS1 CDC10/CDC10-Cherry::URA3 \\
\hline OL2271 & sep7t-522 CDC10-GFP & SEP7t-522-Cherry::URA3/SEP7t-522-Cherry::HIS1 CDC10/CDC10-GFP::ARG4 \\
\hline OL2273 & int1- $\triangle C$-GFP & Int1- $\Delta C(1134-1712)-G F P:: H I S 1 /$ int1 $\triangle:: S A T 1$ \\
\hline OL2274 & int1- $\triangle N-G F P$ & ARG4::int1- $\triangle N(1-1126)-G F P:: H I S 1 /$ int1 $\Delta:: S A T 1$ \\
\hline OL2278 & int1- $\triangle C$-GFP CDC10-Ch & Int1- $\triangle C$ (1134-1712)-GFP::HIS1/int1A::SAT1 CDC10/CDC10-Cherry::URA3 \\
\hline OL2280 & int1- $\triangle N-G F P C D C 10-C h$ & ARG4::int1- $\triangle N(1-1126)-G F P:: H I S 1 /$ int1 $1:: S A T 1$ CDC10/CDC10-Cherry::URA3 \\
\hline OL2304 & int1- $\triangle N$ CDC10-GFP & ARG4::int1- $\triangle N$ (1-1126)-HA::URA3/int1D::SAT1 CDC10/CDC10-GFP::HIS1 \\
\hline OL2310 & $\begin{array}{l}\text { sep7 } \triangle \triangle \text { INT1-GFP } \\
\text { CDC10-Ch }\end{array}$ & sep7D::SAT1/sep7D::ARG4 INT1/INT1-GFP::HIS1 CDC10/CDC10-Cherry::URA3 \\
\hline OL2314 & $\operatorname{int} 1 \Delta \Delta$ & int1 $1:: S A T 1 /$ int1 $1:: A R G 4$ \\
\hline OL2316 & int $1 \triangle \triangle C D C 10-G F P$ & int1 $\triangle:: S A T 1 /$ int1 $\triangle:: A R G 4$ CDC10/CDC10-GFP::URA3 \\
\hline OL2317 & CDC10-GFP INT1-HA & CDC10/CDC10-GFP::ARG4 INT1/INT1-HA::URA3 \\
\hline OL2328 & $\begin{array}{l}\text { int } 1 \triangle \triangle C D C 10-G F P \\
M L C 1-C h\end{array}$ & int1D::SAT1/int1 $:: A R G 4$ CDC10/CDC10-GFP::URA3 MLC1/MLC1-Cherry::HIS1 \\
\hline OL2338 & CDC10-GFP MLC1-Ch & CDC10/CDC10-GFP MLC1/MLC1-Cherry::HIS1 \\
\hline OL2347 & NOP1-Ch & NOP1/NOP1-Cherry::URA3 \\
\hline OL2354 & int1 $\triangle \triangle S P A 2-G F P$ & int1 $\triangle:: S A T 1 /$ int1 $\triangle:: A R G 4$ SPA2/SPA2-GFP::HIS1 \\
\hline OL2368 & CDC12-TAP-TAG & CDC12/CDC12-TAP-TAG::ARG4 \\
\hline
\end{tabular}




\begin{tabular}{|c|c|c|}
\hline Estirpe & Nombre & Genotipo \\
\hline OL2374 & SEC3-GFP & SEC3/SEC3-GFP::URA3 \\
\hline OL2382 & Int1 $\triangle \triangle S E C 3-G F P$ & int1D::SAT1/int1 $\triangle:: A R G 4$ SEC3/SEC3-GFP::URA3 \\
\hline OL2389 & $\begin{array}{l}\text { int } 1 \Delta \Delta \\
\text { GIN4-GFP CDC10-Ch }\end{array}$ & int1 $\triangle:: S A T 1 /$ int1D::ARG4 GIN4/GIN4-GFP::URA3 CDC10/CDC10-Cherry::HIS1 \\
\hline OL2391 & SEC3-GFP CDC10-Ch & SEC3/SEC3-GFP::URA3 CDC10/CDC10-Cherry::HIS1 \\
\hline OL2393 & GIN4-GFP CDC10-Ch & GIN4/GIN4-GFP::URA3 CDC10/CDC10-Cherry::HIS1 \\
\hline OL2399 & $\operatorname{sep} 7-3 A$ & SEP7(T659A-S665A-S668A)-GFP::ARG4/SEP7(T659A-S665A-S668A)-GFP::HIS1 \\
\hline OL2417 & $\begin{array}{l}\text { sep7 } \triangle \triangle \\
\text { SEC3-GFP CDC10-Ch }\end{array}$ & sep7D::SAT1/sep7D::ARG4 SEC3/SEC3-GFP::URA3 CDC10/CDC10-Cherry::HIS1 \\
\hline OL2421 & $\begin{array}{l}\operatorname{sep} 7 \Delta \Delta \\
\text { GIN4-GFP CDC10-Ch }\end{array}$ & sep7D::SAT1/sep7D::ARG4 GIN4/GIN4-GFP::URA3 CDC10/CDC10-Cherry::HIS1 \\
\hline OL2506 & int1 $\triangle \triangle S E P 7-H A$ & 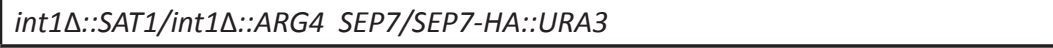 \\
\hline OL2509 & $\operatorname{int} 1 \Delta \Delta \operatorname{sep} 7 \Delta \Delta$ & 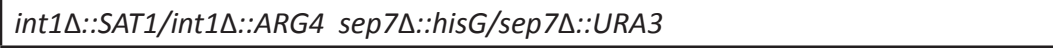 \\
\hline OL2513 & int $1 \Delta \triangle \operatorname{sep} 7 \triangle \triangle C D C 10-G F P$ & 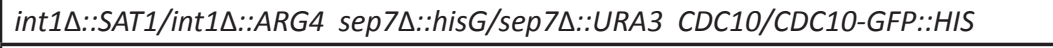 \\
\hline OL2514 & int $1 \Delta \triangle \operatorname{sep} 7 \Delta \triangle N O P 1-C h$ & 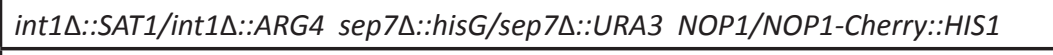 \\
\hline OL2520 & int $1 \Delta \Delta$ rts $1 \Delta \Delta$ & 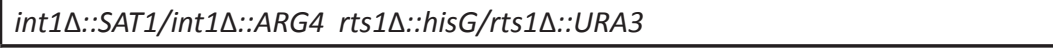 \\
\hline OL2526 & $r t s 1 \Delta \Delta$ & rts1 $1:: A R G 4 / r t s 1 \Delta:: H I S 1$ \\
\hline OL2530 & $r t s 1 \Delta \Delta \operatorname{sep} 7 \Delta \Delta$ & 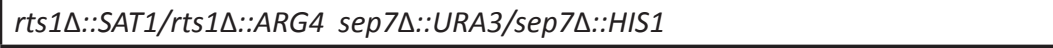 \\
\hline OL2532 & $\operatorname{int} 1 \Delta \Delta c d c 10 \Delta \Delta$ & 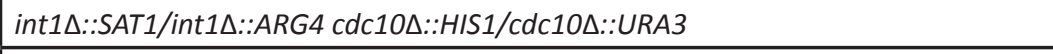 \\
\hline OL2536 & int $1 \Delta \triangle \operatorname{sep} 7 \triangle \triangle T U B 2-G F P$ & 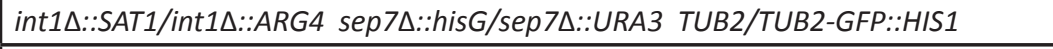 \\
\hline OL2538 & SEP7-Ch CDC11-GFP & SEP7-Cherry::HIS1/SEP7-Cherry::URA3 CDC11-GFP::ARG4/CDC11-GFP::SAT1 \\
\hline OL2546 & sep $7-2 E$ & SEP7(S14E;S22E)::HIS1/SEP7(S14E;S22E)::ARG4 \\
\hline OL2550 & RTS1-GFP & RTS1/RTS1-GFP::HIS1 \\
\hline OL2552 & sep7 $\triangle \triangle R T S 1-G F P$ & sep7D::SAT1/sep7A::HIS1, RTS1/RTS1-GFP::URA3 \\
\hline OL2553 & int1 $\triangle \triangle R T S 1-G F P$ & int1D::SAT1/int1A::ARG4 RTS1/RTS1-GFP::HIS1 \\
\hline OL2555 & int1 $\Delta \Delta \operatorname{sep} 7 \Delta \triangle R T S 1-G F P$ & 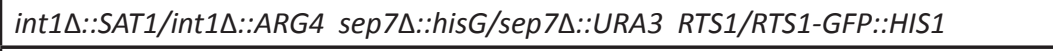 \\
\hline OL2556 & GLC7-GFP & GLC7/GLC7-GFP::HIS1 \\
\hline OL2558 & $\operatorname{sep} 7 \triangle \triangle$ GLC7-GFP & sep7D::SAT1/sep7D::HIS1 GLC7/GLC7-GFP::URA3 \\
\hline OL2561 & rts1 $\triangle \triangle G L C 7-G F P$ & rts1D::HIS1/rts1D::ARG4 GLC7/GLC7-GFP::URA3 \\
\hline OL2563 & int $1 \Delta \Delta \operatorname{sep} 7 \Delta \triangle$ GLC7-GFP & 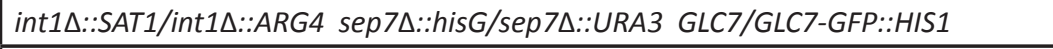 \\
\hline OL2565 & int $1 \triangle \triangle C D C 14-G F P$ & int1 $:: S A T 1 /$ int1 $1:: A R G 4$ CDC14/CDC14-GFP::HIS1 \\
\hline OL2567 & $r t s 1 \triangle \triangle C D C 14-G F P$ & rts14::HIS1/rts1D::ARG4 CDC14/CDC14-GFP::URA3 \\
\hline OL2570 & $\begin{array}{l}\text { int } 1 \Delta \Delta \operatorname{sep} 7 \Delta \Delta \\
C D C 14-G F P\end{array}$ & 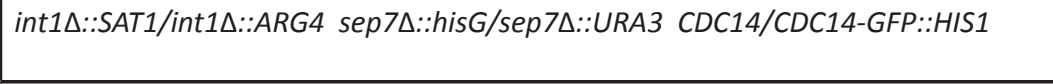 \\
\hline OL2572 & $\operatorname{sep} 7 \triangle \triangle E L M 1-G F P$ & sep7D::SAT1/sep7D::HIS1 ELM1/ELM1-GFP::URA3 \\
\hline OL2575 & $r t s 1 \triangle \triangle E L M 1-G F P$ & rts1D::HIS1/rts1D::ARG4 ELM1/ELM1-GFP::URA3 \\
\hline OL2576 & $\begin{array}{l}\text { int1 } 1 \Delta \Delta \operatorname{sep} 7 \Delta \Delta \\
\text { ELM1-GFP }\end{array}$ & 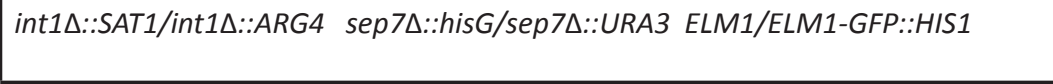 \\
\hline OL2582 & $\operatorname{sep} 7 \triangle \triangle C D C 14-G F P$ & sep7D::SAT1/sep7D::HIS1 CDC14/CDC14-GFP::URA3 \\
\hline OL2583 & ELM1-GFP & ELM1/ELM1-GFP::HIS1 \\
\hline OL2585 & int1 $\triangle \triangle E L M 1-G F P$ & int1 $\triangle:: S A T 1 /$ int1 $1:: A R G 4$ ELM1/ELM1-GFP::HIS1 \\
\hline OL2586 & int1 $\triangle \triangle G L C 7-G F P$ & int1D::SAT1/int1D::ARG4 GLC7/GLC7-GFP::HIS1 \\
\hline OL2598 & $\operatorname{sep} 7-2 A$ & SEP7(S14A;S22A)::HIS1/SEP7(S14A;S22A)::ARG4 \\
\hline OL2632 & sep7-2A-Ch & SEP7(S14A;S22A)::HIS1/SEP7(S14A;S22A)::ARG4-Cherry::URA3 \\
\hline OL2634 & sep7-2E-Ch & SEP7(S14E;S22E)::HIS1/SEP7(S14E;S22E)::ARG4-Cherry::URA3 \\
\hline OL2636 & SEP7-10A & $\begin{array}{l}\text { SEP7 (S444A; T445A; S446A; S454A; S455A; S456A; S468A; S470A; T471A; S473A) } \\
\text {-Cherry::HIS1) } \\
\text { SEP7 (S444A; T445A; S446A; S454A; S455A; S456A; S468A; S470A; T471A; S473A)- } \\
\text { Cherry::ARG4 }\end{array}$ \\
\hline
\end{tabular}


Tabla 3. Anticuerpos utilizados en este trabajo.

\begin{tabular}{|l|l|l|}
\hline Nombre & Procedencia & Casa Comercial \\
\hline Anti-Cdc11 (y-415) & Conejo & Santa Cruz Biotechnology \\
\hline Anti-GFP (JL-8) & Ratón & Living Colors \\
\hline Anti-GFP (3H9) & Rata & Chromotek \\
\hline Anti-RFP (3F5) & Ratón & Chromotek \\
\hline Anti-cMyc (9E-10) & Ratón & Santa Cruz Biotechnology \\
\hline Anti-HA high Affinity & Rata & Roche \\
\hline Anti-Conejo ECL & Ratón & Santa Cruz Biotechnology \\
\hline Anti-Rata ECL & Cabra & Santa Cruz Biotechnology \\
\hline Anti-Ratón ECL & Oveja & Amersham \\
\hline
\end{tabular}

Tabla 4. Recursos bioinformáticos utilizados durante este trabajo.

\begin{tabular}{|l|l|}
\hline \multicolumn{1}{|c|}{ Programa } & \multicolumn{1}{c|}{ Dirección electrónica } \\
\hline Adobe $^{\circledR}$ Photoshop CS5 & http://www.adobe.com/ \\
\hline EndNote $^{\circledR}$ X6 & http://www.endnote.com/ \\
\hline DNASTAR (Lasergene) & http://www.dnastar.com/ \\
\hline Base de datos de C. albicans & http://www.candidagenome.org/ \\
\hline Base de datos de S. cerevisiae & http://www.yeastgenome.org/ \\
\hline GeneDB & http://www.genedb.org/ \\
\hline BLAST & http://blast.ncbi.nlm.nih.gov/ \\
\hline SMART & http://smart.embl-heidelberg.de/ \\
\hline Image J & http://rsbweb.nih.gov/ij/ \\
\hline Clustal Omega & http://www.ebi.ac.uk/Tools/msa/clustalo/ \\
\hline Pfam & http://pfam.xfam.org/ \\
\hline Interpro & http://www.ebi.ac.uk/interpro/ \\
\hline MetaMorph ${ }^{\circledR} 7.5$ & http://www.moleculardevices.com/ \\
\hline Kinasephos 2.0 & http://kinasephos2.mbc.nctu.edu.tw/ \\
\hline
\end{tabular}





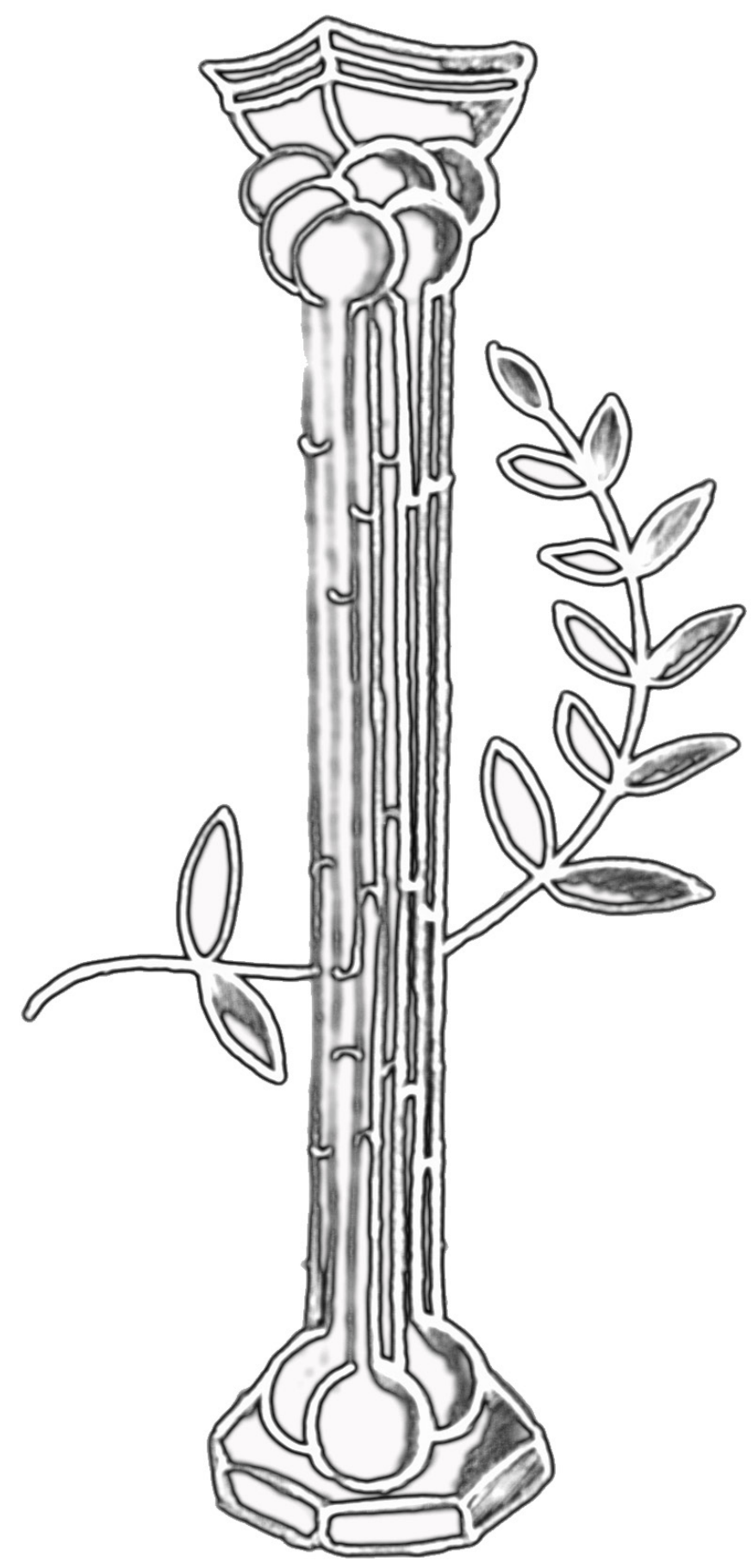

Summary 

Importance of the septin ring plasticity in the biology of $C$. albicans

\section{Introduction.}

Candida albicans is both a prevalent human commensal and the most commonly human fungal pathogen found. This lifestyle is dependent on its ability to undergo rapid genetic and epigenetic changes, often in response to specific environmental cues. A parasexual cycle has been described in $C$. albicans that includes several unique properties when compared to the related model yeast, Saccharomyces cerevisiae (reviewed in Bennett, 2015; Zhang et al., 2015; Schmid et al., 2016). C. albicans is able to adopt three different morphologies: yeast, pseudohyphae and hyphae (Berman and Sudbery, 2002). Morphogenesis has been a research focus in C. albicans because virulence is associated with the ability to switch between the yeast and hyphal forms.

The $C$. albicans cell cycle is driven by the cyclin-dependent protein kinase Cdc28 (also known as Cdk1), which plays an essential role in the morphogenesis of yeast and hyphae. Although fundamental aspects of cyclin dependent kinase (CDK) are similar across yeast species, the global pattern of transcription for cell cycle genes is very different between S. cerevisiae and C. albicans (reviewed in Berman, 2006; Wang, 2009). Other kinases, like Cbk1, are also required for efficient apical growth, proper mating projection morphology, bipolar bud site selection in diploid cells, and cell separation, controlling the transcription factor Ace2 (Bidlingmaier et al., 2001; Colman-Lerner et al., 2001).

This work focuses on the study of septin proteins, which play important roles in septum formation, cell division and other cellular processes. The $C$. albicans genome encodes five septins, close homologs to those of $S$. cerevisiae. Deletion analysis showed that $C D C 3$ and $C D C 12$ are essential for viability in C. albicans. In contrast, the $\operatorname{sep} 7 \Delta \Delta, c d c 10 \Delta \Delta$ and $c d c 11 \Delta \Delta$ mutants are viable but display conditional defects in cytokinesis, localization of cell wall chitin, and bud morphology. The mutant phenotypes are not identical, however, indicating that these septins carry out different functions. The viable septin mutants could be induced to undergo hyphal morphogenesis, but formed hyphae with abnormal curvature (Warenda and Konopka, 2002).

In yeast and pseudohyphae, a septin patch forms at the site of bud emergence. As the bud grows, the septin complex forms a ring that expands to form a collar covering the bud neck. Mitosis occurs across the plane of the bud neck, and during cytokinesis the septin collar splits into two rings, serving as scaffold to organize the actomyosin ring (AMR) and the proteins involved in the formation of the primary and secondary septa. In hyphae, evagination of the tube is accompanied by the formation of a septin patch which remains at the germ-tube neck known as the basal septin band. However, this septin complex does not mature into a ring; rather, it forms a band of longitudinal septin bars. As the germ tube elongates, septins localize to the tip forming a cap, which is the origin of the septin ring that is assembled within the germ tube rather than at its neck (Warenda and Konopka, 2002; Sudbery et al., 2004).

A common structural feature of all septins from yeast to human is the presence of a GTPase domain. This domain is flanked by a short basic rich region on the $\mathrm{N}$-terminal end and by a conserved domain that is unique to the septins on the C-terminal end (septin unique element or SUE). The region of basic amino acids is thought to mediate binding to phosphoinositide-containing membranes. Most S. cerevisiae septins also contain a C-terminal extension (CTE) that contains a coiled-coil domain, 
although it is absent in Cdc10 (Douglas et al., 2005; Versele and Thorner, 2005; Pan et al., 2007; Sirajuddin et al., 2007; Weirich et al., 2008; Estey et al., 2011; Fung et al., 2014).

Yeast septins form stable rod-shaped hetero-octamers in solution (Sep7/Cdc11-Cdc12-Cdc3Cdc10-Cdc10-Cdc3-Cdc12-Cdc11/Sep7)(Bertin et al., 2008). The octamers polymerize head-to-head to assemble high-order structures, such as filaments. The current model of the architecture of the septin ring throughout the cell cycle is based on the work of Ong et al. (2014). The early hourglass consists of septin double filaments oriented along the mother-bud axis. In the late hourglass, these double filaments are connected by periodic circumferential single filaments on the membrane-proximal side and are associated with centrally located, circumferential, myosin-Il thick filaments on the membrane-distal side. The double ring consists of exclusively circumferential septin filaments. Live-cell imaging studies indicate that the hourglass-to-double ring transition is accompanied by loss of septin subunits from the hourglass and reorganization of the remaining subunits into the double ring.

Cdc11 and Shs1 are the most closely related septins, but they have diverged in their function, despite occupying the same terminal position in the octamers (Pan et al. , 2007). The fact that substitution of one subunit with an other related, and its state of modification can affect the supramolecular arrangement of septin structures suggests that, in other organisms (such as humans) with an even greater repertoire of septin genes, replacement of specific subunits with alternative ones is the molecular basis for producing septin complexes with different structural properties and, hence, different functional specificity. Thus, in such cases, the presence of multiple related subunits generates physiological plasticity rather than mere redundancy (Garcia et al., 2011).

Septins are post-translationally modified by SUMOylation, acetylation and phosphorylation. By far, the best characterized and most abundant modification is phosphorylation. Many mutations affecting the phosphorylation sites result in morphogenesis or cytokinesis defects (reviewed in Hernández-Rodríguez and Momany, 2012), and Shs1 is the most abundantly modified septin by phosphorylation (Egelhofer et al., 2008; Garcia et al., 2011).

The septins at the bud neck function as scaffold for other proteins involved in fundamental and diverse processes, such as the establishment of cell polarity, cell wall synthesis, spindle positioning, regulation of the mitotic checkpoint, cytokinesis, bud site selection or DNA damage response (Chang and Peter, 2003; Lew, 2003; Keaton and Lew, 2006; Spiliotis and Nelson, 2006; Park and Bi, 2007; Barral and Kinoshita, 2008; Weirich et al., 2008; Gilden and Krummel, 2010; Gladfelter, 2010; Moore and Cooper, 2010; Spiliotis, 2010; Merlini and Piatti, 2011; Bi and Park, 2012; Howell and Lew, 2012; Markus et al., 2012). The septins also function as diffusion barrier to confine some proteins in specific cellular compartments, such as the bud or the neck region during cytokinesis (Barral et al., 2000; Dobbelaere and Barral, 2004). In budding yeast, septins are also required for the neck localization of some components of the spindle position checkpoint (SPOC), a mechanism that delays mitotic exit when the anaphase spindle fails to extend toward the mother-daughter axis. In C. albicans, septins are also involved in the inhibition of septum degradation after cytokinesis, a special characteristic of hyphal growth. It has been shown that the properties of the septin ring are modified in hyphae in a Sep7-dependent manner, and that this is required to inhibit cell separation of the hyphal compartments (González-Novo et al., 2008). 
Selection of the budding site in S. cerevisiae requires several components that function as cortical landmarks. Bud4 is a protein necessary for the formation of the axial landmark specific of haploid cells, which remains associated to the septin ring throughout the cycle. Although its localization depends on septins, Bud4 is necessary for the stable inheritance of septin rings after cytokinesis. Bud4 contains a DUF1709 domain (anillin) and a PH (Pleckstrin Homology) domain (Kang et al., 2013). In bud4 $\Delta$ mutants, the septins form a ring-like structure at the mother-bud neck that fails to re-arrange into a double ring early in cytokinesis. Strikingly, AMR assembly and constriction, the localization of membrane-trafficking and extracellular-matrix-remodeling factors, cytokinesis, and cell-wall-septum formation all occur efficiently in bud $4 \Delta$ mutants. Thus, diffusion barriers formed by the septin double ring do not appear to be critical for S. cerevisiae cytokinesis (Wloka et al., 2011; Eluere et al., 2012; Kang et al., 2013). Bud4 has a low degree of sequence similarity (18\%) to mammalian anillin (Oegema et al., 2000), and homologs are found in other fungi, such as the $C$. albicans Int1. The common function of anillin and fungal proteins appears to be the regulation of cytokinesis, and in most cases, this involves interaction with septins (Piekny and Maddox, 2010).

\section{Objectives.}

The general objective is the study of various aspects of the septin ring regulation and its relationship with the morphogenesis in opportunistic pathogen C. albicans.

\section{Results and Discussion.}

\subsection{Septin gene dosage play a fundamental role in the inhibition of hyphal cell separation.}

$\operatorname{sep} 7 \Delta \Delta$ cells have a mild phenotype in yeast, and hyphae are similar to those of a wild-type, with respect to its size and morphology (Warenda and Konopka, 2002). However, sep7 $\Delta \Delta$ hyphae fail to inhibit cell separation (González-Novo et al., 2008). Since C. albicans cells are diploid, to analyze the role of Sep7 and other septins in cell separation, a collection of heterozygous mutants in all septin genes was generated. During yeast growth, all of them were similar to the wild-type. However, analysis of the phenotype during hyphal development indicated that septin gene dosage was important to regulate hyphal separation, although not all septins had the same contribution. Thus, only in SEP7+/- and $C D C 11+/$ - heterozygous mutants cell separation was activated in hyphae. Interestingly, SEP7+/- hyphae had a percentage of hyphal cell separation intermediate (around 20\%) between a wild-type strain and a sep $7 \Delta \Delta$ (10\% and $30 \%$, respectively) after $3.5 \mathrm{~h}$ of filamentation (Fig. I). CDC11+/- also showed a high percentage of cell separation. Therefore, these results suggest that the relative proportion of Sep7 and Cdc11, the two septins that cap the octamers, is important to maintain the hyphal compartments attached during filamentation.

A prediction of this model is that restoring the 1:1 proportion of Sep7 and Cdc11 should complement the phenotype of $S E P 7+/$ - and $C D C 11+/$ - heterozygous mutants. Therefore, we constructed all possible combinations of double heterozygous mutants, reducing the gene dosage of two septins genes in each strain. When cell separation during hyphal development was analyzed in these strains, we found that the $C D C 11+/-S E P 7+/-$ combination complemented the separation defect and hyphae were similar to the wild-type. Interestingly, reduction of $C D C 10$ dosage in a SEP7+/- background also resulted in complementation of the phenotype, since the percentage of separated hyphae in the SEP7+/$C D C 10+/-$ mutants was also similar to the wild-type. None of the other combinations with SEP7+/- 

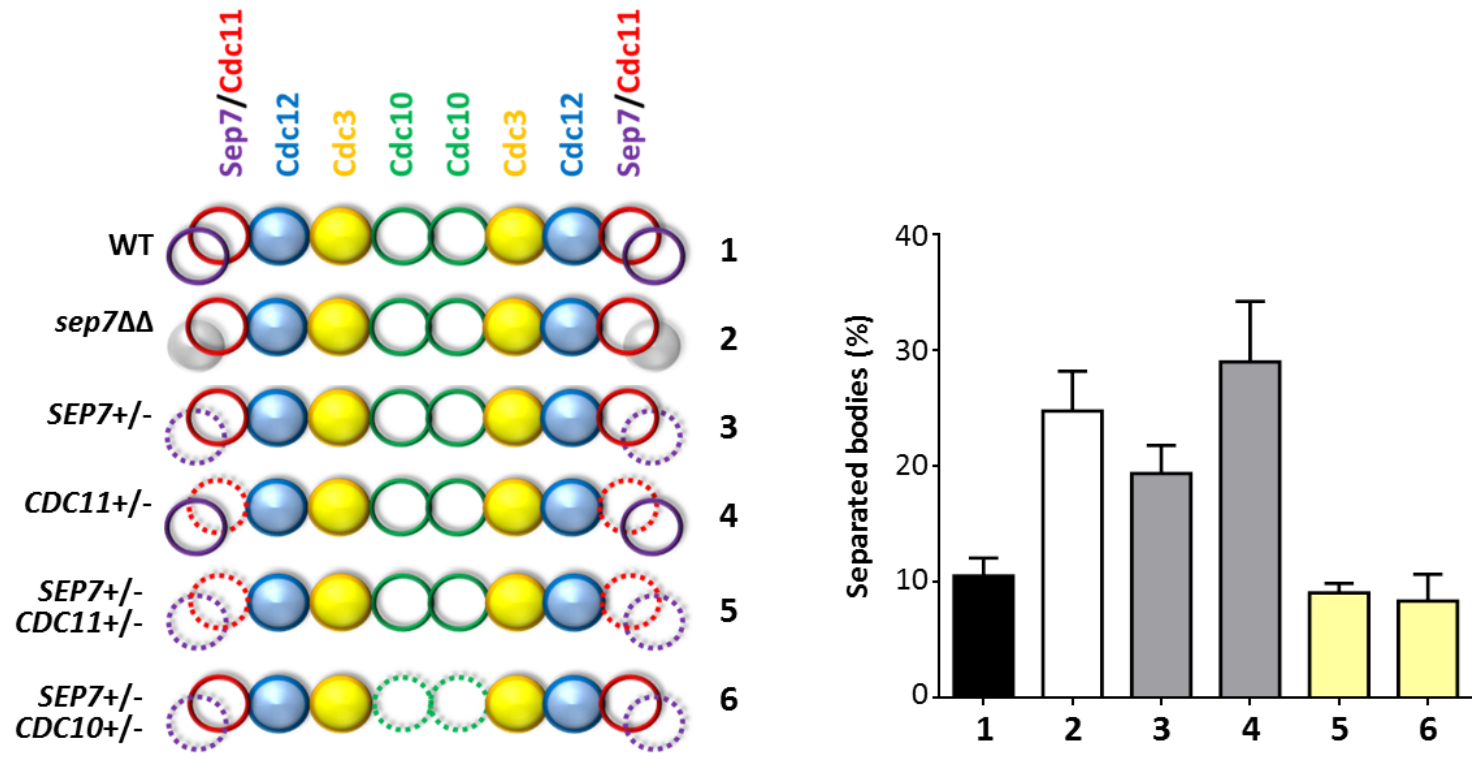

Figure I. Effects of septin gene dosage reduction during hyphal growth. Schematic representation of the septin octamers formed in the wild type (WT), the null mutant sep7 $\triangle \triangle$ and the heterozygous mutants (SEP7+/-, CDC11+/-, SEP7+/- CDC11+/and SEP7+/- CDC10 +/-). The graph shows the percentage of separated bodies of the different strains and is the mean of at least three independent experiments, with SEM after $3.5 \mathrm{~h}$ of filamentation.

or $C D C 11+/$ - complemented the separation defect. Therefore, these results clearly indicate that the relative proportions of the Sep7, Cdc10 and Cdc11 play an important role in inhibiting cell separation during hyphal growth (Fig. I).

The above results suggested that the yeast and hyphae septin rings might have different properties, perhaps due to a different proportion of the septin octamers. An interesting possibility to explain the difference between the two morphologies is that hyphal septin rings have different structural components, not present in yeast, such as Sep7-Cdc11 mixed octamers. To study this possibility, centrifugation in sucrose gradients and immunoprecipitation experiments were performed in high salt conditions, which have been described to dissociate the filaments into their basic components, the octamers (Garcia et al., 2011; Sellin et al., 2011; Sellin et al., 2012). When yeast and hyphae extracts were analyzed, a reproducible difference in sedimentation of the octamers was observed, with the hyphae octamers normally sedimenting in lighter fractions that those of yeasts. Using the fractions of the gradient containing the peak of septin octamers, the existence of Sep7-Cdc11 mixed octamers was tested by precipitating Cdc11 and analyzing the presence of Sep7 in the immunoprecipitates. The results showed that a small fraction of Sep7 (1-2\% of total) was present in the IPs, and that its relative abundance did not vary between yeast and hyphae. Therefore, as in S. cerevisiae (Garcia et al., 2011), there is no evidence of the existence of Cdc11-Sep7 hetero-octamers and the small fraction observed is not developmentally regulated.

Based on the above results, we postulate that the differences between yeast and hyphae septin rings could be due to a change in the relative proportions of the septin octamers in the two morphologies, thereby altering the properties of the supramolecular structures. This hypothesis is based on the model for the organization of the filaments in the bud neck in S. cerevisiae (Ong et al., 2014). In C. albicans, the parallel and orthogonal filaments would be formed by Cdc11. Sep7 should be present in the orthogonal 
filaments mixed with Cdc11 (Booth et al., 2015; Finnigan et al., 2015b). According to this model, the formation of orthogonal filaments conditions the ring structure, which would be sensitive to changes in the proportion of Sep7 and Cdc11 octamers. In fact, the SEP7+/- and CDC11+/- heterozygous mutants trigger hyphal separation while the SEP7+/- CDC11+/- mutant restores the wild-type phenotype. It is possible that in the SEP7 +/- mutant, the proportion of orthogonal filaments formed by Sep7 is lower, altering its curvature. Similarly, in the CDC11 +/- mutant a decrease the number of parallel and orthogonal double filaments formed by $\mathrm{Cdc11}$ would be expected. Consistent with this idea, the double heterozygous SEP7 +/-CDC11 +/- mutant reestablishes inhibition of cell separation by restoring the relative proportion of parallel and orthogonal filaments to that similar of a wild-type strain.

3.2. Regulation of Sep7, Cdc11 and Cdc12 by phosphorylation in the different morphologies of c. albicans.

Sep7 is a phosphoprotein in vivo whose phosphorylation is dependent on the morphological state (González-Novo et al., 2008). Bioinformatics studies predicted that both Sep7 and Cdc11 contain multiple putative phosphorylation sites by different kinases. To investigate which of the predicted residues were indeed phosphorylated in vivo and to try to identify putative phosphorylation sites specific of one of the morphologies, Sep7 and Cdc11 were purified and analyzed by mass spectrometry. This analysis allowed the identification of 23 sites in Sep7 (4 of which are specific of hyphae) and 5 in Cdc11 that are common to both morphologies. While this analysis was under development, the phosphoproteome of C. albicans hyphae was published (Willger et al., 2015), and there is a large overlap in the sites identified (Fig. II). Sep7 and Cdc11 differ primarily at the CTE, which is longer in Sep7 and contains two groups of phosphorylation sites. These were named Group I (between SUE and coiled-coil) and Group II (between the coiled-coil and end) for their analysis. Interestingly, another difference was observed at

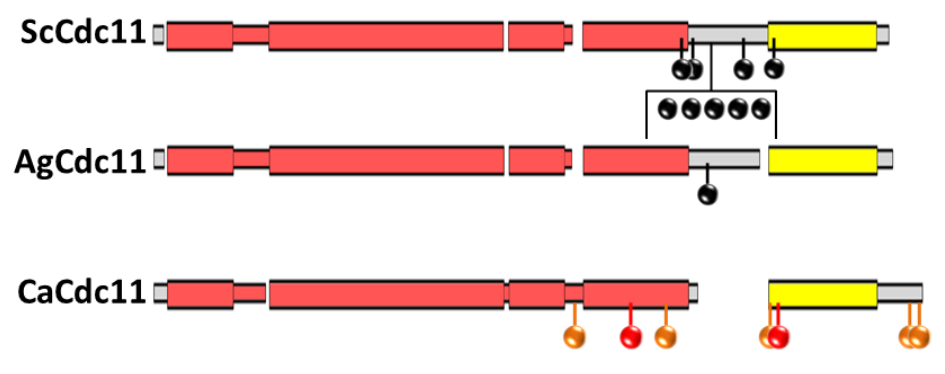

\section{S. cerevisiae | Phosphorylated \\ A. gossypii site}

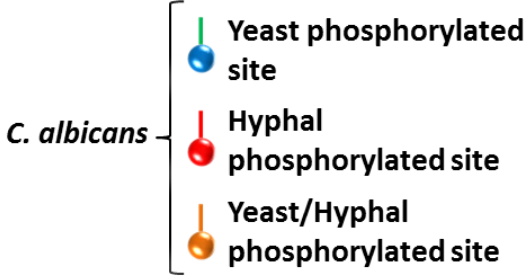

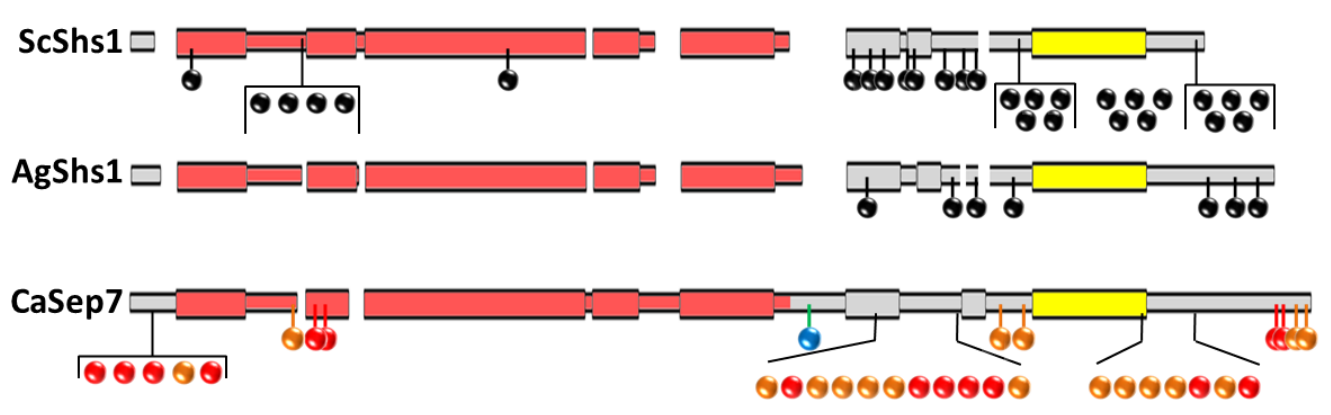

Figure II. Regulation of Cdc11 and Shs1/Sep7 by phosphorylation. Schematic representation of Cdc11 and Shs1/Sep7 of S. cerevisiae, A. gossypii and C. albicans and the phosphorylation sites identified in vivo. The GTPase (red) and the coiled-coil (yellow) domains are indicated. Gaps represent regions not present in a protein. Data for ScShs1 and ScCdc11 was taken from SGD and for AgShs1 and AgCdc11 from DeMay et al. (2009) and Meseroll et al. (2013). C. albicans phosphorylation sites represent the combined results of our analysis and the sites identified by Willger et al. (2015). 
the N-terminus, since Sep7 contains several phosphorylation sites that are absent in Cdc11, most of which are specific of hyphae.

When the phosphorylation pattern was compared to those described in S. cerevisiae and A. gosypii, some interesting differences were observed (Fig. II). First, the conservation of phosphorylated sites on Cdc11 is poor among the three species. It is interesting that the region between the GTPase domain and the coiled-coil in S. cerevisiae and A. gossypii is longer (42 and 36 aa, respectively) than in C. albicans and it contains most of the sites identified in these organisms. In $C$. albicans, the sites map to the end of GTPase domain, to the beginning of the coiled-coil (which is in the same position than one of ScCdc11) and to the C-terminal end, which is slightly longer (17 aa) and contains two specific sites (Ser394 and Ser395) that have been described as essential for filamentation (Sinha et al., 2007)(Fig. II). For Shs1-Sep7, although the degree of sequence conservation between the three organisms is low, the global pattern is conserved, since the sites are concentrated in two regions, one between the GTPase domain and the coiled-coil and another between the coiled-coil and the end of the protein (Fig. II).

Since Sep7 was important to inhibit hyphal separation and since it contained several hyphae-specific phosphorylation sites, it could be possible that these specific posttranslational modifications control septin ring structure and/or function. Therefore, we next sought to investigate whether the Sep7 CTE and its modifications had any role on C. albicans biology. As a first approach, the importance of the CTE in the inhibition of cell separation was analyzed by generating mutants with C-terminal truncations of Sep7 (sep7t-394, sep7t-522, sep7t-580 and sep7t-629). The results provided some interesting conclusions about the functionality of this region in $C$. albicans. First, the coiled-coil is not necessary to maintain the hyphal compartments attached, since the sep7t-522 and sep7t-580 mutants had a percentage of separate bodies similar to that of the wild-type strain, although Sep7t-580 contains the coiled-coil and Sep7t-522 does not. This is in contrast with recent studies in S. cerevisiae and A. gossypii that have shown that the coiled-coil is the most important region for functionality (Meseroll et al.,

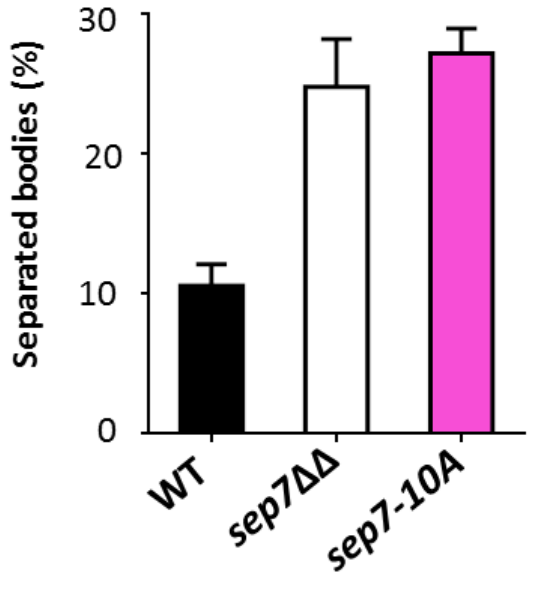

Figure III. Group I phosphorylation sites are important for Sep7 function in hyphae. The sep7-10A mutant had a high percentage of cell separation in hyphae growth. The graph shows the percentage of separated bodies in the wild type (WT), sep7 $\Delta \Delta$ and sep7-10A strains and is the mean of at least three independent experiments, with SEM after $3.5 \mathrm{~h}$ of filamentation.
2013; Finnigan et al., 2015b). Second, the region between aa 394 and 522 is essential for inhibiting separation because Sep7t-394 hyphae separated and Sep7t-522 did not. Interestingly, this region (between the globular domain and the coiled-coil) contains one of the phosphorylation clusters identified (the so called Group I), so it is possible that Sep7 function during filamentous growth could be regulated by phosphorylation of this region.

Based on the above results, the importance of Group I phosphorylation in the inhibition of hyphal separation was analyzed. To this end, a mutant strain containing Ala replacements in 10 sites that are phosphorylated in hyphae or in both morphologies (Ser444, Thr445, Ser446, Ser454, Ser455, Ser456, Ser468, Ser470, Thr471 and Ser473) was constructed by site-directed mutagenesis and named sep7-10A. This mutant had a phenotype similar to that of the $\operatorname{sep} 7 \Delta \Delta$ mutant when cell separation was determined (Fig. III). The Sep7-10A protein normally localized to the yeast bud neck and to hyphal septin rings, indicating that phosphorylation of these sites does not regulate the recruitment of Sep7 to the 
septin ring. Therefore, phosphorylation of Group I seems to be specifically required to control this particular feature of $C$. albicans biology, not present in S. cerevisiae or A. gosypii. We speculate that phosphorylation of this region during hyphal growth could be necessary to recruit to the septin ring a negative regulator of separation. Alternatively, it is also possible that a positive factor that activates separation is recruited to yeast septin rings through interaction with this region of Sep7, and that the hyphae-specific phosphorylation of this region inhibits its recruitment to the hyphal rings. This could be the case of $\mathrm{Cdc} 14$, the phosphatase that in $C$. albicans activates cell separation (Clemente-Blanco et al., 2006). It has been shown that Cdc14 localizes to the yeast septin rings, but not to hyphal rings, and that deletion of Sep7 allows its incorporation to the hyphal rings (González-Novo et al., 2008).

We also analyzed the function of some of the Group // phosphorylation sites, those near the end of the protein by constructing mutant strains carrying Ala substitutions. Two mutants were generated, sep7-3A (Thr659, Ser665 and Ser668) and sep7-8A (Ser645, Thr646, Thr651, Ser652, Thr659, Thr661, Ser665 and Ser668). sep7-3A mutant had no relevant phenotype during yeast or hyphal growth. By contrast, sep7-8A yeast cells were normal, but during hyphal development many of the septin rings were abnormally formed. Most of the rings were aberrant and had V-shape morphology (Fig. IV). By time-lapse microscopy we confirmed that the duplication time of the hyphal septin rings was significantly longer than a wild-type strain, although they were finally able to assemble the AMR and complete cytokinesis.

A phosphorylation region specific for Sep7 that is not present in S. cerevisiae or A. gosypii Shs1 is the $\mathrm{N}$-terminus, which contains several residues that are specifically phosphorylated in hyphae, suggesting that they might play a regulatory role in this morphology. These sites are located immediately preceding the $\alpha 0$ helix, a region important for interaction with acidic phospholipids and for septin-septin interaction (Zhang et al., 1999; Bertin et al., 2010). To analyze this region, we constructed the sep7-2A and sep7-2E mutants by site-directed mutagenesis, modifying two of the residues that were specific for hyphae

A

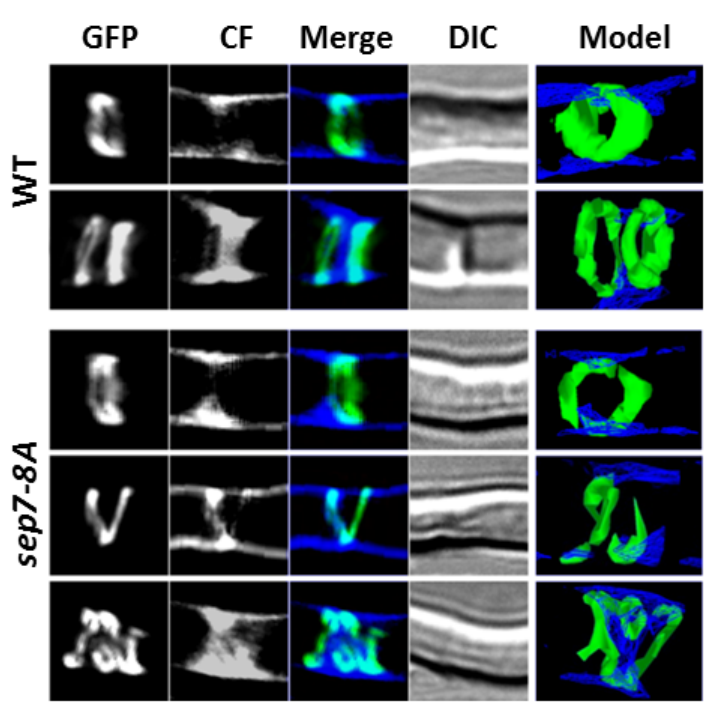

B
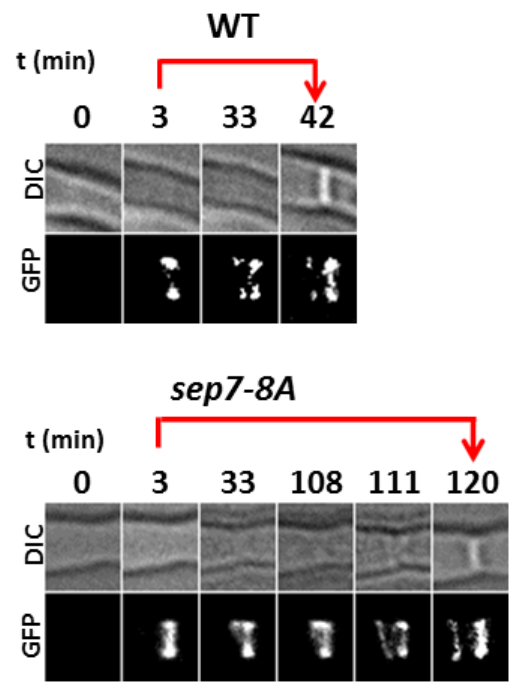

Figure IV. Phosphorylation of the Sep7 C-terminal end is important for proper septin ring duplication in hyphae. (A). Single and double septin rings during filamentation in the wild type (WT) and sep7-8A strains. The images show the Sep7-GFP fluorescence and calcofluor staining (CF). To the right, a 3D model of each ring. Scale bar, $2 \mu \mathrm{m}$. (B). Time-lapse analysis of Sep7-GFP (WT) and Sep7-8A-GFP fluorescence during hyphal growth. Images of differential interference contrast (DIC) and fluorescence are shown. 


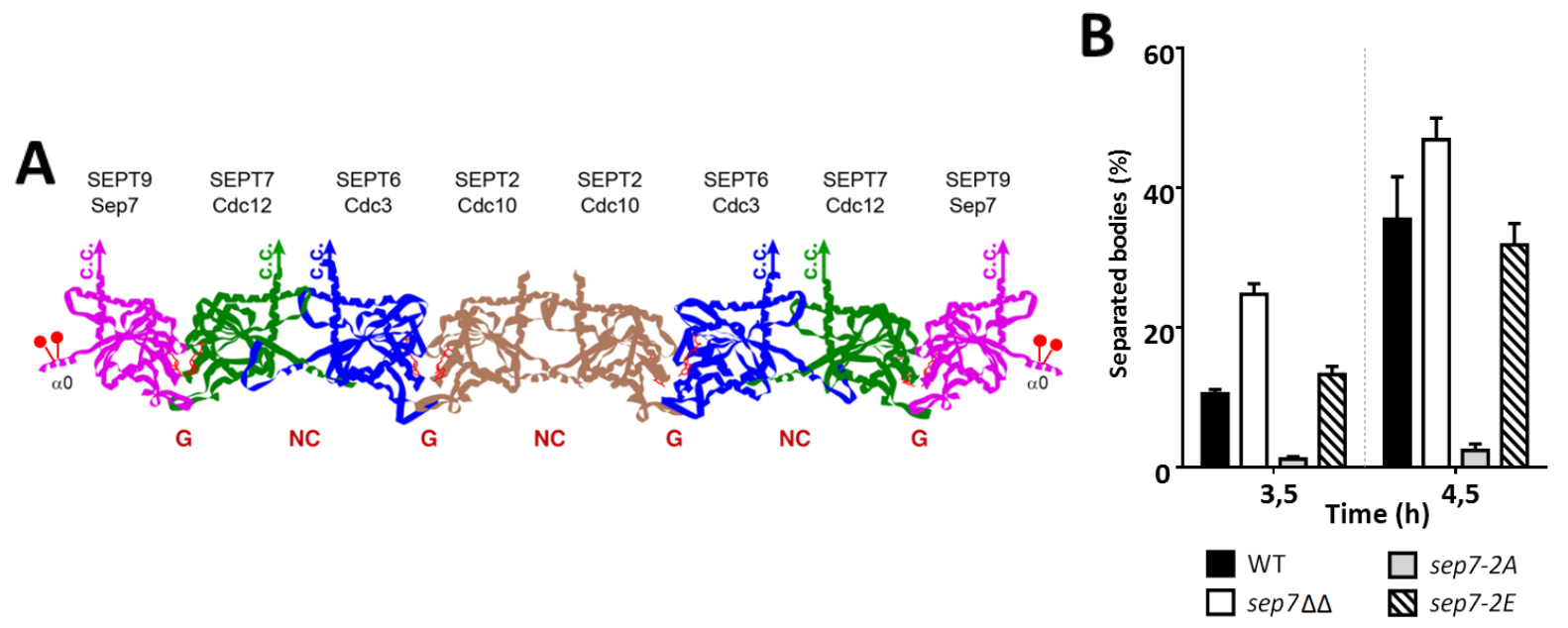

Figure V. The phosphorylation of the Sep7 $\mathrm{N}$-terminus is also important for its function in hyphae. (A). Model of the septin octamer based on the crystal structure of the human septin complex, showing the position of the putative phosphorylation sites (red) at the N-terminus of Sep7. (B). The sep7-2A mutant has a low percentage of hyphal separation. The graph shows the percentage of separated bodies in the wild type (WT), sep $7 \Delta \Delta$, sep7-2A and sep7-2E strains and is the mean of at least three independent experiments, with SEM after $3.5 \mathrm{~h}$ of filamentation.

(Ser14 and Ser22). Yeast cells of the sep7-2A and sep7-2E mutants were similar to the wild-type, and the Sep7-2A and Sep7-2E proteins localized to normal septin rings. However, during hyphal growth cell separation was almost completely abolished in the sep $7-2 \mathrm{~A}$ mutant, and even after $4.5 \mathrm{~h}$ of filamentation most of the hyphal compartments remained attached in contrast to wild-type and sep7-2E hyphae. When the localization of Sep7-2A was analyzed in hyphae, we observed that in many cases the hyphal septin rings were abnormally assembled and Sep7-2A was diffuse in the membrane of the hyphae. In addition, no primary septum staining was observed (by calcofluor staining) even though hyphae appeared to have assembled a septum by DIC microscopy (Fig. V). This could explain the total absence of separation in the sep7-2A mutant, since chitinases and glucanases cannot perform its function if the primary septum is not properly formed. Since the phosphorylated sites mutated are close to the $\alpha 0$ helix that contains a tract of basic residues required for association with acidic phospholipids, it is possible that phosphorylation of this region could modulate the affinity of Sep7 for membrane lipids. The fact that these mutations specifically affect the assembly of hyphal septin rings could be an indication that the lipid composition of the bud neck and the hyphal membrane is different, and hence the difficulty of compacting hyphal rings. Alternatively, it is also possible that phosphorylation of this region could modulate the interaction between adjacent octamers, since the $\alpha 0$ helix is essential for the formation of the NC interfaz, and this could be critical for the assembly of supramolecular hyphal structures.

The importance of posttranslational modifications in other septins was also analyzed by studying Cdc12 mutants. This septin was chosen because it contains 4 potential CDK phosphorylation sites, one of which can also be target of Cbk1 (Ser64). It has been recently described that the Cbk1-Mob2 complex is also required to inhibit separation of the hyphal compartments (Calderón-Noreña et al., 2015). To analyze whether this regulation involved phosphorylation of Ser64 by Cbk1-Mob2, the cdc12-1A mutant (S64A) was constructed, but no relevant phenotype was observed either in yeast or hyphae. We also constructed the $c d c 12-3 A$ and $c d c 12-3 E$ (Ser64, Thr92 and Ser178) or $c d c 12-4 A$ and $c d c 12-4 E$ (Ser64, Thr92, Ser178 and Thr202) mutants. The two phosphomutant strains behave as a wild-type strain both in yeast and hyphae. However, the $c d c 12-3 E$ and $c d c 12-4 E$ strains had defects during hyphal growth, although yeast cells were similar to the wild type. These two strains had a high percentage of hyphae with 

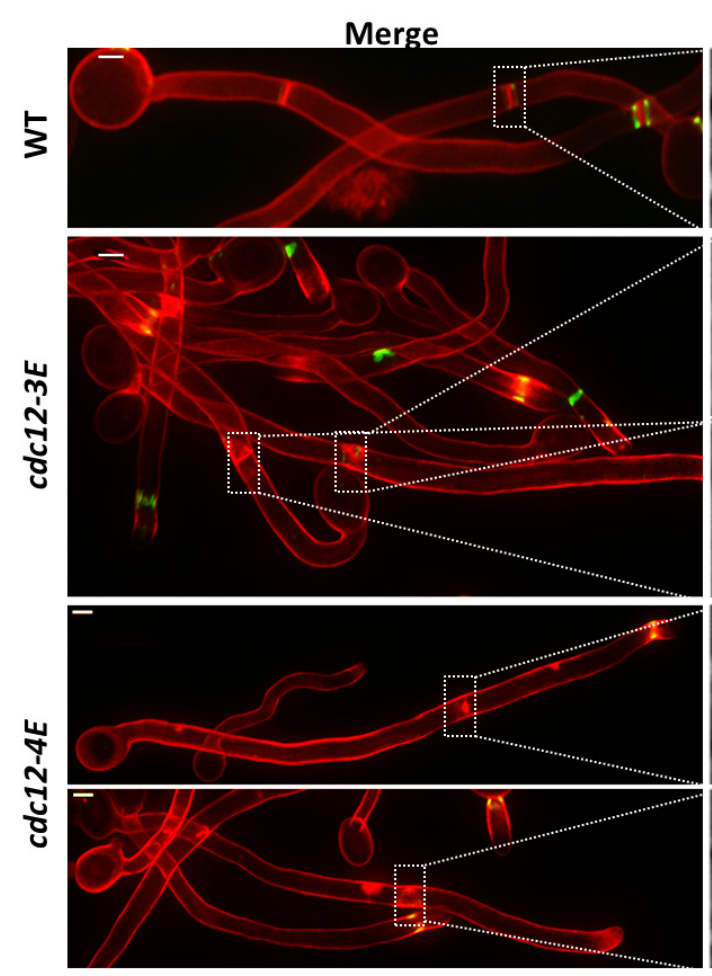
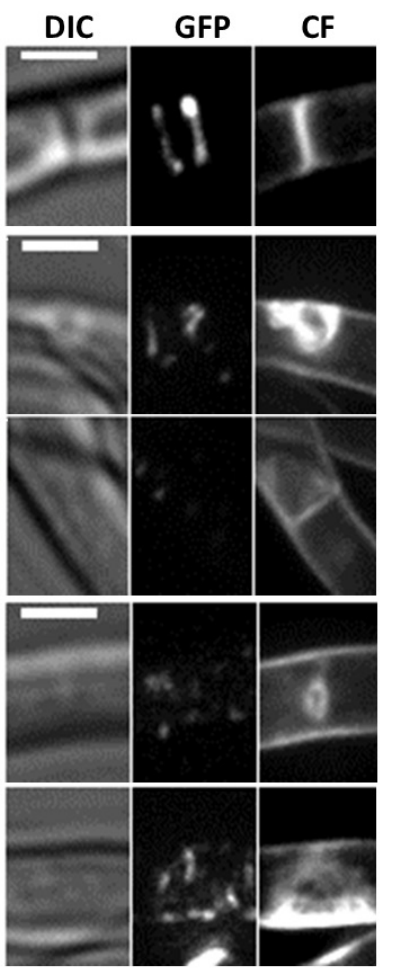

Figure VI. Analisys of putative Cdc12 phosphorylation sites. (A). Phenotype of hyphae from the wild type (WT), $c d c 12-3 E$ and cdc12-4E mutants. Images of differential interference contrast (DIC), Cdc12-GFP fluorescence and calcofluor (CF) are shown. The merged image shows GFP fluorescence (green) and calcofluor (red). The images are the maximum projection of 10 planes acquired every $0.4 \mu \mathrm{m}$. Scale bar, $2 \mu \mathrm{m}$.

incomplete or absent septa, at the time when a wild-type strain had delimited at least the first compartment. The Cdc12-3E and Cdc12-4E proteins normally localized to the bud neck of yeast cells, and septum assembly was normal. However, during

hyphal growth Cdc12-3E and Cdc12-4E failed to assemble a compact septin ring (often clouds or spirals of septins were observed), resulting in defects in the assembly of the septum, which was not complete and chitin was deposited in the lateral hyphal cell wall (Fig. VI). Therefore, these results suggest that Cdc12 might be phosphorylated during yeast growth, and that this phosphorylation should be removed during hyphal growth to allow the formation of septin rings.

In summary, our results indicate that septins have evolved in C. albicans, after its evolutionary divergence from S. cerevisiae, adapting their function to regulate some features that are specific to the pleomorphic condition of this filamentous fungus. Our results clearly indicate that yeast and hyphal rings have different properties, perhaps as a consequence of the adaptation of this structure to the particular characteristics of each morphology, and that Sep7 and its phosphorylation in specific regions has an important role in the regulation of hyphal separation.

\subsection{The anillin Int1 and septin ring stability.}

Int1 is the only anillin homolog in C. albicans, and since it is required for stability of the septin rings in other yeasts, we decided to analyze its role in the regulation in septins in this organism. As a first approach, Int1 dynamics and localization through the cell cycle was analyzed by time-lapse microscopy. This analysis showed that Int1 and septins colocalized throughout the cell cycle, first appearing at the presumptive budding site and the neck as single rings that duplicated before cytokinesis. In addition, analysis of Int1 localization in septin mutants $(\operatorname{sep} 7 \Delta \Delta$ and $c d c 10 \Delta \Delta)$ indicated the Int1 recruitment to the neck is partially dependent on the septins, since its intensity was reduce in the two mutants as compared to the wild type.

To analyze the function of Int1 in septin dynamics, an int1 $\Delta \Delta$ mutant carrying Cdc10-GFP was generated. In this mutant, no double septin rings could be observed, although single rings were similar 


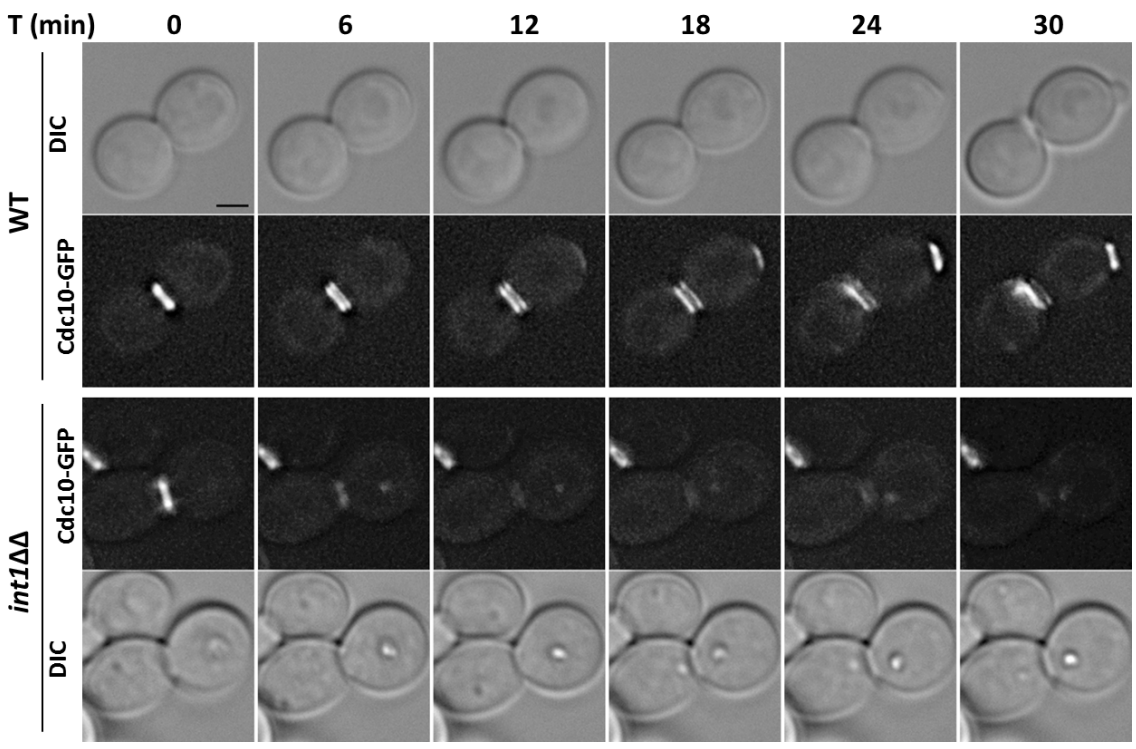

Figure VII. Septins rings are unstable after duplication in int $1 \Delta \Delta$ cells. Time-lapse analysis of septin ring duplication in wild type (WT) and int1 $\Delta \Delta$ yeast cells. Differential interference contrast (DIC) and Cdc10-GFP fluorescence images are shown. The GFP image is the maximum projection of 10 planes acquired every $0.4 \mu \mathrm{m}$. Scale bar, $2 \mu \mathrm{m}$.

to those of the wild-type strain (Fig. VII). This phenotype is similar to that described in S. cerevisiae for the bud4A mutant (Kang et al., 2013). By time-lapse microscopy using strains containing Cdc10-GFP Mlc1-Cherry (a component of the AMR), we found that septin rings became unstable and disappeared coincident with the AMR constriction. However, the absence of double septin rings had no effects on AMR contraction dynamics or septum assembly, suggesting that they are not essential to complete cytokinesis once AMR contraction has started.

To dissect the Int1 regions necessary for its function, we constructed two truncated versions of the protein, deleting the $\mathrm{N}$-terminal region (aa 1-1134) in one of them and the C-terminal end containing the conserved Anillin and PH domains in the other (aa 1134-1711). These strains were named int1- $\Delta N$ and int1- $\Delta C$, respectively. Both truncated forms localized to the bud neck with the septins, although the intensity of Int1- $\triangle C$-GFP was significantly lower than that of Int1-GFP or Int1- $\Delta N-G F P$. Therefore, the C-terminal region of Int1 seems to be necessary for proper localization at the bud neck. This is in good agreement with the fact that int1- $\Delta C$ cells had a phenotype similar to that of the int $1 \Delta \Delta$ mutant and failed to maintain the duplicated septin rings, while int1- $\Delta \mathrm{N}$ cells had a low percentage of poorly assembled double rings, around $20 \%$. These results indicate that the $\mathrm{C}$-terminal region of Int1 containing the Anillin and $\mathrm{PH}$ domains is essential for maintaining the stability of duplicated septin rings, although the $\mathrm{N}$-terminal region also plays a minor role in this process.

Since Int1 was required for the stability of septin rings, we decided to construct double mutant strains combining INT1 deletion with deletion of the septin genes. During yeast growth, the int1 $\Delta \Delta$ $\operatorname{sep} 7 \Delta \Delta$ mutant had additive defects, showing slightly asymmetric septin rings (sep $7 \Delta \Delta$ ) and disassembly of the rings after duplication (int1 $\Delta \Delta$ ). We also observed an unexpected phenotype, which was the presence of large cells, often multinucleated (Fig. VIII). Interestingly, this defect was not common to other double mutants with septin genes, since the morphology and size of int $1 \Delta \Delta c d c 10 \Delta \Delta$ cells was similar to the wild-type strain, and no multinucleated cells were observed (Fig. VIII). To characterize the nature of this defect with more detail we used time-lapse microscopy in wild-type and int $1 \Delta \Delta$ cells contain either Nop1-GFP (a nucleolar marker) or Tub1-GFP (a component of the spindle). This analysis showed that mutant cells often arrested in anaphase, and orientation of the mitotic spindle towards the bud was clearly delayed in comparison to the wild-type strain. Also, with high frequency 

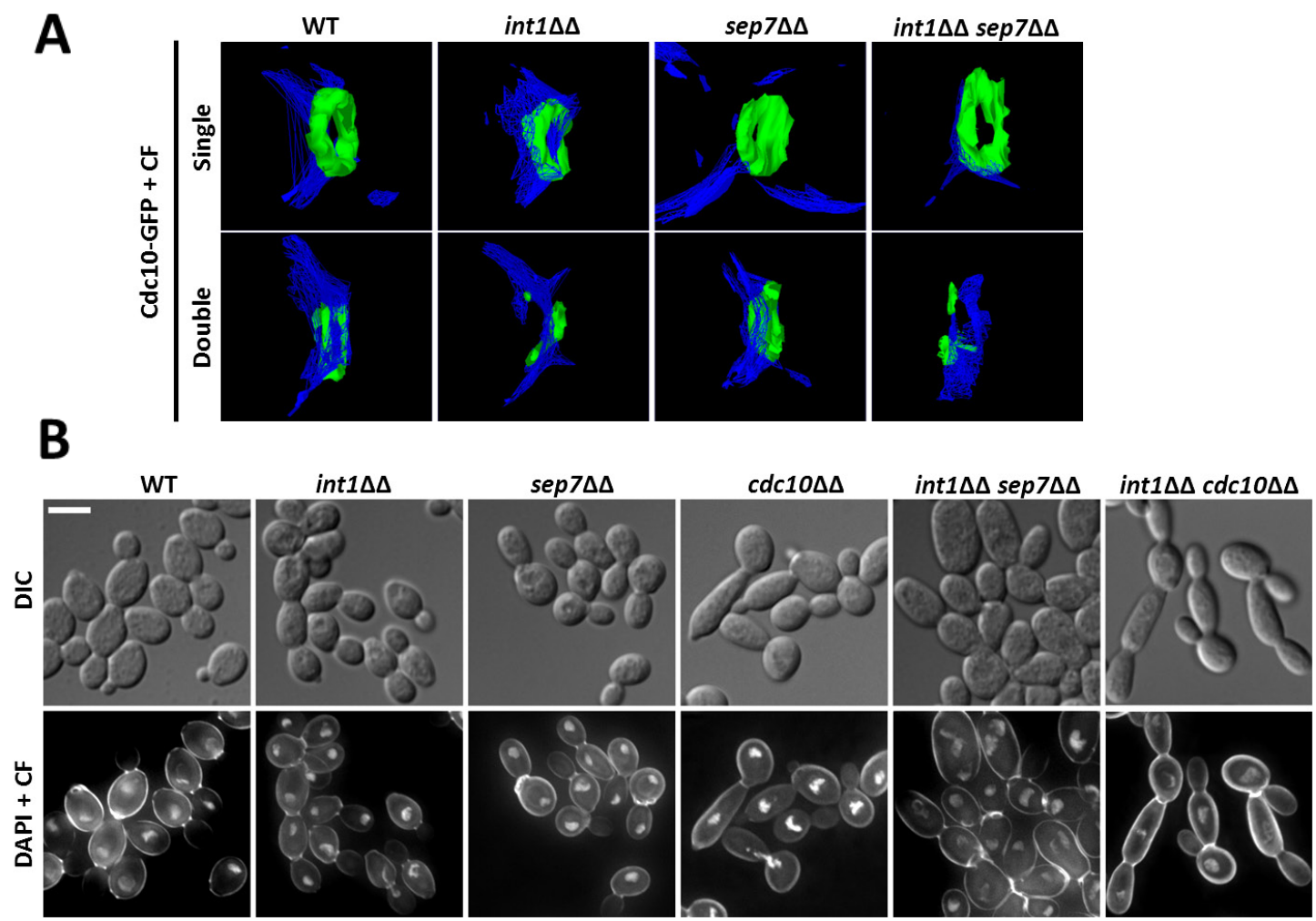

Figure VIII. Phenotype of int1 $\Delta \Delta$ in combination with deletion of septin genes. (A). 3D reconstruction of single and double Cdc10-GFP rings in wild type (WT), int $1 \Delta \Delta, \operatorname{sep} 7 \Delta \Delta$ and int1 $\Delta \Delta \operatorname{sep} 7 \Delta \Delta$ strains. (B). Phenotype of the wild type (WT), int1 $1 \Delta \Delta$, $\operatorname{sep} 7 \Delta \Delta, c d c 10 \Delta \Delta$, int $1 \Delta \Delta \operatorname{sep} 7 \Delta \Delta$ and $\operatorname{int} 1 \Delta \Delta c d c 10 \Delta \Delta$ strains. Differential interference contrast (DIC) and fluorescence (DAPI and calcofluor, CF staining) images are shown. The fluorescence images are the maximum projection of 3 planes acquired every $0.4 \mu \mathrm{m}$. Scale bar, $5 \mu \mathrm{m}$.

mitosis occurred perpendicular to the mother-daughter axis, generating polyploid cells. In S. cerevisiae, the spindle position checkpoint (SPOC) delays mitotic exit when the anaphase spindle is not properly oriented, and several of the regulatory proteins of this checkpoint localize to the neck, such as the Elm1 kinase or the Glc7 phosphatase. Therefore, we analyzed the localization of these regulatory proteins in wild-type and int $1 \Delta \Delta \operatorname{sep} 7 \Delta \Delta$ cells. The results indicated that their association to the neck was reduced, both in the number of cells and the intensity of the fluorescent protein in mutant cells.

It has been described that the $\operatorname{rts} 1 \Delta \Delta$ mutant has a similar phenotype to that found for int $1 \Delta \Delta \operatorname{sep} 7 \Delta \Delta$ cells, with a fraction of cells with aberrant morphology and polyploidy (Doctoral Thesis of Caballero-Lima, 2009). To analyze the relationship between Int1, Sep7 and Rts1, the int1 $\Delta \Delta$ rts $1 \Delta \Delta$ and $r t s 1 \Delta \Delta \operatorname{sep} 7 \Delta \Delta$ mutants were constructed. Morphology of the cells and ploidy was analyzed in the double and single mutants by microscopic inspection and FACs analysis. The results indicated that $r t s 1 \Delta \Delta$, int $1 \Delta \Delta \operatorname{sep} 7 \Delta \Delta, r t s 1 \Delta \Delta$ int $1 \Delta \Delta$ and $r t s 1 \Delta \Delta \operatorname{sep} 7 \Delta \Delta$ mutants had an increase in the percentage of large cells which usually contained more than one nucleus, although the phenotype was more pronounced in the $r t s 1 \Delta \Delta \operatorname{sep} 7 \Delta \Delta$ mutant, suggesting that Rts1 and Sep7 act in two different pathways to regulate nuclear segregation. We also observed that in some cases cells have defects in cytokinesis, resulting in three compartments sharing a common cytoplasm with four nuclei. Segregation of four nuclei in three compartments would generate polyploid cells, explaining the appearance of these cells. In spite of the segregation problems, all the strains are viable, and in some cases polyploid cells can revert to uninuclear cells when one of the spindles is properly oriented in mother-daughter axis and the other perpendicular. For that reason, in these strains there are always two populations of cells: a fraction of normal size cells with a single nucleus and another population larger and multinucleated. 
These results indicate that septins (at least Sep7), in combination with other elements of the neck such as Int1 or Rts1, are involved in a number of cell cycle processes as bud emergence and growth, mitotic spindle orientation, and in the spindle positioning checkpoint (SPOC). 


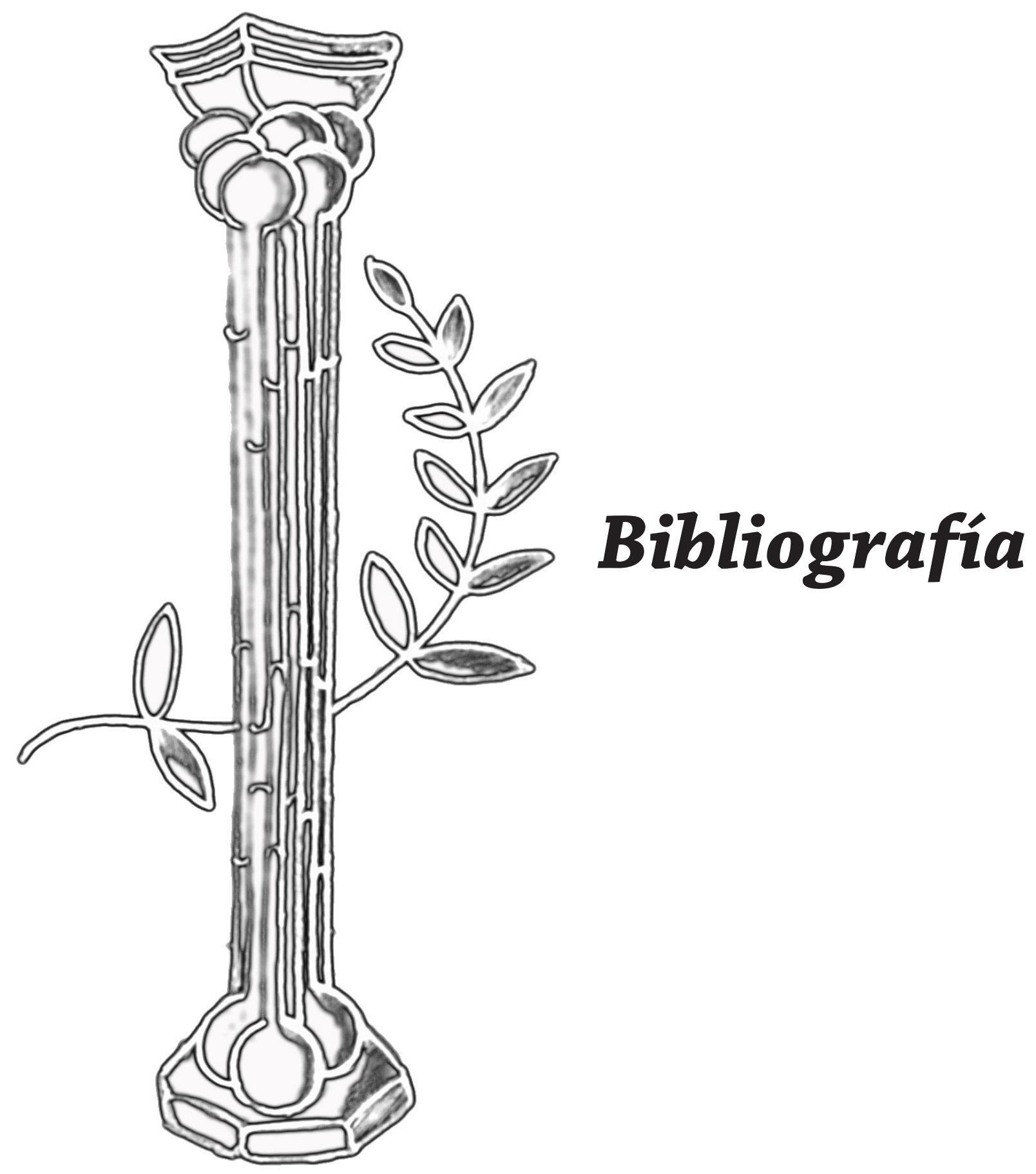



Asano, S., J.E. Park, L.R. Yu, M. Zhou, K. Sakchaisri, C.J. Park, Y.H. Kang, J. Thorner, T.D. Veenstra, y K.S. Lee. 2006. Direct phosphorylation and activation of a Nim1-related kinase Gin4 by Elm1 in budding yeast. J. Biol. Chem. 281:27090-27098.

Asleson, C.M., E.S. Bensen, C.A. Gale, A.S. Melms, C. Kurischko, y J. Berman. 2001. Candida albicans INT1-induced filamentation in Saccharomyces cerevisiae depends on Sla2p. Mol. Cell. Biol. 21:1272-1284.

Avruch, J., D. Zhou, J. Fitamant, N. Bardeesy, F. Mou, y L.R. Barrufet. 2012. Protein kinases of the Hippo pathway: regulation and substrates. Semin. Cell Dev. Biol. 23:770-784.

Bachewich, C., y M. Whiteway. 2005. Cyclin CIn3p links G1 progression to hyphal and pseudohyphal development in Candida albicans. Eukaryot. Cell. 4:95-102.

Baladrón, V., S. Ufano, E. Dueñas, A.B. Martín-Cuadrado, F. del Rey, y C.R. Vázquez de Aldana. 2002. Eng1p, an endo-1,3-beta-glucanase localized at the daughter side of the septum, is involved in cell separation in Saccharomyces cerevisiae. Eukaryot. Cell. 1:774-786.

Barral, Y., y M. Kinoshita. 2008. Structural insights shed light onto septin assemblies and function. Curr. Opin. Cell Biol. 20:12-18.

Barral, Y., V. Mermall, M.S. Mooseker, y M. Snyder. 2000. Compartmentalization of the cell cortex by septins is required for maintenance of cell polarity in yeast. Mol. Cell. 5:841-851.

Barral, Y., M. Parra, S. Bidlingmaier, y M. Snyder. 1999. Nim1-related kinases coordinate cell cycle progression with the organization of the peripheral cytoskeleton in yeast. Genes Dev. 13:176-187.

Bassilana, M., J. Blyth, y R.A. Arkowitz. 2003. Cdc24, the GDP-GTP exchange factor for Cdc42, is required for invasive hyphal growth of Candida albicans. Eukaryot. Cell. 2:9-18.

Bassilana, M., J. Hopkins, y R.A. Arkowitz. 2005. Regulation of the Cdc42/Cdc24 GTPase module during Candida albicans hyphal growth. Eukaryot. Cell. 4:588-603.

Bennett, R.J. 2015. The parasexual lifestyle of Candida albicans. Curr. Opin. Microbiol. 28:10-17.

Bensen, E.S., A. Clemente-Blanco, K.R. Finley, J. Correa-Bordes, y J. Berman. 2005. The mitotic cyclins Clb2p and Clb4p affect morphogenesis in Candida albicans. Mol. Biol. Cell. 16:3387-3400.

Berlin, A., A. Paoletti, y F. Chang. 2003. Mid2p stabilizes septin rings during cytokinesis in fission yeast. J. Cell Biol. 160:1083-1092.

Berman, J. 2006. Morphogenesis and cell cycle progression in Candida albicans. Curr. Opin. Microbiol. 9:595-601.

Berman, J., y P.E. Sudbery. 2002. Candida albicans: a molecular revolution built on lessons from budding yeast. Nat. Rev. Genet. 3:918-930.

Bertin, A., M.A. McMurray, P. Grob, S.S. Park, G. Garcia, 3rd, I. Patanwala, H.L. Ng, T. Alber, J. Thorner, y E. Nogales. 2008. Saccharomyces cerevisiae septins: supramolecular organization of heterooligomers and the mechanism of filament assembly. Proc Natl Acad Sci U S A. 105:8274-8279.

Bertin, A., M.A. McMurray, J. Pierson, L. Thai, K.L. McDonald, E.A. Zehr, G. Garcia, 3rd, P. Peters, J. Thorner, y E. Nogales. 2012. Three-dimensional ultrastructure of the septin filament network in Saccharomyces cerevisiae. Mol. Biol. Cell. 23:423-432.

Bertin, A., M.A. McMurray, L. Thai, G. Garcia, 3rd, V. Votin, P. Grob, T. Allyn, J. Thorner, y E. Nogales. 2010. Phosphatidylinositol-4,5-bisphosphate promotes budding yeast septin filament assembly and organization. J. Mol. Biol. 404:711-731.

Bertin, A., y E. Nogales. 2012. Septin filament organization in Saccharomyces cerevisiae. Commun. Integr. Biol. 5:503-505.

Bezanilla, M., A.S. Gladfelter, D.R. Kovar, y W.L. Lee. 2015. Cytoskeletal dynamics: a view from the membrane. J. Cell Biol. 209:329-337.

Bi, E., P. Maddox, D.J. Lew, E.D. Salmon, J.N. McMillan, E. Yeh, y J.R. Pringle. 1998. Involvement of an actomyosin contractile ring in Saccharomyces cerevisiae cytokinesis. J. Cell Biol. 142:1301-1312.

Bi, E., y H.O. Park. 2012. Cell polarization and cytokinesis in budding yeast. Genetics. 191:347-387.

Bidlingmaier, S., E.L. Weiss, C. Seidel, D.G. Drubin, y M. Snyder. 2001. The Cbk1p pathway is important for polarized cell growth and cell separation in Saccharomyces cerevisiae. Mol. Cell. Biol. 21:2449-2462.

Bishop, A., R. Lane, R. Beniston, B. Chapa-y-Lazo, C. Smythe, y P. Sudbery. 2010. Hyphal growth in Candida albicans requires the phosphorylation of Sec2 by the Cdc28-Ccn1/Hgc1 kinase. EMBO J. 29:2930-2942.

Biswas, S., P. Van Dijck, y A. Datta. 2007. Environmental sensing and signal transduction pathways regulating morphopathogenic determinants of Candida albicans. Microbiol. Mol. Biol. Rev. 71:348-376.

Bloecher, A., y K. Tatchell. 2000. Dynamic localization of protein phosphatase type 1 in the mitotic cell cycle of Saccharomyces cerevisiae. J. Cell Biol. 149:125-140.

Booth, E.A., E.W. Vane, D. Dovala, y J. Thorner. 2015. A Förster Resonance Energy Transfer (FRET)-based system provides insight into the ordered assembly of yeast septin hetero-octamers. J. Biol. Chem. 290:28388-28401. 
Botstein, D., y G.R. Fink. 2011. Yeast: an experimental organism for 21st Century biology. Genetics. 189:695-704.

Bouquin, N., Y. Barral, R. Courbeyrette, M. Blondel, M. Snyder, y C. Mann. 2000. Regulation of cytokinesis by the Elm1 protein kinase in Saccharomyces cerevisiae. J. Cell Sci. 113:1435-1445.

Bridges, A.A., y A.S. Gladfelter. 2015. Septin Form and Function at the Cell Cortex. J. Biol. Chem. 290:17173-17180.

Bridges, A.A., H. Zhang, S.B. Mehta, P. Occhipinti, T. Tani, y A.S. Gladfelter. 2014. Septin assemblies form by diffusion-driven annealing on membranes. Proc Natl Acad Sci U S A. 111:2146-2151.

Caballero-Lima, D. 2009. Tesis Doctoral: Mecanismos moleculares que regulan la asimetría y citoquinesis durante el desarrollo hifal de Candida albicans. Universidad de Extremadura.

Caballero-Lima, D., I.N. Kaneva, S.P. Watton, P.E. Sudbery, y C.J. Craven. 2013. The spatial distribution of the exocyst and actin cortical patches is sufficient to organize hyphal tip growth. Eukaryot. Cell. 12:998-1008.

Caballero-Lima, D., y P.E. Sudbery. 2014. In Candida albicans, phosphorylation of Exo84 by Cdk1-Hgc1 is necessary for efficient hyphal extension. Mol. Biol. Cell. 25:1097-1110.

Calderón-Noreña, D.M., A. González-Novo, S. Orellana-Muñoz, P. Gutiérrez-Escribano, Y. Arnáiz-Pita, E. DueñasSantero, M.B. Suárez, M.E. Bougnoux, F. Del Rey, G. Sherlock, C. D’Enfert, J. Correa-Bordes, y C.R. Vázquez de Aldana. 2015. A single nucleotide polymorphism uncovers a novel function for the transcription factor Ace2 during Candida albicans hyphal development. PloS Genet. 11:e1005152.

Cannon, J.F. 2010. Function of protein phosphatase-1, Glc7, in Saccharomyces cerevisiae. Adv Appl Microbiol. 73:27-59.

Cao, L., X. Ding, W. Yu, X. Yang, S. Shen, y L. Yu. 2007. Phylogenetic and evolutionary analysis of the septin protein family in metazoan. FEBS Lett. 581:5526-5532.

Casamayor, A., y M. Snyder. 2002. Bud-site selection and cell polarity in budding yeast. Curr. Opin. Microbiol. 5:179-186.

Casamayor, A., y M. Snyder. 2003. Molecular dissection of a yeast septin: distinct domains are required for septin interaction, localization, and function. Mol. Cell. Biol. 23:2762-2777.

Castillon, G.A., N.R. Adames, C.H. Rosello, H.S. Seidel, M.S. Longtine, J.A. Cooper, y R.A. Heil-Chapdelaine. 2003. Septins have a dual role in controlling mitotic exit in budding yeast. Curr. Biol. 13:654-658.

Caudron, F., y Y. Barral. 2009. Septins and the lateral compartmentalization of eukaryotic membranes. Dev. Cell. 16:493-506.

Caviston, J.P., M. Longtine, J.R. Pringle, y E. Bi. 2003. The role of Cdc42p GTPase-activating proteins in assembly of the septin ring in yeast. Mol. Biol. Cell. 14:4051-4066.

Caydasi, A.K., B. Ibrahim, y G. Pereira. 2010a. Monitoring spindle orientation: Spindle position checkpoint in charge. Cell Div. 5:28.

Caydasi, A.K., B. Kurtulmus, M.I. Orrico, A. Hofmann, B. Ibrahim, y G. Pereira. 2010b. Elm1 kinase activates the spindle position checkpoint kinase Kin4. J. Cell Biol. 190:975-989.

Caydasi, A.K., y G. Pereira. 2009. Spindle alignment regulates the dynamic association of checkpoint proteins with yeast spindle pole bodies. Dev. Cell. 16:146-156.

Caydasi, A., y G. Pereira. 2012. SPOC alert-when chromosomes get the wrong direction. Exp. Cell Res. 318:14211427.

Clay, L., F. Caudron, A. Denoth-Lippuner, B. Boettcher, S. Buvelot Frei, E.L. Snapp, y Y. Barral. 2014. A sphingolipiddependent diffusion barrier confines ER stress to the yeast mother cell. Elife. 3:e01883.

Clemente-Blanco, A., A. González-Novo, F. Machín, D. Caballero-Lima, L. Aragón, M. Sánchez, C.R. Vázquez de Aldana, J. Jiménez, y J. Correa-Bordes. 2006. The Cdc14p phosphatase affects late cell-cycle events and morphogenesis in Candida albicans. J. Cell Sci. 119:1130-1143.

Coles, C.H., y F. Bradke. 2015. Coordinating neuronal actin-microtubule dynamics. Curr. Biol. 25:R677-691.

Colman-Lerner, A., T.E. Chin, y R. Brent. 2001. Yeast Cbk1 and Mob2 activate daughter-specific genetic programs to induce asymmetric cell fates. Cell. 107:739-750.

Corvest, V., S. Bogliolo, P. Follette, R.A. Arkowitz, y M. Bassilana. 2013. Spatiotemporal regulation of Rho1 and Cdc42 activity during Candida albicans filamentous growth. Mol. Microbiol. 89:626-648.

Court, H., y P. Sudbery. 2007. Regulation of Cdc42 GTPase activity in the formation of hyphae in Candida albicans. Mol. Biol. Cell. 18:265-281.

Crampin, H., K. Finley, M. Gerami-Nejad, H. Court, C. Gale, J. Berman, y P. Sudbery. 2005. Candida albicans hyphae have a Spitzenkörper that is distinct from the polarisome found in yeast and pseudohyphae. J. Cell Sci. 118:2935-2947.

Chan, G.K., S.T. Liu, y T.J. Yen. 2005. Kinetochore structure and function. Trends Cell. Biol. 15:589-598.

Chang, F., y M. Peter. 2003. Yeasts make their mark. Nat. Cell. Biol. 5:294-299.

Chant, J. 1999. Cell polarity in yeast. Annu Rev Cell Dev Biol. 15:365-391. 
Chant, J., y J.R. Pringle. 1995. Patterns of bud-site selection in the yeast Saccharomyces cerevisiae. J. Cell Biol. 129:751-765.

Chao, J.T., A.K. Wong, S. Tavassoli, B.P. Young, A. Chruscicki, N.N. Fang, L.J. Howe, T. Mayor, L.J. Foster, y C.J. Loewen. 2014. Polarization of the endoplasmic reticulum by ER-septin tethering. Cell. 158:620-632.

Chapa y Lazo, B., S. Bates, y P. Sudbery. 2005. The G1 cyclin Cln3 regulates morphogenesis in Candida albicans. Eukaryot. Cell. 4:90-94.

Chavez-Dozal, A.A., S.M. Bernardo, y S.A. Lee. 2016. The exocyst in Candida albicans polarized secretion and filamentation. Curr. Genet. 62:343-346.

Chen, H., M. Fujita, Q. Feng, J. Clardy, y G.R. Fink. 2004. Tyrosol is a quorum-sensing molecule in Candida albicans. Proc Natl Acad Sci U S A. 101:5048-5052.

Chen, X., D.J. Ebbole, y Z. Wang. 2015. The exocyst complex: delivery hub for morphogenesis and pathogenesis in filamentous fungi. Curr. Opin. Plant Biol. 28:48-54.

De Luca, C., M. Guglielminetti, A. Ferrario, M. Calabr, y E. Casari. 2012. Candidemia: species involved, virulence factors and antimycotic susceptibility. New Microbiol. 35:459-468.

DeMay, B.S., X. Bai, L. Howard, P. Occhipinti, R.A. Meseroll, E.T. Spiliotis, R. Oldenbourg, y A.S. Gladfelter. 2011. Septin filaments exhibit a dynamic, paired organization that is conserved from yeast to mammals. J. Cell Biol. 193:1065-1081.

DeMay, B.S., R.A. Meseroll, P. Occhipinti, y A.S. Gladfelter. 2009. Regulation of distinct septin rings in a single cell by Elm1p and Gin4p kinases. Mol. Biol. Cell. 20:2311-2326.

DeMay, B.S., R.A. Meseroll, P. Occhipinti, y A.S. Gladfelter. 2010. Cellular requirements for the small molecule forchlorfenuron to stabilize the septin cytoskeleton. Cytoskeleton. 67:383-399.

Dobbelaere, J., y Y. Barral. 2004. Spatial coordination of cytokinetic events by compartmentalization of the cell cortex. Science. 305:393-396.

Dobbelaere, J., M.S. Gentry, R.L. Hallberg, y Y. Barral. 2003. Phosphorylation-dependent regulation of septin dynamics during the cell cycle. Dev. Cell. 4:345-357.

Douglas, L.M., F.J. Alvarez, C. McCreary, y J.B. Konopka. 2005. Septin function in yeast model systems and pathogenic fungi. Eukaryot. Cell. 4:1503-1512.

Dunkler, A., A. Walther, C.A. Specht, y J. Wendland. 2005. Candida albicans CHT3 encodes the functional homolog of the Cts1 chitinase of Saccharomyces cerevisiae. Fungal Genet. Biol. 42:935-947.

Egelhofer, T.A., J. Villen, D. McCusker, S.P. Gygi, y D.R. Kellogg. 2008. The septins function in G1 pathways that influence the pattern of cell growth in budding yeast. PloS One. 3:e2022.

Eluere, R., I. Varlet, A. Bernadac, y M.N. Simon. 2012. CDK and the anillin homolog Bud4 define a new pathway regulating septin organization in yeast. Cell Cycle. 11:151-158.

Enloe, B., A. Diamond, y A.P. Mitchell. 2000. A single-transformation gene function test in diploid Candida albicans. J. Bacteriol. 182:5730-5736.

Esteban, P.F., I. Ríos, R. García, E. Dueñas, J. Pla, M. Sánchez, C.R. Vázquez de Aldana, y F. del Rey. 2005. Characterization of the CaENG1 gene encoding an endo-1,3-beta-glucanase involved in cell separation in Candida albicans. Curr. Microbiol. 51:385-392.

Estey, M.P., M.S. Kim, y W.S. Trimble. 2011. Septins. Curr. Biol. 21:R384-387.

Field, C.M., y B.M. Alberts. 1995. Anillin, a contractile ring protein that cycles from the nucleus to the cell cortex. J. Cell Biol. 131:165-178.

Finnigan, G.C., E.A. Booth, A. Duvalyan, E.N. Liao, y J. Thorner. 2015a. The carboxy-terminal tails of septins Cdc11 and Shs1 recruit myosin-II binding factor Bni5 to the bud neck in Saccharomyces cerevisiae. Genetics. 200:843862.

Finnigan, G.C., J. Takagi, C. Cho, y J. Thorner. 2015b. Comprehensive genetic analysis of paralogous terminal septin subunits Shs1 and Cdc11 in Saccharomyces cerevisiae. Genetics. 200:821-841.

Foley, E.A., y T.M. Kapoor. 2013. Microtubule attachment and spindle assembly checkpoint signalling at the kinetochore. Nat. Rev. Mol. Cell Biol. 14:25-37.

Fonzi, W.A., y M.Y. Irwin. 1993. Isogenic strain construction and gene mapping in Candida albicans. Genetics. 134:717-728.

Frazier, J.A., M.L. Wong, M.S. Longtine, J.R. Pringle, M. Mann, T.J. Mitchison, y C. Field. 1998. Polymerization of purified yeast septins: evidence that organized filament arrays may not be required for septin function. J. Cell Biol. 143:737-749.

Fung, K.Y., L. Dai, y W.S. Trimble. 2014. Cell and molecular biology of septins. Int. Rev. Cell Mol. Biol. 310:289-339.

Gale, C., M. Gerami-Nejad, M. McClellan, S. Vandoninck, M.S. Longtine, y J. Berman. 2001. Candida albicans Int1p interacts with the septin ring in yeast and hyphal cells. Mol. Biol. Cell. 12:3538-3549. 


\section{Bibliografía}

Gale, C.. C.M. Bendel, M. McClellan, M. Hauser, J.M. Becker, J. Berman, y M.K. Hostetter. 1998. Linkage of adhesion, filamentous growth, and virulence in Candida albicans to a single gene, INT1. Science. 279:1355-1358.

Gao, L., W. Liu, y A. Bretscher. 2010. The yeast formin Bnr1p has two localization regions that show spatially and temporally distinct association with septin structures. Mol. Biol. Cell. 21:1253-1262.

Garcia, G., 3rd, A. Bertin, Z. Li, Y. Song, M.A. McMurray, J. Thorner, y E. Nogales. 2011. Subunit-dependent modulation of septin assembly: budding yeast septin Shs1 promotes ring and gauze formation. J. Cell Biol. 195:993-1004.

Gilden, J., y M.F. Krummel. 2010. Control of cortical rigidity by the cytoskeleton: emerging roles for septins. Cytoskeleton. 67:477-486.

Gladfelter, A.S. 2010. Guides to the final frontier of the cytoskeleton: septins in filamentous fungi. Curr. Opin. Microbiol. 13:720-726.

Gladfelter, A.S., I. Bose, T.R. Zyla, E.S. Bardes, y D.J. Lew. 2002. Septin ring assembly involves cycles of GTP loading and hydrolysis by Cdc42p. J. Cell Biol. 156:315-326.

Gladfelter, A.S., J.R. Pringle, y D.J. Lew. 2001. The septin cortex at the yeast mother-bud neck. Curr. Opin. Microbiol. 4:681-689.

Gladfelter, A.S., T.R. Zyla, y D.J. Lew. 2004. Genetic interactions among regulators of septin organization. Eukaryot. Cell. 3:847-854.

González-Novo, A. 2005. Tesis Doctoral: Función de las septinas en la morfogénesis y virulencia de Candida albicans. Universidad de Salamanca.

González-Novo, A., J. Correa-Bordes, L. Labrador, M. Sánchez, C.R. Vázquez de Aldana, y J. Jiménez. 2008. Sep7 is essential to modify septin ring dynamics and inhibit cell separation during Candida albicans hyphal growth. Mol. Biol. Cell. 19:1509-1518.

González-Novo, A., L. Labrador, M.E. Pablo-Hernando, J. Correa-Bordes, M. Sánchez, J. Jiménez, y C.R. Vázquez de Aldana. 2009. Dbf2 is essential for cytokinesis and correct mitotic spindle formation in Candida albicans. Mol. Microbiol. 72:1364-1378.

Gozalbo, D., P. Roig, E. Villamon, y M.L. Gil. 2004. Candida and candidiasis: the cell wall as a potential molecular target for antifungal therapy. Curr Drug Targets Infect Disord. 4:117-135.

Gutiérrez-Escribano, P., A. González-Novo, M.B. Suárez, C.R. Li, Y. Wang, C.R. Vázquez de Aldana, y J. CorreaBordes. 2011. CDK-dependent phosphorylation of Mob2 is essential for hyphal development in Candida albicans. Mol. Biol. Cell. 22:2458-2469.

Gutiérrez-Escribano, P., U. Zeidler, M.B. Suárez, S. Bachellier-Bassi, A. Clemente-Blanco, J. Bonhomme, C.R. Vázquez de Aldana, C. D’Enfert, y J. Correa-Bordes. 2012. The NDR/LATS kinase Cbk1 controls the activity of the transcriptional regulator Bcr1 during biofilm formation in Candida albicans. PLoS Pathog. 8:e1002683.

Haarer, B.K., y J.R. Pringle. 1987. Immunofluorescence localization of the Saccharomyces cerevisiae CDC12 gene product to the vicinity of the 10-nm filaments in the mother-bud neck. Mol. Cell. Biol. 7:3678-3687.

Hartwell, L.H. 1971. Genetic control of the cell division cycle in yeast. IV. Genes controlling bud emergence and cytokinesis. Exp. Cell Res. 69:265-276.

Harvey, K.F., y I.K. Hariharan. 2012. The Hippo pathway. Cold Spring Harb Perspect Biol. 4:a011288.

Hazan, I., M. Sepulveda-Becerra, y H. Liu. 2002. Hyphal elongation is regulated independently of cell cycle in Candida albicans. Mol. Biol. Cell. 13:134-145.

Hergovich, A. 2011. MOB control: reviewing a conserved family of kinase regulators. Cell Signal. 23:1433-1440.

Hergovich, A. 2012. Mammalian Hippo signalling: a kinase network regulated by protein-protein interactions. Biochem. Soc. Trans. 40:124-128.

Hernández-Rodríguez, Y., y M. Momany. 2012. Posttranslational modifications and assembly of septin heteropolymers and higher-order structures. Curr. Opin. Microbiol. 15:660-668.

Hickman, M.A., G. Zeng, A. Forche, M.P. Hirakawa, D. Abbey, B.D. Harrison, Y.M. Wang, C.H. Su, R.J. Bennett, Y. Wang, y J. Berman. 2013. The 'obligate diploid' Candida albicans forms mating-competent haploids. Nature. 494:55-59.

Holmes, J.K., y M.J. Solomon. 1996. A predictive scale for evaluating cyclin-dependent kinase substrates. A comparison of p34cdc2 and p33cdk2. J. Biol. Chem. 271:25240-25246.

Holt, L.J., B.B. Tuch, J. Villen, A.D. Johnson, S.P. Gygi, y D.O. Morgan. 2009. Global analysis of Cdk1 substrate phosphorylation sites provides insights into evolution. Science. 325:1682-1686.

Hornby, J.M., E.C. Jensen, A.D. Lisec, J.J. Tasto, B. Jahnke, R. Shoemaker, P. Dussault, y K.W. Nickerson. 2001. Quorum sensing in the dimorphic fungus Candida albicans is mediated by farnesol. Appl. Environ. Microbiol. 67:2982-2992.

Howell, A.S., y D.J. Lew. 2012. Morphogenesis and the cell cycle. Genetics. 190:51-77. 
Huang, Z.X., P. Zhao, G.S. Zeng, Y.M. Wang, I. Sudbery, y Y. Wang. 2014. Phosphoregulation of Nap1 plays a role in septin ring dynamics and morphogenesis in Candida albicans. mBio. 5:e00915-00913.

Iwase, M., J. Luo, E. Bi, y A. Toh-e. 2007. Shs1 plays separable roles in septin organization and cytokinesis in Saccharomyces cerevisiae. Genetics. 177:215-229.

Iwase, M., y A. Toh-e. 2001. Nis1 encoded by YNL078W: a new neck protein of Saccharomyces cerevisiae. Genes Genet. Syst. 76:335-343.

John, C.M., R.K. Hite, C.S. Weirich, D.J. Fitzgerald, H. Jawhari, M. Faty, D. Schlapfer, R. Kroschewski, F.K. Winkler, T. Walz, Y. Barral, y M.O. Steinmetz. 2007. The Caenorhabditis elegans septin complex is nonpolar. EMBO J. 26:3296-3307.

Johnson, E.S., y G. Blobel. 1999. Cell cycle-regulated attachment of the ubiquitin-related protein SUMO to the yeast septins. J. Cell Biol. 147:981-994.

Jones, L.A., y P.E. Sudbery. 2010. Spitzenkörper, exocyst, and polarisome components in Candida albicans hyphae show different patterns of localization and have distinct dynamic properties. Eukaryot. Cell. 9:1455-1465.

Jones, T., N.A. Federspiel, H. Chibana, J. Dungan, S. Kalman, B.B. Magee, G. Newport, Y.R. Thorstenson, N. Agabian, P.T. Magee, R.W. Davis, y S. Scherer. 2004. The diploid genome sequence of Candida albicans. Proc Natl Acad Sci U S A. 101:7329-7334.

Justa-Schuch, D., Y. Heilig, C. Richthammer, y S. Seiler. 2010. Septum formation is regulated by the RHO4-specific exchange factors BUD3 and RGF3 and by the landmark protein BUD4 in Neurospora crassa. Mol. Microbiol. 76:220-235.

Kabir, M.A., M.A. Hussain, y Z. Ahmad. 2012. Candida albicans: A model organism for studying fungal pathogens. ISRN Microbiol. 2012:538694.

Kadota, J., T. Yamamoto, S. Yoshiuchi, E. Bi, y K. Tanaka. 2004. Septin ring assembly requires concerted action of polarisome components, a PAK kinase Cla4p, and the actin cytoskeleton in Saccharomyces cerevisiae. Mol. Biol. Cell. 15:5329-5345.

Kaneko, A., T. Umeyama, N. Hanaoka, B.C. Monk, Y. Uehara, y M. Niimi. 2004. Tandem affinity purification of the Candida albicans septin protein complex. Yeast. 21:1025-1033.

Kang, P.J., E. Angerman, C.H. Jung, y H.O. Park. 2012. Bud4 mediates the cell-type-specific assembly of the axial landmark in budding yeast. J. Cell Sci. 125:3840-3849.

Kang, P.J., J.K. Hood-DeGrenier, y H.O. Park. 2013. Coupling of septins to the axial landmark by Bud4 in budding yeast. J. Cell Sci. 126:1218-1226.

Keaton, M.A., y D.J. Lew. 2006. Eavesdropping on the cytoskeleton: progress and controversy in the yeast morphogenesis checkpoint. Curr. Opin. Microbiol. 9:540-546.

Kelly, M.T., D.M. MacCallum, S.D. Clancy, F.C. Odds, A.J. Brown, y G. Butler. 2004. The Candida albicans CaACE2 gene affects morphogenesis, adherence and virulence. Mol. Microbiol. 53:969-983.

Kim, M.S., C.D. Froese, M.P. Estey, y W.S. Trimble. 2011. SEPT9 occupies the terminal positions in septin octamers and mediates polymerization-dependent functions in abscission. J. Cell Biol. 195:815-826.

Kinoshita, M., C.M. Field, M.L. Coughlin, A.F. Straight, y T.J. Mitchison. 2002. Self- and actin-templated assembly of mammalian septins. Dev. Cell. 3:791-802.

Klis, F.M., P. de Groot, y K. Hellingwerf. 2001. Molecular organization of the cell wall of Candida albicans. Med. Mycol. 39 Suppl 1:1-8.

Kozubowski, L., H. Panek, A. Rosenthal, A. Bloecher, D.J. DeMarini, y K. Tatchell. 2003. A Bni4-Glc7 phosphatase complex that recruits chitin synthase to the site of bud emergence. Mol. Biol. Cell. 14:26-39.

Krenn, V., y A. Musacchio. 2015. The Aurora B kinase in chromosome bi-orientation and spindle checkpoint signaling. Front Oncol. 5:225.

Kuranda, M.J., y P.W. Robbins. 1987. Cloning and heterologous expression of glycosidase genes from Saccharomyces cerevisiae. Proc Natl Acad Sci U S A. 84:2585-2589.

Kurischko, C., V.K. Kuravi, N. Wannissorn, P.A. Nazarov, M. Husain, C. Zhang, K.M. Shokat, J.M. McCaffery, y F.C. Luca. 2008. The yeast LATS/Ndr kinase Cbk1 regulates growth via Golgi-dependent glycosylation and secretion. Mol. Biol. Cell. 19:5559-5578.

Kusch, J., A. Meyer, M.P. Snyder, y Y. Barral. 2002. Microtubule capture by the cleavage apparatus is required for proper spindle positioning in yeast. Genes Dev. 16:1627-1639.

Kushner, S. 1978. An improved method for transformation of Escherichia coli with ColE1 derived plasmids. Genetic Engineering. H. S. Boyer y S. Nicosia n (eds.). Elservier/North-Holland Publishing Co. Amsterdam. pp 17-24.

Lampson, M.A., y I.M. Cheeseman. 2011. Sensing centromere tension: Aurora B and the regulation of kinetochore function. Trends Cell. Biol. 21:133-140.

Lee, P.R., S. Song, H.S. Ro, C.J. Park, J. Lippincott, R. Li, J.R. Pringle, C. De Virgilio, M.S. Longtine, y K.S. Lee. 2002. Bni5p, a septin-interacting protein, is required for normal septin function and cytokinesis in Saccharomyces cerevisiae. Mol. Cell. Biol. 22:6906-6920. 


\section{Bibliografía}

Lesage, B., J. Qian, y M. Bollen. 2011. Spindle checkpoint silencing: PP1 tips the balance. Curr. Biol. 21:R898-903. Lew, D.J. 2003. The morphogenesis checkpoint: how yeast cells watch their figures. Curr. Opin. Cell Biol. 15:648653.

Li, C.R., J.Y. Au Yong, Y.M. Wang, y Y. Wang. 2012a. CDK regulates septin organization through cell-cycle-dependent phosphorylation of the Nim1-related kinase Gin4. J. Cell Sci. 125:2533-2543.

Li, C.R., R.T. Lee, Y.M. Wang, X.D. Zheng, y Y. Wang. 2007. Candida albicans hyphal morphogenesis occurs in Sec3pindependent and Sec3p-dependent phases separated by septin ring formation. J. Cell Sci. 120:1898-1907.

Li, L., C. Zhang, y J.B. Konopka. 2012b. A Candida albicans temperature-sensitive cdc12-6 mutant identifies roles for septins in selection of sites of germ tube formation and hyphal morphogenesis. Eukaryot. Cell. 11:1210-1218.

Lin, J.I., C.L. Poon, y K.F. Harvey. 2013. The Hippo size control pathway-ever expanding. Sci Signal. 6:pe4.

Lindsey, R., y M. Momany. 2006. Septin localization across kingdoms: three themes with variations. Curr. Opin. Microbiol. 9:559-565.

Lippincott, J., y R. Li. 1998. Sequential assembly of myosin II, an IQGAP-like protein, and filamentous actin to a ring structure involved in budding yeast cytokinesis. J. Cell Biol. 140:355-366.

Liu, Q., Q. Han, N. Wang, G. Yao, G. Zeng, Y. Wang, Z. Huang, Y. Wang, y J. Sang. 2016. Tpd3-Pph21 phosphatase plays a direct role in Sep7 dephosphorylation in Candida albicans. Mol. Microbiol. 10.1111/mmi.13376.

Loeb, J.D., M. Sepulveda-Becerra, I. Hazan, y H. Liu. 1999. A G1 cyclin is necessary for maintenance of filamentous growth in Candida albicans. Mol. Cell. Biol. 19:4019-4027.

London, N., y S. Biggins. 2014. Signalling dynamics in the spindle checkpoint response. Nat. Rev. Mol. Cell Biol. 15:736-747.

Longtine, M.S., y E. Bi. 2003. Regulation of septin organization and function in yeast. Trends Cell. Biol. 13:403-409.

Longtine, M.S., H. Fares, y J.R. Pringle. 1998. Role of the yeast Gin4p protein kinase in septin assembly and the relationship between septin assembly and septin function. J. Cell Biol. 143:719-736.

Longtine, M.S., C.L. Theesfeld, J.N. McMillan, E. Weaver, J.R. Pringle, y D.J. Lew. 2000. Septin-dependent assembly of a cell cycle-regulatory module in Saccharomyces cerevisiae. Mol. Cell. Biol. 20:4049-4061.

Lorenz, M.C., J.A. Bender, y G.R. Fink. 2004. Transcriptional response of Candida albicans upon internalization by macrophages. Eukaryot. Cell. 3:1076-1087.

Luedeke, C., S.B. Frei, I. Sbalzarini, H. Schwarz, A. Spang, y Y. Barral. 2005. Septin-dependent compartmentalization of the endoplasmic reticulum during yeast polarized growth. J. Cell Biol. 169:897-908.

Luo, G., J. Zhang, y W. Guo. 2014. The role of Sec3p in secretory vesicle targeting and exocyst complex assembly. Mol. Biol. Cell. 25:3813-3822.

Maerz, S., y S. Seiler. 2010. Tales of RAM and MOR: NDR kinase signaling in fungal morphogenesis. Curr. Opin. Microbiol. 13:663-671.

Markus, S.M., K.A. Kalutkiewicz, y W.L. Lee. 2012. Astral microtubule asymmetry provides directional cues for spindle positioning in budding yeast. Exp. Cell Res. 318:1400-1406.

Marston, A.L. 2014. Chromosome segregation in budding yeast: sister chromatid cohesion and related mechanisms. Genetics. 196:31-63.

Martin, S.W., y J.B. Konopka. 2004. SUMO modification of septin-interacting proteins in Candida albicans. J. Biol. Chem. 279:40861-40867.

McCarty, T.P., y P.G. Pappas. 2016. Invasive Candidiasis. Infect Dis Clin North Am. 30:103-124.

McCreath, K.J., C.A. Specht, Y. Liu, y P.W. Robbins. 1996. Molecular cloning of a third chitinase gene (CHT1) from Candida albicans. Yeast. 12:501-504.

McCreath, K.J., C.A. Specht, y P.W. Robbins. 1995. Molecular cloning and characterization of chitinase genes from Candida albicans. Proc Natl Acad Sci U S A. 92:2544-2548.

Mcllhatton, M.A., J.F. Burrows, P.G. Donaghy, S. Chanduloy, P.G. Johnston, y S.E. Russell. 2001. Genomic organization, complex splicing pattern and expression of a human septin gene on chromosome 17q25.3. Oncogene. 20:5930-5939.

McMurray, M.A., A. Bertin, G. Garcia, 3rd, L. Lam, E. Nogales, y J. Thorner. 2011. Septin filament formation is essential in budding yeast. Dev. Cell. 20:540-549.

McMurray, M.A., y J. Thorner. 2009. Septins: molecular partitioning and the generation of cellular asymmetry. Cell Div. 4:18.

McNemar, M.D., y W.A. Fonzi. 2002. Conserved serine/threonine kinase encoded by CBK1 regulates expression of several hypha-associated transcripts and genes encoding cell wall proteins in Candida albicans. J. Bacteriol. 184:2058-2061.

Meitinger, F., M.E. Boehm, A. Hofmann, B. Hub, H. Zentgraf, W.D. Lehmann, y G. Pereira. 2011. Phosphorylationdependent regulation of the F-BAR protein Hof1 during cytokinesis. Genes Dev. 25:875-888.

Meitinger, F., S. Palani, y G. Pereira. 2012. The power of MEN in cytokinesis. Cell Cycle. 11:219-228. 
Meng, Z., T. Moroishi, y K.L. Guan. 2016. Mechanisms of Hippo pathway regulation. Genes Dev. 30:1-17.

Merlini, L., y S. Piatti. 2011. The mother-bud neck as a signaling platform for the coordination between spindle position and cytokinesis in budding yeast. Biol. Chem. 392:805-812.

Meseroll, R.A., L. Howard, y A.S. Gladfelter. 2012. Septin ring size scaling and dynamics require the coiled-coil region of Shs1p. Mol. Biol. Cell. 23:3391-3406.

Meseroll, R.A., P. Occhipinti, y A.S. Gladfelter. 2013. Septin phosphorylation and coiled-coil domains function in cell and septin ring morphology in the filamentous fungus Ashbya gossypii. Eukaryot. Cell. 12:182-193.

Mino, A., K. Tanaka, T. Kamei, M. Umikawa, T. Fujiwara, y Y. Takai. 1998. Shs1p: a novel member of septin that interacts with Spa2p, involved in polarized growth in Saccharomyces cerevisiae. Biochem. Biophys. Res. Commun. 251:732-736.

Moore, J.K., y J.A. Cooper. 2010. Coordinating mitosis with cell polarity: Molecular motors at the cell cortex. Semin Cell Dev Biol. 21:283-289.

Moore, J.K., V. Magidson, A. Khodjakov, y J.A. Cooper. 2009. The spindle position checkpoint requires positional feedback from cytoplasmic microtubules. Curr. Biol. 19:2026-2030.

Mortensen, E.M., H. McDonald, J. Yates, 3rd, y D.R. Kellogg. 2002. Cell cycle-dependent assembly of a Gin4-septin complex. Mol. Biol. Cell. 13:2091-2105.

Musacchio, A., y E.D. Salmon. 2007. The spindle-assembly checkpoint in space and time. Nat. Rev. Mol. Cell. Biol. 8:379-393.

Nelson, W.J. 2003. Adaptation of core mechanisms to generate cell polarity. Nature. 422:766-774.

Neukirchen, D., y F. Bradke. 2011. Neuronal polarization and the cytoskeleton. Semin. Cell Dev. Biol. 22:825-833.

Nobile, C.J., y A.P. Mitchell. 2006. Genetics and genomics of Candida albicans biofilm formation. Cell Microbiol. 8:1382-1391.

Noble, S.M., S. French, L.A. Kohn, V. Chen, y A.D. Johnson. 2010. Systematic screens of a Candida albicans homozygous deletion library decouple morphogenetic switching and pathogenicity. Nat. Genet. 42:590-598.

Noble, S.M., y A.D. Johnson. 2007. Genetics of Candida albicans, a diploid human fungal pathogen. Annu. Rev. Genet. 41:193-211.

Odds, F.C. 1987. Candida infections: an overview. Crit. Rev. Microbiol. 15:1-5.

Oegema, K., M.S. Savoian, T.J. Mitchison, y C.M. Field. 2000. Functional analysis of a human homologue of the Drosophila actin binding protein anillin suggests a role in cytokinesis. J. Cell Biol. 150:539-552.

Ofir, A., y D. Kornitzer. 2010. Candida albicans cyclin Clb4 carries S-phase cyclin activity. Eukaryot. Cell. 9:1311-1319.

Oh, Y., y E. Bi. 2011. Septin structure and function in yeast and beyond. Trends Cell. Biol. 21:141-148.

Okada, S., M. Leda, J. Hanna, N.S. Savage, E. Bi, y A.B. Goryachev. 2013. Daughter cell identity emerges from the interplay of Cdc42, septins, and exocytosis. Dev. Cell. 26:148-161.

Okuzaki, D., S. Tanaka, H. Kanazawa, y H. Nojima. 1997. Gin4 of S. cerevisiae is a bud neck protein that interacts with the Cdc28 complex. Genes Cells. 2:753-770.

Ong, K., C. Wloka, S. Okada, T. Svitkina, y E. Bi. 2014. Architecture and dynamic remodelling of the septin cytoskeleton during the cell cycle. Nat. Commun. 5:5698.

Pan, F., R.L. Malmberg, y M. Momany. 2007. Analysis of septins across kingdoms reveals orthology and new motifs. BMC Evol. Biol. 7:103.

Paoletti, A., y F. Chang. 2000. Analysis of mid1p, a protein required for placement of the cell division site, reveals a link between the nucleus and the cell surface in fission yeast. Mol. Biol. Cell. 11:2757-2773.

Park, H.O., y E. Bi. 2007. Central roles of small GTPases in the development of cell polarity in yeast and beyond. Microbiol. Mol. Biol. Rev. 71:48-96.

Pfaller, M.A., y D.J. Diekema. 2007. Epidemiology of invasive candidiasis: a persistent public health problem. Clin Microbiol Rev. 20:133-163.

Phan, Q.T., P.H. Belanger, y S.G. Filler. 2000. Role of hyphal formation in interactions of Candida albicans with endothelial cells. Infect. Immun. 68:3485-3490.

Piekny, A.J., y A.S. Maddox. 2010. The myriad roles of Anillin during cytokinesis. Semin Cell Dev Biol. 21:881-891.

Pringle, J.R., E. Bi, H.A. Harkins, J.E. Zahner, C. De Virgilio, J. Chant, K. Corrado, y H. Fares. 1995. Establishment of cell polarity in yeast. Cold Spring Harb Symp Quant Biol. 60:729-744.

Ramos, A., y F.D. Camargo. 2012. The Hippo signaling pathway and stem cell biology. Trends Cell. Biol. 22:339-346.

Rebelo, S., M. Santos, F. Martins, E.F. da Cruz e Silva, y O.A. da Cruz e Silva. 2015. Protein phosphatase 1 is a key player in nuclear events. Cell Signal. 27:2589-2598.

Reijnst, P., A. Walther, y J. Wendland. 2011. Dual-colour fluorescence microscopy using yEmCherry-/GFP-tagging of eisosome components Pil1 and Lsp1 in Candida albicans. Yeast. 28:331-338.

Reuss, O., A. Vik, R. Kolter, y J. Morschhauser. 2004. The SAT1 flipper, an optimized tool for gene disruption in Candida albicans. Gene. 341:119-127. 


\section{Bibliografía}

Riquelme, M. 2013. Tip growth in filamentous fungi: a road trip to the apex. Annu. Rev. Microbiol. 67:587-609.

Riquelme, M., y E. Sánchez-León. 2014. The Spitzenkörper: a choreographer of fungal growth and morphogenesis. Curr. Opin. Microbiol. 20:27-33.

Saarikangas, J., y Y. Barral. 2011. The emerging functions of septins in metazoans. EMBO Rep. 12:1118-1126.

Sadian, Y., C. Gatsogiannis, C. Patasi, O. Hofnagel, R.S. Goody, M. Farkasovsky, y S. Raunser. 2013. The role of Cdc42 and Gic1 in the regulation of septin filament formation and dissociation. Elife. 2:e01085.

Sambrook, J., y D.W. Russell. 2001. Molecular Cloning: A laboratory manual. Cold Spring Harbour. New York: Cold Spring Harbour Laboratory Press.

Saputo, S., Y. Chabrier-Rosello, F.C. Luca, A. Kumar, y D.J. Krysan. 2012. The RAM network in pathogenic fungi. Eukaryot. Cell. 11:708-717.

Sassoon, I., F.F. Severin, P.D. Andrews, M.R. Taba, K.B. Kaplan, A.J. Ashford, M.J. Stark, P.K. Sorger, y A.A. Hyman. 1999. Regulation of Saccharomyces cerevisiae kinetochores by the type 1 phosphatase Glc7p. Genes Dev. 13:545-555.

Schmid, J., P.T. Magee, B.R. Holland, N. Zhang, R.D. Cannon, y B.B. Magee. 2016. Last hope for the doomed? Thoughts on the importance of a parasexual cycle for the yeast Candida albicans. Curr. Genet. 62:81-85.

Schmidt, M., A. Varma, T. Drgon, B. Bowers, y E. Cabib. 2003. Septins, under Cla4p regulation, and the chitin ring are required for neck integrity in budding yeast. Mol. Biol. Cell. 14:2128-2141.

Schulze, J., y U. Sonnenborn. 2009. Yeasts in the gut: from commensals to infectious agents. Dtsch Arztebl Int. 106:837-842.

Segal, M. 2011. Mitotic exit control: a space and time odyssey. Curr. Biol. 21:R857-859.

Seiler, S., y D. Justa-Schuch. 2010. Conserved components, but distinct mechanisms for the placement and assembly of the cell division machinery in unicellular and filamentous ascomycetes. Mol. Microbiol. 78:10581076.

Sellin, M.E., L. Sandblad, S. Stenmark, y M. Gullberg. 2011. Deciphering the rules governing assembly order of mammalian septin complexes. Mol. Biol. Cell. 22:3152-3164.

Sellin, M.E., S. Stenmark, y M. Gullberg. 2012. Mammalian SEPT9 isoforms direct microtubule-dependent arrangements of septin core heteromers. Mol. Biol. Cell. 23:4242-4255.

Shapiro, R.S., P. Uppuluri, A.K. Zaas, C. Collins, H. Senn, J.R. Perfect, J. Heitman, y L.E. Cowen. 2009. Hsp90 orchestrates temperature-dependent Candida albicans morphogenesis via Ras1-PKA signaling. Curr. Biol. 19:621-629.

Shareck, J., y P. Belhumeur. 2011. Modulation of morphogenesis in Candida albicans by various small molecules. Eukaryot. Cell. 10:1004-1012.

Shcheprova, Z., S. Baldi, S.B. Frei, G. Gonnet, y Y. Barral. 2008. A mechanism for asymmetric segregation of age during yeast budding. Nature. 454:728-734.

Shulewitz, M.J., C.J. Inouye, y J. Thorner. 1999. HsI7 localizes to a septin ring and serves as an adapter in a regulatory pathway that relieves tyrosine phosphorylation of $\mathrm{Cdc} 28$ protein kinase in Saccharomyces cerevisiae. Mol. Cell. Biol. 19:7123-7137.

Si, H., W.R. Rittenour, K. Xu, M. Nicksarlian, A.M. Calvo, y S.D. Harris. 2012. Morphogenetic and developmental functions of the Aspergillus nidulans homologues of the yeast bud site selection proteins Bud4 and AxI2. Mol. Microbiol. 85:252-270.

Sinha, I., Y.M. Wang, R. Philp, C.R. Li, W.H. Yap, y Y. Wang. 2007. Cyclin-dependent kinases control septin phosphorylation in Candida albicans hyphal development. Dev. Cell. 13:421-432.

Sirajuddin, M., M. Farkasovsky, F. Hauer, D. Kuhlmann, I.G. Macara, M. Weyand, H. Stark, y A. Wittinghofer. 2007. Structural insight into filament formation by mammalian septins. Nature. 449:311-315.

Smolka, M.B., S.H. Chen, P.S. Maddox, J.M. Enserink, C.P. Albuquerque, X.X. Wei, A. Desai, R.D. Kolodner, y H. Zhou. 2006. An FHA domain-mediated protein interaction network of Rad53 reveals its role in polarized cell growth. J. Cell Biol. 175:743-753.

Song, Y., S.A. Cheon, K.E. Lee, S.Y. Lee, B.K. Lee, D.B. Oh, H.A. Kang, y J.Y. Kim. 2008. Role of the RAM network in cell polarity and hyphal morphogenesis in Candida albicans. Mol. Biol. Cell. 19:5456-5477.

Spiliotis, E.T. 2010. Regulation of microtubule organization and functions by septin GTPases. Cytoskeleton. 67:339-345.

Spiliotis, E.T., y A.S. Gladfelter. 2012. Spatial guidance of cell asymmetry: septin GTPases show the way. Traffic. 13:195-203.

Spiliotis, E.T., y W.J. Nelson. 2006. Here come the septins: novel polymers that coordinate intracellular functions and organization. J. Cell Sci. 119:4-10.

Steinberg, G. 2007. Hyphal growth: a tale of motors, lipids, and the Spitzenkörper. Eukaryot. Cell. 6:351-360. 
Sudbery, P. 2011a. Fluorescent proteins illuminate the structure and function of the hyphal tip apparatus. Fungal Genet. Biol. 48:849-857.

Sudbery, P., N. Gow, y J. Berman. 2004. The distinct morphogenic states of Candida albicans. Trends Microbiol. 12:317-324.

Sudbery, P.E. 2011b. Growth of Candida albicans hyphae. Nat. Rev. Microbiol. 9:737-748.

Swaney, D.L., P. Beltrao, L. Starita, A. Guo, J. Rush, S. Fields, N.J. Krogan, y J. Villen. 2013. Global analysis of phosphorylation and ubiquitylation cross-talk in protein degradation. Nat Methods. 10:676-682.

Takahashi, Y., M. Iwase, M. Konishi, M. Tanaka, A. Toh-e, y Y. Kikuchi. 1999. Smt3, a SUMO-1 homolog, is conjugated to $\mathrm{Cdc3}$, a component of septin rings at the mother-bud neck in budding yeast. Biochem. Biophys. Res. Commun. 259:582-587.

Tang, C.S., y S.I. Reed. 2002. Phosphorylation of the septin cdc3 in g1 by the cdc28 kinase is essential for efficient septin ring disassembly. Cell Cycle. 1:42-49.

Tasto, J.J., J.L. Morrell, y K.L. Gould. 2003. An anillin homologue, Mid2p, acts during fission yeast cytokinesis to organize the septin ring and promote cell separation. J. Cell Biol. 160:1093-1103.

Torres, E.M., B.R. Williams, y A. Amon. 2008. Aneuploidy: cells losing their balance. Genetics. 179:737-746.

Tortorano, A.M., C. Kibbler, J. Peman, H. Bernhardt, L. Klingspor, y R. Grillot. 2006. Candidaemia in Europe: epidemiology and resistance. Int J Antimicrob Agents. 27:359-366.

Vázquez de Aldana, C.R. and Correa-Bordes, J. 2012. Integrating CDK signaling in Candida albicans environmental sensing networks. Morphogenesis and Pathogenicity in Fungy. 22:81-96.

Versele, M., B. Gullbrand, M.J. Shulewitz, V.J. Cid, S. Bahmanyar, R.E. Chen, P. Barth, T. Alber, y J. Thorner. 2004. Protein-protein interactions governing septin heteropentamer assembly and septin filament organization in Saccharomyces cerevisiae. Mol. Biol. Cell. 15:4568-4583.

Versele, M., y J. Thorner. 2004. Septin collar formation in budding yeast requires GTP binding and direct phosphorylation by the PAK, Cla4. J. Cell Biol. 164:701-715.

Versele, M., y J. Thorner. 2005. Some assembly required: yeast septins provide the instruction manual. Trends Cell. Biol. 15:414-424.

Virag, A., y S.D. Harris. 2006. The Spitzenkörper: a molecular perspective. Mycol Res. 110:4-13.

Vrabioiu, A.M., y T.J. Mitchison. 2006. Structural insights into yeast septin organization from polarized fluorescence microscopy. Nature. 443:466-469.

Vrabioiu, A.M., y T.J. Mitchison. 2007. Symmetry of septin hourglass and ring structures. J. Mol. Biol. 372:37-49.

Walther, A., y J. Wendland. 2003. An improved transformation protocol for the human fungal pathogen Candida albicans. Curr. Genet. 42:339-343.

Wang, A., P.P. Raniga, S. Lane, Y. Lu, y H. Liu. 2009. Hyphal chain formation in Candida albicans: Cdc28-Hgc1 phosphorylation of Efg1 represses cell separation genes. Mol. Cell. Biol. 29:4406-4416.

Wang, H., Z.X. Huang, J.Y. Yong, H. Zou, G. Zeng, J. Gao, Y. Wang, A.H. Wong, y Y. Wang. 2016. CDK phosphorylates the polarisome scaffold Spa2 to maintain its localization at the site of cell growth. Mol. Microbiol.10.1111/ mmi.13386.

Wang, Y. 2009. CDKs and the yeast-hyphal decision. Curr. Opin. Microbiol. 12:644-649.

Wang, Y. 2016. Hgc1-Cdc28-how much does a single protein kinase do in the regulation of hyphal development in Candida albicans? J Microbiol. 54:170-177.

Warenda, A.J., y J.B. Konopka. 2002. Septin function in Candida albicans morphogenesis. Mol. Biol. Cell. 13:27322746.

Weirich, C.S., J.P. Erzberger, y Y. Barral. 2008. The septin family of GTPases: architecture and dynamics. Nat. Rev. Mol. Cell. Biol. 9:478-489.

Weiss, E.L. 2012. Mitotic exit and separation of mother and daughter cells. Genetics. 192:1165-1202.

Wightman, R., S. Bates, P. Amornrrattanapan, y P. Sudbery. 2004. In Candida albicans, the Nim1 kinases Gin4 and Hsl1 negatively regulate pseudohypha formation and Gin4 also controls septin organization. J. Cell Biol. 164:581-591.

Wilson, R.B., D. Davis, y A.P. Mitchell. 1999. Rapid hypothesis testing with Candida albicans through gene disruption with short homology regions. J. Bacteriol. 181:1868-1874.

Willger, S.D., Z. Liu, R.A. Olarte, M.E. Adamo, J.E. Stajich, L.C. Myers, A.N. Kettenbach, y D.A. Hogan. 2015. Analysis of the Candida albicans phosphoproteome. Eukaryot. Cell. 14:474-485.

Williams, S.E., y E. Fuchs. 2013. Oriented divisions, fate decisions. Curr. Opin. Cell Biol. 25:749-758.

Winey, M., y K. Bloom. 2012. Mitotic spindle form and function. Genetics. 190:1197-1224.

Witte, H., y F. Bradke. 2008. The role of the cytoskeleton during neuronal polarization. Curr Opin Neurobiol. 18:479-487. 


\section{Bibliografía}

Wloka, C., R. Nishihama, M. Onishi, Y. Oh, J. Hanna, J.R. Pringle, M. Krauss, y E. Bi. 2011. Evidence that a septin diffusion barrier is dispensable for cytokinesis in budding yeast. Biol. Chem. 392:813-829.

Wu, H., J. Guo, Y.T. Zhou, y X.D. Gao. 2015. The anillin-related region of Bud4 is the major functional determinant for Bud4's function in septin organization during bud growth and axial bud site selection in budding yeast. Eukaryot. Cell. 14:241-251.

Yamagishi, Y., T. Sakuno, Y. Goto, y Y. Watanabe. 2014. Kinetochore composition and its function: lessons from yeasts. FEMS Microbiol. Rev. 38:185-200.

Yu, F.X., y K.L. Guan. 2013. The Hippo pathway: regulators and regulations. Genes Dev. 27:355-371.

Yu, F.X., B. Zhao, y K.L. Guan. 2015. Hippo pathway in organ size control, tissue homeostasis, and cancer. Cell. 163:811-828.

Zacchi, L.F., W.L. Schulz, y D.A. Davis. 2010. HOS2 and HDA1 encode histone deacetylases with opposing roles in Candida albicans morphogenesis. PloS One. 5:e12171.

Zhang, J., C. Kong, H. Xie, P.S. McPherson, S. Grinstein, y W.S. Trimble. 1999. Phosphatidylinositol polyphosphate binding to the mammalian septin H5 is modulated by GTP. Curr. Biol. 9:1458-1467.

Zhang, N., B.B. Magee, P.T. Magee, B.R. Holland, E. Rodrigues, A.R. Holmes, R.D. Cannon, y J. Schmid. 2015. Selective advantages of a parasexual cycle for the yeast Candida albicans. Genetics. 200:1117-1132.

Zheng, X., Y. Wang, y Y. Wang. 2004. Hgc1, a novel hypha-specific G1 cyclin-related protein regulates Candida albicans hyphal morphogenesis. EMBO J. 23:1845-1856.

Zheng, X.D., R.T. Lee, Y.M. Wang, Q.S. Lin, y Y. Wang. 2007. Phosphorylation of Rga2, a Cdc42 GAP, by CDK/Hgc1 is crucial for Candida albicans hyphal growth. EMBO J. 26:3760-3769. 